\title{
Evaluating the protocol of the spectrum of hot mix asphalt mixes produced in West Virginia
}

Laura Dalton

Follow this and additional works at: https://researchrepository.wvu.edu/etd

\section{Recommended Citation}

Dalton, Laura, "Evaluating the protocol of the spectrum of hot mix asphalt mixes produced in West Virginia" (2016). Graduate Theses, Dissertations, and Problem Reports. 5431.

https://researchrepository.wvu.edu/etd/5431

This Thesis is protected by copyright and/or related rights. It has been brought to you by the The Research Repository @ WVU with permission from the rights-holder(s). You are free to use this Thesis in any way that is permitted by the copyright and related rights legislation that applies to your use. For other uses you must obtain permission from the rights-holder(s) directly, unless additional rights are indicated by a Creative Commons license in the record and/ or on the work itself. This Thesis has been accepted for inclusion in WVU Graduate Theses, Dissertations, and Problem Reports collection by an authorized administrator of The Research Repository @ WVU. For more information, please contact researchrepository@mail.wvu.edu. 
Evaluating the Protocol of the Spectrum of Hot Mix Asphalt Mixes Produced in West Virginia

\title{
Laura Dalton
}

\author{
Thesis submitted to the \\ Benjamin Statler College of Engineering and Mineral Resources \\ at West Virginia University \\ in partial fulfillment of the requirements for the degree of \\ Master of Science in Civil and Environmental Engineering
}

John P. Zaniewski, Ph. D., P.E., Chair

John Quaranta, Ph. D.

Karl Barth, Ph. D.

Department of Civil Engineering

Morgantown, West Virginia

2016

Keywords: Fatigue, Flow Number, Dynamic Modulus, AMPT, CoreLok

Copyright 2016 Laura Dalton 


\begin{abstract}
Evaluating the Protocol of the Spectrum of Hot Mix Asphalt Mixes Produced in West Virginia Laura Dalton
\end{abstract}

Reviewing asphalt concrete plant-produced mixes in a laboratory setting provides further insight into pavement characteristics. Nine mix designs provided from five hot mix asphalt plant producers were evaluated throughout this research. Five mixes were Wearing I and four mixes were Base II/19 mm each of which contained various aggregate sources. First, the determination of bulk specific gravity was performed using three methods: Saturated Surface-Dry, CoreLok, and Dimensional (volumetric mass density). Moreover, assessing a mix's inherent capability to be uniformly compacted is integral in both laboratory and field evaluations. The nine mix designs were assessed for uniformity following AASHTO PP 60 standard.

Furthermore, the Asphalt Mixture Performance Tester (AMPT) is a new performance testing machine that has dynamic modulus, flow number, and fatigue testing capabilities. This research focused on using the AMPT to determine dynamic modulus, fatigue characterization, and flow number values of the asphalt mixes. Master curves were developed using Mastersolver Version 2.2 to review the stiffness of the mixes. Asphalt Pavement Hierarchical Analysis Toolbox - Fatigue Program (Alpha-Fatigue ${ }^{\mathrm{TM}}$ software) was utilized to determine fatigue coefficients used to model the traditional fatigue equation. Yang Huang's KENPAVE was used to develop a range of strain-modulus curves. Next, AMPT dynamic modulus values and fatigue K-value outputs were then compared using the KENPAVE strain outputs at a specified frequency level. Lastly, flow number was evaluated for rutting resistance and compared among mix designs using two methods: AMPT averaging method and the Francken Model. 


\section{ACKNOWLEDGMENTS}

I would like to thank my advisor, Dr. John Zaniewski, for his guidance and assistance in completing this research and for providing me with the opportunity to further my education. I would also like to thank my committee members, Dr. John Quaranta and Dr. Karl Barth, for each

of their contributions in bringing this thesis to fruition. Being surrounded and influenced by these wonderful minds has helped me grow both in my career and as a person.

This research would not be possible without the funding and support from the West Virginia Division of Highways (WVDOH). I am truly thankful for their support of the West Virginia University Asphalt Technology Program.

Next, I want to thank my fellow graduate student Justin Pentz for all his assistance and insight into the completion of this research topic. This research would not be what it is without your contributions. Lastly, I want to thank my family and friends for their support and providing advice throughout this process. 


\section{Table of Contents}

List of Figures ............................................................................................................... vii

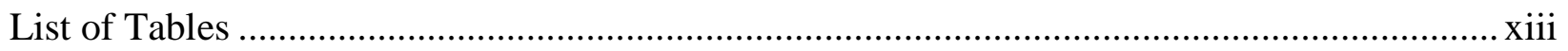

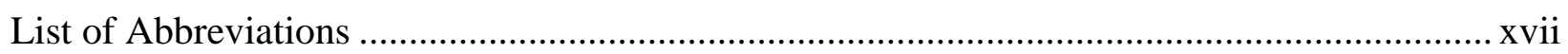

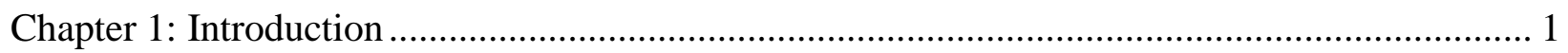

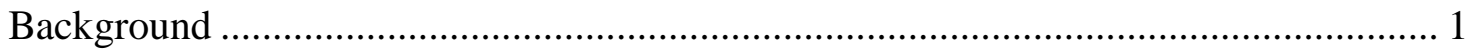

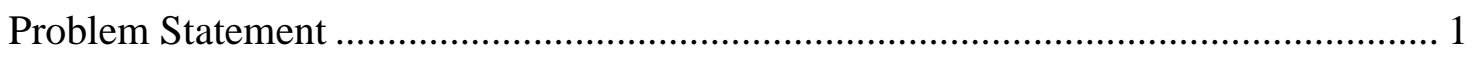

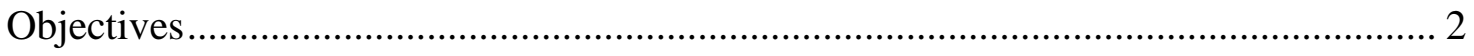

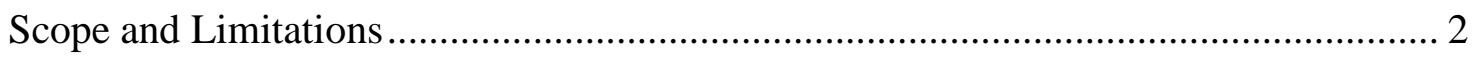

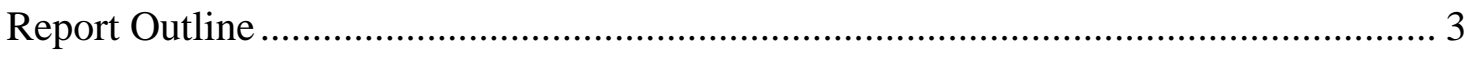

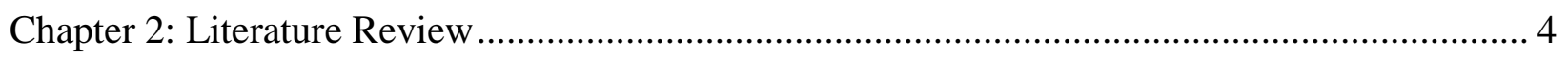

Asphalt Mixture Design .......................................................................................... 4

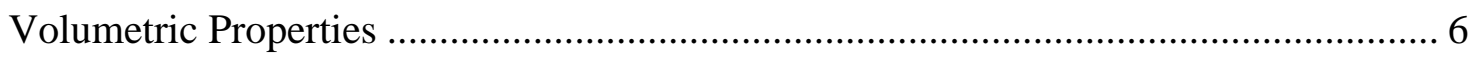

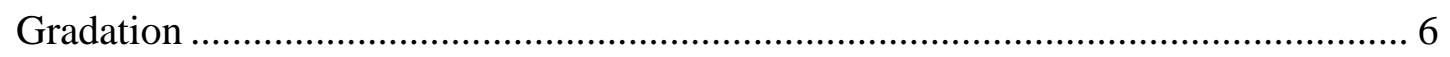

Maximum Specific Gravity (Rice) ……………………...................................... 7

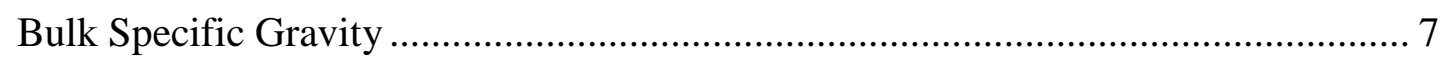

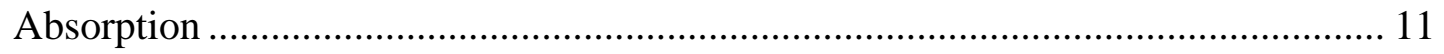

Research Comparing Bulk Specific Gravity Methods .................................................. 11

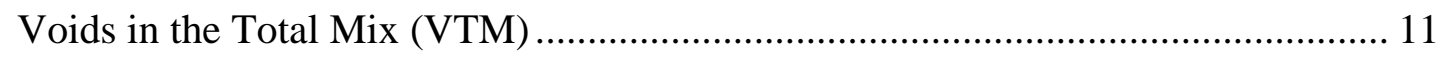

Assessing Test Specimen Uniformity....................................................................... 13

Voids in the Mineral Aggregate (VMA) ............................................................... 14

Voids Filled with Asphalt (VFA) ......................................................................... 14

Asphalt Mixture Performance Tester (AMPT) ……………………………………..... 14

Dynamic Modulus and Phase Angle ……………………................................... 15

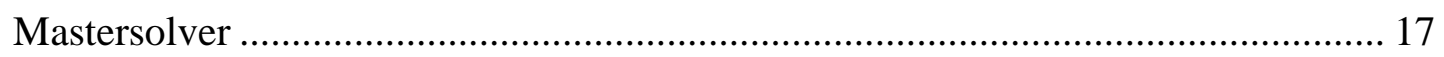


Fatigue Damage and Testing ............................................................................ 18

Rutting and Flow Number Test ......................................................................... 21

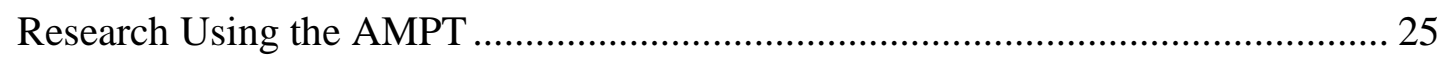

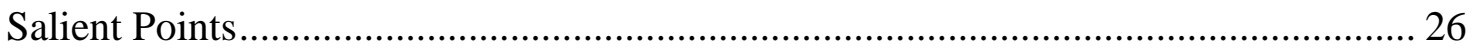

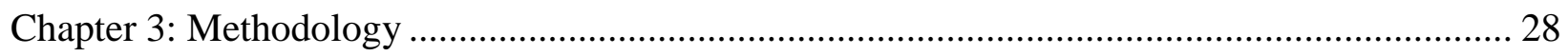

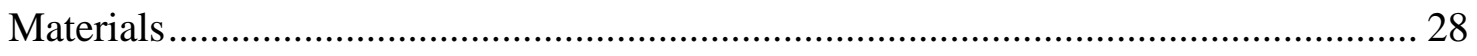

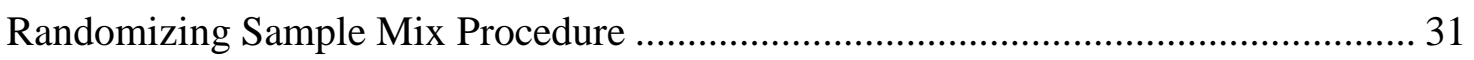

Sample Preparation and Fabrication ………………............................................... 33

Dynamic Modulus and Specimen Uniformity .............................................................. 37

Fatigue Procedure (............................................................................................... 40

Flow Number Procedure ……………………………......................................... 43

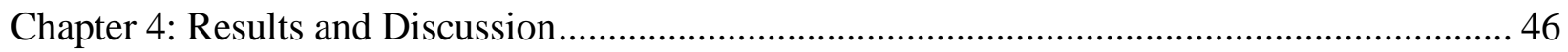

Maximum Specific Gravity ………………………............................................ 46

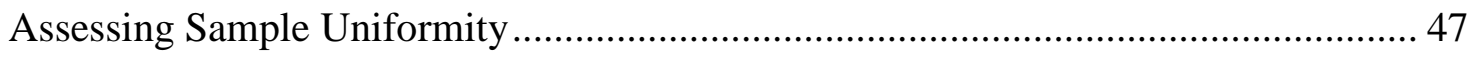

Comparing Sections and Intact Sample Air Voids .................................................... 48

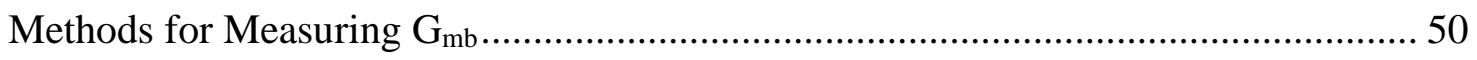

Effective Sample Trimming on Air Voids .............................................................. 52

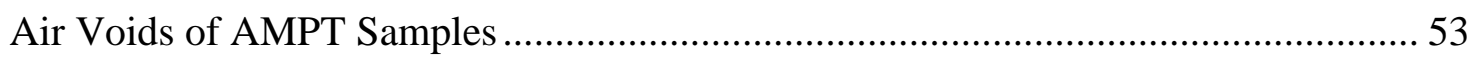

Dynamic Modulus and Phase Angle ………………............................................... 54

Master Curve Comparison ....................................................................................... 59

Fatigue

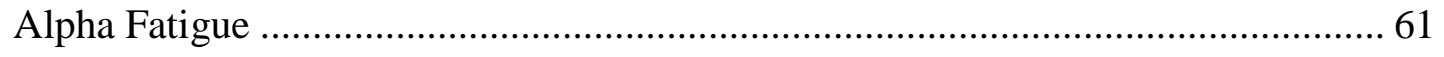

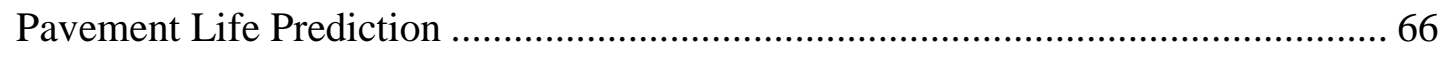

Alpha-Fatigue Pavement Life Prediction ................................................................ 69

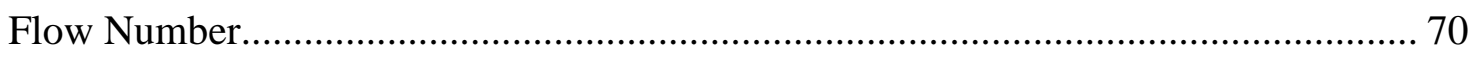




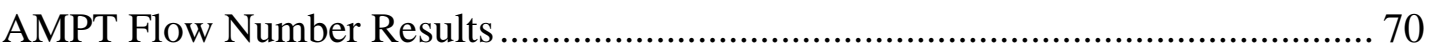

Francken Model Flow Number Results.................................................................... 72

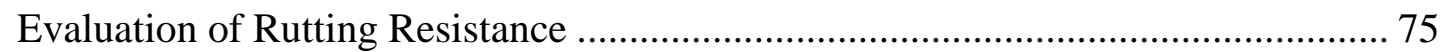

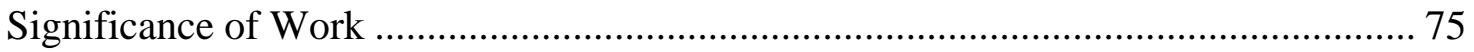

Chapter 5: Conclusions and Recommendations …………....................................................... 76

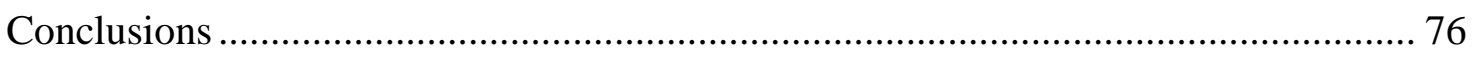

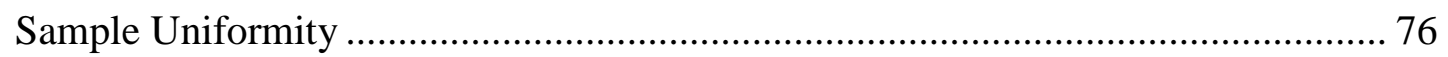

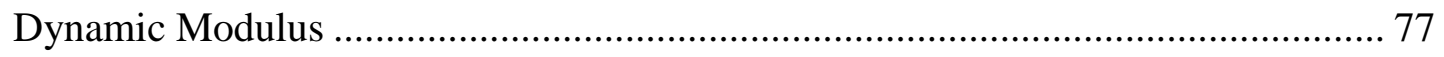

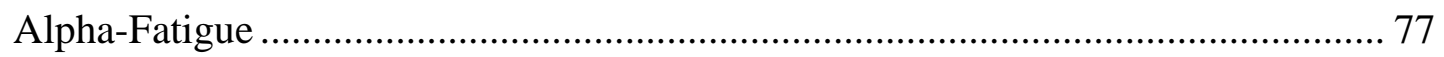

KENPAVE .................................................................................................... 77

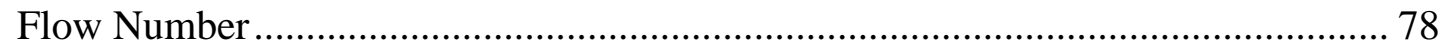

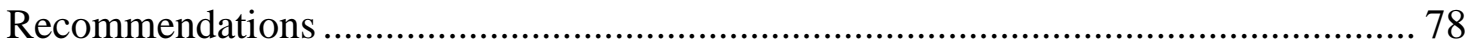

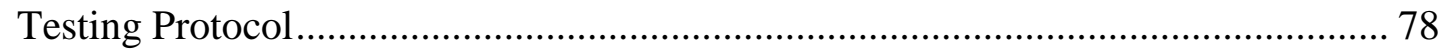

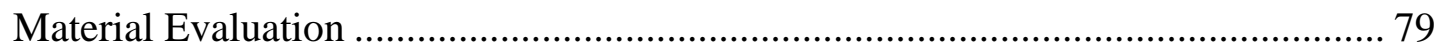

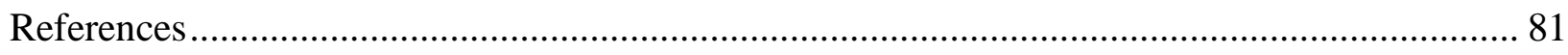

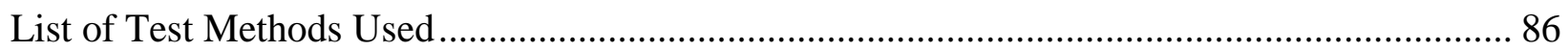

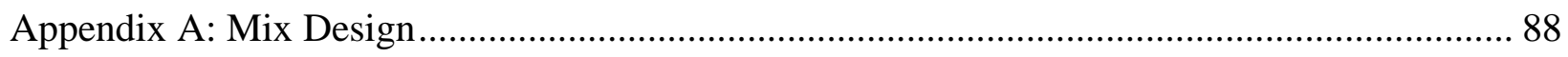

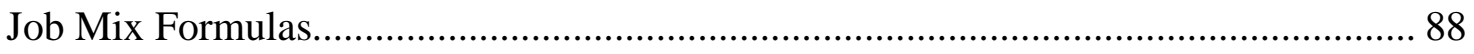

Appendix B: Volumetric Properties and SGC Data ………................................................ 108

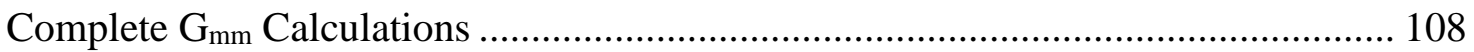

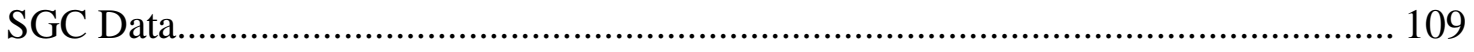

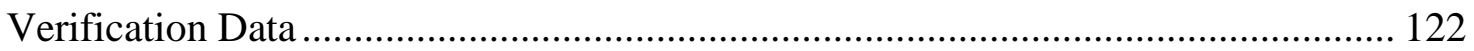

Bulk Specific Gravities $\left(\mathrm{G}_{\mathrm{mb}}\right)$ for Sample Thirds ................................................... 123

Full Sample Volumetrics - Bulk Mix Specific Gravities $\left(\mathrm{G}_{\mathrm{mb}}\right)$ Before and After Coring and Sawing..... 
Geometry and VTM, VMA, and VFA for Full Samples

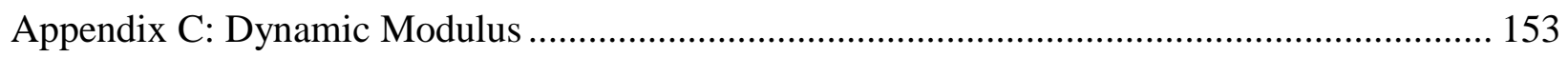

Dynamic Modulus MEPDG Outputs ............................................................... 153

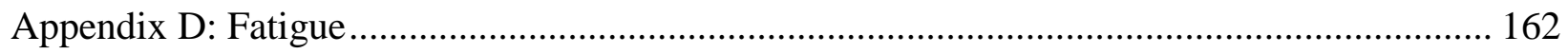

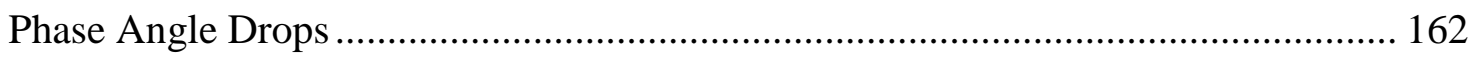

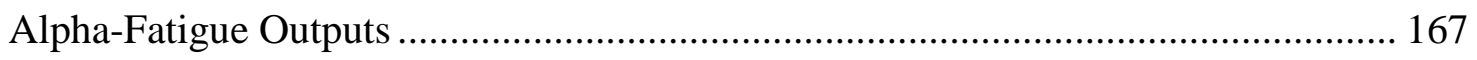

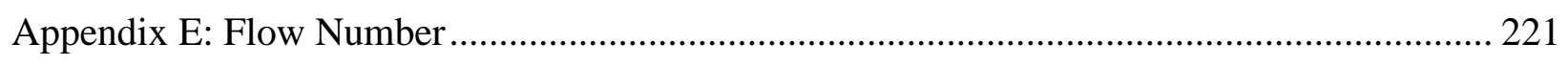

Francken Model Fitting Coefficients ......................................................... 221

Appendix F: Additional Images of Laboratory Equipment ................................................ 222 


\section{List of Figures}

Figure 1: Superpave Gyratory Compactor and Molds ............................................................ 5

Figure 2: Compacted Asphalt with Water Filled Voids (Yan, 2012) ...................................... 8

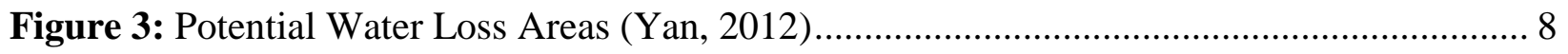

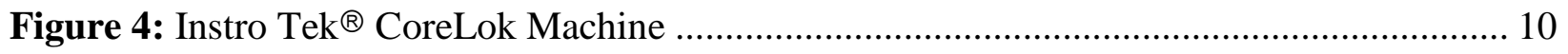

Figure 5: Typical Dynamic Modulus Test Data (Bonaquist et al., 2003)............................... 16

Figure 6: Alpha-Fatigue Phase Angle Drop ...................................................................... 19

Figure 7: Alpha Fatigue Simple Model Characterization Interface....................................... 20

Figure 8: Classical Flow Number Test Relationship between Permanent Strain and Loading

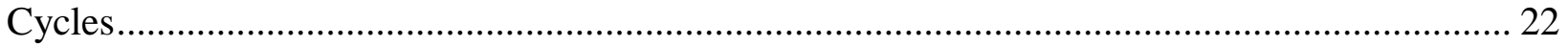

Figure 9: Typical Repeated Load Test and Flow Number (Bonaquist et al., 2003) ................. 23

Figure 10: Table Covered in Release Paper................................................................. 31

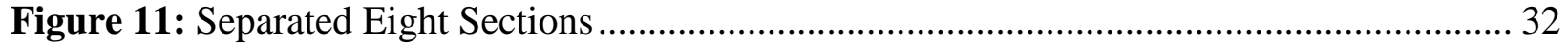

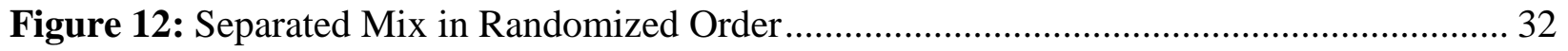

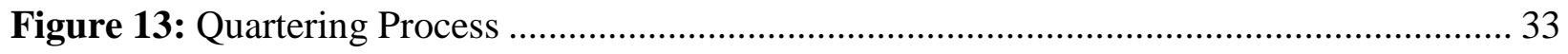

Figure 14: Marshall Pills made at the WVDOH site in Charleston, WV ................................ 35

Figure 15: CoreLok Vacuum-Sealed Gyratory Sample...................................................... 36

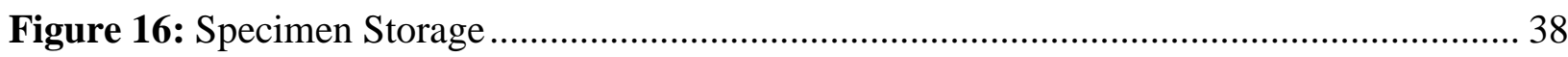

Figure 17: Flow Diagram of Air Void Uniformity Evaluation.............................................. 39

Figure 18: KP483 Sample 8 Middle Failure ..................................................................... 42

Figure 19: AA937 S8 AMPT Permanent Axial Strain and Francken Model .......................... 45

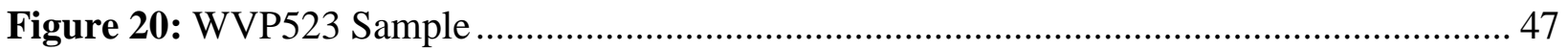

Figure 21: Line of Equality Chart SSD Verses CoreLok Method ........................................... 50

Figure 22: Line of Equality Chart Dimensional Verses SSD Method .................................... 51

Figure 23: Line of Equality Chart Dimensional Verses CoreLok Method .............................. 51

Figure 24: 9.5 mm NMAS CoreLok VTM Before and After Trimming ................................ 52

Figure 25: 19 mm NMAS CoreLok VTM Before and After Trimming ................................. 53

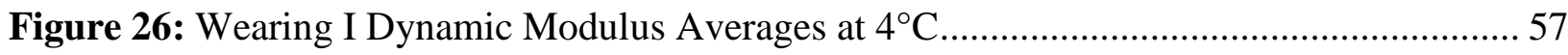

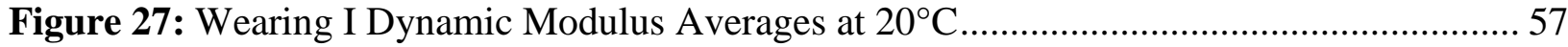

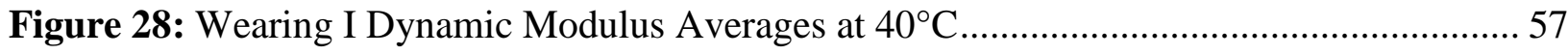




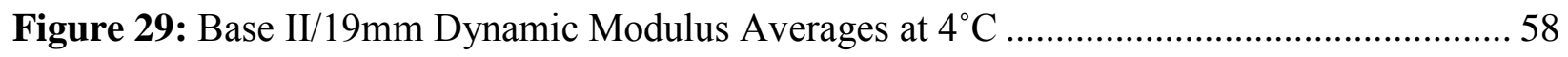

Figure 30: Base II/19mm Dynamic Modulus Averages at $20^{\circ} \mathrm{C}$........................................... 58

Figure 31: Base II/19mm Dynamic Modulus Averages at $40^{\circ} \mathrm{C}$......................................... 59

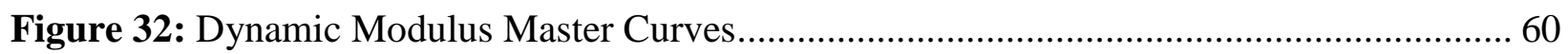

Figure 33: Alpha-Fatigue Phase Angle Failure Cycle Identification Box without Drop ........... 61

Figure 34: Visualization of Fatigue Equations Using Peak Analyzed K-Values ..................... 65

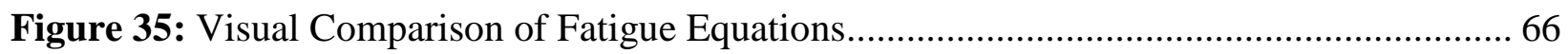

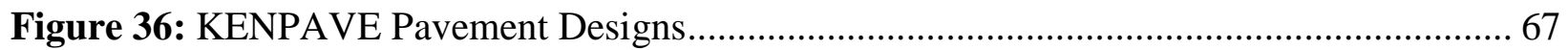

Figure 37: Full Depth and Conventional Pavement Strain Based Fatigue ............................. 67

Figure 38: WVP882 Flow Number Sample 5 Permanent Strain and Strain Rate...................... 72

Figure 39: AA937 Flow Number Sample 8 Permanent Strain and Strain Rate......................... 72

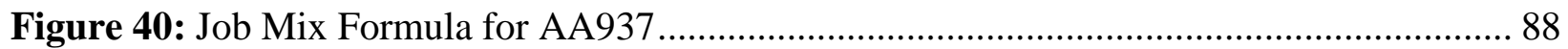

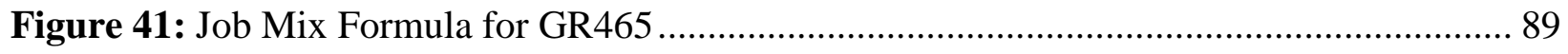

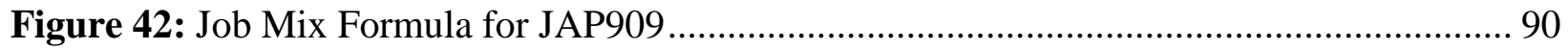

Figure 43: Job Mix Formula for JFA060 ..................................................................... 91

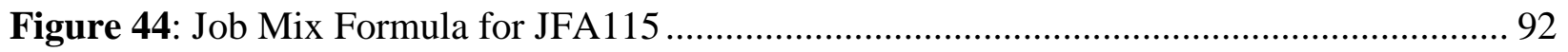

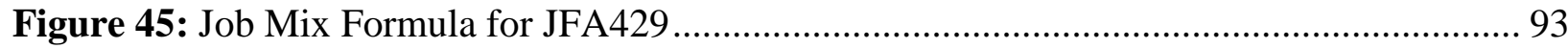

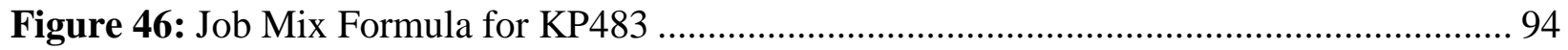

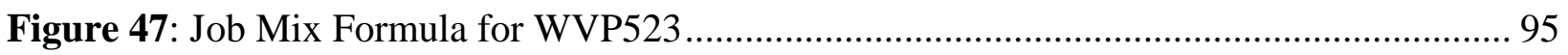

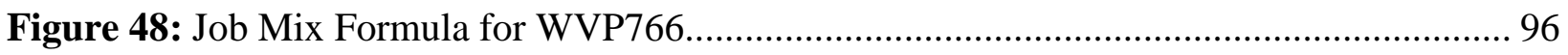

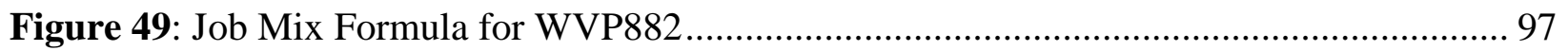

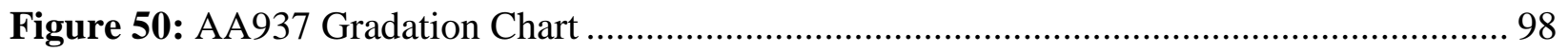

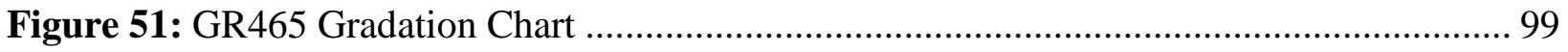

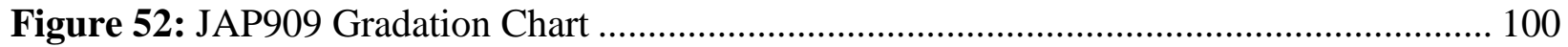

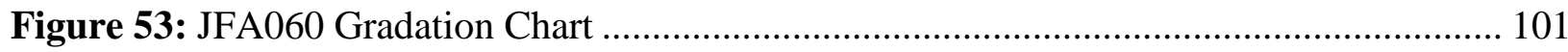

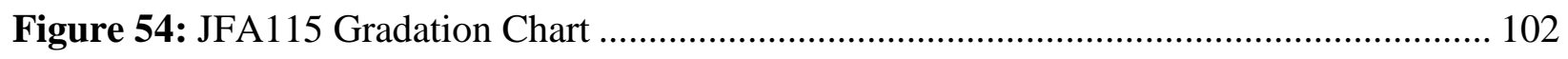

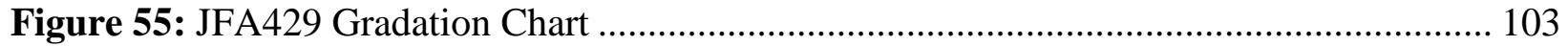

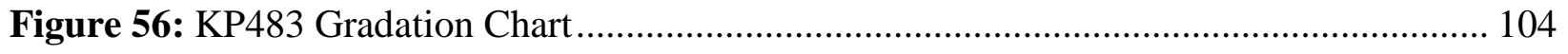

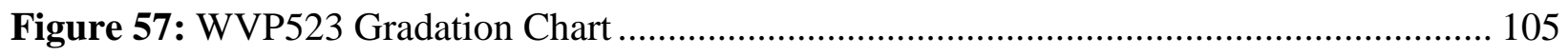

Figure 58: WVP766 Gradation Chart ............................................................................. 106

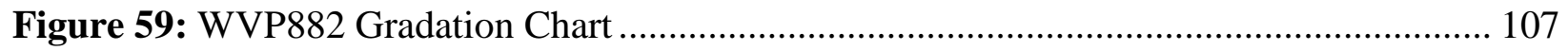


Figure 60: Phase Angle Drop for AA937 S5, S6, and S7 ................................................ 162

Figure 61: Phase Angle Drop for JAP909 S6, S7, and S8 ............................................... 162

Figure 62: Phase Angle Drop for JFA060 S5, S6, and S7 ............................................... 163

Figure 63: Phase Angle Drop for JFA115 S6, S7, and S8 ............................................... 163

Figure 64: Phase Angle Drop for JFA429 S6, S7, and S8 ............................................... 164

Figure 65: Phase Angle Drop for KP483 S6, S7, and S8 ................................................. 164

Figure 66: Phase Angle Drop for WVP523 S6, S7, and S8 ............................................ 165

Figure 67: Phase Angle Drop for WVP766 S6, S7, and S8 ............................................. 165

Figure 68: Phase Angle Drop for WVP882 S7, S8, and S9 ........................................... 166

Figure 69: Alpha-Fatigue AA937 Peak Dynamic Modulus Output ..................................... 167

Figure 70: Alpha-Fatigue AA937 Peak Damage Functions Output..................................... 168

Figure 71: Alpha-Fatigue AA937 Peak Model Prediction Output ........................................ 169

Figure 72: Alpha-Fatigue AA937 Default Dynamic Modulus Output .................................. 170

Figure 73: Alpha-Fatigue AA937 Default Damage Functions Output................................. 171

Figure 74: Alpha-Fatigue AA937 Default Model Prediction Output ................................... 172

Figure 75: Alpha-Fatigue JAP909 Peak Dynamic Modulus Output ................................... 173

Figure 76: Alpha-Fatigue JAP909 Peak Damage Functions Output ..................................... 174

Figure 77: Alpha-Fatigue JAP909 Peak Model Prediction Output ...................................... 175

Figure 78: Alpha-Fatigue JAP909 Default Dynamic Modulus Output ................................. 176

Figure 79: Alpha-Fatigue JAP909 Default Damage Functions Output ................................. 177

Figure 80: Alpha-Fatigue JAP909 Default Model Prediction Output ................................... 178

Figure 81: Alpha-Fatigue JFA060 Peak Dynamic Modulus Output .................................... 179

Figure 82: Alpha-Fatigue JFA060 Peak Damage Functions Output .................................... 180

Figure 83: Alpha-Fatigue JFA060 Peak Model Prediction Output ...................................... 181

Figure 84: Alpha-Fatigue JFA060 Default Dynamic Modulus Output ................................. 182

Figure 85: Alpha-Fatigue JFA060 Default Damage Functions Output ................................ 183

Figure 86: Alpha-Fatigue JFA060 Default Model Prediction Output ................................... 184

Figure 87: Alpha-Fatigue JFA115 Peak Dynamic Modulus Output .................................... 185

Figure 88: Alpha-Fatigue JFA115 Peak Damage Functions Output .................................... 186

Figure 89: Alpha-Fatigue JFA115 Peak Model Prediction Output ...................................... 187

Figure 90: Alpha-Fatigue JFA115 Default Dynamic Modulus Output ................................. 188 
Figure 91: Alpha-Fatigue JFA115 Default Damage Functions Output................................. 189

Figure 92: Alpha-Fatigue JFA115 Default Model Prediction Output .................................... 190

Figure 93: Alpha-Fatigue JFA429 Peak Dynamic Modulus Output .................................... 191

Figure 94: Alpha-Fatigue JFA060 Peak Damage Functions Output ..................................... 192

Figure 95: Alpha-Fatigue JFA429 Peak Model Prediction Output ...................................... 193

Figure 96: Alpha-Fatigue JFA429 Default Dynamic Modulus Output ................................. 194

Figure 97: Alpha-Fatigue JFA429 Default Damage Functions Output................................. 195

Figure 98: Alpha-Fatigue JFA429 Default Model Prediction Output ................................... 196

Figure 99: Alpha-Fatigue KP483 Peak Dynamic Modulus Output...................................... 197

Figure 100: Alpha-Fatigue KP483 Peak Damage Functions Output.................................... 198

Figure 101: Alpha-Fatigue KP483 Peak Model Prediction Output ...................................... 199

Figure 102: Alpha-Fatigue KP483 Default Dynamic Modulus Output.................................. 200

Figure 103: Alpha-Fatigue KP483 Default Damage Functions Output ............................... 201

Figure 104: Alpha-Fatigue KP483 Default Model Prediction Output................................... 202

Figure 105: Alpha-Fatigue WVP523 Peak Dynamic Modulus Output ................................ 203

Figure 106: Alpha-Fatigue WVP523 Peak Damage Functions Output................................ 204

Figure 107: Alpha-Fatigue WVP523 Peak Model Prediction Output .................................... 205

Figure 108: Alpha-Fatigue WVP523 Default Dynamic Modulus Output............................. 206

Figure 109: Alpha-Fatigue WVP523 Default Damage Functions Output.............................. 207

Figure 110: Alpha-Fatigue WVP523 Default Model Prediction Output ................................ 208

Figure 111: Alpha-Fatigue WVP766 Peak Dynamic Modulus Output ................................. 209

Figure 112: Alpha-Fatigue WVP766 Peak Damage Functions Output................................ 210

Figure 113: Alpha-Fatigue WVP766 Peak Model Prediction Output .................................. 211

Figure 114: Alpha-Fatigue WVP766 Default Dynamic Modulus Output............................. 212

Figure 115: Alpha-Fatigue WVP766 Default Damage Functions Output (S7 at $15^{\circ} \mathrm{C}$ is S8) ... 213

Figure 116: Alpha-Fatigue WVP766 Default Model Prediction Output ............................... 214

Figure 117: Alpha-Fatigue WVP882 Peak Dynamic Modulus Output .................................. 215

Figure 118: Alpha-Fatigue WVP882 Peak Damage Functions Output................................. 216

Figure 119: Alpha-Fatigue WVP882 Peak Model Prediction Output ................................... 217

Figure 120: Alpha-Fatigue WVP882 Default Dynamic Modulus Output.............................. 218

Figure 121: Alpha-Fatigue WVP882 Default Damage Functions Output.............................. 219 
Figure 122: Alpha-Fatigue WVP882 Default Model Prediction Output ................................ 220

Figure 123: Coring and Sawing Laboratory Equipment................................................. 222

Figure 124: CoreLok Adjustments for Gyratory Samples................................................ 222

Figure 125: Conditional Chamber for Temperatures $17^{\circ} \mathrm{C}$ and Lower ................................ 223 


\section{List of Tables}

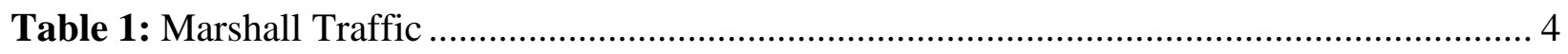

Table 2: Literature Review Target Air Void Contents for Performance Testing.......................... 12

Table 3: AASHTO PP 61 Recommended Testing Temperatures and Loading Frequencies ...... 17

Table 4: Regression Coefficients from Hou (2009) and Witczak et al. (2013) ............................ 21

Table 5: Flow Number Test Parameters ............................................................................. 24

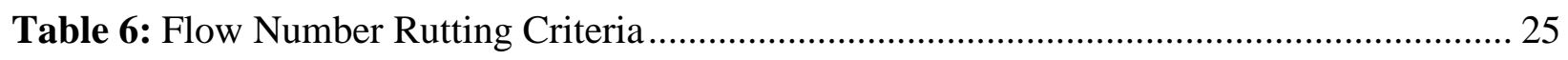

Table 7: Mixes Provided from Asphalt Plants throughout West Virginia ................................... 28

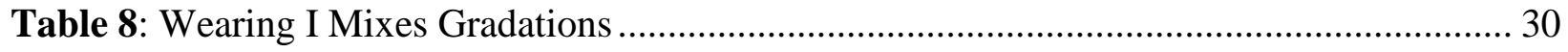

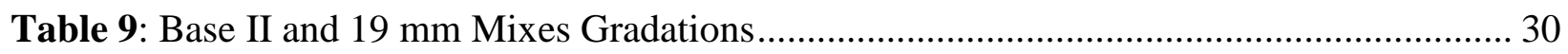

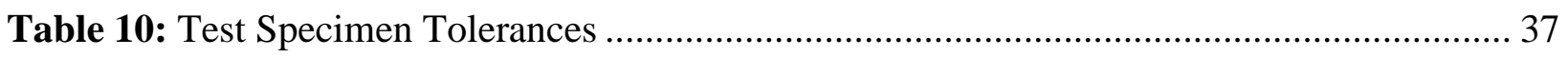

Table 11: Mix Masses Placed in Mold Used for Each Sample Set............................................. 37

Table 12: On-specimen Strain Adjustments for Second and Third Fatigue Specimen ................ 41

Table 13: Cycles to Failure Micro Strain Adjustments for Replicates ........................................ 41

Table 14: Fatigue Testing Compilation .................................................................................... 43

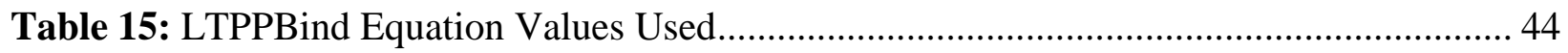

Table 16: Variation in $\mathrm{G}_{\mathrm{mm}}$ between JMF and Laboratory ...................................................... 46

Table 17: $T$-statistic for the Three $\mathrm{G}_{\mathrm{mb}}$ Methods and Averaged Values ...................................... 48

Table 18: Comparison of Sample Third Air Void Averages to Entire Sample Air Void Average

Table 19: Phase Angles Averages and Standard Deviations from DM Testing .......................... 54

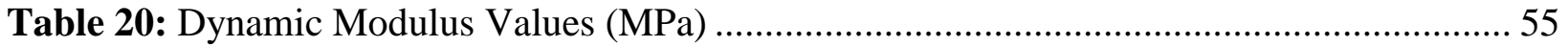

Table 21: Dynamic Modulus Averages, Standard Deviation, and Coefficient of Variation (MPa) 56

Table 22: Master Curve Final Parameters.............................................................................. 60

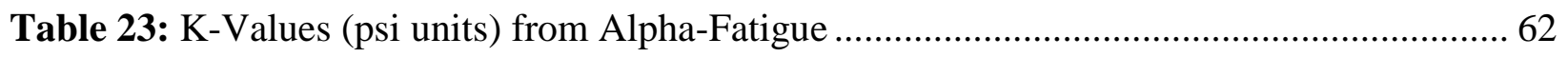

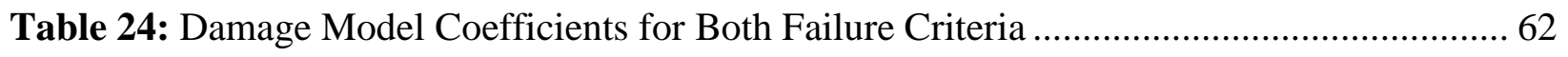

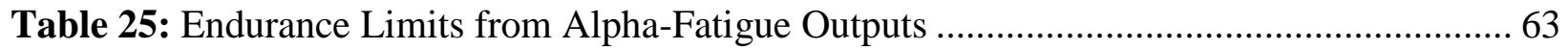

Table 26: Endurance Limits Ranking for Peak and Default K-values........................................... 64

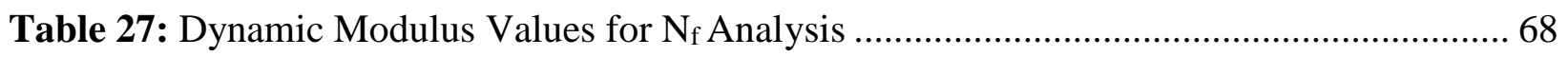


Table 28: KENPAVE Full Depth and Conventional $N_{\mathrm{f}}$ Values ........................................... 68

Table 29: Conventional Pavement KENPAVE Analysis Using Alpha-Fatigue K-Values ......... 69

Table 30: Data Smoothing Flow Number and Permanent Strain for Wearing I Mixes.............. 70

Table 31: Data Smoothing Flow Number and Permanent Strain for Base II and $19 \mathrm{~mm}$ Mixes 71

Table 32: Francken Model Flow Number Summary of Wearing I Mixes................................ 73

Table 33: Francken Model Flow Number Summary of Base II and 19 mm Mixes ................. 73

Table 34: Flow Number Differences between Data Smoothing and Francken Model ............... 74

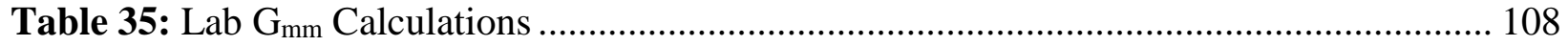

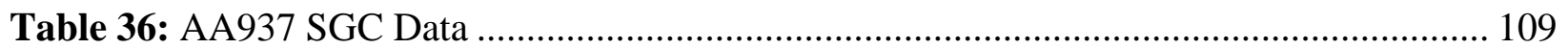

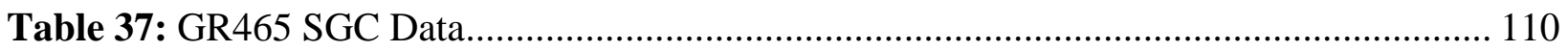

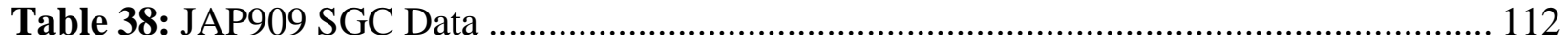

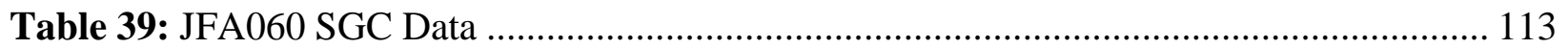

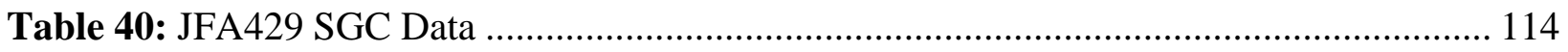

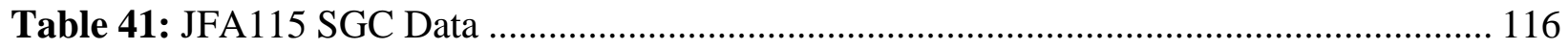

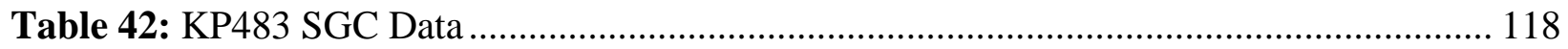

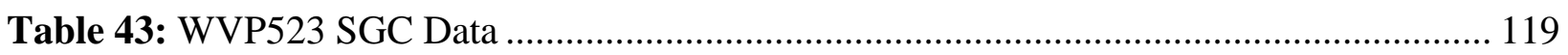

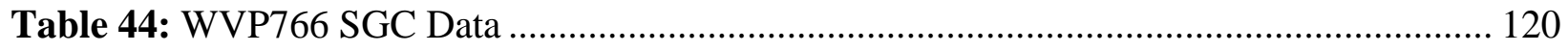

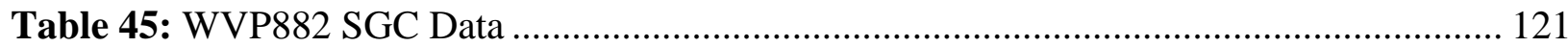

Table 46: Marshall Verification Data ............................................................................ 122

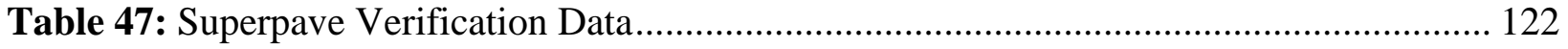

Table 48: Bulk Mix Specific Gravities $\left(\mathrm{G}_{\mathrm{mb}}\right)$ for Thirds ............................................. 123

Table 49: AA937 Sample Thirds Geometry and VTM.................................................. 125

Table 50: JAP909 Sample Thirds Geometry and VTM.................................................... 125

Table 51: JFA060 Sample Thirds Geometry and VTM................................................. 126

Table 53: JFA115 Sample Thirds Geometry and VTM.................................................... 126

Table 52: JFA429 Sample Thirds Geometry and VTM................................................... 127

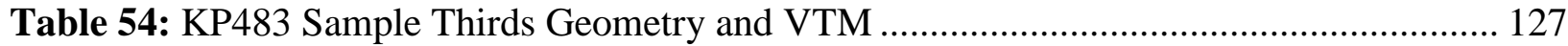

Table 55: WVP523 Sample Thirds Geometry and VTM …........................................... 128

Table 56: WVP766 Sample Thirds Geometry and VTM .............................................. 128

Table 57: WVP882 Sample Thirds Geometry and VTM .................................................. 129

Table 58: AA937 $\mathrm{G}_{\mathrm{mb}}$ Before and After Trimming ....................................................... 130 


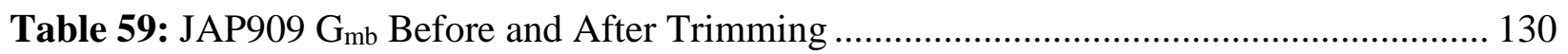

Table 60: JFA060 $\mathrm{G}_{\mathrm{mb}}$ Before and After Trimming ............................................................... 131

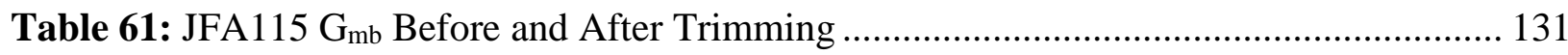

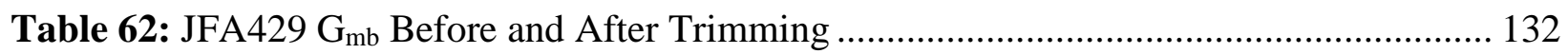

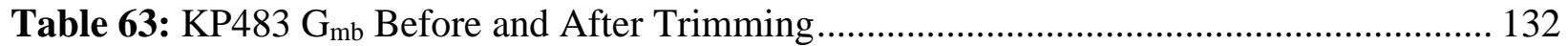

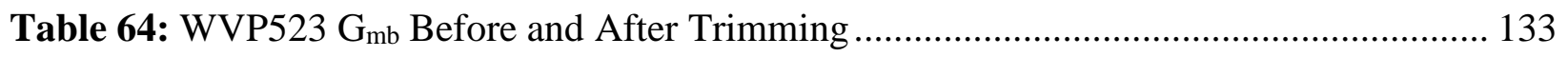

Table 65: WVP766 G $\mathrm{G}_{\mathrm{mb}}$ Before and After Trimming ......................................................... 133

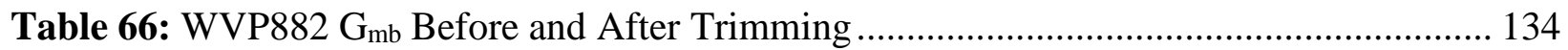

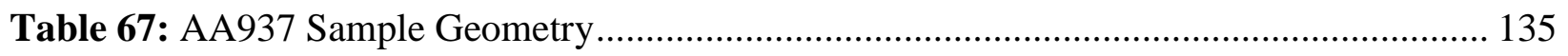

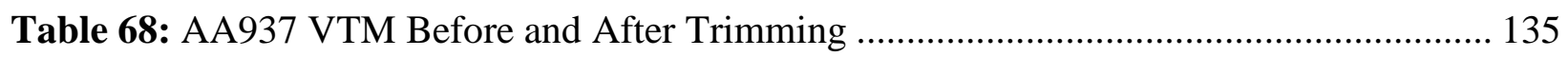

Table 69: AA937 VMA Before and After Trimming ........................................................... 136

Table 70: AA937 VFA Before and After Trimming ............................................................... 136

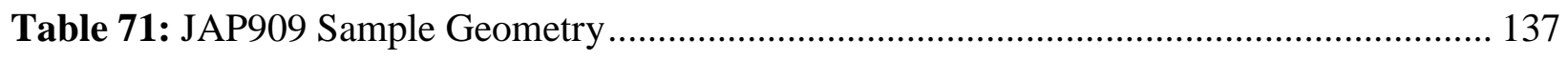

Table 72: JAP909 VTM Before and After Trimming.......................................................... 137

Table 73: JAP909 VMA Before and After Trimming ……….............................................. 138

Table 74: JAP909 VFA Before and After Trimming ........................................................... 138

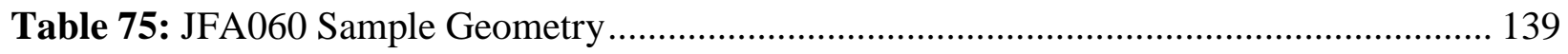

Table 76: JFA060 VTM Before and After Trimming......................................................... 139

Table 77: JFA060 VMA Before and After Trimming ......................................................... 140

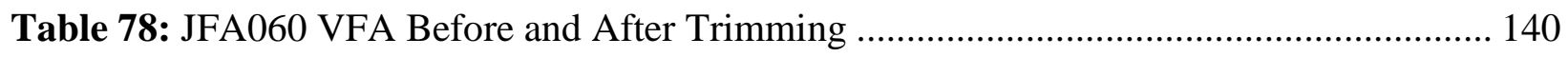

Table 79: JFA115 Sample Geometry ................................................................................... 141

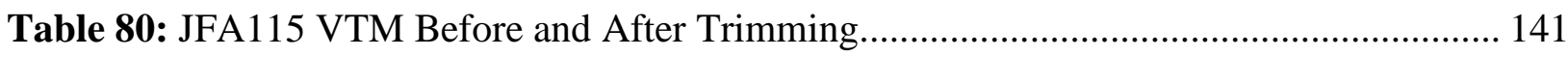

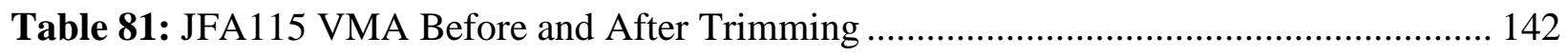

Table 82: JFA115 VFA Before and After Trimming ............................................................ 142

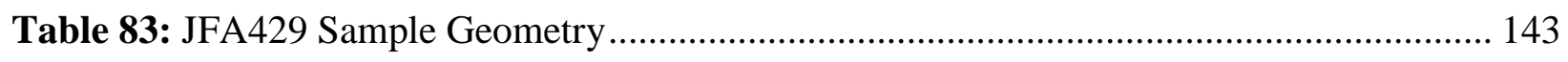

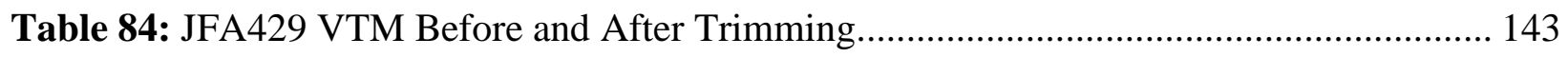

Table 85: JFA429 VMA Before and After Trimming ............................................................ 144

Table 86: JFA429 VFA Before and After Trimming ............................................................ 144

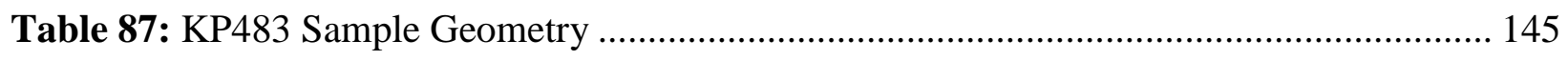

Table 88: KP483 VTM Before and After Trimming ............................................................. 145

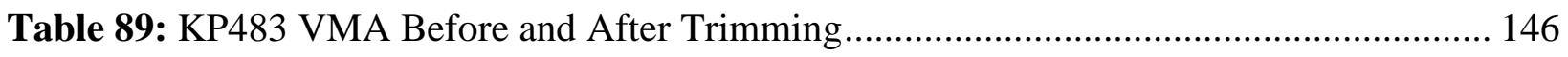




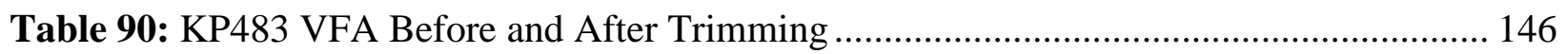

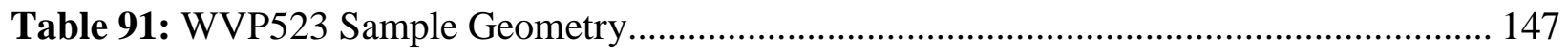

Table 92: WVP523 VTM Before and After Trimming .......................................................... 147

Table 93: WVP523 VMA Before and After Trimming .................................................... 148

Table 94: WVP523 VFA Before and After Trimming ........................................................... 148

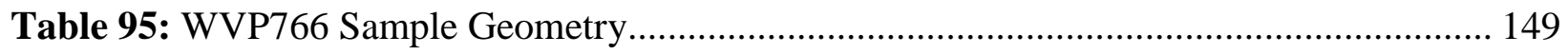

Table 96: WVP766 VTM Before and After Trimming ........................................................ 149

Table 97: WVP766 VMA Before and After Trimming ........................................................ 150

Table 98: WVP766 VFA Before and After Trimming .............................................................. 150

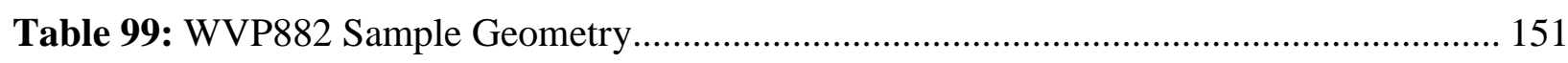

Table 100: WVP882 VTM Before and After Trimming ......................................................... 151

Table 101: WVP882 VMA Before and After Trimming .......................................................... 152

Table 102: WVP882 VFA Before and After Trimming ........................................................ 152

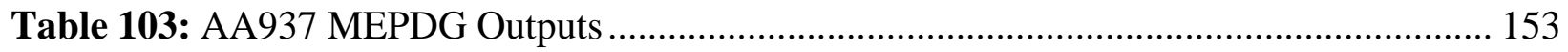

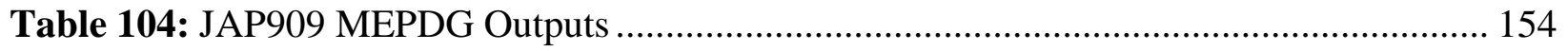

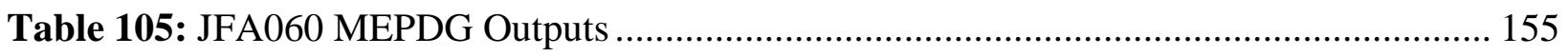

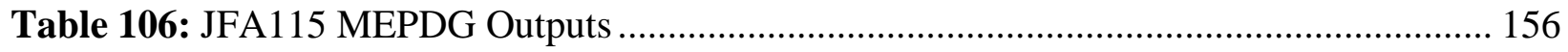

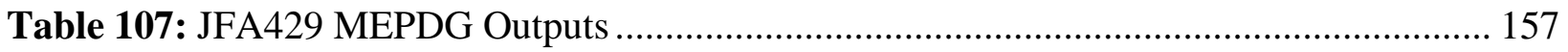

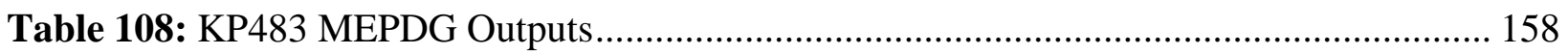

Table 109: WVP523 MEPDG Outputs ............................................................................. 159

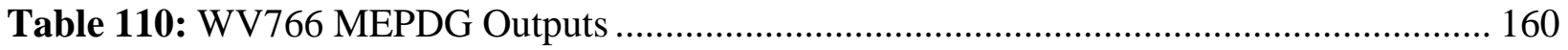

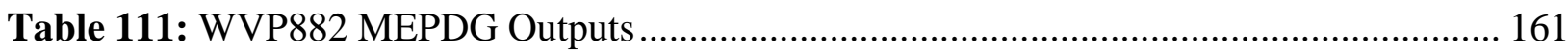




\section{List of Abbreviations}

$$
\begin{aligned}
& \text { Abs. = Absorption } \\
& \text { AMPT = Asphalt Mixture Performance Tester } \\
& \text { AVG = Average } \\
& \text { B = Bottom } \\
& \text { CL = CoreLok } \\
& \text { CV = Coefficient of Variation } \\
& \text { DM = Dynamic Modulus } \\
& \text { Dim. = Dimensional } \\
& \text { ESAL = Equivalent Single Axle Load } \\
& \text { FN = Flow Number } \\
& \text { FT = Fatigue Test } \\
& \text { GYR = Gyrations } \\
& \text { H = High } \\
& \text { L = Low }
\end{aligned}
$$

LVDT $=$ Linear Variable Differential Transformer

$\mathrm{M}=$ Middle

NMAS $=$ Nominal Maximum Aggregate Size

$\mathrm{PG}=$ Performance Grade

RAP $=$ Reclaimed Asphalt Pavement

REP $=$ Replicate

$\mathrm{S}=$ Sample

$\mathrm{SD}=$ Standard Deviation

SGC $=$ Superpave Gyratory Compactor

SS $=$ Sample (Bulk)

SSD $=$ Saturated Surface-Dry

STAT $=$ Statistic

$\mathrm{T}=\mathrm{Top}$

VFA = Voids Filled with Asphalt

$\mathrm{VMA}=$ Voids in the Mineral Aggregate

$\mathrm{VTM}=$ Void in the Total Mix 


\section{Chapter 1: Introduction}

\section{Background}

Roadway infrastructure connects people to their destinations. Continuing to facilitate smooth transition from one place to another requires more extensive research of asphalt pavement distress, deterioration, and failure. Rutting and fatigue distress are common causes of premature failure of asphalt pavements. According to the 2015 West Virginia Blue Ribbon Commission on Highways (WVBRH), driving on rough roads costs West Virginia motorists a total of $\$ 400$ million annually in extra vehicle operating costs which include accelerated vehicle depreciation, additional repair costs, increased fuel consumption, and tire wear (WVBRCH, 2015). In West Virginia alone, there are approximately 36,000 miles of state-maintained highways. Economically, the state of West Virginia spent $\$ 30$ million on pavement preservation in 2012 and $\$ 500$ million for annual paving maintenance was passed in 2015 (WVBRH, 2015). Therefore, in situ pavements and maintenance of roads must meet design specifications as closely as possible.

There are numerous hot mix asphalt plants throughout the state of West Virginia. Each has its own asphalt mix designs used for construction and maintenance. Reviewing and analyzing asphalt mixes generated by various state asphalt plants allows a quantitative comparison of mix designs for the state. Meeting modern performance demands is essential to the continued success of pavement life. Fatigue and rutting damage are two primary forms of pavement deterioration which can be analyzed using the Asphalt Mixture Performance Tester (AMPT). Analyzing said distresses and dynamic modulus values of the asphalt concrete sources currently used throughout the state can provide insight for manufacturer's current mix designs and how the material properties contrast among WV state plants.

\section{Problem Statement}

This research was completed to compare and contrast a sample of mix designs currently used on WV roadways using the Asphalt Mixture Performance Tester (AMPT). Evaluating pavements subjected to existing traffic volumes throughout WV can provide insight to both the 
WVDOH and supporting contractors on their product's material properties and performance. The AMPT has dynamic modulus, fatigue, flow time, and flow number testing capabilities.

Expanding knowledge on how pavements should perform and withstand loading and environmental distress contributes to saving time and money over a pavement's lifespan. This research provides a quantitative analysis of how a sample of mix designs performed.

\section{Objectives}

There were two main objectives for this research: 1) test WV plant-produced mixes using the Asphalt Mixture Performance Tester (AMPT) and 2) provide a comparison of the mixes and their performance in uniformity, dynamic modulus, fatigue, and flow number testing.

Achieving these objectives is important because the studied asphalt concrete mixes are used throughout WV for past and current paving projects. Understanding what comprises each mix design compared to the aforementioned material performance properties, allows the state to better understand how the mixes compare to one another according to composition.

\section{Scope and Limitations}

The amount of HMA provided from each plant was limited to what was received. All mixes were plant-produced. There was no way to verify mix designs because correction factors and raw aggregate were not available to make laboratory replicate mixes. Once a mix had run out, an entire new batch would have had to have been acquired with all preliminary volumetric measurements and testing being rerun because the mix could have subtle changes in gradation between batches.

This research was performed on production samples collected from contractors during a limited time frame. There was no opportunity to designate mix types. As a result, there was no statistically designed experimental plan for this research. Thus, the results provide insight into the mixes produced in West Virginia, but there are limitations to the conclusions that can be drawn from the results. 


\section{Report Outline}

There are five sections to this report starting with the first chapter being the introduction. Chapter two is a literature review covering HMA, Volumetric Properties, AMPT, Dynamic Modulus and Phase Angle, Fatigue, and Flow Number. Chapter three describes the research methodology for the project. The fourth chapter presents a summary of data, Mastersolver, Alpha-Fatigue, KENPAVE, and Flow Number results. Chapter five summarizes conclusions and provides recommendations for future work. Lastly, the appendices provide supplemental data. 


\section{Chapter 2: Literature Review}

\section{Asphalt Mixture Design}

Hot mix asphalt (HMA) is a composite material comprised of aggregates, asphalt binder, and air voids. At various temperatures, asphalt mixtures behave differently. At low temperatures, HMA behaves similarly to elastic solids while at high temperatures the composite has the viscous properties of a liquid while maintaining some properties of plastic solids (Rodezno, 2010). There are three main mix design methods: Hveem, Marshall, and Superpave. Marshall and Superpave are explained in more detail below.

Marshall Design Method was developed by Bruce G. Marshall of the Mississippi Highway Department in 1939. During World War II, the U.S. Army Corp of Civil Engineers refined this mix design method to accommodate increased wheel loads and tire pressures of military aircrafts. Development was continued by U.S. Waterways Experiment Station (WES) through the 1950s looking at material tests, traffic loading, and weather influence. In Marshall Design Method, selecting a binder content that correlates to a desired density while maintaining minimum stability, flow range values, and volumetric properties is the primary goal (Cross, 1992 \& Vasavi, 2002).

The Marshall method is still used in some states for its simplicity, compaction, and low cost. There are six steps in the design process: (1) Aggregate selection; (2) Asphalt binder selection; (3) Sample preparation; (4) Stability determination using Marshall stability and flow test; (5) Volumetric analysis; and (6) Optimum asphalt binder content selection. Marshall samples are compacted using the Marshall Hammer. The number of blows applied to each side of a sample is based on the traffic volume, Table 1 (Gillispie, 2011). The Marshall mix design method implemented in West Virginia is set forth in MP 401.02.22. In general it follows the recommendations of the Asphalt Institute with the exception that the compaction level of 50 blows per side is used for both light and medium traffic.

Table 1: Marshall Traffic

\begin{tabular}{|c|c|c|}
\hline Marshall Traffic & Number of Blows & ESAL \\
\hline Medium & 50 & $10^{4}$ to $10^{6}$ \\
\hline Heavy & 75 & $10^{6}<$ \\
\hline
\end{tabular}


In 1987 Strategic Highway Research Program (SHRP) began the development of the Superior Performing Asphalt Paving (Superpave) mix design method which was subsequently implemented by the Federal Highway Administration (FHWA) in 1993 (Al-Mistarehi, 2014). The new mix design method was created to accommodate modern traffic patterns and heavier axle loads. Superpave contains five main steps: (1) Aggregate selection; (2) Asphalt binder selection; (3) Design aggregate structure; (4) Design binder content; and (5) Moisture sensitivity

The Superpave Gyratory Compactor (SGC) was designed to better simulate field compaction and make more consistent samples than the Marshall hammer. The SGC applies a $600 \mathrm{kPa}$ load to a specimen cross section diameter of $150 \mathrm{~mm}$ at a $1.16^{\circ}$ tilt and gyrates molds at a rate of $30 \pm 0.5$ gyrations per minute (AASHTO T 312). Advantages of this laboratory compaction method are transverse movement of asphalt mix particles; larger molds retain heat longer; and the tilted rotation better mimics that of a field compactor. Samples are compacted to the design number of gyrations, and then the volumetric properties are measured to determine if the samples meet design criteria. The SGC was designed to prepare samples measuring $150 \mathrm{~mm}$ in diameter by $115 \pm 5 \mathrm{~mm}$ height to accommodate large stone mixes up to $37.5 \mathrm{~mm}$. An image of an SGC and SGC mold can be seen in Figure 1.

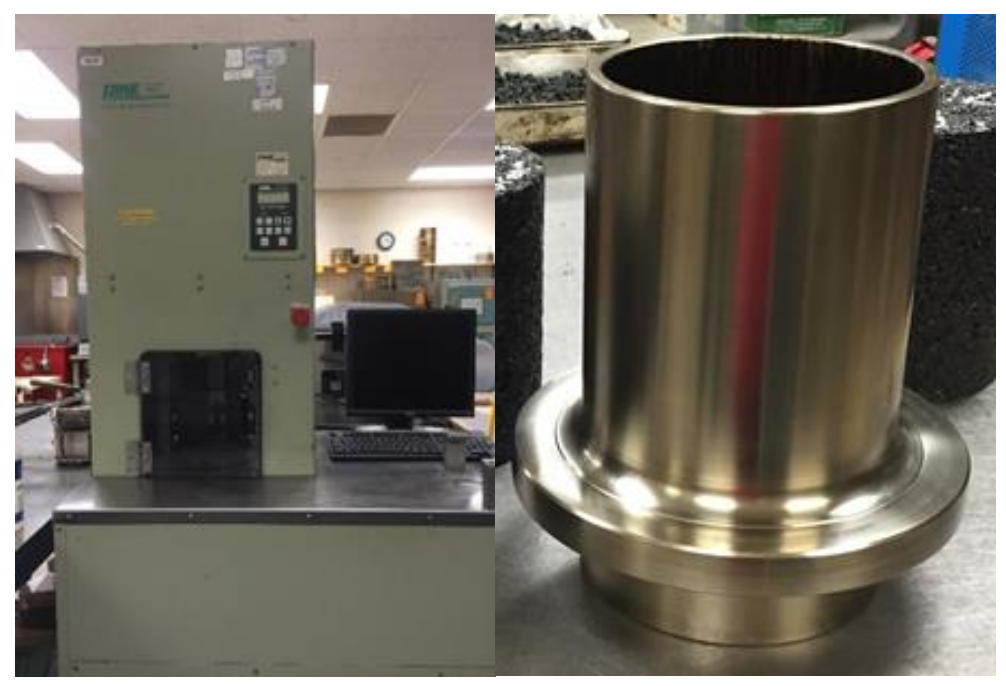

Figure 1: Superpave Gyratory Compactor and Molds

Regardless of method, the main reason for constructing a mix design is to determine suitable combinations of aggregates and asphalt binder content to achieve optimum pavement performance. The job mix formula (JMF) is like a "recipe" for the design. A JMF is refined 
within the asphalt mixture plant where the mix is proportioned, heated, and mix design components are combined (Mohammad et al., 2015).

Slag and Reclaimed Asphalt Pavement (RAP) are two materials found in literature to have both positive and negative impacts on asphalt concrete material properties. Some advantages of RAP include conservation of asphalt and aggregate resources, conservation of energy, and reduction in construction costs. It has been found that RAP can enhance mix stiffness properties (Smith, 2015). However, it has also been found that fatigue life can decrease when a high percentage of RAP is used (Vukosavljevic, 2006).

Slag is a stone-like, waste-matter byproduct separated from metals during the refining of iron ore. This material is incorporated in numerous WV mix designs because it is a readily available product in the southwestern part of the state. According to John Emry of the National Slag Association (1984), the incorporation of slag as an aggregate has both positive and negative features. Slag has shown to resist abrasion due to its high particle density adding to better skid resistance than natural aggregate (Emry, 1984 \& Haifang et al., 2014). However, some drawbacks to slag include that it is inherently brittle, contains a high iron content which can lead to rust, has a porous exterior, and can be expansive. Within a mix plant, aggregates are not always completely coated with binder. Fine aggregates comprised of highly oxidative material can expand and disintegrate over time leading to weak points in an asphalt structure.

\section{Volumetric Properties}

According to Cornelison (2013), in-place volumetric properties are the number one contributing factor to asphalt pavement performance and durability. Determining the volumetric properties involves a combination of the aggregate properties, admixture type, and asphalt binder properties. Gradation, maximum specific gravity, bulk specific gravity, absorption, voids in the total mix (VTM) or air voids, voids in the mineral aggregate (VMA), and voids filled with asphalt (VFA) are discussed in further detail.

\section{Gradation}

According to Cornelison (2013), minor deviations in gradation or asphalt binder is tolerable if volumetric properties still meet requirements. On the contrary, Mohammad et al. 
(2015) found that slight differences in gradation, while within tolerances, might lead to significant differences in important volumetric properties, such as air voids and VFA.

\section{Maximum Specific Gravity (Rice)}

James M. Rice developed the maximum specific gravity (Rice) test method which became an ASTM standard in 1964. This allowed an indirect determination of mixture air voids when compared to bulk specific gravity of a compacted specimen while accounting for asphalt absorption to the aggregate (Cornelison, 2013). Specific gravity is the ratio of the mass of a solid or liquid to the mass of an equal volume of distilled water at a specified temperature. The maximum specific gravity of a mix is the specific gravity of the mix excluding air voids. In other words, $G_{m m}$ is the case if all air was removed from a mix and only the aggregate and asphalt binder remained. This calculation is critical in determining the air void content in HMA. Equation 1 displays the calculation.

$G_{m m}=\frac{M_{S}}{M_{s}+M_{b s}-M_{b m s}}$

Where:

$M_{s}=$ Dry Mass of Sample, $g$

$M_{b s}=$ Mass of Vacuum Bowl Submerged, $g$

$M_{b m s}=$ Mass of bowl and submerged sample in water, $g$

\section{Bulk Specific Gravity}

Bulk specific gravity of a mixture $\left(\mathrm{G}_{\mathrm{mb}}\right)$ is used to determine the specific gravity of a compacted asphalt sample by relating the weight of a sample to the volume of water it displaces. While multiple bulk specific gravity measurement methods are available, AASHTO T 166 saturated-surface dry (SSD) is the standard recommendation. Figure 2 displays voids on the outer surface of an asphalt sample filled with water as opposed to Figure 3 showing all the places water can be lost when performing the SSD method. If these voids are not filled with water, then they are not accounted for in the calculation which leads to inaccurate measurements. However, 
CoreLok method is becoming the preferred method of the WVDOH. Three methods are listed and explained below: SSD, CoreLok, and Dimensional.

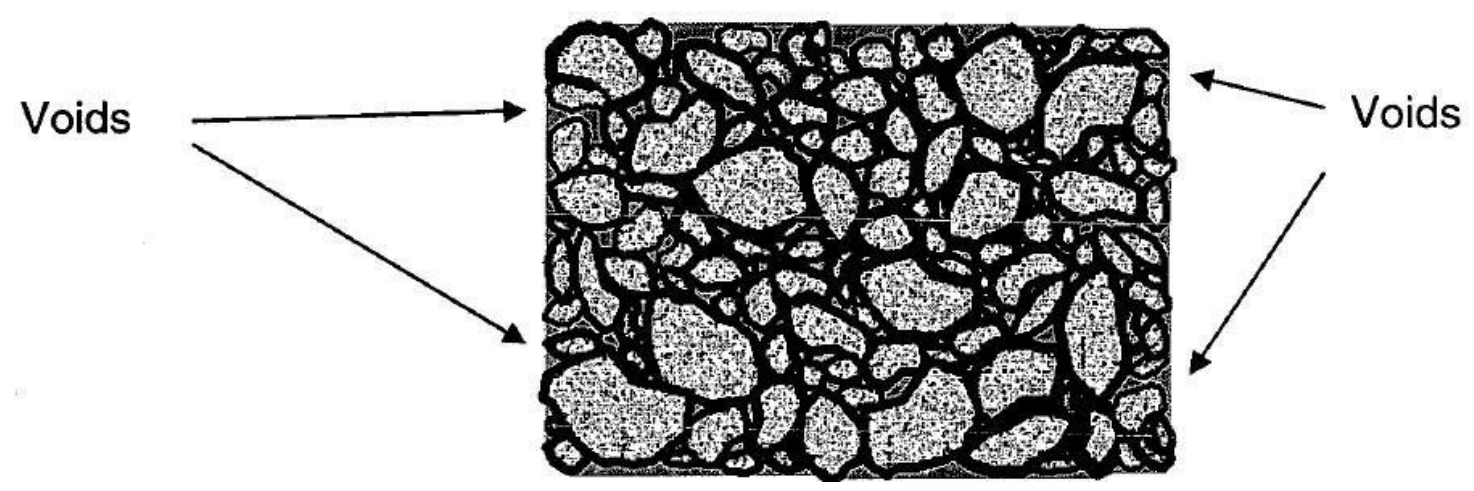

Figure 2: Compacted Asphalt with Water Filled Voids (Yan, 2012)

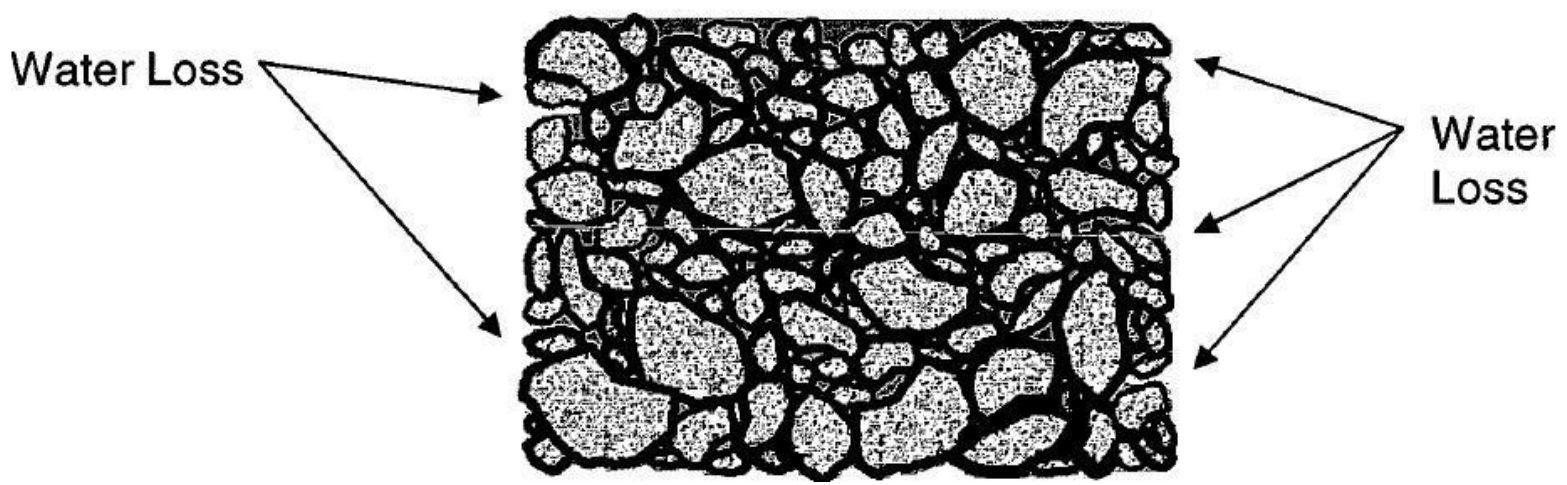

Figure 3: Potential Water Loss Areas (Yan, 2012)

\section{Saturated Surface-Dry (SSD)}

From AASHTO T 166, SSD stands for saturated surface-dry and is defined as the specimen condition when the external air voids are filled with water and the surface is dry. Procedurally, this method involves weighing and recording the dry sample mass, submerging the specimen in $77^{\circ} \mathrm{F}\left(25^{\circ} \mathrm{C}\right)$ water for 3 to 5 minutes and recording the submerged weight. Lastly, the sample is removed from the water, rolled one full diameter on a damp towel, each face (top and bottom) of the sample is blotted on the towel, and the surface-dried sample weight is measured. Equation 2 shows the calculation for SSD.

$G_{m b}=\frac{M_{D R Y}}{M_{S S D}-M_{S U B}}$ 
Where:

$M_{D R Y}=$ Mass of dry specimen, $g$

$M_{S S D}=$ Mass of saturated surface dry specimen, $g$

$M_{S U B}=$ Mass of specimen submerged in water, $g$

If the surface of the sample has large voids, then the drying process may remove too much water. Hence, the SSD method should not be used if the sample has more than two percent absorption.

\section{CoreLok}

The CoreLok $\mathrm{G}_{\mathrm{mb}}$ method evolved from an increased use in coarse and open graded mixes $\left(\right.$ CoreLok $^{\circledR}$ Operator's Guide, 2011). Determining accurate bulk specific gravity measurements for open graded mixes can be difficult due to their high absorption and drainage rates. AASHTO T 331 test specification requires vacuum sealing the sample. The Instro Tek ${ }^{\circledR}$ CoreLok machine can be used (Figure 4). This is a volumetric measurement made using a vacuum chamber to shrink wrap a plastic bag around the sample. This is a ten step process: 1) weigh sample, 2) weigh the bag, 3) place sample in the bag inside the vacuum sealing machine, 4) vacuum seal sample, 5) weigh vacuumed sample, 6) submerge vacuumed sample in water, 7) record submerged mass, 8) remove from water, 9) cut bag and remove sample, and 10) weigh sample once more. Step 10 is used to ensure no more than five grams of water permeated the bag. The calculation can be seen in Equation 3. CoreLok method involves a bag correction factor which is located in the CoreLok manual.

$G_{m b}=\frac{M_{s}}{\left(\left(M_{b}+M_{s a}\right)-M_{s s}\right)-\frac{M_{b}}{G_{b a}}}$

Where:

$M_{b}=$ bag mass, $g$

$M_{s a}=$ dry sample mass after water submersion, $g$

$M_{s s}=$ sealed sample mass in water, $g$

$G_{b a}=$ bag apparent gravity

$M_{s}=$ mass of dry core 


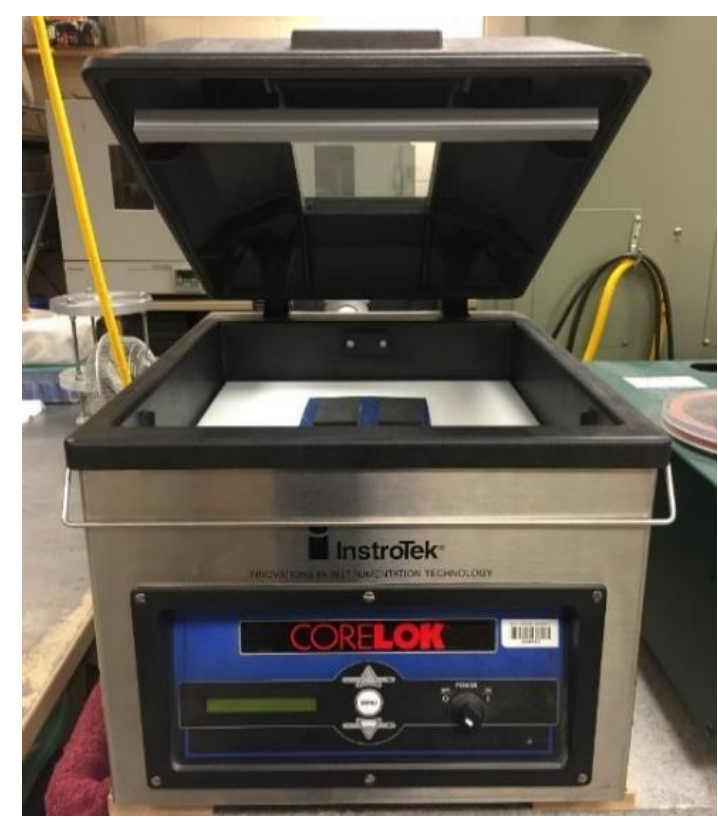

Figure 4: Instro Tek ${ }^{\circledR}$ CoreLok Machine

\section{Dimensional}

The height-diameter method or dimensional method is based on the standard specified in AASHTO T 269. Procedurally, this $\mathrm{G}_{\mathrm{mb}}$ method is most advantageous because it is simple, quick, and inexpensive. The height-diameter sample dimensions and mass of the sample are needed to calculate sample density. Equation 4 displays the calculation.

$G_{m b}=1000 \times\left(\frac{\rho_{\text {sample }}}{\rho_{\text {water }}}\right)$

Where:

$\rho_{\text {sample }}=$ density of the sample (mass of the sample divided by the volume)

$\rho_{\text {water }}=$ density of water at $25^{\circ} \mathrm{C}\left(0.99707 \mathrm{~g} / \mathrm{cm}^{3}\right)$

This method treats the voids on the surface of the sample as part of the volume of the sample. For samples compacted with either the Marshall hammer or SGC, these surface voids should not be considered as part of the sample. However, the external voids on cut faces produced by sawing and coring are part of the sample's volume and should be included when determining the bulk specific gravity. 


\section{Absorption}

Absorption is defined as the amount of water "absorbed" by an asphalt specimen when submerged in water. This is an indication of a pavement's ability to withstand water permeation. Equation 5 displays the calculation for water absorption of an asphalt concrete sample.

Water Absorption (\%) $=\frac{M_{S S D}-M_{D R Y}}{M_{D R Y}}$

Where:

$M_{D R Y}=$ Mass of dry specimen, $g$

$M_{S S D}=$ Mass of saturated surface dry specimen, $g$

Note in Equation 5 that the amount of water "absorbed" is the difference between the mass at SSD and the dry mass. Hence, absorption is primarily based on the volume of the external voids and does not indicate the volume of the internal voids.

\section{Research Comparing Bulk Specific Gravity Methods}

According to AASHTO T 166 SSD may be used for fine graded mixes when water absorption is less than 2.0 percent. SSD is also considered adequate for determining the $\mathrm{G}_{\mathrm{mb}}$ of conventionally designed fine-graded mixes, but can give erroneous results for coarse-graded mixes. Moreover, Griffith (2009) claims $\mathrm{G}_{\mathrm{mb}}$ values from SSD and CoreLok testing methods were significantly different when specimens have low air void contents, and the CoreLok method results in lower bulk specific gravity measurements than the SSD method. However, as the air void content increased the differences between the two methods diverged (Griffith, 2009).

\section{Voids in the Total Mix (VTM)}

Air void distribution is key to continued integrity of pavement life and directly related to the bulk specific gravity of an asphalt mixture. Air void distribution is related to numerous pavement factors such as mix gradation, compaction effort, and compaction method. The higher the air void content, the increased likelihood of interconnected air voids throughout a pavement. 
Interconnected air voids create areas for water to become trapped which can cause thermal cracking when subjected to cold weather and freeze-thaw cycles.

Once bulk specific gravity value is determined, the main air void calculation among the three methods is the same. Equation 6 displays the VTM calculation.

$V T M=100 \times\left(1-\frac{G_{m b}}{G_{m m}}\right)$

Where:

$G_{m b}=$ bulk specific of the compacted mix

$G_{m m}=$ theoretical maximum specific gravity of the mix

Cornelison (2013) claims a reduction in air voids below 8.0 percent will result in significant fatigue life improvement, moisture resistance, and raveling resistance. Field target air void content ranges from 5 to 8 percent with anything over 8 percent considered unacceptable. Table 2 summarizes target air void values used in literature. In Table 2 DM, FN, and FT stand for dynamic modulus, flow number, and fatigue. As can be seen, 7.0 \pm 0.5 percent has been well documented in literature as a target air void content for testing with $10.0 \pm 0.5$ percent being the higher end of the range. Witczak (2013) found that the percent air voids for fatigue testing "was insignificant, especially at lower asphalt contents."

Table 2: Literature Review Target Air Void Contents for Performance Testing

\begin{tabular}{|c|c|c|}
\hline Reference Article & Target Air Void Content & Testing \\
\hline Bonaquist, 2010 & $7.0 \pm 0.5 \%$ & DM and FN \\
\hline Bonaquist, 2011b & $7.0 \pm 0.5 \%$ & DM and FN \\
\hline Vukosavljevic, 2006 & $4.0 \pm 0.5 \%$ and $6.0 \pm 1.0 \%$ & FT \\
\hline Rodezno, 2010 & $4.0 \pm 0.5 \%, 7.0 \pm 0.5 \%$, and $10.0 \pm 0.5 \%$ & FN \\
\hline Witczak et al., 2013 & $4.0 \pm 0.5 \%, 7.0 \pm 0.5 \%$, and $9.0 \pm 0.5 \%($ PG 64-22) & FT \\
\hline Hou, 2009 & $5.5 \pm 0.5 \%$ & FT \\
\hline
\end{tabular}

Chen et al. (2013) found that air voids close to the mold boundary were much higher than other regions, coarse aggregate $(\mathrm{CA})$ ratio influenced vertical air void distribution (gradations with higher CA ratio resulted in more uniform air voids), and the height of an asphalt mixture specimen had a significant effect on vertical air void distributions. 


\section{Assessing Test Specimen Uniformity}

For AMPT testing the air void uniformity is critical. AASHTO PP 60 specifies the method for testing the uniformity of air voids. After compaction, the samples are cored and trimmed to the dimensions used for AMPT testing. AASHTO PP 60 requires testing three replicate samples. Each replicate is cut into thirds. The $G_{m b}$ of each slice is measured and a t-test is used to determine if the $\mathrm{G}_{\mathrm{mb}}$ of the middle slice is statistically different from the top or bottom slices using equations 7 and 8 . The test statistic must be less than 2.78 to conclude that top and middle or bottom and middle slices possess equal $\mathrm{G}_{\mathrm{mb}}$ values. The test does not require a comparison between top and bottom thirds.

$$
s=\sqrt{\frac{s_{t, b}^{2}+s_{m}^{2}}{2}}
$$

Where:

$s=$ computed standard deviation

$s_{t, b}{ }^{2}=$ computed variance for the top or bottom slices

$s_{m}{ }^{2}=$ computed variance for the middle slices

$t=\frac{\left(\bar{y}_{t, b}-\bar{y}_{m}\right)}{0.8165(s)}$

Where:

$t=$ test statistic

$y_{t, b}=$ computed mean for the top or bottom slices

$y_{m}=$ computed mean for the middle slices

According to AASHTO PP 60, significant differences in $G_{m b}$ of the top and bottom slices relative to the middle indicate a systematic variation in density within the specimen; specimen with differences in the $G_{m b}$ for the top or bottom slices relative to the middle slices on the order of 0.025 have performed satisfactorily in the dynamic modulus, flow number, flow time, and continuum damage fatigue tests; and altering the height of the SGC specimen can improve the 
uniformity of the density in the test specimen. This result justifies coring and trimming laboratory compacted samples prior to performance testing.

\section{Voids in the Mineral Aggregate (VMA)}

Voids in the mineral aggregate indicate the film thickness on the surface of the aggregate. This is the limiting criteria for the minimum amount of binder needed to coat the aggregate. The calculation is shown in Equation 9.

$V M A=\frac{G_{m b} P_{s}}{G_{s b}}$

Where:

$G_{m b}=$ bulk specific of the compacted mix

$P_{s}=$ percent of aggregate in the mix

$G_{s b}=$ specific gravity of the bulk aggregate

\section{Voids Filled with Asphalt (VFA)}

Voids Filled with Asphalt is the amount of VMA that is filled with asphalt. This determines the maximum amount of asphalt needed for a mix design. Researchers have reported good correlations between VFA and rutting susceptibility (Cross, 1992). Equation 10 displays the VFA calculation.

$V F A=100 \times \frac{V M A-V T M}{V M A}$

Where:

$V M A=$ voids in the mineral aggregate

$V T M=$ volume of air voids

\section{Asphalt Mixture Performance Tester (AMPT)}

Formerly known as the Simple Performance Tester (SPT), the Asphalt Mixture Performance Tester (AMPT) is a servo-hydraulic testing machine engineered as a result of 
NCHRP Project 9-19, Superpave Support and Performance Models Management and NCHRP Project 9-29, Simple Performance Tester for Superpave Mix Design (OPT, 2013). The AMPT has flow time, flow number, dynamic modulus, and fatigue testing capabilities. The output of the AMPT can be used in AASHTOWare ${ }^{\circledR}$ Pavement ME Design.

\section{Dynamic Modulus and Phase Angle}

Dynamic modulus is a material property indicative of a mix's stiffness and is used to calculate other distresses such as rutting and fatigue cracking. Mathematically, the dynamic modulus is defined as the maximum (peak) dynamic stress divided by the recoverable axial strain (Equation 11). Dynamic modulus of an asphalt mixture is known to be dependent on variables such as temperature and loading rate in addition to mixture characteristics such as binder stiffness, gradation, and air voids. Binder stiffness is needed to withstand distress at low temperatures and indirectly influences pavement fatigue failure. Figure 5 displays an idealized stress-strain relationship of a dynamic modulus test on a viscoelastic material.

$\left|E^{*}\right|=\frac{\sigma_{0}}{\varepsilon_{0}}$

Where:

$E^{*}=$ absolute value of the complex modulus (dynamic modulus)

$\sigma_{0}=$ stress

$\varepsilon_{0}=$ strain

Phase angle is the lag between applied shear stress and the resultant shear strain. The phase angle ranges from 0 to $90^{\circ}$ where $\delta=0^{\circ}$ for an elastic material and $\delta=90^{\circ}$ represents a purely viscous material. With an increase in temperature or a decrease in loading frequency, asphalt binder becomes soft allowing the asphalt mix behavior to be dominated by the aggregate (Witczak et al., 2013). At this point the phase angle will increase. It has been found that the phase angle increases with decreasing reduced frequency at a constant reduced frequency until a certain point where it starts to decrease (Witczak et al., 2013). Equation 12 displays the equation for phase angle. 


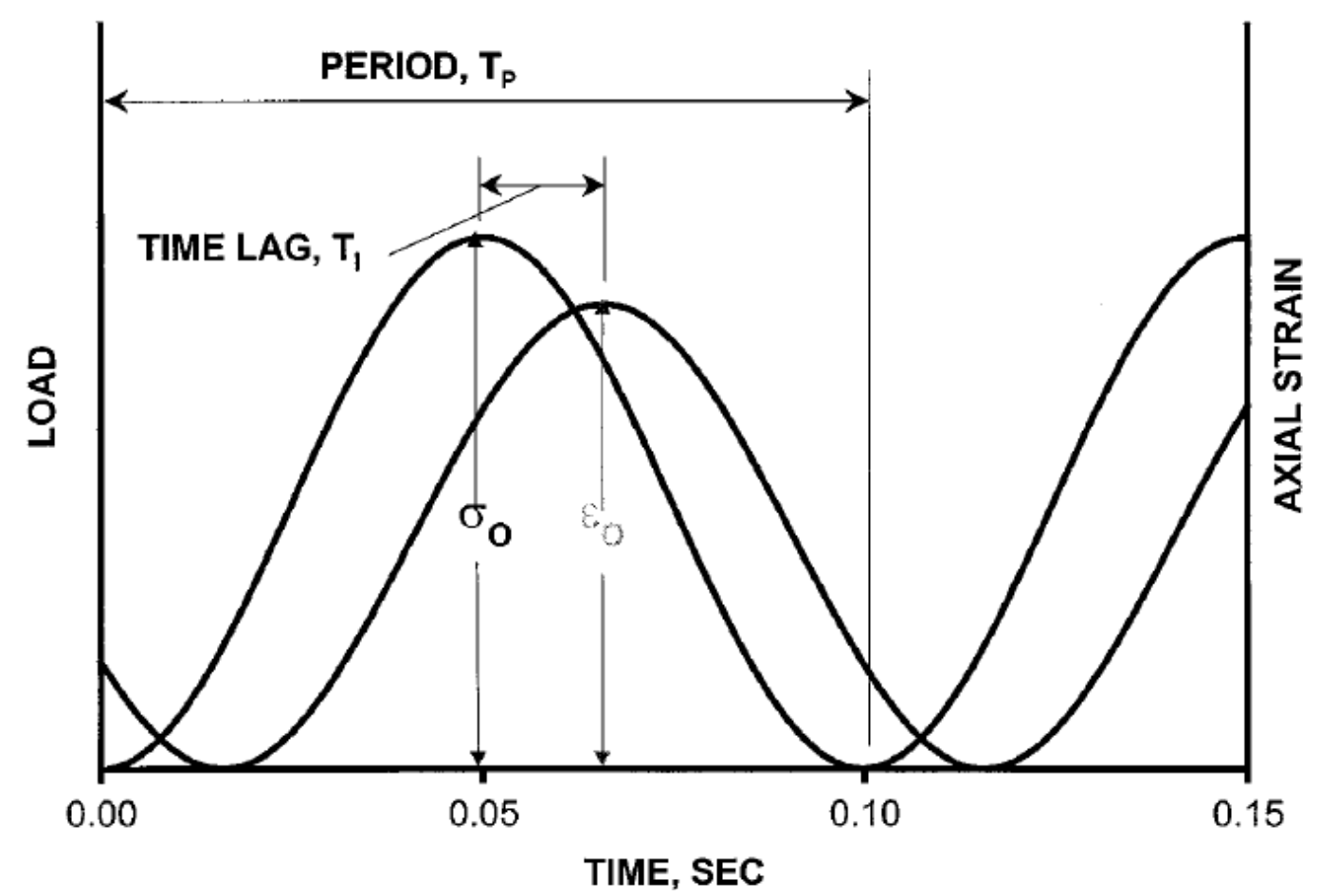

Figure 5: Typical Dynamic Modulus Test Data (Bonaquist et al., 2003)

$\delta=\frac{T_{i}}{T_{p}} \times 360$

Where:

$\delta=$ phase angle in degrees

$T_{i}=$ time lag $($ sec. $)$

$T_{p}=$ time period of applied stress (sec.)

Dynamic modulus testing is a nondestructive test performed at multiple temperatures to determine viscoelastic properties of asphalt mixes over a wide range of temperatures and frequencies (Tran et al., 2013). Table 3 displays the recommended testing temperatures and frequencies according to performance grade following AASHTO PP 61. 
Table 3: AASHTO PP 61 Recommended Testing Temperatures and Loading Frequencies

\begin{tabular}{|c|c|c|c|c|c|}
\hline \multicolumn{2}{|c|}{ PG 58 - XX and softer } & \multicolumn{2}{c|}{ PG 64 - XX and PG 70 - XX } & \multicolumn{2}{c|}{ PG 76- XX and stiffer } \\
\hline Temp. ${ }^{\circ}$ C & $\begin{array}{c}\text { Loading } \\
\text { Frequencies, Hz }\end{array}$ & Temp. ${ }^{\circ}$ C & $\begin{array}{c}\text { Loading } \\
\text { Frequencies, Hz }\end{array}$ & Temp. ${ }^{\circ}$ C & $\begin{array}{c}\text { Loading } \\
\text { Frequencies, Hz }\end{array}$ \\
\hline 4 & $10,1,0.1$ & 4 & $10,1,0.1$ & 4 & $10,1,0.1$ \\
\hline 20 & $10,1,0.1$ & 20 & $10,1,0.1$ & 20 & $10,1,0.1$ \\
\hline 35 & $10,1,0.1$, and 0.01 & 40 & $10,1,0.1$, and 0.01 & 45 & $10,1,0.1$, and 0.01 \\
\hline
\end{tabular}

\section{Mastersolver}

Dr. Ramon Bonaquist, the principal investigator for NCHRP Project 9-29, developed an Excel macro worksheet that computes dynamic modulus master curves from AMPT data. This workbook is now known as Mastersolver. It utilizes a modified version of the MechanisticEmpirical Pavement Design Guide (MEPDG) master curve equation along with the Arrhenius equation and Hirsch model (Bonaquist, 2011a). The modified equation used in Mastersolver is as follows in Equation 13:

$\log \left|E^{*}\right|=\log ($ Min $)+\frac{\log (\operatorname{Max})-\log (\text { Min })}{1+e^{\beta+\gamma \log \left(\omega_{r}\right)}}$

Where:

$\left|E^{*}\right|=$ dynamic modulus

Min = limiting minimum modulus, $k s i$

Max = limiting maximum modulus, $k s i$

$\omega_{r}=$ reduced frequency, $\mathrm{Hz}$

$\beta$ and $\gamma=$ fitting parameters

However, to accommodate the dynamic modulus values tested at various temperatures and frequencies, the master curve must be fitted to a reduced frequency curve. An arbitrary reference temperature of $70^{\circ} \mathrm{F}$ is usually used (Rodezno, 2010). Reduced frequency can be determined using Arrhenius equation shown in Equation 14. Substituting Equation 14 into Equation 13 forms the master curve equation fitted in the Mastersolver workbook.

$$
\log \omega_{r}=\log \omega+\frac{\Delta E_{\alpha}}{19.14714}\left(\frac{1}{T}-\frac{1}{T_{r}}\right)
$$


Where:

$\omega_{\boldsymbol{r}}=$ reduced frequency at the reference temperature, $\mathrm{Hz}$

$\omega=$ loading frequency at the test temperature, $\mathrm{Hz}$

$T_{r}=$ reference temperature, ${ }^{\circ} \mathrm{K}$

$\mathrm{T}=$ test temperature, $\mathrm{Hz}$

$\Delta E_{\alpha}=$ activation energy, $\mathrm{J} / \mathrm{mol}$

The shape of the master curve is characterized by five parameters: $\beta, \gamma, \mathrm{E}_{\min }, \mathrm{E}_{\max }$, and $\Delta \mathrm{EA}$. The parameter $\mathrm{E}_{\max }$ is calculated directly from the volumetrics of the mix so this is not considered a fitted parameter and requires no evaluation. Relationships can be determined by comparing the remaining four parameters and a mixture's components (Roberts et al., 2012). Additionally, Witczak et al. (2013) observed that binder type influences the dynamic modulus master curve.

\section{Fatigue Damage and Testing}

Fatigue damage is a leading cause for pavement failure. Fatigue cracking is defined as a series of longitudinal cracks that can become interconnected overtime. Structural stability is eventually lost at critical locations. In thin pavements subjected to traffic loading, the pavement bottom section is placed in tension and this is where cracking initiates. There are two types of fatigue cracking: bottom-up cracking and a newer acknowledged phenomenon of top-down cracking (Witczak et al., 2013). Bottom-up cracking is considered in a three-step process: crack initiation, propagation, and final fracture failure. Microscopic cracks originally form until reaching a critical size of $7.5 \mathrm{~mm}$ (Little et al., 2001). Location evolves from critical stress and strain point development within the pavement structure. According to Witczak et al. (2013), topdown cracking initiates at the top of thick pavements in areas of high tensile stress as a result of tire-pavement interaction and aging binder.

Numerous fatigue test methodologies have been developed over the past several decades to characterize fatigue behavior in asphalt concrete. A cyclic direct tension-compression test has been developed by Kim et al. at North Carolina State University. This methodology has evolved 
into an AASHTO test method PP 107 for use with the AMPT. Since this was the methodology available for the current research, it is the only method reviewed herein.

Over the years, Kim et al. have developed a simplified-viscoelastic continuum damage (S-VECD) theory for the evaluation of asphalt materials. The details of the process are complex and are well documented elsewhere (Hou, 2009, Underwood et al. 2009, Zhang, 2012, Underwood et al., 2012, LaCroix,, 2013, Witczak et al., 2013, and Sabouri, 2014). The analysis used in this methodology is implemented in the Alpha-Fatigue software. This program uses output files from the AMPT dynamic modulus and fatigue tests to compute the fatigue parameters. There are only two user-interactions in the Alpha-Fatigue software: 1) selecting the "failure" point that corresponds to a specific number of cycles to failure, Figure 6 and 2) selecting either the exponential or power-law model for the normalized pseudo secant modulus (C) versus cumulative damage (S), Figure 7.

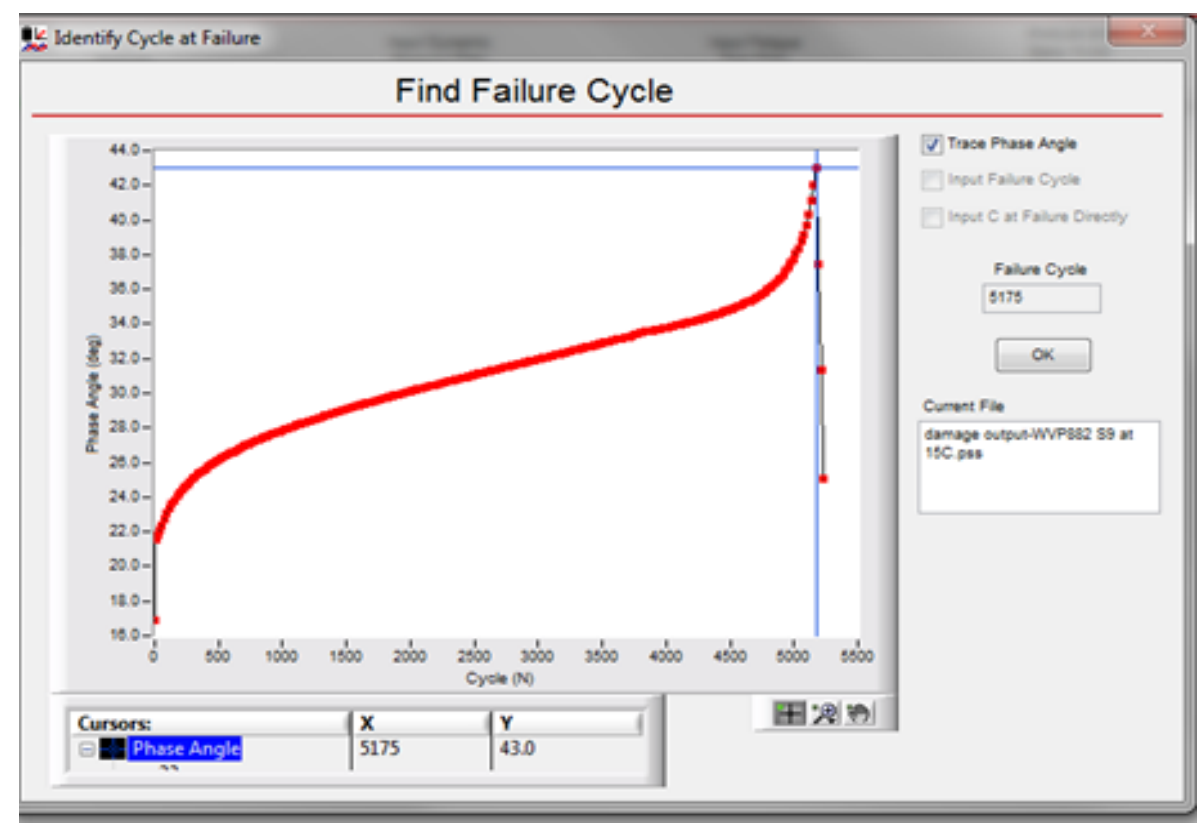

Figure 6: Alpha-Fatigue Phase Angle Drop

For the first user-interaction, the phase angle versus load cycle curve is used for selecting the failure point. The user can allow the software to determine the failure point automatically or can specify a point. Recent studies recommend selecting the point where there is a rapid decrease in the phase angle (Reese, 1997, Hou, 2009, Zhang, 2012, and LaCroix, 2013). For the second user-interaction, the user selects the model with the lower mean square error. 


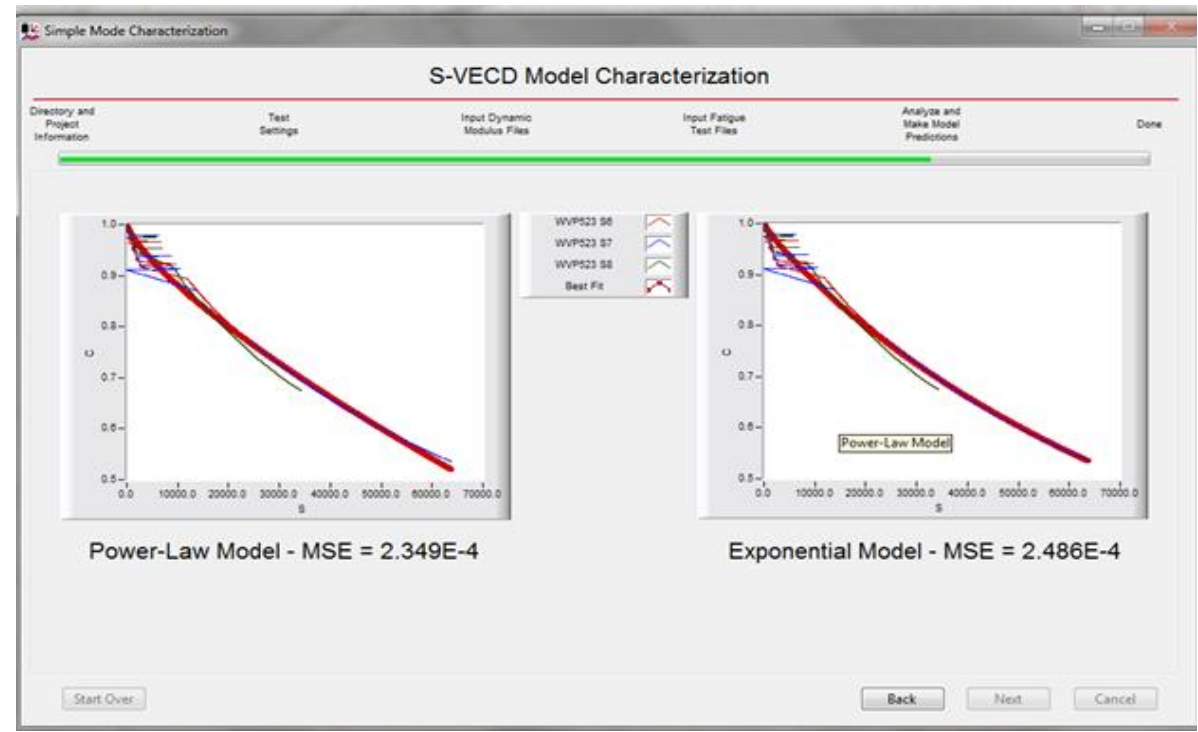

Figure 7: Alpha Fatigue Simple Model Characterization Interface

The Alpha-Fatigue software output provides several alternative formats for fatigue models. For constructing historical fatigue evaluations, the conventional model, Equation 15, was implemented in the current research. The three K-values are constants determined from damage models produced from regression analyses. Once determined, these values can be correlated to field performance.

$N_{f}=K_{1}\left(\frac{1}{\varepsilon_{t}}\right)^{K_{2}}\left(\frac{1}{E}\right)^{K_{3}}$

Where:

$K_{1}, K_{2}, K_{3}=$ constants

$\varepsilon_{t}=\operatorname{strain}$

$E=$ dynamic modulus

The Asphalt Institute has reported $\mathrm{K}_{1}, \mathrm{~K}_{2}$, and $\mathrm{K}_{3}$ values of $0.0796,3.291$, and 0.854 while Shell has used 0.0685, 2.363, and 5.571 (Huang, 2004). Moreover, Hou (2009) completed fatigue testing on a range of mixes. A summary of regression coefficients are displayed in Table 4. K-values vary from the aforementioned constants. 
Furthermore, the endurance limit is defined as the allowable tensile strain below which fatigue cracking does not occur. For strain levels above the endurance limit, considerably more damage is induced. A pavement's endurance limit is believed to vary depending on the mixture properties, gradation, paving temperature, and traffic conditions. Monismith and Nunn recommend a limiting criteria of less than 70 micro strains for tensile strain at the bottom of a composite HMA layer (Lenz, 2011).

Table 4: Regression Coefficients from Hou (2009) and Witczak et al. (2013)

\begin{tabular}{|c|c|c|c|c|}
\hline \multirow{2}{*}{$\begin{array}{c}\text { Reference } \\
\text { Article }\end{array}$} & Mix & $\mathbf{K}_{\mathbf{1}}$ & $\mathbf{K}_{\mathbf{2}}$ & $\mathbf{K}_{\mathbf{3}}$ \\
\hline \multirow{5}{*}{ S9.5C } & $2.40 \mathrm{E}+10$ & 8.253 & 4.821 \\
\cline { 2 - 5 } & S9.5B & $4.89 \mathrm{E}+04$ & 8.253 & 4.099 \\
\cline { 2 - 5 } & I19C & $8.86 \mathrm{E}-06$ & 7.275 & 2.327 \\
\cline { 2 - 5 } & B25B & $4.75 \mathrm{E}-09$ & 7.510 & 1.951 \\
\cline { 2 - 5 } & R9.5C & $1.02 \mathrm{E}+02$ & 7.547 & 3.262 \\
\cline { 2 - 5 } & S12.5C & $1.51 \mathrm{E}-01$ & 7.902 & 3.180 \\
\cline { 2 - 5 } & I19B & $7.21 \mathrm{E}-09$ & 8.090 & 2.329 \\
\cline { 2 - 5 } & RS12.5C & $5.83 \mathrm{E}-09$ & 8.000 & 2.191 \\
\cline { 2 - 5 } & RI19B & $5.07 \mathrm{E}-15$ & 7.391 & 1.135 \\
\cline { 2 - 5 } & RI19C & $1.34 \mathrm{E}-18$ & 7.762 & 0.913 \\
\hline \multirow{3}{*}{$\begin{array}{c}\text { Witczak et al., } \\
2013\end{array}$} & RB25B & $1.42 \mathrm{E}-05$ & 4.942 & 1.681 \\
\cline { 2 - 5 } & $4.5 \%$ VTM/ 5.2\% Binder Content & $9.95 \mathrm{E}-03$ & 3.464 & 1.112 \\
\cline { 2 - 5 } & All Mixtures & $3.28 \mathrm{E}-06$ & 5.281 & 1.825 \\
\hline
\end{tabular}

\section{Rutting and Flow Number Test}

Rutting is defined as permanent deformation of the surface of a pavement in the wheel path which is caused by progressive movement of materials, under repeated loads, either in asphalt pavement or underlying layers (Cross, 1992). Permanent deformation occurs primarily when a pavement is subjected to high temperatures where the structure becomes more viscoelastic-plastic. Any damage that occurs in the viscous state is irreparable. Traffic volume, magnitude of wheel load and tire pressure, environmental conditions, mix properties including 
aggregate characteristics, binder content, and air void levels can all influence rutting in a pavement structure (Rodezno, 2010).

The AMPT flow number test applies a dynamic load for several thousand repetitions and records the accumulation of permanent deformation as a function of the number of cycles. Haversine loading for 0.1 second is applied to the sample followed by a 0.9 second rest period. Typical results between measured permanent strain and load cycle can be divided into three major zones: primary, secondary, and tertiary, Figure 8. It should be noted that Figure 8 was remade to represent the relationship of permanent strain and number of cycles in a flow number test as found in Rodezno (2010). During the primary phase, the strain rate or slope of the curve decreases; in the secondary phase the permanent strain rate becomes constant; and in the tertiary phase the strain rate increases until rupture. Classical rutting evaluation involved the concept of creep where the secondary phase was defined as linear. The flow number can be defined as the load repetition value where shear deformation under constant volume starts or can be defined as the minimum point in the rate of change of permanent strain versus loading time relationship (Rodezno, 2010). Figure 9 displays a completed flow number test where the flow number was determined using the minimum point of change in permanent strain (Bonaquist et al., 2003). The flow number appears to fall somewhere in the secondary phase as opposed to the beginning of tertiary flow as shown in Figure 8. Bonaquist et al. (2003) determined the secondary phase was not linear because the behavior of permanent deformation per cycle of asphalt concrete decreases until it reaches inflection point and then increases.

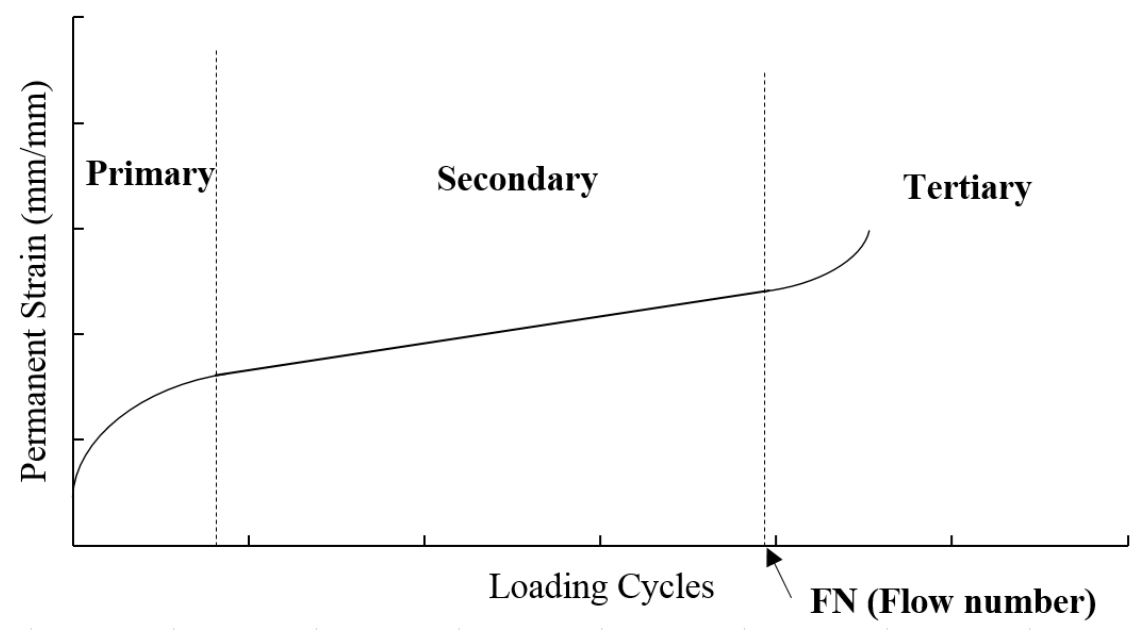

Figure 8: Classical Flow Number Test Relationship between Permanent Strain and Loading Cycles 

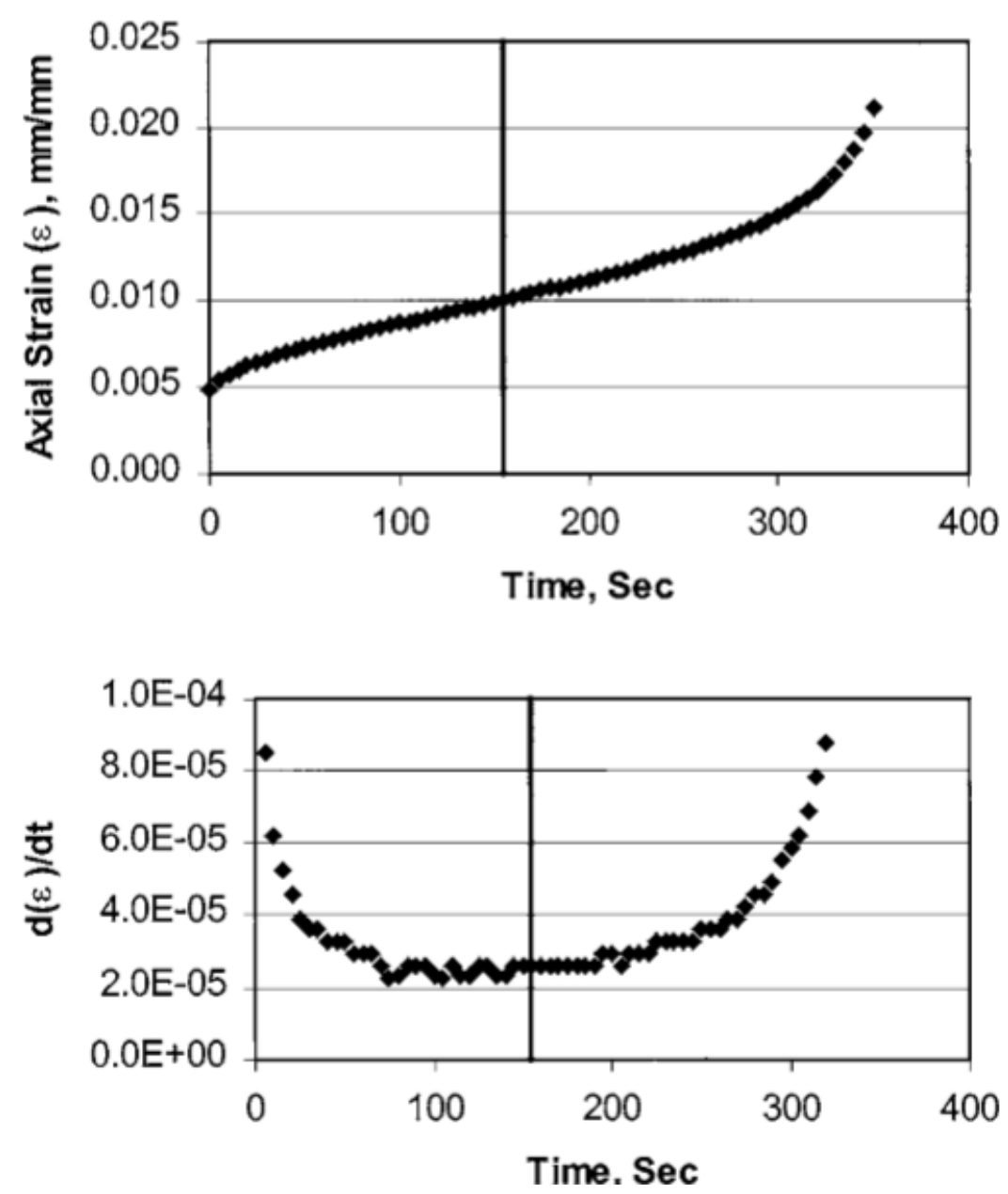

Figure 9: Typical Repeated Load Test and Flow Number (Bonaquist et al., 2003)

The AMPT flow number test has been adopted to evaluate asphalt mixture resistance to permanent deformation. Software provided with the AMPT for running flow number tests uses a data-smoothing model to determine a flow number. Equation 16 is used to find the rate of change of permanent strain using a data-smoothing model.

$\frac{d\left(\varepsilon_{p}\right)_{i}}{d N} \cong \frac{\left(\varepsilon_{p}\right)_{i+\Delta N}-\left(\varepsilon_{p}\right)_{i-\Delta N}}{2 \Delta N}$

Where:

$\frac{d\left(\varepsilon_{p}\right)_{i}}{d N}=$ the rate of change of permanent axial strain at cycle $i$

$\Delta N=$ sampling interval 
$\left(\varepsilon_{p}\right)_{i+\Delta N}=$ permanent strain at cycle $i+\Delta N$

$\left(\varepsilon_{p}\right)_{i-\Delta N}=$ permanent strain at cycle $i-\Delta N$

Some researchers have identified issues with the data averaging method used in the AMPT and have proposed using the Francken model (Von Quintos et al., 2012 \& Biligiri et al., 2007). The Francken model is a combination of a power model and an exponential, Equation 17. The fitting coefficients are determined using numerical optimization. Once fitted the second derivative of the Francken model (Equation 18) is determined and the flow number is the cycle where the second derivative changes from negative to positive. Using the Francken model with a sampling interval of one standardizes the flow number computation and leads to reduced variability in flow number tests on replicate specimens (AASHTO TP 79).

$\varepsilon_{p}=A n^{B}+C\left(e^{D n}-1\right)$

$\frac{d^{2} \varepsilon_{p}}{d n^{2}}=A B(B-1) n^{B-2}+C D^{2} e^{D n}$

Where:

$\varepsilon_{p}=$ permanent axial strain

$n=$ number of cycles

$A, B, C$, and $D=$ fitting coefficients

AASHTO TP 79 flow number test parameters are presented in Table 5 and flow number rutting criteria is located in Table 6 . The test method does not specify if the criteria in Table 6 are applicable to both the data-smoothing and Francken methods for determining flow number.

Table 5: Flow Number Test Parameters

\begin{tabular}{|c|c|}
\hline Test Parameter & Value \\
\hline Test Temperature & Adjusted PG temperature \\
\hline Repeated axial stress & $600 \mathrm{kPa}$ \\
\hline Contact stress & $30 \mathrm{kPa}$ \\
\hline Confining stress & $0 \mathrm{kPa}$ (unconfined) \\
\hline
\end{tabular}


Table 6: Flow Number Rutting Criteria

\begin{tabular}{|c|c|}
\hline Traffic Level, million ESALs & HMA Minimum Average Flow Number \\
\hline$<3$ & - \\
\hline 3 to $<10$ & 50 \\
\hline 10 to $<30$ & 190 \\
\hline $30 \leq$ & 740 \\
\hline
\end{tabular}

\section{Research Using the AMPT}

Hou (2009) expressed the need to develop a model that could characterize fatigue performance quickly using cyclic data for the AMPT. S-VECD developed at North Carolina State University was applied to various asphalt mixtures used throughout North Carolina and the results of this study concluded that VECD model can predict fatigue tests fairly accurately under various temperature conditions and strain levels (Hou, 2009). Additionally, Hou (2009) looked at where fatigue samples fractured when pulled apart. He concluded that both middle-failure (within LVDT gauge points) and end-failure (outside LVDT gauge points) results do not affect damage characterization. However, Witczak et al. (2013) excluded end-failure test results in fatigue failure analysis, claiming it is crucial that failure occurs within the LVDT gauge length.

NCHRP Report 702 documents the results of Phase IV of the NCHRP Report 9-29. This phase involved an interlaboratory study to prepare precision statements for dynamic modulus and phase angle, unconfined flow number, and permanent strain in confined flow number testing. The precision statements for this study were developed using specimens with an air void tolerance range \pm 1.0 percent. No air void effect was detected using this tolerance. Variability within the AMPT tests was found to increase with decreasing specimen stiffness (Bonaquist, 2011b). To further reduce variability of low stiffness dynamic modulus measurements, a potential improvement for the AMPT equipment suggested was using lower spring rate sensors for mounted specimens. Average flow number values from the eight laboratories testing the same $9.5 \mathrm{~mm}$ mix ranged from 50 to 290 . However, the variability of unconfined flow number tests was considered unacceptable.

From 2012 to 2014, the pooled-fund interlaboratory study (ISL) was conducted to determine variability of the dynamic modulus and flow number test conducted on loose plantproduced mix and how results compared to the NCHRP Project 09-29 ISL; and another objective was to examine if the tolerance fabrication could be enlarged from \pm 0.5 percent to \pm 1.0 percent. 
Taylor and Tran (2014) found within-lab variability values to be at or above that of the NCHRP Project 09-29 for dynamic modulus and phase angle while reproducibility was at or below. For flow number both repeatability and reproducibility significantly improved over the Bonaquist (2011b) report. Average flow number values for $12.5 \mathrm{~mm}$ NMAS samples made at 6, 7, and 8 percent air voids were 340, 211, and 145. It was concluded that the fabrication tolerance for air voids should remain at the narrow \pm 0.5 percent.

Roberts et al. (2012) conducted a five year evaluation of the AMPT in Utah. Spring loaded LVDTs were used which creates a spring force on the studs. This force is counteracted by compensating springs on either side of the LVDT. This study explored the difference between the two forces and determined the springs were not providing enough force to counteract the LVDT force (Roberts et al., 2012). Moreover, investigators found that coefficient of variation increased with both a decrease in frequency and increase in temperature during dynamic modulus testing. Most of the coefficient of variation values were below 15 percent when looking at tests run at $20^{\circ} \mathrm{C}$ and a frequency of $1 \mathrm{~Hz}$ with the average coefficient of variation being 10.2 percent. The AMPT was determined to be repeatable and generate precise data.

\section{Salient Points}

- There are numerous methods to determine $\mathrm{G}_{\mathrm{mb}}$. However, which method is best and how methods compare is not fully known.

- Sample uniformity varies with numerous factors: specimen height, mix composition, etc. Sample uniformity must be met to ensure subsequent testing is acceptable.

- A target air void content of $7.0 \pm 0.5$ percent is well documented in literature for dynamic modulus and flow number testing while fatigue is not as well specified (Table 2). However, Witczack et al. (2013) found fatigue parameters are not sensitive to percent air voids.

- Fatigue failure has been extensively studied using a variety of test methods. Kim et al. have determined that the S-VECD analysis method can be used to model any test mode.

- Two methods for determining flow number are suggested in AASHTO TP 79. The flow number computation using the Francken model leads to reduced variability in flow number test replicates. 
- LVDT errors have been problematic in past AMPT use.

- AMPT dynamic modulus and flow number testing repeatability has been quantified in past research. 


\section{Chapter 3: Methodology}

\section{Materials}

As previously mentioned, there were two main objectives for this research: 1) test WV plant-produced mixes using the Asphalt Mixture Performance Tester (AMPT) and 2) provide a comparison of the mixes and their performance in uniformity, dynamic modulus, fatigue, and flow number testing. These objectives were completed following the methodologies explained herein. Both Marshall and Superpave asphalt mixes were provided for this research through the West Virginia Division of Highways (WVDOH). The mixes are from various HMA plants located throughout West Virginia. Five paving companies provided samples. Nominal maximum aggregate sizes (NMAS) of 9.5 and 19 mm were provided. Mixes are listed in Table 7.

Table 7: Mixes Provided from Asphalt Plants throughout West Virginia

\begin{tabular}{|c|c|c|c|c|c|c|}
\hline Company & $\begin{array}{c}\text { Plant } \\
\text { Location }\end{array}$ & Mix NMAS & $\begin{array}{c}\text { Binder } \\
\text { Content } \\
(\%)\end{array}$ & Mix Type & $\begin{array}{l}\text { Design } \\
\text { Traffic }\end{array}$ & HМА Туре \\
\hline $\begin{array}{c}\text { American Asphalt } \\
\text { of WV }\end{array}$ & St. Albans & $9.5 \mathrm{~mm}(3 / 8 ")$ & 5.6 & Marshall & Heavy & $\begin{array}{c}\text { Wearing I } \\
\text { RAP }\end{array}$ \\
\hline Greer Industries & Morgantown & $9.5 \mathrm{~mm}(3 / 8 ")$ & 5.7 & Marshall & Heavy & Wearing I \\
\hline $\begin{array}{l}\text { Jefferson Asphalt } \\
\text { Paving }\end{array}$ & Millville & 19 mm (3/4") & 4.9 & Marshall & Medium & Base II \\
\hline J. F. Allen Co. & Saltwell & $19 \mathrm{~mm}(3 / 4 ")$ & 4.9 & Marshall & Heavy & Base II \\
\hline J. F. Allen Co. & Saltwell & $9.5 \mathrm{~mm}(3 / 8 ")$ & 5.8 & Marshall & Medium & Wearing I \\
\hline J. F. Allen Co. & Saltwell & $19 \mathrm{~mm}(3 / 4 ")$ & 4.9 & Superpave & $\begin{array}{c}3 \text { to }<30 \\
\text { million }\end{array}$ & $19 \mathrm{~mm}$ \\
\hline Kelly Paving & Benwood & $9.5 \mathrm{~mm}(3 / 8 ")$ & 5.6 & Marshall & Heavy & $\begin{array}{c}\text { Wearing I } \\
\text { Skid w/RAP }\end{array}$ \\
\hline $\begin{array}{l}\text { West Virginia } \\
\text { Paving, Inc. }\end{array}$ & Dunbar & 19 mm (3/4") & 4.6 & Marshall & Heavy & $\begin{array}{l}\text { Base II } \\
\text { w/RAP }\end{array}$ \\
\hline $\begin{array}{l}\text { West Virginia } \\
\text { Paving, Inc. }\end{array}$ & Parkersburg & $9.5 \mathrm{~mm}(3 / 8 ")$ & 5.9 & Marshall & Heavy & $\begin{array}{l}\text { Wearing I } \\
\text { RAP }\end{array}$ \\
\hline $\begin{array}{l}\text { West Virginia } \\
\text { Paving, Inc. }\end{array}$ & Dunbar & $9.5 \mathrm{~mm}(3 / 8 ")$ & 6.1 & Marshall & Heavy & $\begin{array}{l}\text { Wearing I } \\
\text { Skid-RAP }\end{array}$ \\
\hline
\end{tabular}


Due to limited mix quantities only nine of the ten mixes were used for the full gamut of testing. Throughout the rest of this report, mixes are identified by a company acronym followed by the last three digits of the mix design number. Each mix was designed with PG 64-22 binder. Below are the mixture descriptions:

American Asphalt of $W V(A A)$

- AA937 is a fine-graded Wearing I mix containing 35 percent \#8 limestone, 16 percent limestone, 34 percent natural sand, and 15 percent RAP.

\section{Greer Industries (GR)}

- GR465 is a course-graded Wearing I mix comprised of 48 percent \#8 limestone, 32 percent limestone, and 20 percent limestone.

\section{Jefferson Asphalt Paving (JAP)}

- JAP909 is a fine-graded Base II mix comprised of 50 percent \#67 and 50 percent \#10 limestone only.

JF Allen (JFA)

- JFA060 is a fine/coarse graded Base II mix comprised of 30 percent \#67 limestone, 36 percent \#8 limestone, 33 percent limestone sand, and 1 percent BHF.

- JFA115 is a coarse-graded Wearing I mix comprised of 40 percent \#67 limestone, 50 percent limestone sand, 9 percent \#9 limestone, and 1 percent BHF.

- JFA429 is the only $19 \mathrm{~mm}$ mix. It is a fine gradation design comprised of 33 percent \#67 limestone, 20 percent \#8 limestone, 14 percent \#9 limestone, 32 percent limestone, and 1 percent BHF.

Kelly Paving (KP)

- KP483 is a coarse-graded Wearing I mix comprised of 44 percent \#8 limestone, 19 percent natural sand, 22 percent limestone, and 15 percent RAP. 
West Virginia Paving (WVP)

- WVP523 is a fine-graded Base II mix that contains 40 percent \#67 limestone, 9 percent limestone, 25 percent natural sand, 10 percent slag, 1 percent baghouse fines (BHF), and 15 percent RAP.

- WVP766 is a coarse-graded Wearing I mix consisting of 40 percent \#8 limestone, 9 percent limestone, 25 percent natural sand, 10 percent slag, 1 percent BHF, and 15 percent RAP.

- WVP882 is a coarse-graded Wearing I mix containing 30 percent \#8 slag, 29 percent limestone, 25 percent natural sand, 1 percent BHF, and 15 percent RAP.

The American Asphalt, Kelly Paving, and WV Paving mixes contained natural sands and 15 percent RAP. All other mixes contained 100 percent crushed limestone aggregate. The three West Virginia Paving mixes included slag.

Table 8 displays the gradations of each Wearing I mix and Table 9 displays the Base II/19 mm mix details. All JMFs and power 0.45 gradation charts are available in Appendix A.

Table 8: Wearing I Mixes Gradations

\begin{tabular}{|c|c|c|c|c|c|c|c|c|}
\cline { 2 - 9 } \multicolumn{1}{c|}{} & \multicolumn{9}{c|}{ Sieve (mm) } \\
\hline Mix & 12.5 & 9.5 & 4.75 & 2.36 & 1.18 & 600 & 300 & 75 \\
\hline AA937 & 100 & 96 & 66 & 48 & 37 & 28 & 11 & 5.3 \\
\hline JFA115 & 100 & 98 & 66 & 44 & 28 & 19 & 13 & 4.9 \\
\hline KP482 & 100 & 98 & 58 & 38 & 23 & 13 & 9 & 5.4 \\
\hline WVP766 & 100 & 95 & 62 & 41 & 30 & 22 & 11 & 4.8 \\
\hline WVP882 & 100 & 94 & 66 & 43 & 30 & 23 & 13 & 6.2 \\
\hline
\end{tabular}

Table 9: Base II and 19 mm Mixes Gradations

\begin{tabular}{|c|c|c|c|c|c|c|c|c|c|c|}
\cline { 2 - 12 } \multicolumn{1}{c|}{} & \multicolumn{10}{c|}{ Sieve (mm) } \\
\hline Mix & 25 & 19 & 12.5 & 9.5 & 4.75 & 2.36 & 1.18 & 600 & 300 & 75 \\
\hline JAP909 & 100 & 93 & - & 67 & 52 & 35 & - & 14 & 10 & 5 \\
\hline JFA060 & 100 & 97 & 83 & 75 & 47 & 30 & 18 & 12 & 9 & 4.9 \\
\hline JFA429 & 100 & 100 & 81 & 70 & 49 & 30 & 19 & 13 & 9 & 4.3 \\
\hline WVP523 & 100 & 97 & 81 & 72 & 57 & 43 & 33 & 25 & 13 & 5.7 \\
\hline
\end{tabular}




\section{Randomizing Sample Mix Procedure}

Each sample set was weighed and inventoried on the day of delivery. The first step in the experimental plan was to randomize each batch of asphalt provided. This was completed to minimize the effect of variability. The following 23 steps were taken to randomize the asphalt mixtures:

1. Clean work tables with WD-40 and grease lighting.

2. Cover table in release paper for a clean, stick-free work surface as seen in Figure 10.

3. Remove asphalt mixture from boxes and place in pans.

4. Place in ovens.

5. Heat all mix.

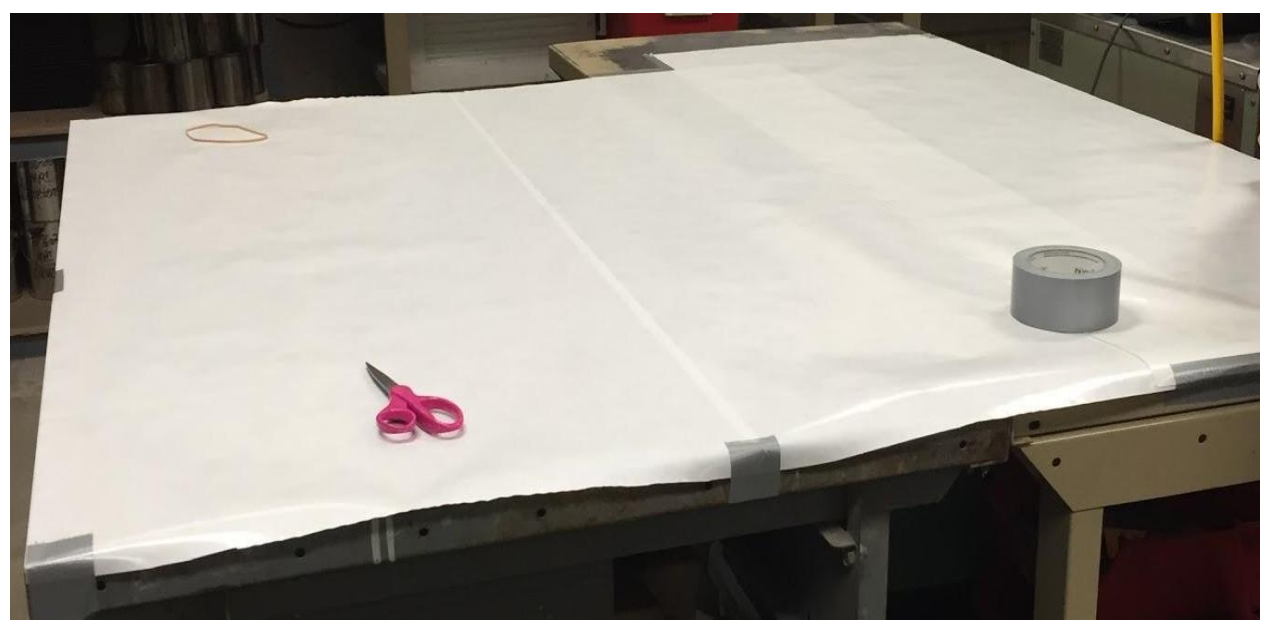

Figure 10: Table Covered in Release Paper

6. Once HMA reaches $105^{\circ} \mathrm{F}\left(41^{\circ} \mathrm{C}\right)$ remove from oven and break apart into two smaller sections to quicken the heating process.

7. Place back in oven.

8. Wait until $150^{\circ} \mathrm{F}\left(65^{\circ} \mathrm{C}\right)$ is reached.

9. Remove three pans randomly.

10. Thoroughly mix contents together on table.

11. Break mix into eight sections as seen in Figure 11. 


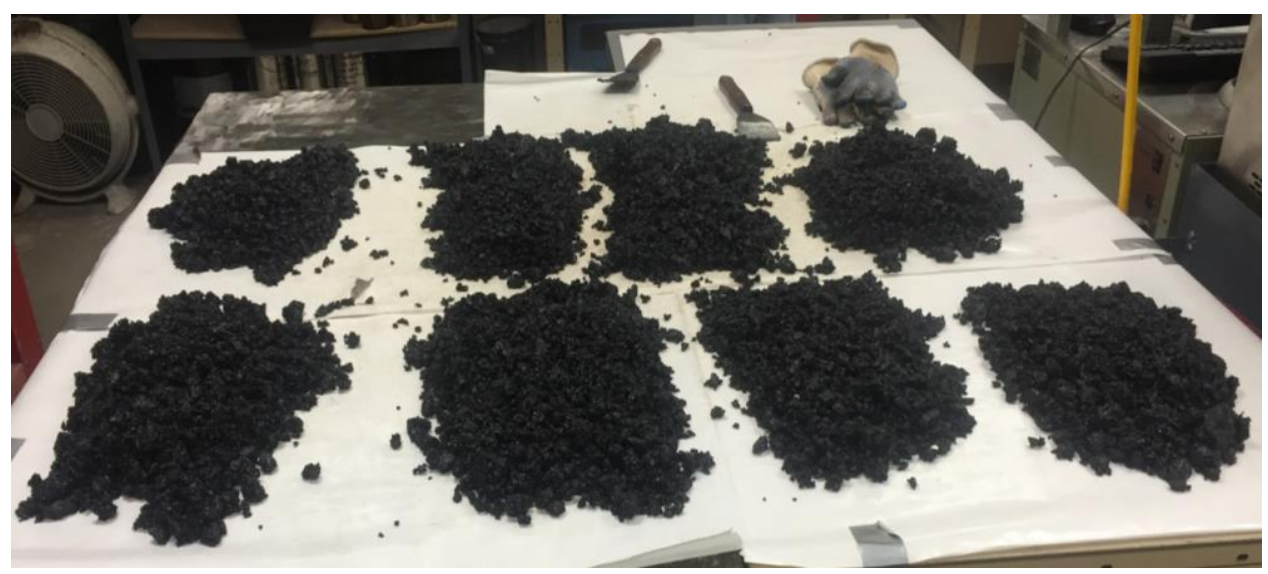

Figure 11: Separated Eight Sections

12. Generate random numbers using Excel command RANDBETWEEN $(1,8)$ and label as seen in Figure 12. These batched quantities are pre-samples.

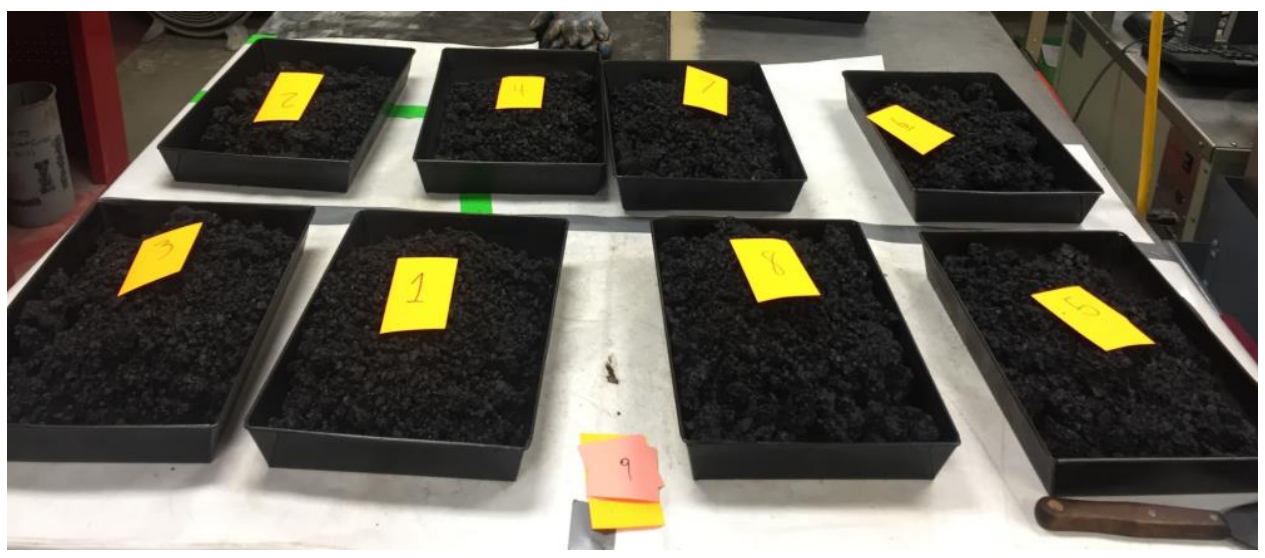

Figure 12: Separated Mix in Randomized Order

13. Pre-sample one is then placed in a new pan according to the random number generated and weighed to 3,875 grams (half a full sample size).

14. Continue through pre-sample eight.

15. If sample is overweight, place in a pan as extra to be remixed later.

16. If weight is under, grab mix from the next mix pile.

17. All left over mix is remixed together to form more half samples until the mix remaining cannot constitute an entire half sample. This is done by mixing the leftovers together, separating into four quarters as seen in Figure 13 and combining opposite quarters. 


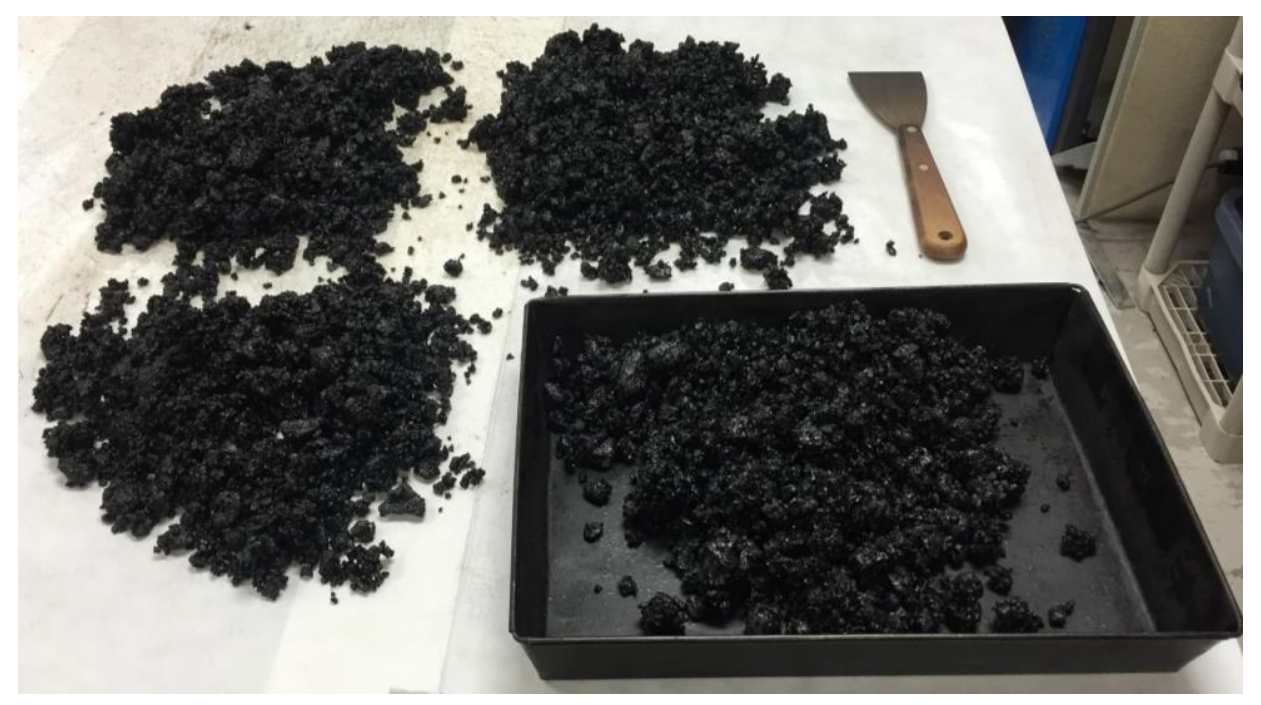

Figure 13: Quartering Process

18. Place extra in a pan and set aside.

19. Repeat steps 9-14 for remaining mix.

20. Generate random numbers using Excel command: RANDBETWEEN(1, number of half the samples being produced).

21. Combine pre-sample halves to create whole samples.

22. Place in labeled boxes or plastic bags for storage.

23. Repeat for additional nine mix sets.

Throughout the entire process steps were taken to eliminate bias. When mix had to be removed from a pan, mix was removed from different pan locations.

\section{Sample Preparation and Fabrication}

Maximum specific gravity $\left(\mathrm{G}_{\mathrm{mm}}\right)$ values were determined following AASHTO T 209. For plant-produced mixes the samples were heated to $105^{\circ} \mathrm{C}$, broken apart, allowed to cool to room temperature, and were tested. This step was completed for the ten mixes to compare to the Job Mix Formulas (JMF) values.

All but one mix was Marshall which required experimenting to see how Marshall mixes would compact in the SGC. GR465 was the first mix set evaluated as a starting point. Samples were made with the assumption that each mix set reached absorption and aging when mixed at 
the mixing plants. Following past WVU laboratory experience (Smith, 2015 \& Turner, 2015) the GR465 samples were made to be $180 \mathrm{~mm}$ tall by $150 \mathrm{~mm}$ diameter with a target air void content of $7.0 \pm 0.5$ percent. Literature supported this target air void value as described in Table 2 in Chapter 2.

Initial mix mass was calculated using AASHTO PP 60 (Equation 19). The mass calculated was 7,209 grams which translated to a mix amount exceeding mold capacity. Approximately 7,130 grams of mix were placed in the mold, but the SGC was unable to compact to the specified $180 \mathrm{~mm}$ height, instead reaching $185 \mathrm{~mm}$. This sample was excluded for air void testing and further adjustments were estimated for subsequent samples resulting in a final mass of 6620 grams.

Mass $=\left[\frac{100-\left(V_{a t}+F\right) 100}{100}\right] G_{m m} \times 176.7147 \times H$

Where:

$V_{a t}=$ target air void content

$F=$ air void adjustment factor (1.0 for fine-graded and 1.5 for coarse-graded mixtures)

$G_{m m}=$ theoretical maximum specific gravity of the mix

$H=$ sample height, $\mathrm{cm}$

A second sample was generated to $180 \mathrm{~mm}$ height using the aforementioned adjusted mix mass and successfully compressed to $180 \mathrm{~mm}$. Having become a trial and error process, two subsequent samples were made using a slightly lowered mass of 6,600 grams. The following day air voids were determined by running both CoreLok and SSD bulk specific gravity tests. All four samples were a VTM of approximately 12 percent which was significantly higher than the target air void content of $7.0 \pm 0.5$ percent. Also, the absorption was 5.5 percent which was also exceedingly high.

To verify these values, one bulk pill was made using the remaining GR465 material. The VTM was 10 percent as opposed to the target $4 \pm 0.5$ percent and had a high absorption of 3.0 percent. Marshall verification pills were compacted to verify the mixes. The appropriate traffic counts (50 or 75 hammer drops) were found in the JMFs for each of the remaining eight Marshall mixes. Three verification pills for each were made using the Marshall hammer. Figure 
14 displays the eight Marshall sets made following ASTM D6929. Next, VTM for each Marshall sample was determined using three methods: CoreLok, SSD, and Dimensional. None of the mixes showed cause for concern.

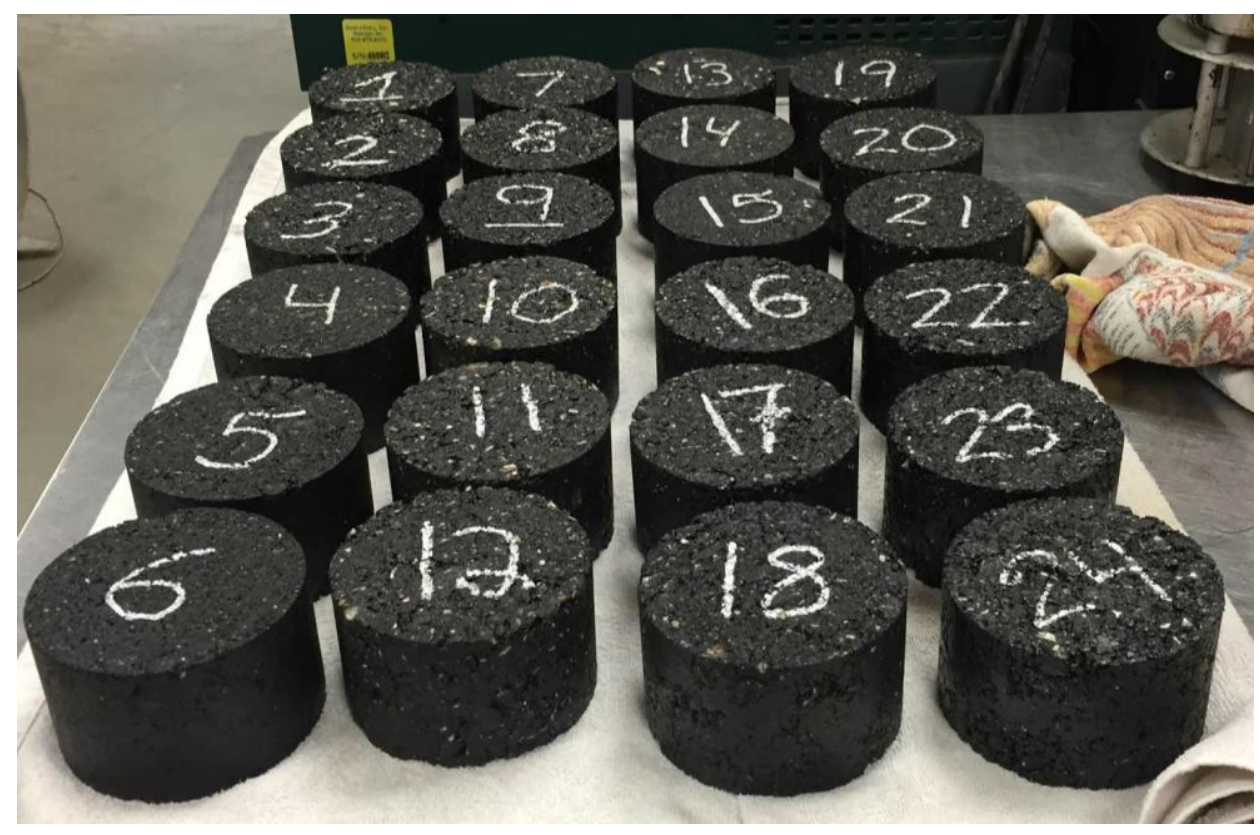

Figure 14: Marshall Pills made at the WVDOH site in Charleston, WV

To verify the sole Superpave mix (JFA429), two bulk verification samples were made. They came out to be reasonable so no further investigation was needed. All verification data are found in Appendix B.

From this information, it was decided to move forward using the SGC for compaction. Sample height was lowered to $170 \mathrm{~mm}$ from $180 \mathrm{~mm}$ to negate the prior issue of fitting required mix mass in the mold. As previously mentioned, pills were made with the assumption that each mix set reached absorption and aging when mixed at the mixing plants. Mixes were heated to uniform temperature using JMF compaction temperatures, removed, weighed to required mix mass, placed in the SGC mold, compacted using the SGC, and cooled in the mold for 30 minutes to one hour. Next, the sample was removed and set to cool for approximately 16 hours.

The following day, $\mathrm{G}_{\mathrm{mb}}$ and VTM measurements were obtained using CoreLok, SSD, and Dimensional. The CoreLok machine had not been used on full sized $(170 \mathrm{~mm})$ compacted specimen in the WVU laboratory. To make this feasible, some adjustments were made to get 
VTM measurements using CoreLok (Appendix F). An image of a CoreLok vacuum-sealed gyratory sample can be seen in Figure 15.

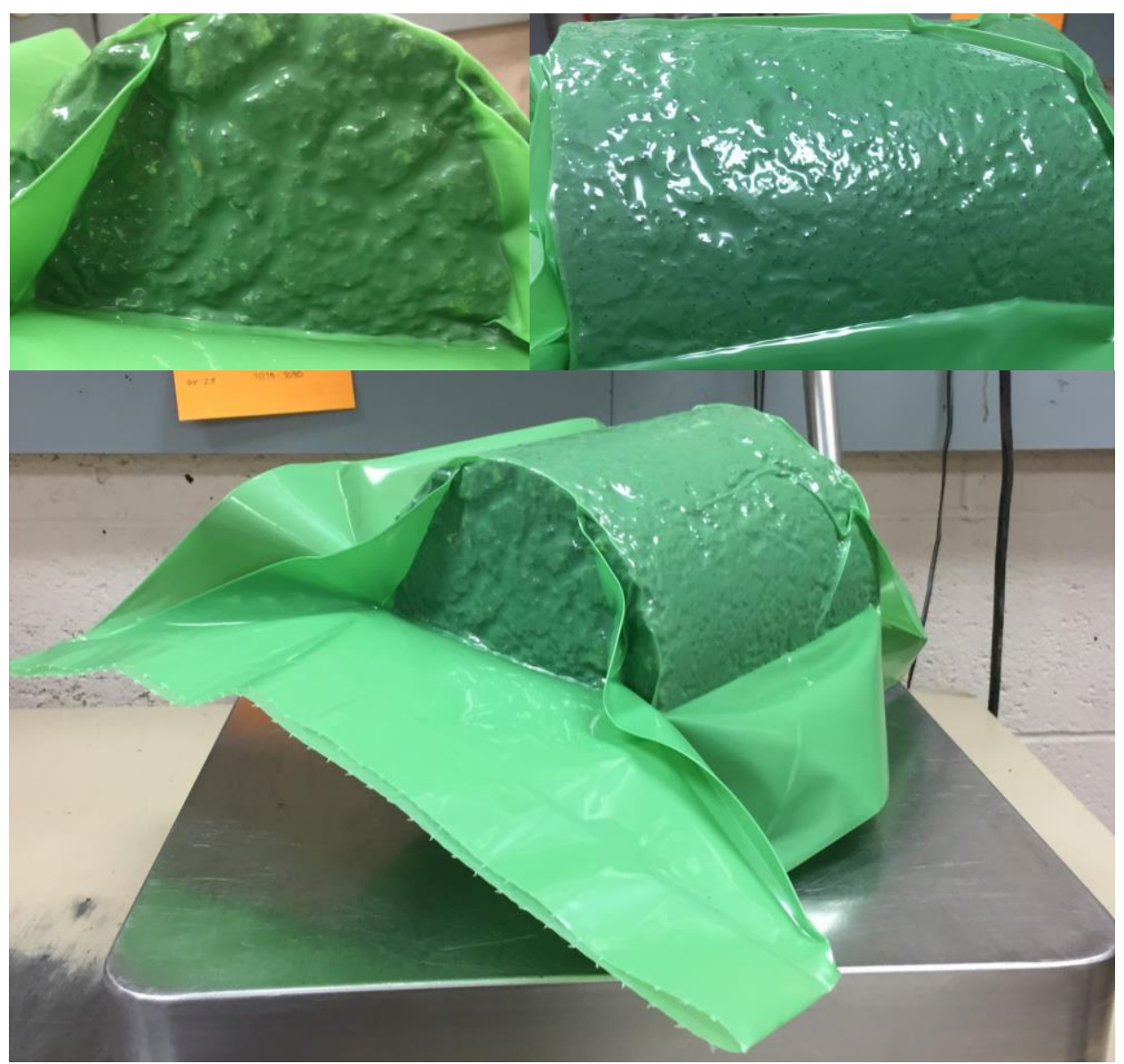

Figure 15: CoreLok Vacuum-Sealed Gyratory Sample

Equation 19 was not accurate for the first Marshall mix evaluated. Instead, high and low mix masses were estimated and compacted for each mix. From here air voids were calculated for the gyratory samples. The correlation between a compacted specimen and a cored and sawed specimen VTM was determined for each mix type. Using the laboratory core drill and wet saw, specimens were cut to the AASHTO PP 60 required tolerances displayed in Table 10. Linear interpolation using the CoreLok gyratory VTMs was used to determine mass correlations. The CoreLok measurement was used because it is the WVDOH preferred method. Occasionally, high and low samples fell within the $7.0 \pm 0.5$ percent range requiring only minor adjustments while some required extrapolation. 
Table 10: Test Specimen Tolerances

\begin{tabular}{|c|c|}
\hline Item & Specification \\
\hline Average Diameter & 98 to $104 \mathrm{~mm}$ \\
\hline Standard Deviation of Diameter & $\leq 1.0 \mathrm{~mm}$ \\
\hline Height & 147.5 to $152.5 \mathrm{~mm}$ \\
\hline End Flatness & $\leq 0.5 \mathrm{~mm}$ \\
\hline End Perpendicularity & $\leq 1.0 \mathrm{~mm}$ \\
\hline
\end{tabular}

The mix masses and air voids used for dynamic modulus, flow number, and fatigue testing are summarized in Table 11. The dynamic modulus and flow number samples were cut to $150 \mathrm{~mm}$ while the fatigue samples were trimmed to $130 \mathrm{~mm}$. It was found the shorter fatigue samples had lower air voids than the taller samples. It is hypothesized this was the result of removing more of the lower density material from the ends of the fatigue samples. This is discussed further in the Fatigue Procedure section.

Table 11: Mix Masses Placed in Mold Used for Each Sample Set

\begin{tabular}{|c|c|c|c|}
\hline Mix & DM/FN Mass (g) & FT Mass $(\mathbf{g})$ & AVG VTM (\%) \\
\hline AA937 & 6,650 & 6,650 & 7.0 \\
\hline JAP909 & 7,115 & 7,115 & 6.6 \\
\hline JFA060 & 6,750 & 6,727 & 7.0 \\
\hline JFA115 & 6,735 & 6,720 & 6.8 \\
\hline JFA429 & 6,800 & 6,745 & 6.7 \\
\hline KP483 & 6,675 & 6,675 & 6.7 \\
\hline WVP523 & 6,735 & 6,720 & 6.7 \\
\hline WVP766 & 6,705 & 6,680 & 6.8 \\
\hline WVP882 & 6,585 & 6,560 & 6.8 \\
\hline
\end{tabular}

\section{Dynamic Modulus and Specimen Uniformity}

Sample specifications for dynamic modulus and flow number samples per AASHTO PP 60 are listed in Table 10. End flatness and perpendicularity were checked along with height prior to running all three VTM methods on cored and sawed samples. Additionally, to avoid unnecessary exposure to light and excess oxygenation, samples were stored in plastic bags and placed in a dark cabinet as seen in Figure 16. All samples were tested within two weeks of being cored and sawed. 


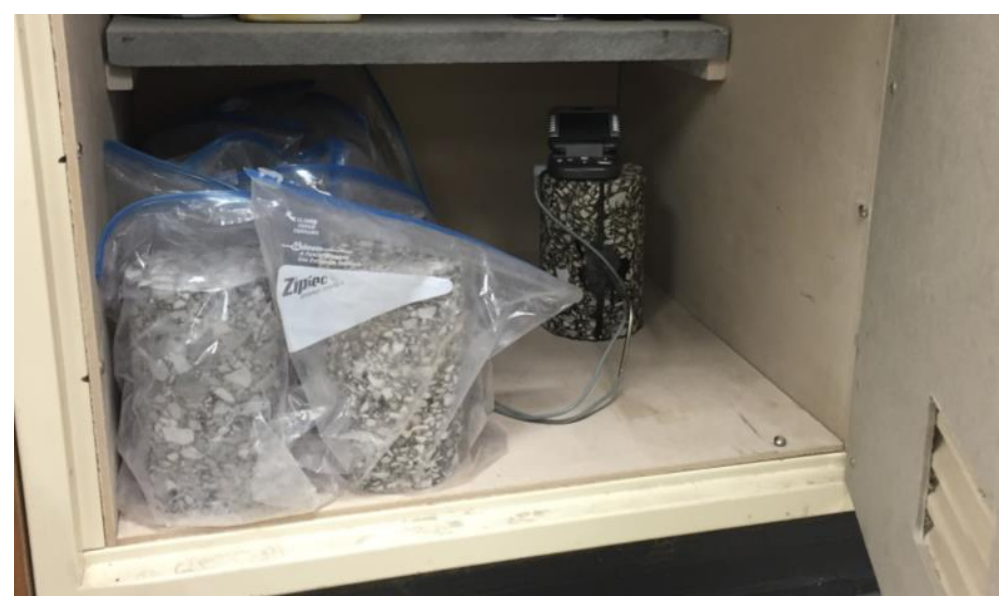

Figure 16: Specimen Storage

As previously mentioned, all mix designs contain PG 64-22 binder so every sample was run using the same temperatures and frequencies listed in Table 3. Prior to testing, the samples were temperature conditioned to the test temperatures. A dummy sample containing a thermometer drilled into its core was used to monitor conditioning temperatures. Images of the equipment are available in Appendix F. Devcon 5-minute Epoxy Gel was used to adhere gauge points to samples.

Although dynamic modulus testing is considered nondestructive, testing at the lower temperatures and higher frequencies could cause the least damage while the higher would theoretically cause the most. Therefore, specimens were first tested at $4^{\circ} \mathrm{C}$, then $20^{\circ} \mathrm{C}$, and lastly at $40^{\circ} \mathrm{C}$ to avoid any discrepancies in the material property evaluation. After testing was completed, the dynamic modulus samples were cut into thirds and used to assess specimen uniformity per AASHTO PP 60. Figure 17 summarizes the steps taken to identify mix masses and verify specimen uniformity. 


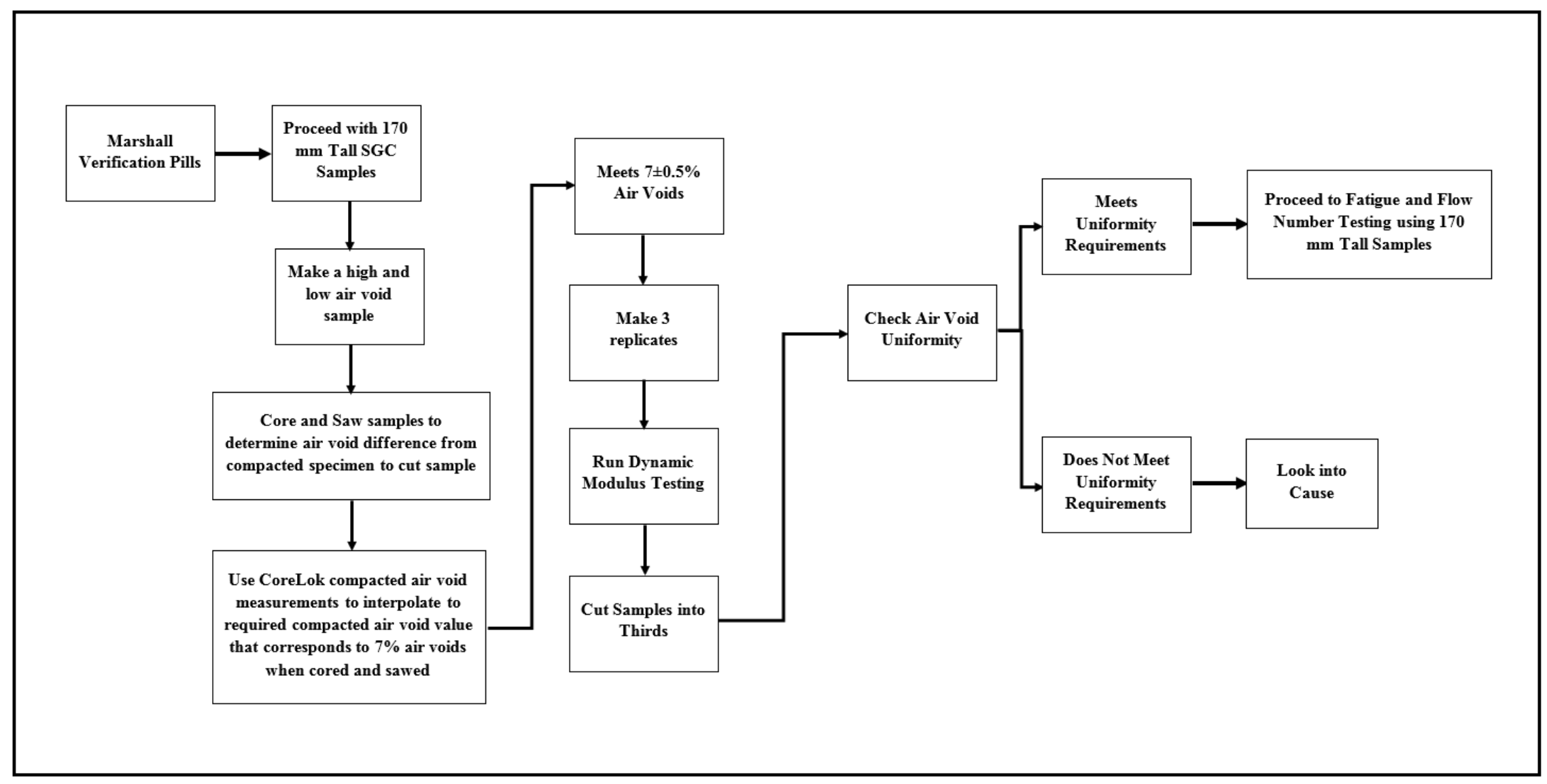

Figure 17: Flow Diagram of Air Void Uniformity Evaluation 


\section{Fatigue Procedure}

The first fatigue set contained one sample from each mix type. Following AASHTO TP 107, samples were cut down to $130 \mathrm{~mm}$ height. The most compactive effort occurs toward the center of a SGC sample so there was concern that some samples would fall out of the VTM range. While the target air void thirds showed no indication for concern, this step was still deemed necessary.

As anticipated, there were issues with samples falling out of the VTM specifications. Minor adjustments were made to the mix masses throughout fatigue testing to avoid subsequent samples from falling out of range (Table 11). For most mix sets, there was not enough mix to repeat the high and low air void procedure to pinpoint the mix mass required for the shorter samples. Six of the 27 fatigue samples fell below 6.5 percent. These samples are bolded in Table 14. Since Witczack et al. (2013) found that fatigue results were not sensitive to air voids, the samples that were out of the target range were tested for fatigue.

The test specification calls for a minimum of three samples so three replicates for each mix were made. A combination of Devcon 10110 and resin was used to adhere samples to the end platens per the test specification protocol. An additional step of heating end platens to $40^{\circ} \mathrm{C}$ facilitated better adhesion of the steel putty to sample interface. Testing temperature was determined using LTPPBind 98 percent reliability climatic Performance Grade (PG) for Morgantown, WV. The high temperature was $58^{\circ} \mathrm{C}$ and the low was $-22^{\circ} \mathrm{C}$. Using Equation 20 , the final testing temperature for all fatigue testing was determined to be $15^{\circ} \mathrm{C}$.

$T\left({ }^{\circ} \mathrm{C}\right)=\frac{\text { High temperature binder } P G \text { grade }- \text { Low temperature binder } P G \text { grade }}{2}-3$

From AASHTO TP 107, the second and third fatigue replicate micro strain values are adjusted according to number of cycles to failure $\left(\mathrm{N}_{\mathrm{f}}\right)$ from the first completed test as seen in Table 12. Fatigue tests were performed for one of the three replicates for all of the mixes in order to determine the initial $\mathrm{N}_{\mathrm{f}}$ for each mix. Two samples from the first round of testing did not meet an ending criteria: AA937 and WVP882. AA937 sample 5 reached 4,620 cycles before the AMPT encountered an LVDT error. When the error occurred, the sample had reached 15 percent 
of its dynamic modulus. Reviewing the data confirmed that the number of cycles to failure would not have exceeded the 5,000 cycle limit. Therefore, the $\mathrm{N}_{\mathrm{f}}$ range 1,000 to 5,000 was used for replicate micro strain adjustments. WVP882 S7 failed at 30,710 cycles at approximately 30 percent of the dynamic modulus criteria. The next threshold value cutoff is 100,000 cycles. Therefore, $\mathrm{N}_{\mathrm{f}}$ range 20,000 to 100,000 micro strain adjustments were used. Three replicates from each mix type were tested per the test protocol with subsequent replicates tested at the appropriate adjusted micro strain values which can be seen in Table 13.

Table 12: On-specimen Strain Adjustments for Second and Third Fatigue Specimen

\begin{tabular}{|c|c|c|}
\hline Case & $\boldsymbol{\varepsilon}_{\mathrm{os} 2}$ & $\boldsymbol{\varepsilon}_{\mathrm{os} 3}$ \\
\hline $500<N_{f 1}<1,000$ & $\varepsilon_{\mathrm{os} 1}-100$ & $\varepsilon_{\mathrm{os} 1}-150$ \\
\hline $1,000<N_{f 1}<5,000$ & $\varepsilon_{\mathrm{os} 1}-50$ & $\varepsilon_{\mathrm{os} 1}-100$ \\
\hline $5,000<N_{f 1}<20,000$ & $\varepsilon_{\mathrm{os} 1}+50$ & $\varepsilon_{\mathrm{os} 1}-50$ \\
\hline $20,000<N_{f 1}<100,000$ & $\varepsilon_{\mathrm{os} 1}+100$ & $\varepsilon_{\mathrm{os} 1}+50$ \\
\hline $100,000<N_{f 1}$ & $\varepsilon_{\mathrm{os} 1}+150$ & $\varepsilon_{\mathrm{os} 1}+100$ \\
\hline
\end{tabular}

Table 13: Cycles to Failure Micro Strain Adjustments for Replicates

\begin{tabular}{|c|c|c|c|c|c|}
\hline Mix & $\mathbf{N}_{\mathbf{f}}$ & $\mathbf{\varepsilon o s 1}=\mathbf{3 0 0}$ & $\boldsymbol{\varepsilon o s}^{2}$ & $\mathbf{\varepsilon o s} 3$ & $\mathbf{N}_{\mathbf{f}}$ Range \\
\hline AA937 & 4,620 & 300 & 250 & 200 & $1,000<\mathrm{N}_{\mathrm{f} 1}<5,000$ \\
\hline JAP 909 & 7,190 & 300 & 350 & 250 & $5,000<\mathrm{N}_{\mathrm{f} 1}<20,000$ \\
\hline JFA060 & 7,350 & 300 & 350 & 250 & $5,000<\mathrm{N}_{\mathrm{f} 1}<20,000$ \\
\hline JFA115 & 22,640 & 300 & 400 & 350 & $20,000<\mathrm{N}_{\mathrm{f} 1}<100,000$ \\
\hline JFA429 & 3,670 & 300 & 250 & 200 & $1,000<\mathrm{N}_{\mathrm{f} 1}<5,000$ \\
\hline KP483 & 13,150 & 300 & 350 & 250 & $5,000<\mathrm{N}_{\mathrm{f} 1}<20,000$ \\
\hline WVP523 & 2,950 & 300 & 250 & 200 & $1,000<\mathrm{N}_{\mathrm{f} 1}<5,000$ \\
\hline WVP766 & 15,840 & 300 & 350 & 250 & $5,000<\mathrm{N}_{\mathrm{f} 1}<20,000$ \\
\hline WVP882 & 30,710 & 300 & 400 & 350 & $20,000<\mathrm{N}_{\mathrm{f} 1}<100,000$ \\
\hline
\end{tabular}

For the third round of testing, upon test completion samples were pulled apart using the AMPT hydraulics. This step was added to identify where the sample failed. In all but two cases, the samples separated within the $70 \mathrm{~mm}$ gauge length.

Table 14 summarizes all fatigue samples including: the VTM of each sample; dynamic modulus from the fingerprint test; dynamic modulus ratios (DMR); if an LVDT error occurred during the test; if there was a phase angle drop; and where the sample fractured with respect to the gauge points. In the Error column, Completed indicates no LVDT error occurred. For 
fracture location, Middle means the failure fell within all three gauge point sets, Figure 18, and End means the sample broke outside the gauge points. One sample (JFA429 S8) cracked below two gauge point sets and within one set (Middle/End). Also, dynamic modulus ratio (DMR) and fingerprint dynamic modulus values are reported. A DMR value between 0.9 and 1.1 guarantees the linear viscoelastic properties obtained from the dynamic modulus tests can be used effectively in S-VECD analysis (Kim, 2015). Two samples fell outside of this range (AA937 S5 and JFA429 S6). However, the rationale for this recommendation is not documented and there is no discussion of the consequences of having a DMR outside this range. It should be noted that all samples that fell outside the air void range remained within the aforementioned DMR range except JFA429 sample 6.

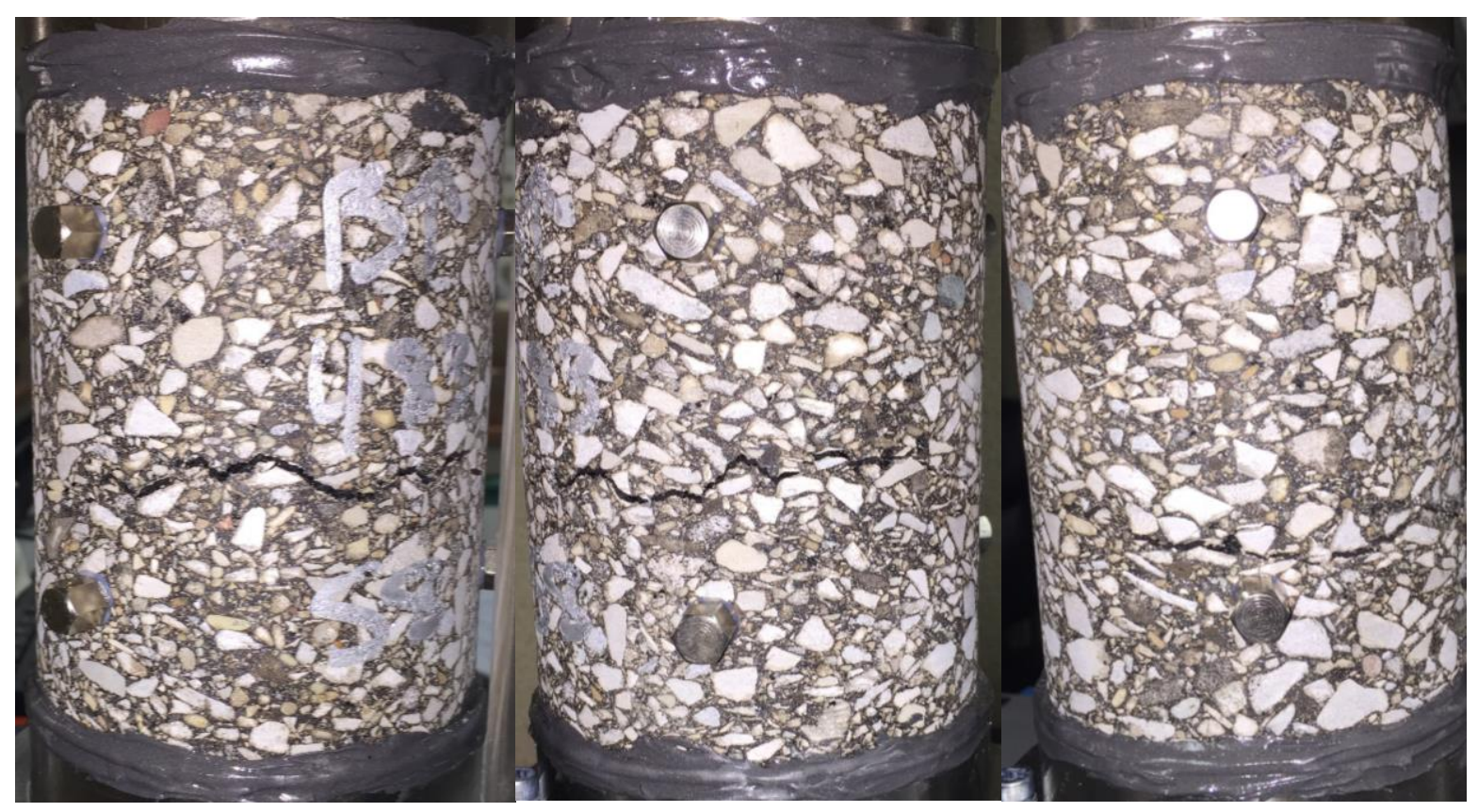

Figure 18: KP483 Sample 8 Middle Failure 
Table 14: Fatigue Testing Compilation

\begin{tabular}{|c|c|c|c|c|c|c|c|}
\hline Mix & REP & $\begin{array}{l}\text { VTM } \\
(\%)\end{array}$ & $\begin{array}{l}\mid \mathbf{E}^{*} \text { |linger } \\
\text { (MPa) }\end{array}$ & DMR & Error & $\begin{array}{c}\text { Phase Angle } \\
\text { Drop }\end{array}$ & $\begin{array}{c}\text { Failure } \\
\text { Location }\end{array}$ \\
\hline \multirow{3}{*}{ AA937 } & 1 (S5) & 7.0 & 11,379 & 1.2 & LVDT 1 & No & - \\
\hline & 2 (S6) & 6.4 & 11,140 & 1.1 & LVDT 3 & Yes & Middle \\
\hline & 3 (S7) & 6.3 & 11,349 & 1.1 & LVDT 1 & Yes & Middle \\
\hline \multirow{3}{*}{ JAP909 } & 1 (S6) & 6.4 & 11,859 & 1.1 & Completed & No & - \\
\hline & 2 (S7) & 6.7 & 11,921 & 1.1 & Completed & Yes & - \\
\hline & $3(\mathrm{~S} 8)$ & 6.7 & 11,803 & 1.1 & LVDT 3 & Yes & Middle \\
\hline \multirow{3}{*}{ JFA060 } & 1 (S5) & 6.9 & 9,502 & 1.0 & LVDT 1 & Yes & - \\
\hline & 2 (S6) & 6.3 & 10,447 & 1.1 & Completed & No & - \\
\hline & 3 (S7) & 7.0 & 10,028 & 1.0 & Completed & No & Middle \\
\hline \multirow{3}{*}{ JFA115 } & 1 (S6) & 7.0 & 8,686 & 1.0 & Completed & No & - \\
\hline & 2 (S7) & 6.5 & 8,697 & 1.0 & LVDT 1 & Yes & - \\
\hline & 3 (S8) & 6.9 & 9,405 & 1.0 & Completed & Yes & Middle \\
\hline \multirow{3}{*}{ JFA429 } & 1 (S6) & 6.3 & 11,478 & 1.2 & Completed & Yes & - \\
\hline & 2 (S7) & 6.5 & 10,234 & 1.1 & LVDT 1 & Yes & - \\
\hline & 3 (S8) & 6.9 & 10,244 & 1.1 & LVDT 3 & Yes & Middle/End \\
\hline \multirow{3}{*}{ KP483 } & 1 (S6) & 6.5 & 8,161 & 0.9 & Completed & Yes & - \\
\hline & 2 (S7) & 6.8 & 8,995 & 1.0 & LVDT 2 & Yes & - \\
\hline & $3(\mathrm{~S} 8)$ & 6.7 & 9,688 & 1.1 & LVDT 2 & No & Middle \\
\hline \multirow{3}{*}{ WVP523 } & 1 (S6) & 7.2 & 10,763 & 1.1 & LVDT 2 & Yes & - \\
\hline & 2 (S7) & 6.8 & 10,720 & 1.1 & LVDT 2 & Yes & End \\
\hline & $3(\mathrm{~S} 8)$ & 6.7 & 10,555 & 1.0 & LVDT 3 & No & Middle \\
\hline \multirow{3}{*}{ WVP766 } & 1 (S6) & 6.7 & 9,757 & 1.1 & LVDT 2 & Yes & - \\
\hline & 2 (S7) & 6.7 & 9,678 & 1.1 & LVDT 3 & Yes & - \\
\hline & $3(\mathrm{~S} 8)$ & 7.0 & 9,231 & 1.0 & LVDT 3 & Yes & Middle \\
\hline \multirow{3}{*}{ WVP882 } & 1 (S7) & 6.3 & 9,420 & 1.1 & LVDT 2 & No & - \\
\hline & $2(\mathrm{~S} 8)$ & 6.7 & 9,680 & 1.1 & Completed & Yes & - \\
\hline & 3 (S9) & 6.7 & 8,980 & 1.0 & Completed & Yes & Middle \\
\hline
\end{tabular}

\section{Flow Number Procedure}

The flow number specimen conditioning procedure was not performed in the laboratory for the plant-produced mixes, it was assumed that mixes met full absorption and aging at the HMA plants. This is the accepted procedure specified by the WVDOH for testing plant produced quality control samples. Four flow number replicates were made at $7.0 \pm 0.5$ percent air voids to evaluate the rutting resistance. All samples used for flow number testing met AASHTO PP 60 precision standards and air void content of 7.0 \pm 0.5 percent except one, WVP523 S9, which fell out of air void range. Two mixes, JFA115 and JFA429, have only three and two replicates because not enough mix was available to make four samples. 
Temperatures for the two mix types analyzed (Wearing I and Base II/19mm) were determined using LTPPBind Version 3.1 Beta software. The equation provided in the software for LTPP High Pavement Temperature Model was used to determine an initial temperature in the Morgantown, WV, area from the two locations provided within the software. The locations were Morgantown Municipal AP (WV6202) and Morgantown L \& D (WV6212). The equation and variables are listed in Equation 21 and values used are displayed in Table 15.

$T_{\text {pav }}=54.32+0.78 T_{\text {air }}-0.0025 \mathrm{Lat}^{2}-15.1 \log 10(H+25)+z \sqrt{9+0.61 S_{\text {air }}^{2}}$

Where:

$T_{p a v}=$ the high asphalt cement pavement temperature below surface, ${ }^{\circ} \mathrm{C}$

$T_{\text {air }}=$ the high air temperature, ${ }^{\circ} \mathrm{C}$

$L_{a t}=$ the latitude of the section, ${ }^{\circ}$

$H=$ the depth to surface, $\mathrm{mm}$

$S_{a i r}=$ the standard deviation of the 7 day mean air temperature, ${ }^{\circ} \mathrm{C}$

$z=$ the standard normal distribution table

Table 15: LTPPBind Equation Values Used

\begin{tabular}{|c|c|c|c|c|}
\hline $\mathbf{T}_{\text {air }}$ & Latitude & $\mathbf{H}(\mathbf{m m})$ & $\begin{array}{c}\mathbf{z} \text { at 50\% } \\
\text { reliability }\end{array}$ & Sair \\
\hline 32.4 & 39.6428 & $25 / 50$ & 0 & 1.7 \\
\hline
\end{tabular}

First, the program averaged the two Morgantown stations to be $49.9^{\circ} \mathrm{C}$ at $50 \mathrm{~mm}$ depth. However, the calculated value using Equation 21 at the two locations resulted in an average value of $47.2^{\circ} \mathrm{C}\left(47.1\right.$ and $\left.47.3^{\circ} \mathrm{C}\right)$. The results from the equation varied slightly from the values provided in the software so 0.4 was added to the average value of the two for a final value of $47.6^{\circ} \mathrm{C}$. From here the program value and the adjusted calculated value were averaged. For 19 $\mathrm{mm}$ mixes, the test temperature used was $49^{\circ} \mathrm{C}$.

The same procedure was conducted for the Wearing I $(9.5 \mathrm{~mm})$ mixes evaluated, but at a depth of $25 \mathrm{~mm}$ below the ground surface. The program average from the two Morgantown stations was $51.9^{\circ} \mathrm{C}$. However, the calculated value using Equation 21 resulted in an average 
value of $49.9^{\circ} \mathrm{C}\left(49.9\right.$ and $\left.49.8^{\circ} \mathrm{C}\right)$ so 0.4 was added resulting in a final value of $50.3^{\circ} \mathrm{C}$. The final averaged value was calculated to $51^{\circ} \mathrm{C}$. Similar to dynamic modulus testing, a dummy sample containing a thermometer placed in its center was placed in the conditioning oven with the samples prior to testing.

All flow number testing was completed following and using the aforementioned information. Once testing was completed, two methods were used to find the flow number: the AMPT averaging method and the Francken model. The Francken model fitting coefficients were found using nonlinear regression in MATLAB. The code can be seen below:

$\mathrm{n}=$ table (Cycle, Microstrain);

modelfun $=@(x, n)\left(x(1) *\left(n(:, 1) \cdot{ }^{\wedge}(x(2))\right)\right)+(x(3) *(\exp (x(4) * n(:, 1))-1)) ;$

beta $0=\left[\begin{array}{llll}600 & 0.5 & 100 & 0.001\end{array}\right] ;$

mdl = fitnlm (n, modelfun, beta 0$)$

Figure 19 displays the Francken model fitted equation and corresponding AMPT permanent axial strain data from AA937 sample 8 flow number test. All Francken model fitting coefficients are located in Appendix E.

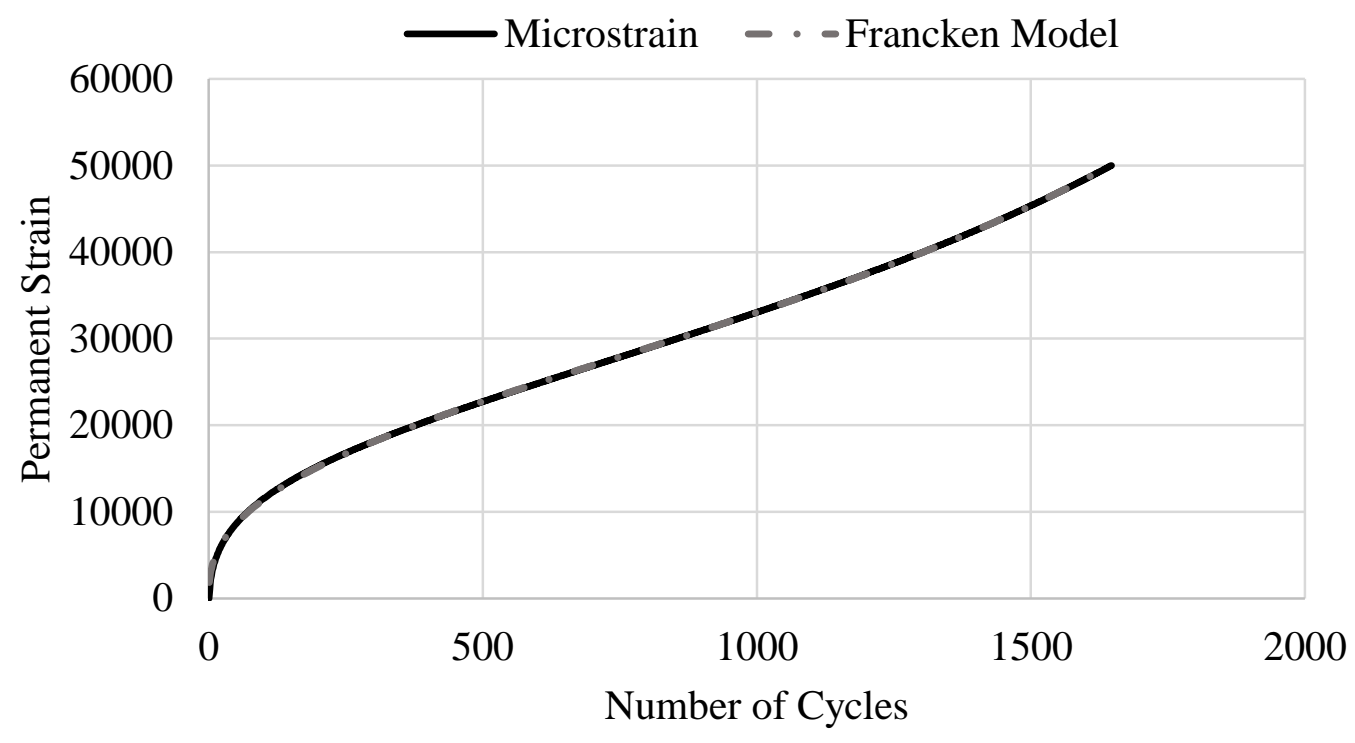

Figure 19: AA937 S8 AMPT Permanent Axial Strain and Francken Model 


\section{Chapter 4: Results and Discussion}

This section presents testing results and all additional analyses performed. Since this is an evaluation of numerous mixes provided from contractors throughout $\mathrm{WV}$, multiple comparisons are made ranging from similar mix types to mix types provided from a manufacturer to all mixes. In the data tables, samples are identified by the producer mix identifications in one column and if needed a second column shows the replicate number. For example, S4 is the fourth replicate of a $\operatorname{mix}$.

\section{Maximum Specific Gravity}

Laboratory $\mathrm{G}_{\mathrm{mm}}$ values varied from JMF values. All but one mix had a higher $\mathrm{G}_{\mathrm{mm}}$ value as seen in Table 16. Only two of the samples fell within the acceptable range of 0.024 for AASHTO T 209 multilaboratory precision. There can be multiple reasons why the $\mathrm{G}_{\mathrm{mm}}$ from mix design does not match the $\mathrm{G}_{\mathrm{mm}}$ from plant produced mixes such as variations in percent binder, stockpile gradations, etc. The complete laboratory test data are available in Appendix B. These data demonstrate the single-operator precision of the tests done during this research are within variability allowed in AASHTO T 209. Proceeding forward, the laboratory $\mathrm{G}_{\mathrm{mm}}$ values were used for all subsequent calculations.

Table 16: Variation in $\mathrm{G}_{\mathrm{mm}}$ between JMF and Laboratory

\begin{tabular}{|c|c|c|c|}
\hline Mix & JMF Gmm & AVG Lab Gmm & Difference \\
\hline AA937 & 2.447 & 2.489 & 0.042 \\
\hline JAP909 & 2.613 & 2.644 & 0.031 \\
\hline JFA060 & 2.500 & 2.528 & 0.028 \\
\hline JFA115 & 2.459 & 2.494 & 0.035 \\
\hline JFA429 & 2.500 & 2.530 & 0.030 \\
\hline KP483 & 2.440 & 2.471 & 0.031 \\
\hline WVP523 & 2.473 & 2.493 & 0.020 \\
\hline WVP766 & 2.476 & 2.475 & -0.001 \\
\hline WVP882 & 2.408 & 2.447 & 0.039 \\
\hline
\end{tabular}




\section{Assessing Sample Uniformity}

To preserve materials, air void uniformity was evaluated using the samples tested for dynamic modulus. Air void uniformity was conducted using AASHTO PP 60 with the exception that sample uniformity was conducted at $7.0 \pm 0.5$ percent and not $5.0 \pm 0.5$ percent air voids as the test specifies. It was more beneficial to investigate uniformity at $7.0 \pm 0.5$ percent given all test samples were made at this target. Each of the three $150 \mathrm{~mm}$ replicates was cut into equal thirds (approximately $50 \mathrm{~mm}$ ). Next, the samples were measured using the SSD, CoreLok, and Dimensional methods and the averaged $\mathrm{G}_{\mathrm{mb}}$ was computed.

As previously mentioned, the AASHTO PP 60 test statistic must be less than 2.78 to reject the null hypothesis that the sample means are equal. All mixes except WVP523 and WVP882 met air void uniformity test. WVP523 did not meet requirements for three of the four $\mathrm{G}_{\mathrm{mb}}$ methods evaluated (SSD, CoreLok, and average) in the top-middle comparison while WVP882 did not meet requirements in SSD for middle-bottom thirds. The t-statistics for each method can be seen in Table 17.

Figure 20 displays images of one WVP523 sample at four angles rotated approximately ninety degrees. Visually there appears to be segregation with irregular heterogeneity between the bottom and top sample halves and from one side to the other. In the bottom portion of the rightmost image, no large aggregates can be seen. This irregularity may have led to the topmiddle third not meeting acceptable air void uniformity.

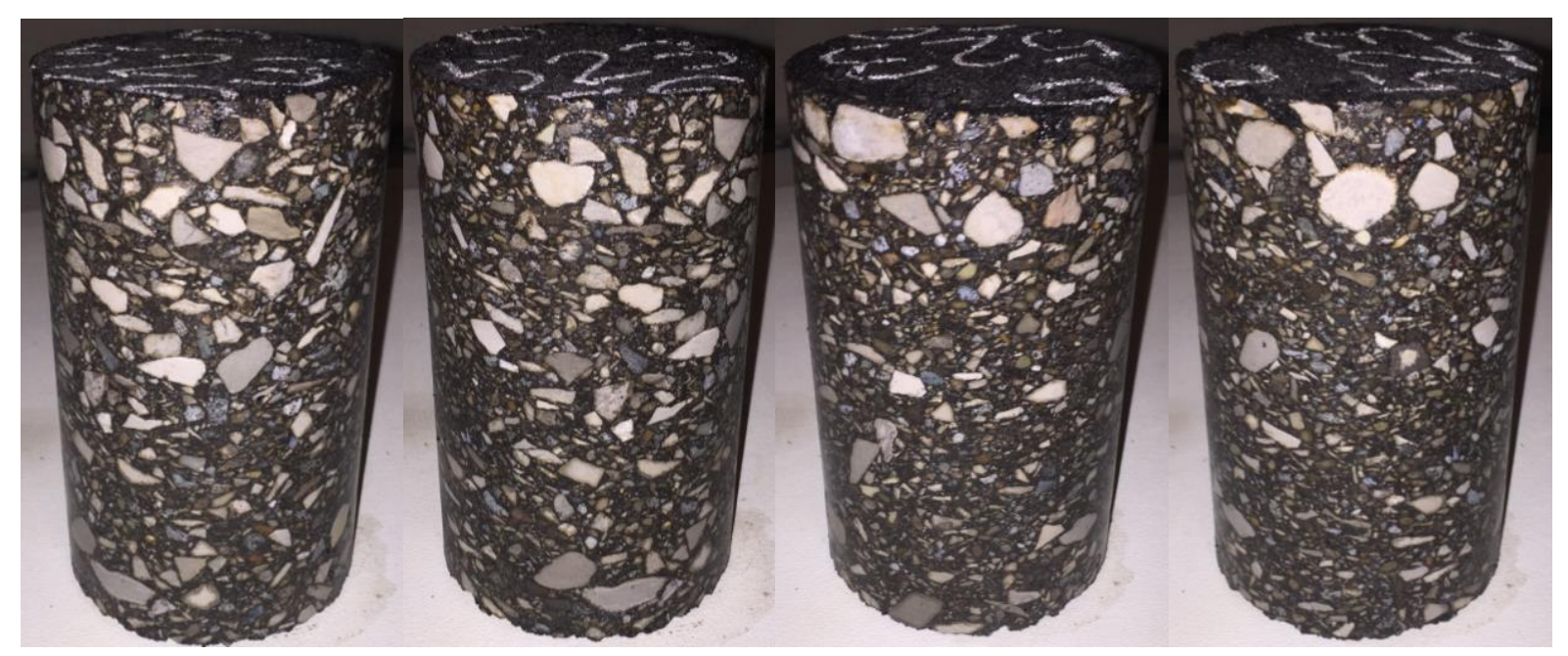

Figure 20: WVP523 Sample 
Table 17: T-statistic for the Three $\mathrm{G}_{\mathrm{mb}}$ Methods and Averaged Values

\begin{tabular}{|c|c|c|c|c|c|c|c|c|c|c|c|c|c|}
\hline \multirow[b]{3}{*}{ Mix } & \multirow[b]{3}{*}{ REP } & \multicolumn{12}{|c|}{$\mathbf{G}_{\mathrm{mb}}$ Method t-statistics } \\
\hline & & \multicolumn{3}{|c|}{ SSD } & \multicolumn{3}{|c|}{ CL } & \multicolumn{3}{|c|}{ Dim. } & \multicolumn{3}{|c|}{ AVG } \\
\hline & & T-M & B-M & T-B & T-M & B-M & T-B & T-M & B-M & T-B & T-M & B-M & T-B \\
\hline \multirow{3}{*}{ AA937 } & $1(\mathrm{~S} 1)$ & \multirow{3}{*}{0.186} & \multirow{3}{*}{0.010} & \multirow{3}{*}{0.775} & \multirow{3}{*}{0.108} & \multirow{3}{*}{0.537} & \multirow{3}{*}{0.658} & \multirow{3}{*}{0.099} & \multirow{3}{*}{0.586} & \multirow{3}{*}{0.555} & \multirow{3}{*}{0.017} & \multirow{3}{*}{0.685} & \multirow{3}{*}{0.659} \\
\hline & $2(\mathrm{~S} 3)$ & & & & & & & & & & & & \\
\hline & $3(\mathrm{~S} 4)$ & & & & & & & & & & & & \\
\hline \multirow{3}{*}{ JAP909 } & $1(\mathrm{~S} 2)$ & \multirow{3}{*}{1.048} & \multirow{3}{*}{0.036} & \multirow{3}{*}{0.520} & \multirow{3}{*}{0.307} & \multirow{3}{*}{0.205} & \multirow{3}{*}{0.378} & \multirow{3}{*}{0.253} & & & & & \\
\hline & $2(\mathrm{~S} 3)$ & & & & & & & & 0.223 & 0.616 & 0.546 & 0.374 & 1.010 \\
\hline & $3(\mathrm{~S} 4)$ & & & & & & & & & & & & \\
\hline & $1(\mathrm{~S} 2)$ & & & & & & & & & & & & \\
\hline JFA060 & $2(\mathrm{~S} 3)$ & 0.675 & 0.351 & 0.181 & 0.346 & 0.107 & 0.401 & 0.002 & 0.127 & 0.117 & 0.157 & 0.134 & 0.277 \\
\hline & $3(\mathrm{~S} 4)$ & & & & & & & & & & & & \\
\hline & $1(\mathrm{~S} 3)$ & & & & & & & & & & & & \\
\hline JFA115 & $2(\mathrm{~S} 4)$ & 0.555 & 0.215 & 0.403 & 0.840 & 0.213 & 0.526 & 0.736 & 0.915 & 1.247 & 0.794 & 0.481 & 0.763 \\
\hline & 3 (S5) & & & & & & & & & & & & \\
\hline & $1(\mathrm{~S} 3)$ & & & & & & & & & & & & \\
\hline JFA429 & $2(\mathrm{~S} 4)$ & 0.838 & 2.090 & 2.710 & 0.061 & 1.044 & 2.393 & 0.871 & 1.486 & 0.392 & 0.889 & 2.408 & 2.073 \\
\hline & 3 (S5) & & & & & & & & & & & & \\
\hline & $1(\mathrm{~S} 2)$ & & & & & & & & & & & & \\
\hline KP483 & $2(\mathrm{~S} 3)$ & 0.501 & 0.724 & 1.295 & 0.584 & 0.910 & 1.044 & 0.322 & 0.741 & 0.853 & 0.475 & 0.787 & 1.064 \\
\hline & $3(\mathrm{~S} 4)$ & & & & & & & & & & & & \\
\hline & $1(\mathrm{~S} 3)$ & & & & & & & & & & & & \\
\hline WVP523 & $2(\mathrm{~S} 4)$ & 3.335 & 0.634 & 1.194 & 7.691 & 2.048 & 1.699 & 1.680 & 1.249 & 0.156 & 4.191 & 1.281 & 1.009 \\
\hline & 3 (S5) & & & & & & & & & & & & \\
\hline & $1(\mathrm{~S} 3)$ & & & & & & & & & & & & \\
\hline WVP766 & $2(\mathrm{~S} 4)$ & 1.896 & 0.384 & 1.405 & 1.948 & 0.647 & 0.659 & 0.094 & 0.370 & 0.570 & 1.113 & 0.158 & 0.857 \\
\hline & 3 (S5) & & & & & & & & & & & & \\
\hline & 1 (S1) & & & & & & & & & & & & \\
\hline WVP882 & $2(\mathrm{~S} 3)$ & 0.713 & 3.023 & 0.633 & 0.614 & 1.568 & 0.148 & 1.309 & 1.949 & 0.190 & 0.851 & 2.135 & 0.288 \\
\hline & 3 (S4) & & & & & & & & & & & & \\
\hline
\end{tabular}

Only one of the nine mixes was evaluated to have high variability when considering the CoreLok results, WVP523. For this sample the t-statistic was much higher than the t-statistics for the SSD and Dimensional methods. This suggests there was an issue with the CoreLok testing of this sample. The overall results in Table 17 demonstrate the air void variability within the samples is reasonable.

\section{Comparing Sections and Intact Sample Air Voids}

During the analysis of the sections, it was noticed that the air voids of the sections were higher than the air voids of the intact samples by 0.4 percent as compiled in Table 18. This issue is not addressed in AASHTO PP 60. The reason for the difference is not apparent and no further analysis was conducted. 
Table 18: Comparison of Sample Third Air Void Averages to Entire Sample Air Void Average

\begin{tabular}{|c|c|c|c|c|c|c|c|c|c|c|}
\hline \multirow[b]{2}{*}{ Mix } & \multirow[b]{2}{*}{ REP } & \multicolumn{3}{|c|}{ Ranking } & \multicolumn{3}{|c|}{ AVG (\%) } & \multirow[b]{2}{*}{$\begin{array}{c}\text { Thirds } \\
\text { AVG }\end{array}$} & \multirow[b]{2}{*}{$\begin{array}{c}\text { Intact } \\
\text { Sample }\end{array}$} & \multirow[b]{2}{*}{ Difference } \\
\hline & & $\mathbf{T}$ & $\mathbf{M}$ & B & $\mathbf{T}$ & $\mathbf{M}$ & B & & & \\
\hline \multirow{3}{*}{ AA937 } & $1(\mathrm{~S} 1)$ & 1 & 0 & -1 & 8.2 & 7.9 & 7.0 & 7.7 & 7.3 & 0.4 \\
\hline & $2(\mathrm{~S} 3)$ & 0 & 1 & -1 & 7.6 & 8.3 & 7.5 & 7.8 & 7.4 & 0.4 \\
\hline & $3(\mathrm{~S} 4)$ & 1 & -1 & 0 & 8.0 & 7.7 & 8.0 & 7.9 & 7.5 & 0.4 \\
\hline \multirow{3}{*}{ JAP909 } & $1(\mathrm{~S} 2)$ & 1 & 0 & -1 & 7.4 & 6.9 & 6.4 & 6.9 & 6.6 & 0.3 \\
\hline & $2(\mathrm{~S} 3)$ & 1 & -1 & 0 & 7.5 & 7.0 & 7.5 & 7.3 & 6.9 & 0.4 \\
\hline & 3 (S4) & -1 & 1 & 0 & 7.0 & 7.6 & 7.2 & 7.3 & 6.9 & 0.4 \\
\hline \multirow{3}{*}{ JFA060 } & $1(\mathrm{~S} 2)$ & 1 & -1 & 0 & 8.1 & 7.6 & 7.9 & 7.9 & 7.5 & 0.4 \\
\hline & $2(\mathrm{~S} 3)$ & 0 & 1 & -1 & 7.5 & 7.5 & 7.2 & 7.4 & 7.1 & 0.3 \\
\hline & $3(\mathrm{~S} 4)$ & 0 & -1 & 1 & 7.3 & 7.3 & 7.3 & 7.3 & 7.0 & 0.3 \\
\hline \multirow{3}{*}{ JFA115 } & $1(\mathrm{~S} 3)$ & 1 & 0 & -1 & 7.1 & 7.0 & 6.6 & 6.9 & 6.5 & 0.4 \\
\hline & $2(\mathrm{~S} 4)$ & 1 & 0 & -1 & 7.5 & 7.1 & 6.6 & 7.1 & 6.6 & 0.5 \\
\hline & 3 (S5) & -1 & 0 & 1 & 7.0 & 7.2 & 7.6 & 7.3 & 6.8 & 0.5 \\
\hline \multirow{3}{*}{ JFA429 } & $1(\mathrm{~S} 3)$ & 0 & 1 & -1 & 7.1 & 7.7 & 6.7 & 7.2 & 6.9 & 0.3 \\
\hline & 2 (S4) & 0 & 1 & -1 & 7.2 & 7.3 & 7.1 & 7.2 & 6.8 & 0.4 \\
\hline & 3 (S5) & 1 & 0 & -1 & 7.1 & 6.9 & 6.8 & 6.9 & 6.5 & 0.4 \\
\hline \multirow{3}{*}{ KP483 } & $1(\mathrm{~S} 2)$ & 1 & 0 & -1 & 8.2 & 7.6 & 7.1 & 7.6 & 7.2 & 0.4 \\
\hline & $2(\mathrm{~S} 3)$ & 1 & -1 & 0 & 7.2 & 6.7 & 6.8 & 6.9 & 6.5 & 0.4 \\
\hline & $3(\mathrm{~S} 4)$ & -1 & 1 & 0 & 6.8 & 7.0 & 6.9 & 6.9 & 6.6 & 0.3 \\
\hline \multirow{3}{*}{ WVP523 } & $1(\mathrm{~S} 3)$ & 1 & -1 & 0 & 7.8 & 7.0 & 7.0 & 7.3 & 6.7 & 0.6 \\
\hline & $2(\mathrm{~S} 4)$ & 1 & -1 & 0 & 7.7 & 7.3 & 7.4 & 7.5 & 6.8 & 0.7 \\
\hline & 3 (S5) & 1 & -1 & 0 & 8.2 & 7.0 & 8.1 & 7.8 & 7.5 & 0.3 \\
\hline \multirow{3}{*}{ WVP766 } & $1(\mathrm{~S} 3)$ & 1 & 0 & -1 & 7.5 & 6.9 & 6.7 & 7.0 & 6.6 & 0.4 \\
\hline & $2(\mathrm{~S} 4)$ & 0 & -1 & 1 & 7.1 & 6.9 & 7.6 & 7.2 & 7.0 & 0.2 \\
\hline & 3 (S5) & 1 & 0 & -1 & 7.7 & 7.6 & 7.2 & 7.5 & 7.2 & 0.3 \\
\hline \multirow{3}{*}{ WVP882 } & $1(\mathrm{~S} 1)$ & 1 & -1 & 0 & 7.9 & 6.5 & 7.2 & 7.2 & 6.9 & 0.3 \\
\hline & 2 (S3) & -1 & 0 & 1 & 6.7 & 7.2 & 7.3 & 7.1 & 6.7 & 0.4 \\
\hline & $3(\mathrm{~S} 4)$ & 0 & -1 & 1 & 7.0 & 6.8 & 7.3 & 7.0 & 6.8 & 0.2 \\
\hline \multirow{3}{*}{ Total } & 1's & 16 & 6 & 5 & & & & & & \\
\hline & 0's & 7 & 10 & 10 & & & & & & \\
\hline & -1 's & 4 & 11 & 12 & & & & & & \\
\hline
\end{tabular}

The middle section should have the lowest air void content because the most compactive effort occurs towards the center of a sample during compaction. However, this was not the case. The highest and lowest thirds varied among Top (T), Middle (M), and Bottom (B) thirds. For further review a 1, 0, or -1 was assigned to the highest, second highest, and lowest air void measurement for each sample third, Table 18. The hundredth decimal place was used when two air void measurements were equal. If the Top, Middle, and Bottom sections were always highest, second highest, and lowest the sum of the columns would be 27, 0, and negative 27. However, this was not the case. The Top section resulted in the highest summed value inferring the highest air void content occurred more frequently in the Top sample sections. The Middle and Bottom 
sections ended with sums of negative five and negative seven. This infers the second highest or the lowest air void content occurred more frequently in the Middle and Bottom sections than in the Top.

An additional comparison of sections was completed using the 27 air void values for top, middle, and bottom in Table 28. An overall t-test comparing all top-middle, middle-bottom, and top-bottom air void measurements was completed. Respectively, a p-value of 0.06 to 0.6 was found when comparing the top-middle and bottom-middle and, therefore, fail to reject the null hypothesis of equal means for these two evaluations. The top-bottom comparison resulted in a pvalue of 0.03 meaning there was sufficient evidence to reject the null hypothesis of equal means for this comparison.

\section{Methods for Measuring $\mathrm{G}_{\mathrm{mb}}$}

Next, line of equality graphs were made to compare the three $G_{m b}$ methods. Both $G_{m b}$ values from the gyratory specimen (Before) and the cored/sawed (After) are plotted in Figures 21-23.

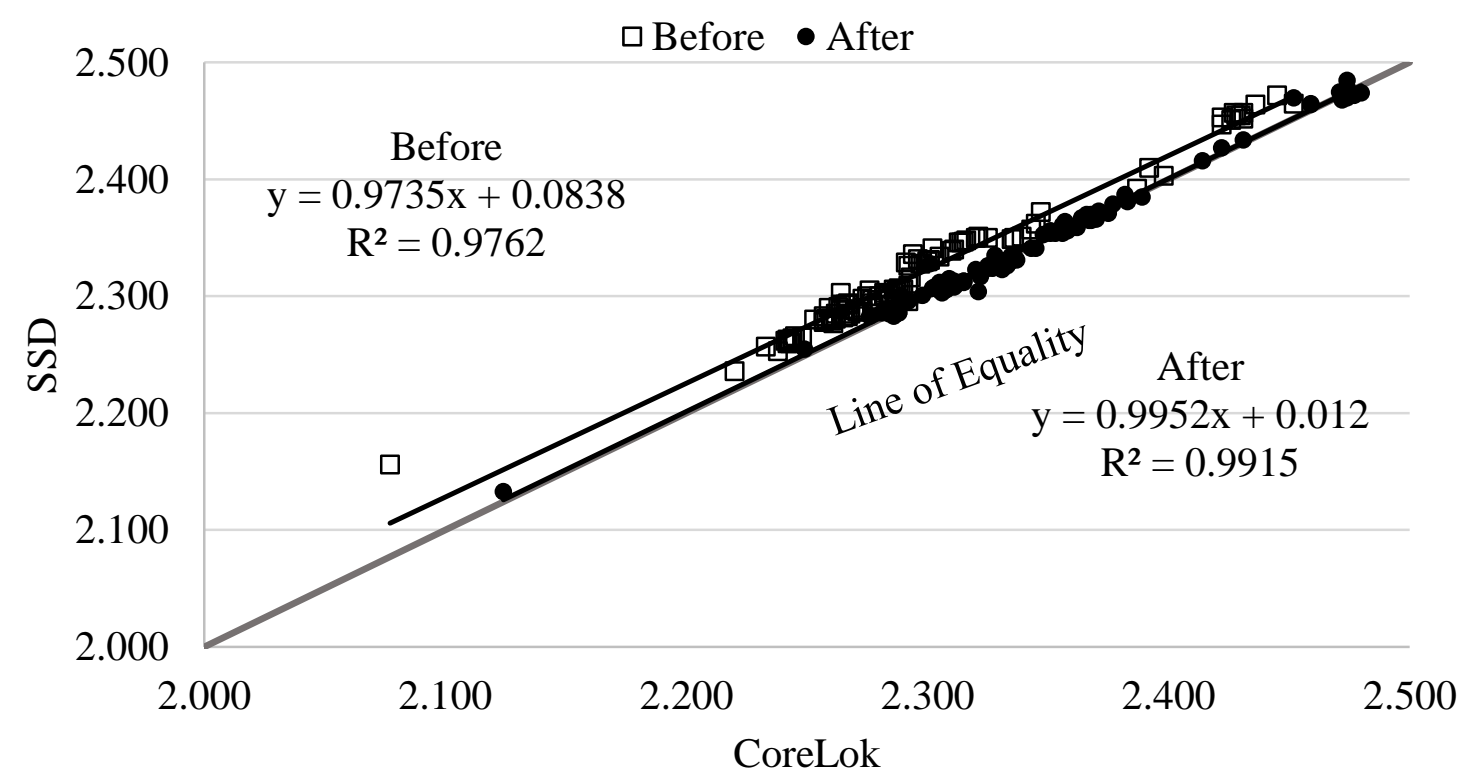

Figure 21: Line of Equality Chart SSD Verses CoreLok Method 


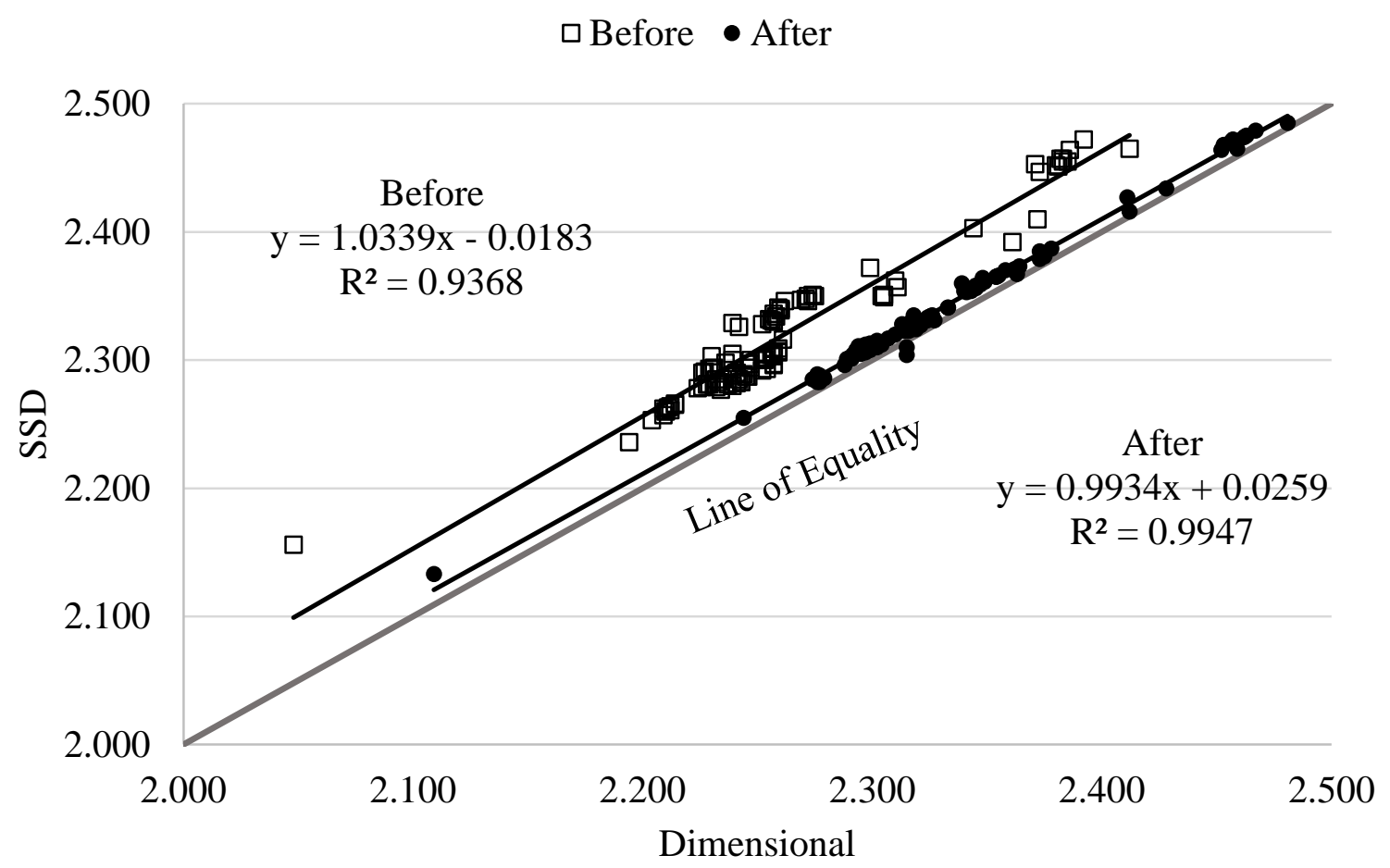

Figure 22: Line of Equality Chart Dimensional Verses SSD Method

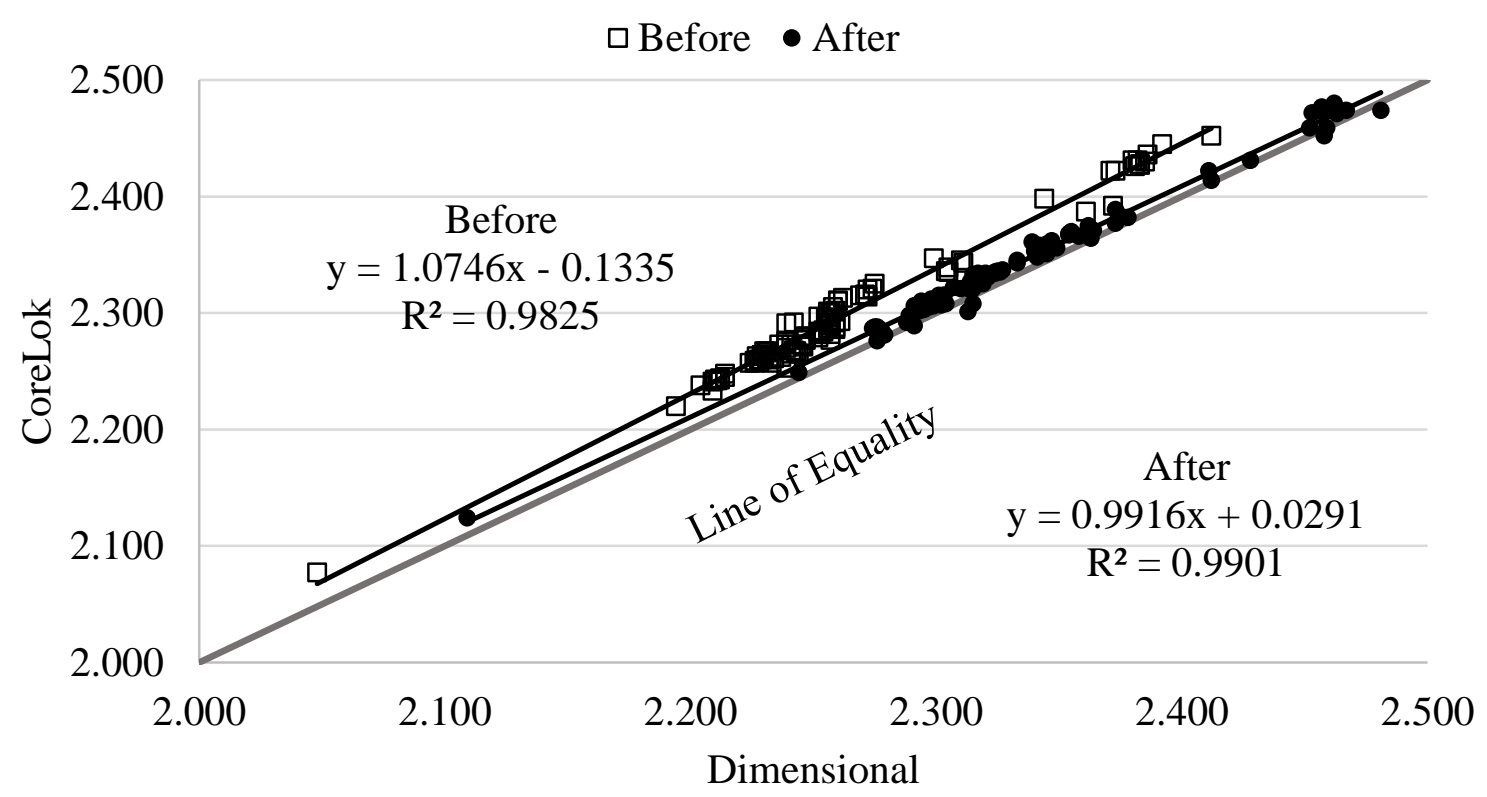

Figure 23: Line of Equality Chart Dimensional Verses CoreLok Method 
Each After comparison has an $\mathrm{R}^{2}$ value higher than 0.99 . This infers a good correlation between any two of the three bulk specific gravity methods reviewed. The $G_{m b}$ values for compacted (Before) samples had lower $\mathrm{R}^{2}$ values for each comparison. SSD compared with Dimensional resulted in the best After comparison, but the worst for Before. Griffith (2009) found that the difference between SSD and CoreLok method $\mathrm{G}_{\mathrm{mb}}$ values diverged at high air voids ( 5 to 8 percent). The air void content in this study was $7.0 \pm 0.5$ percent so the correlation between CoreLok and SSD is consistent with Griffith's findings.

\section{Effective Sample Trimming on Air Voids}

Line of equality graphs using CoreLok VTM values were plotted for Before and After cored and sawed samples. Figure 24 displays all $9.5 \mathrm{~mm}$ NMAS mixes and Figure 25 displays 19 mm NMAS mixes. The 9.5 mm NMAS show a good correlation between Before and After VTM measurements with an $\mathrm{R}^{2}$ value of 0.96 . The $19 \mathrm{~mm}$ NMAS plot has a lower $\mathrm{R}^{2}$ value of 0.80 . The larger NMAS could have more variability between the Before and After VTMs.

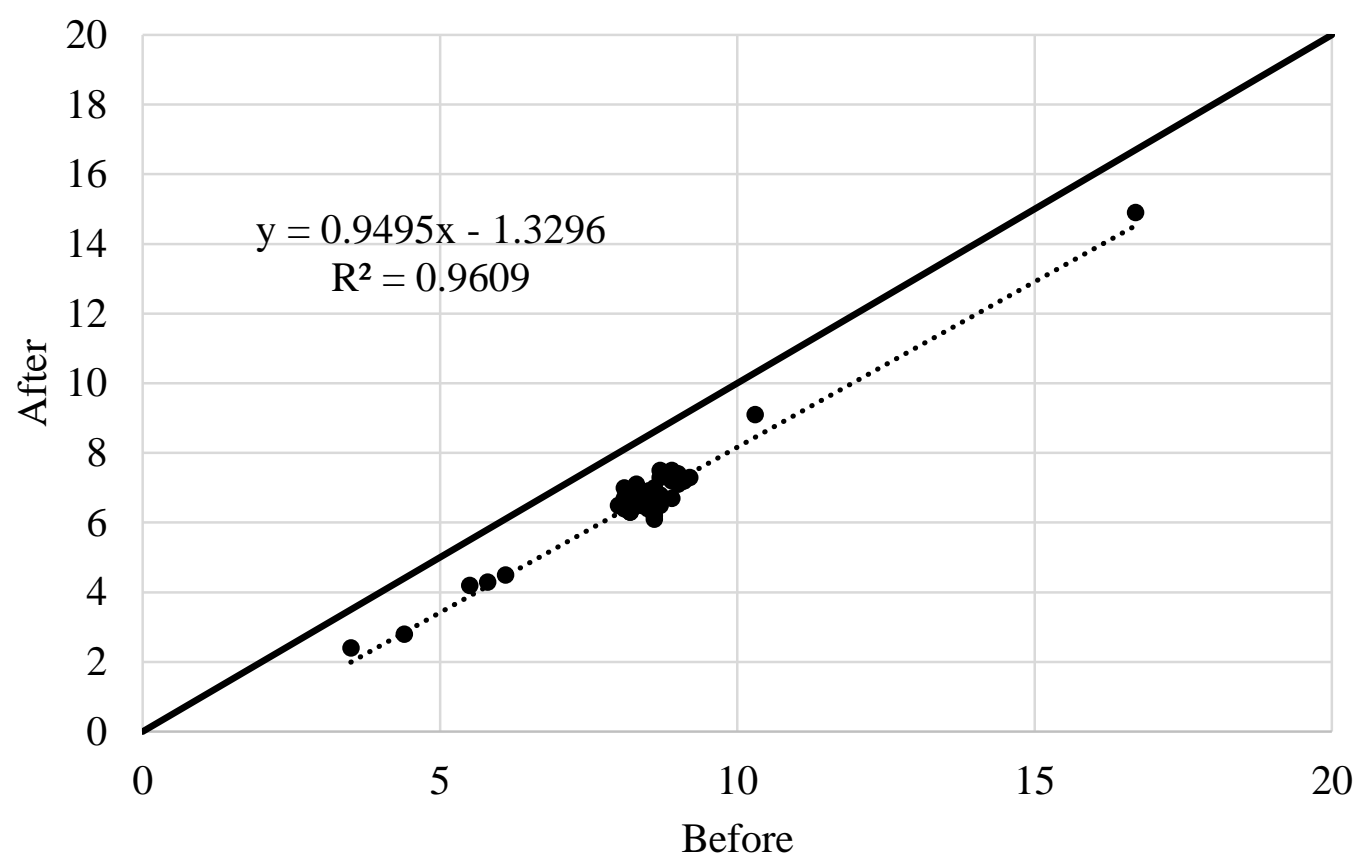

Figure 24: 9.5 mm NMAS CoreLok VTM Before and After Trimming 


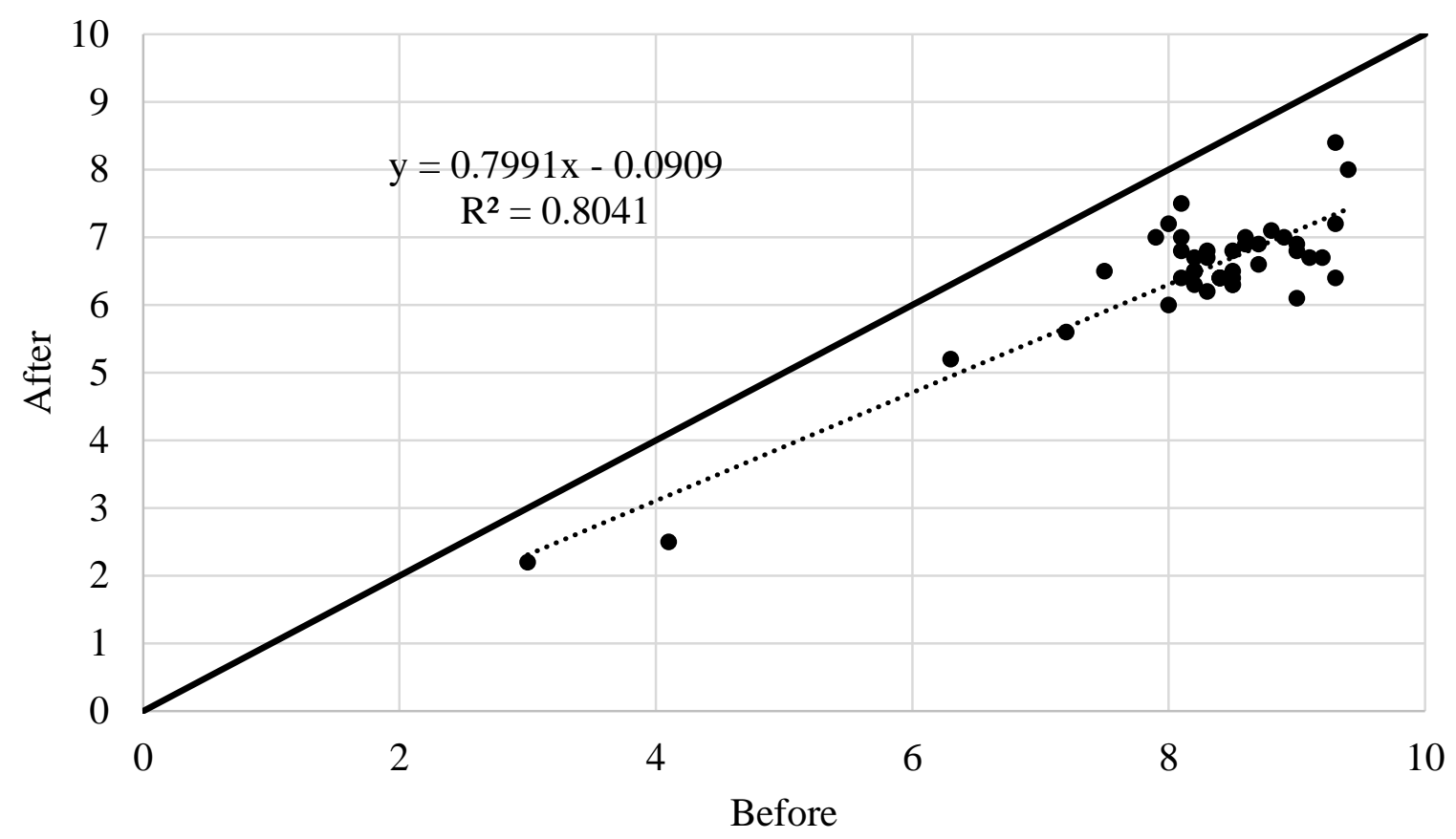

Figure 25: 19 mm NMAS CoreLok VTM Before and After Trimming

The equations in Figure 24 and 25 may be used to estimate if a compacted sample will have an acceptable VTM for AMPT testing after trimming. Thus, trimming samples can be avoided for samples that will not meet the AMPT requirements for VTM.

\section{Air Voids of AMPT Samples}

All dynamic modulus (DM) samples were made and tested before moving to fatigue (FT) testing. Next, the same was done with fatigue samples prior to flow number (FN) testing. To check the target of 7.0 \pm 0.5 percent VTM range remained consistent between test apparatuses, all air voids were compared using a student t-test. For SSD, CoreLok, Dimensional, and Averaged air void values, the means of FN compared to DM test specimens were equal. FT compared with DM means were not equal for SSD, CoreLok, and Average, but were equal for the Dimensional measurements. FT compared with FN were not equal for all air void methods. Variability among mixes could influence the statistical comparison of the methods so each set of test replicates were compared within their mix sets (i.e. AA937 DM compared only to AA937 FN). Only the 
average air voids were reviewed for DM-FT, FN-FT, and DM-FT and means were found to be equal within each mix design for each set of testing completed. All air void measurements are available in Appendix B.

\section{Dynamic Modulus and Phase Angle}

Phase angle $(\delta)$ and modulus $\left(\mathrm{E}^{*}\right)$ were obtained at the various testing temperatures for all nine mixes with three replicates per mix. Table 19 contains all phase angle averages and standard deviations from AMPT testing.

Table 19: Phase Angles Averages and Standard Deviations from DM Testing

\begin{tabular}{|c|c|c|c|c|c|c|c|c|c|c|c|}
\hline \multirow[b]{3}{*}{ Mix } & \multirow[b]{3}{*}{ STAT } & \multicolumn{10}{|c|}{ Test Temperature } \\
\hline & & \multicolumn{3}{|c|}{$4^{\circ} \mathrm{C}$} & \multicolumn{3}{|c|}{$20^{\circ} \mathrm{C}$} & \multicolumn{4}{|c|}{$40^{\circ} \mathrm{C}$} \\
\hline & & $0.1 \mathrm{~Hz}$ & $1.0 \mathrm{~Hz}$ & $10 \mathrm{~Hz}$ & $0.1 \mathrm{~Hz}$ & $1.0 \mathrm{~Hz}$ & $10 \mathrm{~Hz}$ & $0.01 \mathrm{~Hz}$ & $0.1 \mathrm{~Hz}$ & $1.0 \mathrm{~Hz}$ & $10 \mathrm{~Hz}$ \\
\hline \multirow{2}{*}{ AA937 } & AVG & 15.2 & 11.4 & 8.8 & 28.4 & 23.3 & 17.9 & 28.2 & 32.1 & 30.3 & 32.9 \\
\hline & SD & 0.7 & 0.5 & 0.4 & 0.7 & 0.6 & 0.4 & 1.0 & 0.9 & 6.6 & 0.6 \\
\hline \multirow{2}{*}{ JAP909 } & $\mathrm{AVG}$ & 21.7 & 16.1 & 11.7 & 33.5 & 29.7 & 23.6 & 22.5 & 28.2 & 32.5 & 38.4 \\
\hline & $\mathrm{SD}$ & 1.0 & 0.9 & 0.7 & 0.1 & 0.1 & 0.0 & 0.5 & 0.4 & 2.4 & 0.9 \\
\hline \multirow{2}{*}{ JFA060 } & $\mathrm{AVG}$ & 18.5 & 13.4 & 9.8 & 31.2 & 27.5 & 21.7 & 23.1 & 28.0 & 31.0 & 35.6 \\
\hline & $\mathrm{SD}$ & 0.3 & 0.3 & 0.3 & 0.5 & 0.6 & 0.6 & 1.4 & 0.9 & 3.3 & 0.6 \\
\hline \multirow{2}{*}{ JFA115 } & $\mathrm{AVG}$ & 17.5 & 12.9 & 9.8 & 29.8 & 25.8 & 20.7 & 24.2 & 28.7 & 30.0 & 33.7 \\
\hline & SD & 0.2 & 0.3 & 0.3 & 0.3 & 0.3 & 0.3 & 0.6 & 0.5 & 3.3 & 0.6 \\
\hline \multirow{2}{*}{ JFA429 } & $\mathrm{AVG}$ & 17.8 & 13.0 & 9.6 & 29.7 & 25.8 & 20.5 & 22.5 & 27.2 & 29.6 & 33.8 \\
\hline & $\mathrm{SD}$ & 0.2 & 0.2 & 0.3 & 0.1 & 0.2 & 0.2 & 0.9 & 0.7 & 3.3 & 0.2 \\
\hline \multirow{2}{*}{ KP483 } & $\mathrm{AVG}$ & 16.5 & 12.5 & 9.7 & 28.7 & 24.4 & 19.3 & 26.7 & 30.8 & 30.1 & 32.8 \\
\hline & $\mathrm{SD}$ & 0.4 & 0.3 & 0.3 & 0.6 & 0.5 & 0.4 & 0.7 & 0.8 & 5.3 & 0.6 \\
\hline \multirow{2}{*}{ WVP523 } & AVG & 16.4 & 12.3 & 9.5 & 30.3 & 25.4 & 19.7 & 27.1 & 32.1 & 31.7 & 34.6 \\
\hline & SD & 0.3 & 0.1 & 0.1 & 0.5 & 0.4 & 0.3 & 0.3 & 0.5 & 5.9 & 0.9 \\
\hline \multirow{2}{*}{ WVP766 } & $\mathrm{AVG}$ & 18.0 & 13.5 & 10.2 & 31.3 & 26.4 & 20.5 & 26.2 & 31.7 & 32.2 & 35.0 \\
\hline & SD & 0.5 & 0.4 & 0.3 & 0.3 & 0.1 & 0.1 & 0.5 & 0.6 & 5.2 & 0.4 \\
\hline \multirow{2}{*}{ WVP882 } & $\mathrm{AVG}$ & 18.5 & 13.7 & 10.4 & 31.8 & 27.6 & 21.9 & 26.1 & 31.6 & 32.8 & 36.2 \\
\hline & $\mathrm{SD}$ & 0.7 & 0.5 & 0.4 & 0.6 & 0.6 & 0.4 & 1.0 & 0.6 & 4.1 & 0.4 \\
\hline
\end{tabular}

Table 20 contains all the dynamic modulus values from testing and Table 21 displays the averages, standard deviation, and coefficient of variation for each mix set. 
Table 20: Dynamic Modulus Values (MPa)

\begin{tabular}{|c|c|c|c|c|c|c|c|c|c|c|c|}
\hline \multirow[b]{3}{*}{ Mix } & \multirow[b]{3}{*}{ REP } & \multicolumn{10}{|c|}{ Test Temperature } \\
\hline & & \multicolumn{3}{|c|}{$4^{\circ} \mathrm{C}$} & \multicolumn{3}{|c|}{$20^{\circ} \mathrm{C}$} & \multicolumn{4}{|c|}{$40^{\circ} \mathrm{C}$} \\
\hline & & $\begin{array}{l}0.1 \\
\mathrm{~Hz}\end{array}$ & $\begin{array}{l}1.0 \\
\mathrm{~Hz}\end{array}$ & $\begin{array}{l}10 \\
\mathrm{~Hz}\end{array}$ & $\begin{array}{l}0.1 \\
\mathrm{~Hz}\end{array}$ & $\begin{array}{l}1.0 \\
\mathrm{~Hz}\end{array}$ & $10 \mathrm{~Hz}$ & $\begin{array}{c}0.01 \\
\mathrm{~Hz}\end{array}$ & $\begin{array}{l}0.1 \\
\mathrm{~Hz}\end{array}$ & $\begin{array}{l}1.0 \\
\mathrm{~Hz}\end{array}$ & $10 \mathrm{~Hz}$ \\
\hline \multirow{3}{*}{ AA937 } & $1(\mathrm{~S} 1)$ & 8,684 & 11,791 & 15,000 & 2,713 & 4,853 & 7,754 & 180.4 & 407.3 & 977.8 & 2,195 \\
\hline & $2(\mathrm{~S} 3)$ & 8,275 & 11,448 & 14,768 & 2,669 & 4,849 & 7,878 & 186.6 & 388.6 & 909.5 & 2,107 \\
\hline & 3 (S4) & 8,677 & 11,675 & 14,701 & 2,536 & 4,669 & 7,540 & 154.9 & 341.4 & 845.2 & 2,022 \\
\hline \multirow{3}{*}{ JAP909 } & $1(\mathrm{~S} 2)$ & 7,483 & 11,782 & 16,800 & 1,904 & 4,181 & 7,815 & 127.1 & 233.7 & 567.6 & 1,493 \\
\hline & $2(\mathrm{~S} 3)$ & 8,396 & 12,821 & 17,817 & 2,001 & 4,282 & 7,859 & 110.8 & 220 & 574.5 & 1,610 \\
\hline & $3(\mathrm{~S} 4)$ & 9,283 & 14,390 & 19,908 & 2,106 & 4,569 & 8,475 & 117.3 & 228.5 & 595.3 & 1,644 \\
\hline \multirow{3}{*}{ JFA060 } & $1(\mathrm{~S} 2)$ & 8,277 & 11,857 & 15,491 & 2,100 & 4,184 & 7,262 & 147.7 & 272.4 & 639.9 & 1,667 \\
\hline & $2(\mathrm{~S} 3)$ & 7,363 & 10,711 & 14,139 & 1,761 & 3,590 & 6,399 & 125.4 & 239.9 & 570.3 & 1,408 \\
\hline & $3(\mathrm{~S} 4)$ & 8,961 & 13,041 & 17,248 & 2,249 & 4,503 & 7,921 & 184.3 & 338.2 & 788 & 1,902 \\
\hline \multirow{3}{*}{ JFA115 } & $1(\mathrm{~S} 3)$ & 7,800 & 11,188 & 14,756 & 2,012 & 3,843 & 6,628 & 164.9 & 318.8 & 735.7 & 1,709 \\
\hline & $2(\mathrm{~S} 4)$ & 8,133 & 11,947 & 15,802 & 2,172 & 4,153 & 7,137 & 149.6 & 295.1 & 704.5 & 1,705 \\
\hline & 3 (S5) & 7,127 & 10,213 & 13,555 & 2,002 & 3,749 & 6,330 & 166.1 & 303.8 & 661.3 & 1,557 \\
\hline \multirow{3}{*}{ JFA429 } & $1(\mathrm{~S} 3)$ & 8,492 & 12,165 & 15,932 & 2,396 & 4,577 & 7,786 & 197.3 & 349.6 & 783.3 & 1,938 \\
\hline & $2(\mathrm{~S} 4)$ & 7,730 & 10,971 & 14,290 & 2,245 & 4,277 & 7,224 & 165.5 & 299.3 & 681.5 & 1,697 \\
\hline & 3 (S5) & 8,245 & 11,679 & 15,073 & 2,213 & 42,10 & 7,176 & 204.5 & 349.9 & 753.3 & 1,764 \\
\hline \multirow{3}{*}{ KP483 } & $1(\mathrm{~S} 2)$ & 7,107 & 9,951 & 13005 & 2,241 & 4,092 & 6,715 & 161.6 & 331.6 & 775.5 & 1,771 \\
\hline & $2(\mathrm{~S} 3)$ & 8,375 & 11,792 & 15,387 & 2,316 & 4,335 & 7,321 & 164.6 & 360.3 & 867.5 & 2,028 \\
\hline & $3(\mathrm{~S} 4)$ & 7,941 & 10,979 & 14,154 & 2,320 & 4,199 & 6,917 & 197.2 & 403.6 & 913.3 & 1,988 \\
\hline \multirow{3}{*}{ WVP523 } & $1(\mathrm{~S} 3)$ & 9,211 & 12,734 & 16,420 & 2,560 & 4,711 & 7,827 & 177.9 & 402.9 & 981.5 & 2,238 \\
\hline & $2(\mathrm{~S} 4)$ & 8,939 & 12,511 & 16,217 & 2,466 & 4,604 & 7,721 & 151.5 & 340.5 & 846.9 & 1,986 \\
\hline & 3 (S5) & 8,559 & 12,085 & 15,808 & 2,296 & 4,344 & 7,368 & 129.8 & 282.2 & 706.5 & 1,698 \\
\hline \multirow{3}{*}{ WVP766 } & $1(\mathrm{~S} 3)$ & 7,983 & 11,396 & 14,995 & 2,064 & 4,006 & 6,900 & 129.9 & 276.6 & 683.8 & 1,699 \\
\hline & $2(\mathrm{~S} 4)$ & 7,013 & 9,844 & 13,220 & 1,958 & 3,840 & 6,543 & 131.4 & 298.7 & 752 & 1,894 \\
\hline & 3 (S5) & 7,116 & 10,265 & 13,741 & 2,008 & 3,965 & 6,813 & 128.1 & 289.3 & 743.6 & 1,823 \\
\hline \multirow{3}{*}{ WVP882 } & $1(\mathrm{~S} 1)$ & 7,923 & 11,461 & 15,116 & 1,861 & 3,751 & 6,699 & 111.4 & 241.7 & 628.2 & 1,592 \\
\hline & $2(\mathrm{~S} 3)$ & 6,965 & 10,267 & 13,879 & 1,753 & 3,486 & 6,228 & 109.2 & 226 & 576.8 & 1,484 \\
\hline & $3(\mathrm{~S} 4)$ & 7,574 & 10,912 & 14,477 & 1,899 & 3,683 & 6,463 & 114 & 250.3 & 639.7 & 1,586 \\
\hline
\end{tabular}


Table 21: Dynamic Modulus Averages, Standard Deviation, and Coefficient of Variation (MPa)

\begin{tabular}{|c|c|c|c|c|c|c|c|c|c|c|c|}
\hline \multirow[b]{3}{*}{ Mix } & & \multicolumn{10}{|c|}{ Test Temperature } \\
\hline & & \multicolumn{3}{|c|}{$4^{\circ} \mathrm{C}$} & \multicolumn{3}{|c|}{$20^{\circ} \mathrm{C}$} & \multicolumn{4}{|c|}{$40^{\circ} \mathrm{C}$} \\
\hline & REP & $10 \mathrm{~Hz}$ & $1.0 \mathrm{~Hz}$ & $0.1 \mathrm{~Hz}$ & $10 \mathrm{~Hz}$ & $1.0 \mathrm{~Hz}$ & $0.1 \mathrm{~Hz}$ & $10 \mathrm{~Hz}$ & $1.0 \mathrm{~Hz}$ & $0.1 \mathrm{~Hz}$ & $0.01 \mathrm{~Hz}$ \\
\hline \multirow{3}{*}{ AA937 } & $\mathrm{AVG}$ & 14,823 & 11,638 & 8,545 & 7,724 & 4,790 & 2,639 & 2,108 & 911 & 379 & 174 \\
\hline & $\mathrm{SD}$ & 156.9 & 174.5 & 234.1 & 171.0 & 105.1 & 92.2 & 86.5 & 66.3 & 34.0 & 16.8 \\
\hline & $\mathrm{CV}(\%)$ & 1.1 & 1.5 & 2.7 & 2.2 & 2.2 & 3.5 & 4.1 & 7.3 & 9.0 & 9.7 \\
\hline \multirow{3}{*}{ JAP909 } & AVG & 18,175 & 12,998 & 8,387 & 8,050 & 4,344 & 2,004 & 1,582 & 579 & 227 & 118 \\
\hline & SD & $1,584.6$ & $1,312.9$ & 900.0 & 369.0 & 201.3 & 101.0 & 79.2 & 14.4 & 6.9 & 8.2 \\
\hline & $\mathrm{CV}(\%)$ & 8.7 & 10.1 & 10.7 & 4.6 & 4.6 & 5.0 & 5.0 & 2.5 & 3.0 & 6.9 \\
\hline \multirow{3}{*}{ JFA060 } & $\mathrm{AVG}$ & 15,626 & 11,870 & 8,200 & 7,194 & 4,092 & 2,037 & 1,659 & 666 & 284 & 152 \\
\hline & $\mathrm{SD}$ & $1,558.9$ & $1,165.1$ & 801.8 & 763.3 & 463.4 & 250.1 & 247.1 & 111.2 & 50.1 & 29.7 \\
\hline & $\mathrm{CV}(\%)$ & 10.0 & 9.8 & 9.8 & 10.6 & 11.3 & 12.3 & 14.9 & 16.7 & 17.7 & 19.5 \\
\hline \multirow{3}{*}{ JFA115 } & AVG & 14,704 & 11,116 & 7,687 & 6,698 & 3,915 & 2,062 & 1,657 & 701 & 306 & 160 \\
\hline & $\mathrm{SD}$ & $1,124.4$ & 869.2 & 512.5 & 408.1 & 211.4 & 95.4 & 86.6 & 37.4 & 12.0 & 9.2 \\
\hline & $\mathrm{CV}(\%)$ & 7.6 & 7.8 & 6.7 & 6.1 & 5.4 & 4.6 & 5.2 & 5.3 & 3.9 & 5.7 \\
\hline \multirow{3}{*}{ JFA429 } & $\mathrm{AVG}$ & 15,098 & 11,605 & 8,156 & 7,395 & 4,355 & 2,285 & 1,800 & 739 & 333 & 189 \\
\hline & SD & 821.3 & 600.4 & 388.8 & 339.2 & 195.4 & 97.7 & 124.4 & 52.3 & 29.1 & 20.8 \\
\hline & $\mathrm{CV}(\%)$ & 5.4 & 5.2 & 4.8 & 4.6 & 4.5 & 4.3 & 6.9 & 7.1 & 8.7 & 11.0 \\
\hline \multirow{3}{*}{ KP483 } & AVG & 14,182 & 10,907 & 7,808 & 6,984 & 4,209 & 2,292 & 1,929 & 852 & 365 & 174 \\
\hline & $\mathrm{SD}$ & $1,191.2$ & 922.6 & 644.4 & 308.6 & 121.8 & 44.5 & 138.3 & 70.2 & 36.2 & 19.7 \\
\hline & $\mathrm{CV}(\%)$ & 8.4 & 8.5 & 8.3 & 4.4 & 2.9 & 1.9 & 7.2 & 8.2 & 9.9 & 11.3 \\
\hline \multirow{3}{*}{ WVP523 } & $\mathrm{AVG}$ & 16,148 & 12,443 & 8,903 & 7,639 & 4,553 & 2,441 & 1,974 & 845 & 342 & 153 \\
\hline & SD & 311.7 & 329.7 & 327.5 & 240.3 & 188.7 & 133.8 & 270.2 & 137.5 & 60.4 & 24.1 \\
\hline & $\mathrm{CV}(\%)$ & 1.9 & 2.7 & 3.7 & 3.1 & 4.1 & 5.5 & 13.7 & 16.3 & 17.7 & 15.7 \\
\hline \multirow{3}{*}{ WVP766 } & AVG & 13,985 & 10,502 & 7,371 & 6,752 & 3,937 & 2,010 & 1,805 & 726 & 288 & 130 \\
\hline & SD & 912.4 & 802.6 & 532.8 & 186.2 & 86.5 & 53.0 & 98.7 & 37.2 & 11.1 & 1.7 \\
\hline & $\mathrm{CV}(\%)$ & 6.5 & 7.6 & 7.2 & 2.8 & 2.2 & 2.6 & 5.5 & 5.1 & 3.8 & 1.3 \\
\hline \multirow{3}{*}{ WVP882 } & AVG & 14,491 & 10,880 & 7,487 & 6,463 & 3,640 & 1,838 & 1,554 & 615 & 239 & 112 \\
\hline & SD & 618.6 & 597.6 & 484.8 & 235.5 & 137.6 & 75.7 & 60.7 & 33.5 & 12.3 & 2.4 \\
\hline & $\mathrm{CV}(\%)$ & 4.3 & 5.5 & 6.5 & 3.6 & 3.8 & 4.1 & 3.9 & 5.4 & 5.1 & 2.2 \\
\hline
\end{tabular}

Each mix had coefficient of variation values below 15 percent for all dynamic modulus testing conducted at $4^{\circ} \mathrm{C}$ and $20^{\circ} \mathrm{C}$. As the testing temperature increased, the coefficient of variation increased in some cases. However, all testing at $40^{\circ} \mathrm{C}$ coefficient of variation values remained below 20 percent.

To further compare the mixes, averages for the dynamic modulus values at each temperature and frequency were calculated and plotted by NMAS. A comparison of all Wearing I mixes provided from four different companies are compared in Figures 26-28. The same was done for all Base II/19 mm mixes provided from three separate companies and are shown in Figures 29-31. 


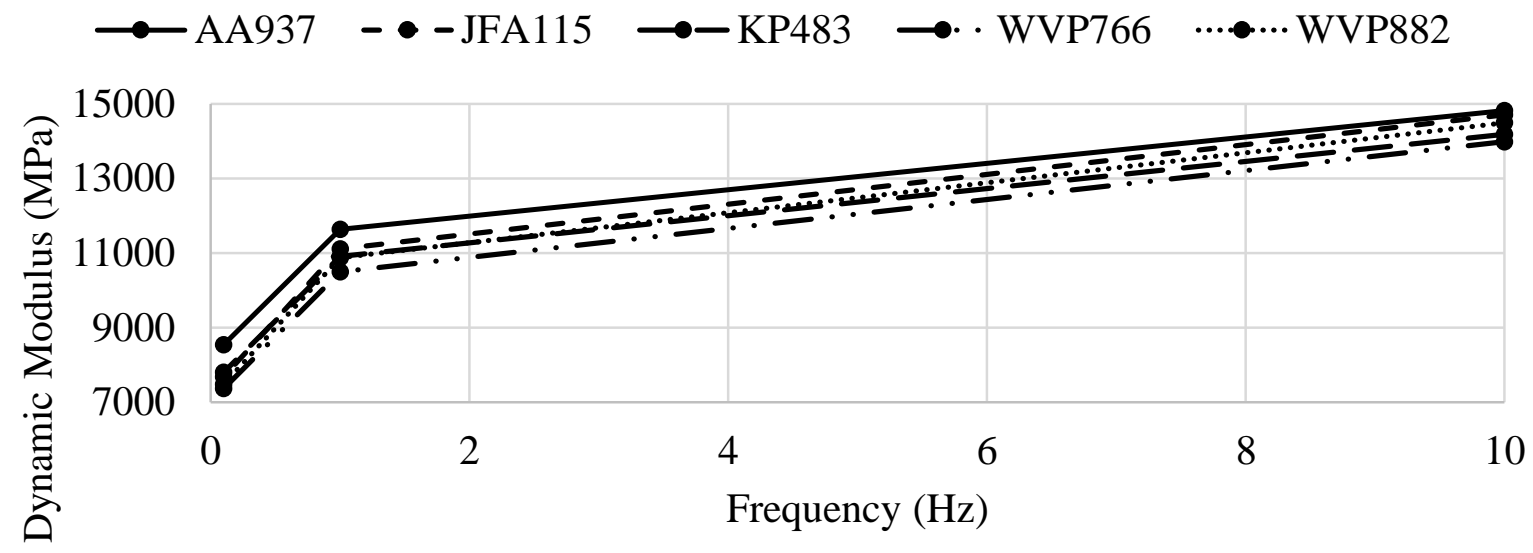

Figure 26: Wearing I Dynamic Modulus Averages at $4^{\circ} \mathrm{C}$

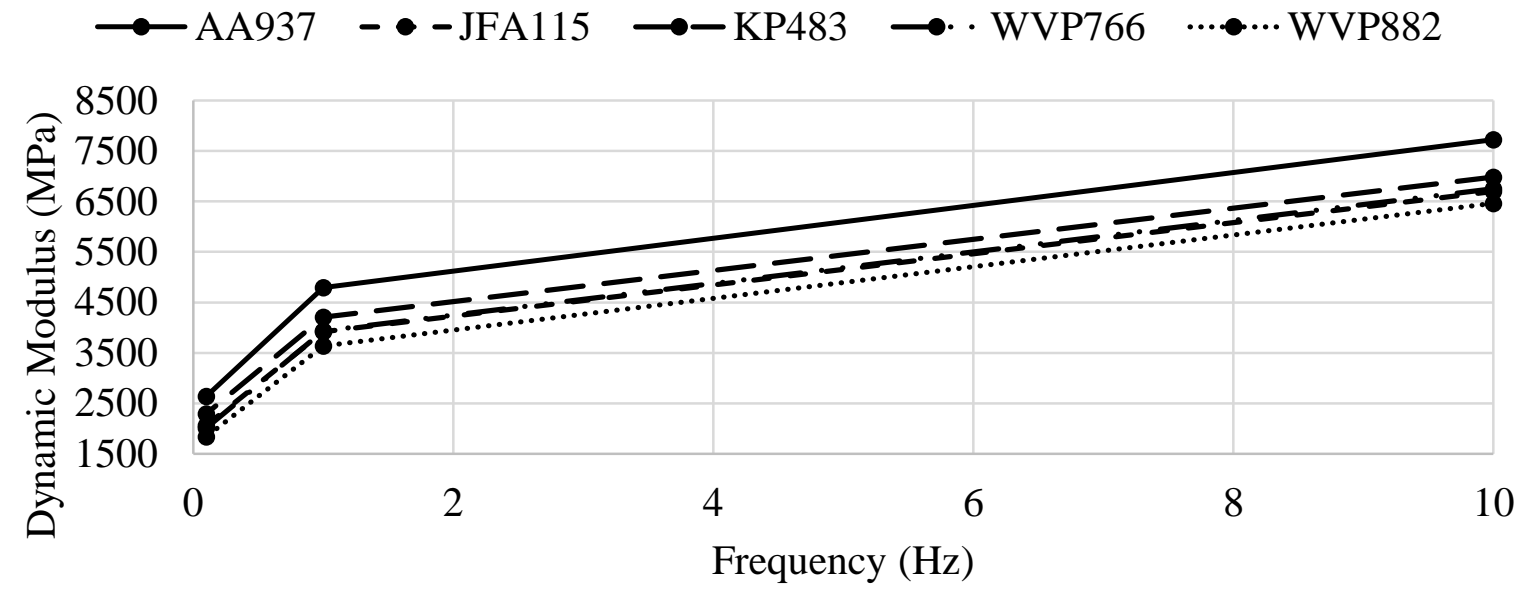

Figure 27: Wearing I Dynamic Modulus Averages at $20^{\circ} \mathrm{C}$

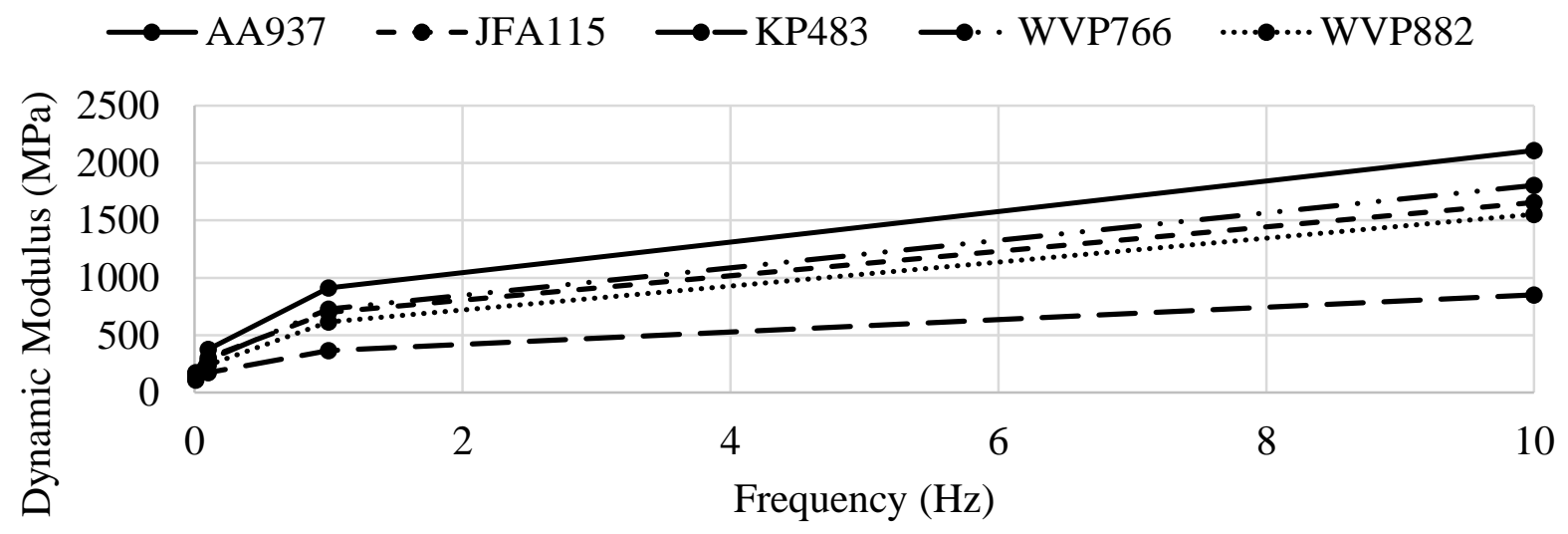

Figure 28: Wearing I Dynamic Modulus Averages at $40^{\circ} \mathrm{C}$ 
The five Wearing I mixes performed within reasonable range of one another at $4{ }^{\circ} \mathrm{C}$ testing. AA937 performed at the highest value while WVP766 had the lowest average dynamic modulus at each frequency tested. Similarly, the five Wearing I mixes performed within a reasonable range of one another with AA937 performing the highest at $20^{\circ} \mathrm{C}$ testing. However, WVP882 had the lowest average dynamic modulus values at this testing temperature. Moreover, at $40^{\circ} \mathrm{C}$ the five Wearing I dynamic modulus values varied. AA937 had the highest average values at each frequency, but performed approximately two and a half times higher than the lowest performing mix which was JFA115. WVP766, WVP882, and KP483 performed similarly.

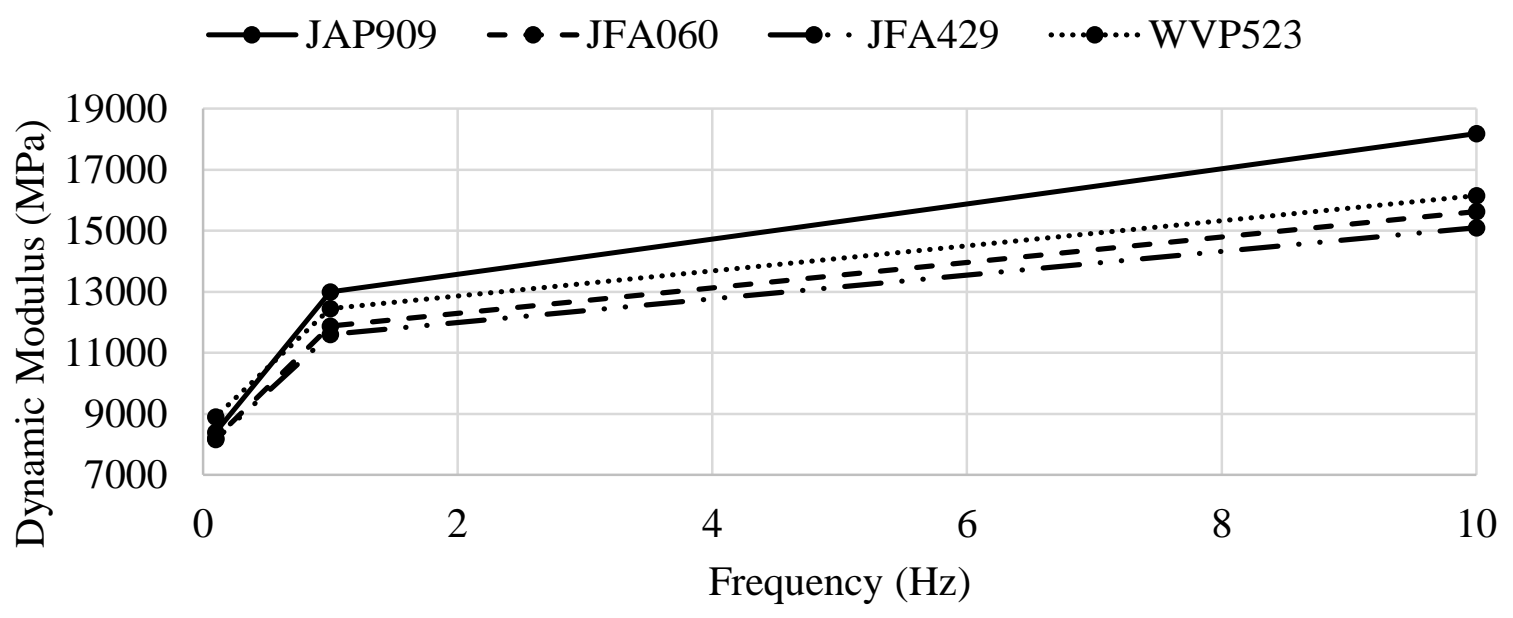

Figure 29: Base II/19mm Dynamic Modulus Averages at $4^{\circ} \mathrm{C}$

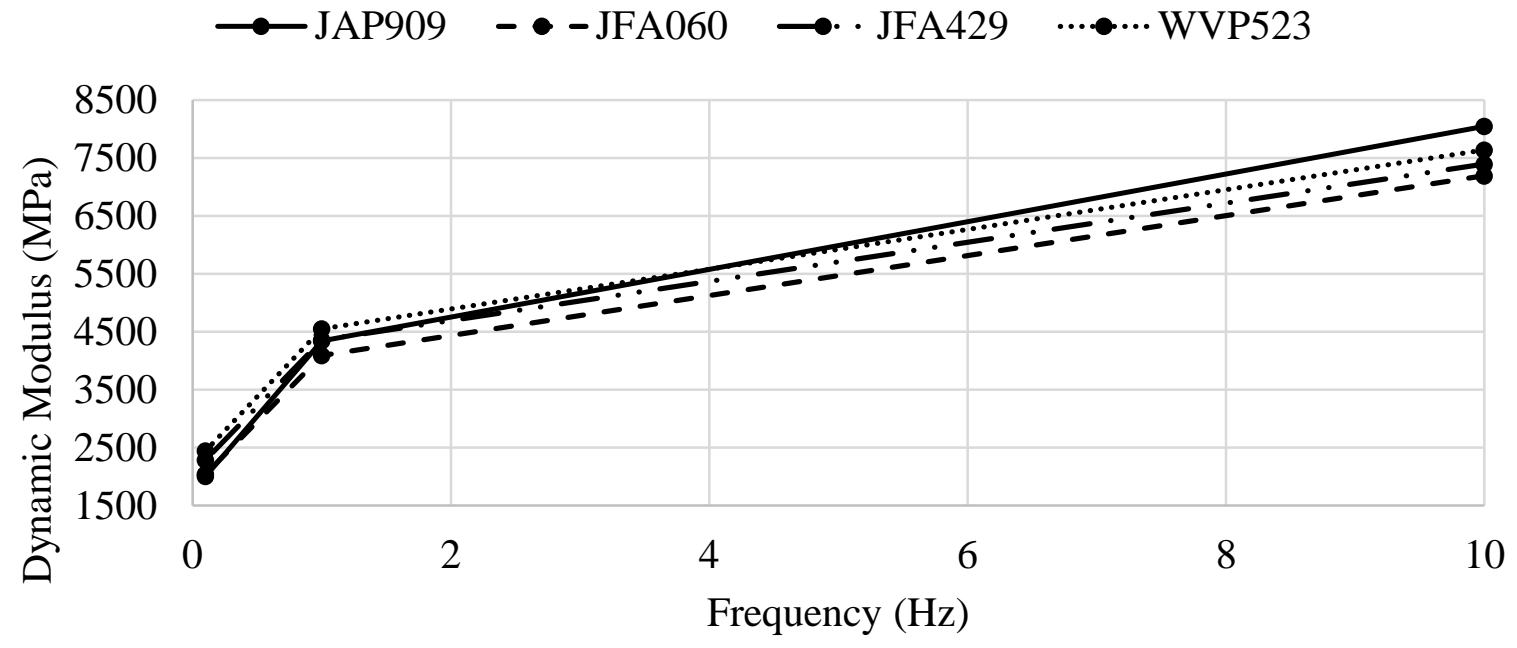

Figure 30: Base II/19mm Dynamic Modulus Averages at $20^{\circ} \mathrm{C}$ 


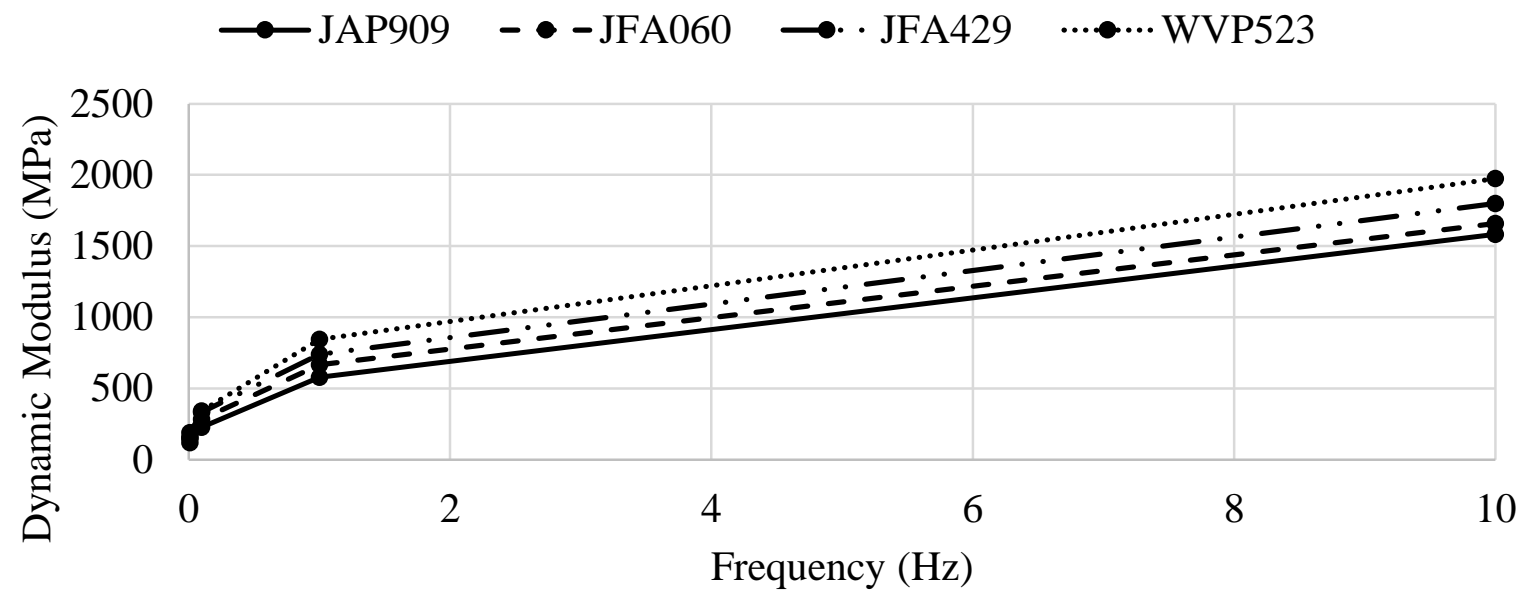

Figure 31: Base II/19mm Dynamic Modulus Averages at $40^{\circ} \mathrm{C}$

For the three Base II and one $19 \mathrm{~mm}$ mix, JAP909 had the highest average dynamic modulus values at $4^{\circ} \mathrm{C}$ while the other three mixes performed similarly. Moreover, at $20^{\circ} \mathrm{C}$ the four mixes performed similarly at each frequency with some overlapping at lower frequencies. At $40^{\circ} \mathrm{C}$, JAP909 performed the lowest while WVP523 performed the highest.

\section{Master Curve Comparison}

Samples were analyzed using Mastersolver Version 2.2 for each individual mix. Using the Excel solver feature provided in the spreadsheet the master curves were generated. The shape of the master curve is characterized by five parameters: $\beta, \gamma, \mathrm{E}_{\min }, \mathrm{E}_{\max }$, and $\Delta \mathrm{EA}$. Table 22 shows the final parameters from each mix analyzed, the averages, and the goodness of fit. All goodness of fit ratings were excellent.

Witczak et al. (2013) found the $\beta$ fitting parameter varied with VTM and with binder content. For PG 64-22 binder at 7.0 percent air voids, $\beta$ values were 1.529, 1.120, and 1.036 for 4.0 percent, 4.5 percent, and 5.0 percent binder content. In this research, the binder content for the mixes varies between a range of 4.6 percent and 6.1 percent. The $\beta$ values in this study all vary slightly. All mixes containing RAP had higher $\beta$ values (AA937, KP483, WVP523, WVP766, and WVP882) than mixes not containing RAP. Smith (2015) found a difference in the $\beta$ term between 0 percent RAP and 25 percent RAP with PG 70-22 was 0.47238 . While this is a different binder grade, the inclusion of RAP appears to have a correlation to the $\beta$ term. 
Table 22: Master Curve Final Parameters

\begin{tabular}{|c|c|c|c|c|c|c|c|c|c|}
\hline \multirow[b]{2}{*}{ Mix } & & & & & & & \multicolumn{3}{|c|}{ Goodness of Fit } \\
\hline & $\begin{array}{c}\text { Binder } \\
\text { Content } \\
(\%)\end{array}$ & $\underset{(\mathbf{k s i})}{\operatorname{Max} E}$ & $\begin{array}{c}\text { Min } \\
\mathbf{E} \\
(\mathbf{k s i})\end{array}$ & $\boldsymbol{\beta}$ & $\gamma$ & $\Delta \mathbf{E A}$ & $\mathbf{R}^{2}$ & $\mathbf{S}_{\mathrm{e}} / \mathbf{S}_{\mathbf{y}}$ & Rating \\
\hline AA937 & 5.6 & $3,186.6$ & 2.2 & -1.356 & -0.471 & 205,255 & 0.999 & 0.02 & Excellent \\
\hline JAP909 & 4.6 & $3,239.9$ & 5.3 & -1.097 & -0.616 & 196,033 & 0.998 & 0.02 & Excellent \\
\hline JFA060 & 4.9 & $3,214.1$ & 5.8 & -1.045 & -0.553 & 201,283 & 0.998 & 0.03 & Excellent \\
\hline JFA115 & 5.8 & $3,212.7$ & 4.5 & -1.063 & -0.503 & 204,246 & 0.998 & 0.03 & Excellent \\
\hline JFA429 & 4.9 & $3,246.9$ & 6.4 & -1.049 & -0.522 & 205,637 & 0.999 & 0.03 & Excellent \\
\hline KP483 & 5.6 & $3,194.7$ & 2.8 & -1.214 & -0.470 & 200,270 & 0.999 & 0.02 & Excellent \\
\hline WVP523 & 4.6 & $3,230.7$ & 2.2 & -1.311 & -0.485 & 201,316 & 0.999 & 0.02 & Excellent \\
\hline WVP766 & 5.9 & $3,150.2$ & 2.0 & -1.228 & -0.494 & 192,136 & 0.999 & 0.03 & Excellent \\
\hline WVP882 & 6.1 & $3,163.5$ & 2.4 & -1.156 & -0.511 & 198,081 & 0.998 & 0.03 & Excellent \\
\hline \multicolumn{2}{|c|}{ Average } & $3,204.4$ & 3.73 & -1.17 & -0.51 & 200,473 & & & \\
\hline
\end{tabular}

The Master Curves are presented in Figure 32. All MEDPG output data are in Appendix C. The curves are consistent with no clear distinction between a $9.5 \mathrm{~mm}$ and a $19 \mathrm{~mm}$ NMAS. At lower frequencies there was more variation with the curves converging at a higher reduced frequency.

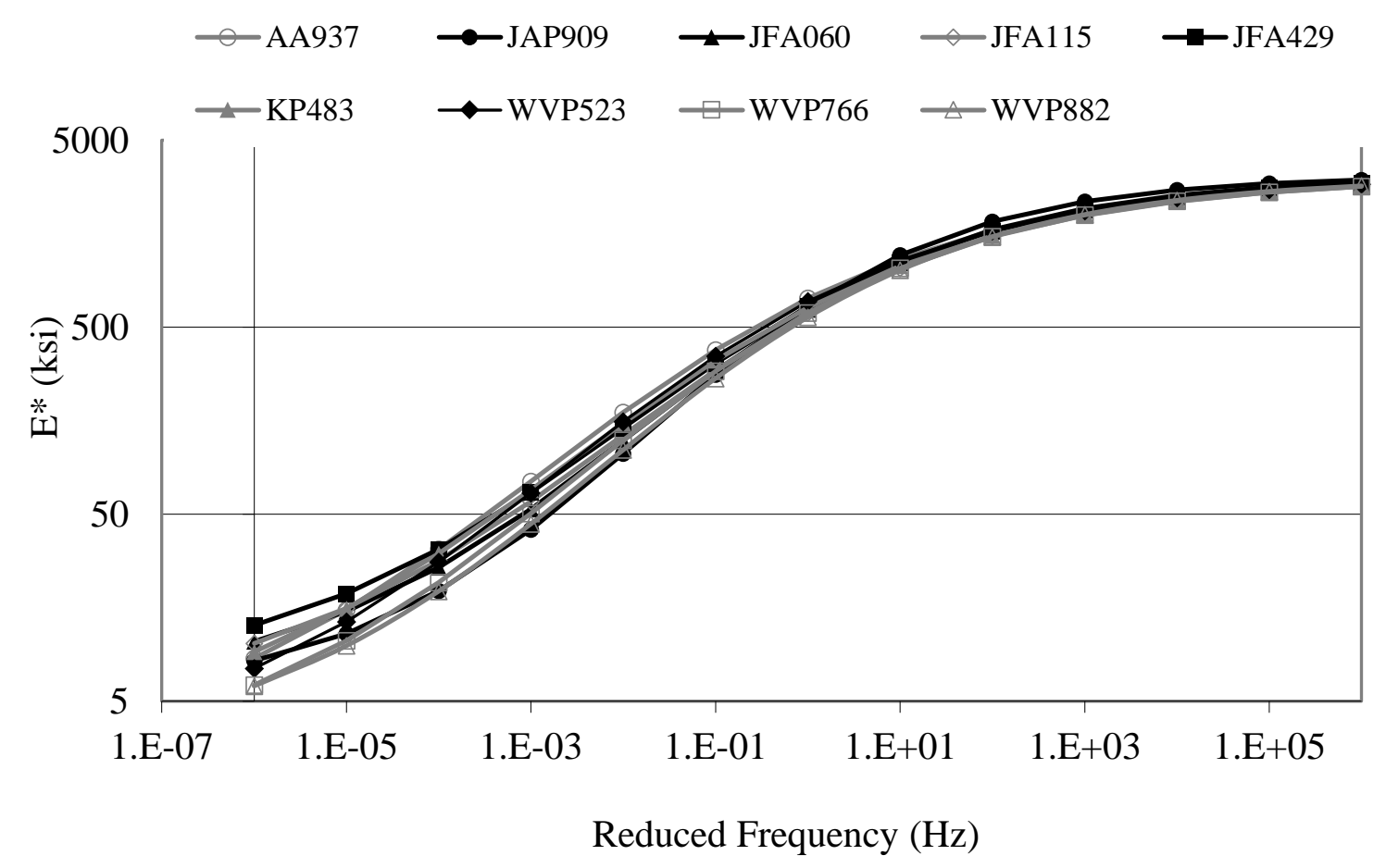

Figure 32: Dynamic Modulus Master Curves 


\section{Fatigue}

A summary of fatigue testing was documented in Table 14 from Chapter 3. Three failure criterion were used to evaluate a completed test: 10 percent of the initial modulus reached, an increase in phase angle followed by an immediate drop, or the number of cycles exceeding 100,000. All the tests terminated before 100,000 cycles. There were issues with LVDT errors prior to test completion and a couple samples breaking prior to test completion. However, nearly all tested fatigue samples either a drop in phase angle or 10 percent of the modulus. All fatigue data is located in Appendix D.

\section{Alpha Fatigue}

The Alpha-Fatigue ${ }^{\mathrm{TM}}$ software generates an output model from dynamic modulus and fatigue replicates. Each mix type was analyzed separately with two analyses performed: one allowing the software to select the failure point (Default) and a second choosing the peak point prior to the phase angle drop (Peak). Eight of twenty-seven tests did not display the sudden phase angle drop required in the "Identify Cycle at Failure" screen. In this case, the highest graph point was selected as the failure point. An example of a sample without a phase angle drop is shown in Figure 33.

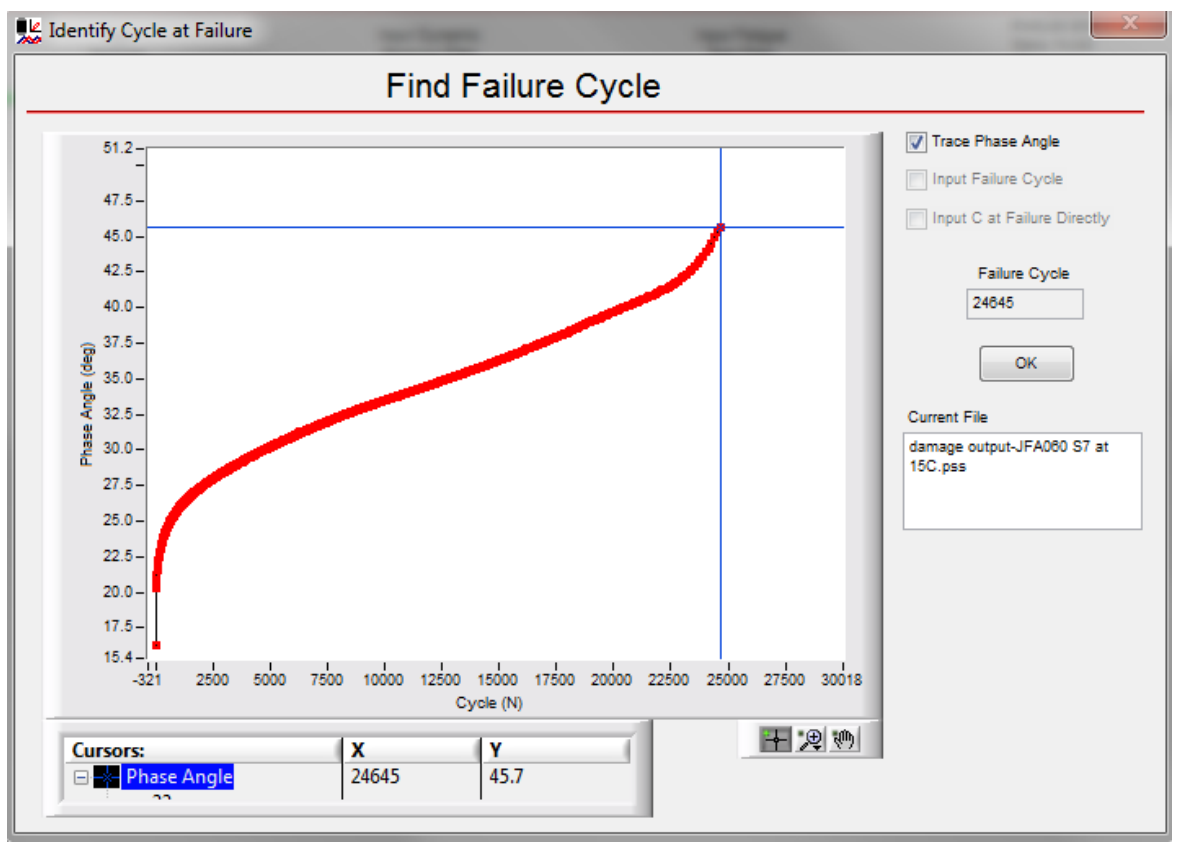

Figure 33: Alpha-Fatigue Phase Angle Failure Cycle Identification Box without Drop 
KP483 fatigue test samples had one erroneous sample (S6) which was excluded for the Default analysis. Alpha-Fatigue could not find an adequate model to fit the three samples so only two were analyzed. This could affect the accuracy of the fitted model and endurance limits for this replicate set.

The K-values for Equation 15 and the damage model coefficients for both failure criteria are summarized in Tables 23 and 24. K-values differ significantly between the two failure criteria. This was further investigated in graphical comparisons shown later. Moreover, from Table 24 the $r$ parameter increased by one magnitude when picking the cycle corresponding to the phase angle drop. The $s$ parameter increased by approximately 0.2 when the default was used and damage coefficients $a$ and $b$ had minor changes between the two failure criteria.

Table 23: K-Values (psi units) from Alpha-Fatigue

\begin{tabular}{|c|c|c|c|c|c|c|}
\hline & Peak & Default & Peak & Default & Peak & Default \\
\hline Mix & $\mathrm{K}_{1}$ & $\mathrm{~K}_{1}$ & $\mathrm{~K}_{2}$ & $\mathrm{~K}_{2}$ & $\mathrm{~K}_{3}$ & $\mathrm{~K}_{3}$ \\
\hline AA937 & $9.16 \mathrm{E}+08$ & $2.83 \mathrm{E}+02$ & 7.188 & 4.237 & -5.106 & -2.361 \\
\hline JAP909 & $2.87 \mathrm{E}+11$ & $1.03 \mathrm{E}+07$ & 4.505 & 2.899 & -3.812 & -2.264 \\
\hline JFA060 & $3.59 \mathrm{E}+12$ & $4.40 \mathrm{E}+07$ & 5.191 & 4.077 & -4.399 & -3.078 \\
\hline JFA115 & $6.88 \mathrm{E}+12$ & $3.07 \mathrm{E}+07$ & 5.002 & 3.46 & -4.286 & -2.659 \\
\hline JFA429 & $3.84 \mathrm{E}+19$ & $4.03 \mathrm{E}+06$ & 7.851 & 3.542 & -7.098 & -2.621 \\
\hline *KP483 & $1.16 \mathrm{E}+16$ & $4.20 \mathrm{E}+05$ & 7.612 & 6.153 & -6.45 & -4.013 \\
\hline WVP523 & $1.40 \mathrm{E}+15$ & $9.91 \mathrm{E}+03$ & 8.161 & 4.62 & -6.672 & -2.851 \\
\hline WVP766 & $3.30 \mathrm{E}+13$ & $2.07 \mathrm{E}+05$ & 6.154 & 3.241 & -5.129 & -2.202 \\
\hline WVP882 & $1.40 \mathrm{E}+10$ & $2.81 \mathrm{E}+06$ & 4.178 & 3.069 & -3.423 & -2.296 \\
\hline $\begin{array}{l}\text { Asphalt } \\
\text { Institute }\end{array}$ & \multicolumn{2}{|c|}{0.0796} & & & -0.854 \\
\hline
\end{tabular}

Table 24: Damage Model Coefficients for Both Failure Criteria

\begin{tabular}{|c|c|c|c|c|c|c|c|c|c|}
\hline & Peak & Default & Peak & Default & Both & Peak & Default & Peak & Default \\
\hline Mix & $a$ & $a$ & $b$ & $b$ & $\alpha$ & $r$ & $r$ & $s$ & $s$ \\
\hline AA937 & $-1.92 \mathrm{E}-05$ & $-2.68 \mathrm{E}-05$ & 0.932 & 0.900 & 3.711 & $3.83 \mathrm{E}+05$ & $8.41 \mathrm{E}+04$ & -0.775 & -0.594 \\
\hline JAP909 & $-4.80 \mathrm{E}-04$ & $-7.48 \mathrm{E}-04$ & 0.667 & 0.623 & 3.361 & $4.15 \mathrm{E}+05$ & $9.14 \mathrm{E}+04$ & -0.674 & -0.593 \\
\hline JFA060 & $-1.10 \mathrm{E}-04$ & $-1.91 \mathrm{E}-04$ & 0.789 & 0.737 & 3.657 & $4.79 \mathrm{E}+05$ & $1.33 \mathrm{E}+05$ & -0.706 & -0.623 \\
\hline JFA115 & $-2.97 \mathrm{E}-04$ & $-3.27 \mathrm{E}-04$ & 0.699 & 0.689 & 3.802 & $5.60 \mathrm{E}+05$ & $1.22 \mathrm{E}+05$ & -0.696 & -0.577 \\
\hline JFA429 & $-1.37 \mathrm{E}-04$ & $-1.08 \mathrm{E}-04$ & 0.773 & 0.796 & 3.850 & $7.89 \mathrm{E}+05$ & $9.11 \mathrm{E}+04$ & -0.797 & -0.577 \\
\hline KP483 & $-1.47 \mathrm{E}-05$ & $-1.22 \mathrm{E}-05$ & 0.957 & 0.977 & 3.811 & $6.01 \mathrm{E}+05$ & $2.01 \mathrm{E}+05$ & -0.791 & -0.725 \\
\hline WVP523 & $-3.54 \mathrm{E}-05$ & $-3.57 \mathrm{E}-05$ & 0.885 & 0.883 & 3.629 & $5.37 \mathrm{E}+05$ & $5.08 \mathrm{E}+05$ & -0.807 & -0.637 \\
\hline WVP766 & $-1.01 \mathrm{E}-04$ & $-9.34 \mathrm{E}-04$ & 0.792 & 0.799 & 3.580 & $5.33 \mathrm{E}+05$ & $7.90 \mathrm{E}+04$ & -0.747 & -0.540 \\
\hline WVP882 & $-2.74 \mathrm{E}-04$ & $-3.85 \mathrm{E}-04$ & 0.714 & 0.680 & 3.531 & $3.23 \mathrm{E}+05$ & $7.48 \mathrm{E}+04$ & -0.647 & -0.541 \\
\hline
\end{tabular}


Table 25 contains the micro strain endurance limits for all Alpha-Fatigue analyses and Table 26 displays the rankings of each for the Peak failure criteria. The AMPT fatigue test was performed at $15^{\circ} \mathrm{C}$. However, the Alpha-Fatigue software uses transfer functions to estimate endurance limits for other temperatures. The endurance limit approximately doubled at 5, 10, 15, and $20^{\circ} \mathrm{C}$ and nearly tripled at $25^{\circ} \mathrm{C}$ for the Peak failure as compared to the Default failure.

The rankings show that using the two different criteria resulted in mixes having different endurance limits. JFA429 had the highest endurance limit when the Peak failure was used, but had the sixth lowest endurance limit when the Default was used. WVP882 and JAP909 have the lowest endurance limit micro strains in all cases.

Underwood et al. (2012) reported endurance limit values in the range 100 to 150 for mixes with an unmodified asphalt content of 4.5 to 6.1 percent. Only the $25^{\circ} \mathrm{C}$ test results with the Peak failure criteria in Table 25 are similar to the results reported by Underwood et al. (2012). Based on this observation, only the peak failure criteria are considered in the following. The Superpave mix (JFA429) had the highest endurance limit threshold in all cases when using Peak K-values.

Table 25: Endurance Limits from Alpha-Fatigue Outputs

\begin{tabular}{|c|c|c|c|c|c|c|c|c|c|c|}
\hline \multicolumn{10}{|c|}{ Endurance Limit (micro strain) } \\
\hline & \multicolumn{3}{|c|}{$\mathbf{5}^{\circ} \mathbf{C}$} & \multicolumn{2}{|c|}{$\mathbf{1 0}^{\circ} \mathbf{C}$} & \multicolumn{2}{|c|}{$\mathbf{1 5}^{\circ} \mathbf{C}$} & \multicolumn{2}{|c|}{$\mathbf{2 0}^{\circ} \mathbf{C}$} & \multicolumn{2}{|c|}{$\mathbf{2 5}^{\circ} \mathbf{C}$} \\
\hline Mix & Peak & Default & Peak & Default & Peak & Default & Peak & Default & Peak & Default \\
\hline AA937 & 51 & 24 & 55 & 24 & 61 & 26 & 70 & 28 & 91 & 34 \\
\hline JAP909 & 33 & 9 & 36 & 10 & 42 & 11 & 50 & 13 & 69 & 17 \\
\hline JFA060 & 44 & 21 & 48 & 23 & 55 & 26 & 66 & 30 & 91 & 39 \\
\hline JFA115 & 48 & 17 & 54 & 19 & 63 & 21 & 76 & 25 & 104 & 33 \\
\hline JFA429 & 67 & 17 & 75 & 18 & 90 & 20 & 111 & 23 & 154 & 29 \\
\hline KP483 & 64 & 41 & 70 & 43 & 82 & 47 & 97 & 53 & 131 & 67 \\
\hline WVP523 & 58 & 25 & 63 & 26 & 73 & 28 & 86 & 30 & 117 & 38 \\
\hline WVP766 & 56 & 16 & 61 & 16 & 72 & 18 & 85 & 20 & 114 & 25 \\
\hline WVP882 & 33 & 11 & 36 & 12 & 41 & 14 & 49 & 16 & 66 & 21 \\
\hline
\end{tabular}


Table 26: Endurance Limits Ranking for Peak and Default K-values

\begin{tabular}{|c|c|c|c|c|c|}
\hline \multicolumn{7}{|c|}{ Peak Rank } \\
\hline Mix & $\mathbf{5}^{\circ} \mathbf{C}$ & $\mathbf{1 0}^{\circ} \mathbf{C}$ & $\mathbf{1 5}^{\circ} \mathbf{C}$ & $\mathbf{2 0}^{\circ} \mathbf{C}$ & $\mathbf{2 5}^{\circ} \mathbf{C}$ \\
\hline AA937 & 5 & 5 & 6 & 6 & $6 / 7$ \\
\hline JAP909 & $8 / 9$ & $8 / 9$ & 8 & 8 & 8 \\
\hline JFA060 & 7 & 6 & 7 & 7 & $6 / 7$ \\
\hline JFA115 & 6 & 7 & 5 & 5 & 5 \\
\hline JFA429 & 1 & 1 & 1 & 1 & 1 \\
\hline KP483 & 2 & 2 & 2 & 2 & 2 \\
\hline WVP523 & 3 & 3 & 3 & 3 & 3 \\
\hline WVP766 & 4 & 4 & 4 & 4 & 4 \\
\hline WVP882 & $8 / 9$ & $8 / 9$ & 9 & 9 & 9 \\
\hline
\end{tabular}

Fatigue K-values, Table 23, for each mix set vary from the Asphalt Institute constants. To compare laboratory values and the fatigue equation's behavior, a dynamic modulus value of 1,310,000 psi and several strain levels were plugged into Equation 15 for each Alpha-Fatigue Kvalues and are plotted in Figure 34 for the Peak failure criteria. The Asphalt Institute fatigue equation has a field calibration factor of 18.4 to adjust for laboratory to field differences (ARA, Inc., 2004). Field calibration factor was removed to adjust the Asphalt Institute equation to represent laboratory results. Both the adjusted Asphalt Institute and original equations are displayed in Figure 34 for comparison.

In Figure 34, both a representative full depth and conventional pavement strain found from the KENPAVE analysis was plotted. The KENPAVE analysis is explained in more detail in the Pavement Life Prediction section. As seen in Figure 34, JFA429, a 19 mm Superpave mix, showed the best performance. WVP882, a Wearing I Marshall mix, showed the worst performance. However, all mixes tested in this study show better fatigue properties than is predicted by the adjusted Asphalt Institute equation.

Underwood et al. (2012) says the limit of asphalt concrete mixtures is the strain level at which fatigue failure occurs at 50 million cycles. This limit is plotted in Figure 34, a vertical projection from this limit to the $\mathrm{x}$-axis indicates the endurance limit for the mixes. JFA429 falls at approximately 100 micro strains at the endurance limit plotted in Figure 34. This micro strain value falls between the Alpha-Fatigue endurance limits, Table 26 , for $15^{\circ} \mathrm{C}$ and $20^{\circ} \mathrm{C}$. However, JFA115 meets the endurance limit at 60 micro strains which falls between Alpha-Fatigue endurance limits from for $10^{\circ} \mathrm{C}$ and $15^{\circ} \mathrm{C}$. Similar discrepancies were found with the other mixes. 
The reason for these discrepancies could not be determined from the Alpha-Fatigue documentation.

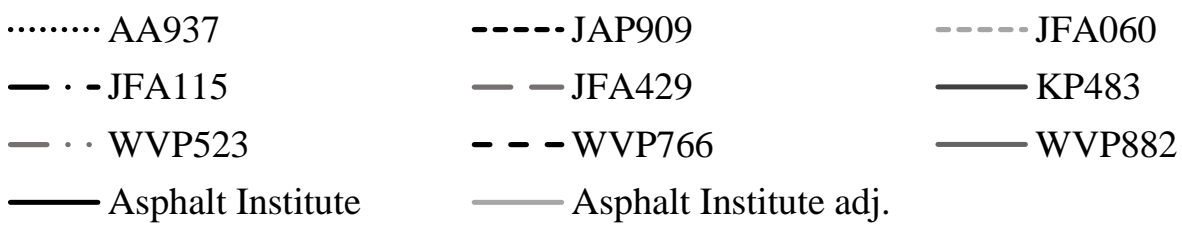

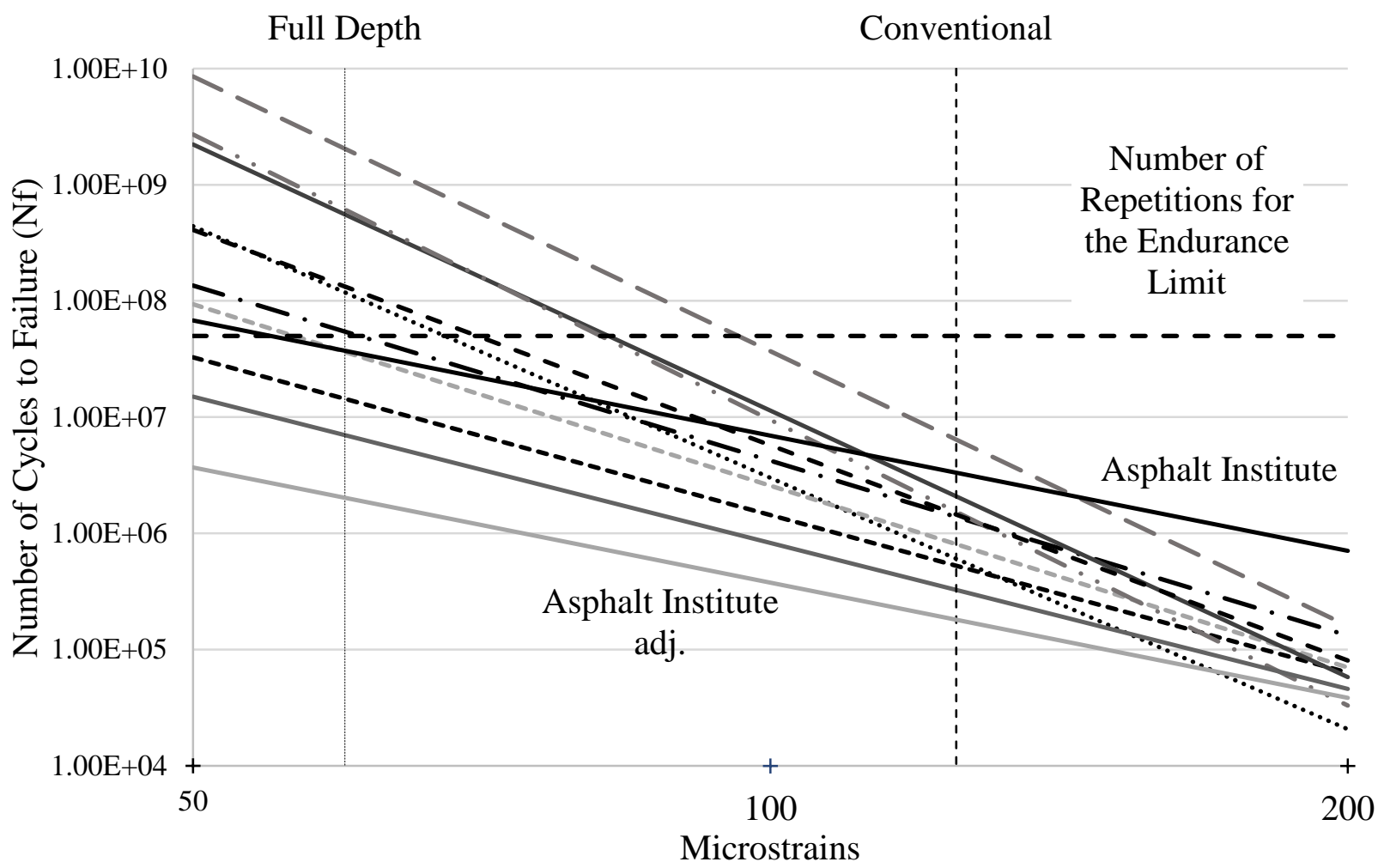

Figure 34: Visualization of Fatigue Equations Using Peak Analyzed K-Values

Figure 35 includes Hou (2009) and Witczak et al. (2013) models (Table 4) plotted with the highest and lowest performing fatigue coefficient results from this research, Table 23 . The Hou models resulted in high number of cycles to failure; the only Hou model plotted is for the lowest fatigue performance (RI19B). 


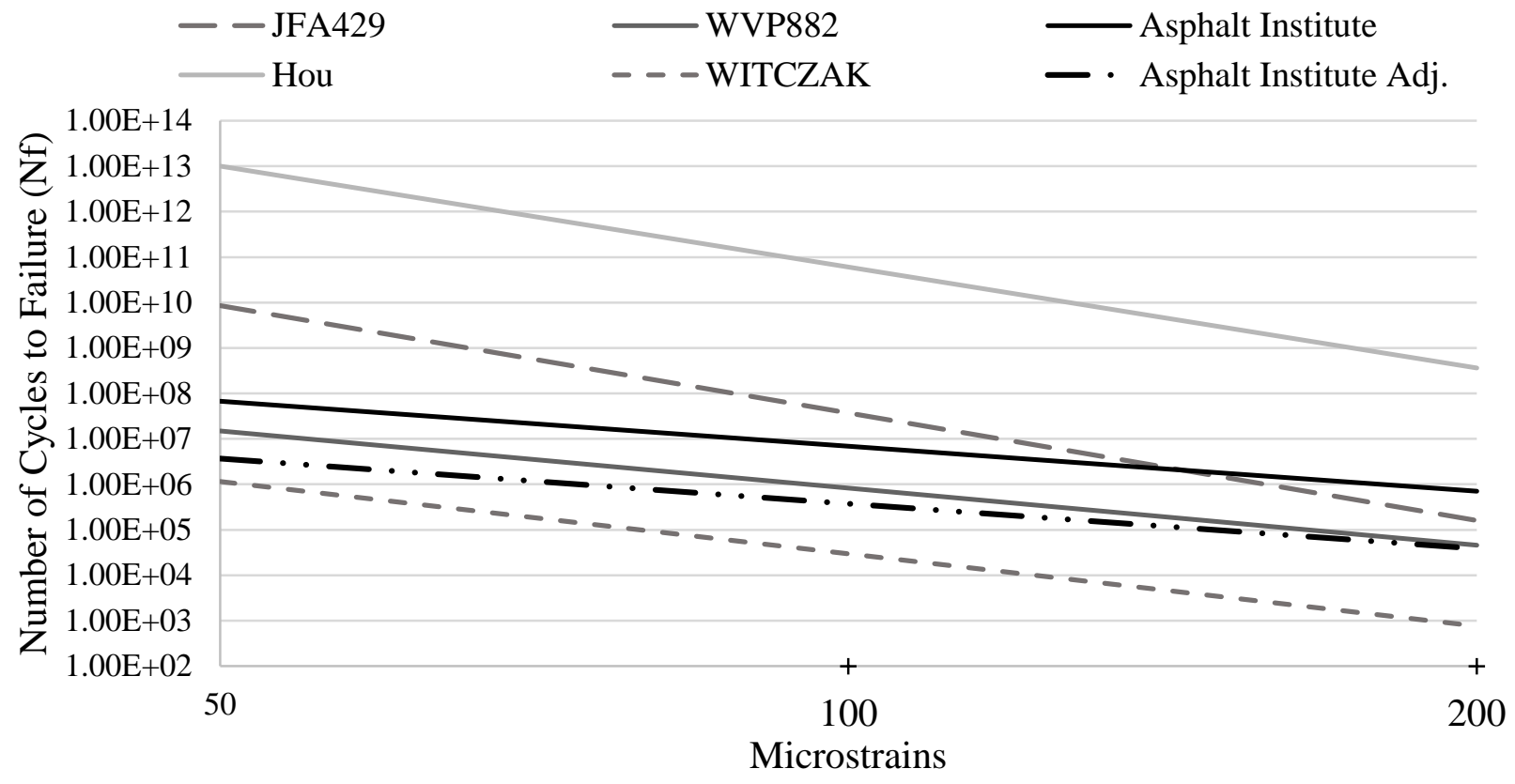

Figure 35: Visual Comparison of Fatigue Equations

\section{Pavement Life Prediction}

The dynamic modulus samples were analyzed using KENPAVE. Following Smith's (2015) KENPAVE analysis, modulus verses strain graphs were created for a range of moduli (200,000 to 1,000,000 psi) for both a full-depth pavement and conventional pavement. Images of both each pavement designs are displayed in Figure 36. The KENAPAVE analysis involved some assumptions. Subbase material moduli were chosen based on past knowledge, and the pavement was analyzed as linear as opposed to viscoelastic. Also, a traditional full-depth pavement is constructed with multiple lifts with the NMAS increasing with the depth of the lift. For this analysis the asphalt lift consisted of a single layer of the material being analyzed.

For loading, a dual axle with a 4500 pound load per tire (18-kip ESAL) and 110 psi tire pressure with a contact radius of 3.61 inches, a travel speed of $55 \mathrm{mph}$ was used to calculate a frequency of $1.866 \mathrm{~Hz}$. The tensile strain at the bottom of the asphalt layer was computed for under one tire and between the tires; the maximum value was selected. The strain and dynamic modulus values were plotted, Figure 37. 

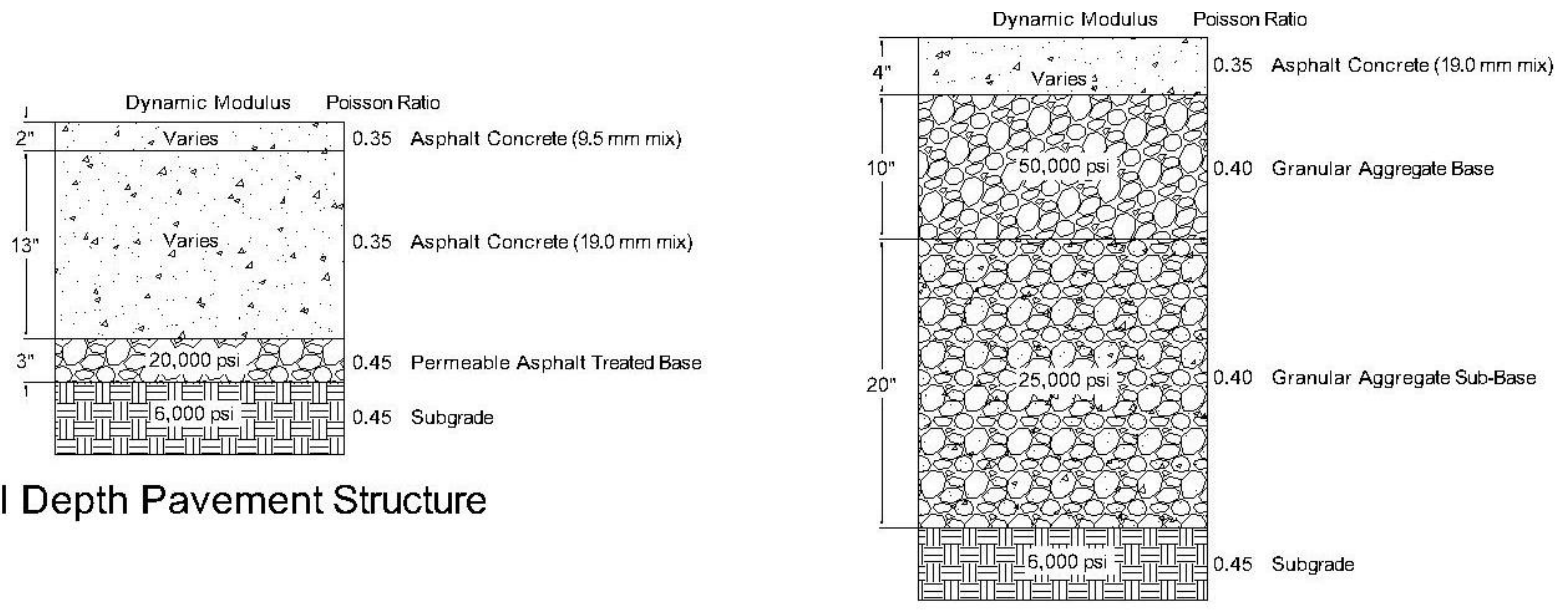

Conventional Pavement Structure

Figure 36: KENPAVE Pavement Designs

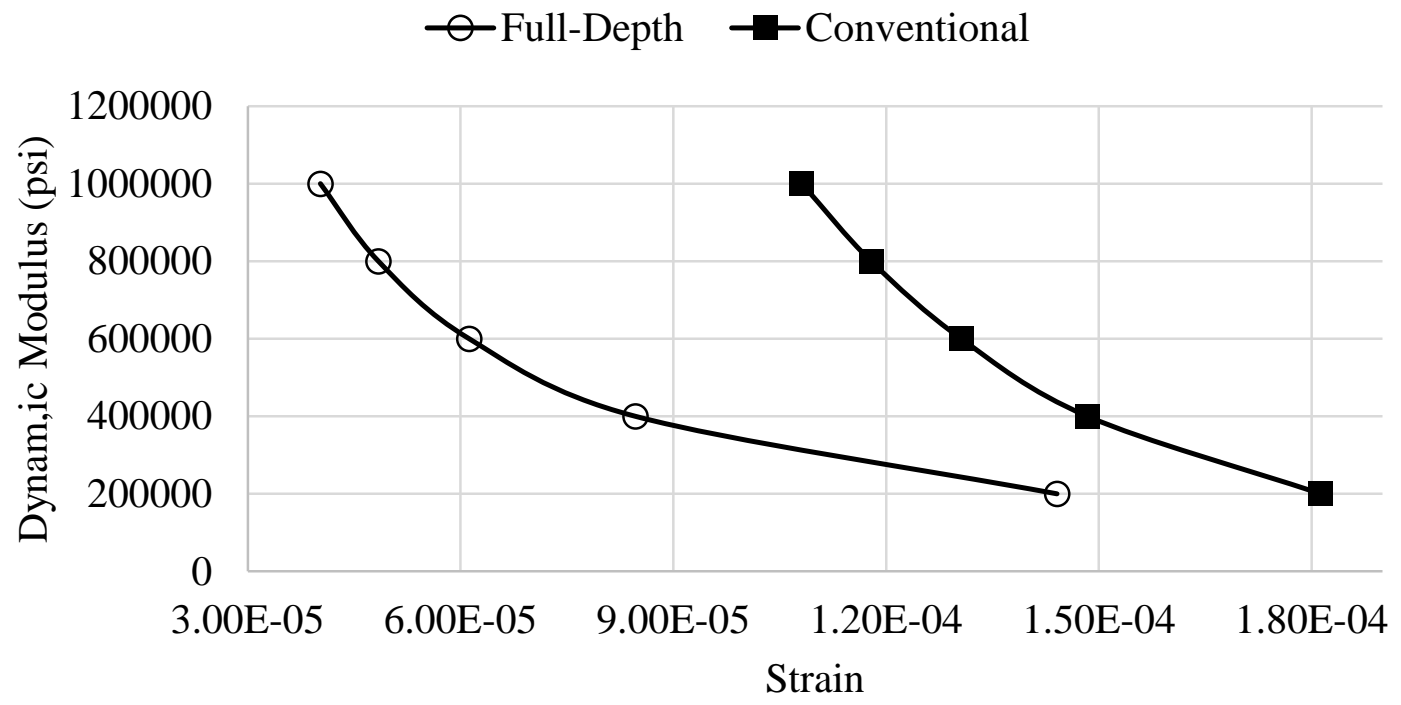

Figure 37: Full Depth and Conventional Pavement Strain Based Fatigue

Using Figures 27 and 30, dynamic moduli corresponding to $1.866 \mathrm{~Hz}$ at $20^{\circ} \mathrm{C}$ were determined, as presented in Table 27. The Asphalt Institute fatigue coefficients were placed into Equation 15 to form Equation 22:

$N_{f}=0.0796\left(\frac{1}{\varepsilon_{t}}\right)^{3.291}\left(\frac{1}{E}\right)^{0.854}$ 
Where:

$N_{f}=$ number of passes to fatigue

$\varepsilon=$ strain

$E=$ dynamic modulus (psi)

Table 27: Dynamic Modulus Values for $\mathrm{N}_{\mathrm{f}}$ Analysis

\begin{tabular}{|c|c|c|}
\hline Mix & E $(\mathbf{M P a})$ & $\mathbf{E}$ (psi) \\
\hline AA937 & 5,071 & 735,000 \\
\hline JAP909 & 4,698 & 681,000 \\
\hline JFA060 & 4,389 & 637,000 \\
\hline JFA115 & 4,181 & 606,000 \\
\hline JFA429 & 4,645 & 674,000 \\
\hline KP483 & 4,474 & 649,000 \\
\hline WVP523 & 4,848 & 703,000 \\
\hline WVP766 & 4,206 & 610,000 \\
\hline WVP882 & 3,910 & 567,000 \\
\hline
\end{tabular}

The dynamic moduli in Table 27 were used to find strain values from Figure 37. From there, the strain and modulus were used in Equation 22 to estimate fatigue life, Table 28.

Table 28: KENPAVE Full Depth and Conventional $\mathrm{N}_{\mathrm{f}}$ Values

\begin{tabular}{|c|c|c|c|c|c|}
\cline { 3 - 6 } \multicolumn{2}{c|}{} & \multicolumn{2}{c|}{ Full Depth } & \multicolumn{2}{c|}{ Conventional } \\
\hline \multirow{2}{*}{ Mix } & $\mathbf{E}(\mathbf{p s i})$ & $\begin{array}{c}\boldsymbol{\varepsilon} \\
\text { (micro strain) }\end{array}$ & $\mathbf{N}_{\mathbf{f}}$ & $\begin{array}{c}\boldsymbol{\varepsilon} \\
\text { (micro strain) }\end{array}$ & $\mathbf{N}_{\mathbf{f}}$ \\
\hline AA937 & 735,000 & 52 & $9.77 \mathrm{E}+07$ & 120 & $6.23 \mathrm{E}+06$ \\
\hline JAP909 & 681,000 & 55 & $8.67 \mathrm{E}+07$ & 123 & $6.13 \mathrm{E}+06$ \\
\hline JFA060 & 637,000 & 58 & $7.70 \mathrm{E}+07$ & 125 & $6.16 \mathrm{E}+06$ \\
\hline JFA115 & 606,000 & 61 & $6.81 \mathrm{E}+07$ & 127 & $6.10 \mathrm{E}+06$ \\
\hline JFA429 & 674,000 & 56 & $8.24 \mathrm{E}+07$ & 123 & $6.19 \mathrm{E}+06$ \\
\hline KP483 & 649,000 & 57 & $8.03 \mathrm{E}+07$ & 125 & $6.06 \mathrm{E}+06$ \\
\hline WVP523 & 703,000 & 54 & $8.96 \mathrm{E}+07$ & 121 & $6.30 \mathrm{E}+06$ \\
\hline WVP766 & 610,000 & 60 & $7.15 \mathrm{E}+07$ & 127 & $6.06 \mathrm{E}+06$ \\
\hline WVP882 & 567,000 & 64 & $6.15 \mathrm{E}+07$ & 130 & $5.98 \mathrm{E}+06$ \\
\hline
\end{tabular}

Strains for the full depth pavement are below recommended micro strain values for perpetual pavements of 70 micro strains (Lenz, 2011). The full depth analysis indicates this is a 
perpetual pavement design. The minimum estimated fatigue life for the full depth pavement is $61.5 \times 10^{6}$ ESALs, which is much greater than the expected truck loads on West Virginia pavements. The conventional pavement fatigue lives were approximately six million ESALs regardless of the mix type, Table 28.

\section{Alpha-Fatigue Pavement Life Prediction}

The fatigue samples were analyzed using the KENPAVE strain values found previously and K-values produced from the Alpha-Fatigue analyses. As stated previously, strains for the full depth pavement are far below recommended micro strain values so the full depth pavement was not reviewed further. Alpha-Fatigue K-values and dynamic modulus averages were used in Equation 15 to produce the number of cycles to failure for conventional pavement design. The results are listed in Table 29. Choosing the Peak failure criteria resulted in higher $\mathrm{N}_{\mathrm{f}}$ values in all cases compared to the Asphalt Institute. Even though the critical micro strains for the conventional pavement are well in excess of the criteria for a perpetual pavement, the estimates from the Alpha Fatigue equation show the expected fatigue life of the pavement is in excess of $50 \times 10^{6}$ applications, well in excess of the expected design traffic that would be used by the WVDOH when considering a conventional pavement. Furthermore the Alpha Fatigue results were not corrected with the field calibration factor which would increase the estimate of fatigue life by a factor of 18.4 .

Table 29: Conventional Pavement KENPAVE Analysis Using Alpha-Fatigue K-Values

\begin{tabular}{|c|c|c|c|c|}
\cline { 3 - 4 } \multicolumn{2}{c|}{} & Alpha-Fatigue & Asphalt Institute \\
\hline Mix & $\mathbf{E}$ (psi) & $\boldsymbol{\varepsilon}$ (micro strain) & $\mathbf{N}_{\mathbf{f}}$ & $\mathbf{N}_{\mathbf{f}}$ \\
\hline AA937 & 735,000 & 120 & $1.30 \mathrm{E}+07$ & $6.29 \mathrm{E}+06$ \\
\hline JAP909 & 681,000 & 123 & $6.15 \mathrm{E}+06$ & $6.19 \mathrm{E}+06$ \\
\hline JFA060 & 637,000 & 125 & $1.64 \mathrm{E}+07$ & $6.11 \mathrm{E}+06$ \\
\hline JFA115 & 606,000 & 127 & $2.98 \mathrm{E}+07$ & $6.05 \mathrm{E}+06$ \\
\hline JFA429 & 674,000 & 123 & $6.76 \mathrm{E}+08$ & $6.18 \mathrm{E}+06$ \\
\hline KP483 & 649,000 & 125 & $1.61 \mathrm{E}+08$ & $6.13 \mathrm{E}+06$ \\
\hline WVP523 & 703,000 & 121 & $9.72 \mathrm{E}+07$ & $6.23 \mathrm{E}+06$ \\
\hline WVP766 & 610,000 & 127 & $5.76 \mathrm{E}+07$ & $6.06 \mathrm{E}+06$ \\
\hline WVP882 & 567,000 & 130 & $4.29 \mathrm{E}+06$ & $5.97 \mathrm{E}+06$ \\
\hline
\end{tabular}




\section{Flow Number}

\section{AMPT Flow Number Results}

All flow number data is summarized in Tables 30 and 31. Each Wearing I mix met AASHTO TP 79 specifications for acceptable range of replicates, but JFA115 coefficient of variation value was higher than the acceptable coefficient of variation value of 32.9 percent for $9.5 \mathrm{~mm}$ mixes. The acceptable coefficient of variance for $19 \mathrm{~mm}$ NMAS is 58.5 percent according to AASHTO TP 79. Each set of Base II/19 mm mix replicates met this requirement. The sample replicate range for all mixes are well within the acceptable range of the test method.

Tables 30 and 31 also present VTM, flow number, and permanent strain (micro strain at flow point) values per AASHTO TP 79 reporting requirements. AA937 resulted in the highest average flow number of the five Wearing I mixes with a value of 687. KP483 had the next highest flow number at a value of 567. JFA115 had a lower value of 321 with WVP766 and WVP882 performing comparably with values of 262 and 265.

Table 30: Data Smoothing Flow Number and Permanent Strain for Wearing I Mixes

\begin{tabular}{|c|c|c|c|c|c|c|c|c|c|}
\hline Mix & REP & VTM & FN & AVG & SD & $\begin{array}{l}\text { CV } \\
(\%)\end{array}$ & $\begin{array}{c}\text { Microstrain } \\
\text { at Flow Point }\end{array}$ & AVG & SD \\
\hline \multirow{4}{*}{ AA937 } & 1 (S8) & 7.4 & 625 & \multirow{4}{*}{687} & \multirow{4}{*}{52} & \multirow{4}{*}{7.5} & 27,411 & \multirow{4}{*}{27,334} & \multirow{4}{*}{556} \\
\hline & $2(\mathrm{~S} 9)$ & 7.3 & 706 & & & & 27,545 & & \\
\hline & $3(\mathrm{~S} 10)$ & 7.3 & 671 & & & & 26,543 & & \\
\hline & 4 (S11) & 7.5 & 747 & & & & 27,836 & & \\
\hline \multirow{4}{*}{ JFA115 } & 1 (S9) & 7.1 & 232 & \multirow{4}{*}{321} & \multirow{4}{*}{111} & \multirow{4}{*}{34.6} & 20,219 & \multirow{4}{*}{21,766} & \multirow{4}{*}{1,540} \\
\hline & $2(\mathrm{~S} 10)$ & 6.9 & 285 & & & & 23,298 & & \\
\hline & $3(\mathrm{~S} 11)$ & 6.7 & 445 & & & & 21,782 & & \\
\hline & & - & & & & & - & & \\
\hline \multirow{4}{*}{ KP483 } & 1 (S5) & 6.7 & 467 & \multirow{4}{*}{567} & \multirow{4}{*}{41} & \multirow{4}{*}{8.5} & 20,602 & \multirow{4}{*}{21,042} & \multirow{4}{*}{331} \\
\hline & 2 (S9) & 6.8 & 534 & & & & 21,184 & & \\
\hline & $3(\mathrm{~S} 10)$ & 6.8 & 437 & & & & 21,002 & & \\
\hline & 4 (S11) & 6.9 & 483 & & & & 21,378 & & \\
\hline \multirow{4}{*}{ WVP766 } & $1(\mathrm{~S} 9)$ & 6.6 & 201 & \multirow{4}{*}{262} & \multirow{4}{*}{55} & \multirow{4}{*}{21.1} & 20,173 & \multirow{4}{*}{20,913} & \multirow{4}{*}{984} \\
\hline & $2(\mathrm{~S} 10)$ & 6.9 & 238 & & & & 22,277 & & \\
\hline & $3(\mathrm{~S} 11)$ & 7.0 & 330 & & & & 20,212 & & \\
\hline & $4(\mathrm{~S} 12)$ & 6.8 & 279 & & & & 20,988 & & \\
\hline \multirow{4}{*}{ WVP882 } & $1(\mathrm{~S} 5)$ & 6.8 & 230 & \multirow{4}{*}{265} & \multirow{4}{*}{33} & \multirow{4}{*}{12.6} & 21,992 & \multirow{4}{*}{23,080} & \multirow{4}{*}{1,790} \\
\hline & $2(\mathrm{~S} 6)$ & 6.7 & 270 & & & & 21,410 & & \\
\hline & $3(\mathrm{~S} 10)$ & 6.7 & 250 & & & & 23,502 & & \\
\hline & $4(\mathrm{~S} 11)$ & 6.7 & 308 & & & & 25,417 & & \\
\hline
\end{tabular}


Table 31: Data Smoothing Flow Number and Permanent Strain for Base II and 19 mm Mixes

\begin{tabular}{|c|c|c|c|c|c|c|c|c|c|}
\hline Mix & REP & VTM & FN & AVG & SD & $\begin{array}{l}\mathrm{CV} \\
(\%)\end{array}$ & $\begin{array}{c}\text { Microstrain } \\
\text { at Flow Point }\end{array}$ & AVG & SD \\
\hline \multirow{4}{*}{ JAP909 } & 1 (S5) & 7.0 & 260 & \multirow{4}{*}{266} & \multirow{4}{*}{13} & \multirow{4}{*}{5.0} & 20,986 & \multirow{4}{*}{22,591} & \multirow{4}{*}{1,074} \\
\hline & $2(\mathrm{~S} 9)$ & 6.6 & 255 & & & & 23,075 & & \\
\hline & $3(\mathrm{~S} 10)$ & 6.8 & 285 & & & & 23,044 & & \\
\hline & $4(\mathrm{~S} 11)$ & 6.5 & 264 & & & & 23,260 & & \\
\hline \multirow{4}{*}{ JFA060 } & $1(\mathrm{~S} 8)$ & 7.2 & 262 & \multirow{4}{*}{346} & \multirow{4}{*}{123} & \multirow{4}{*}{35.5} & 21,919 & \multirow{4}{*}{22,590} & \multirow{4}{*}{693} \\
\hline & $2(\mathrm{~S} 9)$ & 7.1 & 290 & & & & 22,097 & & \\
\hline & 3 (S10) & 7.0 & 303 & & & & 23,360 & & \\
\hline & $4(\mathrm{~S} 11)$ & 6.6 & 528 & & & & 22,984 & & \\
\hline \multirow{4}{*}{ JFA429 } & 1 (S9) & 6.6 & 370 & \multirow{4}{*}{459} & \multirow{4}{*}{126} & \multirow{4}{*}{27.4} & 18,792 & \multirow{4}{*}{19,311} & \multirow{4}{*}{734} \\
\hline & $2(\mathrm{~S} 10)$ & 7.0 & 548 & & & & 19,830 & & \\
\hline & 3 & - & - & & & & - & & \\
\hline & 4 & - & - & & & & - & & \\
\hline \multirow{4}{*}{ WVP523 } & 1 (S9) & 6.2 & 649 & \multirow{4}{*}{628} & \multirow{4}{*}{47} & \multirow{4}{*}{7.5} & 20,851 & \multirow{4}{*}{21,955} & \multirow{4}{*}{1,663} \\
\hline & $2(\mathrm{~S} 10)$ & 6.9 & 561 & & & & 20,878 & & \\
\hline & $3(\mathrm{~S} 11)$ & 6.6 & 632 & & & & 21,715 & & \\
\hline & $4(\mathrm{~S} 12)$ & 7.1 & 670 & & & & 24,376 & & \\
\hline
\end{tabular}

The WVP523 S9 performed within the acceptable range for four replicates so an additional sample was not made. WVP523 resulted in the highest average flow number of the four Base II/19mm pavement designs with a value of 628. JFA429 had the next highest flow number at a value of 459 and JFA060 had the third with an average of 346. JAP909 resulted in the lowest average of 266.

Figure 38 displays one flow number test from this research. During this test tertiary flow appears to have been achieved. However, tertiary flow was barely reached during other flow number tests, Figure 39. This is an artifact of the definition of flow number used in the test method. Flow number occurs at either the minimum strain rate using the smoothing criteria or at the inflection point using the Francken model. Therefore, it is not necessary to extend the test into the tertiary stage. 


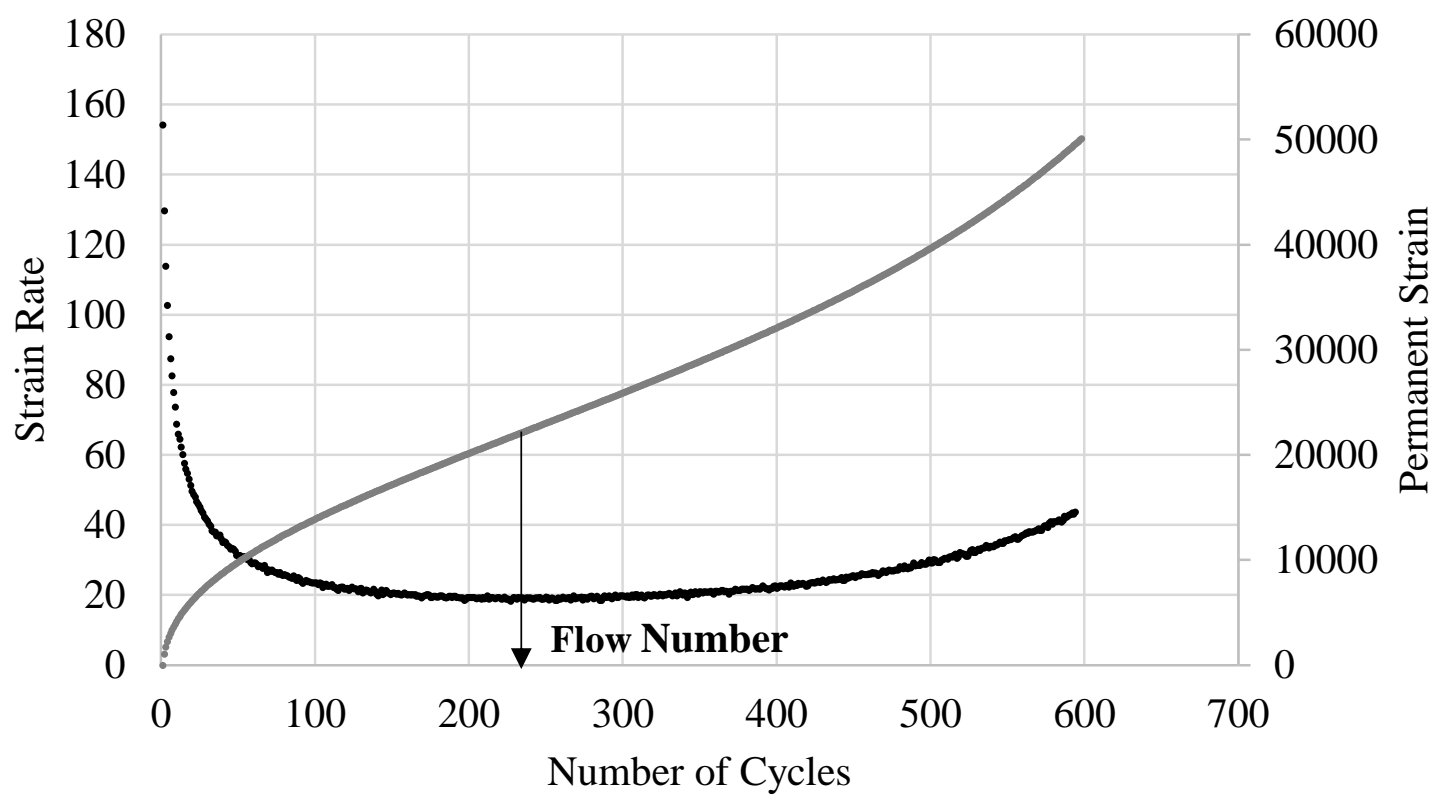

Figure 38: WVP882 Flow Number Sample 5 Permanent Strain and Strain Rate

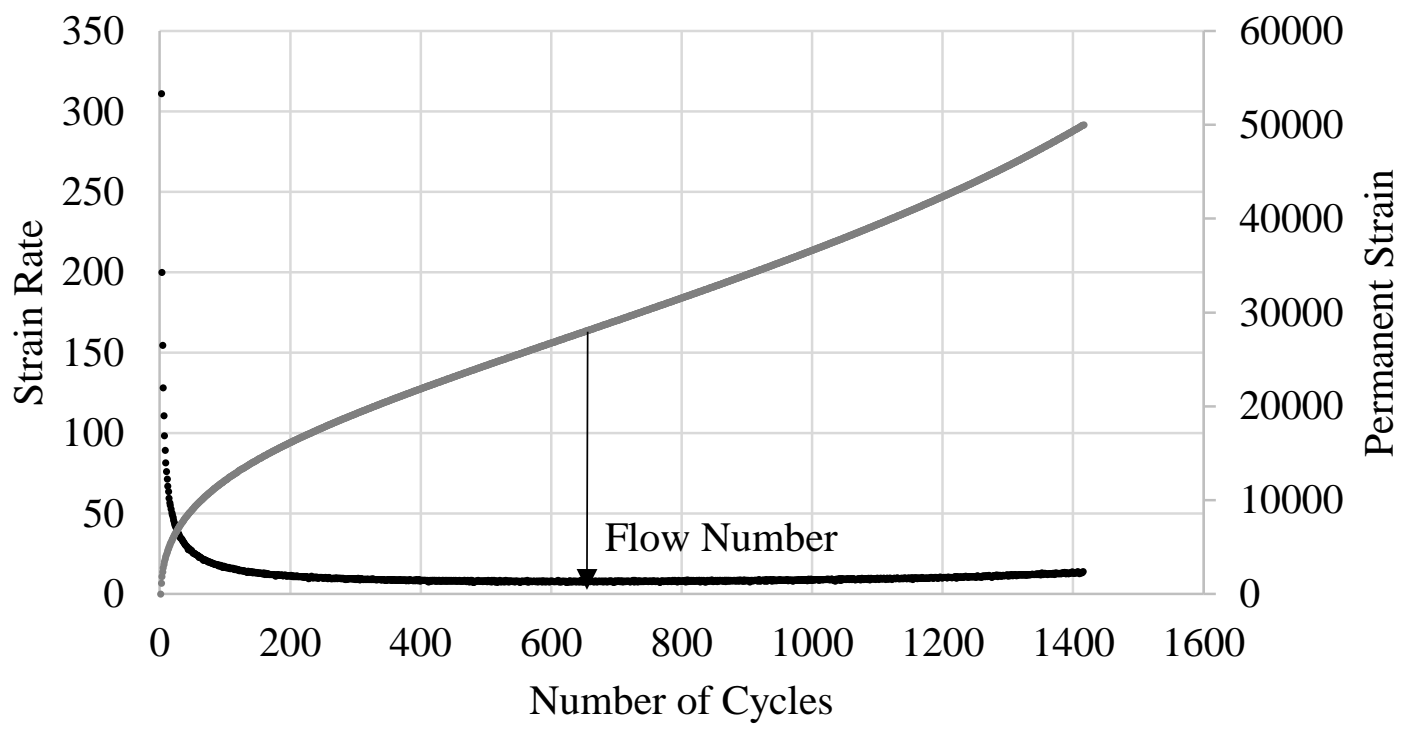

Figure 39: AA937 Flow Number Sample 8 Permanent Strain and Strain Rate

Francken Model Flow Number Results

For further review, the Francken model was pursued to see if there was any difference in the flow number values. The Francken model was fit to the data using nonlinear regression in MATLAB. All averages, standard deviations, and coefficient of variation values are reported in 
Tables 32 and 33. The Francken model averages are moderately higher than the data smoothing averages for all mixes except WVP523.

Table 32: Francken Model Flow Number Summary of Wearing I Mixes

\begin{tabular}{|c|c|c|c|c|c|c|}
\hline Mix & REP & VTM & FN & AVG & SD & CV (\%) \\
\hline \multirow{4}{*}{ AA937 } & $1(\mathrm{~S} 8)$ & 7.4 & 651 & \multirow{4}{*}{722} & \multirow{4}{*}{49} & \multirow{4}{*}{6.9} \\
\hline & 2 (S9) & 7.3 & 760 & & & \\
\hline & 3 (S10) & 7.3 & 725 & & & \\
\hline & 4 (S11) & 7.5 & 751 & & & \\
\hline \multirow{3}{*}{ JFA115 } & 1 (S9) & 7.1 & 263 & \multirow{3}{*}{338} & \multirow{3}{*}{119} & \multirow{3}{*}{35.2} \\
\hline & 2 (S10) & 6.9 & 276 & & & \\
\hline & 3 (S11) & 6.7 & 475 & & & \\
\hline \multirow{4}{*}{ KP483 } & 1 (S5) & 6.7 & 440 & \multirow{4}{*}{491} & \multirow{4}{*}{58} & \multirow{4}{*}{11.8} \\
\hline & 2 (S9) & 6.8 & 569 & & & \\
\hline & 3 (S10) & 6.8 & 454 & & & \\
\hline & 4 (S11) & 6.9 & 499 & & & \\
\hline \multirow{4}{*}{ WVP766 } & 1 (S9) & 6.6 & 218 & \multirow{4}{*}{274} & \multirow{4}{*}{54} & \multirow{4}{*}{19.6} \\
\hline & 2 (S10) & 6.9 & 246 & & & \\
\hline & 3 (S11) & 7.0 & 341 & & & \\
\hline & 4 (S12) & 6.8 & 290 & & & \\
\hline \multirow{4}{*}{ WVP882 } & 1 (S5) & 6.8 & 252 & \multirow{4}{*}{274} & \multirow{4}{*}{22} & \multirow{4}{*}{8.1} \\
\hline & 2 (S6) & 6.7 & 295 & & & \\
\hline & 3 (S10) & 6.7 & 257 & & & \\
\hline & 4 (S11) & 6.7 & 290 & & & \\
\hline
\end{tabular}

Table 33: Francken Model Flow Number Summary of Base II and 19 mm Mixes

\begin{tabular}{|c|c|c|c|c|c|c|}
\hline Mix & REP & VTM & FN & AVG & SD & CV (\%) \\
\hline \multirow{4}{*}{ JAP909 } & 1 (S5) & 7.0 & 276 & \multirow{4}{*}{284} & \multirow{4}{*}{20} & \multirow{4}{*}{6.9} \\
\hline & 2 (S9) & 6.6 & 267 & & & \\
\hline & 3 (S10) & 6.8 & 312 & & & \\
\hline & $4(\mathrm{~S} 11)$ & 6.5 & 282 & & & \\
\hline \multirow{4}{*}{ JFA060 } & 1 (S8) & 7.2 & 290 & \multirow{4}{*}{362} & \multirow{4}{*}{99} & \multirow{4}{*}{27.3} \\
\hline & 2 (S9) & 7.1 & 336 & & & \\
\hline & $3(\mathrm{~S} 10)$ & 7.0 & 314 & & & \\
\hline & $4(\mathrm{~S} 11)$ & 6.6 & 507 & & & \\
\hline \multirow{2}{*}{ JFA429 } & 1 (S9) & 6.6 & 423 & \multirow{2}{*}{517} & \multirow{2}{*}{133} & \multirow{2}{*}{25.7} \\
\hline & $2(\mathrm{~S} 10)$ & 7.0 & 611 & & & \\
\hline \multirow{4}{*}{ WVP523 } & $1(\mathrm{~S} 9)$ & 6.2 & 646 & \multirow{4}{*}{594} & \multirow{4}{*}{36} & \multirow{4}{*}{6.0} \\
\hline & $2(\mathrm{~S} 10)$ & 6.9 & 588 & & & \\
\hline & $3(\mathrm{~S} 11)$ & 6.6 & 577 & & & \\
\hline & 4 (S12) & 7.1 & 566 & & & \\
\hline
\end{tabular}

Table 34 summarizes all flow number values and the difference between the two methods reviewed. In some cases, the Francken model value is higher while in other instances the data smoothing flow number is higher. However, for most mixes the Francken model resulted in a higher flow number. 
Table 34: Flow Number Differences between Data Smoothing and Francken Model

\begin{tabular}{|c|c|c|c|c|}
\hline Mix & REP & Data Smoothing & Francken Model & Difference \\
\hline \multirow{4}{*}{ AA937 } & S8 & 625 & 651 & 26 \\
\hline & S9 & 706 & 760 & 54 \\
\hline & $\mathrm{S} 10$ & 671 & 725 & 54 \\
\hline & S11 & 747 & 751 & 4 \\
\hline \multirow{4}{*}{ JAP909 } & S5 & 260 & 276 & 16 \\
\hline & S9 & 255 & 267 & 12 \\
\hline & $\mathrm{S} 10$ & 285 & 312 & 27 \\
\hline & S11 & 264 & 282 & 18 \\
\hline \multirow{4}{*}{ JFA060 } & S8 & 262 & 290 & 28 \\
\hline & S9 & 290 & 336 & 46 \\
\hline & $\mathrm{S} 10$ & 303 & 314 & 11 \\
\hline & S11 & 528 & 507 & -21 \\
\hline \multirow{3}{*}{ JFA115 } & S9 & 232 & 263 & 31 \\
\hline & $\mathrm{S} 10$ & 285 & 276 & -9 \\
\hline & S11 & 445 & 475 & 30 \\
\hline \multirow{2}{*}{ JFA429 } & S9 & 370 & 423 & 53 \\
\hline & $\mathrm{S} 10$ & 548 & 611 & 63 \\
\hline \multirow{4}{*}{ KP483 } & S5 & 467 & 440 & -27 \\
\hline & S9 & 534 & 569 & 35 \\
\hline & $\mathrm{S} 10$ & 437 & 454 & 17 \\
\hline & S11 & 483 & 499 & 16 \\
\hline \multirow{4}{*}{ WVP523 } & S9 & 649 & 646 & -3 \\
\hline & $\mathrm{S} 10$ & 561 & 588 & 27 \\
\hline & S11 & 632 & 577 & -55 \\
\hline & $\mathrm{S} 12$ & 670 & 566 & -104 \\
\hline \multirow{4}{*}{ WVP766 } & S9 & 201 & 218 & 17 \\
\hline & $\mathrm{S} 10$ & 238 & 246 & 8 \\
\hline & $\mathrm{S} 11$ & 330 & 341 & 11 \\
\hline & $\mathrm{S} 12$ & 279 & 290 & 11 \\
\hline \multirow{4}{*}{ WVP882 } & S5 & 230 & 252 & 22 \\
\hline & S6 & 270 & 295 & 25 \\
\hline & $\mathrm{S} 10$ & 250 & 257 & 7 \\
\hline & S11 & 308 & 290 & -18 \\
\hline
\end{tabular}




\section{Evaluation of Rutting Resistance}

Two mixes do not have the four replicates required due to material shortage (JFA429 and JFA115), but all average flow number values were reviewed for rutting resistance. Table 6 from Chapter 2 shows the ESALs cutoff for HMA rutting from AASHTO TP 79. As shown in Tables 32 and 33, each mix analyzed had an average flow number greater than 190 and less than 740 which is the minimum average flow number limits for 10 to 30 million and greater than 30 million ESALs. This means each mix met rutting resistance criteria within this respect and could be expected to withstand 10 to 30 million ESALs without accumulating significant rutting.

AA937, KP483, WVP523, WVP766, and WVP882 all contained natural sands in their mix compositions. Excessive natural sand (30 percent) in a mix design has been found to be the most significant factor influencing permanent deformation (Rushing and Little, 2013). WVP766 and WVP882, both Wearing I mixes containing 25 percent natural sands, performed the worst for rutting. However, AA937, KP483, and WVP523 contained 30, 19, and 25 percent natural sands, but resulted as the three highest flow number averages of all mixes evaluated.

\section{Significance of Work}

The work completed herein was the first AMPT testing performed on West Virginia plant-produced mixes. All findings contribute insight into the mixes provided for this research. Additionally, expanding knowledge on the AMPT is beneficial for future work completed at the WVU Asphalt Technology laboratory. Gaining better understanding on all AMPT material property testing apparatuses ensures that the AMPT is functioning properly and producing acceptable data. This is integral to producing meaningful results and reaching conclusions from all AMPT research. 


\section{Chapter 5: Conclusions and Recommendations}

\section{Conclusions}

\section{Sample Uniformity}

All sample sets met the AASHTO PP 60 uniformity requirements except WVP523 in the top-middle evaluation. The samples used for dynamic modulus testing were evaluated for uniformity on the assumption that the dynamic modulus test does not damage the samples since a low stress level is used for dynamic modulus testing. The target air void content of these samples was 7 percent whereas the recommended air voids for the uniformity test is 5.5 percent. There is a logical argument for evaluating the uniformity at the target air voids for the test being performed. The flow number and fatigue test samples were not tested for uniformity as these tests have a potential to alter the void structure of the sample. It was assumed the flow number and fatigue samples had acceptable uniformity based of the results of the tests on the dynamic modulus samples.

During the analysis of the sections, it was noticed that the air voids of the sections were higher than the air voids of the intact samples by 0.4 percent, Table 18 . This issue is not addressed in AASHTO PP 60 and the reason for the difference is not apparent.

Strong correlations among all three $\mathrm{G}_{\mathrm{mb}}$ methods (CoreLok, SSD, and Dimensional) were found when plotted on line of equality graphs. Moreover, the equations in Figure 22 and 23 may be used to estimate if a compacted sample will have an acceptable VTM for AMPT testing after trimming for 9.5 and $19 \mathrm{~mm}$ NMAS mixes. Trimming samples can be avoided for samples that will not meet the AMPT requirements for VTM.

When testing for uniformity all Dimensional $\mathrm{G}_{\mathrm{mb}}$ comparisons for all mixes met the AASHTO PP 60 requirements. From these findings, Dimensional is arguably the most accurate method when calculating the $G_{m b}$ value of a sample with cut faces. Moreover, all sample sets met the AASHTO PP 60 t-statistic limit for uniformity except WVP523 in the top-middle evaluation for SSD, CoreLok, and Average. While this set did not meet uniformity, all testing resulted in comparable dynamic modulus and flow number results to mixes with the same NMAS. 


\section{Dynamic Modulus}

Dynamic modulus values fell within an acceptable coefficient of variation range at $4^{\circ} \mathrm{C}$ and $20^{\circ} \mathrm{C}$. At $40^{\circ} \mathrm{C}$ the coefficient of variation increased above 15 percent for two mixes (JFA060 and WVP523), but still remained below 20 percent. These coefficient of variation and repeatability values for AMPT dynamic modulus testing were consistent with Robert et al. (2012) AMPT study. These findings show the AMPT produced reliable data for this research.

The $\beta$ fitting parameter appears to have a correlation to the inclusion of RAP in a mix design consistent with Smith (2015) findings. However, at $20^{\circ} \mathrm{C}$ the average dynamic modulus of the RAP and virgin mixes was virtually identical. Lastly, the Master curves for all mix designs followed a similar fit. At lower reduced frequencies the values ranged slightly, but converged with increased reduced frequency. Two mix nominal maximum aggregate sizes were evaluated, but NMAS does not appear to have an impact on the curve fit.

\section{Alpha-Fatigue}

Two failure methods were analyzed using Alpha-Fatigue software: one using the phase angle drop failure criteria (Peak) and the second allowing the Alpha-Fatigue software to choose the failure point using built in functions (Default). The Peak criteria resulted in reasonable micro strain endurance limits while the Default did not. Therefore, only the Peak Alpha-Fatigue results were reviewed further. The one Superpave mix analyzed, JFA429, resulting in the highest endurance limit.

Results found in this research vary from the Asphalt Institute equation and the adjusted equation. Comparing the K-values found in this study to past results of Hou (2009) and Witczak et al. (2013), showed some discrepancies. No distinctions between mixes containing RAP or between different NMAS designs were apparent in this analysis.

\section{KENPAVE}

The full depth pavement evaluated indicated the pavement met the criteria for a perpetual pavement design with respect to fatigue life. For the conventional pavement design, the fatigue life estimate using the Alpha-Fatigue results and the Peak phase angle criteria were greater than the fatigue life estimated by the Asphalt Institute fatigue equation in all cases. 


\section{Flow Number}

The flow number concept is often explained using conventional models of creep behavior that describes the creep rate in the secondary phase as linear behavior. The creep of asphalt concrete does not display linear behavior. Therefore, the flow number of asphalt concrete is defined as the point of minimum change in the rate of permanent strain accumulation. Due to minor fluctuations in the permanent strain data, the test method recommends a smoothing technique to determine the flow number with the Francken model being an alternative. Although the smoothing process is simple, it is sensitive to the sampling interval selected. The Francken model uses all the data from the flow number test and defines the flow number as the cycle where the second derivative changes from positive to negative. Although the analysis needed for the Francken model is somewhat complex, it can be readily handled with nonlinear regression using MATLAB or other statistical software packages.

Both the data smoothing and the Francken model are reasonable methods for determining flow number. All mix types met rutting resistance requirements for both methods evaluated. Each mix could be expected to withstand 10 to 30 million ESALs without accumulating significant permanent deformation. A Wearing I, RAP containing mix (AA937) performed the highest with an average flow number of 687. WVP523 which was a Base II mix had the second highest average flow number value of 625 . This sample set also had a replicate fall below the air void range, but still performed well within the acceptable flow number range. All mix replicates met coefficient of variation requirements except JFA115. From this testing, the AMPT produced repeatable data.

\section{Recommendations}

\section{Testing Protocol}

The effect of air voids on fatigue performance should be evaluated with the intent of defining an air void level to use for fatigue testing.

Further investigation using the AMPT and Alpha-Fatigue software is needed. Values found with the WVU laboratory differ from that of the Asphalt Institute and other references. 
Some fatigue samples did not break within the gauge points which infers the LVDT readings were not monitoring the strained area of the sample accurately. Looking into this in future AMPT fatigue testing can be done by breaking samples after each test to verify deformation is occurring within the LVDT gauge length.

In the AASHTO PP 60 assessing uniformity section, top-bottom bulk specific gravity comparison is not a requirement. Adding this comparison to the standard should be considered.

\section{Material Evaluation}

The Superpave $19 \mathrm{~mm}$ mix performed better than the other mixes with respect to fatigue. However, this observation is based on a single sample. A designed experiment should be performed with factors that include contractor, mix type, and aggregate type to develop a statistically significant data base. This would be a preliminary step into the use of a mechanistic pavement design method such as MEPDG. This investigation should include all the asphalt concrete materials used in the state.

The potential of evaluating mixes during the mix design should be evaluated to optimize material characteristics. For example surface mixes could be evaluated to minimized rutting potential while base mixes could be optimized to improve fatigue resistance.

A process should be implemented whereby different mix designs are evaluated with the AMPT and the performance of pavements constructed with these mixes is monitored over time.

A method to look at the variability among test replicates in Alpha-Fatigue would be ideal. How the program is currently designed, replicates are tested at different micro strain values and fatigue coefficients are produced from all three replicates. This does not allow a comparison to be completed.

Large quantities of one mix should be obtained to look at a range of air voids for fatigue testing. A large quantity of mix would also allow more than one set of fatigue replicates to be made and tested to review determine if there is any variability in the final Alpha-Fatigue coefficients.

For a more accurate KENPAVE analysis, WV-produced $37.5 \mathrm{~mm}$ mixes should be analyzed for more accurate strain values at the bottom of the asphalt layer.

To reduce segregation, mixes may need remixed immediately before being placed in the mold for compaction. 
Lastly, in Table 25 the micro strain endurance limits increase at a linear rate until the last temperature shift between $20^{\circ} \mathrm{C}$ and $25^{\circ} \mathrm{C}$ where the micro strain endurance limit abruptly increases. The reason for this is unknown and should be investigated further. 


\section{References}

Al-Mistarehi, Bara'. Superpave System Verses Marshall Design Procedure for Asphalt Paving Mixtures (Comparative Study). University of Stuttgart Geschwister-Scholl, Germany. Global Journal of Research in Engineering, Vol. 14, 2014, pp. 45-52.

ALPHA - F User Guide (2014). “Alpha-Fatigue”. IPC Global, Raleigh, NC.

ARA, Inc. ERES Division. (2004). Guide for Mechanistic-Empirical Design of New and Rehabilitated Pavement Structures Appendix II-1: Calibration of Fatigue Cracking Models for Flexible Pavements. Transportation Research Board National Research Council, Washington, D.C.

Asphalt Institute. (1996). "Mix Design Methods for Asphalt Concrete and other Hot Mix type". Manual Serial No. 2, Sixth Edition, Lexington, Kentucky.

Biligiri, K. P., Kaloush, K. E., Mamlouk, M. S., and Witczak, M.W. (2007). Rational Modeling of Tertiary Flow for Asphalt Mixtures. Journal of the Transportation Research Board, No. 2001, pp. 63-72. Transportation Research Board of the National Academies, Washington, D.C.

Bonaquist, R. (2010). Wisconsin Mixture Characterization Using the Asphalt Mixture Performance Tester (AMPT) on Historical Aggregate Structures. Wisconsin Highway Research Program, Madison.

Bonaquist, R. (2011a). "MasterSolver: Version 2.2 [Software]”. Available from http://apps.trb.org/cmsfeed/TRBNetProjectDisplay.asp?ProjectID=963.

Bonaquist, R. (2011b). NCHRP Report 702: Precision of the Dynamic Modulus and Flow Number Tests Conducted with the Asphalt Mixture Performance Tester. Transportation Research Board, Washington, D. C. 
Bonaquist, R. F., Christensen, D. W., and Stump, W. (2003). NCHRP Report 513 - Simple Perforce Tester for Superpave Mix Design: First-Article Development and Evaluation. Transportation Research Board, Washington, D.C.

Chen, J., B. Huang, and X. Shu. (2013). Air-Void Distribution Analysis of Asphalt Mixture Using Discrete Element Method. ASCE: Journal of Materials in Civil Engineering. Vol. 25 , Issue 10.

Cornelison, D. L. (2013). "Road Building Fundamentals: Volumetric Properties of Asphalt". Presented at Arizona Pavements and Materials Conference.

Cross, S. A. (1992). A National Study of Rutting in Hot Mix Asphalt (HMA) Pavements. Ph. D. dissertation. Auburn University, Auburn, Alabama.

Emry, J. (1984). Steel Slag Utilization in Asphalt Mixes. National Slag Association, Canadian Technical Asphalt Association Proceedings, Brampton, Ontario.

Gillispie, A. C. (2011). "Materials Procedure: Guide to Designing Hot-Mix Asphalt Using the Marshall Design Method (MP 401.02.22)”. West Virginia Department of Transportation Division of Highways Materials Control, Soils, and Testing Division, Charleston.

Griffith, Francis T. (2009). Investigation of the Measurements of Bulk Specific Gravity of Compacted Specimens by Various Methods. MS thesis. University of Arkansas, Fayetteville.

Haifang, W., Edward, W., and Sushanta, B. (2014). Evaluation of Steel Slag as Hot Mix Asphalt Aggregate. Washington Center for Asphalt Technology, Pullman.

Hou, T. (2009). Fatigue Performance Prediction of north Carolina Mixtures Using Simplified Viscoelastic Continuum Damage Model. MS thesis. North Carolina State University, Raleigh.

Huang, Y. H. (2004). "Pavement Analysis and Design”. Second Edition. Pearson Education. Upper Saddle River, New Jersey. 
Instro Tek ${ }^{\circledR}$ Incorporated. (2011). “CoreLok ${ }^{\circledR}$ Operator's Guide”. Raleigh, NC.

Little, D.N., Lytton, R.L., Williams, D., \& Chen, C.W. (2001). Microdamage Healing in Asphalt and Asphalt Concrete, Volume I: Microdamage and Microdamage Healing Project Summary Report (FHWA-RD-98-141). Federal Highway Administration, Washington, D.C.

Mohammad, L. N. et al. (2015). NCHRP Report 818: Comparing the Volumetric and Mechanical Properties of Laboratory and Field Specimens of Asphalt Concrete. Transportation Research Board of the National Academies, Washington, D.C.

Kim, D. (2015). Modulus and Permanent Deformation Characterization of Asphalt Mixtures and Pavements. Ph. D. dissertation. North Carolina State University, Raleigh.

LaCroix, A. T. (2013). Performance Prediction of the NCAT Test Track Pavements Using Mechanistic Models. Ph. D. dissertation. North Carolina State University, Raleigh.

Lenz, R. W. (2011). "Pavement Design Guide, Section 5: Perpetual Pavement Design and Mechanistic Design Guidelines”. Retrieved June 24, 2016 from http://onlinemanuals.txdot.gov/txdotmanuals/pdm/perpetual_pavement_design_and_mec hanistic_design_guidelines.htm.

Prowell, B. D. et al. (2010). NCHRP Report 646: Validating the Fatigue Endurance Limit for Hot Mix Asphalt. Transportation Research Board, Washington, D.C.

Reese, R. (1997). Properties of Aged Asphalt Binder Related to Asphalt Concrete Fatigue Life. Journal of the Association of Asphalt Paving Technologists, Vol. 66, pp. 604-632.

Roberts, L., Romero, P., VanFrank, K., \& Ferrin, R. (2012). Evaluation of the Asphalt Mixture Performance Tester (AMPT): Utah Experience. Transportation Research Board 2012 Annual Meeting.

Rodezno, M. C. (2010). Rutting Criteria for Asphalt Mixtures Based on Flow Number Analysis. $\mathrm{Ph}$. D. dissertation. Arizona State University, Fayetteville. 
Rushing, J.F. and Little, D. N. (2013). Creep and Repeated Creep-Recovery as Rutting Performance Tests for Airport HMA Mix Design. Transportation Research Board 2013 Annual Meeting.

Sabouri, M. (2014). Development of a Unified Fatigue Failure Criterion for Asphalt Mixtures and Its Applications to Reclaimed Asphalt Pavement (RAP) Mixtures. Ph. D. dissertation. North Carolina State University, Raleigh.

Smith, L. (2015). Comparison of the Fatigue Characteristics of Recycled Asphalt Pavements. MS thesis. West Virginia University, Morgantown.

Taylor, A. and Tran, N. (2014). Results of Inter-laboratory Study for AMPT Pooled Fund Study TPF-5(178). National Center for Asphalt Technology at Auburn University, Alabama.

Tran, N. H., Taylor, A. J., Withee, J. N. (2013). Western Workshop on Asphalt Mixture Performance Tester: Summary Report. National Center for Asphalt Technology at Auburn University, Alabama.

Turner, K. (2015). Evaluation of Asphalt Mixture Performance Tester and Testing Protocol. MS thesis. West Virginia University, Morgantown.

Underwood, B. S., Baek, C., and Kim, Y. R. (2012). Simplified Viscoelastic Continuum Damage Model as Platform for Asphalt Concrete Fatigue Analysis. Journal of Transportation Research Board, No. 2296, pp. 36-45.

Underwood, B. S., Kim, Y. R., and Guddati, M. N. (2009). Improved Calculation Method of Damage Parameter in Viscoelastic Continuum Damage Model. International Journal of Pavement Engineering, Vol. 11, No. 6, pp. 495-476.

Office of Pavement Technology (OPT). (2013). Asphalt Mixture Performance Tester (AMPT). U.S. Department of Transportation Federal Highway Administration.

Vasavi, K. (2002). Comparison of 19mm Superpave and Marshall Base II mixes in West Virginia. MS thesis. West Virginia University, Morgantown. 
Von Quintus, H. L., Mallela, J., Bonaquist, R. Schwartz, C. W., and Carvelho, R. L. (2012). NCHRP Report 719: Calibration of Rutting Models for Structural and Mix Design. Transportation Research Board, Washington, D.C.

Vukosavljevic, Dragon. (2006). Fatigue Characteristics of Field HMA Surface Mixtures Containing Recycled Asphalt Pavement (RAP). MS thesis. University of Tennessee, Knoxville.

West Virginia Blue Ribbon Commission on Highways. (2015). Investigating in West Virginia's Future: Phase I. West Virginia Department of Transportation, West Virginia.

Witczak, M., Mamlouk, M., Souliman, M., and Zeiada, W. (2013). NCHRP Report 9-44A: Validating an Endurance Limit for HMA Pavements: Laboratory Experiment and Algorithm Development. Transportation Research Board, Washington, D.C.

Yan, Y. (2012). Hot Mix Asphalt Concrete Density, Bulk Specific Gravity, and Permeability. Ph. D. dissertation. West Virginia University, Morgantown.

Zhang, J. (2012). Development of Failure Criteria for Asphalt Concrete Mixtures under Fatigue Loading. MS thesis. North Carolina State University, Raleigh. 


\section{List of Test Methods Used}

AASHTO PP 60: Preparation of Cylindrical Performance Test Specimens Using the Superpave Gyratory Compactor. Washington, DC: American Association of State Highway and Transportation Officials, 2015.

AASHTO PP 61: Developing Dynamic Modulus Master Curves using AMPT. Washington, DC: American Association of State Highway and Transportation Officials, 2015.

AASHTO TP 107: Determining the Damage Characteristics Curve of Asphalt Mixtures from Direct Tension Cyclic Fatigue Tests. Washington, DC: American Association of State Highway and Transportation Officials, 2015.

AASHTO T 166: Bulk Specific Gravity of Compacted Hot Mix Asphalt (HMA) Using Saturated Surface-Dry Specimens. Washington, DC: American Association of State Highway and Transportation Officials, 2015.

AASHTO T 209: Theoretical Maximum Specific Gravity $\left(G_{m m}\right)$ and Density of Hot Mix Asphalt (HMA). Washington, DC: American Association of State Highway and Transportation Officials, 2015.

AASHTO T 245: Resistance to Plastic Flow of Asphalt Mixtures Using Marshall Apparatus. Washington, DC: American Association of State Highway and Transportation Officials, 2015.

AASHTO T 269: Percent of Air Voids in Compacted Dense and Open Asphalt Mixtures. Washington, DC: American Association of State Highway and Transportation Officials, 2015.

AASHTO T 312: Preparing and Determining the Density of Hot Mix Asphalt (HMA) by Means of the Superpave Gyratory Compactor. Washington, DC: American Association of State Highway Transportation Officials, 2015. 
AASHTO T 331: Bulk Specific Gravity and Density of Compacted Hot Mix Asphalt (HMA) Using Automatic Vacuum Sealing Method. Washington, DC: American Association of State Highway and Transportation Officials, 2015.

AASHTO T 342: Determining Dynamic Modulus of Hot Mix Asphalt. Washington, DC:

American Association of State Highway and Transportation Officials, 2015.

ASTM D6929: Standard Practice for Preparation of Bituminous Specimens Using Marshall Apparatus. ASTM International, West Conshohocken, PA, 2010. 


\section{Appendix A: Mix Design}

\section{Job Mix Formulas}

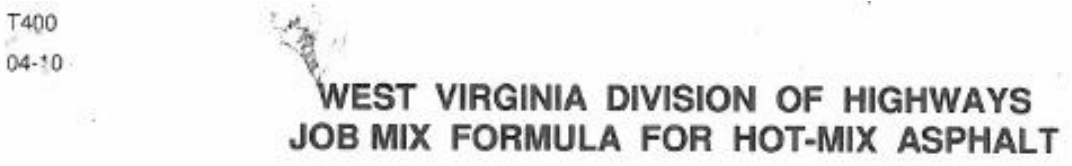

\begin{tabular}{|c|c|c|c|c|c|c|c|c|c|c|}
\hline \multicolumn{2}{|c|}{ Report Number: } & \multicolumn{3}{|c|}{1432937} & \multicolumn{3}{|c|}{ Date Accepted: } & \multicolumn{3}{|c|}{ April 23, 2013} \\
\hline \multicolumn{2}{|l|}{ HMA Type: } & \multicolumn{3}{|c|}{ Wearing-1 w/RAP } & \multicolumn{3}{|c|}{ HMA Code: } & \multicolumn{3}{|c|}{13966} \\
\hline \multicolumn{2}{|c|}{ Producer: } & \multicolumn{3}{|c|}{ American Asphalt of WV } & \multicolumn{3}{|c|}{ Plant Location: } & \multicolumn{3}{|c|}{ St. Albans, WV } \\
\hline \multicolumn{2}{|c|}{ Designed By: } & \multicolumn{3}{|c|}{ Bill Cottle } & \multicolumn{3}{|c|}{ Design Lab: } & \multicolumn{3}{|c|}{ American Asphatt of WV, Kenova, WV } \\
\hline \multicolumn{2}{|c|}{ Plant Type: } & \multicolumn{3}{|c|}{ Batch } & \multicolumn{3}{|c|}{ Plant Make: } & \multicolumn{3}{|c|}{ Barber Greene } \\
\hline \multicolumn{2}{|l|}{ Plant Code: } & \multicolumn{3}{|c|}{ A117C } & \multicolumn{3}{|c|}{ Traffic Type: } & \multicolumn{3}{|c|}{ Heavy } \\
\hline \multicolumn{11}{|c|}{ MIX COMPOSITION } \\
\hline Coar: & se Agg & regate So & urce & Code & & Fine & Aggregate & te Source & & Code \\
\hline $\mathrm{CA}_{1}$ & intain $M$ & laterials, Oli & ive Hill, 1 & M378A & $\mathrm{FA}_{1}$ & Mour & ntain Materic & rials, Olive Hill, $\mathrm{K}$ & KY & M378A \\
\hline $\mathrm{CA}_{2}$ & & & & & $\mathrm{FA}_{2}$ & Letart S & Sand \& Gravel & el, Gallipolis Ferry, & WV & E006A \\
\hline $\mathrm{CA}_{3}$ & & & & & $\mathrm{FA}_{3}$ & & & & & \\
\hline & & $\mathrm{CA}_{1}$ & & $\mathrm{CA}_{2}$ & $\mathrm{CA}_{3}$ & & $\mathrm{FA}_{1}$ & $\mathrm{FA}_{2}$ & & $\mathrm{FA}_{3}$ \\
\hline Agg. Type & & \#8 Limestc & one & & & & Limestone & Natural & & \\
\hline Agg. Code & & 1135 & & & & & 1116 & 1115 & & \\
\hline$\%$ Total Ag & & 35 & & & & & 16 & \begin{tabular}{l|l|} 
& 34 \\
\end{tabular} & & \\
\hline$\%$ RAP Tota & agg.: & & 15 & Bler & ended Binc & $\operatorname{der} \mathrm{G}^{*} / \mathrm{s}$ & sin delta if : & f $>25 \%$ RAP: & & \\
\hline$\%$ Binder In & RAP D & esign: & & \begin{tabular}{|l|l|}
.8 & $\mathrm{Bi}$ \\
\end{tabular} & inder Typ & & PG 64-22 & Binder Cod & de: & 1093 \\
\hline Binder Sou & Irce: & & elly Liqu & juid Division, r & Kanauga, & $\mathrm{OH}$ & \begin{tabular}{l|l} 
& Binde \\
\end{tabular} & der SourceCod & de: & M001A \\
\hline & & & Sieve F & Fraction & & & & Voids filled with & & hes to \\
\hline Sieve & & Allow & rable & Sieve & & Allo & wable As & Asphalt (VFA) \% & Asphe & lalt Ratio \\
\hline Size & Targe & Min. & Max. & Size & Target & Min. & Max. & \begin{tabular}{|l|l}
74 \\
\end{tabular} & & 0.9 \\
\hline $2^{\prime \prime}(50 \mathrm{~mm})$ & & & & $\# 4(4.75 \mathrm{~mm})$ & 66 & & 80 & Temperatı & ure Ra & ange \\
\hline $1.5^{\prime \prime}(37.5 \mathrm{~mm})$ & & & & $\# 8(2.36 \mathrm{~mm})$ & 48 & 42 & 54 & Completed & Mixtur & re ( $\left.{ }^{\circ} \mathrm{F}\right)$ \\
\hline $1^{\prime \prime}(25 \mathrm{~mm})$ & & & & $\# 16$ (1.18 mm) & 37 & & & Desirable & Temp & . Range \\
\hline $3 / 4^{\prime \prime}(19 \mathrm{~mm})$ & & & & $\# 30(600 \mu \mathrm{m})$ & 28 & & & Mean Temp. & Min. & Max. \\
\hline $1 / 2^{\prime \prime}(12.5 \mathrm{~mm})$ & 100 & 100 & 100 & $\# 50(300 \mu \mathrm{m})$ & 11 & & & & & \\
\hline $3 / 8^{\prime \prime}(9.5 \mathrm{~mm})$ & 96 & 85 & 100 & $\# 200$ (75 нm) & 5.3 & 2.0 & 9.0 & 300 & 275 & 325 \\
\hline & & & & JOB MIX FC & ORMULA & VALU & JES & & & \\
\hline a & & & & \begin{tabular}{l|l|} 
& Job \\
\end{tabular} & Mix Form & nula & Plant I & Mix Formula & Toler & rances \\
\hline Specific gravit & ty stone & Design & Propert & & sign Targ & ets & Minim & \begin{tabular}{|l|l|} 
mum & \\
\end{tabular} & Maxim & num \\
\hline bulk (Gsb): & 2.610 & Aspha & alt (\%) & & 5.6 & & & 2 & 6.0 & \\
\hline Maximu & & Air Voi & ids (\%) & & 4.0 & & & .5 & 5.5 & \\
\hline Density (k & $\left.\mathrm{g} / \mathrm{m}^{3}\right)$ & VMA & $(\%)$ & & 15.5 & & & 4.5 & 16.5 & \\
\hline & & Stabil & ity $(\mathrm{N})$ & & 10737 & & & 000 & NA & \\
\hline 2447 & & Flow (0 & $.25 \mathrm{~mm}$ ) & & 11 & & & 8 & 14 & \\
\hline Desirable Mean T & Temperatu & Ire for Laborato & ry Specim & nens ( $F$ ): & Compaction $T$ & Temperatu & 288 & Milixing Tempe & erature: & 315 \\
\hline Remarks: & & & & & & & & & & \\
\hline
\end{tabular}

Figure 40: Job Mix Formula for AA937 
WEST VIRGINIA DIVISION OF HIGHWAYS JOB MIX FORMULA FOR HOT-MIX ASPHALT

\begin{tabular}{|lc|lc|}
\hline Report Number: & 1360465 & Date Accepted: & March 9, 2004 \\
\hline HMA Type: & Wearing-1 & HMA Code: & 13966 \\
\hline Producer: & Greer Asphalt & Plant Location: & Greer, WV \\
\hline Designed By: & Rich Nuzum & Design Lab: & Clarksburg Asphalt \\
\hline Plant Type: & Batch & Plant Make: & McCarter \\
\hline Plant Code: & G012A & Traffic Type: & Heavy \\
\hline
\end{tabular}

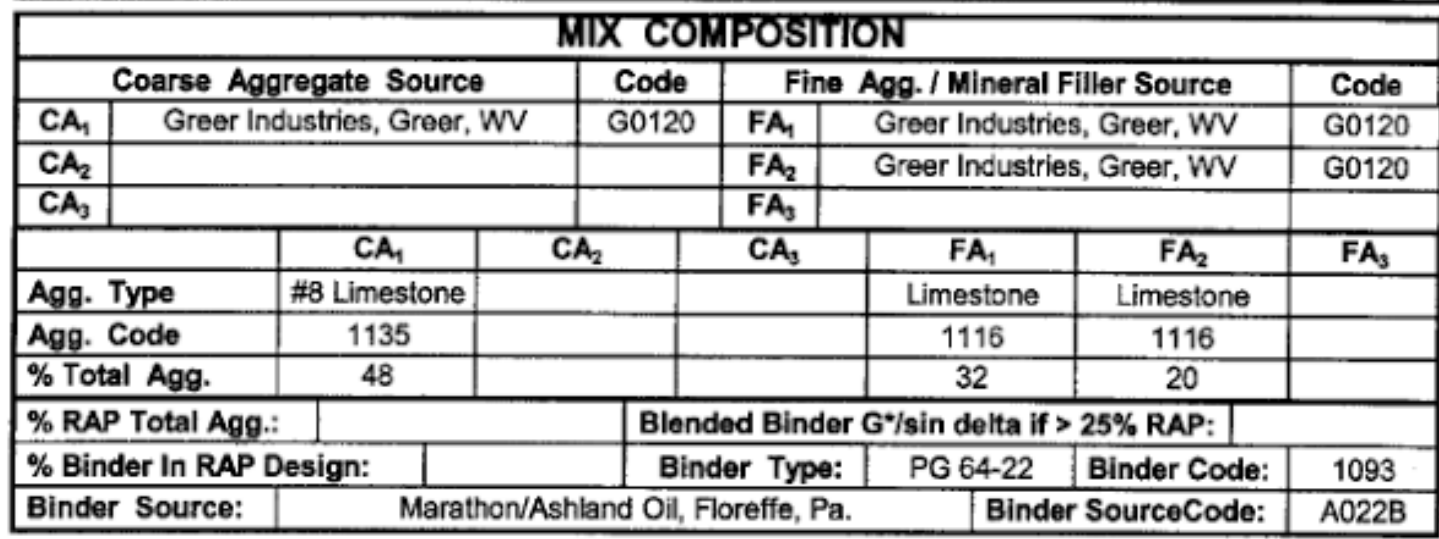

\begin{tabular}{|c|c|c|c|c|c|c|c|c|c|c|}
\hline \multicolumn{8}{|c|}{ Sieve Fraction } & \multirow{3}{*}{\begin{tabular}{|c|}
$\begin{array}{c}\text { Voids filled with } \\
\text { Asphalt"VFA"(\$) }\end{array}$ \\
75 \\
\end{tabular}} & \multirow{3}{*}{\multicolumn{2}{|c|}{$\begin{array}{c}\begin{array}{c}\text { Fines to } \\
\text { Asphalt Ratio }\end{array} \\
0.8 \\
\end{array}$}} \\
\hline \multirow{2}{*}{$\begin{array}{l}\text { Sieve } \\
\text { Size }\end{array}$} & \multirow[b]{2}{*}{ Target } & \multicolumn{2}{|c|}{ Allowable } & \multirow{2}{*}{\begin{tabular}{|l|} 
Sieve \\
Size \\
\end{tabular}} & \multirow[b]{2}{*}{ Target } & \multicolumn{2}{|c|}{ Allowable } & & & \\
\hline & & Min. & Max. & & & Min. & Max. & & & \\
\hline $2 "(50 \mathrm{~mm})$ & & & & $\# 4(4.75 \mathrm{~mm})$ & 60 & & 80 & \multirow{2}{*}{\multicolumn{3}{|c|}{$\begin{array}{l}\text { Temperature Range } \\
\text { Completed Mixture }\left({ }^{\circ} \mathrm{F}\right)\end{array}$}} \\
\hline $1.5^{\prime \prime}(37.5 \mathrm{~mm})$ & & & & $\# 8(2.36 \mathrm{~mm})$ & 39 & 33 & 45 & & & \\
\hline $1^{\prime \prime}(25 \mathrm{~mm})$ & & & & \#16(1.18 mm) & 23 & & & \multirow{2}{*}{\begin{tabular}{c|c} 
Desirable \\
Mean Temp.
\end{tabular}} & \multicolumn{2}{|c|}{ Temp. Range } \\
\hline $3 / 4^{*}(19 \mathrm{~mm})$ & & & & $\# 30(600 \mu \mathrm{m})$ & 12 & & & & Min. & Max. \\
\hline $1 / 2^{\prime \prime}(12.5 \mathrm{~mm})$ & 100 & 100 & 100 & $\# 50(300 \mu \mathrm{m})$ & 7 & & & & & \\
\hline $3 / 8^{\prime \prime}(9.5 \mathrm{~mm})$ & 95 & 85 & 100 & $\# 200(75 \mu \mathrm{m})$ & 4.4 & 2.0 & 9.0 & 295 & 270 & 320 \\
\hline
\end{tabular}

\begin{tabular}{|c|c|c|c|c|}
\hline \multicolumn{5}{|c|}{ JOB MIX FORMULA VALUES } \\
\hline \multicolumn{3}{|c|}{ Job Mix Formula Targets } & \multicolumn{2}{|c|}{ Job Mix Formula Tolerances } \\
\hline Specific gravity stone & Design Property & Accepted Target & Minimum & Maximum \\
\hline bulk (Gsb): $\quad 2.662$ & Asphalt (\%) & 5.7 & 5.3 & 6.1 \\
\hline \multirow{2}{*}{$\begin{array}{c}\text { Maximum } \\
\text { Density }\left(\mathrm{kg} / \mathrm{m}^{3}\right)\end{array}$} & Air Voids (\%) & 4.0 & 2.5 & 5.5 \\
\hline & VMA (\%) & 15.7 & 14.7 & 16.7 \\
\hline \multirow[b]{2}{*}{2476} & Stability $(\mathrm{N})$ & 10400 & 8000 & NA \\
\hline & Flow $(0.25 \mathrm{~mm})$ & 11 & 8 & 14 \\
\hline
\end{tabular}

Remarks:

Figure 41: Job Mix Formula for GR465 


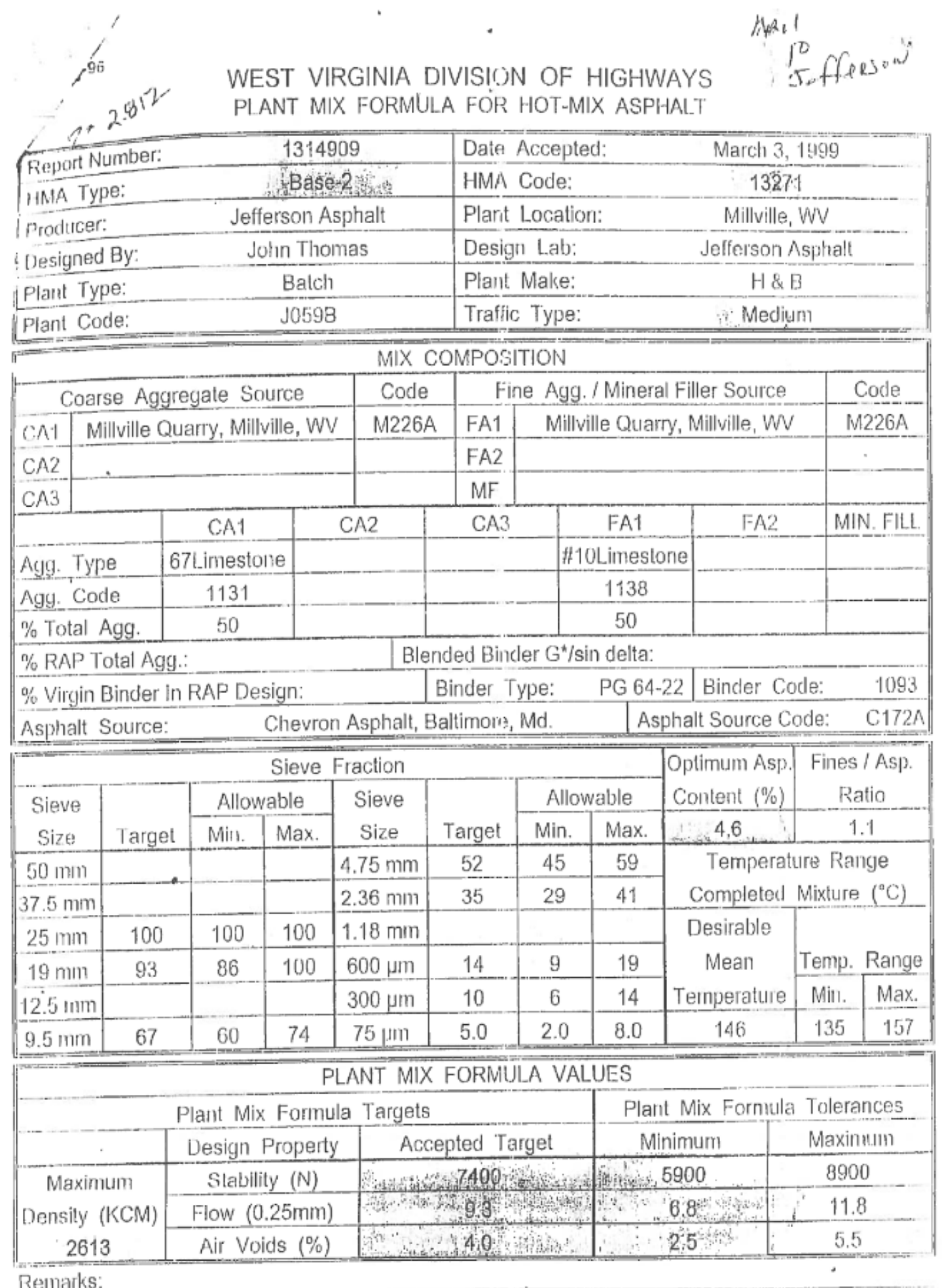

Figure 42: Job Mix Formula for JAP909 
$T 400$

04-10

\section{WEST VIRGINIA DIVISION OF HIGHWAYS JOB MIX FORMULA FOR HOT-MIX ASPHALT}

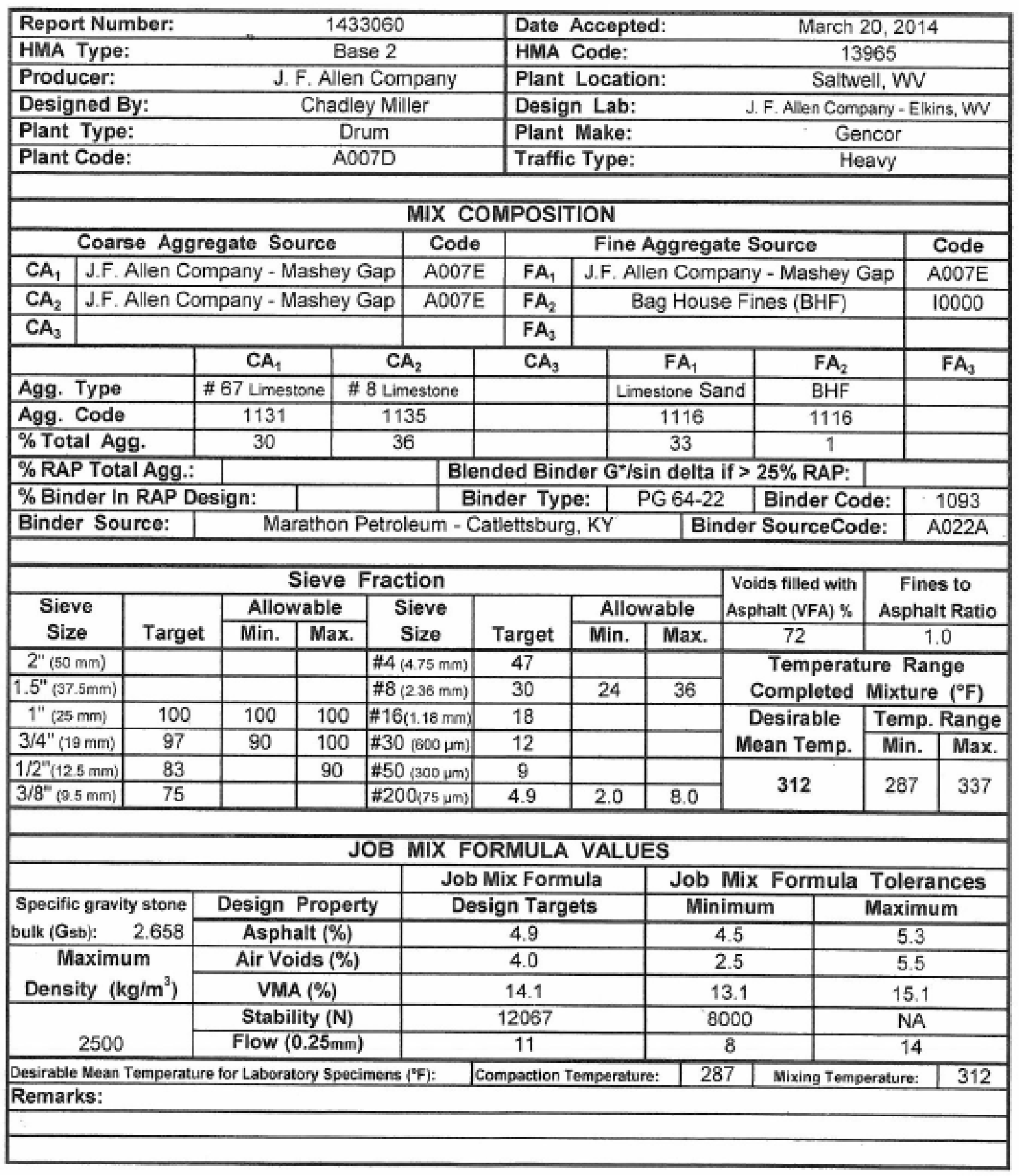

Figure 43: Job Mix Formula for JFA060 


\section{WEST VIRGINIA DIVISION OF HIGHWAYS JOB MIX FORMULA FOR HOT-MIX ASPHALT}

\begin{tabular}{|lc|lc|}
\hline Report Number: & \multicolumn{1}{c|}{1361115} & Date Accepted: & June 30,2004 \\
\hline HMA Type: & Wearing-1 & HMA Code: & 13273 \\
\hline Producer: & J.F. Allen Co. & Plant Location: & Saltwell, WV \\
\hline Designed By: & Tarra Sponaugle & Design Lab: & J.F. Allen \\
\hline Plant Type: & Drum & Plant Make: & Gencor \\
\hline Plant Code: & A007D & Traffic Type: & Medium \\
\hline
\end{tabular}

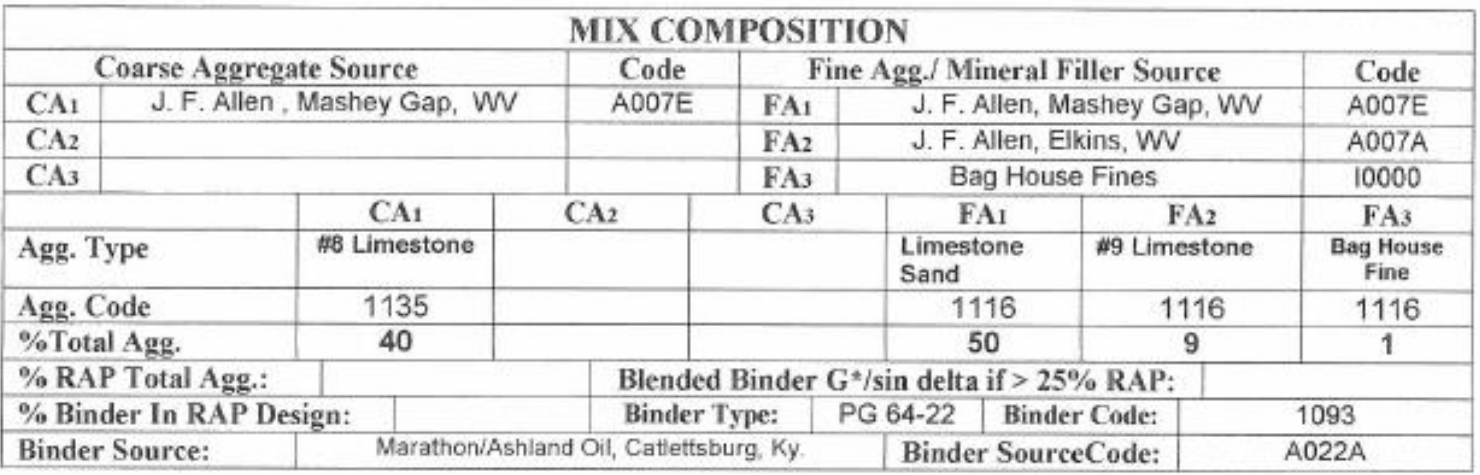

\begin{tabular}{|c|c|c|c|c|c|c|c|c|c|c|}
\hline \multicolumn{8}{|c|}{ SIEVE FRACTION } & \multirow{3}{*}{$\begin{array}{c}\begin{array}{c}\text { Voids filled with } \\
\text { Asphalt "VFA" (\%) }\end{array} \\
76\end{array}$} & \multirow{3}{*}{\multicolumn{2}{|c|}{$\begin{array}{c}\begin{array}{c}\text { Fines to } \\
\text { Asphalt Ratio }\end{array} \\
0.8\end{array}$}} \\
\hline \multirow{2}{*}{$\begin{array}{c}\text { Sieve } \\
\text { Size }\end{array}$} & \multirow[b]{2}{*}{ Target } & \multicolumn{2}{|c|}{ Allowable } & \multirow{2}{*}{$\begin{array}{l}\text { Sieve } \\
\text { Size }\end{array}$} & \multirow[b]{2}{*}{ Target } & \multicolumn{2}{|c|}{ Allowable } & & & \\
\hline & & Min & Max & & & Min & Max & & & \\
\hline $2^{\prime \prime}$ (sinnew) & & & & \#4 (4.25 mas) & 66 & & 80 & \multirow{2}{*}{\multicolumn{3}{|c|}{$\begin{array}{c}\text { Temperature Range } \\
\text { Completed Mixture }\left({ }^{\circ} \mathbf{F}\right)\end{array}$}} \\
\hline $1.5^{*}$ (37.5nam) & & & & $\# 8025 \mathrm{~mm}$ & 44 & 38 & 50 & & & \\
\hline 1" (25numa) & & & & $\$ 16$ (1.15 mise & 28 & & & \multirow{2}{*}{$\begin{array}{l}\text { Desirable } \\
\text { Mean Temp. }\end{array}$} & \multicolumn{2}{|c|}{ Temp. Range } \\
\hline $3 / 4^{\prime \prime}(19 \operatorname{man})$ & & & & $\# 30$ (ตAs unis) & 19 & & & & Min. & Max. \\
\hline $1 / 2^{\prime \prime}$ (12.5nem) & 100 & 100 & 100 & $\# 50$ (9no uni) & 13 & & & & & \\
\hline $3 / 8^{\prime \prime}$ (9.smis) & 98 & 85 & 100 & $\# 200$ (75 ume & 4.9 & 2.0 & 9.0 & 310 & 285 & 335 \\
\hline
\end{tabular}

\begin{tabular}{|c|c|c|c|c|}
\hline \multicolumn{5}{|c|}{ JOB MIX FORMULA VALUES } \\
\hline \multicolumn{4}{|c|}{ Job Mix Formula Targets } & \multicolumn{2}{c|}{ Job Mix Formula Tolerances } \\
\hline \multirow{2}{*}{$\begin{array}{c}\text { Speeific gravity bulk stone } \\
\text { (Gsb): } 2.629\end{array}$} & Design Property & Accepted Target & Minimum & Maximum \\
\cline { 2 - 5 } & Asphalt (\%) & 5.8 & 5.4 & 6.2 \\
\hline \multirow{2}{*}{$\begin{array}{c}\text { Maximum } \\
\text { Density (kg/m3) }\end{array}$} & Air Voids (\%) & 4.0 & 2.5 & 5.5 \\
\cline { 2 - 5 } & VMA (\%) & 15.5 & 14.5 & NA \\
\cline { 2 - 5 } 2459 & Stability (N) & 13,350 & 5,300 & 14.0 \\
\cline { 2 - 5 }
\end{tabular}

Gsb : 2.639/ 2015

Max Density : 2470

$/ 2015$

Oven Calibration : - 0.39/2009

Figure 44: Job Mix Formula for JFA115 


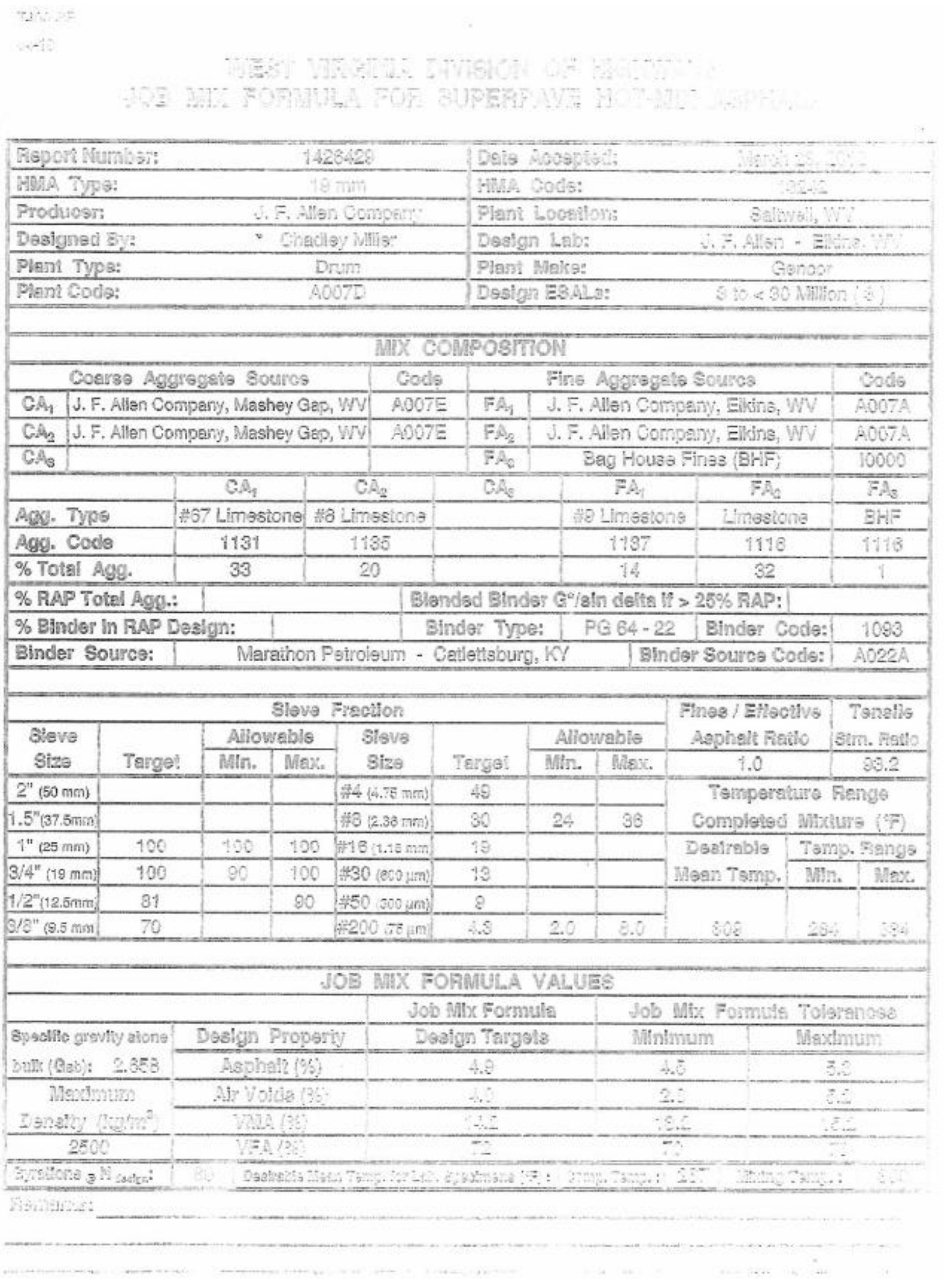

Figure 45: Job Mix Formula for JFA429 

JOB MIX FORMULA FOR HOT-MIX ASPHALT

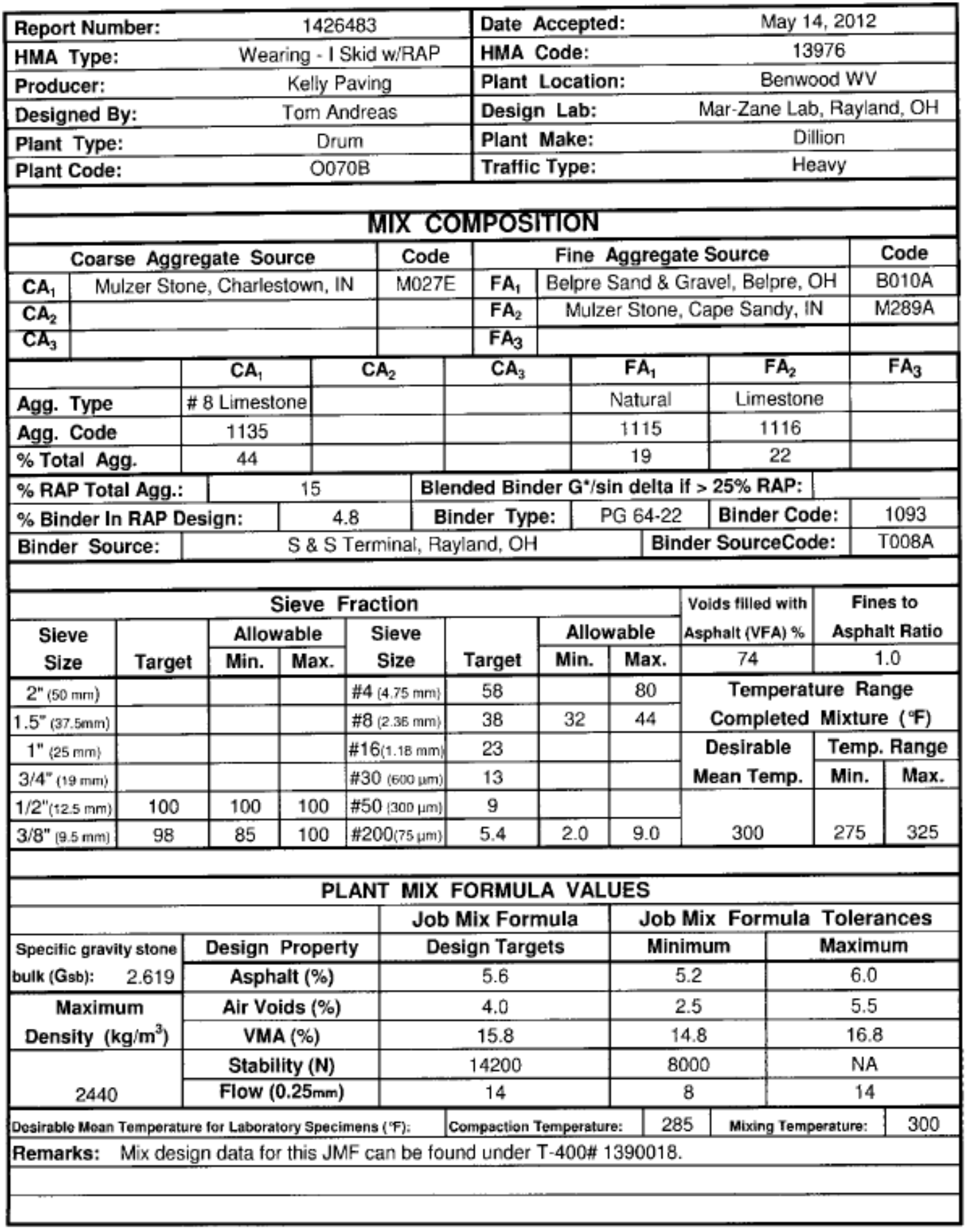

Figure 46: Job Mix Formula for KP483 


\section{WEST VIRGINIA DIVISION OF HIGHWAYS JOB MIX FORMULA FOR HOT-MIX ASPHALT}

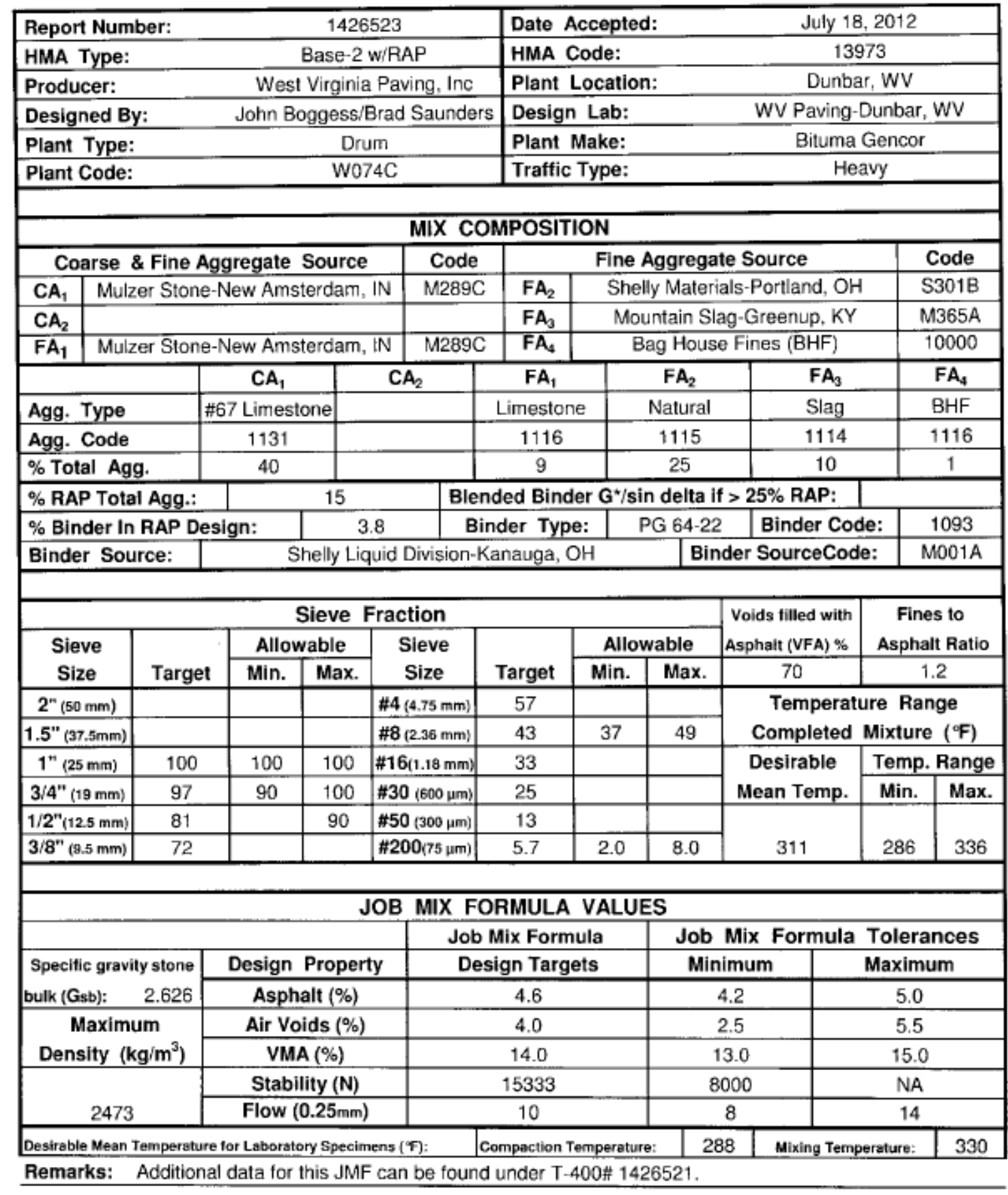

Figure 47: Job Mix Formula for WVP523 
04-10

\section{WEST VIRGINIA DIVISION OF HIGHWAYS} JOB MIX FORMULA FOR HOT-MIX ASPHALT

\begin{tabular}{|c|c|c|c|c|c|c|c|c|c|c|c|c|}
\hline \multicolumn{2}{|c|}{ Report Number: } & \multicolumn{4}{|c|}{1436766} & \multicolumn{3}{|c|}{ Date Accepted: } & \multicolumn{4}{|c|}{ March 9, 2015} \\
\hline \multicolumn{2}{|c|}{ HMA Type: } & \multicolumn{4}{|c|}{ Wearing 1-RAP } & \multicolumn{3}{|c|}{ HMA Code: } & \multicolumn{4}{|c|}{13974} \\
\hline Producer: & & \multicolumn{4}{|c|}{ Camden Materials } & \multicolumn{3}{|c|}{ Plant Location: } & \multicolumn{4}{|c|}{ Parkersburg, WV } \\
\hline Designed B & & \multicolumn{4}{|c|}{ Brad Saunders/ Jason Frame } & \multicolumn{3}{|c|}{ Design Lab: } & \multicolumn{4}{|c|}{ WV Paving-Dunbar, WV } \\
\hline \multicolumn{2}{|c|}{ Plant Type: } & \multicolumn{4}{|c|}{ Drum } & \multicolumn{3}{|c|}{ Plant Make: } & \multicolumn{4}{|c|}{ ASTEC } \\
\hline \multicolumn{2}{|l|}{ Plant Code: } & \multicolumn{4}{|c|}{$\mathrm{B} 104 \mathrm{H}$} & \multicolumn{3}{|c|}{ Traffic Type: } & \multicolumn{4}{|c|}{ Heavy } \\
\hline \multicolumn{13}{|c|}{ MIX COMPOSITION } \\
\hline Coar: & se AggI & regate Sou & urce & & Code & & Fine & Aggrega & ate So & ource & & Code \\
\hline $\mathrm{CA}_{1}$ & armeuse & Lime-Mays & sville, KY & & D113A & $\mathrm{FA}_{2}$ & Belpre & e S \& G-L & -Little & Hocking, O & & $\mathrm{B} 010 \mathrm{~A}$ \\
\hline $\mathrm{CA}_{2}$ & & & & & & $\mathrm{FA}_{3}$ & Mou & untain Sla & lag-Gr & ireenup, KY & & M365A \\
\hline $\mathrm{FA}_{1}$ & armeuse & Lime-Mays & sville, KY & & $\mathrm{D} 113 \mathrm{~A}$ & $\mathrm{FA}_{4}$ & & Bag Ho & touse I & Fines & & 10000 \\
\hline & & $\mathrm{CA}_{1}$ & & $\mathrm{C}$ & \begin{tabular}{|l|l}
$\mathrm{A}_{2}$ & \\
\end{tabular} & $\mathrm{FA}_{1}$ & & $\mathrm{FA}_{2}$ & & $\mathrm{FA}_{3}$ & & $\mathrm{FA}_{4}$ \\
\hline Agg. Type & & $\# 8$ Limestor & one & & & Limestor & & Natural & & Slag & & BHF \\
\hline Agg. Code & & 1135 & & & & 1116 & & 1115 & & 1114 & & 1116 \\
\hline$\%$ Total $\mathrm{Ag}$ & & 40 & & & & 9 & & 25 & & 10 & & 1 \\
\hline$\%$ RAP Tota & Agg.: & & 15 & & Bler & nded Binc & ler G*/si & n delta if & if $>25$ & 5\% RAP: & & \\
\hline$\%$ Binder In & RAP De & esign: & & 2 & & inder Typ & & PG 64-22 & & Binder Cod & & 1093 \\
\hline Binder Sou & rce: & & helly Liq & quid t & Division-K & Kanauga, & $\mathrm{DH}$ & \begin{tabular}{l|l} 
& Bin \\
\end{tabular} & nder S & SourceCode & & M001A \\
\hline & & & Sieve $\mathbf{F}$ & Frac & tion & & & & Void: & ds filled with & Fine & es to \\
\hline Sieve & & Allow & vable & & ieve & & Allon & wable & Asph: & halt (VFA) \% & Asphat & It Ratio \\
\hline Size & Targe & Min. & Max. & & Size & Target & Min. & Max. & & \begin{tabular}{l|l}
73 \\
\end{tabular} & & 0.8 \\
\hline 2" $(50 \mathrm{~mm})$ & & & & $\# 4$ ( & $4.75 \mathrm{~mm})$ & 62 & & 80 & & Temperatu & Ire Ran & nge \\
\hline $1.5^{\prime \prime}(37.5 \mathrm{~mm})$ & & & & $\# 8$ & $2.36 \mathrm{~mm})$ & 41 & 35 & 47 & & Completed & Mixture & $\left({ }^{\circ} \mathrm{F}\right)$ \\
\hline $1 "(25 \mathrm{~mm})$ & & & & $\# 16$ & $(1.18 \mathrm{~mm})$ & 30 & & & & esirable & Temp. & Range \\
\hline $3 / 4^{\prime \prime}(19 \mathrm{~mm})$ & & & & $\# 30$ & $(600 \mu \mathrm{m})$ & 22 & & & & ean Temp. & Min. & Max. \\
\hline $1 / 2^{\prime \prime}(12.5 \mathrm{~mm})$ & 100 & 100 & 100 & $\# 50$ & $(300 \mu \mathrm{m})$ & 11 & & & & & & \\
\hline $3 / 8 "(9.5 \mathrm{~mm})$ & 95 & 85 & 100 & $\# 20$ & $0(75 \mu \mathrm{m})$ & 4.8 & 2.0 & 9.0 & & 311 & 286 & 336 \\
\hline & & & & OB & MIX FC & ORMULA & VALUE & & & & & \\
\hline & & & & & Job & Mix Form & Iula & Job & Mix & Formula & Tolera & ances \\
\hline Specific gravit & ty stone & Design & Propert & & Des & sign Targ & ets & Mini & nimum & & Maximu & um \\
\hline bulk (Gsb): & 2.643 & Aspha & alt (\%) & & & 5.9 & & & 5.5 & & 6.3 & \\
\hline Maximu & & Air Voi & ids (\%) & & & 4.0 & & & 2.5 & & 5.5 & \\
\hline Density ( $k$ & $\left.g / m^{3}\right)$ & VMA & $A(\%)$ & & & 15.5 & & & 14.5 & & 16.5 & \\
\hline & & Stabili & lity $(\mathrm{N})$ & & & 12199 & & & 8000 & & NA & \\
\hline 2476 & & Flow 10 & $0.25 \mathrm{~mm})$ & & & 10.0 & & & 8 & & 14 & \\
\hline Desirable Mean T & Temperatur & re for Laborator & ry Specim & hens $f^{\circ}$ & & Compaction 1 & emperature & & 88 & Mixing Tempe & erature: & 312 \\
\hline Remarks: & & & & & & & & & & & & \\
\hline
\end{tabular}

Figure 48: Job Mix Formula for WVP766 
WV DOH MCS\&T Approval

T400

Reviewed by: D. Phippa $/$ r. Wobeck

04-10

Approved by:

WEST VIRGINIA DIVISION OF HIGHWAYS Date: Nu21,2015 JOB MIX FORMULA FOR HOT-MIX ASPHALT

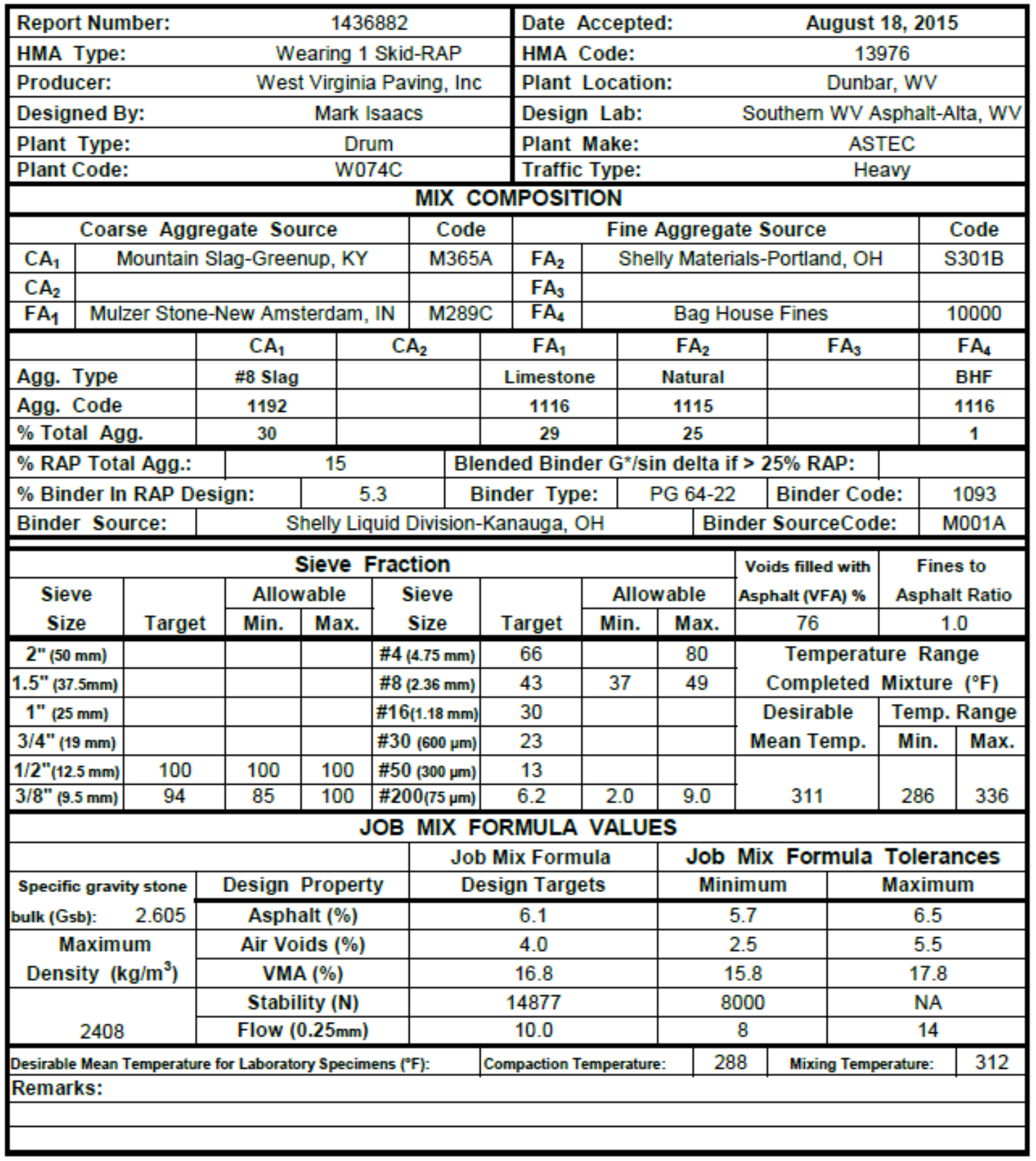

Figure 49: Job Mix Formula for WVP882 


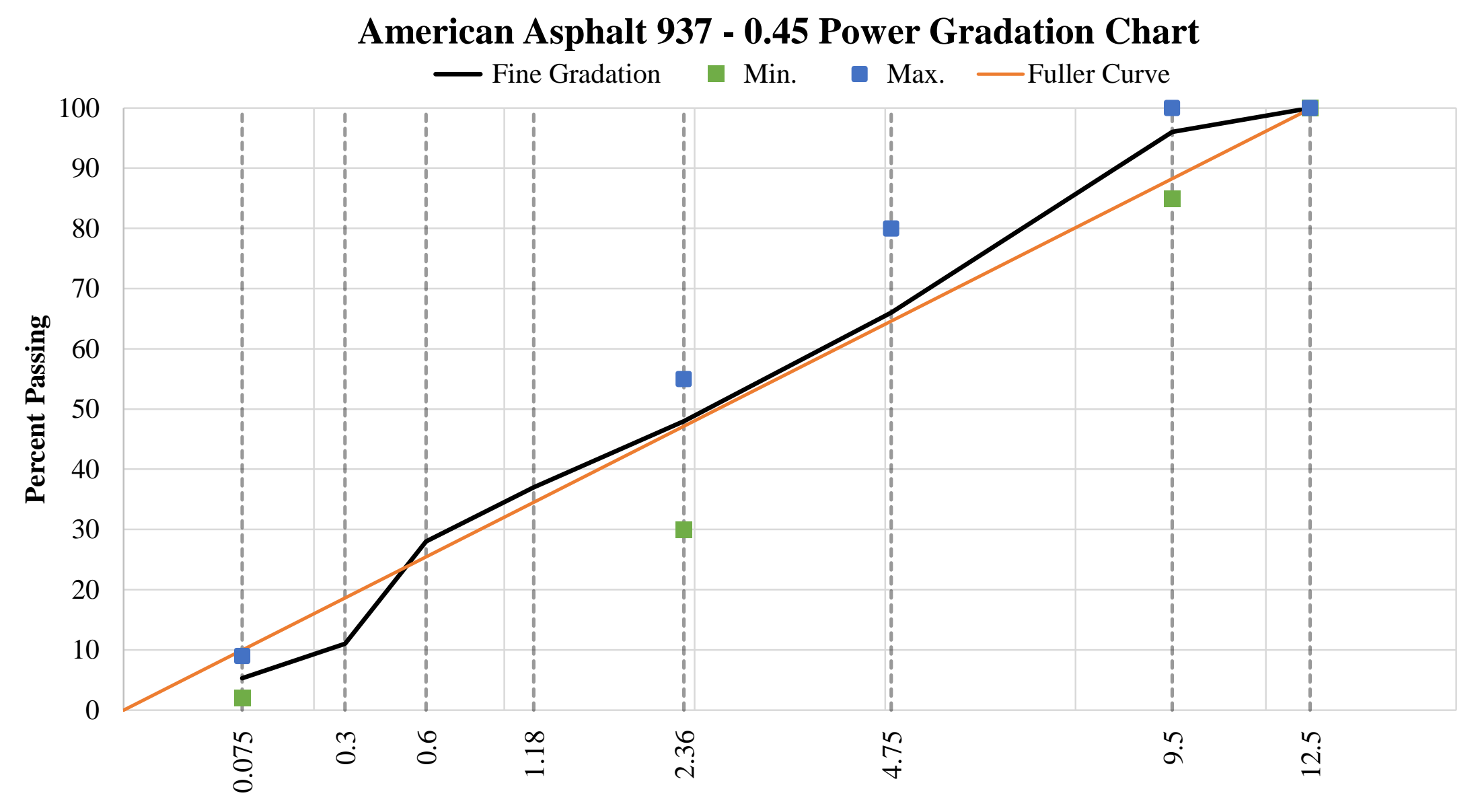

Sieve Size (mm)

Figure 50: AA937 Gradation Chart 


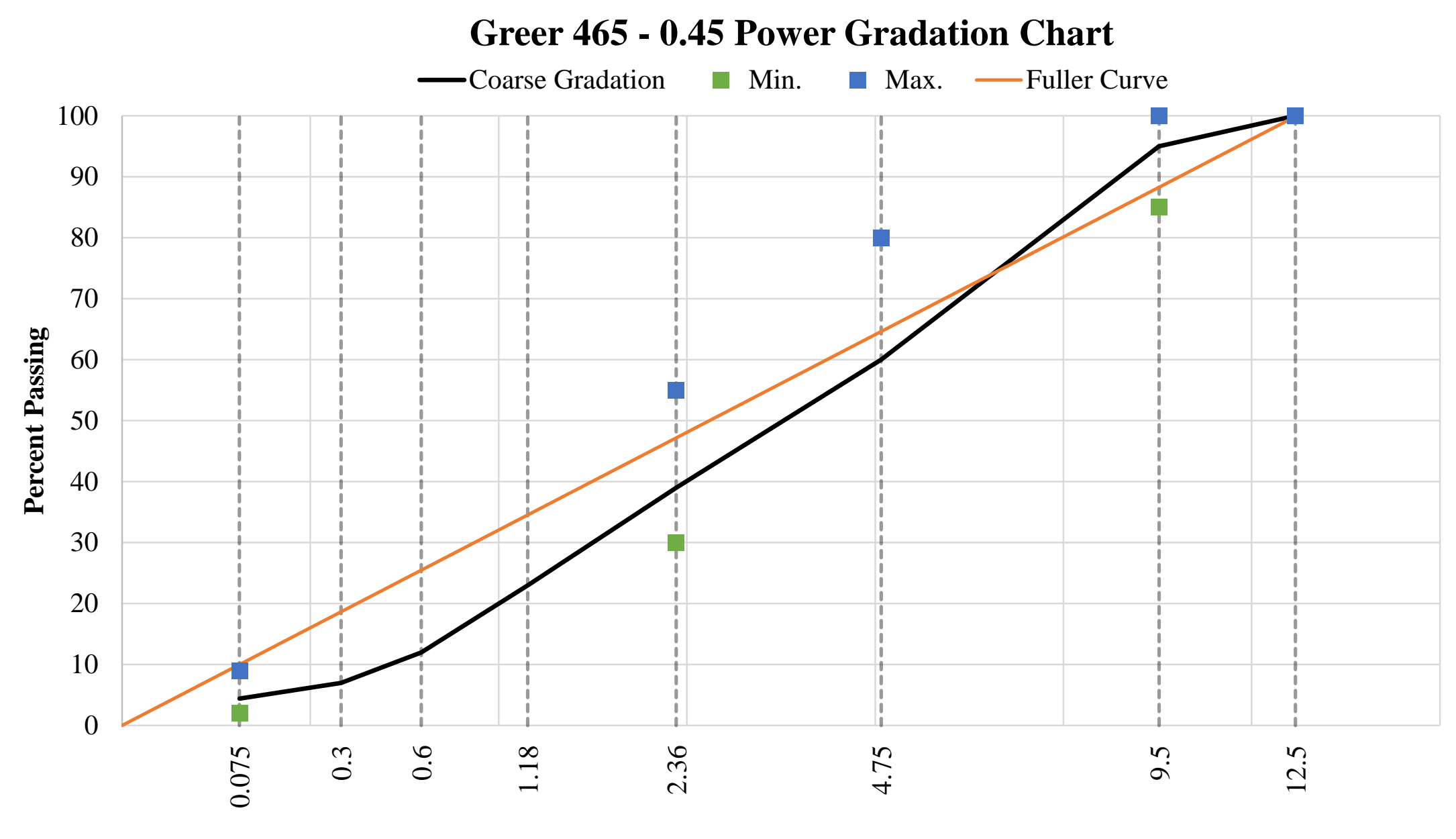

Sieve Size (mm)

Figure 51: GR465 Gradation Chart 


\section{Jefferson Asphalt Paving 909 - 0.45 Power Gradation Chart}

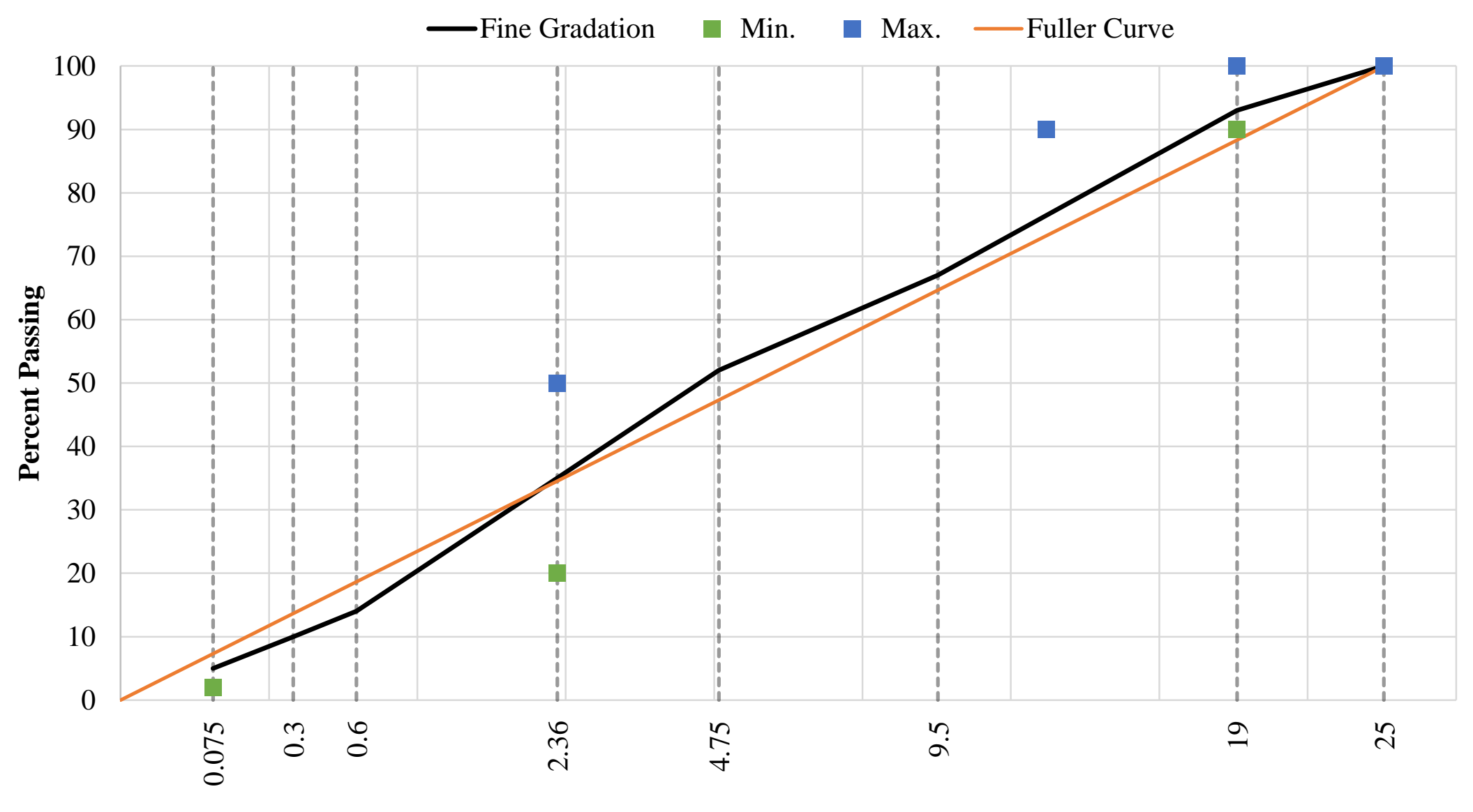

Sieve Size (mm)

Figure 52: JAP909 Gradation Chart 


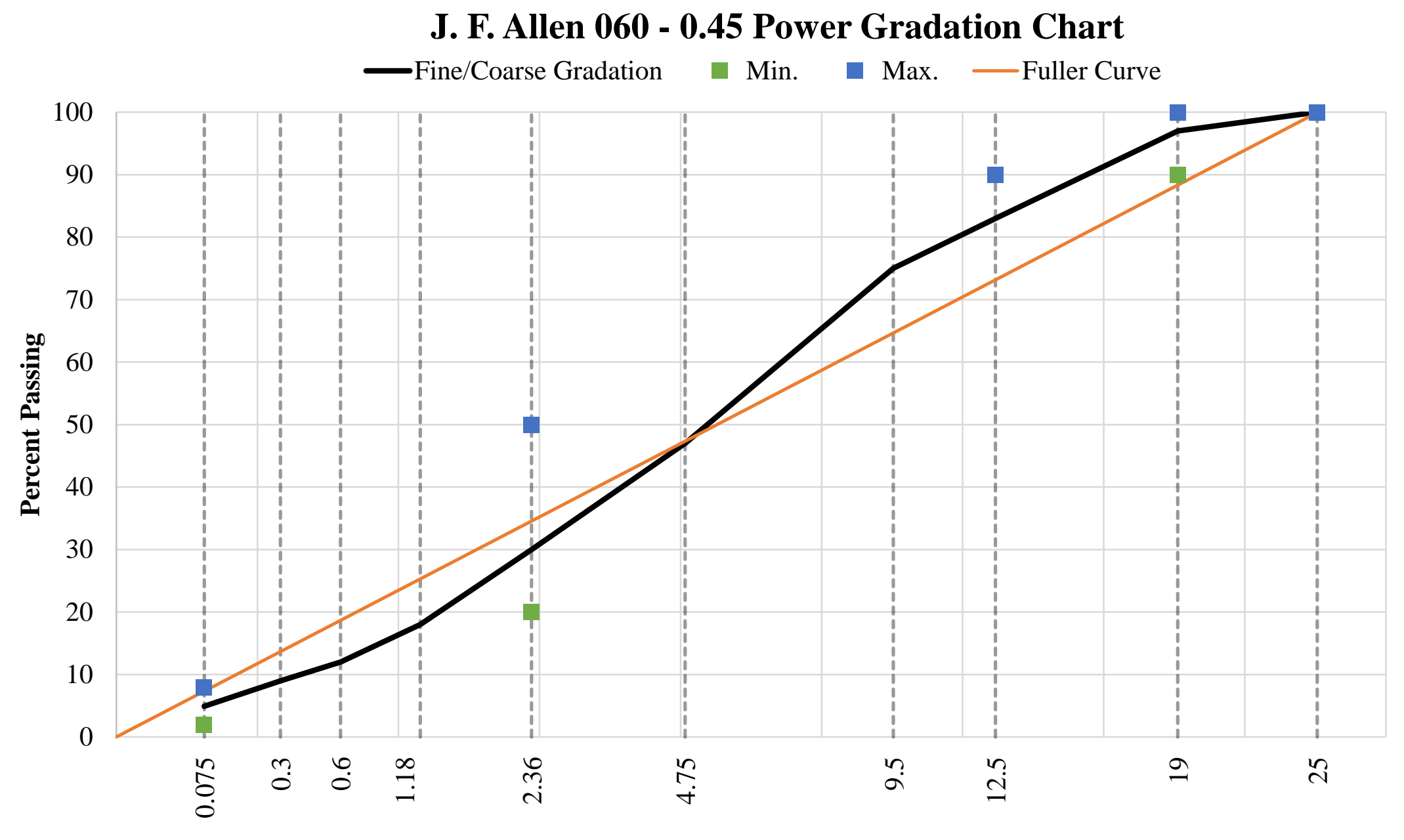

Sieve Size (mm)

Figure 53: JFA060 Gradation Chart 


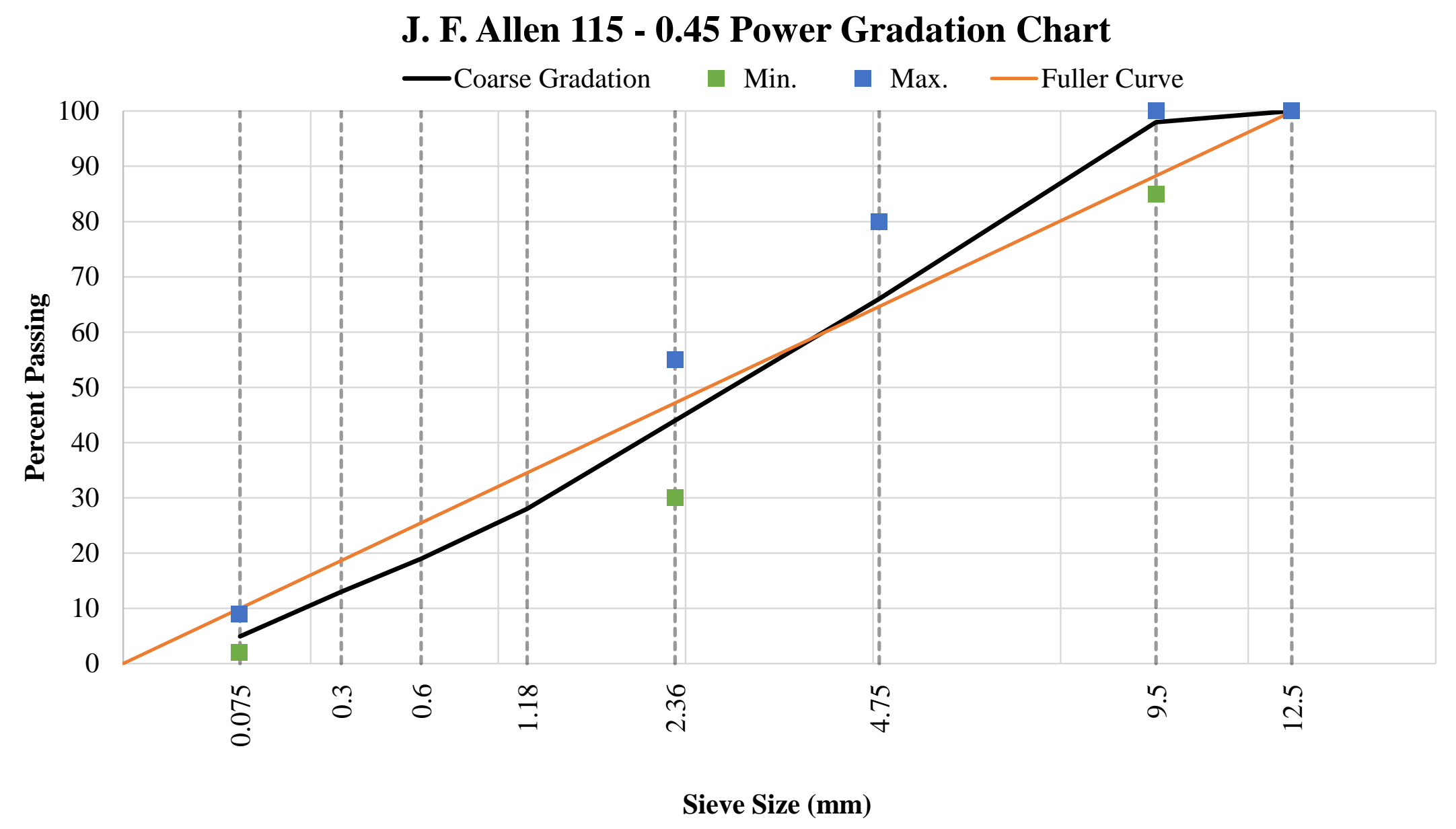

Figure 54: JFA115 Gradation Chart 


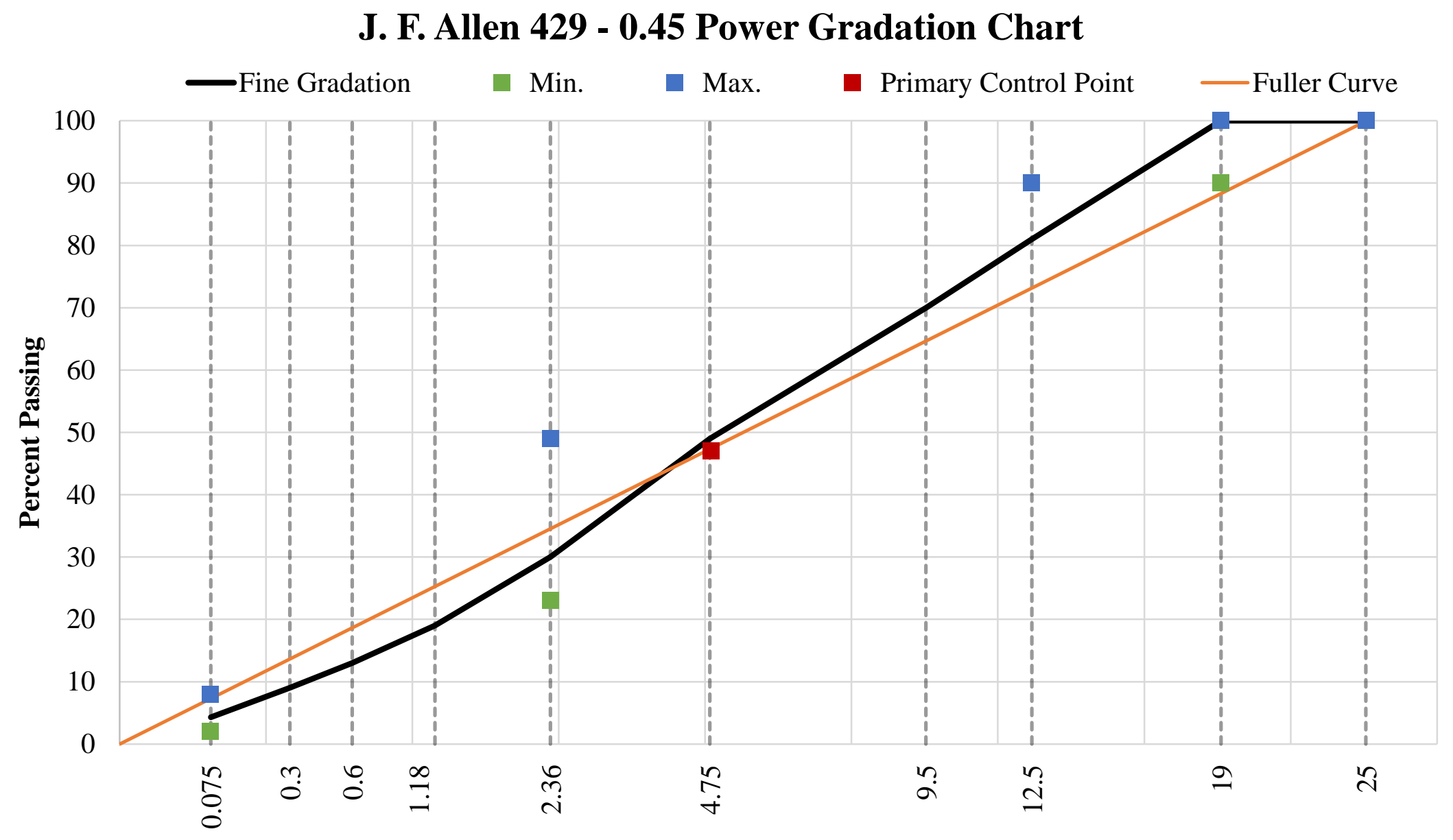

Sieve Size (mm)

Figure 55: JFA429 Gradation Chart 


\section{Kelly Paving 483 - 0.45 Power Gradation Chart}

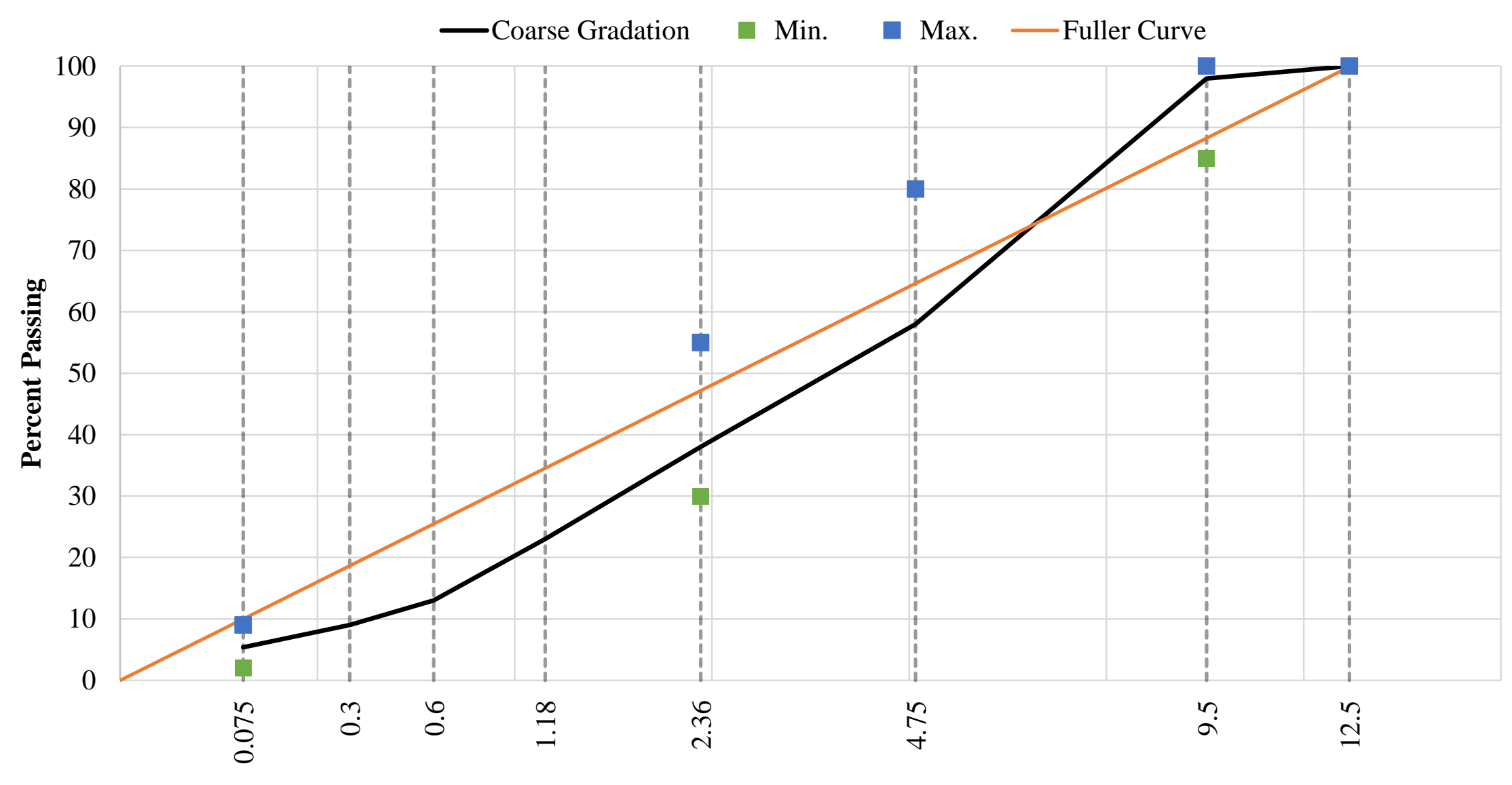

Sieve Size (mm)

Figure 56: KP483 Gradation Chart 


\section{West Virginia Paving 523 - 0.45 Power Gradation Chart}

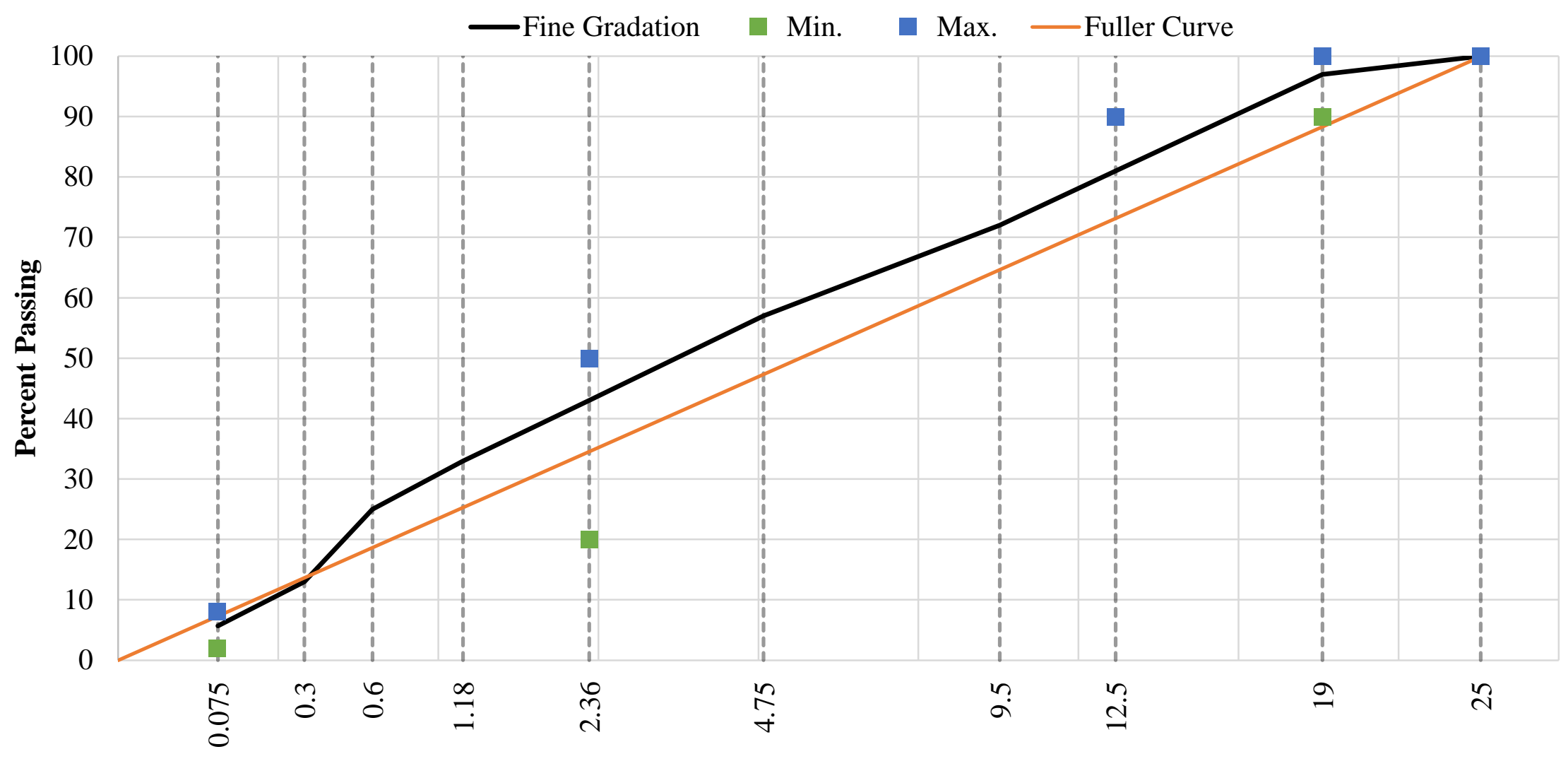

Sieve Size (mm)

Figure 57: WVP523 Gradation Chart 
West Virginia Paving 766 - 0.45 Power Gradation Chart

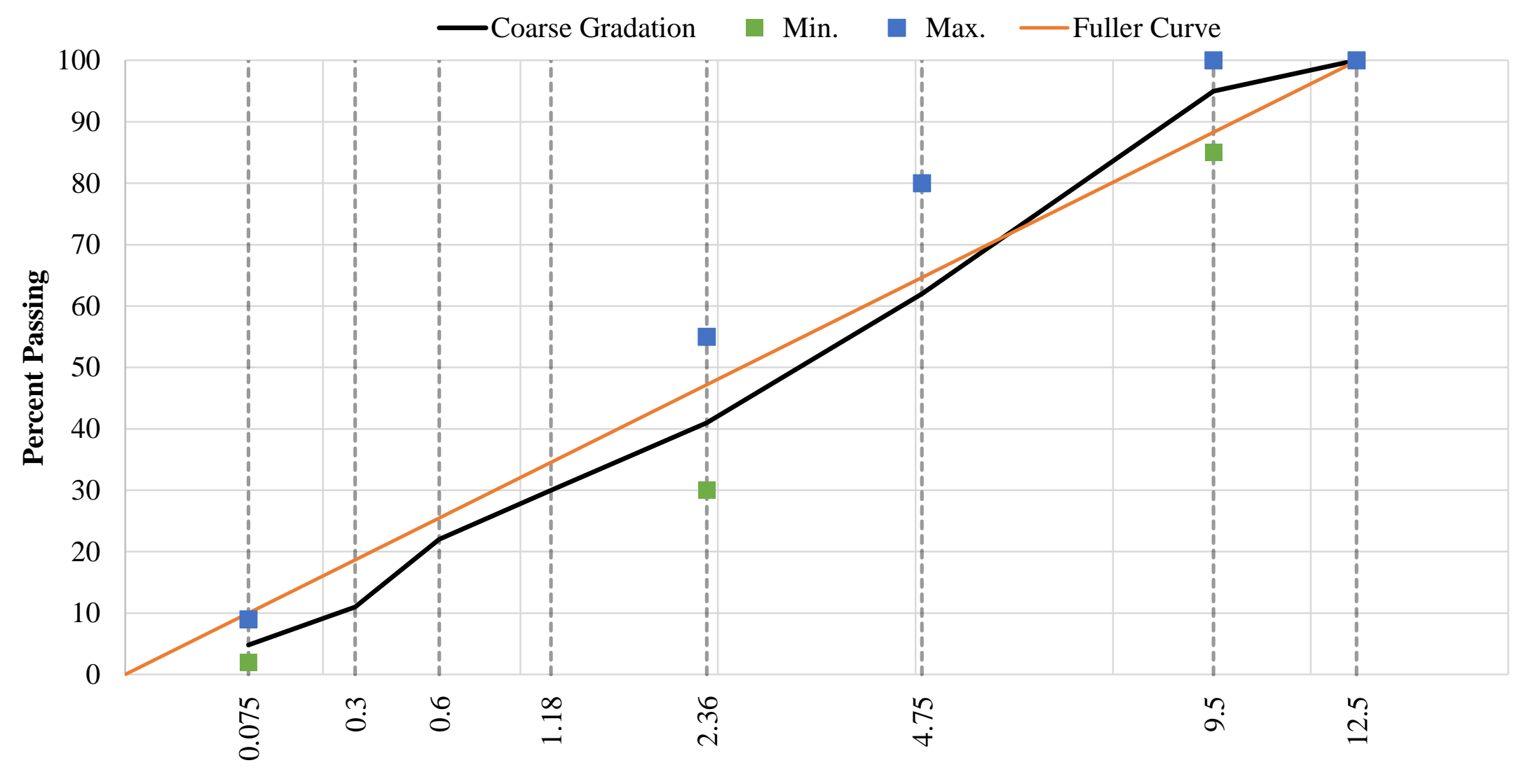

Sieve Size (mm)

Figure 58: WVP766 Gradation Chart 


\section{West Virginia Paving 882 - 0.45 Power Gradation Chart}

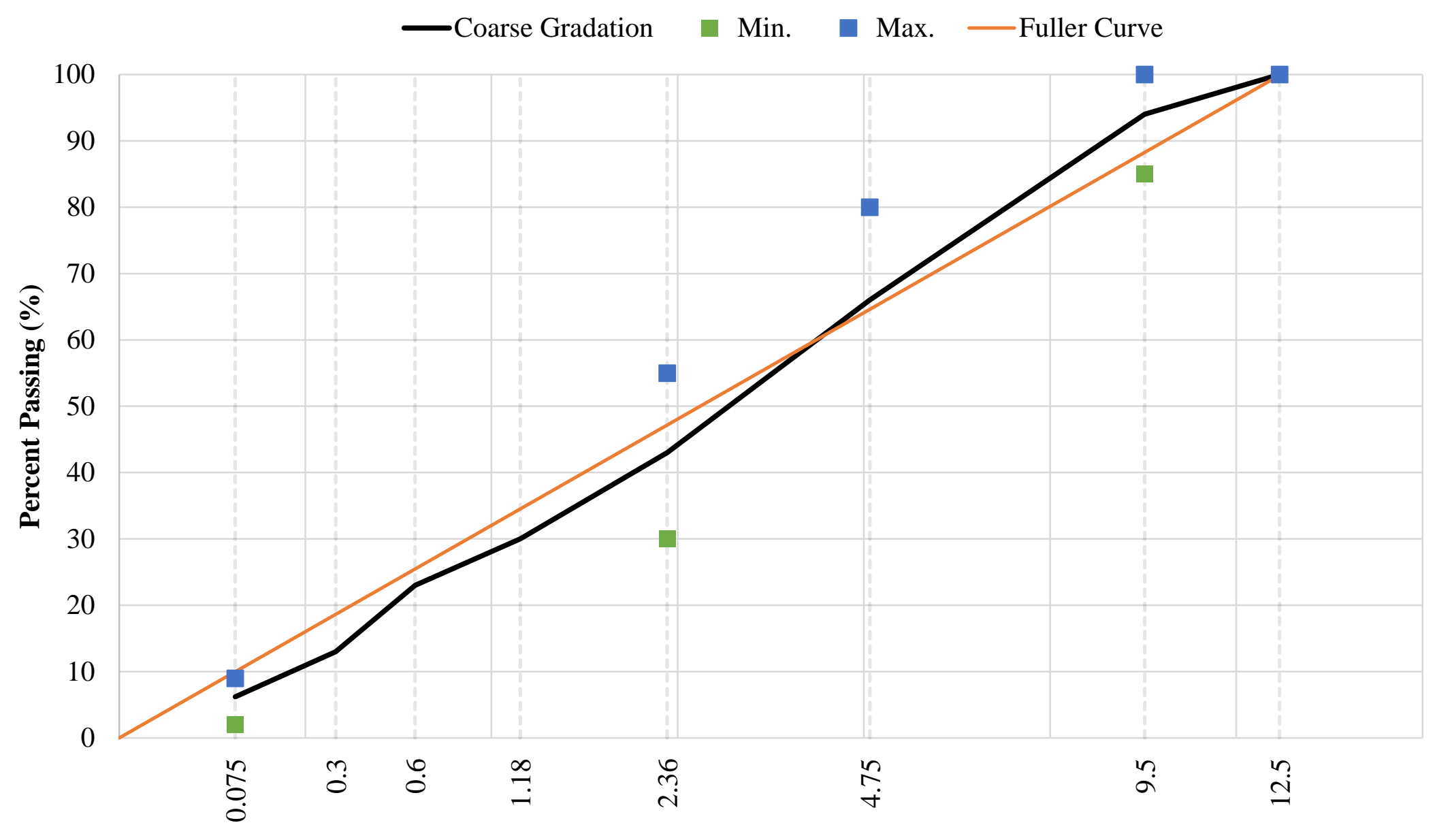

Sieve Size (mm)

Figure 59: WVP882 Gradation Chart 


\section{Appendix B: Volumetric Properties and SGC Data}

\section{Complete $\mathrm{G}_{\mathrm{mm}}$ Calculations}

Table 35: Lab $\mathrm{G}_{\mathrm{mm}}$ Calculations

\begin{tabular}{|c|c|c|c|c|c|}
\hline Mix ID & Trial 1 & Trial 2 & Average & Range & SD \\
\hline GR456 & 2.475 & 2.479 & 2.477 & 0.0040 & 0.0029 \\
\hline AA937 & 2.488 & 2.490 & 2.489 & 0.0017 & 0.0012 \\
\hline JAP909 & 2.644 & 2.643 & 2.644 & 0.0011 & 0.0008 \\
\hline JFA060 & 2.527 & 2.530 & 2.528 & 0.0028 & 0.0020 \\
\hline JFA115 & 2.496 & 2.492 & 2.494 & 0.0033 & 0.0023 \\
\hline JFA429 & 2.532 & 2.526 & 2.529 & 0.0056 & 0.0040 \\
\hline KP483 & 2.474 & 2.468 & 2.471 & 0.0059 & 0.0042 \\
\hline WVP523 & 2.495 & 2.491 & 2.493 & 0.0048 & 0.0034 \\
\hline WVP766 & 2.474 & 2.473 & 2.474 & 0.0010 & 0.0007 \\
\hline WVP882 & 2.450 & 2.443 & 2.447 & 0.0078 & 0.0049 \\
\hline
\end{tabular}

$*$ Single operator precision: standard deviation $=0.0051$ and range of two results $=0.014$ 
SGC Data

Table 36: AA937 SGC Data

\begin{tabular}{|c|c|c|c|c|c|c|c|c|c|c|c|}
\hline & \multicolumn{11}{|c|}{ Height Increments (mm) } \\
\hline GYR & S1 & S2 & S3 & S4 & S5 & S6 & S7 & S8 & S9 & S10 & S11 \\
\hline 0 & 202.7 & 210.3 & 204.7 & 202.7 & 206.1 & 203.8 & 204.4 & 203.2 & 202.6 & 202.9 & 204.1 \\
\hline 1 & 195.2 & 203.0 & 197.4 & 195.4 & 198.8 & 196.5 & 197.1 & 195.8 & 195.2 & 195.4 & 196.7 \\
\hline 2 & $\overline{190.9}$ & 198.6 & 192.9 & 191.0 & 194.5 & 192.3 & 192.7 & $\overline{191.4}$ & 190.9 & 191.2 & 192.3 \\
\hline 3 & 187.8 & 195.3 & 189.7 & 187.8 & 191.3 & 189.0 & 189.5 & 188.2 & 187.7 & 188.0 & 189.2 \\
\hline 4 & 185.3 & 192.7 & 187.1 & 185.3 & 188.7 & 186.5 & 187.0 & 185.6 & 185.1 & 185.5 & 186.6 \\
\hline 5 & $\overline{183.2}$ & 190.7 & 185.0 & $\overline{183.3}$ & 186.6 & $\overline{184.4}$ & 185.0 & 183.5 & $\overline{183.1}$ & 183.4 & 184.6 \\
\hline 6 & $\overline{181.4}$ & 188.9 & 183.2 & 181.5 & 184.9 & 182.7 & 183.3 & 181.7 & 181.3 & 181.7 & 182.8 \\
\hline 7 & 179.9 & 187.4 & 181.7 & 180.0 & 183.4 & 181.2 & 181.8 & 180.2 & 179.8 & 180.2 & 181.3 \\
\hline 8 & 178.6 & 186.0 & 180.3 & 178.7 & 182.0 & 179.9 & 180.5 & 178.9 & 178.5 & 178.9 & 180.0 \\
\hline 9 & 177.5 & 184.8 & 179.2 & 177.5 & 180.9 & 178.7 & 179.3 & 177.7 & 177.4 & 177.8 & 178.8 \\
\hline 10 & 176.4 & 183.8 & 178.1 & 176.5 & 179.8 & 177.7 & 178.2 & 176.6 & 176.3 & 176.7 & 177.7 \\
\hline 11 & 175.5 & 182.8 & 177.1 & 175.6 & 178.8 & 176.7 & 177.3 & 175.7 & 175.4 & 175.7 & 176.8 \\
\hline 12 & 174.6 & 181.9 & 176.3 & 174.8 & 178.0 & 175.9 & 176.4 & 174.8 & 174.5 & 174.9 & 175.9 \\
\hline 13 & 173.9 & 181.2 & 175.5 & 174.0 & 177.2 & 175.1 & 175.6 & 174.0 & 173.7 & 174.1 & 175.1 \\
\hline 14 & 173.1 & 180.4 & 174.8 & 173.3 & 176.4 & 174.4 & 174.9 & 173.3 & 173.0 & 173.4 & 174.4 \\
\hline 15 & 172.5 & 179.7 & 174.1 & 172.6 & 175.7 & 173.7 & 174.2 & 172.6 & 172.3 & 172.7 & 173.7 \\
\hline 16 & 171.9 & 179.1 & 173.4 & 172.0 & 175.1 & 173.1 & 173.5 & 172.0 & 171.7 & 172.1 & 173.0 \\
\hline 17 & 171.3 & 178.5 & 172.9 & 171.4 & 174.5 & 172.5 & 172.9 & 171.4 & 171.1 & 171.5 & 172.5 \\
\hline 18 & 170.7 & 178.0 & 172.3 & 170.9 & 174.0 & 171.9 & 172.4 & 170.8 & 170.6 & 170.9 & 171.9 \\
\hline 19 & 170.2 & 177.4 & 171.8 & 170.4 & 173.4 & 171.4 & 171.9 & 170.3 & 170.0 & 170.4 & 171.4 \\
\hline 20 & 169.7 & 176.9 & 171.3 & 169.9 & 172.9 & 170.9 & 171.4 & 169.8 & 169.6 & 169.9 & 170.9 \\
\hline 21 & 169.3 & 176.5 & 170.8 & 169.4 & 172.5 & 170.4 & 170.9 & 169.3 & 169.1 & 169.4 & 170.4 \\
\hline 22 & & 176.0 & 170.4 & & 172.0 & 170.0 & 170.5 & & & & 170.0 \\
\hline 23 & & 175.6 & 169.9 & & 171.6 & 169.6 & 170.0 & & & & 169.5 \\
\hline 24 & & 175.2 & 169.5 & & 171.2 & 169.2 & 169.6 & & & & \\
\hline 25 & & 174.8 & & & 170.8 & & 169.2 & & & & \\
\hline 26 & & 174.4 & & & 170.5 & & & & & & \\
\hline 27 & & 174.1 & & & 170.1 & & & & & & \\
\hline 28 & & 173.7 & & & 169.8 & & & & & & \\
\hline 29 & & 173.4 & & & 169.4 & & & & & & \\
\hline Break & & & & & & & & & & & \\
\hline 40 & & 170.4 & & & & & & & & & \\
\hline 41 & & 170.2 & & & & & & & & & \\
\hline 42 & & 170.0 & & & & & & & & & \\
\hline 43 & & 169.8 & & & & & & & & & \\
\hline 44 & & 169.6 & & & & & & & & & \\
\hline
\end{tabular}


Table 37: GR465 SGC Data

\begin{tabular}{|c|c|c|c|c|c|}
\hline & \multicolumn{5}{|c|}{ Height Increments (mm) } \\
\hline GYR & S0 & S1 & S2 & S3 & Bulk Sample \\
\hline 0 & 0.0 & 227.6 & 226.8 & 226.5 & 157.8 \\
\hline 1 & 0.0 & 219.2 & 218.5 & 218.1 & 150.7 \\
\hline 2 & 227.5 & 214.2 & 213.5 & 213.2 & 146.8 \\
\hline 3 & 224.8 & 210.2 & 209.8 & 209.4 & 144.1 \\
\hline 4 & 222.0 & 207.2 & 206.8 & 206.4 & 141.9 \\
\hline 5 & 219.6 & 204.7 & 204.2 & 203.8 & 140.1 \\
\hline 6 & 217.5 & 202.5 & 202.0 & 201.7 & 138.7 \\
\hline 7 & 215.8 & 200.7 & 200.2 & 199.9 & 137.4 \\
\hline 8 & 214.2 & 199.1 & 198.6 & 198.3 & 136.4 \\
\hline 9 & 212.8 & 197.7 & 197.2 & 196.9 & 135.4 \\
\hline 10 & 211.6 & 196.4 & 195.9 & 195.7 & 134.5 \\
\hline 11 & 210.5 & 195.3 & 194.7 & 194.5 & 133.8 \\
\hline 12 & 209.4 & 194.2 & 193.7 & 193.5 & 133.1 \\
\hline 13 & 208.5 & 193.3 & 192.7 & 192.6 & 132.5 \\
\hline 14 & 207.6 & 192.4 & 191.9 & 191.7 & 131.9 \\
\hline 15 & 206.8 & 191.6 & 191.0 & 190.9 & 131.3 \\
\hline 16 & 206.1 & 190.9 & 190.3 & 190.2 & 130.8 \\
\hline 17 & 205.3 & 190.2 & 189.6 & 189.5 & 130.4 \\
\hline 18 & 204.7 & 189.5 & 189.0 & 188.8 & 129.9 \\
\hline 19 & 204.1 & 188.9 & 188.4 & 188.2 & 129.5 \\
\hline 20 & 203.5 & 188.4 & 187.8 & 187.6 & 129.2 \\
\hline 21 & 202.9 & 187.8 & 187.2 & 187.1 & 128.8 \\
\hline 22 & 202.4 & 187.3 & 186.7 & 186.6 & 128.5 \\
\hline 23 & 201.9 & 186.9 & 186.3 & 186.1 & 128.1 \\
\hline 24 & 201.4 & 186.4 & 185.8 & 185.6 & 127.8 \\
\hline 25 & 201.0 & 186.0 & 185.4 & 185.2 & 127.5 \\
\hline 26 & 200.5 & 185.6 & 184.9 & 184.8 & 127.3 \\
\hline 27 & 200.1 & 185.2 & 184.6 & 184.4 & 127.0 \\
\hline 28 & 199.7 & 184.8 & 184.2 & 184.0 & 126.7 \\
\hline 29 & 199.3 & 184.4 & 183.8 & 183.7 & 126.5 \\
\hline 30 & 199.0 & 184.1 & 183.5 & 183.3 & 126.3 \\
\hline 31 & 198.6 & 183.8 & 183.1 & 183.0 & 126.0 \\
\hline 32 & 198.3 & 183.5 & 182.8 & 182.7 & 125.8 \\
\hline 33 & 198.0 & 183.2 & 182.5 & 182.3 & 125.6 \\
\hline 34 & 197.6 & 182.9 & 182.2 & 182.0 & 125.4 \\
\hline 35 & 197.3 & 182.6 & 181.9 & 181.8 & 125.2 \\
\hline 36 & 197.1 & 182.3 & 181.7 & 181.5 & 125.1 \\
\hline 37 & 196.8 & 182.1 & 181.4 & 181.2 & 124.9 \\
\hline 38 & 196.5 & 181.8 & 181.2 & 181.0 & 124.7 \\
\hline 39 & 196.2 & 181.6 & 180.9 & 180.7 & 124.5 \\
\hline 40 & 196.0 & 181.3 & 180.7 & 180.5 & 124.4 \\
\hline 41 & 195.7 & 181.1 & 180.4 & 180.2 & 124.2 \\
\hline Break & & & & & \\
\hline
\end{tabular}




\begin{tabular}{|c|c|c|c|c|c|}
\hline 42 & 195.5 & 180.9 & 180.2 & 180.0 & 124.1 \\
\hline 43 & 195.3 & 180.7 & 180.0 & 179.8 & 123.9 \\
\hline 44 & 195.0 & 180.4 & 179.8 & 179.6 & 123.8 \\
\hline 45 & 194.8 & 180.2 & 179.6 & & 123.7 \\
\hline 46 & 194.6 & 180.0 & & & 123.5 \\
\hline 47 & 194.4 & 179.9 & & & 123.4 \\
\hline 48 & 194.2 & 179.7 & & & 123.3 \\
\hline 49 & 194.0 & & & & 123.1 \\
\hline 50 & 193.8 & & & & 123.0 \\
\hline 51 & 193.6 & & & & 122.9 \\
\hline 52 & 193.4 & & & & 122.8 \\
\hline 53 & 193.2 & & & & 122.7 \\
\hline 54 & 193.1 & & & & 122.6 \\
\hline 55 & 192.9 & & & & 122.5 \\
\hline 56 & 192.7 & & & & 122.4 \\
\hline 57 & 192.6 & & & & 122.3 \\
\hline 58 & 192.4 & & & & 122.2 \\
\hline 59 & 192.3 & & & & 122.1 \\
\hline 60 & 192.1 & & & & 122.0 \\
\hline 61 & 192.0 & & & & 121.9 \\
\hline 62 & 191.8 & & & & 121.8 \\
\hline 63 & 191.7 & & & & 121.7 \\
\hline 64 & 191.5 & & & & 121.6 \\
\hline 65 & 191.4 & & & & 121.5 \\
\hline 66 & 191.3 & & & & 121.4 \\
\hline 67 & 191.1 & & & & 121.4 \\
\hline 68 & 191.0 & & & & 121.3 \\
\hline 69 & 190.9 & & & & 121.2 \\
\hline 70 & 190.7 & & & & 121.1 \\
\hline 71 & 190.6 & & & & 121.1 \\
\hline 72 & 190.5 & & & & 121.0 \\
\hline 73 & 190.4 & & & & 120.9 \\
\hline 74 & 190.3 & & & & 120.8 \\
\hline 75 & 190.2 & & & & 120.8 \\
\hline 76 & 190.1 & & & & 120.7 \\
\hline 77 & 189.9 & & & & 120.6 \\
\hline 78 & 189.8 & & & & 120.6 \\
\hline 79 & 189.7 & & & & 120.5 \\
\hline 80 & 189.6 & & & & 120.5 \\
\hline 81 & 189.5 & & & & \\
\hline 82 & 189.4 & & & & \\
\hline 83 & 189.3 & & & & \\
\hline 84 & 189.2 & & & & \\
\hline
\end{tabular}


Table 38: JAP909 SGC Data

\begin{tabular}{|c|c|c|c|c|c|c|c|c|c|c|c|}
\hline & \multicolumn{11}{|c|}{ Height Increments (mm) } \\
\hline GYR & S1 & $\mathbf{S 2}$ & S3 & S4 & S5 & S6 & S7 & S8 & S9 & S10 & S11 \\
\hline 0 & 200.1 & 204.2 & 203.1 & 203.1 & 203.3 & 203.0 & 202.8 & 201.9 & 201.5 & 202.6 & 201.6 \\
\hline 1 & 192.6 & 196.9 & 195.4 & 195.6 & 195.8 & 195.6 & 195.5 & 194.5 & 194.2 & 195.2 & 194.3 \\
\hline 2 & 188.5 & 192.7 & 191.2 & 191.5 & 191.7 & 191.6 & 191.2 & 190.4 & 190.1 & 190.9 & 190.0 \\
\hline 3 & 185.5 & 189.7 & 188.2 & 188.5 & 188.6 & 188.5 & 188.2 & 187.4 & 187.1 & 188.0 & 187.0 \\
\hline 4 & 183.2 & 187.3 & 185.8 & 186.2 & 186.2 & 186.3 & 185.8 & 185.1 & 184.7 & 185.6 & 184.7 \\
\hline 5 & 181.3 & 185.4 & 183.9 & 184.3 & 184.3 & 184.3 & 183.9 & 183.2 & 182.9 & 183.7 & 182.8 \\
\hline 6 & 179.7 & 183.8 & 182.3 & 182.7 & 182.7 & 182.8 & 182.2 & 181.6 & 181.3 & 182.1 & 181.3 \\
\hline 7 & 178.4 & 182.4 & 181.0 & 181.3 & 181.4 & 181.4 & 180.9 & 180.2 & 179.9 & 180.7 & 179.9 \\
\hline 8 & 177.2 & 181.2 & 179.8 & 180.1 & 180.2 & 180.2 & 179.7 & 179.0 & 178.8 & 179.5 & 178.7 \\
\hline 9 & 176.1 & 180.2 & 178.7 & 179.1 & 179.1 & 179.2 & 178.6 & 178.0 & 177.7 & 178.5 & 177.7 \\
\hline 10 & 175.2 & 179.2 & 177.8 & 178.1 & 178.2 & 178.3 & 177.7 & 177.1 & 176.8 & 177.5 & 176.8 \\
\hline 11 & 174.4 & 178.3 & 177.0 & 177.3 & 177.4 & 177.5 & 176.8 & 176.3 & 176.0 & 176.7 & 176.0 \\
\hline 12 & 173.6 & 177.6 & 176.2 & 176.6 & 176.6 & 176.7 & 176.0 & 175.5 & 175.2 & 175.9 & 175.3 \\
\hline 13 & 172.9 & 176.9 & 175.5 & 175.9 & 175.9 & 176.0 & 175.3 & 174.8 & 174.6 & 175.3 & 174.6 \\
\hline 14 & 172.3 & 176.2 & 174.9 & 175.2 & 175.3 & 175.4 & 174.7 & 174.2 & 173.9 & 174.6 & 174.0 \\
\hline 15 & 171.7 & 175.6 & 174.3 & 174.7 & 174.7 & 174.8 & 174.1 & 173.6 & 173.3 & 174.0 & 173.4 \\
\hline 16 & 171.2 & 175.1 & 173.7 & 174.1 & 174.1 & 174.3 & 173.5 & 173.1 & 172.8 & 173.5 & 172.9 \\
\hline 17 & 170.7 & 174.6 & 173.2 & 173.6 & 173.6 & 173.8 & 173.0 & 172.6 & 172.3 & 173.0 & 172.4 \\
\hline 18 & 170.2 & 174.1 & 172.8 & 173.1 & 173.1 & 173.3 & 172.5 & 172.1 & 171.8 & 172.5 & 171.9 \\
\hline 19 & 169.8 & 173.6 & 172.3 & 172.7 & 172.6 & 172.8 & 172.1 & 171.7 & 171.4 & 172.1 & 171.5 \\
\hline 20 & 169.3 & 173.2 & 171.9 & 172.3 & 172.2 & 172.4 & 171.6 & 171.2 & 171.0 & 171.6 & 171.1 \\
\hline 21 & & 172.8 & 171.5 & 171.9 & 171.8 & 172.0 & 171.2 & 170.8 & 170.6 & 171.3 & 170.7 \\
\hline 22 & & 172.4 & 171.1 & 171.5 & 171.4 & 171.6 & 170.8 & 170.5 & 170.2 & 170.9 & 170.3 \\
\hline 23 & & 172.0 & 170.7 & 171.1 & 171.1 & 171.3 & 170.5 & 170.1 & 169.9 & 170.5 & 170.0 \\
\hline 24 & & 171.7 & 170.4 & 170.8 & 170.7 & 170.9 & 170.1 & 169.7 & 169.5 & 170.2 & 169.6 \\
\hline 25 & & 171.3 & 170.0 & 170.5 & 170.4 & 170.6 & 169.8 & 169.4 & & 169.9 & \\
\hline 26 & & 171.0 & 169.7 & 170.1 & 170.0 & 170.3 & 169.5 & & & 169.5 & \\
\hline 27 & & 170.7 & 169.4 & 169.9 & 169.7 & 170.0 & & & & & \\
\hline 28 & & 170.4 & & 169.6 & 169.4 & 169.7 & & & & & \\
\hline 29 & & 170.1 & & & & 169.5 & & & & & \\
\hline 30 & & 169.9 & & & & & & & & & \\
\hline 31 & & 169.6 & & & & & & & & & \\
\hline
\end{tabular}


Table 39: JFA060 SGC Data

\begin{tabular}{|c|c|c|c|c|c|c|c|c|c|c|c|}
\hline & \multicolumn{11}{|c|}{ Height Increments (mm) } \\
\hline GYR & S1 & $\mathbf{S 2}$ & $\mathbf{S 3}$ & $\mathbf{S 4}$ & S5 & S6 & S7 & S8 & S9 & S10 & S11 \\
\hline 0 & 221.4 & 204.4 & 206.4 & 206.5 & 206.5 & 207.0 & 205.7 & 206.0 & 205.4 & 205.9 & 207.2 \\
\hline 1 & 213.6 & 196.7 & 198.7 & 198.8 & 198.7 & 199.4 & 198.2 & 198.4 & 197.7 & 198.4 & 199.8 \\
\hline 2 & 209.0 & 192.5 & 194.4 & 194.6 & 194.4 & 195.2 & 193.9 & 194.1 & 193.5 & 194.3 & 195.5 \\
\hline 3 & 205.6 & 189.4 & 191.2 & 191.4 & 191.3 & 192.1 & 190.7 & 190.9 & 190.4 & 191.2 & 192.3 \\
\hline 4 & 203.0 & 186.8 & 188.7 & 189.0 & 188.8 & 189.6 & 188.2 & 188.5 & 187.9 & 188.8 & 189.9 \\
\hline 5 & 200.8 & 184.9 & 186.7 & 187.0 & 186.7 & 187.5 & 186.2 & 186.5 & 185.9 & 186.8 & 187.9 \\
\hline 6 & 199.0 & 183.2 & 185.0 & 185.3 & 185.1 & 185.8 & 184.5 & 184.8 & 184.3 & 185.1 & 186.2 \\
\hline 7 & 197.4 & 181.8 & 183.5 & 183.9 & 183.6 & 184.4 & 183.0 & 183.3 & 182.8 & 183.7 & 184.8 \\
\hline 8 & 196.1 & 180.5 & 182.3 & 182.6 & 182.3 & 183.1 & 181.8 & 182.1 & 181.6 & 182.4 & 183.5 \\
\hline 9 & 194.9 & 179.5 & 181.1 & 181.5 & 181.2 & 182.0 & 180.7 & 181.0 & 180.5 & 181.3 & 182.4 \\
\hline 10 & 193.8 & 178.5 & 180.2 & 180.5 & 180.2 & 181.0 & 179.6 & 180.0 & 179.5 & 180.3 & 181.4 \\
\hline 11 & 192.8 & 177.6 & 179.2 & 179.6 & 179.3 & 180.1 & 178.8 & 179.1 & 178.6 & 179.4 & 180.4 \\
\hline 12 & 192.0 & 176.8 & 178.4 & 178.8 & 178.5 & 179.3 & 178.0 & 178.3 & 177.8 & 178.6 & 179.6 \\
\hline 13 & 191.2 & 176.1 & 177.7 & 178.1 & 177.8 & 178.5 & 177.2 & 177.5 & 177.1 & 177.9 & 178.9 \\
\hline 14 & 190.4 & 175.4 & 177.0 & 177.4 & 177.1 & 177.8 & 176.5 & 176.8 & 176.4 & 177.2 & 178.2 \\
\hline 15 & 189.7 & 174.8 & 176.3 & 176.8 & 176.5 & 177.2 & 175.9 & 176.2 & 175.8 & 176.5 & 177.5 \\
\hline 16 & 189.1 & 174.2 & 175.7 & 176.2 & 175.9 & 176.6 & 175.3 & 175.6 & 175.2 & 175.9 & 176.9 \\
\hline 17 & 188.5 & 173.7 & 175.1 & 175.6 & 175.3 & 176.0 & 174.8 & 175.1 & 174.6 & 175.4 & 176.4 \\
\hline 18 & 187.9 & 173.2 & 174.6 & 175.1 & 174.8 & 175.5 & 174.3 & 174.6 & 174.1 & 174.9 & 175.8 \\
\hline 19 & 187.4 & 172.7 & 174.1 & 174.6 & 174.3 & 175.0 & 173.8 & 174.1 & 173.6 & 174.4 & 175.4 \\
\hline 20 & 186.9 & 172.2 & 173.7 & 174.2 & 173.9 & 174.5 & 173.3 & 173.6 & 173.2 & 173.9 & 174.9 \\
\hline 21 & 186.4 & 171.8 & 173.2 & 173.7 & 173.4 & 174.1 & 172.9 & 173.2 & 172.7 & 173.5 & 174.5 \\
\hline 22 & 186.0 & 171.4 & 172.8 & 173.3 & 173.0 & 173.7 & 172.5 & 172.8 & 172.3 & 173.1 & 174.0 \\
\hline 23 & 185.6 & 171.0 & 172.4 & 172.9 & 172.6 & 173.3 & 172.1 & 172.4 & 171.9 & 172.7 & 173.6 \\
\hline 24 & 185.2 & 170.7 & 172.1 & 172.5 & 172.3 & 172.9 & 171.7 & 172.0 & 171.6 & 172.3 & 173.3 \\
\hline 25 & 184.8 & 170.3 & 171.7 & 172.2 & 171.9 & 172.5 & 171.3 & 171.7 & 171.2 & 172.0 & 172.9 \\
\hline 26 & 184.4 & 170.0 & 171.4 & 171.9 & 171.6 & 172.2 & 171.0 & 171.3 & 170.9 & 171.6 & 172.6 \\
\hline 27 & 184.1 & 169.7 & 171.0 & 171.5 & 171.2 & 171.9 & 170.6 & 171.0 & 170.5 & 171.3 & 172.2 \\
\hline 28 & 183.7 & & 170.7 & 171.2 & 170.9 & 171.5 & 170.3 & 170.7 & 170.2 & 171.0 & 171.9 \\
\hline 29 & 183.4 & & 170.4 & 170.9 & 170.6 & 171.2 & 170.0 & 170.4 & 169.9 & 170.7 & 171.6 \\
\hline 30 & 183.1 & & 170.1 & 170.6 & 170.3 & 170.9 & 169.7 & 170.1 & 169.6 & 170.4 & 171.3 \\
\hline 31 & 182.8 & & 169.9 & 170.4 & 170.1 & 170.6 & 169.5 & 169.8 & & 170.1 & 171.1 \\
\hline 32 & 182.5 & & 169.6 & 170.1 & 169.8 & 170.4 & & 169.6 & & 169.9 & 170.8 \\
\hline 33 & 182.2 & & & 169.8 & 169.6 & 170.1 & & & & 169.6 & 170.5 \\
\hline 34 & 182.0 & & & 169.6 & & 169.9 & & & & & 170.3 \\
\hline 35 & 181.7 & & & & & 169.6 & & & & & 170.0 \\
\hline 36 & 181.5 & & & & & & & & & & 169.8 \\
\hline 37 & 181.2 & & & & & & & & & & 169.6 \\
\hline Break & $\ldots$ & & & & & & & & & & \\
\hline 159 & 170.1 & & & & & & & & & & \\
\hline 160 & 170.0 & & & & & & & & & & \\
\hline 161 & 170.0 & & & & & & & & & & \\
\hline 162 & 170.0 & & & & & & & & & & \\
\hline 163 & 170.0 & & & & & & & & & & \\
\hline
\end{tabular}


Table 40: JFA429 SGC Data

\begin{tabular}{|c|c|c|c|c|c|c|c|c|c|c|c|c|}
\hline & \multicolumn{12}{|c|}{ Height Increments (mm) } \\
\hline GYR & SS1 & 6S2 & S1 & $\mathbf{S 2}$ & S3 & S4 & S5 & S6 & S7 & S8 & S9 & S10 \\
\hline 0 & 38.4 & 40.8 & 208.7 & 215.2 & 213.9 & 213.9 & 213.4 & 212.3 & 211.5 & 210.9 & 211.7 & 212.1 \\
\hline 1 & & & & & & & & & & & 03.8 & \\
\hline 2 & 9.5 & 1.7 & 96.7 & 202.9 & 201.6 & 01.6 & 01.2 & $\overline{00.0}$ & 199.2 & 198.7 & 99.4 & 200.0 \\
\hline 3 & 27.3 & 29.5 & 93.5 & 99.6 & $\overline{98.3}$ & 98.3 & 97.9 & 96.7 & 195.9 & 195.5 & 196.2 & 196.7 \\
\hline 4 & 5.6 & 27.8 & 91.1 & 97.0 & & & & & & & & 194.1 \\
\hline 5 & 4.3 & 26.5 & 189.1 & 194.9 & 193.5 & 93.6 & 93.4 & 92.2 & 191.4 & 190.9 & 191.6 & 192.0 \\
\hline 6 & 3.2 & 25.4 & 187.4 & 193.1 & 91.7 & 91.8 & 91.6 & 90.5 & 189.7 & 189.1 & 189.8 & 190.3 \\
\hline 7 & 2.2 & 24.4 & 86.0 & 91.6 & 90.1 & 90.3 & 90.1 & 89.1 & 188.2 & 187.7 & 188.4 & 188.7 \\
\hline 8 & 1.4 & 23.6 & 34.7 & 90.2 & 88.8 & & & & & & & 187.4 \\
\hline 9 & 20.7 & 22.8 & 183.6 & 89.0 & 87.6 & 87.8 & 87.7 & 86.7 & 85.8 & 85.2 & 85.9 & 186.2 \\
\hline 10 & 20.1 & 22.1 & 82.6 & 87.9 & 186.6 & 186.8 & 186.6 & 185.6 & 184.8 & 184.2 & 184.8 & 185.1 \\
\hline 11 & 9.5 & 21.5 & 31.7 & 87.0 & 85.6 & 85.8 & 85.7 & 84.7 & 183.9 & 183.3 & 183.9 & 184.2 \\
\hline 12 & & & & 86.1 & 84.8 & & & & & & & 183.3 \\
\hline 13 & 8.5 & 20.5 & 180.2 & 185.3 & 84.0 & 84.2 & 84.1 & 83.2 & 182.3 & 181.7 & 182.3 & 182.5 \\
\hline 14 & 8.0 & 20.0 & 79.5 & 84.6 & 83.2 & 83.5 & 83.4 & 82.5 & 181.6 & 181.0 & 181.6 & 181.8 \\
\hline 15 & & 19.6 & & & 82.6 & 82.8 & & & & & & 181.1 \\
\hline & & & & & & & & & & & & \\
\hline 17 & 6.8 & 18.8 & 177.7 & 182.7 & 181.4 & 81.6 & 181.6 & & 179.8 & 179.1 & 179.8 & 179.8 \\
\hline 18 & 6.5 & 8.5 & 177.1 & 82.1 & 80.8 & 81.1 & & & 179.2 & 178.6 & 179.2 & 179.3 \\
\hline 19 & & & & & & & & & & & & \\
\hline 20 & 5.9 & 17.8 & 176.2 & 181.1 & 179.8 & 180.1 & .1 & 179.2 & 178.3 & 177.6 & 178.2 & 178.3 \\
\hline 21 & 5.6 & 17.5 & 175.7 & 180.6 & 179.4 & 179.6 & 179.6 & 178.7 & 177.8 & 177.2 & 177.8 & $\overline{177.9}$ \\
\hline 22 & & 7.3 & 175.3 & .2 & 78.9 & 79.2 & 9.2 & & 77.4 & 176.8 & 177.3 & 177.4 \\
\hline 23 & & & 174.9 & & & & & & 177.0 & & 177.0 & 177.0 \\
\hline 24 & 4.8 & 16.8 & 174.5 & 179.4 & 178.1 & 78.4 & 178.4 & 177.5 & 176.6 & 176.0 & 176.6 & 176.6 \\
\hline 25 & 4.6 & 16.5 & 174.1 & 179.0 & 177.7 & 178.1 & 178.0 & 177.2 & 176.2 & 175.6 & 176.2 & 176.3 \\
\hline 26 & & 116.3 & & & 177.4 & 77.7 & 77.7 & & & 175.2 & 175.8 & 175.9 \\
\hline 27 & & & 173.4 & 178.3 & 177.0 & 177.4 & & & 175.6 & 174.9 & 175.5 & 175.6 \\
\hline 28 & 3.9 & 15.9 & 173.1 & 177.9 & 176.7 & 177.1 & 177.0 & 176.2 & 175.2 & 174.6 & 175.2 & 175.3 \\
\hline 29 & & & & & 6.4 & 6.8 & & & 74.9 & 174.3 & 174.9 & 174.9 \\
\hline 30 & & & 172.5 & 177.3 & & 176.5 & & & 174.6 & 174.0 & 174.6 & 174.7 \\
\hline 31 & & 115.3 & 172.2 & 177.0 & 175.8 & 176.2 & 176.1 & 175.3 & 174.3 & 173.7 & 174.3 & 174.4 \\
\hline 32 & & & & 176.7 & & 175.9 & 175.8 & 175.0 & 174.0 & 173.4 & 174.0 & 174.1 \\
\hline 33 & & & & 176.4 & & 175.6 & & 174.8 & 173.8 & 173.2 & 173.8 & 173.8 \\
\hline 34 & 12.9 & 114.8 & 171.4 & 176.2 & 175.0 & 175.4 & 175.3 & 174.5 & 173.5 & 172.9 & 173.5 & 173.6 \\
\hline 35 & 112.7 & 114.6 & 171.2 & 175.9 & 174.7 & 175.1 & 175.1 & 174.3 & 173.3 & 172.7 & 173.3 & 173.3 \\
\hline 36 & & 114.5 & 170.9 & 175.7 & 174.5 & 174.9 & 174.8 & 174.0 & 173.0 & 172.4 & 173.0 & 173.1 \\
\hline 37 & 112.4 & 114.3 & 170.7 & 175.4 & 174.2 & 174.6 & 174.6 & 173.8 & 172.8 & 172.2 & 172.8 & 172.8 \\
\hline
\end{tabular}




\begin{tabular}{|c|c|c|c|c|c|c|c|c|c|c|c|c|}
\hline 38 & 112.3 & 114.2 & 170.5 & 175.2 & 174.0 & 174.4 & 174.4 & 173.6 & 172.6 & 171.9 & 172.6 & 172.6 \\
\hline 39 & 112.1 & 114.0 & 170.3 & 175.0 & 173.8 & 174.2 & 174.2 & 173.4 & 172.3 & 171.7 & 172.3 & 172.4 \\
\hline 40 & 112.0 & 113.9 & 170.1 & 174.7 & 173.6 & 174.0 & 174.0 & 173.2 & 172.1 & 171.5 & 17.1 & 172.2 \\
\hline$\overline{41}$ & 111.9 & 113.8 & 169.9 & 174.5 & 173.4 & 173.8 & 173.8 & 173.0 & 171.9 & 171.3 & 171.9 & 172.0 \\
\hline$\overline{42}$ & 111.7 & 113.6 & 169.7 & 174.3 & 173.1 & 173.6 & 173.6 & 172.8 & 171.7 & 171.1 & 171.7 & 171.8 \\
\hline 43 & 111.6 & 113.5 & & 174.1 & 173.0 & 173.4 & 173.4 & 172.6 & 171.5 & 170.9 & 171.5 & 171.6 \\
\hline 44 & 111.5 & 113.4 & & 173.9 & 172.8 & 173.2 & 173.2 & 172.4 & 171.3 & 170.8 & 171.3 & 171.4 \\
\hline 45 & 111.4 & 113.3 & & 173.7 & 172.6 & 173.0 & 173.0 & 172.2 & 171.1 & 170.6 & 171.1 & 171.2 \\
\hline 46 & 111.3 & 113.2 & & 173.6 & 172.4 & 172.8 & 172.8 & 172.0 & 171.0 & 170.4 & 171.0 & 171.0 \\
\hline 47 & 111.1 & 113.1 & & 173.4 & 172.2 & 172.6 & 172.6 & 171.8 & 170.8 & 170.3 & 170.8 & 170.8 \\
\hline 48 & 111.0 & 113.0 & & 173.2 & 172.0 & 172.5 & 172.5 & 171.7 & 170.6 & 170.1 & 170.6 & 170.7 \\
\hline 49 & 110.9 & 112.8 & & 173.0 & 171.9 & 172.3 & 172.3 & 171.5 & 170.5 & 169.9 & 170.4 & 170.5 \\
\hline 50 & 110.8 & 112.7 & & 172.9 & 171.7 & 172.1 & 172.1 & 171.3 & 170.3 & 169.8 & 170.3 & 170.3 \\
\hline 51 & 110.7 & 112.6 & & 172.7 & 171.5 & 172.0 & 172.0 & 171.2 & 170.1 & & 170.1 & 170.2 \\
\hline 52 & 110.6 & 112.5 & & 172.6 & 171.4 & 171.8 & 171.8 & 171.0 & 170.0 & & 169.9 & 170.0 \\
\hline 53 & 110.5 & 112.4 & & 172.4 & 171.2 & 171.6 & 171.7 & 170.9 & 169.8 & & 169.8 & 169.9 \\
\hline 54 & 110.5 & 112.3 & & 172.2 & 171.0 & 171.5 & 171.5 & 170.7 & & & & 169.7 \\
\hline 55 & 110.4 & 112.3 & & 172.1 & 170.9 & 171.3 & 171.4 & 170.6 & & & & \\
\hline 56 & 110.3 & 112.2 & & 172.0 & 170.7 & 171.2 & 171.3 & 170.5 & & & & \\
\hline 57 & 110.2 & 112.1 & & 171.8 & 170.6 & 171.0 & 171.1 & 170.3 & & & & \\
\hline 58 & 110.1 & 112.0 & & 171.7 & 170.5 & 170.9 & 171.0 & 170.2 & & & & \\
\hline 59 & 110.0 & 111.9 & & 171.5 & 170.3 & 170.7 & 170.9 & 170.0 & & & & \\
\hline 60 & 109.9 & 111.8 & & 171.4 & 170.2 & 170.6 & 170.7 & 169.9 & & & & \\
\hline 61 & 109.9 & 111.7 & & 171.3 & 170.1 & 170.5 & 170.6 & 169.8 & & & & \\
\hline 62 & 109.8 & 111.7 & & 171.1 & 169.9 & 170.4 & 170.5 & & & & & \\
\hline 63 & 109.7 & 111.6 & & 171.0 & 169.8 & 170.2 & 170.4 & & & & & \\
\hline 64 & 109.6 & 111.5 & & 170.9 & & 170.1 & 170.2 & & & & & \\
\hline 65 & 109.6 & 111.4 & & 170.8 & & 170.0 & $\begin{array}{l}170.1 \\
\end{array}$ & & & & & \\
\hline 66 & 109.5 & 111.3 & & 170.7 & & 169.9 & 170.0 & & & & & \\
\hline 67 & 109.4 & 111.3 & & 170.5 & & & 169.9 & & & & & \\
\hline 68 & 109.3 & 111.2 & & 170.4 & & & 169.8 & & & & & \\
\hline 69 & 109.3 & 1111.1 & & 170.3 & & & & & & & & \\
\hline 70 & 109.2 & 1111.1 & & 1770.2 & & & & & & & & \\
\hline 71 & 109.1 & 111.0 & & 170.1 & & & & & & & & \\
\hline 72 & 109.1 & 110.9 & & 170.0 & & & & & & & & \\
\hline 73 & 109.0 & 110.9 & & 169.9 & & & & & & & & \\
\hline 74 & 108.9 & 110.8 & & 169.8 & & & & & & & & \\
\hline 75 & 108.9 & 110.7 & & & & & & & & & & \\
\hline 76 & 108.8 & 110.7 & & & & & & & & & & \\
\hline 77 & 108.8 & 110.6 & & & & & & & & & & \\
\hline 78 & 108.7 & 110.5 & & & & & & & & & & \\
\hline 79 & 108.6 & 110.5 & & & & & & & & & & \\
\hline 80 & 108.6 & 110.4 & & & & & & & & & & \\
\hline
\end{tabular}


Table 41: JFA115 SGC Data

\begin{tabular}{|c|c|c|c|c|c|c|c|c|c|c|c|}
\hline & \multicolumn{11}{|c|}{ Height Increments (mm) } \\
\hline GYR & S1 & $\mathbf{S 2}$ & S3 & S4 & S5 & S6 & S7 & S8 & S9 & S10 & S11 \\
\hline 0 & 215.1 & 186.3 & 210.1 & 208.2 & 209.8 & 208.4 & 208.8 & 208.1 & 208.5 & 208.5 & 209.5 \\
\hline 1 & 207.5 & 179.2 & 202.4 & 200.8 & 202.1 & 200.8 & 201.4 & 200.5 & 200.8 & 201.0 & 201.8 \\
\hline 2 & 203.0 & 175.1 & 198.0 & 196.4 & 197.7 & 196.5 & 197.1 & 196.1 & 196.5 & 196.6 & 197.4 \\
\hline 3 & 199.6 & 172.3 & 194.7 & 193.3 & 194.5 & 193.3 & 193.9 & 193.0 & 193.2 & 193.4 & 194.2 \\
\hline 4 & 197.1 & 170.0 & 192.1 & 190.8 & 191.9 & 190.8 & 191.3 & 190.4 & 190.7 & 190.9 & 191.7 \\
\hline 5 & 194.9 & 168.2 & 190.0 & 188.7 & 189.8 & 188.8 & 189.3 & 188.4 & 188.6 & 188.8 & 189.6 \\
\hline 6 & 193.1 & 166.6 & 188.2 & 187.0 & 188.1 & 187.0 & 187.5 & 186.6 & 186.9 & 187.0 & 187.8 \\
\hline 7 & 191.6 & & 186.7 & 185.5 & 186.6 & 185.6 & 186.0 & 185.2 & 185.4 & 185.5 & 186.4 \\
\hline 8 & 190.2 & & 185.4 & 184.2 & 185.2 & 184.2 & 184.7 & 183.9 & 184.1 & 184.2 & 185.0 \\
\hline 9 & 189.0 & & 184.2 & 183.1 & 184.1 & 183.1 & 183.6 & 182.7 & 182.9 & 183.0 & 183.9 \\
\hline 10 & 187.9 & & 183.2 & 182.0 & 183.0 & 182.0 & 182.5 & 181.7 & 181.9 & 182.0 & 182.8 \\
\hline 11 & 187.0 & & 182.2 & 181.1 & 182.1 & 181.1 & 181.6 & 180.8 & 181.0 & 181.0 & 181.9 \\
\hline 12 & 186.1 & & 181.3 & 180.3 & 181.2 & 180.2 & 180.7 & 179.9 & 180.1 & 180.1 & 181.0 \\
\hline 13 & 185.3 & & 180.5 & 179.5 & 180.4 & 179.5 & 180.0 & 179.1 & 179.3 & 179.4 & 180.3 \\
\hline 14 & 184.5 & & 179.8 & 178.8 & 179.7 & 178.7 & 179.2 & 178.4 & 178.6 & 178.6 & 179.5 \\
\hline 15 & 183.8 & & 179.2 & 178.1 & 179.0 & 178.1 & 178.6 & 177.7 & 177.9 & 178.0 & 178.9 \\
\hline 16 & 183.2 & & 178.5 & 177.5 & 178.4 & 177.4 & 178.0 & 177.1 & 177.3 & 177.4 & 178.2 \\
\hline 17 & 182.6 & & 177.9 & 176.9 & 177.8 & 176.9 & 177.4 & 176.5 & 176.7 & 176.8 & 177.7 \\
\hline 18 & 182.1 & & 177.4 & 176.4 & 177.2 & 176.3 & 176.8 & 176.0 & 176.2 & 176.2 & 177.1 \\
\hline 19 & 181.5 & & 176.9 & 175.9 & 176.7 & 175.8 & 176.3 & 175.5 & 175.7 & 175.7 & 176.6 \\
\hline 20 & 81.0 & & 176.4 & 175.4 & 176.2 & 175.3 & 175.8 & 175.0 & 175.2 & 175.2 & 176.1 \\
\hline 21 & 180.6 & & 175.9 & 175.0 & 175.8 & 174.9 & 175.3 & 174.6 & 174.7 & 174.8 & 175.6 \\
\hline 22 & 180.1 & & 175.5 & 174.5 & 175.3 & 174.4 & 174.9 & 174.1 & 174.3 & 174.3 & 175.2 \\
\hline 23 & 179.7 & & 175.1 & 174.1 & 174.9 & 174.0 & 174.5 & 173.7 & 173.9 & 173.9 & 174.8 \\
\hline 24 & 179.3 & & 174.7 & 173.7 & 174.5 & 173.6 & 174.1 & 173.3 & 173.5 & 173.5 & 174.4 \\
\hline 25 & 178.9 & & 174.3 & 173.4 & 174.1 & 173.3 & 173.7 & 172.9 & 173.1 & 173.1 & 174.0 \\
\hline 26 & 178.5 & & 173.9 & 173.0 & 173.8 & 172.9 & 173.4 & 172.6 & 172.8 & 172.8 & 173.6 \\
\hline 27 & 178.2 & & 173.6 & 172.7 & 173.4 & 172.6 & 173.0 & 172.2 & 172.4 & 172.4 & 173.3 \\
\hline 28 & 177.8 & & 173.3 & 172.4 & 173.1 & 172.2 & 172.7 & 171.9 & 172.1 & 172.1 & 173.0 \\
\hline 29 & 177.5 & & 172.9 & 172.0 & 172.8 & 171.9 & 172.4 & 171.6 & 171.8 & 171.8 & 172.7 \\
\hline 30 & 177.2 & & 172.6 & 171.7 & 172.5 & 171.6 & 172.1 & 171.3 & 171.5 & 171.5 & 172.4 \\
\hline 31 & 176.9 & & 172.3 & 171.5 & 172.2 & 171.3 & 171.8 & 171.0 & 171.2 & 171.2 & 172.1 \\
\hline 32 & 176.6 & & 172.1 & 171.2 & 171.9 & 171.0 & 171.5 & 170.7 & 170.9 & 170.9 & 171.8 \\
\hline 33 & 176.3 & & 171.8 & 170.9 & 171.6 & 170.8 & 171.2 & 170.4 & 170.6 & 170.6 & 171.5 \\
\hline 34 & 176.0 & & 171.5 & 170.6 & 171.4 & 170.5 & 171.0 & 170.2 & 170.4 & 170.4 & 171.2 \\
\hline 35 & 175.8 & & 171.3 & 170.4 & 171.1 & 170.2 & 170.7 & 169.9 & 170.1 & 170.1 & 171.0 \\
\hline 36 & 175.5 & & 171.0 & 170.1 & 170.9 & 170.0 & 170.5 & 169.7 & 169.9 & 169.9 & 170.7 \\
\hline 37 & 175.3 & & 170.8 & 169.9 & 170.6 & 169.8 & 170.2 & & 169.7 & 169.6 & 170.5 \\
\hline
\end{tabular}




\begin{tabular}{|c|c|c|c|c|c|c|c|c|c|c|c|}
\hline 38 & 175.0 & & 170.5 & 169.7 & 170.4 & & 170.0 & & & & 170.3 \\
\hline 39 & 174.8 & & 170.3 & & 170.2 & & 169.8 & & & & 170.1 \\
\hline 40 & 174.6 & & 170.1 & & 170.0 & & & & & & 169.8 \\
\hline 41 & 174.4 & & 169.9 & & 169.8 & & & & & & 169.7 \\
\hline 42 & 174.2 & & 169.7 & & & & & & & & \\
\hline Break & $\ldots$ & & & & & & & & & & \\
\hline 67 & 170.3 & & & & & & & & & & \\
\hline 68 & 170.2 & & & & & & & & & & \\
\hline 69 & 170.1 & & & & & & & & & & \\
\hline 70 & 170.0 & & & & & & & & & & \\
\hline 71 & 169.9 & & & & & & & & & & \\
\hline
\end{tabular}


Table 42: KP483 SGC Data

\begin{tabular}{|c|c|c|c|c|c|c|c|c|c|c|c|}
\hline & \multicolumn{11}{|c|}{ Height Increments (mm) } \\
\hline GYR & S1 & $\mathbf{S 2}$ & S3 & S4 & S5 & S6 & S7 & S8 & S9 & S10 & S11 \\
\hline 0 & 210.6 & 201.5 & 203.5 & 204.7 & 202.7 & 202.4 & 201.8 & 202.3 & 203.3 & 202.9 & 203.2 \\
\hline 1 & 203.2 & 194.1 & 196.1 & 197.6 & 195.4 & 195.2 & 194.7 & 195.0 & 196.1 & 195.6 & 196.0 \\
\hline 2 & 198.9 & 190.1 & 192.1 & 193.4 & 191.4 & 191.2 & 190.6 & 190.9 & 191.9 & 191.5 & 191.9 \\
\hline 3 & 195.8 & 187.1 & 189.2 & 190.4 & 188.3 & 188.2 & 187.6 & 187.9 & 188.9 & 188.5 & 188.8 \\
\hline 4 & 193.4 & 184.8 & 186.9 & 188.1 & 185.9 & 185.9 & 185.3 & 185.6 & 186.6 & 186.2 & 186.5 \\
\hline 5 & 191.3 & 182.9 & 185.0 & 186.1 & 184.0 & 184.0 & 183.4 & 183.7 & 184.7 & 184.3 & 184.6 \\
\hline 6 & 189.6 & 181.4 & 183.4 & 184.5 & 182.5 & 182.4 & 181.8 & 182.1 & 183.1 & 182.8 & 183.0 \\
\hline 7 & 188.2 & 180.0 & 182.1 & 183.2 & 181.1 & 181.1 & 180.5 & 180.8 & 181.7 & 181.4 & 181.7 \\
\hline 8 & 187.0 & 178.8 & 180.9 & 182.0 & 179.9 & 179.9 & 179.3 & 179.6 & 180.6 & 180.2 & 180.5 \\
\hline 9 & 185.9 & 177.8 & 179.9 & 180.9 & 178.9 & 178.9 & 178.3 & 178.6 & 179.6 & 179.2 & 179.5 \\
\hline 10 & 185.0 & 176.9 & 179.0 & 180.0 & 178.0 & 177.9 & 177.4 & 177.7 & 178.6 & 178.3 & 178.5 \\
\hline 11 & 184.1 & 176.1 & 178.2 & 179.2 & 177.2 & 177.1 & 176.5 & 176.8 & 177.8 & 177.4 & 177.7 \\
\hline 12 & 183.3 & 175.3 & 177.4 & 178.4 & 176.4 & 176.4 & 175.8 & 176.1 & 177.1 & 176.7 & 176.9 \\
\hline 13 & 182.6 & 174.6 & 176.7 & 177.7 & 175.8 & 175.7 & 175.1 & 175.4 & 176.4 & 176.0 & 176.3 \\
\hline 14 & 181.9 & 174.0 & 176.1 & 177.1 & 175.1 & 175.1 & 174.5 & 174.8 & 175.8 & 175.4 & 175.6 \\
\hline 15 & 181.3 & 173.4 & 175.5 & 176.5 & 174.6 & 174.5 & 173.9 & 174.2 & 175.2 & 174.8 & 175.0 \\
\hline 16 & 180.8 & 172.9 & 175.0 & 175.9 & 174.0 & 174.0 & 173.3 & 173.7 & 174.7 & 174.2 & 174.5 \\
\hline 17 & 180.3 & 172.4 & 174.5 & 175.4 & 173.5 & 173.4 & 172.8 & 173.1 & 174.2 & 173.7 & 174.0 \\
\hline 18 & 179.8 & 171.9 & 174.0 & 174.9 & 173.0 & 173.0 & 172.4 & 172.7 & 173.7 & 173.2 & 173.5 \\
\hline 19 & 179.3 & 171.5 & 173.6 & 174.5 & 172.6 & 172.5 & 171.9 & 172.2 & 173.3 & 172.8 & 173.1 \\
\hline 20 & 178.9 & 171.1 & 173.2 & 174.1 & 172.2 & 172.1 & 171.5 & 171.8 & 172.9 & 172.4 & 172.6 \\
\hline 21 & 178.5 & 170.7 & 172.8 & 173.7 & 171.8 & 171.7 & 171.1 & 171.4 & 172.5 & 172.0 & 172.3 \\
\hline 22 & 178.1 & 170.3 & 172.4 & 173.3 & 171.4 & 171.4 & 170.8 & 171.1 & 172.1 & 171.6 & 171.9 \\
\hline 23 & 177.7 & 170.0 & 172.0 & 172.9 & 171.1 & 171.0 & 170.4 & 170.7 & 171.7 & 171.3 & 171.5 \\
\hline 24 & 177.4 & 169.7 & 171.7 & 172.6 & 170.7 & 170.7 & 170.1 & 170.4 & 171.4 & 170.9 & 171.2 \\
\hline 25 & 177.0 & & 171.4 & 172.3 & 170.4 & 170.4 & 169.7 & 170.1 & 171.1 & 170.6 & 170.9 \\
\hline 26 & 176.7 & & 171.1 & 171.9 & 170.1 & 170.1 & 169.4 & 169.8 & 170.8 & 170.3 & 170.6 \\
\hline 27 & 176.4 & & 170.8 & 171.6 & 169.8 & 169.8 & & 169.5 & 170.5 & 170.0 & 170.3 \\
\hline 28 & 176.1 & & 170.5 & 171.4 & 169.6 & 169.5 & & & 170.2 & 169.7 & 170.0 \\
\hline 29 & 175.8 & & 170.2 & 171.1 & & & & & 170.0 & & 169.7 \\
\hline 30 & 175.6 & & 170.0 & 170.8 & & & & & 169.7 & & \\
\hline 31 & 175.3 & & 169.7 & 170.6 & & & & & & & \\
\hline 32 & 175.1 & & & 170.3 & & & & & & & \\
\hline 33 & 174.8 & & & 170.1 & & & & & & & \\
\hline 34 & 174.6 & & & 169.9 & & & & & & & \\
\hline 35 & 174.3 & & & 169.7 & & & & & & & \\
\hline Break & $\ldots$ & & & & & & & & & & \\
\hline 63 & 170.0 & & & & & & & & & & \\
\hline 64 & 169.9 & & & & & & & & & & \\
\hline 65 & 169.8 & & & & & & & & & & \\
\hline
\end{tabular}


Table 43: WVP523 SGC Data

\begin{tabular}{|c|c|c|c|c|c|c|c|c|c|c|c|c|}
\hline & \multicolumn{12}{|c|}{ Height Increments (mm) } \\
\hline GYR & S1 & S2 & S3 & S4 & S5 & S6 & S7 & S8 & S9 & S10 & S11 & S12 \\
\hline 0 & 197.0 & 203.5 & 193.1 & 191.5 & 190.8 & 191.5 & 191.4 & 192.5 & 193.2 & 192.7 & 192.7 & 191.9 \\
\hline 1 & 190.3 & 196.7 & 186.5 & 185.0 & 184.5 & 185.0 & 184.7 & 185.9 & 186.5 & 186.0 & 186.1 & 185.4 \\
\hline 2 & 186.6 & 193.0 & 182.9 & 181.6 & 181.1 & 181.5 & 181.4 & 182.4 & 182.9 & 182.4 & 182.6 & 181.9 \\
\hline 3 & 184.1 & 190.5 & 180.4 & 179.2 & 178.7 & 179.1 & 179.0 & 179.9 & 180.4 & 179.9 & 180.2 & 179.5 \\
\hline 4 & 182.2 & 188.5 & 178.5 & 177.3 & 176.9 & 177.2 & 177.1 & 178.1 & 178.5 & 178.1 & 178.3 & 177.7 \\
\hline 5 & 180.6 & 186.9 & 177.0 & 175.9 & 175.5 & 175.7 & 175.7 & 176.6 & 176.9 & 176.6 & 176.8 & 176.2 \\
\hline 6 & 179.3 & 185.6 & 175.7 & 174.7 & 174.2 & 174.5 & 174.4 & 175.3 & 175.7 & 175.3 & 175.5 & 175.0 \\
\hline 7 & 178.3 & 184.5 & 174.7 & 173.6 & 173.2 & 173.5 & 173.4 & 174.3 & 174.6 & 174.3 & 174.5 & 174.0 \\
\hline 8 & 177.3 & 183.5 & 173.7 & 172.7 & 172.4 & 172.6 & 172.5 & 173.4 & 173.7 & 173.4 & 173.6 & 173.1 \\
\hline 9 & 176.5 & 182.7 & 173.0 & 172.0 & 171.6 & 171.8 & 171.8 & 172.6 & 172.9 & 172.6 & 172.8 & 172.3 \\
\hline 10 & 175.8 & 182.0 & 172.2 & 171.3 & 170.9 & 171.1 & 171.1 & 171.9 & 172.2 & 171.9 & 172.1 & 171.6 \\
\hline 11 & 175.2 & 181.3 & 171.6 & 170.7 & 170.4 & 170.5 & 170.5 & 171.2 & 171.6 & 171.2 & 171.4 & 171.0 \\
\hline 12 & 174.6 & 180.7 & 171.0 & 170.1 & 169.8 & 169.9 & 169.9 & 170.7 & 171.0 & 170.7 & 170.9 & 170.4 \\
\hline 13 & 174.0 & 180.2 & 170.5 & 169.6 & 169.3 & 169.4 & 169.4 & 170.2 & 170.5 & 170.2 & 170.3 & 169.9 \\
\hline 14 & 173.6 & 179.7 & 170.0 & 169.1 & & & & 169.7 & 170.0 & 169.7 & 169.9 & 169.4 \\
\hline 15 & 173.1 & 179.2 & 169.6 & & & & & 169.2 & 169.6 & 169.2 & 169.4 & \\
\hline 16 & 172.7 & 178.8 & 169.2 & & & & & & 169.1 & & & \\
\hline 17 & 172.3 & 178.4 & & & & & & & & & & \\
\hline 18 & 171.9 & 178.0 & & & & & & & & & & \\
\hline 19 & 171.6 & 177.7 & & & & & & & & & & \\
\hline 20 & 171.3 & 177.3 & & & & & & & & & & \\
\hline 21 & 171.0 & 177.0 & & & & & & & & & & \\
\hline 22 & 170.7 & 176.7 & & & & & & & & & & \\
\hline 23 & 170.4 & 176.4 & & & & & & & & & & \\
\hline 24 & 170.2 & 176.2 & & & & & & & & & & \\
\hline 25 & 169.9 & 175.9 & & & & & & & & & & \\
\hline 26 & 169.7 & 175.7 & & & & & & & & & & \\
\hline Break & & $\ldots$ & & & & & & & & & & \\
\hline 71 & & 170.2 & & & & & & & & & & \\
\hline 72 & & 170.1 & & & & & & & & & & \\
\hline 73 & & 170.0 & & & & & & & & & & \\
\hline 74 & & 170.0 & & & & & & & & & & \\
\hline 75 & & 169.9 & & & & & & & & & & \\
\hline
\end{tabular}


Table 44: WVP766 SGC Data

\begin{tabular}{|c|c|c|c|c|c|c|c|c|c|c|c|c|}
\hline & \multicolumn{12}{|c|}{ Height Increments (mm) } \\
\hline GYR & S1 & $\mathbf{S 2}$ & S3 & S4 & S5 & S6 & S7 & S8 & S9 & S10 & S11 & S12 \\
\hline 0 & 196.4 & 211.8 & 200.9 & 201.1 & 201.2 & 201.3 & 200.0 & 199.5 & 200.1 & 200.8 & 201.0 & 201.0 \\
\hline 1 & 189.4 & 204.6 & 193.9 & 193.9 & 194.1 & 194.2 & 193.1 & 192.6 & 193.0 & 193.7 & 193.9 & 194.1 \\
\hline 2 & 185.4 & 200.5 & 189.9 & 190.0 & 190.1 & 190.3 & 189.2 & 188.6 & 189.1 & 189.7 & 190.0 & 190.1 \\
\hline 3 & 182.6 & 197.4 & 187.0 & 187.1 & 187.2 & 187.4 & 186.3 & 185.8 & 186.1 & 186.8 & 187.1 & 187.2 \\
\hline 4 & 180.4 & 195.1 & 184.8 & 184.9 & 185.0 & 185.2 & 184.1 & 183.6 & 183.9 & 184.6 & 184.9 & 185.0 \\
\hline 5 & 178.6 & 193.2 & 183.0 & 183.1 & 183.1 & 183.4 & 182.3 & 181.8 & 182.2 & 182.8 & 183.1 & 183.1 \\
\hline 6 & 177.1 & 191.6 & 181.5 & 181.6 & 181.6 & 181.9 & 180.8 & 180.3 & 180.6 & 181.2 & 181.6 & 181.7 \\
\hline 7 & 175.9 & 190.2 & 180.2 & 180.3 & 180.3 & 180.6 & 179.5 & 179.0 & 179.4 & 180.0 & 180.3 & 180.4 \\
\hline 8 & 174.8 & 189.0 & 179.1 & 179.2 & 179.2 & 179.4 & 178.4 & 177.9 & 178.3 & 178.8 & 179.2 & 179.3 \\
\hline 9 & 173.8 & 188.0 & 178.1 & 178.2 & 178.2 & 178.4 & 177.4 & 177.0 & 177.3 & 177.9 & 178.2 & 178.3 \\
\hline 10 & 172.9 & 187.1 & 177.3 & 177.4 & 177.3 & 177.6 & 176.5 & 176.1 & 176.4 & 177.0 & 177.3 & 177.4 \\
\hline 11 & 172.2 & 186.2 & 176.5 & 176.6 & 176.5 & 176.8 & 175.7 & 175.4 & 175.6 & 176.2 & 176.5 & 176.6 \\
\hline 12 & 171.4 & 185.5 & 175.8 & 175.9 & 175.8 & 176.1 & 175.0 & 174.6 & 174.9 & 175.5 & 175.8 & 175.9 \\
\hline 13 & 170.8 & 184.8 & 175.1 & 175.2 & 175.1 & 175.4 & 174.4 & 174.0 & 174.3 & 174.8 & 175.1 & 175.3 \\
\hline 14 & 170.2 & 184.2 & 174.5 & 174.6 & 174.5 & 174.8 & 173.8 & 173.4 & 173.7 & 174.2 & 174.5 & 174.7 \\
\hline 15 & 169.7 & 183.6 & 173.9 & 174.1 & 173.9 & 174.2 & 173.2 & 172.9 & 173.1 & 173.6 & 174.0 & 174.1 \\
\hline 16 & 169.1 & 183.0 & 173.4 & 173.5 & 173.4 & 173.7 & 172.7 & 172.4 & 172.6 & 173.1 & 173.5 & 173.6 \\
\hline 17 & & 182.5 & 172.9 & 173.1 & 172.9 & 173.2 & 172.2 & 171.9 & 172.1 & 172.6 & 173.0 & 173.1 \\
\hline 18 & & 182.0 & 172.5 & 172.6 & 172.5 & 172.8 & 171.8 & 171.4 & 171.6 & 172.2 & 172.5 & 172.7 \\
\hline 19 & & 181.6 & 172.1 & 172.2 & 172.1 & 172.4 & 171.3 & 171.0 & 171.2 & 171.8 & 172.1 & 172.3 \\
\hline 20 & & 181.2 & 171.7 & 171.8 & 171.6 & 172.0 & 170.9 & 170.6 & 170.8 & 171.4 & 171.7 & 171.9 \\
\hline 21 & & 180.8 & 171.3 & 171.4 & 171.3 & 171.6 & 170.5 & 170.2 & 170.4 & 171.0 & 171.3 & 171.5 \\
\hline 22 & & 180.4 & 170.9 & 171.1 & 170.9 & 171.2 & 170.2 & 169.9 & 170.1 & 170.6 & 170.9 & 171.1 \\
\hline 23 & & 180.0 & 170.6 & 170.7 & 170.6 & 170.9 & 169.8 & 169.5 & 169.7 & 170.3 & 170.6 & 170.8 \\
\hline 24 & & 179.7 & 170.3 & 170.4 & 170.2 & 170.6 & 169.5 & & 169.4 & 169.9 & 170.3 & 170.5 \\
\hline 25 & & 179.4 & 170.0 & 170.1 & 169.9 & 170.3 & & & & 169.6 & 170.0 & 170.2 \\
\hline 26 & & 179.1 & 169.7 & 169.8 & 169.6 & 170.0 & & & & & 169.7 & 169.9 \\
\hline 27 & & 178.8 & & 169.5 & & 169.7 & & & & & & 169.6 \\
\hline Break & & $\ldots$ & & & & & & & & & & \\
\hline 98 & & 170.1 & & & & & & & & & & \\
\hline 99 & & 170.1 & & & & & & & & & & \\
\hline 100 & & 170.0 & & & & & & & & & & \\
\hline 101 & & 170.0 & & & & & & & & & & \\
\hline 102 & & 169.9 & & & & & & & & & & \\
\hline
\end{tabular}


Table 45: WVP882 SGC Data

\begin{tabular}{|c|c|c|c|c|c|c|c|c|c|c|c|}
\hline & \multicolumn{10}{|c|}{ Height Increments (mm) } \\
\hline GYR & S1 & S2 & S3 & S4 & S5 & S6 & S7 & S8 & S9 & S10 & S11 \\
\hline 0 & 191.4 & 201.3 & 191.9 & 191.6 & 192.1 & 191.9 & 192.9 & 191.4 & 190.7 & 192.4 & 192.7 \\
\hline 1 & 184.6 & 194.4 & 185.2 & 184.8 & 185.4 & 185.3 & 186.1 & 184.8 & 183.9 & 185.7 & 186.0 \\
\hline 2 & 181.0 & 190.6 & 181.5 & 181.3 & 181.8 & 181.6 & 182.5 & 181.1 & 180.3 & 182.1 & 182.3 \\
\hline 3 & 178.3 & 187.8 & 178.9 & 178.8 & 179.2 & 178.9 & 179.9 & 178.5 & 177.7 & 179.4 & 179.6 \\
\hline 4 & 176.3 & 185.7 & 176.9 & 176.7 & 177.1 & 177.0 & 177.8 & 176.4 & 175.7 & 177.3 & 177.6 \\
\hline 5 & 174.7 & 184.0 & 175.2 & 175.1 & 175.4 & 175.3 & 176.2 & 174.8 & 174.1 & 175.7 & 175.9 \\
\hline 6 & 173.3 & 182.6 & 173.9 & 173.8 & 174.1 & 174.0 & 174.8 & 173.4 & 172.8 & 174.3 & 174.5 \\
\hline 7 & 172.2 & 181.4 & 172.7 & 172.6 & 172.9 & 172.8 & 173.6 & 172.2 & 171.6 & 173.1 & 173.3 \\
\hline 8 & 171.2 & 180.3 & 171.7 & 171.6 & 171.9 & 171.8 & 172.6 & 171.2 & 170.6 & 172.1 & 172.3 \\
\hline 9 & 170.3 & 179.4 & 170.8 & 170.7 & 171.0 & 170.9 & 171.6 & 170.3 & 169.8 & 171.2 & 171.5 \\
\hline 10 & 169.5 & 178.5 & 170.0 & 170.0 & 170.2 & 170.1 & 170.8 & 169.5 & 168.9 & 170.4 & 170.6 \\
\hline 11 & 168.8 & 177.8 & 169.2 & 169.2 & 169.5 & 169.4 & 170.1 & 168.7 & & 169.7 & 169.9 \\
\hline 12 & & 177.1 & & & 168.8 & 168.81 & 169.5 & & & 169.0 & 169.2 \\
\hline 13 & & 176.5 & & & & & 168.8 & & & & \\
\hline 14 & & 175.9 & & & & & & & & & \\
\hline 15 & & 175.4 & & & & & & & & & \\
\hline 16 & & 174.9 & & & & & & & & & \\
\hline 17 & & 174.4 & & & & & & & & & \\
\hline 18 & & 174.0 & & & & & & & & & \\
\hline 19 & & 173.5 & & & & & & & & & \\
\hline 20 & & 173.2 & & & & & & & & & \\
\hline 21 & & 172.8 & & & & & & & & & \\
\hline 22 & & 172.5 & & & & & & & & & \\
\hline 23 & & 172.1 & & & & & & & & & \\
\hline 24 & & 171.8 & & & & & & & & & \\
\hline 25 & & 171.5 & & & & & & & & & \\
\hline 26 & & 171.3 & & & & & & & & & \\
\hline 27 & & 171.0 & & & & & & & & & \\
\hline 28 & & 170.7 & & & & & & & & & \\
\hline 29 & & 170.5 & & & & & & & & & \\
\hline 30 & & 170.3 & & & & & & & & & \\
\hline 31 & & 170.1 & & & & & & & & & \\
\hline 32 & & 169.8 & & & & & & & & & \\
\hline 33 & & 169.7 & & & & & & & & & \\
\hline
\end{tabular}


Verification Data

Table 46: Marshall Verification Data

\begin{tabular}{|c|c|c|c|c|c|c|c|c|c|c|}
\hline \multirow{2}{*}{ Sample \# } & \multicolumn{1}{|c|}{ Diameter $(\mathbf{m m})$} & \multicolumn{2}{|c|}{ Height $(\mathbf{m m})$} & \multicolumn{2}{|c|}{ SSD } & \multicolumn{2}{|c|}{ CL } & \multicolumn{2}{c|}{ Dim. } \\
\cline { 2 - 11 } & AVG & SD & AVG & SD & Gmb & VTM & Gmb & VTM & Gmb & VTM \\
\hline AA937_10 & 101.60 & 0.00 & 62.19 & 0.05 & 2.424 & 2.6 & 2.394 & 3.8 & 2.380 & 4.4 \\
\hline AA937_11 & 101.60 & 0.00 & 62.46 & 0.06 & 2.422 & 2.7 & 2.386 & 4.2 & 2.366 & 5.0 \\
\hline AA937_12 & 101.60 & 0.00 & 62.23 & 0.05 & 2.423 & 2.7 & 2.389 & 4.0 & 2.373 & 4.7 \\
\hline JAP909_22 & 101.50 & 0.00 & 61.19 & 0.15 & 2.539 & 4.1 & 2.503 & 5.5 & 2.472 & 6.7 \\
\hline JAP909_23 & 101.60 & 0.00 & 61.10 & 0.02 & 2.543 & 4.0 & 2.505 & 5.4 & 2.470 & 6.7 \\
\hline JAP909_24 & 101.60 & 0.00 & 61.22 & 0.15 & 2.534 & 4.3 & 2.499 & 5.6 & 2.464 & 6.9 \\
\hline JFA060_1 & 101.70 & 0.00 & 63.00 & 0.04 & 2.436 & 3.6 & 2.395 & 5.2 & 2.349 & 7.1 \\
\hline JFA060_2 & 101.70 & 0.00 & 62.68 & 0.12 & 2.446 & 3.2 & 2.412 & 4.6 & 2.364 & 6.5 \\
\hline JFA060_3 & 101.60 & 0.00 & 61.85 & 0.15 & 2.447 & 3.2 & 2.414 & 4.5 & 2.395 & 5.3 \\
\hline JFA115_7 & 101.70 & 0.00 & 62.89 & 0.02 & 2.387 & 4.1 & 2.360 & 5.2 & 2.378 & 4.5 \\
\hline JFA115_8 & 101.70 & 0.00 & 64.56 & 0.08 & 2.380 & 4.4 & 2.347 & 5.7 & 2.324 & 6.6 \\
\hline JFA115_9 & 101.70 & 0.00 & 64.64 & 0.07 & 2.386 & 4.1 & 2.346 & 5.7 & 2.322 & 6.7 \\
\hline KP483_16 & 101.60 & 0.00 & 63.75 & 0.09 & 2.362 & 4.4 & 2.333 & 5.6 & 2.313 & 6.4 \\
\hline KP483_17 & 101.60 & 0.00 & 63.59 & 0.03 & 2.365 & 4.3 & 2.341 & 5.3 & 2.323 & 6.0 \\
\hline KP483_18 & 101.70 & 0.00 & 63.15 & 0.04 & 2.367 & 4.2 & 2.339 & 5.3 & 2.321 & 6.1 \\
\hline WVP523_13 & 101.60 & 0.00 & 63.04 & 0.08 & 2.404 & 3.6 & 2.386 & 4.3 & 2.374 & 4.8 \\
\hline WVP523_14 & 101.70 & 0.00 & 63.32 & 0.05 & 2.400 & 3.7 & 2.384 & 4.4 & 2.368 & 5.0 \\
\hline WVP523_15 & 101.65 & 0.00 & 63.66 & 0.07 & 2.401 & 3.7 & 2.384 & 4.4 & 2.363 & 5.2 \\
\hline WVP766_19 & 101.60 & 0.00 & 63.80 & 0.22 & 2.384 & 3.6 & 2.361 & 4.6 & 2.334 & 5.7 \\
\hline WVP766_20 & 101.60 & 0.00 & 63.70 & 0.17 & 2.383 & 3.7 & 2.362 & 4.5 & 2.335 & 5.6 \\
\hline WVP766_21 & 101.65 & 0.00 & 63.60 & 0.20 & 2.384 & 3.6 & 2.362 & 4.5 & 2.336 & 5.6 \\
\hline WVP882_4 & 101.60 & 0.00 & 63.33 & 0.07 & 2.386 & 2.5 & 2.369 & 3.2 & 2.354 & 3.8 \\
\hline WVP882_5 & 101.60 & 0.00 & 62.89 & 0.02 & 2.400 & 1.9 & 2.374 & 3.0 & 2.368 & 3.2 \\
\hline WVP882_6 & 101.60 & 0.00 & 63.42 & 0.03 & 2.394 & 2.2 & 2.377 & 2.8 & 2.364 & 3.4 \\
\hline
\end{tabular}

Table 47: Superpave Verification Data

\begin{tabular}{|c|c|c|c|c|c|c|c|c|c|c|}
\hline \multirow{2}{*}{ Sample \# } & \multicolumn{2}{|c|}{ Diameter $(\mathbf{m m})$} & \multicolumn{2}{c|}{ Height $(\mathbf{m m})$} & \multicolumn{2}{c|}{ SSD } & \multicolumn{2}{c|}{ CoreLok } & \multicolumn{2}{c|}{ Dimensional } \\
\cline { 2 - 11 } & AVG & SD & AVG & SD & Gmb & VTM & Gmb & VTM & Gmb & VTM \\
\hline JFA429_SS1 & 149.97 & 0.07 & 108.54 & 0.08 & 2.378 & 6.1 & 2.349 & 7.1 & 2.301 & 9.0 \\
\hline JFA429_SS2 & 149.83 & 0.07 & 110.36 & 0.07 & 2.378 & 6.1 & 2.351 & 7.1 & 2.307 & 8.8 \\
\hline
\end{tabular}




\section{Bulk Specific Gravities $\left(\mathrm{G}_{\mathrm{mb}}\right)$ for Sample Thirds}

Table 48: Bulk Mix Specific Gravities $\left(\mathrm{G}_{\mathrm{mb}}\right)$ for Thirds

\begin{tabular}{|c|c|c|c|c|}
\hline \multirow{2}{*}{$\overline{\mathbf{M i x}}$} & \multirow[b]{2}{*}{ Section } & \multicolumn{3}{|c|}{$\mathbf{G}_{\mathbf{m b}}$} \\
\hline & & SSD & CoreLok & Dimensional \\
\hline \multirow{9}{*}{937} & TOP & 2.298 & 2.286 & 2.275 \\
\hline & TOP & 2.317 & 2.370 & 2.349 \\
\hline & TOP & 2.296 & 2.304 & 2.275 \\
\hline & MIDDLE & 2.304 & 2.303 & 2.272 \\
\hline & MIDDLE & 2.296 & 2.377 & 2.358 \\
\hline & MIDDLE & 2.308 & 2.292 & 2.257 \\
\hline & BOTTOM & 2.322 & 2.326 & 2.299 \\
\hline & BOTTOM & 2.309 & 2.397 & 2.378 \\
\hline & BOTTOM & 2.301 & 2.310 & 2.286 \\
\hline \multirow{9}{*}{909} & TOP & 2.460 & 2.457 & 2.389 \\
\hline & TOP & 2.450 & 2.454 & 2.431 \\
\hline & TOP & 2.470 & 2.476 & 2.430 \\
\hline & MIDDLE & 2.470 & 2.469 & 2.382 \\
\hline & MIDDLE & 2.470 & 2.469 & 2.445 \\
\hline & MIDDLE & 2.460 & 2.456 & 2.441 \\
\hline & BOTTOM & 2.480 & 2.488 & 2.404 \\
\hline & BOTTOM & 2.450 & 2.451 & 2.448 \\
\hline & BOTTOM & 2.460 & 2.462 & 2.434 \\
\hline \multirow{9}{*}{060} & TOP & 2.337 & 2.325 & 2.465 \\
\hline & TOP & 2.347 & 2.349 & 2.314 \\
\hline & TOP & 2.349 & 2.350 & 2.324 \\
\hline & MIDDLE & 2.340 & 2.335 & 2.450 \\
\hline & MIDDLE & 2.348 & 2.343 & 2.329 \\
\hline & MIDDLE & 2.357 & 2.357 & 2.324 \\
\hline & BOTTOM & 2.334 & 2.330 & 2.475 \\
\hline & BOTTOM & 2.356 & 2.356 & 2.322 \\
\hline & BOTTOM & 2.348 & 2.353 & 2.330 \\
\hline \multirow{9}{*}{115} & TOP & 2.324 & 2.318 & 2.307 \\
\hline & TOP & 2.315 & 2.313 & 2.297 \\
\hline & TOP & 2.326 & 2.325 & 2.306 \\
\hline & MIDDLE & 2.324 & 2.321 & 2.311 \\
\hline & MIDDLE & 2.324 & 2.322 & 2.306 \\
\hline & MIDDLE & 2.322 & 2.322 & 2.302 \\
\hline & BОTТОМ & 2.339 & 2.326 & 2.321 \\
\hline & BOTTOM & 2.326 & 2.337 & 2.322 \\
\hline & ВОТТОМ & 2.311 & 2.308 & 2.298 \\
\hline
\end{tabular}




\begin{tabular}{|c|c|c|c|c|}
\hline \multirow{9}{*}{429} & TOP & 2.359 & 2.350 & 2.359 \\
\hline & TOP & 2.358 & 2.348 & 2.339 \\
\hline & TOP & 2.364 & 2.346 & 2.332 \\
\hline & MIDDLE & 2.346 & 2.335 & 2.343 \\
\hline & MIDDLE & 2.353 & 2.344 & 2.328 \\
\hline & MIDDLE & 2.366 & 2.364 & 2.334 \\
\hline & BOTTOM & 2.371 & 2.357 & 2.357 \\
\hline & BOTTOM & 2.363 & 2.350 & 2.351 \\
\hline & BOTTOM & 2.371 & 2.363 & 2.334 \\
\hline \multirow{9}{*}{483} & TOP & 2.282 & 2.270 & 2.256 \\
\hline & TOP & 2.301 & 2.296 & 2.281 \\
\hline & TOP & 2.313 & 2.308 & 2.290 \\
\hline & MIDDLE & 2.290 & 2.290 & 2.267 \\
\hline & MIDDLE & 2.317 & 2.307 & 2.289 \\
\hline & MIDDLE & 2.308 & 2.300 & 2.283 \\
\hline & BOTTOM & 2.306 & 2.303 & 2.281 \\
\hline & BOTTOM & 2.314 & 2.306 & 2.286 \\
\hline & BOTTOM & 2.312 & 2.301 & 2.287 \\
\hline \multirow{9}{*}{523} & TOP & 2.312 & 2.294 & 2.295 \\
\hline & TOP & 2.312 & 2.302 & 2.288 \\
\hline & TOP & 2.293 & 2.294 & 2.279 \\
\hline & MIDDLE & 2.331 & 2.317 & 2.309 \\
\hline & MIDDLE & 2.326 & 2.320 & 2.287 \\
\hline & MIDDLE & 2.325 & 2.321 & 2.310 \\
\hline & BOTTOM & 2.339 & 2.317 & 2.300 \\
\hline & BOTTOM & 2.321 & 2.309 & 2.293 \\
\hline & BOTTOM & 2.301 & 2.297 & 2.274 \\
\hline \multirow{9}{*}{766} & TOP & 2.297 & 2.291 & 2.277 \\
\hline & TOP & 2.303 & 2.302 & 2.288 \\
\hline & TOP & 2.286 & 2.290 & 2.269 \\
\hline & MIDDLE & 2.310 & 2.310 & 2.289 \\
\hline & MIDDLE & 2.309 & 2.313 & 2.287 \\
\hline & MIDDLE & 2.300 & 2.296 & 2.261 \\
\hline & BOTTOM & 2.312 & 2.311 & 2.298 \\
\hline & BOTTOM & 2.297 & 2.284 & 2.272 \\
\hline & BOTTOM & 2.304 & 2.305 & 2.279 \\
\hline \multirow{9}{*}{882} & TOP & 2.267 & 2.246 & 2.251 \\
\hline & TOP & 2.290 & 2.287 & 2.272 \\
\hline & TOP & 2.283 & 2.284 & 2.264 \\
\hline & MIDDLE & 2.289 & 2.290 & 2.284 \\
\hline & MIDDLE & 2.279 & 2.268 & 2.264 \\
\hline & MIDDLE & 2.288 & 2.288 & 2.271 \\
\hline & BOTTOM & 2.276 & 2.271 & 2.265 \\
\hline & BOTTOM & 2.275 & 2.268 & 2.260 \\
\hline & BOTTOM & 2.277 & 2.273 & 2.258 \\
\hline
\end{tabular}


Sample Thirds Geometry and VTM

Table 49: AA937 Sample Thirds Geometry and VTM

\begin{tabular}{|c|c|c|c|c|c|c|c|c|}
\cline { 2 - 9 } \multicolumn{1}{c|}{} & \multicolumn{2}{c|}{ Diameter } & \multicolumn{2}{c|}{ Height } & \multicolumn{4}{c|}{ VTM } \\
\hline S\# & AVG & SD & AVG & SD & SSD & CL & Dim. & AVG \\
\hline S1_T & 100.49 & 0.04 & 47.48 & 0.05 & 7.7 & 8.2 & 8.6 & 8.2 \\
\hline S1_M & 100.46 & 0.01 & 47.07 & 0.25 & 7.5 & 7.5 & 8.7 & 7.9 \\
\hline S1_B & 100.46 & 0.00 & 48.67 & 0.29 & 6.7 & 6.6 & 7.6 & 7.0 \\
\hline S2_T & 100.45 & 0.05 & 49.28 & 0.29 & 4.6 & 4.8 & 5.6 & 5.0 \\
\hline S2_M & 100.45 & 0.06 & 49.66 & 0.12 & 4.6 & 4.5 & 5.3 & 4.8 \\
\hline S2_B & 100.41 & 0.03 & 46.21 & 0.08 & 4.0 & 3.7 & 4.5 & 4.1 \\
\hline S3_T & 100.46 & 0.01 & 49.34 & 0.36 & 6.9 & 7.4 & 8.6 & 7.6 \\
\hline S3_M & 100.47 & 0.01 & 48.15 & 0.48 & 7.8 & 7.9 & 9.3 & 8.3 \\
\hline S3_B & 100.48 & 0.01 & 46.34 & 0.25 & 7.2 & 7.2 & 8.2 & 7.5 \\
\hline S4_T & 100.46 & 0.01 & 48.44 & 0.25 & 7.8 & 7.9 & 8.4 & 8.0 \\
\hline S4_M & 100.45 & 0.02 & 47.42 & 0.31 & 7.3 & 7.6 & 8.3 & 7.7 \\
\hline S4_B & 100.48 & 0.02 & 47.75 & 0.13 & 7.6 & 7.9 & 8.5 & 8.0 \\
\hline
\end{tabular}

Table 50: JAP909 Sample Thirds Geometry and VTM

\begin{tabular}{|c|c|c|c|c|c|c|c|c|}
\cline { 2 - 9 } \multicolumn{1}{c|}{} & \multicolumn{2}{c}{ Diameter } & \multicolumn{2}{c|}{ Height } & \multicolumn{4}{c|}{ VTM } \\
\hline S\# & AVG & SD & AVG & SD & SSD & CL & Dim. & AVG \\
\hline S1_T & 100.45 & 0.10 & 43.81 & 0.25 & 8.1 & 8.1 & 9.6 & 8.6 \\
\hline S1_M & 100.51 & 0.01 & 49.19 & 0.31 & 8.9 & 8.8 & 9.9 & 9.2 \\
\hline S1_B & 100.33 & 0.04 & 49.99 & 0.49 & 7.9 & 8 & 9.1 & 8.3 \\
\hline S2_T & 100.60 & 0.05 & 49.66 & 0.33 & 7.1 & 7.1 & 8.1 & 7.4 \\
\hline S2_M & 100.56 & 0.06 & 47.58 & 0.10 & 6.6 & 6.6 & 7.5 & 6.9 \\
\hline S2_B & 100.59 & 0.02 & 45.86 & 0.40 & 6 & 5.9 & 7.4 & 6.4 \\
\hline S3_T & 100.63 & 0.06 & 47.31 & 0.05 & 7.3 & 7.2 & 8.1 & 7.5 \\
\hline S3_M & 100.59 & 0.06 & 46.31 & 0.06 & 6.7 & 6.6 & 7.7 & 7.0 \\
\hline S3_B & 100.57 & 0.01 & 47.34 & 0.12 & 7.2 & 7.3 & 7.9 & 7.5 \\
\hline S4_T & 100.76 & 0.18 & 46.96 & 0.33 & 6.7 & 6.3 & 7.9 & 7.0 \\
\hline S4_M & 100.66 & 0.11 & 48.57 & 0.77 & 7.1 & 7.1 & 8.7 & 7.6 \\
\hline S4_B & 100.51 & 0.04 & 46.20 & 0.17 & 7.1 & 6.9 & 7.6 & 7.2 \\
\hline
\end{tabular}


Table 51: JFA060 Sample Thirds Geometry and VTM

\begin{tabular}{|c|c|c|c|c|c|c|c|c|}
\cline { 2 - 10 } \multicolumn{1}{c|}{} & \multicolumn{2}{c|}{ Diameter } & \multicolumn{2}{c|}{ Height } & \multicolumn{4}{c|}{ VTM } \\
\hline S\# & AVG & SD & AVG & SD & SSD & CL & Dim. & AVG \\
\hline S1_T & 100.33 & 0.07 & 47.4 & 0.46 & 1.8 & 1.9 & 2.5 & 2.1 \\
\hline S1_M & 100.38 & 0 & 48.5 & 0.29 & 2.4 & 2.5 & 3.1 & 2.7 \\
\hline S1_B & 100.37 & 0.04 & 46.76 & 0.11 & 1.6 & 2.0 & 2.1 & 1.9 \\
\hline S2_T & 100.43 & 0.01 & 46.07 & 0.2 & 7.6 & 8.1 & 8.5 & 8.1 \\
\hline S2_M & 100.45 & 0.01 & 46.8 & 0.1 & 7.4 & 7.6 & 7.9 & 7.6 \\
\hline S2_B & 100.36 & 0.04 & 47.87 & 0.15 & 7.7 & 7.8 & 8.2 & 7.9 \\
\hline S3_T & 100.5 & 0.13 & 46.54 & 0.12 & 7.2 & 7.1 & 8.1 & 7.5 \\
\hline S3_M & 100.6 & 0.08 & 47.45 & 0.09 & 7.1 & 7.3 & 8.1 & 7.5 \\
\hline S3_B & 100.44 & 0.01 & 48.62 & 0.22 & 6.8 & 6.8 & 7.9 & 7.2 \\
\hline S4_T & 100.5 & 0.04 & 47.66 & 0.07 & 7.1 & 7.0 & 7.7 & 7.3 \\
\hline S4_M & 100.5 & 0.04 & 47.38 & 0.34 & 6.8 & 6.8 & 8.2 & 7.3 \\
\hline S4_B & 100.41 & 0.03 & 48.11 & 0.2 & 7.1 & 6.9 & 8 & 7.3 \\
\hline
\end{tabular}

Table 53: JFA115 Sample Thirds Geometry and VTM

\begin{tabular}{|c|c|c|c|c|c|c|c|c|}
\cline { 2 - 10 } \multicolumn{1}{c|}{} & \multicolumn{2}{c|}{ Diameter } & \multicolumn{2}{c|}{ Height } & \multicolumn{4}{c|}{ VTM } \\
\hline S\# & AVG & SD & AVG & SD & SSD & CL & Dim. & AVG \\
\hline S1_T & 100.36 & 0 & 47.5 & 0.16 & 4.7 & 4.7 & 5.2 & 4.9 \\
\hline S1_M & 100.35 & 0.02 & 48.28 & 0.08 & 4.9 & 5.1 & 5.4 & 5.1 \\
\hline S1_B & 100.35 & 0.01 & 48.19 & 0.11 & 4.5 & 4.6 & 4.9 & 4.7 \\
\hline S2_T & 100.17 & 0.07 & 45.99 & 0.25 & 14.6 & 14.9 & 16.2 & 15.2 \\
\hline S2_M & 100.29 & 0.01 & 48.19 & 0.09 & 14.2 & 14.6 & 13.9 & 14.2 \\
\hline S2_B & 100.23 & 0.01 & 49 & 0.1 & 15.2 & 16 & 17.6 & 16.3 \\
\hline S3_T & 100.49 & 0.01 & 47.98 & 0.12 & 6.8 & 7.1 & 7.5 & 7.1 \\
\hline S3_M & 100.39 & 0.01 & 49.36 & 0.19 & 6.8 & 6.9 & 7.3 & 7.0 \\
\hline S3_B & 100.41 & 0.02 & 45.93 & 0.17 & 6.2 & 6.7 & 6.9 & 6.6 \\
\hline S4_T & 100.46 & 0.02 & 46.18 & 0.2 & 7.2 & 7.3 & 7.9 & 7.5 \\
\hline S4_M & 100.44 & 0.01 & 48.38 & 0.32 & 6.8 & 6.9 & 7.6 & 7.1 \\
\hline S4_B & 100.46 & 0.04 & 47.58 & 0.16 & 6.7 & 6.3 & 6.9 & 6.6 \\
\hline S5_T & 100.43 & 0.02 & 47.33 & 0.25 & 6.7 & 6.8 & 7.5 & 7.0 \\
\hline S5_M & 100.48 & 0.01 & 48.15 & 0.22 & 6.9 & 6.9 & 7.7 & 7.2 \\
\hline S5_B & 100.42 & 0.01 & 46.37 & 0.07 & 7.4 & 7.5 & 7.9 & 7.6 \\
\hline
\end{tabular}


Table 52: JFA429 Sample Thirds Geometry and VTM

\begin{tabular}{|c|c|c|c|c|c|c|c|c|}
\cline { 2 - 9 } \multicolumn{1}{c|}{} & \multicolumn{2}{c|}{ Diameter } & \multicolumn{2}{c|}{ Height } & \multicolumn{4}{c|}{ VTM } \\
\hline S\# & AVG & SD & AVG & SD & SSD & CL & Dim. & AVG \\
\hline S1_T & 100.35 & 0.02 & 47.25 & 0.34 & 7.2 & 7.2 & 8.3 & 7.6 \\
\hline S1_M & 100.33 & 0.00 & 48.62 & 0.24 & 8.4 & 9.3 & 9.2 & 9.0 \\
\hline S1_B & 100.34 & 0.02 & 37.94 & 19.70 & 7.7 & 8.0 & 9.0 & 8.2 \\
\hline S2_T & 100.41 & 0.00 & 47.55 & 0.26 & 5.7 & 5.9 & 6.7 & 6.1 \\
\hline S2_M & 100.39 & 0.00 & 46.84 & 0.20 & 6.4 & 6.2 & 7.3 & 6.6 \\
\hline S2_B & 100.39 & 0.03 & 49.30 & 0.58 & 5.4 & 5.7 & 6.8 & 6.0 \\
\hline S3_T & 100.46 & 0.03 & 49.79 & 0.13 & 6.7 & 7.1 & 7.5 & 7.1 \\
\hline S3_M & 100.48 & 0.01 & 49.07 & 0.16 & 7.3 & 7.7 & 8.0 & 7.7 \\
\hline S3_B & 100.42 & 0.03 & 43.78 & 0.15 & 6.2 & 6.8 & 7.0 & 6.7 \\
\hline S4_T & 100.44 & 0.04 & 47.44 & 0.25 & 6.8 & 7.1 & 7.8 & 7.2 \\
\hline S4_M & 100.46 & 0.01 & 47.59 & 0.07 & 7.0 & 7.3 & 7.7 & 7.3 \\
\hline S4_B & 100.49 & 0.01 & 48.28 & 0.28 & 6.5 & 7.1 & 7.7 & 7.1 \\
\hline S5_T & 100.43 & 0.01 & 48.07 & 0.26 & 6.5 & 7.2 & 7.7 & 7.1 \\
\hline S5_M & 100.44 & 0.02 & 47.97 & 0.42 & 6.4 & 6.5 & 7.7 & 6.9 \\
\hline S5_B & 100.47 & 0.01 & 47.80 & 0.21 & 6.2 & 6.6 & 7.5 & 6.8 \\
\hline
\end{tabular}

Table 54: KP483 Sample Thirds Geometry and VTM

\begin{tabular}{|c|c|c|c|c|c|c|c|c|}
\cline { 2 - 9 } \multicolumn{1}{c|}{} & \multicolumn{2}{c|}{ Diameter } & \multicolumn{2}{c|}{ Height } & \multicolumn{4}{c|}{ VTM } \\
\hline S\# & AVG & SD & AVG & SD & SSD & CL & Dim. & AVG \\
\hline S1_T & 100.41 & 0.02 & 47.61 & 0.45 & 4.4 & 4.5 & 5.3 & 4.7 \\
\hline S1_M & 100.40 & 0.03 & 48.05 & 0.14 & 4.4 & 4.5 & 5.1 & 4.7 \\
\hline S1_B & 100.45 & 0.05 & 46.97 & 0.07 & 3.8 & 4.2 & 4.2 & 4.1 \\
\hline S2_T & 100.55 & 0.04 & 47.87 & 0.36 & 7.6 & 8.2 & 8.7 & 8.2 \\
\hline S2_M & 100.49 & 0.05 & 47.97 & 0.17 & 7.3 & 7.3 & 8.2 & 7.6 \\
\hline S2_B & 100.42 & 0.04 & 47.71 & 0.32 & 6.7 & 6.8 & 7.7 & 7.1 \\
\hline S3_T & 100.45 & 0.01 & 47.13 & 0.27 & 6.9 & 7.1 & 7.7 & 7.2 \\
\hline S3_M & 100.48 & 0.00 & 48.84 & 0.16 & 6.2 & 6.6 & 7.4 & 6.7 \\
\hline S3_B & 100.44 & 0.04 & 46.54 & 0.32 & 6.3 & 6.7 & 7.5 & 6.8 \\
\hline S4_T & 100.45 & 0.01 & 46.60 & 0.25 & 6.4 & 6.6 & 7.3 & 6.8 \\
\hline S4_M & 100.44 & 0.00 & 49.12 & 0.25 & 6.6 & 6.9 & 7.6 & 7.0 \\
\hline S4_B & 100.47 & 0.02 & 47.71 & 0.11 & 6.4 & 6.9 & 7.5 & 6.9 \\
\hline
\end{tabular}


Table 55: WVP523 Sample Thirds Geometry and VTM

\begin{tabular}{|c|c|c|c|c|c|c|c|c|}
\cline { 2 - 9 } \multicolumn{1}{c|}{} & \multicolumn{2}{c|}{ Diameter } & \multicolumn{2}{c|}{ Height } & \multicolumn{4}{c|}{ VTM } \\
\hline S\# & AVG & SD & AVG & SD & SSD & CL & Dim. & AVG \\
\hline S1_T & 100.41 & 0.01 & 46.89 & 0.31 & 5.2 & 5.4 & 6.0 & 5.5 \\
\hline S1_M & 100.43 & 0.01 & 48.49 & 0.33 & 4.9 & 4.8 & 6.0 & 5.2 \\
\hline S1_B & 100.45 & 0.03 & 47.22 & 0.07 & 5.4 & 5.4 & 6.0 & 5.6 \\
\hline S2_T & 100.46 & 0.04 & 47.56 & 0.13 & 2.6 & 2.6 & 4.6 & 3.3 \\
\hline S2_M & 100.43 & 0.01 & 49.56 & 0.29 & 2.3 & 2.5 & 3.5 & 2.8 \\
\hline S2_B & 100.46 & 0.02 & 47.26 & 0.31 & 2.4 & 2.5 & 2.6 & 2.5 \\
\hline S3_T & 100.44 & 0.01 & 48.35 & 0.05 & 7.3 & 8.0 & 8.0 & 7.8 \\
\hline S3_M & 100.48 & 0.01 & 47.5 & 0.26 & 6.5 & 7.1 & 7.4 & 7.0 \\
\hline S3_B & 100.47 & 0.04 & 48.53 & 0.12 & 6.2 & 7.1 & 7.8 & 7.0 \\
\hline S4_T & 100.47 & 0.01 & 45.54 & 0.18 & 7.3 & 7.7 & 8.2 & 7.7 \\
\hline S4_M & 100.48 & 0.01 & 50.96 & 0.61 & 6.7 & 6.9 & 8.3 & 7.3 \\
\hline S4_B & 100.50 & 0.05 & 47.02 & 0.28 & 6.9 & 7.4 & 8.0 & 7.4 \\
\hline S5_T & 100.43 & 0.01 & 47.28 & 0.09 & 8.0 & 8.0 & 8.6 & 8.2 \\
\hline S5_M & 100.43 & 0.02 & 48.58 & 0.31 & 6.7 & 6.9 & 7.3 & 7.0 \\
\hline S5_B & 100.46 & 0.01 & 47.21 & 0.38 & 7.7 & 7.9 & 8.8 & 8.1 \\
\hline
\end{tabular}

Table 56: WVP766 Sample Thirds Geometry and VTM

\begin{tabular}{|c|c|c|c|c|c|c|c|c|}
\cline { 2 - 10 } \multicolumn{1}{c|}{} & \multicolumn{2}{c}{ Diameter } & \multicolumn{2}{c|}{ Height } & \multicolumn{4}{c|}{ VTM } \\
\hline S\# & AVG & SD & AVG & SD & SSD & CL & Dim. & AVG \\
\hline S1_T & 100.58 & 0.09 & 48.41 & 0.27 & 8.7 & 8.9 & 9.7 & 9.1 \\
\hline S1_M & 100.52 & 0.01 & 46.70 & 0.35 & 9.0 & 9.1 & 10.1 & 9.4 \\
\hline S1_B & 100.50 & 0.09 & 47.83 & 0.06 & 8.9 & 9.2 & 9.8 & 9.3 \\
\hline S2_T & 100.50 & 0.14 & 45.73 & 0.07 & 2.6 & 2.7 & 3.3 & 2.9 \\
\hline S2_M & 100.51 & 0.03 & 48.52 & 0.41 & 2.4 & 2.2 & 3.2 & 2.6 \\
\hline S2_B & 100.47 & 0.01 & 48.02 & 0.28 & 2.5 & 2.5 & 3.0 & 2.7 \\
\hline S3_T & 100.59 & 0.03 & 49.81 & 0.08 & 7.2 & 7.4 & 7.8 & 7.5 \\
\hline S3_M & 100.67 & 0.06 & 45.46 & 0.19 & 6.6 & 6.6 & 7.4 & 6.9 \\
\hline S3_B & 100.56 & 0.06 & 47.38 & 0.07 & 6.5 & 6.6 & 7.0 & 6.7 \\
\hline S4_T & 100.54 & 0.01 & 48.25 & 0.07 & 6.9 & 7.0 & 7.4 & 7.1 \\
\hline S4_M & 100.53 & 0.03 & 47.64 & 0.46 & 6.7 & 6.5 & 7.5 & 6.9 \\
\hline S4_B & 100.52 & 0.05 & 46.02 & 0.15 & 7.1 & 7.7 & 8.0 & 7.6 \\
\hline S5_T & 100.54 & 0.05 & 47.41 & 0.13 & 7.6 & 7.4 & 8.2 & 7.7 \\
\hline S5_M & 100.53 & 0.06 & 47.89 & 0.37 & 7.0 & 7.2 & 8.5 & 7.6 \\
\hline S5_B & 100.50 & 0.08 & 47.79 & 0.46 & 6.9 & 6.8 & 7.8 & 7.2 \\
\hline
\end{tabular}


Table 57: WVP882 Sample Thirds Geometry and VTM

\begin{tabular}{|c|c|c|c|c|c|c|c|c|}
\cline { 2 - 10 } \multicolumn{1}{c|}{} & \multicolumn{2}{c|}{ Diameter } & \multicolumn{2}{c|}{ Height } & \multicolumn{4}{c|}{ VTM } \\
\hline S\# & AVG & SD & AVG & SD & SSD & CL & Dim. & AVG \\
\hline S1_T & 100.50 & 0.00 & 48.00 & 0.28 & 7.4 & 8.2 & 8.0 & 7.9 \\
\hline S1_M & 100.49 & 0.06 & 45.89 & 0.05 & 6.5 & 6.4 & 6.6 & 6.5 \\
\hline S1_B & 100.49 & 0.01 & 49.75 & 0.14 & 7.1 & 7.2 & 7.4 & 7.2 \\
\hline S2_T & 100.50 & 0.01 & 49.65 & 0.08 & 3.3 & 3.2 & 3.9 & 3.5 \\
\hline S2_M & 100.49 & 0.01 & 47.34 & 0.26 & 2.8 & 2.9 & 3.8 & 3.2 \\
\hline S2_B & 100.39 & 0.01 & 46.84 & 0.30 & 2.8 & 3.0 & 3.9 & 3.2 \\
\hline S3_T & 100.46 & 0.01 & 48.68 & 0.08 & 6.5 & 6.5 & 7.2 & 6.7 \\
\hline S3_M & 100.47 & 0.03 & 46.97 & 0.19 & 6.9 & 7.3 & 7.5 & 7.2 \\
\hline S3_B & 100.42 & 0.03 & 47.89 & 0.20 & 7.1 & 7.3 & 7.6 & 7.3 \\
\hline S4_T & 100.46 & 0.01 & 47.58 & 0.22 & 6.8 & 6.6 & 7.5 & 7.0 \\
\hline S4_M & 100.44 & 0.05 & 46.25 & 0.16 & 6.6 & 6.5 & 7.2 & 6.8 \\
\hline S4_B & 100.44 & 0.04 & 47.70 & 0.15 & 7.0 & 7.1 & 7.7 & 7.3 \\
\hline
\end{tabular}


Full Sample Volumetrics - Bulk Mix Specific Gravities $\left(\mathrm{G}_{\mathrm{mb}}\right)$ Before and After Coring and Sawing

Table 58: AA937 $\mathrm{G}_{\mathrm{mb}}$ Before and After Trimming

\begin{tabular}{|c|c|c|c|c|c|c|c|}
\cline { 3 - 8 } \multicolumn{2}{c|}{} & \multicolumn{3}{c|}{ Before } & \multicolumn{3}{c|}{ After } \\
\hline Test & S\# & Dim. & CoreLok & SSD & Dim. & CoreLok & SSD \\
\hline DM & 1 & 2.230 & 2.267 & 2.293 & 2.302 & 2.309 & 2.315 \\
\hline L & 2 & 2.310 & 2.345 & 2.362 & 2.378 & 2.382 & 2.387 \\
\hline DM & 3 & 2.230 & 2.264 & 2.303 & 2.297 & 2.305 & 2.312 \\
\hline DM & 4 & 2.231 & 2.267 & 2.294 & 2.295 & 2.303 & 2.308 \\
\hline FT & 5 & 2.236 & 2.273 & 2.298 & 2.313 & 2.301 & 2.328 \\
\hline FT & 6 & 2.239 & 2.276 & 2.305 & 2.324 & 2.335 & 2.331 \\
\hline FT & 7 & 2.239 & 2.275 & 2.300 & 2.325 & 2.336 & 2.334 \\
\hline FN & 8 & 2.229 & 2.264 & 2.293 & 2.294 & 2.31 & 2.311 \\
\hline FN & 9 & 2.231 & 2.266 & 2.293 & 2.298 & 2.312 & 2.311 \\
\hline FN & 10 & 2.227 & 2.263 & 2.291 & 2.299 & 2.311 & 2.313 \\
\hline FN & 11 & 2.226 & 2.259 & 2.290 & 2.293 & 2.306 & 2.308 \\
\hline
\end{tabular}

Table 59: JAP909 $\mathrm{G}_{\mathrm{mb}}$ Before and After Trimming

\begin{tabular}{|c|c|c|c|c|c|c|c|}
\cline { 2 - 8 } \multicolumn{2}{c|}{} & \multicolumn{3}{c|}{ Before } & \multicolumn{3}{c|}{ After } \\
\hline Test & S \# & Dim. & CoreLok & SSD & Dim. & CoreLok & SSD \\
\hline H & 1 & 2.344 & 2.398 & 2.403 & 2.411 & 2.422 & 2.427 \\
\hline DM & 2 & 2.392 & 2.445 & 2.472 & 2.463 & 2.471 & 2.475 \\
\hline DM & 3 & 2.386 & 2.436 & 2.464 & 2.459 & 2.459 & 2.465 \\
\hline DM & 4 & 2.382 & 2.431 & 2.457 & 2.458 & 2.452 & 2.470 \\
\hline FN & 5 & 2.385 & 2.430 & 2.455 & 2.452 & 2.459 & 2.464 \\
\hline FT & 6 & 2.380 & 2.431 & 2.452 & 2.467 & 2.474 & 2.479 \\
\hline FT & 7 & 2.373 & 2.422 & 2.447 & 2.458 & 2.474 & 2.471 \\
\hline FT & 8 & 2.371 & 2.422 & 2.453 & 2.456 & 2.474 & 2.470 \\
\hline FN & 9 & 2.383 & 2.427 & 2.457 & 2.457 & 2.477 & 2.472 \\
\hline FN & 10 & 2.383 & 2.428 & 2.455 & 2.453 & 2.472 & 2.468 \\
\hline FN & 11 & 2.381 & 2.426 & 2.451 & 2.462 & 2.48 & 2.474 \\
\hline
\end{tabular}


Table 60: JFA060 $\mathrm{G}_{\mathrm{mb}}$ Before and After Trimming

\begin{tabular}{|c|c|c|c|c|c|c|c|}
\cline { 3 - 8 } \multicolumn{2}{c|}{} & \multicolumn{3}{c|}{ Before } & \multicolumn{3}{c|}{ After } \\
\hline Test & S \# & Dim. & CoreLok & SSD & Dim. & CoreLok & SSD \\
\hline L & 1 & 2.412 & 2.452 & 2.465 & 2.481 & 2.474 & 2.485 \\
\hline DM & 2 & 2.242 & 2.292 & 2.326 & 2.333 & 2.345 & 2.341 \\
\hline DM & 3 & 2.260 & 2.311 & 2.34 & 2.343 & 2.351 & 2.354 \\
\hline DM & 4 & 2.259 & 2.302 & 2.341 & 2.345 & 2.351 & 2.356 \\
\hline FT & 5 & 2.260 & 2.310 & 2.339 & 2.339 & 2.361 & 2.360 \\
\hline FT & 6 & 2.256 & 2.301 & 2.331 & 2.362 & 2.375 & 2.371 \\
\hline FT & 7 & 2.252 & 2.297 & 2.328 & 2.342 & 2.358 & 2.356 \\
\hline FN & 8 & 2.258 & 2.305 & 2.334 & 2.341 & 2.348 & 2.353 \\
\hline FN & 9 & 2.257 & 2.300 & 2.33 & 2.340 & 2.353 & 2.354 \\
\hline FN & 10 & 2.257 & 2.300 & 2.33 & 2.342 & 2.356 & 2.354 \\
\hline FN & 11 & 2.257 & 2.294 & 2.336 & 2.354 & 2.367 & 2.365 \\
\hline
\end{tabular}

Table 61: JFA115 $\mathrm{G}_{\mathrm{mb}}$ Before and After Trimming

\begin{tabular}{|c|c|c|c|c|c|c|c|}
\cline { 3 - 8 } \multicolumn{2}{c|}{} & \multicolumn{3}{c|}{ Before } & \multicolumn{3}{c|}{ After } \\
\hline Test & S \# & Dim. & CoreLok & SSD & Dim. & CoreLok & SSD \\
\hline L & 1 & 2.311 & 2.343 & 2.357 & 2.375 & 2.383 & 2.381 \\
\hline H & 2 & 2.048 & 2.077 & 2.156 & 2.109 & 2.124 & 2.133 \\
\hline DM & 3 & 2.257 & 2.290 & 2.306 & 2.327 & 2.337 & 2.331 \\
\hline DM & 4 & 2.259 & 2.292 & 2.309 & 2.324 & 2.334 & 2.333 \\
\hline DM & 5 & 2.256 & 2.287 & 2.304 & 2.316 & 2.331 & 2.323 \\
\hline FT & 6 & 2.247 & 2.279 & 2.297 & 2.314 & 2.32 & 2.323 \\
\hline FT & 7 & 2.247 & 2.280 & 2.300 & 2.326 & 2.335 & 2.335 \\
\hline FT & 8 & 2.247 & 2.277 & 2.294 & 2.317 & 2.325 & 2.326 \\
\hline FN & 9 & 2.253 & 2.282 & 2.300 & 2.310 & 2.321 & 2.320 \\
\hline FN & 10 & 2.254 & 2.284 & 2.302 & 2.314 & 2.325 & 2.325 \\
\hline FN & 11 & 2.253 & 2.282 & 2.301 & 2.320 & 2.334 & 2.329 \\
\hline
\end{tabular}


Table 62: JFA429 $\mathrm{G}_{\mathrm{mb}}$ Before and After Trimming

\begin{tabular}{|c|c|c|c|c|c|c|c|}
\cline { 3 - 8 } \multicolumn{2}{c|}{} & \multicolumn{3}{c|}{ Before } & \multicolumn{3}{c|}{ After } \\
\hline Test & S \# & Dim. & CoreLok & SSD & Dim. & CoreLok & SSD \\
\hline H & 1 & 2.239 & 2.291 & 2.329 & 2.318 & 2.328 & 2.335 \\
\hline L & 2 & 2.299 & 2.347 & 2.372 & 2.373 & 2.389 & 2.385 \\
\hline DM & 3 & 2.275 & 2.325 & 2.350 & 2.349 & 2.356 & 2.361 \\
\hline DM & 4 & 2.272 & 2.320 & 2.350 & 2.348 & 2.357 & 2.364 \\
\hline DM & 5 & 2.274 & 2.321 & 2.351 & 2.358 & 2.366 & 2.370 \\
\hline FT & 6 & 2.269 & 2.315 & 2.347 & 2.364 & 2.371 & 2.373 \\
\hline FT & 7 & 2.262 & 2.313 & 2.346 & 2.355 & 2.37 & 2.366 \\
\hline FT & 8 & 2.255 & 2.296 & 2.332 & 2.347 & 2.362 & 2.359 \\
\hline FN & 9 & 2.271 & 2.316 & 2.348 & 2.354 & 2.368 & 2.365 \\
\hline FN & 10 & 2.272 & 2.314 & 2.346 & 2.345 & 2.359 & 2.358 \\
\hline
\end{tabular}

Table 63: $\mathrm{KP} 483 \mathrm{G}_{\mathrm{mb}}$ Before and After Trimming

\begin{tabular}{|c|c|c|c|c|c|c|c|}
\cline { 3 - 8 } \multicolumn{2}{c|}{} & \multicolumn{3}{c|}{ Before } & \multicolumn{3}{c|}{ After } \\
\hline Test & S \# & Dim. & CoreLok & SSD & Dim. & CoreLok & SSD \\
\hline L & 1 & 2.305 & 2.335 & 2.349 & 2.362 & 2.368 & 2.370 \\
\hline DM & 2 & 2.224 & 2.257 & 2.278 & 2.288 & 2.292 & 2.296 \\
\hline DM & 3 & 2.239 & 2.270 & 2.288 & 2.303 & 2.315 & 2.313 \\
\hline DM & 4 & 2.241 & 2.273 & 2.290 & 2.303 & 2.309 & 2.314 \\
\hline FN & 5 & 2.228 & 2.260 & 2.281 & 2.295 & 2.306 & 2.306 \\
\hline FT & 6 & 2.229 & 2.260 & 2.281 & 2.303 & 2.315 & 2.313 \\
\hline FT & 7 & 2.228 & 2.258 & 2.281 & 2.299 & 2.306 & 2.308 \\
\hline FT & 8 & 2.226 & 2.257 & 2.279 & 2.298 & 2.311 & 2.308 \\
\hline FN & 9 & 2.232 & 2.262 & 2.285 & 2.295 & 2.307 & 2.307 \\
\hline FN & 10 & 2.233 & 2.257 & 2.283 & 2.297 & 2.308 & 2.306 \\
\hline FN & 11 & 2.232 & 2.260 & 2.279 & 2.292 & 2.306 & 2.304 \\
\hline
\end{tabular}


Table 64: WVP523 $\mathrm{G}_{\mathrm{mb}}$ Before and After Trimming

\begin{tabular}{|c|c|c|c|c|c|c|c|}
\cline { 3 - 8 } \multicolumn{2}{c|}{} & \multicolumn{3}{c|}{ Before } & \multicolumn{3}{c|}{ After } \\
\hline Test & S \# & Dim. & CoreLok & SSD & Dim. & CoreLok & SSD \\
\hline H & 1 & 2.304 & 2.336 & 2.350 & 2.363 & 2.364 & 2.367 \\
\hline L & 2 & 2.372 & 2.392 & 2.410 & 2.428 & 2.431 & 2.434 \\
\hline DM & 3 & 2.257 & 2.282 & 2.303 & 2.321 & 2.331 & 2.327 \\
\hline DM & 4 & 2.259 & 2.286 & 2.306 & 2.319 & 2.325 & 2.324 \\
\hline DM & 5 & 2.257 & 2.292 & 2.296 & 2.302 & 2.307 & 2.310 \\
\hline FT & 6 & 2.252 & 2.279 & 2.292 & 2.315 & 2.321 & 2.304 \\
\hline FT & 7 & 2.252 & 2.284 & 2.301 & 2.315 & 2.333 & 2.326 \\
\hline FT & 8 & 2.254 & 2.285 & 2.293 & 2.317 & 2.334 & 2.330 \\
\hline FN & 9 & 2.261 & 2.293 & 2.316 & 2.333 & 2.343 & 2.341 \\
\hline FN & 10 & 2.259 & 2.288 & 2.307 & 2.314 & 2.327 & 2.324 \\
\hline FN & 11 & 2.257 & 2.289 & 2.305 & 2.321 & 2.332 & 2.330 \\
\hline FN & 12 & 2.257 & 2.277 & 2.297 & 2.307 & 2.322 & 2.317 \\
\hline
\end{tabular}

Table 65: WVP766 $\mathrm{G}_{\mathrm{mb}}$ Before and After Trimming

\begin{tabular}{|c|c|c|c|c|c|c|c|}
\cline { 3 - 8 } \multicolumn{2}{c|}{} & \multicolumn{3}{c|}{ Before } & \multicolumn{3}{c|}{ After } \\
\hline Test & S \# & Dim. & CoreLok & SSD & Dim. & CoreLok & SSD \\
\hline H & 1 & 2.194 & 2.220 & 2.236 & 2.244 & 2.249 & 2.255 \\
\hline L & 2 & 2.361 & 2.387 & 2.392 & 2.412 & 2.414 & 2.416 \\
\hline DM & 3 & 2.245 & 2.273 & 2.287 & 2.315 & 2.308 & 2.310 \\
\hline DM & 4 & 2.244 & 2.265 & 2.289 & 2.293 & 2.302 & 2.307 \\
\hline DM & 5 & 2.242 & 2.268 & 2.285 & 2.289 & 2.298 & 2.301 \\
\hline FT & 6 & 2.239 & 2.253 & 2.280 & 2.304 & 2.308 & 2.312 \\
\hline FT & 7 & 2.237 & 2.262 & 2.281 & 2.300 & 2.312 & 2.310 \\
\hline FT & 8 & 2.234 & 2.261 & 2.277 & 2.292 & 2.305 & 2.305 \\
\hline FN & 9 & 2.246 & 2.271 & 2.287 & 2.301 & 2.315 & 2.312 \\
\hline FN & 10 & 2.243 & 2.267 & 2.283 & 2.295 & 2.307 & 2.305 \\
\hline FN & 11 & 2.241 & 2.265 & 2.282 & 2.291 & 2.306 & 2.303 \\
\hline FN & 12 & 2.243 & 2.266 & 2.283 & 2.297 & 2.308 & 2.309 \\
\hline
\end{tabular}


Table 66: WVP882 $\mathrm{G}_{\mathrm{mb}}$ Before and After Trimming

\begin{tabular}{|c|c|c|c|c|c|c|c|}
\cline { 2 - 8 } \multicolumn{2}{c|}{} & \multicolumn{3}{c|}{ Before } & \multicolumn{3}{c|}{ After } \\
\hline Test & S \# & Dim. & CoreLok & SSD & Dim. & CoreLok & SSD \\
\hline DM & 1 & 2.214 & 2.248 & 2.265 & 2.276 & 2.276 & 2.283 \\
\hline L & 2 & 2.305 & 2.339 & 2.351 & 2.373 & 2.377 & 2.379 \\
\hline DM & 3 & 2.212 & 2.243 & 2.261 & 2.278 & 2.284 & 2.285 \\
\hline DM & 4 & 2.212 & 2.244 & 2.264 & 2.279 & 2.281 & 2.286 \\
\hline FN & 5 & 2.210 & 2.243 & 2.260 & 2.277 & 2.286 & 2.283 \\
\hline FN & 6 & 2.210 & 2.242 & 2.260 & 2.277 & 2.285 & 2.288 \\
\hline FT & 7 & 2.214 & 2.245 & 2.266 & 2.291 & 2.289 & 2.301 \\
\hline FT & 8 & 2.209 & 2.241 & 2.262 & 2.276 & 2.288 & 2.286 \\
\hline FT & 9 & 2.204 & 2.238 & 2.253 & 2.275 & 2.288 & 2.286 \\
\hline FN & 10 & 2.211 & 2.242 & 2.263 & 2.276 & 2.287 & 2.289 \\
\hline FN & 11 & 2.209 & 2.233 & 2.257 & 2.274 & 2.287 & 2.285 \\
\hline
\end{tabular}


Geometry and VTM, VMA, and VFA for Full Samples

Table 67: AA937 Sample Geometry

\begin{tabular}{|c|c|c|c|c|c|}
\hline \multicolumn{2}{|c|}{} & \multicolumn{2}{c|}{ Diameter } & \multicolumn{2}{c|}{ Height } \\
\hline Test & S\# & AVG & SD & AVG & SD \\
\hline DM & 1 & 100.40 & 0.03 & 150.11 & 0.11 \\
\hline L & 2 & 100.38 & 0.03 & 152.22 & 0.10 \\
\hline DM & 3 & 100.43 & 0.02 & 150.32 & 0.12 \\
\hline DM & 4 & 100.40 & 0.03 & 150.84 & 0.11 \\
\hline FT & 5 & 100.43 & 0.02 & 131.86 & 0.18 \\
\hline FT & 6 & 100.39 & 0.02 & 130.44 & 0.05 \\
\hline FT & 7 & 100.41 & 0.04 & 130.82 & 0.04 \\
\hline FN & 8 & 100.45 & 0.02 & 149.85 & 0.30 \\
\hline FN & 9 & 100.45 & 0.01 & 150.73 & 0.16 \\
\hline FN & 10 & 100.44 & 0.02 & 150.65 & 0.15 \\
\hline FN & 11 & 100.44 & 0.01 & 150.57 & 0.10 \\
\hline
\end{tabular}

Table 68: AA937 VTM Before and After Trimming

\begin{tabular}{|c|c|c|c|c|c|c|c|c|c|c|c|c|c|c|c|}
\hline \multicolumn{16}{|c|}{$(\%)$} \\
\hline \multirow[b]{2}{*}{ Test } & \multirow[b]{2}{*}{ S\# } & \multicolumn{5}{|c|}{ Before } & \multicolumn{5}{|c|}{ After } & \multicolumn{4}{|c|}{ Difference } \\
\hline & & Abs. & SSD & CL & Dim. & AVG & & SSD & CL & Dim. & AVG & SSD & CL & Dim. & \\
\hline$\overline{\mathrm{DM}}$ & 1 & 2.0 & 7.9 & 8.9 & 10.4 & 9.1 & & .0 & 7.2 & 7.5 & 7.3 & 0.9 & 1.7 & 2.9 & 1.8 \\
\hline $\mathrm{L}$ & 2 & & & 5.8 & & 6.1 & & & & & & & 1.5 & & 1. \\
\hline$\overline{D M}$ & 3 & & 7 . & 9.0 & & & & & & & 7.4 & & 1.6 & & 1.6 \\
\hline$\overline{\mathrm{DM}}$ & $\overline{4}$ & & 7. & 8.9 & & 9 . & & 7.7 & 7.5 & 7.8 & 7.5 & 0 & 1.4 & & 1.5 \\
\hline$\overline{\text { FT }}$ & 5 & 2. & 7.7 & 8.7 & 10.2 & 8. & & 6 & 7.5 & 7.1 & 7.0 & 1.2 & 1.2 & & 1.9 \\
\hline FT & $\epsilon$ & 1. & $\overline{7.4}$ & 8.6 & 10.1 & 8. & & 6.3 & 6.2 & 6.6 & 6.4 & 1.1 & 2.4 & 5 & 2.3 \\
\hline FT & 7 & 2. & 7.6 & 8.6 & 10.1 & 8. & 0 . & 6.2 & 6.1 & 6.6 & 6.3 & 1.4 & 2.5 & .5 & 2.5 \\
\hline FN & 8 & 1. & $\overline{7.9}$ & 9.1 & 10.5 & 9.2 & 0. & 7.2 & 7.2 & 7.9 & 7.4 & 0.7 & 1.9 & 2.6 & $\overline{1.8}$ \\
\hline FN & 9 & 1.8 & 7.9 & 9.0 & 10.4 & 9.1 & 0.6 & 7.2 & 7.1 & 7.7 & 7.3 & 0.7 & 1.9 & 2.7 & 1.8 \\
\hline$\overline{\mathrm{FN}}$ & 10 & 2.0 & 8.0 & 9.1 & 10.5 & 9.2 & 0.7 & 7.1 & 7.2 & 7.7 & 7.3 & 0.9 & 1.9 & 2.8 & 1.9 \\
\hline $\mathrm{EN}$ & 11 & 2.2 & 8.0 & 9.2 & 10.6 & 9.3 & 1.2 & 7.3 & 7.3 & 7.9 & 7.5 & 0.7 & 1.9 & 2.7 & 1.8 \\
\hline
\end{tabular}


Table 69: AA937 VMA Before and After Trimming

\begin{tabular}{|c|c|c|c|c|c|c|c|c|c|}
\hline \multicolumn{10}{|c|}{ VMA (\%) } \\
\hline & & \multicolumn{9}{|c|}{ Before } & \multicolumn{4}{|c|}{ After } \\
\cline { 3 - 11 } Test & S\# & SSD & CL & Dim. & AVG & SSD & CL & Dim. & AVG \\
\hline DM & 1 & 17.1 & 18.0 & 19.4 & 18.2 & 16.3 & 16.5 & 16.7 & 16.5 \\
\hline L & 2 & 14.6 & 15.2 & 16.4 & 15.4 & 13.7 & 13.8 & 14.0 & 13.8 \\
\hline DM & 3 & 16.7 & 18.1 & 19.4 & 18.1 & 16.4 & 16.6 & 16.9 & 16.6 \\
\hline DM & 4 & 17.0 & 18.0 & 19.3 & 18.1 & 16.5 & 16.7 & 17.0 & 16.7 \\
\hline FT & 5 & 16.9 & 17.8 & 19.1 & 17.9 & 15.8 & 16.8 & 16.4 & 16.3 \\
\hline FT & 6 & 16.6 & 17.7 & 19.0 & 17.8 & 15.7 & 15.6 & 16.0 & 15.7 \\
\hline FT & 7 & 16.8 & 17.7 & 19.0 & 17.8 & 15.6 & 15.5 & 15.9 & 15.7 \\
\hline FN & 8 & 17.1 & 18.1 & 19.4 & 18.2 & 16.4 & 16.4 & 17.0 & 16.6 \\
\hline FN & 9 & 17.1 & 18.0 & 19.3 & 18.1 & 16.4 & 16.4 & 16.9 & 16.6 \\
\hline FN & 10 & 17.1 & 18.2 & 19.5 & 18.3 & 16.3 & 16.4 & 16.9 & 16.5 \\
\hline FN & 11 & 17.2 & 18.3 & 19.5 & 18.3 & 16.5 & 16.6 & 17.1 & 16.7 \\
\hline
\end{tabular}

Table 70: AA937 VFA Before and After Trimming

\begin{tabular}{|c|c|c|c|c|c|c|c|c|c|}
\hline \multicolumn{10}{|c|}{ BFA (\%) } \\
\hline & \multirow{2}{*}{ Test } & S\# & \multicolumn{9}{|c|}{ BSD } & CL & Dim. & AVG & SSD & CL & Dim. & AVG \\
\hline DM & 1 & 53.8 & 50.4 & 46.1 & 50.1 & 56.9 & 56.1 & 55.1 & 56.0 \\
\hline L & 2 & 64.9 & 61.9 & 56.3 & 61.0 & 69.9 & 69.0 & 68.1 & 69.0 \\
\hline DM & 3 & 55.2 & 50.1 & 46.1 & 50.5 & 56.6 & 55.5 & 54.4 & 55.5 \\
\hline DM & 4 & 53.9 & 50.5 & 46.2 & 50.2 & 55.9 & 55.2 & 54.1 & 55.1 \\
\hline FT & 5 & 54.4 & 51.1 & 46.8 & 50.8 & 59.0 & 55.0 & 56.6 & 56.9 \\
\hline FT & 6 & 55.5 & 51.6 & 47.2 & 51.4 & 59.6 & 60.1 & 58.3 & 59.3 \\
\hline FT & 7 & 54.9 & 51.4 & 47.1 & 51.1 & 60.0 & 60.4 & 58.5 & 59.6 \\
\hline FN & 8 & 53.8 & 50.0 & 46.0 & 49.9 & 56.4 & 56.3 & 53.9 & 55.5 \\
\hline FN & 9 & 53.8 & 50.3 & 46.3 & 50.1 & 56.4 & 56.5 & 54.5 & 55.8 \\
\hline FN & 10 & 53.5 & 49.9 & 45.8 & 49.7 & 56.7 & 56.4 & 54.6 & 55.9 \\
\hline FN & 11 & 53.4 & 49.5 & 45.7 & 49.5 & 55.9 & 55.7 & 53.9 & 55.2 \\
\hline
\end{tabular}


Table 71: JAP909 Sample Geometry

\begin{tabular}{|c|c|c|c|c|c|}
\hline \multicolumn{2}{|c|}{} & \multicolumn{2}{c|}{ Diameter } & \multicolumn{2}{c|}{ Height } \\
\hline Test & S\# & AVG & SD & AVG & SD \\
\hline H & 1 & 100.43 & 0.10 & 149.99 & 0.50 \\
\hline DM & 2 & 100.45 & 0.02 & 150.22 & 0.09 \\
\hline DM & 3 & 100.43 & 0.03 & 148.39 & 0.07 \\
\hline DM & 4 & 100.42 & 0.05 & 148.76 & 0.02 \\
\hline FN & 5 & 100.41 & 0.03 & 150.35 & 0.10 \\
\hline FT & 6 & 100.42 & 0.04 & 130.04 & 0.13 \\
\hline FT & 7 & 100.42 & 0.03 & 131.62 & 0.12 \\
\hline FT & 8 & 100.44 & 0.02 & 130.42 & 0.09 \\
\hline FN & 9 & 100.48 & 0.02 & 151.35 & 0.08 \\
\hline FN & 10 & 100.45 & 0.04 & 149.96 & 0.08 \\
\hline FN & 11 & 100.45 & 0.03 & 149.58 & 0.08 \\
\hline
\end{tabular}

Table 72: JAP909 VTM Before and After Trimming

\begin{tabular}{|c|c|c|c|c|c|c|c|c|c|c|c|c|c|c|c|}
\hline \multicolumn{16}{|c|}{ VTM (\%) } \\
\hline \multirow[b]{2}{*}{ Test } & \multirow[b]{2}{*}{ S\# } & \multicolumn{5}{|c|}{ Before } & \multicolumn{5}{|c|}{ After } & \multicolumn{4}{|c|}{ Difference } \\
\hline & & Abs. & SSD & CL & Dim. & AVG & bs. & SSD & CL & Dim. & AVG & SSD & CL & Dim. & AVG \\
\hline $\mathrm{H}$ & 1 & 1.9 & 9.1 & 9.3 & 11.4 & \begin{tabular}{|l|}
9.9 \\
\end{tabular} & 0.5 & 8.2 & 8.4 & \begin{tabular}{|l|}
8.8 \\
\end{tabular} & 8.5 & 0.9 & 0.9 & \begin{tabular}{|l|}
2.6 \\
\end{tabular} & 1.4 \\
\hline DM & 2 & & 6 & 7. & & 7.8 & & & .5 & .8 & 6.6 & & 1.0 & 7 & 1.2 \\
\hline$\overline{\mathrm{DM}}$ & 3 & & 6.8 & 7.9 & & 8.2 & & & 7.0 & 7.0 & 6.9 & & 0.9 & 8 & 1.3 \\
\hline DM & 2 & & 7.1 & 8.0 & 9. & 8.3 & & & 7.2 & 7.0 & 6.9 & 0.5 & 0.8 & .9 & 1.4 \\
\hline FN & 5 & & 7.1 & 8.1 & & 8.3 & & & 7.0 & 7.3 & 7.0 & 0.3 & 1.1 & 2.5 & 1.3 \\
\hline FT & $\epsilon$ & 1. & 7.2 & 8.1 & 10.0 & 8.4 & & 6.2 & 6.4 & 6.7 & 6.4 & 1.0 & 1.7 & 3.3 & 2.0 \\
\hline FT & 7 & 1. & 7.4 & 8.4 & 10.2 & 8.7 & 0.2 & 6.5 & 6.4 & 7.0 & 6.7 & 0.9 & 2.0 & 3.2 & 2.0 \\
\hline FT & 8 & 1. & 7.2 & 8.4 & 10.3 & 8.6 & 0.2 & 6.6 & 6.4 & 7.1 & 6.7 & 0.6 & 2.0 & 3.2 & 1.9 \\
\hline FN & 9 & 1.2 & 7.1 & 8.2 & 9.9 & 8.4 & 0.4 & 6.5 & 6.3 & 7.0 & 6.6 & 0.6 & 1.9 & 2.9 & 1.8 \\
\hline FN & 10 & 1.1 & 7.1 & 8. & 9.9 & 8.4 & 0.3 & 6.6 & 6.5 & 7.2 & 6.8 & 0.5 & 1.7 & 2.7 & 1.6 \\
\hline FN & 11 & 1.3 & 7.3 & 8.3 & 9.9 & 8.5 & 0.3 & 6.4 & 6.2 & 6.9 & 6.5 & 0.9 & 2.1 & 3.0 & 2.0 \\
\hline
\end{tabular}


Table 73: JAP909 VMA Before and After Trimming

\begin{tabular}{|c|c|c|c|c|c|c|c|c|c|}
\hline \multicolumn{10}{|c|}{ BMA (\%) } \\
\hline & & \multicolumn{9}{|c|}{ Before } & \multicolumn{4}{c|}{ After } \\
\cline { 3 - 11 } Test & S\# & SSD & CL & Dim. & AVG & SSD & CL & Dim. & AVG \\
\hline H & 1 & 17.8 & 17.9 & 19.8 & 18.5 & 16.9 & 17.1 & 17.5 & 17.2 \\
\hline DM & 2 & 15.4 & 16.3 & 18.1 & 16.6 & 15.3 & 15.5 & 15.7 & 15.5 \\
\hline DM & 3 & 15.7 & 16.7 & 18.4 & 16.9 & 15.7 & 15.9 & 15.9 & 15.8 \\
\hline DM & 4 & 15.9 & 16.8 & 18.5 & 17.1 & 15.5 & 16.1 & 15.9 & 15.8 \\
\hline FN & 5 & 16.0 & 16.8 & 18.4 & 17.1 & 15.7 & 15.9 & 16.1 & 15.9 \\
\hline FT & 6 & 16.1 & 16.8 & 18.6 & 17.2 & 15.2 & 15.3 & 15.6 & 15.4 \\
\hline FT & 7 & 16.3 & 17.1 & 18.8 & 17.4 & 15.5 & 15.3 & 15.9 & 15.6 \\
\hline FT & 8 & 16.1 & 17.1 & 18.9 & 17.4 & 15.5 & 15.3 & 16.0 & 15.6 \\
\hline FN & 9 & 15.9 & 17.0 & 18.5 & 17.1 & 15.4 & 15.3 & 15.9 & 15.5 \\
\hline FN & 10 & 16.0 & 16.9 & 18.4 & 17.1 & 15.5 & 15.4 & 16.0 & 15.7 \\
\hline FN & 11 & 16.1 & 17.0 & 18.5 & 17.2 & 15.4 & 15.2 & 15.8 & 15.4 \\
\hline
\end{tabular}

Table 74: JAP909 VFA Before and After Trimming

\begin{tabular}{|c|c|c|c|c|c|c|c|c|c|}
\hline \multicolumn{10}{|c|}{ BFA (\%) } \\
\hline \multirow{2}{*}{ Test } & S\# & \multicolumn{9}{|c|}{ Before } & \multicolumn{4}{c|}{ After } \\
\hline & SSD & CL & Dim. & AVG & SSD & CL & Dim. & AVG \\
\hline H & 1 & 48.8 & 48.2 & 42.7 & 46.6 & 51.7 & 51.0 & 49.7 & 50.8 \\
\hline DM & 2 & 57.9 & 53.9 & 47.6 & 53.1 & 58.3 & 57.7 & 56.5 & 57.5 \\
\hline DM & 3 & 56.6 & 52.7 & 46.8 & 52.0 & 56.7 & 55.9 & 55.9 & 56.2 \\
\hline DM & 4 & 55.7 & 52.2 & 46.4 & 51.4 & 57.6 & 55.0 & 55.7 & 56.1 \\
\hline FN & 5 & 55.4 & 52.1 & 46.7 & 51.4 & 56.6 & 55.9 & 54.9 & 55.8 \\
\hline FT & 6 & 55.0 & 52.1 & 46.3 & 51.1 & 59.0 & 58.2 & 57.1 & 58.1 \\
\hline FT & 7 & 54.2 & 51.0 & 45.5 & 50.2 & 57.7 & 58.2 & 55.7 & 57.2 \\
\hline FT & 8 & 55.0 & 51.0 & 45.3 & 50.4 & 57.5 & 58.1 & 55.4 & 57.0 \\
\hline FN & 9 & 55.6 & 51.6 & 46.5 & 51.2 & 57.8 & 58.6 & 55.7 & 57.3 \\
\hline FN & 10 & 55.3 & 51.8 & 46.6 & 51.2 & 57.3 & 57.9 & 55.1 & 56.8 \\
\hline FN & 11 & 54.8 & 51.5 & 46.4 & 50.9 & 58.1 & 59.0 & 56.3 & 57.8 \\
\hline
\end{tabular}


Table 75: JFA060 Sample Geometry

\begin{tabular}{|c|c|c|c|c|c|}
\hline \multicolumn{2}{|c|}{} & \multicolumn{2}{c|}{ Diameter } & \multicolumn{2}{c|}{ Height } \\
\hline Test & S\# & AVG & SD & AVG & SD \\
\hline L & 1 & 100.33 & 0.03 & 149.55 & 0.14 \\
\hline DM & 2 & 100.33 & 0.04 & 148.51 & 0.06 \\
\hline DM & 3 & 100.38 & 0.04 & 150.21 & 0.06 \\
\hline DM & 4 & 100.36 & 0.02 & 150.55 & 0.04 \\
\hline FT & 5 & 100.39 & 0.02 & 129.43 & 0.25 \\
\hline FT & 6 & 100.41 & 0.02 & 130.83 & 0.12 \\
\hline FT & 7 & 100.45 & 0.01 & 131.52 & 0.10 \\
\hline FN & 8 & 100.44 & 0.02 & 150.44 & 0.11 \\
\hline FN & 9 & 100.43 & 0.03 & 150.48 & 0.08 \\
\hline FN & 10 & 100.45 & 0.01 & 152.18 & 0.11 \\
\hline FN & 11 & 100.44 & 0.02 & 150.57 & 0.07 \\
\hline
\end{tabular}

Table 76: JFA060 VTM Before and After Trimming

\begin{tabular}{|c|c|c|c|c|c|c|c|c|c|c|c|c|c|c|c|}
\hline \multicolumn{16}{|c|}{ VTM (\%) } \\
\hline \multirow[b]{2}{*}{ Test } & \multirow[b]{2}{*}{ S\# } & \multicolumn{5}{|c|}{ Before } & \multicolumn{5}{|c|}{ After } & \multicolumn{4}{|c|}{ Difference } \\
\hline & & Abs. & SSD & CL & Dim. & AVG & & SSD & CL & Dim. & AVG & SSD & CL & Dim. & \\
\hline $\mathrm{L}$ & 1 & 0.2 & 2.5 & 3.0 & 4.6 & 3.4 & & 1.7 & 2.2 & 1.9 & 1.9 & 0.8 & 0.8 & \begin{tabular}{|l|}
2.7 \\
\end{tabular} & \\
\hline$\overline{\mathrm{DM}}$ & 2 & & 8 . & 9.3 & & 9 & & & 7 & & 7.5 & & & & 0 \\
\hline$\overline{\mathrm{DM}}$ & 3 & & 7. & 8.6 & & 8. & & 6.9 & 7.0 & 7.3 & 7.1 & & & & .8 \\
\hline$\overline{\mathrm{DM}}$ & 4 & & 7. & 8. & & 9 . & & 6.8 & 7.0 & $\overline{7.2}$ & 7.0 & & 1.9 & & .0 \\
\hline FT & 5 & & 7. & 8.7 & 10.6 & 8. & & 6.7 & 6.6 & 7.5 & 6.9 & 0.8 & 2.1 & .1 & 2.0 \\
\hline FT & 6 & 1. & 7.8 & 9.0 & 10.8 & 9.2 & & 6.2 & 6.1 & 6.6 & 6.3 & 1.6 & 2.9 & 4.2 & 2.9 \\
\hline$\overline{\text { FT }}$ & 7 & 1. & 7.9 & 9.1 & 10.9 & 9.3 & & 6.8 & 6.7 & 7.4 & $\overline{7.0}$ & 1.1 & 2.4 & .5 & 2.3 \\
\hline FN & 8 & 1.2 & 7.7 & 8.8 & 10.7 & 9.1 & & 6.9 & 7.1 & 7.4 & 7.2 & 0.8 & 1.7 & .3 & 1.9 \\
\hline FN & 9 & 1.4 & 7.8 & 9.0 & 10.7 & 9.2 & 0 . & 6.9 & 6.9 & 7.4 & 7.1 & 0.9 & 2.1 & .3 & 2.1 \\
\hline$\overline{\mathrm{FN}}$ & 10 & 1. & 7.8 & 9.0 & 10.7 & $\overline{9.2}$ & 0. & 6.9 & 6.8 & 7.4 & 7.0 & 0.9 & 2.2 & 3.3 & $\overline{2.2}$ \\
\hline $\mathrm{FN}$ & 11 & 1.5 & 7.6 & 9.3 & 10.7 & 9.2 & 0.5 & 6.4 & 6.4 & 6.9 & 6.6 & 1.2 & 2.9 & 3.8 & 2.6 \\
\hline
\end{tabular}


Table 77: JFA060 VMA Before and After Trimming

\begin{tabular}{|c|c|c|c|c|c|c|c|c|c|}
\hline \multicolumn{10}{|c|}{ VMA (\%) } \\
\hline & & \multicolumn{9}{|c|}{ Before } & \multicolumn{4}{c|}{ After } \\
\cline { 3 - 11 } Test & S\# & SSD & CL & Dim. & AVG & SSD & CL & Dim. & AVG \\
\hline L & 1 & 11.8 & 12.3 & 13.7 & 12.6 & 11.1 & 11.5 & 11.2 & 11.3 \\
\hline DM & 2 & 16.8 & 18.0 & 19.8 & 18.2 & 16.2 & 16.1 & 16.5 & 16.3 \\
\hline DM & 3 & 16.3 & 17.3 & 19.2 & 17.6 & 15.8 & 15.9 & 16.2 & 15.9 \\
\hline DM & 4 & 16.2 & 17.6 & 19.2 & 17.7 & 15.7 & 15.9 & 16.1 & 15.9 \\
\hline FT & 5 & 16.3 & 17.4 & 19.1 & 17.6 & 15.6 & 15.5 & 16.3 & 15.8 \\
\hline FT & 6 & 16.6 & 17.7 & 19.3 & 17.9 & 15.2 & 15.0 & 15.5 & 15.2 \\
\hline FT & 7 & 16.7 & 17.8 & 19.4 & 18.0 & 15.7 & 15.6 & 16.2 & 15.8 \\
\hline FN & 8 & 16.5 & 17.5 & 19.2 & 17.7 & 15.8 & 16.0 & 16.2 & 16.0 \\
\hline FN & 9 & 16.6 & 17.7 & 19.3 & 17.9 & 15.8 & 15.8 & 16.3 & 16.0 \\
\hline FN & 10 & 16.6 & 17.7 & 19.2 & 17.8 & 15.8 & 15.7 & 16.2 & 15.9 \\
\hline FN & 11 & 16.4 & 17.9 & 19.2 & 17.8 & 15.4 & 15.3 & 15.8 & 15.5 \\
\hline
\end{tabular}

Table 78: JFA060 VFA Before and After Trimming

\begin{tabular}{|c|c|c|c|c|c|c|c|c|c|}
\hline \multicolumn{10}{|c|}{ VFA (\%) } \\
\hline & & \multicolumn{9}{|c|}{ Before } & \multicolumn{4}{c|}{ After } \\
\cline { 3 - 11 } Test & S\# & SSD & CL & Dim. & AVG & SSD & CL & Dim. & AVG \\
\hline L & 1 & 78.9 & 75.5 & 66.5 & 73.6 & 84.5 & 81.2 & 83.4 & 83.0 \\
\hline DM & 2 & 52.3 & 48.1 & 42.8 & 47.7 & 54.4 & 55.0 & 53.3 & 54.2 \\
\hline DM & 3 & 54.2 & 50.3 & 44.5 & 49.7 & 56.4 & 55.9 & 54.6 & 55.6 \\
\hline DM & 4 & 54.5 & 49.3 & 44.5 & 49.4 & 56.6 & 55.8 & 55.0 & 55.8 \\
\hline FT & 5 & 54 & 50.2 & 44.5 & 49.6 & 57.2 & 57.4 & 54.1 & 56.2 \\
\hline FT & 6 & 53 & 49.1 & 44.2 & 48.8 & 59.0 & 59.6 & 57.5 & 58.7 \\
\hline FT & 7 & 52.5 & 48.7 & 43.8 & 48.3 & 56.6 & 57.0 & 54.5 & 56.0 \\
\hline FN & 8 & 53.4 & 49.6 & 44.3 & 49.1 & 56.1 & 55.5 & 54.4 & 55.3 \\
\hline FN & 9 & 52.9 & 49.0 & 44.2 & 48.7 & 56.3 & 56.2 & 54.3 & 55.6 \\
\hline FN & 10 & 52.9 & 49.1 & 44.3 & 48.8 & 56.2 & 56.5 & 54.5 & 55.8 \\
\hline FN & 11 & 53.7 & 48.3 & 44.2 & 48.7 & 58.1 & 58.3 & 56.3 & 57.6 \\
\hline
\end{tabular}


Table 79: JFA115 Sample Geometry

\begin{tabular}{|c|c|c|c|c|c|}
\hline \multicolumn{2}{|c|}{} & \multicolumn{2}{c|}{ Diameter } & \multicolumn{2}{c|}{ Height } \\
\hline Test & S\# & AVG & SD & AVG & SD \\
\hline L & 1 & 100.34 & 0.03 & 151.35 & 0.08 \\
\hline H & 2 & 100.26 & 0.08 & 150.08 & 0.06 \\
\hline DM & 3 & 100.35 & 0.02 & 150.89 & 0.05 \\
\hline DM & 4 & 100.38 & 0.06 & 149.47 & 0.03 \\
\hline DM & 5 & 100.36 & 0.02 & 149.36 & 0.15 \\
\hline FT & 6 & 100.39 & 0.03 & 131.20 & 0.12 \\
\hline FT & 7 & 100.43 & 0.02 & 131.52 & 0.06 \\
\hline FT & 8 & 100.44 & 0.03 & 131.27 & 0.01 \\
\hline FN & 9 & 100.43 & 0.02 & 150.43 & 0.07 \\
\hline FN & 10 & 100.45 & 0.02 & 149.85 & 0.10 \\
\hline FN & 11 & 100.46 & 0.02 & 151.18 & 0.04 \\
\hline
\end{tabular}

Table 80: JFA115 VTM Before and After Trimming

\begin{tabular}{|c|c|c|c|c|c|c|c|c|c|c|c|c|c|c|c|}
\hline \multicolumn{10}{|c|}{ Test } & S\# & \multicolumn{10}{|c|}{ Before } & \multicolumn{1}{|c|}{ After } & \multicolumn{4}{|c|}{ Difference } \\
\hline & Abs. & SSD & CL & Dim. & AVG & Abs. & SSD & CL & Dim. & AVG & SSD & CL & Dim. & AVG \\
\hline L & 1 & 0.3 & 5.5 & 6.1 & 7.4 & 6.3 & 0.1 & 4.5 & 4.5 & 4.8 & 4.6 & 1.0 & 1.6 & 2.6 & 1.7 \\
\hline H & 2 & 7.6 & 13.6 & 16.7 & 17.9 & 16.1 & 6.5 & 14.5 & 14.9 & 15.4 & 14.9 & -0.9 & 1.8 & 2.5 & 1.2 \\
\hline DM & 3 & 0.7 & 7.5 & 8.2 & 9.5 & 8.4 & 0.2 & 6.5 & 6.3 & 6.7 & 6.5 & 1.0 & 1.9 & 2.8 & 1.9 \\
\hline DM & 4 & 0.8 & 7.4 & 8.1 & 9.4 & 8.3 & 0.2 & 6.5 & 6.4 & 6.8 & 6.6 & 0.9 & 1.7 & 2.6 & 1.7 \\
\hline DM & 5 & 0.7 & 7.6 & 8.3 & 9.5 & 8.5 & 0.2 & 6.8 & 6.6 & 7.1 & 6.8 & 0.8 & 1.7 & 2.4 & 1.7 \\
\hline FT & 6 & 0.8 & 7.9 & 8.6 & 9.9 & 8.8 & 0.3 & 6.9 & 7.0 & 7.2 & 7.0 & 1.0 & 1.6 & 2.7 & 1.8 \\
\hline FT & 7 & 0.9 & 7.8 & 8.6 & 9.9 & 8.8 & 0.2 & 6.4 & 6.4 & 6.7 & 6.5 & 1.4 & 2.2 & 3.2 & 2.3 \\
\hline FT & 8 & 0.7 & 8.0 & 8.7 & 9.9 & 8.9 & 0.2 & 6.7 & 6.8 & 7.1 & 6.9 & 1.3 & 1.9 & 2.8 & 2.0 \\
\hline FN & 9 & 0.6 & 7.8 & 8.5 & 9.7 & 8.7 & 0.2 & 7.0 & 6.9 & 7.4 & 7.1 & 0.8 & 1.6 & 2.3 & 1.6 \\
\hline FN & 10 & 0.7 & 7.7 & 8.4 & 9.6 & 8.6 & 0.2 & 6.8 & 6.8 & 7.2 & 6.9 & 0.9 & 1.6 & 2.4 & 1.7 \\
\hline FN & 11 & 0.9 & 7.7 & 8.5 & 9.7 & 8.6 & 0.3 & 6.6 & 6.4 & 7.0 & 6.7 & 1.1 & 2.1 & 2.7 & 1.9 \\
\hline
\end{tabular}


Table 81: JFA115 VMA Before and After Trimming

\begin{tabular}{|c|c|c|c|c|c|c|c|c|c|}
\hline \multicolumn{10}{|c|}{ BMA (\%) } \\
\hline & & \multicolumn{9}{|c|}{ Before } & \multicolumn{4}{c|}{ After } \\
\cline { 3 - 11 } Test & S\# & SSD & CL & Dim. & AVG & SSD & CL & Dim. & AVG \\
\hline L & 1 & 15.5 & 16.1 & 17.2 & 16.3 & 14.7 & 14.6 & 14.9 & 14.7 \\
\hline H & 2 & 22.8 & 25.6 & 26.6 & 25.0 & 23.6 & 23.9 & 24.4 & 24.0 \\
\hline DM & 3 & 17.4 & 18.0 & 19.1 & 18.2 & 16.5 & 16.3 & 16.6 & 16.5 \\
\hline DM & 4 & 17.3 & 17.9 & 19.1 & 18.1 & 16.4 & 16.4 & 16.7 & 16.5 \\
\hline DM & 5 & 17.4 & 18.1 & 19.1 & 18.2 & 16.8 & 16.5 & 17.0 & 16.8 \\
\hline FT & 6 & 17.7 & 18.4 & 19.5 & 18.5 & 16.8 & 16.9 & 17.1 & 16.9 \\
\hline FT & 7 & 17.6 & 18.3 & 19.5 & 18.5 & 16.3 & 16.3 & 16.7 & 16.4 \\
\hline FT & 8 & 17.8 & 18.4 & 19.5 & 18.6 & 16.7 & 16.7 & 17.0 & 16.8 \\
\hline FN & 9 & 17.6 & 18.2 & 19.3 & 18.4 & 16.9 & 16.8 & 17.2 & 17.0 \\
\hline FN & 10 & 17.5 & 18.1 & 19.2 & 18.3 & 16.7 & 16.7 & 17.1 & 16.8 \\
\hline FN & 11 & 17.6 & 18.2 & 19.3 & 18.4 & 16.5 & 16.4 & 16.9 & 16.6 \\
\hline
\end{tabular}

Table 82: JFA1 15 VFA Before and After Trimming

\begin{tabular}{|c|c|c|c|c|c|c|c|c|c|}
\hline \multicolumn{10}{|c|}{ VFA (\%) } \\
\hline & & \multicolumn{9}{|c|}{ Before } & \multicolumn{4}{c|}{ After } \\
\cline { 3 - 11 } Test & S\# & SSD & CL & Dim. & AVG & SSD & CL & Dim. & AVG \\
\hline L & 1 & 64.7 & 62.2 & 57.3 & 61.4 & 69.1 & 69.5 & 68.0 & 68.9 \\
\hline H & 2 & 40.4 & 34.6 & 32.8 & 35.9 & 38.6 & 37.9 & 36.8 & 37.7 \\
\hline DM & 3 & 56.6 & 54.4 & 50.3 & 53.8 & 60.4 & 61.3 & 59.7 & 60.5 \\
\hline DM & 4 & 57.1 & 54.7 & 50.5 & 54.1 & 60.7 & 60.8 & 59.3 & 60.3 \\
\hline DM & 5 & 56.3 & 54.0 & 50.3 & 53.5 & 59.2 & 60.3 & 58.1 & 59.2 \\
\hline FT & 6 & 55.3 & 52.9 & 49.1 & 52.4 & 59.0 & 58.6 & 57.8 & 58.5 \\
\hline FT & 7 & 55.8 & 53.1 & 49.2 & 52.7 & 61.0 & 60.9 & 59.6 & 60.5 \\
\hline FT & 8 & 55.0 & 52.7 & 49.2 & 52.3 & 59.5 & 59.4 & 58.2 & 59.0 \\
\hline FN & 9 & 55.8 & 53.4 & 49.8 & 53.0 & 58.7 & 58.8 & 57.1 & 58.2 \\
\hline FN & 10 & 56.1 & 53.7 & 49.9 & 53.2 & 59.5 & 59.3 & 57.7 & 58.8 \\
\hline FN & 11 & 55.9 & 53.4 & 49.9 & 53.1 & 60.1 & 60.8 & 58.7 & 59.8 \\
\hline
\end{tabular}


Table 83: JFA429 Sample Geometry

\begin{tabular}{|c|c|c|c|c|c|}
\hline \multicolumn{2}{|c|}{} & \multicolumn{2}{c|}{ Diameter } & \multicolumn{2}{c|}{ Height } \\
\hline Test & S\# & AVG & SD & AVG & SD \\
\hline H & 1 & 100.39 & 0.04 & 150.87 & 0.07 \\
\hline L & 2 & 100.38 & 0.03 & 150.49 & 0.04 \\
\hline DM & 3 & 100.41 & 0.04 & 149.97 & 0.13 \\
\hline DM & 4 & 100.42 & 0.03 & 150.53 & 0.06 \\
\hline DM & 5 & 100.36 & 0.03 & 150.72 & 0.07 \\
\hline FT & 6 & 100.43 & 0.05 & 131.27 & 0.07 \\
\hline FT & 7 & 100.41 & 0.03 & 131.51 & 0.36 \\
\hline FT & 8 & 100.42 & 0.03 & 131.66 & 0.17 \\
\hline FN & 9 & 100.44 & 0.04 & 150.64 & 0.07 \\
\hline FN & 10 & 100.45 & 0.02 & 151.61 & 0.07 \\
\hline
\end{tabular}

Table 84: JFA429 VTM Before and After Trimming

\begin{tabular}{|c|c|c|c|c|c|c|c|c|c|c|c|c|c|c|c|}
\hline \multicolumn{10}{|c|}{ Test } & S\# & \multicolumn{10}{|c|}{ Before } & \multicolumn{10}{|c|}{ After } & \multicolumn{4}{|c|}{ Difference } \\
\hline & Abs. & SSD & CL & Dim. & AVG & Abs. & SSD & CL & Dim. & AVG & SSD & CL & Dim. & AVG \\
\hline H & 1 & 1.6 & 7.9 & 9.4 & 11.5 & 9.6 & 0.5 & 7.7 & 8.0 & 8.4 & 8.0 & 0.2 & 1.4 & 3.1 & 1.6 \\
\hline L & 2 & 0.6 & 6.2 & 7.2 & 9.1 & 7.5 & 0.2 & 5.7 & 5.6 & 6.2 & 5.8 & 0.5 & 1.6 & 2.9 & 1.7 \\
\hline DM & 3 & 0.9 & 7.1 & 8.1 & 10.1 & 8.4 & 0.4 & 6.7 & 6.8 & 7.1 & 6.9 & 0.4 & 1.3 & 3.0 & 1.5 \\
\hline DM & 4 & 0.9 & 7.1 & 8.3 & 10.1 & 8.5 & 0.4 & 6.5 & 6.8 & 7.2 & 6.8 & 0.6 & 1.5 & 2.9 & 1.7 \\
\hline DM & 5 & 1.1 & 7.0 & 8.2 & 10.1 & 8.4 & 0.3 & 6.3 & 6.5 & 6.8 & 6.5 & 0.7 & 1.7 & 3.3 & 1.9 \\
\hline FT & 6 & 1.3 & 7.2 & 8.5 & 10.3 & 8.7 & 0.3 & 6.2 & 6.3 & 6.6 & 6.3 & 1.0 & 2.2 & 3.7 & 2.4 \\
\hline FT & 7 & 1.0 & 7.2 & 8.5 & 10.5 & 8.7 & 0.2 & 6.4 & 6.3 & 6.9 & 6.5 & 0.8 & 2.2 & 3.6 & 2.2 \\
\hline FT & 8 & 1.3 & 7.8 & 9.2 & 10.9 & 9.3 & 0.2 & 6.7 & 6.7 & 7.2 & 6.9 & 1.1 & 2.5 & 3.7 & 2.4 \\
\hline FN & 9 & 1.0 & 7.1 & 8.5 & 10.2 & 8.6 & 0.3 & 6.5 & 6.4 & 6.9 & 6.6 & 0.6 & 2.1 & 3.3 & 2.0 \\
\hline FN & 10 & 1.0 & 7.2 & 8.5 & 10.2 & 8.6 & 0.3 & 6.8 & 6.8 & 7.3 & 7.0 & 0.4 & 1.7 & 2.9 & 1.6 \\
\hline
\end{tabular}


Table 85: JFA429 VMA Before and After Trimming

\begin{tabular}{|c|c|c|c|c|c|c|c|c|c|}
\hline \multicolumn{10}{|c|}{ VMA (\%) } \\
\hline & & \multicolumn{9}{|c|}{ Before } & \multicolumn{4}{c|}{ After } \\
\cline { 3 - 11 } Test & S\# & SSD & CL & Dim. & AVG & SSD & CL & Dim. & AVG \\
\hline H & 1 & 16.7 & 18.0 & 19.9 & 18.2 & 16.5 & 16.7 & 17.1 & 16.7 \\
\hline L & 2 & 15.1 & 16.0 & 17.7 & 16.3 & 14.7 & 14.5 & 15.1 & 14.8 \\
\hline DM & 3 & 15.9 & 16.8 & 18.6 & 17.1 & 15.5 & 15.7 & 16.0 & 15.7 \\
\hline DM & 4 & 15.9 & 17.0 & 18.7 & 17.2 & 15.4 & 15.7 & 16.0 & 15.7 \\
\hline DM & 5 & 15.9 & 17.0 & 18.6 & 17.2 & 15.2 & 15.4 & 15.6 & 15.4 \\
\hline FT & 6 & 16.0 & 17.2 & 18.8 & 17.3 & 15.1 & 15.2 & 15.4 & 15.2 \\
\hline FT & 7 & 16.1 & 17.2 & 19.1 & 17.5 & 15.3 & 15.2 & 15.7 & 15.4 \\
\hline FT & 8 & 16.6 & 17.9 & 19.3 & 17.9 & 15.6 & 15.5 & 16.0 & 15.7 \\
\hline FN & 9 & 16.0 & 17.2 & 18.8 & 17.3 & 15.4 & 15.3 & 15.8 & 15.5 \\
\hline FN & 10 & 16.1 & 17.2 & 18.7 & 17.3 & 15.7 & 15.6 & 16.1 & 15.8 \\
\hline
\end{tabular}

Table 86: JFA429 VFA Before and After Trimming

\begin{tabular}{|c|c|c|c|c|c|c|c|c|c|}
\hline \multicolumn{10}{|c|}{ VFA (\%) } \\
\hline \multirow{2}{*}{ Test } & S\# & \multicolumn{9}{|c|}{ Before } & SSD & CL & Dim. & AVG & SSD & CL & Dim. & AVG \\
\hline H & 1 & 52.6 & 47.9 & 42.3 & 47.6 & 53.3 & 52.4 & 51.0 & 52.2 \\
\hline L & 2 & 59.0 & 55.1 & 48.8 & 54.3 & 61.0 & 61.7 & 59.1 & 60.6 \\
\hline DM & 3 & 55.5 & 52.0 & 46.0 & 51.2 & 57.1 & 56.4 & 55.3 & 56.2 \\
\hline DM & 4 & 55.6 & 51.3 & 45.7 & 50.9 & 57.6 & 56.5 & 55.2 & 56.4 \\
\hline DM & 5 & 55.8 & 51.5 & 45.9 & 51.1 & 58.5 & 57.7 & 56.6 & 57.6 \\
\hline FT & 6 & 55.2 & 50.7 & 45.4 & 50.4 & 59.1 & 58.4 & 57.5 & 58.3 \\
\hline FT & 7 & 55.0 & 50.5 & 44.7 & 50.1 & 58.0 & 58.5 & 56.2 & 57.6 \\
\hline FT & 8 & 53.0 & 48.4 & 43.9 & 48.4 & 56.8 & 56.8 & 54.9 & 56.2 \\
\hline FN & 9 & 55.3 & 50.4 & 45.6 & 50.4 & 57.7 & 58.1 & 56.1 & 57.3 \\
\hline FN & 10 & 54.9 & 50.6 & 45.7 & 50.4 & 56.6 & 56.4 & 54.8 & 55.9 \\
\hline
\end{tabular}


Table 87: KP483 Sample Geometry

\begin{tabular}{|c|c|c|c|c|c|}
\hline \multicolumn{2}{|c|}{} & \multicolumn{2}{c|}{ Diameter } & \multicolumn{2}{c|}{ Height } \\
\hline Test & S\# & AVG & SD & AVG & SD \\
\hline L & 1 & 100.43 & 0.03 & 149.87 & 0.18 \\
\hline DM & 2 & 100.38 & 0.02 & 150.59 & 0.07 \\
\hline DM & 3 & 100.40 & 0.03 & 149.67 & 0.08 \\
\hline DM & 4 & 100.40 & 0.04 & 150.51 & 0.11 \\
\hline FN & 5 & 100.45 & 0.02 & 150.62 & 0.09 \\
\hline FT & 6 & 100.41 & 0.03 & 131.40 & 0.15 \\
\hline FT & 7 & 100.41 & 0.04 & 131.53 & 0.17 \\
\hline FT & 8 & 100.44 & 0.02 & 130.85 & 0.15 \\
\hline FN & 9 & 100.44 & 0.02 & 150.00 & 0.04 \\
\hline FN & 10 & 100.45 & 0.03 & 151.34 & 0.10 \\
\hline FN & 11 & 100.43 & 0.02 & 150.63 & 0.09 \\
\hline
\end{tabular}

Table 88: KP483 VTM Before and After Trimming

\begin{tabular}{|c|c|c|c|c|c|c|c|c|c|c|c|c|c|c|c|}
\hline \multicolumn{16}{|c|}{ VTM (\%) } \\
\hline \multirow{2}{*}{ Test } & \multirow{2}{*}{ S \# } & \multicolumn{5}{|c|}{ Before } & \multicolumn{5}{|c|}{ After } & \multicolumn{4}{|c|}{ Difference } \\
\hline & & Abs. & SSD & $\mathbf{C L}$ & Dim. & AVG & Abs. & SSD & CL & Dim. & AVG & SSD & CL & Dim. & AVG \\
\hline $\mathrm{L}$ & 1 & 0.4 & 4.9 & 5.5 & \begin{tabular}{|l|}
6.7 \\
\end{tabular} & 5.7 & 0.3 & 4.1 & 4.2 & \begin{tabular}{|l|l|}
4.4 & $r$
\end{tabular} & 4.2 & \begin{tabular}{|l|l}
0.8 \\
\end{tabular} & 1.3 & 2.3 & 1.5 \\
\hline DM & 2 & & 7.8 & 8.7 & 10.0 & 8.8 & 0.5 & 7.1 & 7.3 & 7.4 & 7.2 & 0.7 & 1.4 & 2.6 & 1.6 \\
\hline $\mathrm{DM}$ & 3 & 1.3 & 7.4 & 8.2 & 9.4 & 8.3 & 0.4 & 6.4 & 6.3 & 6.8 & 6.5 & 1.0 & 1.9 & 2.6 & 1.8 \\
\hline DM & 4 & 1.2 & 7.3 & 8.0 & 9.3 & 8.2 & 0.4 & 6.4 & 6.5 & 6.8 & 6.6 & 0.9 & 1.5 & 2.5 & 1.6 \\
\hline FN & 5 & 1.4 & 7.7 & 8.5 & 9.8 & 8.7 & 1.1 & 6.7 & 6.7 & 7.1 & 6.8 & 1.0 & 1.8 & 2.7 & 1.9 \\
\hline FT & 6 & 1.7 & 7.7 & 8.6 & 9.8 & 8.7 & 0.4 & 6.4 & 6.3 & 6.8 & 6.5 & 1.3 & 2.3 & 3.0 & 2.2 \\
\hline FT & 7 & 1.6 & 7.7 & 8.6 & 9.8 & 8.7 & 0.4 & 6.6 & 6.7 & 7.0 & 6.8 & 1.1 & 1.9 & 2.8 & 1.9 \\
\hline FT & 8 & 1.5 & 7.8 & 8.6 & 9.9 & 8.8 & 0.3 & 6.6 & 6.5 & 7.0 & 6.7 & 1.2 & 2.1 & 2.9 & 2.1 \\
\hline FN & $\mathrm{g}$ & 1.4 & 7.5 & 8.5 & 9.7 & 8.6 & 0.5 & 6.6 & 6.6 & 7.1 & 6.8 & 0.9 & 1.9 & 2.6 & 1.8 \\
\hline FN & 10 & 1.4 & 7.6 & 8.7 & 9.6 & 8.6 & 0.5 & 6.7 & 6.6 & 7.1 & 6.8 & 0.9 & 2.1 & 2.5 & 1.8 \\
\hline FN & 11 & 1.6 & 7.8 & 8.5 & 9.7 & 8.7 & 0.6 & 6.8 & 6.7 & 7.2 & 6.9 & 1.0 & 1.8 & 2.5 & 1.8 \\
\hline
\end{tabular}


Table 89: KP483 VMA Before and After Trimming

\begin{tabular}{|c|c|c|c|c|c|c|c|c|c|}
\hline \multicolumn{10}{|c|}{ BMA (\%) } \\
\hline \multirow{2}{*}{ Test } & \multirow{2}{*}{ S\# } & \multicolumn{9}{|c|}{ Before } & \multicolumn{4}{c|}{ After } \\
\cline { 3 - 11 } & & SSD & CL & Dim. & AVG & SSD & CL & Dim. & AVG \\
\hline L & 1 & 15.3 & 15.8 & 16.9 & 16.0 & 14.7 & 14.9 & 14.7 & 14.7 \\
\hline DM & 2 & 17.9 & 18.7 & 19.8 & 18.8 & 17.4 & 17.5 & 17.4 & 17.4 \\
\hline DM & 3 & 17.5 & 18.2 & 19.3 & 18.3 & 16.6 & 17.0 & 16.7 & 16.6 \\
\hline DM & 4 & 17.4 & 18.1 & 19.2 & 18.2 & 16.8 & 17.0 & 16.8 & 16.8 \\
\hline FN & 5 & 17.8 & 18.5 & 19.7 & 18.7 & 16.9 & 17.3 & 17.0 & 16.9 \\
\hline FT & 6 & 17.8 & 18.6 & 19.7 & 18.7 & 16.6 & 17.0 & 16.7 & 16.6 \\
\hline FT & 7 & 17.8 & 18.6 & 19.7 & 18.7 & 16.9 & 17.1 & 17.0 & 16.9 \\
\hline FT & 8 & 17.9 & 18.6 & 19.8 & 18.8 & 16.7 & 17.2 & 16.9 & 16.7 \\
\hline FN & 9 & 17.6 & 18.5 & 19.5 & 18.5 & 16.8 & 17.3 & 17.0 & 16.8 \\
\hline FN & 10 & 17.7 & 18.7 & 19.5 & 18.6 & 16.8 & 17.2 & 17.0 & 16.8 \\
\hline FN & 11 & 17.9 & 18.5 & 19.6 & 18.7 & 17.0 & 16.9 & 17.4 & 17.1 \\
\hline
\end{tabular}

Table 90: KP483 VFA Before and After Trimming

\begin{tabular}{|c|c|c|c|c|c|c|c|c|c|}
\hline \multicolumn{10}{|c|}{ VFA (\%) } \\
\hline & & \multicolumn{9}{|c|}{ Before } & \multicolumn{4}{c|}{ After } \\
\cline { 3 - 11 } Test & S\# & SSD & CL & Dim. & AVG & SSD & CL & Dim. & AVG \\
\hline L & 1 & 67.9 & 65.2 & 60.4 & 64.5 & 71.9 & 71.5 & 70.2 & 71.2 \\
\hline DM & 2 & 56.4 & 53.5 & 49.6 & 53.2 & 59 & 58.3 & 57.8 & 58.4 \\
\hline DM & 3 & 57.8 & 55.2 & 51.4 & 54.8 & 61.5 & 61.9 & 59.9 & 61.1 \\
\hline DM & 4 & 58.1 & 55.6 & 51.6 & 55.1 & 61.7 & 60.9 & 60 & 60.9 \\
\hline FN & 5 & 56.8 & 54.0 & 50.1 & 53.6 & 60.4 & 60.4 & 58.7 & 59.9 \\
\hline FT & 6 & 56.7 & 53.9 & 50.2 & 53.6 & 61.6 & 61.8 & 60 & 61.2 \\
\hline FT & 7 & 56.7 & 53.8 & 50.0 & 53.5 & 60.7 & 60.4 & 59.4 & 60.2 \\
\hline FT & 8 & 56.5 & 53.6 & 49.9 & 53.3 & 60.8 & 61.2 & 59.2 & 60.4 \\
\hline FN & 9 & 57.3 & 54.2 & 50.6 & 54.0 & 60.6 & 60.7 & 58.7 & 60 \\
\hline FN & 10 & 57.1 & 53.6 & 50.6 & 53.8 & 60.4 & 60.8 & 59 & 60.1 \\
\hline FN & 11 & 56.4 & 53.9 & 50.5 & 53.6 & 60.1 & 60.4 & 58.4 & 59.6 \\
\hline
\end{tabular}


Table 91: WVP523 Sample Geometry

\begin{tabular}{|c|c|c|c|c|c|}
\hline \multicolumn{2}{|c|}{} & \multicolumn{2}{c|}{ Diameter } & \multicolumn{2}{c|}{ Height } \\
\hline Test & S\# & AVG & SD & AVG & SD \\
\hline H & 1 & 100.43 & 0.02 & 149.40 & 0.03 \\
\hline L & 2 & 100.45 & 0.03 & 150.86 & 0.07 \\
\hline DM & 3 & 100.37 & 0.02 & 151.49 & 0.06 \\
\hline DM & 4 & 100.35 & 0.13 & 150.11 & 0.04 \\
\hline DM & 5 & 100.40 & 0.04 & 150.58 & 0.07 \\
\hline FT & 6 & 100.41 & 0.02 & 130.71 & 0.16 \\
\hline FT & 7 & 100.43 & 0.02 & 132.09 & 0.04 \\
\hline FT & 8 & 100.46 & 0.04 & 131.33 & 0.12 \\
\hline FN & 9 & 100.44 & 0.02 & 148.56 & 0.05 \\
\hline FN & 10 & 100.46 & 0.03 & 150.74 & 0.04 \\
\hline FN & 11 & 100.45 & 0.03 & 150.61 & 0.03 \\
\hline FN & 12 & 100.43 & 0.03 & 149.22 & 0.10 \\
\hline
\end{tabular}

Table 92: WVP523 VTM Before and After Trimming

\begin{tabular}{|c|c|c|c|c|c|c|c|c|c|c|c|c|c|c|c|}
\hline \multicolumn{10}{|c|}{ Test } & S\# & \multicolumn{10}{|c|}{ Before } & \multicolumn{10}{|c|}{ Abs. } & SSD & CL & Dim. & AVG & Abs. & SSD & CL & Dim. & AVG & SSD & CL & Dim. & AVG \\
\hline H & 1 & 0.6 & 5.7 & 6.3 & 7.6 & 6.5 & 0.2 & 5.1 & 5.2 & 5.2 & 5.2 & 0.6 & 1.1 & 2.4 & 1.3 \\
\hline L & 2 & 0.3 & 3.3 & 4.1 & 4.9 & 4.1 & 0.2 & 2.4 & 2.5 & 2.6 & 2.5 & 0.9 & 1.6 & 2.3 & 1.6 \\
\hline DM & 3 & 1.5 & 7.6 & 8.5 & 9.5 & 8.5 & 0.4 & 6.7 & 6.5 & 6.9 & 6.7 & 0.9 & 2.0 & 2.6 & 1.8 \\
\hline DM & 4 & 1.5 & 7.5 & 8.3 & 9.4 & 8.4 & 0.4 & 6.8 & 6.7 & 7.0 & 6.8 & 0.7 & 1.6 & 2.4 & 1.6 \\
\hline DM & 5 & 1.2 & 7.9 & 8.1 & 9.5 & 8.5 & 0.3 & 7.3 & 7.5 & 7.7 & 7.5 & 0.6 & 0.6 & 1.8 & 1.0 \\
\hline FT & 6 & 1.6 & 8.1 & 8.6 & 9.7 & 8.8 & 0.4 & 7.6 & 6.9 & 7.1 & 7.2 & 0.5 & 1.7 & 2.6 & 1.6 \\
\hline FT & 7 & 1.6 & 7.7 & 8.4 & 9.7 & 8.6 & 0.3 & 6.7 & 6.4 & 7.2 & 6.8 & 1.0 & 2.0 & 2.5 & 1.8 \\
\hline FT & 8 & 1.8 & 8.0 & 8.4 & 9.6 & 8.7 & 0.3 & 6.6 & 6.4 & 7.0 & 6.7 & 1.4 & 2.0 & 2.6 & 2.0 \\
\hline FN & 9 & 1.7 & 7.1 & 8.0 & 9.3 & 8.1 & 0.4 & 6.1 & 6.0 & 6.4 & 6.2 & 1.0 & 2.0 & 2.9 & 1.9 \\
\hline FN & 10 & 1.6 & 7.5 & 8.2 & 9.4 & 8.4 & 0.5 & 6.8 & 6.7 & 7.2 & 6.9 & 0.7 & 1.5 & 2.2 & 1.5 \\
\hline FN & 11 & 1.5 & 7.5 & 8.2 & 9.5 & 8.4 & 0.3 & 6.6 & 6.5 & 6.9 & 6.6 & 0.9 & 1.7 & 2.6 & 1.8 \\
\hline FN & 12 & 1.5 & 7.9 & 8.7 & 9.5 & 8.7 & 0.4 & 7.1 & 6.9 & 7.5 & 7.1 & 0.8 & 1.8 & 2.0 & 1.6 \\
\hline
\end{tabular}


Table 93: WVP523 VMA Before and After Trimming

\begin{tabular}{|c|c|c|c|c|c|c|c|c|c|}
\hline \multicolumn{10}{|c|}{ VMA (\%) } \\
\hline \multirow[b]{2}{*}{ Test } & \multirow[b]{2}{*}{ S\# } & \multicolumn{4}{|c|}{ Before } & \multicolumn{4}{|c|}{ After } \\
\hline & & SSD & CL & Dim. & AVG & SSD & CL & Dim. & AVG \\
\hline $\mathrm{H}$ & 1 & 14.6 & 15.1 & 16.3 & 15.3 & 14.0 & 14.1 & 14.2 & 14.1 \\
\hline $\mathrm{L}$ & 2 & 12.4 & 13.1 & 13.8 & 13.1 & 11.6 & 11.7 & 11.8 & 11.7 \\
\hline DM & 3 & 16.4 & 17.1 & 18.0 & 17.2 & 15.5 & 15.3 & 15.7 & 15.5 \\
\hline $\mathrm{DM}$ & 4 & 16.2 & 16.9 & 17.9 & 17.0 & 15.6 & 15.5 & 15.7 & 15.6 \\
\hline DM & 5 & 16.6 & 16.8 & 18.0 & 17.1 & 16.1 & 16.2 & 16.4 & 16.2 \\
\hline FT & 6 & 16.7 & 17.2 & 18.2 & 17.4 & 16.3 & 15.7 & 15.9 & 16.0 \\
\hline FT & 7 & 16.4 & 17.0 & 18.2 & 17.2 & 15.5 & 15.2 & 15.9 & 15.5 \\
\hline FT & 8 & 16.7 & 17.0 & 18.1 & 17.3 & 15.4 & 15.2 & 15.8 & 15.5 \\
\hline FN & 9 & 15.9 & 16.7 & 17.9 & 16.8 & 15.0 & 14.9 & 15.3 & 15.0 \\
\hline FN & 10 & 16.2 & 16.9 & 17.9 & 17.0 & 15.6 & 15.5 & 15.9 & 15.7 \\
\hline FN & 11 & 16.2 & 16.8 & 18.0 & 17.0 & 15.4 & 15.3 & 15.7 & 15.4 \\
\hline FN & 12 & 16.5 & 17.3 & 18.0 & 17.3 & 15.8 & 15.7 & 16.2 & 15.9 \\
\hline
\end{tabular}

Table 94: WVP523 VFA Before and After Trimming

\begin{tabular}{|c|c|c|c|c|c|c|c|c|c|}
\hline \multicolumn{10}{|c|}{ BFA (\%) } \\
\hline \multirow{2}{*}{ Test } & \multirow{2}{*}{ S\# } & \multicolumn{9}{|c|}{ Before } & \multicolumn{4}{c|}{ After } \\
\cline { 3 - 11 } & & SSD & CL & Dim. & AVG & SSD & CL & Dim. & AVG \\
\hline H & 1 & 60.7 & 58.4 & 53.5 & 57.5 & 63.8 & 63.4 & 63.1 & 63.4 \\
\hline L & 2 & 73.3 & 69.0 & 64.8 & 69.0 & 79.6 & 78.7 & 77.8 & 78.7 \\
\hline DM & 3 & 53.3 & 50.5 & 47.4 & 50.4 & 56.9 & 57.5 & 56.0 & 56.8 \\
\hline DM & 4 & 53.8 & 51.1 & 47.7 & 50.9 & 56.5 & 56.6 & 55.8 & 56.3 \\
\hline DM & 5 & 52.3 & 51.7 & 47.4 & 50.5 & 54.3 & 53.9 & 53.1 & 53.8 \\
\hline FT & 6 & 51.8 & 50.1 & 46.8 & 49.6 & 53.5 & 56.0 & 55.1 & 54.9 \\
\hline FT & 7 & 53 & 50.7 & 46.8 & 50.2 & 56.8 & 57.9 & 55.0 & 56.6 \\
\hline FT & 8 & 51.9 & 50.8 & 47.0 & 49.9 & 57.3 & 58.0 & 55.4 & 56.9 \\
\hline FN & 9 & 55.2 & 51.9 & 47.9 & 51.7 & 59.2 & 59.6 & 57.8 & 58.9 \\
\hline FN & 10 & 53.9 & 51.3 & 47.7 & 51.0 & 56.4 & 56.9 & 54.9 & 56.1 \\
\hline FN & 11 & 53.7 & 51.4 & 47.5 & 50.9 & 57.3 & 57.7 & 56.0 & 57.0 \\
\hline FN & 12 & 52.5 & 49.8 & 47.5 & 49.9 & 55.3 & 56.1 & 53.9 & 55.1 \\
\hline
\end{tabular}


Table 95: WVP766 Sample Geometry

\begin{tabular}{|c|c|c|c|c|c|}
\hline \multicolumn{2}{|c|}{} & \multicolumn{2}{c|}{ Diameter } & \multicolumn{2}{c|}{ Height } \\
\hline Test & S\# & AVG & SD & AVG & SD \\
\hline H & 1 & 100.53 & 0.07 & 149.94 & 0.16 \\
\hline L & 2 & 100.49 & 0.07 & 149.27 & 0.45 \\
\hline DM & 3 & 100.45 & 0.04 & 150.34 & 0.06 \\
\hline DM & 4 & 100.47 & 0.04 & 149.41 & 0.14 \\
\hline DM & 5 & 100.43 & 0.06 & 150.00 & 0.02 \\
\hline FT & 6 & 100.39 & 0.02 & 131.62 & 0.19 \\
\hline FT & 7 & 100.42 & 0.02 & 131.71 & 0.16 \\
\hline FT & 8 & 100.42 & 0.03 & 131.52 & 0.11 \\
\hline FN & 9 & 100.41 & 0.01 & 150.53 & 0.15 \\
\hline FN & 10 & 100.47 & 0.01 & 150.71 & 0.05 \\
\hline FN & 11 & 100.43 & 0.03 & 149.83 & 0.12 \\
\hline FN & 12 & 100.42 & 0.04 & 150.66 & 0.17 \\
\hline
\end{tabular}

Table 96: WVP766 VTM Before and After Trimming

\begin{tabular}{|c|c|c|c|c|c|c|c|c|c|c|c|c|c|c|c|}
\hline \multicolumn{16}{|c|}{ VTM (\%) } \\
\hline \multirow{2}{*}{ Test } & \multirow{2}{*}{ S\# } & \multicolumn{5}{|c|}{ Before } & \multicolumn{5}{|c|}{ After } & \multicolumn{4}{|c|}{ Difference } \\
\hline & & Abs. & SSD & CL & Dim. & AVG & Abs. & SSD & $\mathbf{C L}$ & Dim. & AVG & SSD & CL & Dim. & AVG \\
\hline $\mathrm{H}$ & 1 & 2.7 & 9.6 & 10.3 & 11.2 & 10.4 & 1.1 & 8.8 & 9.1 & 9.2 & 9.0 & 0.8 & 1.2 & 2.0 & 1.4 \\
\hline $\mathrm{L}$ & 2 & 0.2 & 3.3 & 3.5 & 4.5 & 3.8 & 0.1 & 2.3 & 2.4 & 2.4 & 2.4 & 1.0 & 1.1 & 2.1 & 1.4 \\
\hline $\mathrm{DM}$ & 3 & 1.1 & 7.6 & 8.1 & 9.1 & 8.3 & 0.4 & 6.6 & 6.7 & 6.3 & 6.6 & 1.0 & 1.4 & 2.8 & 1.7 \\
\hline $\mathrm{DM}$ & 4 & 1.1 & 7.5 & 8.5 & 9.2 & 8.4 & 0.4 & 6.7 & 6.9 & 7.2 & 7.0 & 0.8 & 1.6 & 2.0 & 1.4 \\
\hline $\mathrm{DM}$ & 5 & 1.1 & 7.7 & 8.3 & 9.3 & 8.4 & 0.4 & 7.0 & 7.1 & 7.4 & 7.2 & 0.7 & 1.2 & 1.9 & 1.2 \\
\hline FT & 6 & 1.6 & 7.8 & 8.9 & 9.4 & 8.7 & 0.4 & 6.5 & 6.7 & 6.8 & 6.7 & 1.3 & 2.2 & 2.6 & 2.0 \\
\hline $\mathrm{FT}$ & 7 & 1.2 & 7.8 & 8.6 & 9.5 & 8.6 & 0.3 & 6.6 & 6.5 & 6.9 & 6.7 & 1.2 & 2.1 & 2.6 & 1.9 \\
\hline $\mathrm{FT}$ & 8 & 1.3 & 7.9 & 8.6 & 9.6 & 8.7 & 0.3 & 6.8 & 6.8 & 7.2 & 7.0 & 1.1 & 1.8 & 2.4 & 1.7 \\
\hline $\mathrm{FN}$ & 9 & 1 & 7.5 & 8.2 & 9.1 & 8.3 & 0.3 & 6.5 & 6.4 & 6.9 & 6.6 & 1.0 & 1.8 & 2.2 & 1.7 \\
\hline $\mathrm{FN}$ & 10 & 1.1 & 7.7 & 8.4 & 9.2 & 8.4 & 0.4 & 6.8 & 6.7 & 7.1 & 6.9 & 0.9 & 1.7 & 2.1 & 1.5 \\
\hline $\mathrm{FN}$ & 11 & 1.2 & 7.7 & 8.5 & 9.3 & 8.5 & 0.5 & 6.9 & 6.8 & 7.3 & 7.0 & 0.8 & 1.7 & 2.0 & 1.5 \\
\hline $\mathrm{FN}$ & 12 & 1.3 & 7.7 & 8.4 & 9.2 & 8.4 & 0.4 & 6.7 & 6.7 & 7.1 & 6.8 & 1.0 & 1.7 & 2.1 & 1.6 \\
\hline
\end{tabular}


Table 97: WVP766 VMA Before and After Trimming

\begin{tabular}{|c|c|c|c|c|c|c|c|c|c|}
\hline \multicolumn{10}{|c|}{ BMA (\%) } \\
\hline \multirow{2}{*}{ Test } & S\# & \multicolumn{9}{|c|}{ BSore } & \multicolumn{4}{c|}{ After } \\
\cline { 3 - 11 } & SSD & CL & Dim. & AVG & SSD & CL & Dim. & AVG \\
\hline H & 1 & 20.4 & 21.0 & 21.9 & 21.1 & 19.7 & 19.9 & 20.1 & 19.9 \\
\hline L & 2 & 14.8 & 15.0 & 15.9 & 15.2 & 14.0 & 14.0 & 14.1 & 14.0 \\
\hline DM & 3 & 18.6 & 19.1 & 20.1 & 19.3 & 17.8 & 17.8 & 17.6 & 17.7 \\
\hline DM & 4 & 18.5 & 19.4 & 20.1 & 19.3 & 17.8 & 18.0 & 18.4 & 18.1 \\
\hline DM & 5 & 18.7 & 19.2 & 20.2 & 19.4 & 18.1 & 18.2 & 18.5 & 18.3 \\
\hline FT & 6 & 18.8 & 19.8 & 20.3 & 19.6 & 17.7 & 17.8 & 18.0 & 17.8 \\
\hline FT & 7 & 18.8 & 19.5 & 20.4 & 19.6 & 17.8 & 17.7 & 18.1 & 17.9 \\
\hline FT & 8 & 18.9 & 19.5 & 20.5 & 19.6 & 17.9 & 17.9 & 18.4 & 18.1 \\
\hline FN & 9 & 18.6 & 19.1 & 20.0 & 19.2 & 17.7 & 17.6 & 18.1 & 17.8 \\
\hline FN & 10 & 18.7 & 19.3 & 20.1 & 19.4 & 18.0 & 17.9 & 18.3 & 18.0 \\
\hline FN & 11 & 18.7 & 19.4 & 20.2 & 19.4 & 18.0 & 17.9 & 18.4 & 18.1 \\
\hline FN & 12 & 18.7 & 19.3 & 20.1 & 19.4 & 17.8 & 17.8 & 18.2 & 18.0 \\
\hline
\end{tabular}

Table 98: WVP766 VFA Before and After Trimming

\begin{tabular}{|c|c|c|c|c|c|c|c|c|c|}
\hline \multicolumn{10}{|c|}{ BFA (\%) } \\
\hline \multirow{2}{*}{ Test } & S\# & \multicolumn{9}{|c|}{ BSore } & \multicolumn{4}{c|}{ After } \\
\hline & SSD & CL & Dim. & AVG & SSD & CL & Dim. & AVG \\
\hline H & 1 & 52.9 & 51.0 & 48.8 & 50.9 & 55.1 & 54.4 & 54.3 & 54.6 \\
\hline L & 2 & 77.7 & 76.7 & 72.1 & 75.5 & 83.3 & 82.8 & 83.1 & 83.1 \\
\hline DM & 3 & 59.3 & 57.5 & 54.5 & 57.1 & 62.6 & 62.4 & 64.1 & 63.0 \\
\hline DM & 4 & 59.6 & 56.3 & 54.3 & 56.7 & 62.3 & 61.5 & 60.8 & 61.5 \\
\hline DM & 5 & 59.0 & 56.8 & 54.1 & 56.6 & 61.4 & 60.8 & 60.2 & 60.8 \\
\hline FT & 6 & 58.4 & 54.9 & 53.7 & 55.7 & 63.1 & 62.3 & 62.4 & 62.6 \\
\hline FT & 7 & 58.5 & 56.0 & 53.5 & 56.0 & 62.6 & 63.0 & 61.8 & 62.5 \\
\hline FT & 8 & 58.0 & 55.9 & 53.2 & 55.7 & 62.0 & 61.9 & 60.7 & 61.5 \\
\hline FN & 9 & 59.4 & 57.2 & 54.5 & 57.0 & 63.0 & 63.4 & 61.9 & 62.8 \\
\hline FN & 10 & 58.7 & 56.6 & 54.2 & 56.5 & 61.9 & 62.3 & 61.0 & 61.7 \\
\hline FN & 11 & 58.7 & 56.3 & 54.0 & 56.3 & 61.7 & 62.0 & 60.5 & 61.4 \\
\hline FN & 12 & 58.8 & 56.5 & 54.2 & 56.5 & 62.5 & 62.3 & 61.3 & 62.0 \\
\hline
\end{tabular}


Table 99: WVP882 Sample Geometry

\begin{tabular}{|c|c|c|c|c|c|}
\hline \multicolumn{2}{|c|}{} & \multicolumn{2}{|c|}{ Diameter } & \multicolumn{2}{c|}{ Height } \\
\hline Test & S\# & AVG & SD & AVG & SD \\
\hline DM & 1 & 100.37 & 0.01 & 151.26 & 0.07 \\
\hline L & 2 & 100.42 & 0.06 & 150.63 & 0.07 \\
\hline DM & 3 & 100.37 & 0.02 & 150.93 & 0.08 \\
\hline DM & 4 & 100.37 & 0.02 & 148.88 & 0.05 \\
\hline FN & 5 & 100.32 & 0.16 & 151.83 & 0.03 \\
\hline FN & 6 & 100.39 & 0.05 & 150.16 & 0.04 \\
\hline FT & 7 & 100.43 & 0.02 & 131.93 & 0.11 \\
\hline FT & 8 & 100.42 & 0.02 & 132.20 & 0.07 \\
\hline FT & 9 & 100.45 & 0.02 & 130.68 & 0.11 \\
\hline FN & 10 & 100.44 & 0.02 & 150.01 & 0.07 \\
\hline FN & 11 & 100.44 & 0.02 & 149.45 & 0.14 \\
\hline
\end{tabular}

Table 100: WVP882 VTM Before and After Trimming

\begin{tabular}{|c|c|c|c|c|c|c|c|c|c|c|c|c|c|c|c|}
\hline \multicolumn{16}{|c|}{ VTM (\%) } \\
\hline \multirow[b]{2}{*}{ Test } & \multirow[b]{2}{*}{ S\# } & \multicolumn{5}{|c|}{ Before } & \multicolumn{5}{|c|}{ After } & \multicolumn{4}{|c|}{ Difference } \\
\hline & & Abs. & SSD & $\mathbf{C L}$ & Dim. & $A V C$ & Abs. & SSD & CL & Dim. & AVG & SSD & CL & Dim. & $\mathrm{AVC}$ \\
\hline$\overline{D M}$ & 1 & 0.9 & 7.5 & 8.1 & 9.5 & \begin{tabular}{|l|}
8.4 \\
\end{tabular} & \begin{tabular}{|l|}
0.4 \\
\end{tabular} & 6.8 & 7.0 & 7.0 & 6.9 & 0.7 & 1.1 & 2.5 & 1.5 \\
\hline $\mathrm{L}$ & 2 & & 4.1 & 4.4 & 5.8 & 4.7 & 2 & .9 & 2.8 & 3.0 & 2.9 & 1.1 & 1.6 & & .8 \\
\hline$\overline{\mathrm{DM}}$ & 3 & & 7.7 & 8 & 9.6 & 8 & ( & .7 & 6.6 & 6.9 & 6.7 & 1.0 & 1.7 & & .8 \\
\hline$\overline{\mathrm{DM}}$ & 2 & & 7.6 & & 9. & 8 & 0 & 6.7 & 6.8 & 6.8 & 6.8 & 0.9 & 1.5 & & 1.7 \\
\hline FN & 5 & & 7.7 & & 9. & 8.6 & 0. & 6.8 & 6.6 & 6.9 & 6.8 & 0.9 & 1.7 & & 1.8 \\
\hline$\overline{\mathrm{FN}}$ & $\epsilon$ & & 7.7 & & 9.7 & 8.6 & 0.3 & 6.6 & 6.6 & 6.9 & 6.7 & 1.1 & 1.7 & & 1.9 \\
\hline FT & 7 & & 7.5 & 8. & 9.5 & $\overline{8.4}$ & 0.3 & 6.0 & 6.5 & 6.3 & 6.3 & 1.5 & 1.8 & 3.2 & 2.1 \\
\hline$\overline{\mathrm{FT}}$ & 8 & & 7.7 & 8.4 & 9.7 & 8.6 & 0. & 6.7 & 6.5 & 7.0 & 6.7 & 1.0 & 1.9 & 2.7 & 1.9 \\
\hline FT & 9 & 1. & 8.0 & 8.5 & 9.9 & 8.8 & 0.3 & 6.7 & 6.5 & 7.0 & 6.7 & 1.3 & 2.0 & 2.9 & 2.1 \\
\hline$\overline{\mathrm{FN}}$ & 10 & 1. & 7.6 & 8.4 & 9.6 & 8.5 & 0. & 6.6 & 6.5 & 7.0 & 6.7 & 1.0 & 1.9 & 2.6 & 1.8 \\
\hline $\mathrm{N}$ & & & 7.8 & & 9.7 & & & & 6.5 & 7.0 & 6.7 & 1.1 & 2.2 & 2.7 & 2.0 \\
\hline
\end{tabular}


Table 101: WVP882 VMA Before and After Trimming

\begin{tabular}{|c|c|c|c|c|c|c|c|c|c|}
\hline \multicolumn{10}{|c|}{ BMA (\%) } \\
\hline & & \multicolumn{9}{|c|}{ Before } & \multicolumn{4}{|c|}{ After } \\
\cline { 3 - 11 } Test & S\# & SSD & CL & Dim. & AVG & SSD & CL & Dim. & AVG \\
\hline DM & 1 & 18.4 & 19.0 & 20.2 & 19.2 & 17.7 & 17.9 & 18.0 & 17.9 \\
\hline L & 2 & 15.3 & 15.7 & 16.9 & 16.0 & 14.3 & 14.3 & 14.5 & 14.3 \\
\hline DM & 3 & 18.5 & 19.1 & 20.3 & 19.3 & 17.6 & 17.7 & 17.9 & 17.7 \\
\hline DM & 4 & 18.4 & 19.1 & 20.3 & 19.3 & 17.6 & 17.8 & 17.8 & 17.7 \\
\hline FN & 5 & 18.6 & 19.1 & 20.3 & 19.3 & 17.7 & 17.6 & 17.9 & 17.7 \\
\hline FN & 6 & 18.5 & 19.2 & 20.3 & 19.3 & 17.5 & 17.6 & 17.9 & 17.7 \\
\hline FT & 7 & 18.3 & 19.1 & 20.2 & 19.2 & 17.0 & 17.5 & 17.4 & 17.3 \\
\hline FT & 8 & 18.5 & 19.2 & 20.4 & 19.4 & 17.6 & 17.5 & 18.0 & 17.7 \\
\hline FT & 9 & 18.8 & 19.3 & 20.6 & 19.6 & 17.6 & 17.5 & 18.0 & 17.7 \\
\hline FN & 10 & 18.4 & 19.2 & 20.3 & 19.3 & 17.5 & 17.6 & 18.0 & 17.7 \\
\hline FN & 11 & 18.6 & 19.5 & 20.4 & 19.5 & 17.6 & 17.6 & 18.0 & 17.7 \\
\hline
\end{tabular}

Table 102: WVP882 VFA Before and After Trimming

\begin{tabular}{|c|c|c|c|c|c|c|c|c|c|}
\hline \multicolumn{10}{|c|}{ BFA (\%) } \\
\hline \multirow{2}{*}{ Test } & S\# & \multicolumn{9}{|c|}{ Before } & \multicolumn{4}{c|}{ After } \\
\hline & SSD & CL & Dim. & AVG & SSD & CL & Dim. & AVG \\
\hline DM & 1 & 59.0 & 57.1 & 52.9 & 56.3 & 61.7 & 61.3 & 61.2 & 61.4 \\
\hline L & 2 & 73.7 & 71.9 & 65.9 & 70.5 & 79.8 & 80.2 & 79.1 & 79.7 \\
\hline DM & 3 & 58.5 & 56.6 & 52.7 & 55.9 & 62.0 & 62.4 & 61.5 & 62.0 \\
\hline DM & 4 & 58.9 & 56.7 & 52.6 & 56.1 & 62.1 & 61.9 & 61.7 & 61.9 \\
\hline FN & 5 & 58.3 & 56.6 & 52.5 & 55.8 & 61.7 & 62.7 & 61.3 & 61.9 \\
\hline FN & 6 & 58.3 & 56.5 & 52.5 & 55.8 & 62.4 & 62.6 & 61.3 & 62.1 \\
\hline FT & 7 & 59.1 & 56.8 & 52.9 & 56.3 & 64.6 & 62.9 & 63.5 & 63.7 \\
\hline FT & 8 & 58.6 & 56.3 & 52.3 & 55.7 & 62.1 & 62.9 & 61.1 & 62.0 \\
\hline FT & 9 & 57.4 & 55.9 & 51.7 & 55.0 & 62.1 & 62.9 & 61.0 & 62.0 \\
\hline FN & 10 & 58.8 & 56.4 & 52.6 & 55.9 & 62.5 & 63.0 & 61.2 & 62.2 \\
\hline FN & 11 & 57.9 & 55.3 & 52.3 & 55.2 & 62.1 & 63.0 & 60.9 & 62.0 \\
\hline
\end{tabular}




\section{Appendix C: Dynamic Modulus}

\section{Dynamic Modulus MEPDG Outputs}

Table 103: AA937 MEPDG Outputs

\begin{tabular}{|c|c|c|c|c|c|c|}
\hline $\begin{array}{c}\text { Temp } \\
\left({ }^{\circ} \mathbf{C}\right)\end{array}$ & $\begin{array}{c}\text { Temp } \\
\left({ }^{\circ} \mathbf{F}\right)\end{array}$ & $\begin{array}{c}\text { Frequency } \\
(\mathbf{H z})\end{array}$ & $\begin{array}{c}\text { Shift } \\
\text { Factor }\end{array}$ & $\begin{array}{c}\text { Reduced } \\
\text { Frequency }\end{array}$ & $\begin{array}{c}\mathbf{E}^{*} \\
(\mathbf{k s i})\end{array}$ & $\begin{array}{c}\mathbf{E}^{*} \\
(\mathbf{M P a})\end{array}$ \\
\hline-10.0 & 14 & 25 & 4.167357 & 367533.5 & 2786.5 & 19218.3 \\
\hline-10.0 & 14 & 10 & 4.167357 & 147013.4 & 2712.1 & 18705.5 \\
\hline-10.0 & 14 & 5 & 4.167357 & 73506.7 & 2648.0 & 18263.1 \\
\hline-10.0 & 14 & 1 & 4.167357 & 14701.34 & 2469.8 & 17034.2 \\
\hline-10.0 & 14 & 0.5 & 4.167357 & 7350.67 & 2379.5 & 16411.2 \\
\hline-10.0 & 14 & 0.1 & 4.167357 & 1470.134 & 2136.7 & 14736.7 \\
\hline 4.4 & 40 & 25 & 2.048433 & 2794.947 & 2239.1 & 15443.4 \\
\hline 4.4 & 40 & 10 & 2.048433 & 1117.979 & 2090.8 & 14420.5 \\
\hline 4.4 & 40 & 5 & 2.048433 & 558.9893 & 1969.2 & 13581.4 \\
\hline 4.4 & 40 & 1 & 2.048433 & 111.7979 & 1659.9 & 11448.3 \\
\hline 4.4 & 40 & 0.5 & 2.048433 & 55.89893 & 1518.2 & 10471.0 \\
\hline 4.4 & 40 & 0.1 & 2.048433 & 11.17979 & 1182.7 & 8156.9 \\
\hline 21.1 & 70 & 25 & -0.13803 & 18.1932 & 1284.1 & 8856.1 \\
\hline 21.1 & 70 & 10 & -0.13803 & 7.277281 & 1094.3 & 7547.5 \\
\hline 21.1 & 70 & 5 & -0.13803 & 3.638641 & 955.3 & 6588.5 \\
\hline 21.1 & 70 & 1 & -0.13803 & 0.727728 & 660.9 & 4558.5 \\
\hline 21.1 & 70 & 0.5 & -0.13803 & 0.363864 & 551.0 & 3800.3 \\
\hline 21.1 & 70 & 0.1 & -0.13803 & 0.072773 & 342.7 & 2363.5 \\
\hline 37.8 & 100 & 25 & -2.09013 & 0.203146 & 467.8 & 3226.3 \\
\hline 37.8 & 100 & 10 & -2.09013 & 0.081259 & 354.8 & 2447.1 \\
\hline 37.8 & 100 & 5 & -2.09013 & 0.040629 & 283.8 & 1957.1 \\
\hline 37.8 & 100 & 1 & -2.09013 & 0.008126 & 162.4 & 1120.2 \\
\hline 37.8 & 100 & 0.5 & -2.09013 & 0.004063 & 126.2 & 870.1 \\
\hline 37.8 & 100 & 0.1 & -2.09013 & 0.000813 & 69.4 & 478.4 \\
\hline 54.4 & 130 & 25 & -3.84363 & 0.003584 & 120.5 & 830.8 \\
\hline 54.4 & 130 & 10 & -3.84363 & 0.001433 & 85.7 & 591.1 \\
\hline 54.4 & 130 & 5 & -3.84363 & 0.000717 & 66.2 & 456.6 \\
\hline 54.4 & 130 & 1 & -3.84363 & 0.000143 & 36.8 & 254.0 \\
\hline 54.4 & 130 & 0.5 & -3.84363 & $7.17 \mathrm{E}-05$ & 28.9 & 199.6 \\
\hline 54.4 & 130 & 0.1 & -3.84363 & $1.43 \mathrm{E}-05$ & 17.2 & 118.6 \\
\hline
\end{tabular}


Table 104: JAP909 MEPDG Outputs

\begin{tabular}{|c|c|c|c|c|c|c|}
\hline $\begin{array}{c}\text { Temp } \\
\left({ }^{\circ} \mathbf{C}\right)\end{array}$ & $\begin{array}{c}\text { Temp } \\
\left({ }^{\circ} \mathbf{F}\right)\end{array}$ & $\begin{array}{c}\text { Frequency } \\
(\mathbf{H z})\end{array}$ & $\begin{array}{c}\text { Shift } \\
\text { Factor }\end{array}$ & $\begin{array}{c}\text { Reduced } \\
\text { Frequency }\end{array}$ & $\begin{array}{c}\mathbf{E}^{*} \\
(\mathbf{k s i})\end{array}$ & $\begin{array}{c}\mathbf{E}^{*} \\
(\mathbf{M P a})\end{array}$ \\
\hline-10.0 & 14 & 25 & 3.980122 & 238815.5 & 3000.0 & 20691.0 \\
\hline-10.0 & 14 & 10 & 3.980122 & 95526.18 & 2937.5 & 20259.9 \\
\hline-10.0 & 14 & 5 & 3.980122 & 47763.09 & 2880.4 & 19866.4 \\
\hline-10.0 & 14 & 1 & 3.980122 & 9552.618 & 2708.5 & 18680.2 \\
\hline-10.0 & 14 & 0.5 & 3.980122 & 4776.309 & 2614.5 & 18032.2 \\
\hline-10.0 & 14 & 0.1 & 3.980122 & 955.2618 & 2342.9 & 16159.2 \\
\hline 4.4 & 40 & 25 & 1.9564 & 2261.204 & 2497.9 & 17228.3 \\
\hline 4.4 & 40 & 10 & 1.9564 & 904.4816 & 2332.3 & 16086.2 \\
\hline 4.4 & 40 & 5 & 1.9564 & 452.2408 & 2190.1 & 15105.2 \\
\hline 4.4 & 40 & 1 & 1.9564 & 90.44816 & 1808.0 & 12469.8 \\
\hline 4.4 & 40 & 0.5 & 1.9564 & 45.22408 & 1625.9 & 11213.9 \\
\hline 4.4 & 40 & 0.1 & 1.9564 & 9.044816 & 1188.6 & 8197.7 \\
\hline 21.1 & 70 & 25 & -0.13183 & 18.45486 & 1382.5 & 9535.3 \\
\hline 21.1 & 70 & 10 & -0.13183 & 7.381943 & 1134.2 & 7822.3 \\
\hline 21.1 & 70 & 5 & -0.13183 & 3.690972 & 953.8 & 6578.2 \\
\hline 21.1 & 70 & 1 & -0.13183 & 0.738194 & 588.1 & 4056.4 \\
\hline 21.1 & 70 & 0.5 & -0.13183 & 0.369097 & 461.6 & 3183.7 \\
\hline 21.1 & 70 & 0.1 & -0.13183 & 0.073819 & 246.3 & 1699.0 \\
\hline 37.8 & 100 & 25 & -1.99622 & 0.252183 & 400.9 & 2764.9 \\
\hline 37.8 & 100 & 10 & -1.99622 & 0.100873 & 279.9 & 1930.5 \\
\hline 37.8 & 100 & 5 & -1.99622 & 0.050437 & 210.2 & 1449.7 \\
\hline 37.8 & 100 & 1 & -1.99622 & 0.010087 & 105.7 & 729.1 \\
\hline 37.8 & 100 & 0.5 & -1.99622 & 0.005044 & 78.8 & 543.6 \\
\hline 37.8 & 100 & 0.1 & -1.99622 & 0.001009 & 41.5 & 286.1 \\
\hline 54.4 & 130 & 25 & -3.67094 & 0.005333 & 80.7 & 556.5 \\
\hline 54.4 & 130 & 10 & -3.67094 & 0.002133 & 55.4 & 382.2 \\
\hline 54.4 & 130 & 5 & -3.67094 & 0.001067 & 42.4 & 292.1 \\
\hline 54.4 & 130 & 1 & -3.67094 & 0.000213 & 24.3 & 167.7 \\
\hline 54.4 & 130 & 0.5 & -3.67094 & 0.000107 & 19.8 & 136.6 \\
\hline 54.4 & 130 & 0.1 & -3.67094 & $2.13 \mathrm{E}-05$ & 13.3 & 92.0 \\
\hline & & & & & & \\
\hline
\end{tabular}


Table 105: JFA060 MEPDG Outputs

\begin{tabular}{|c|c|c|c|c|c|c|}
\hline $\begin{array}{c}\text { Temp } \\
\left({ }^{\circ} \mathbf{C}\right)\end{array}$ & $\begin{array}{c}\text { Temp } \\
\left({ }^{\circ} \mathbf{F}\right)\end{array}$ & $\begin{array}{c}\text { Frequency } \\
(\mathbf{H z})\end{array}$ & $\begin{array}{c}\text { Shift } \\
\text { Factor }\end{array}$ & $\begin{array}{c}\text { Reduced } \\
\text { Frequency }\end{array}$ & $\begin{array}{c}\mathbf{E}^{*} \\
(\mathbf{k s i})\end{array}$ & $\begin{array}{c}\mathbf{E}^{*} \\
(\mathbf{M P a})\end{array}$ \\
\hline-10.0 & 14 & 25 & 4.086707 & 305243.7 & 2892.6 & 19950.6 \\
\hline-10.0 & 14 & 10 & 4.086707 & 122097.5 & 2820.1 & 19450.4 \\
\hline-10.0 & 14 & 5 & 4.086707 & 61048.74 & 2755.7 & 19006.3 \\
\hline-10.0 & 14 & 1 & 4.086707 & 12209.75 & 2569.4 & 17721.5 \\
\hline-10.0 & 14 & 0.5 & 4.086707 & 6104.874 & 2471.6 & 17046.3 \\
\hline-10.0 & 14 & 0.1 & 4.086707 & 1220.975 & 2199.8 & 15172.3 \\
\hline 4.4 & 40 & 25 & 2.00879 & 2551.118 & 2332.0 & 16084.0 \\
\hline 4.4 & 40 & 10 & 2.00879 & 1020.447 & 2165.7 & 14936.7 \\
\hline 4.4 & 40 & 5 & 2.00879 & 510.2235 & 2026.8 & 13979.0 \\
\hline 4.4 & 40 & 1 & 2.00879 & 102.0447 & 1667.9 & 11503.7 \\
\hline 4.4 & 40 & 0.5 & 2.00879 & 51.02235 & 1502.5 & 10362.5 \\
\hline 4.4 & 40 & 0.1 & 2.00879 & 10.20447 & 1114.6 & 7687.7 \\
\hline 21.1 & 70 & 25 & -0.13536 & 18.30545 & 1254.2 & 8650.4 \\
\hline 21.1 & 70 & 10 & -0.13536 & 7.322181 & 1037.1 & 7152.8 \\
\hline 21.1 & 70 & 5 & -0.13536 & 3.66109 & 881.2 & 6077.8 \\
\hline 21.1 & 70 & 1 & -0.13536 & 0.732218 & 566.1 & 3904.0 \\
\hline 21.1 & 70 & 0.5 & -0.13536 & 0.366109 & 455.5 & 3141.8 \\
\hline 21.1 & 70 & 0.1 & -0.13536 & 0.073222 & 261.3 & 1802.4 \\
\hline 37.8 & 100 & 25 & -2.04968 & 0.222977 & 386.5 & 2665.9 \\
\hline 37.8 & 100 & 10 & -2.04968 & 0.089191 & 280.7 & 1935.7 \\
\hline 37.8 & 100 & 5 & -2.04968 & 0.044595 & 217.8 & 1502.3 \\
\hline 37.8 & 100 & 1 & -2.04968 & 0.008919 & 118.7 & 818.7 \\
\hline 37.8 & 100 & 0.5 & -2.04968 & 0.00446 & 91.5 & 630.7 \\
\hline 37.8 & 100 & 0.1 & -2.04968 & 0.000892 & 51.2 & 353.3 \\
\hline 54.4 & 130 & 25 & -3.76925 & 0.004253 & 89.8 & 619.7 \\
\hline 54.4 & 130 & 10 & -3.76925 & 0.001701 & 64.2 & 443.1 \\
\hline 54.4 & 130 & 5 & -3.76925 & 0.000851 & 50.4 & 347.6 \\
\hline 54.4 & 130 & 1 & -3.76925 & 0.00017 & 30.2 & 208.2 \\
\hline 54.4 & 130 & 0.5 & -3.76925 & $8.51 \mathrm{E}-05$ & 24.8 & 171.4 \\
\hline 54.4 & 130 & 0.1 & -3.76925 & $1.7 \mathrm{E}-05$ & 16.9 & 116.2 \\
\hline & & & & & & \\
\hline
\end{tabular}


Table 106: JFA115 MEPDG Outputs

\begin{tabular}{|c|c|c|c|c|c|c|}
\hline $\begin{array}{c}\text { Temp } \\
\left({ }^{\circ} \mathbf{C}\right)\end{array}$ & $\begin{array}{c}\text { Temp } \\
\left({ }^{\circ} \mathbf{F}\right)\end{array}$ & $\begin{array}{c}\text { Frequency } \\
(\mathbf{H z})\end{array}$ & $\begin{array}{c}\text { Shift } \\
\text { Factor }\end{array}$ & $\begin{array}{c}\text { Reduced } \\
\text { Frequency }\end{array}$ & $\begin{array}{c}\mathbf{E}^{*} \\
(\mathbf{k s i})\end{array}$ & $\begin{array}{c}\mathbf{E}^{*} \\
(\mathbf{M P a})\end{array}$ \\
\hline-10.0 & 14 & 25 & 4.146868 & 350597.1 & 2802.4 & 19328.2 \\
\hline-10.0 & 14 & 10 & 4.146868 & 140238.9 & 2720.9 & 18766.3 \\
\hline-10.0 & 14 & 5 & 4.146868 & 70119.43 & 2650.2 & 18278.1 \\
\hline-10.0 & 14 & 1 & 4.146868 & 14023.89 & 2451.9 & 16911.0 \\
\hline-10.0 & 14 & 0.5 & 4.146868 & 7011.943 & 2350.9 & 16214.4 \\
\hline-10.0 & 14 & 0.1 & 4.146868 & 1402.389 & 2079.2 & 14340.4 \\
\hline 4.4 & 40 & 25 & 2.038362 & 2730.879 & 2198.0 & 15159.3 \\
\hline 4.4 & 40 & 10 & 2.038362 & 1092.352 & 2032.6 & 14018.5 \\
\hline 4.4 & 40 & 5 & 2.038362 & 546.1758 & 1897.4 & 13086.1 \\
\hline 4.4 & 40 & 1 & 2.038362 & 109.2352 & 1557.5 & 10742.3 \\
\hline 4.4 & 40 & 0.5 & 2.038362 & 54.61758 & 1404.5 & 9686.8 \\
\hline 4.4 & 40 & 0.1 & 2.038362 & 10.92352 & 1051.7 & 7253.6 \\
\hline 21.1 & 70 & 25 & -0.13735 & 18.22165 & 1162.1 & 8014.9 \\
\hline 21.1 & 70 & 10 & -0.13735 & 7.288661 & 966.7 & 6667.2 \\
\hline 21.1 & 70 & 5 & -0.13735 & 3.644331 & 827.3 & 5705.7 \\
\hline 21.1 & 70 & 1 & -0.13735 & 0.728866 & 545.1 & 3759.7 \\
\hline 21.1 & 70 & 0.5 & -0.13735 & 0.364433 & 445.1 & 3070.0 \\
\hline 21.1 & 70 & 0.1 & -0.13735 & 0.072887 & 265.6 & 1831.6 \\
\hline 37.8 & 100 & 25 & -2.07985 & 0.208011 & 374.3 & 2581.7 \\
\hline 37.8 & 100 & 10 & -2.07985 & 0.083204 & 277.7 & 1915.0 \\
\hline 37.8 & 100 & 5 & -2.07985 & 0.041602 & 219.2 & 1511.6 \\
\hline 37.8 & 100 & 1 & -2.07985 & 0.00832 & 123.9 & 854.5 \\
\hline 37.8 & 100 & 0.5 & -2.07985 & 0.00416 & 96.7 & 666.7 \\
\hline 37.8 & 100 & 0.1 & -2.07985 & 0.000832 & 55.1 & 380.0 \\
\hline 54.4 & 130 & 25 & -3.82473 & 0.003743 & 93.1 & 642.0 \\
\hline 54.4 & 130 & 10 & -3.82473 & 0.001497 & 67.4 & 464.8 \\
\hline 54.4 & 130 & 5 & -3.82473 & 0.000749 & 53.2 & 366.7 \\
\hline 54.4 & 130 & 1 & -3.82473 & 0.00015 & 31.8 & 219.4 \\
\hline 54.4 & 130 & 0.5 & -3.82473 & $7.49 \mathrm{E}-05$ & 26.0 & 179.4 \\
\hline 54.4 & 130 & 0.1 & -3.82473 & $1.5 \mathrm{E}-05$ & 17.2 & 118.7 \\
\hline & & & & & & \\
\hline
\end{tabular}


Table 107: JFA429 MEPDG Outputs

\begin{tabular}{|c|c|c|c|c|c|c|}
\hline $\begin{array}{c}\text { Temp } \\
\left({ }^{\circ} \mathbf{C}\right)\end{array}$ & $\begin{array}{c}\text { Temp } \\
\left({ }^{\circ} \mathbf{F}\right)\end{array}$ & $\begin{array}{c}\text { Frequency } \\
(\mathbf{H z})\end{array}$ & $\begin{array}{c}\text { Shift } \\
\text { Factor }\end{array}$ & $\begin{array}{c}\text { Reduced } \\
\text { Frequency }\end{array}$ & $\begin{array}{c}\mathbf{E}^{*} \\
(\mathbf{k s i})\end{array}$ & $\begin{array}{c}\mathbf{E}^{*} \\
(\mathbf{M P a})\end{array}$ \\
\hline-10.0 & 14 & 25 & 4.17512 & 374162.4 & 2889.6 & 19929.2 \\
\hline-10.0 & 14 & 10 & 4.17512 & 149665 & 2814.5 & 19411.7 \\
\hline-10.0 & 14 & 5 & 4.17512 & 74832.49 & 2748.6 & 18957.4 \\
\hline-10.0 & 14 & 1 & 4.17512 & 14966.5 & 2561.3 & 17665.2 \\
\hline-10.0 & 14 & 0.5 & 4.17512 & 7483.249 & 2464.3 & 16996.5 \\
\hline-10.0 & 14 & 0.1 & 4.17512 & 1496.65 & 2199.0 & 15166.8 \\
\hline 4.4 & 40 & 25 & 2.052249 & 2819.613 & 2310.2 & 15933.2 \\
\hline 4.4 & 40 & 10 & 2.052249 & 1127.845 & 2146.7 & 14805.5 \\
\hline 4.4 & 40 & 5 & 2.052249 & 563.9226 & 2011.5 & 13873.3 \\
\hline 4.4 & 40 & 1 & 2.052249 & 112.7845 & 1666.2 & 11491.5 \\
\hline 4.4 & 40 & 0.5 & 2.052249 & 56.39226 & 1508.2 & 10402.0 \\
\hline 4.4 & 40 & 0.1 & 2.052249 & 11.27845 & 1138.7 & 7853.7 \\
\hline 21.1 & 70 & 25 & -0.13829 & 18.18243 & 1247.3 & 8602.3 \\
\hline 21.1 & 70 & 10 & -0.13829 & 7.272974 & 1041.1 & 7180.5 \\
\hline 21.1 & 70 & 5 & -0.13829 & 3.636487 & 892.9 & 6158.6 \\
\hline 21.1 & 70 & 1 & -0.13829 & 0.727297 & 590.7 & 4074.1 \\
\hline 21.1 & 70 & 0.5 & -0.13829 & 0.363649 & 483.0 & 3330.9 \\
\hline 21.1 & 70 & 0.1 & -0.13829 & 0.07273 & 289.0 & 1993.1 \\
\hline 37.8 & 100 & 25 & -2.09402 & 0.201333 & 402.7 & 2777.1 \\
\hline 37.8 & 100 & 10 & -2.09402 & 0.080533 & 299.0 & 2062.3 \\
\hline 37.8 & 100 & 5 & -2.09402 & 0.040267 & 236.3 & 1629.9 \\
\hline 37.8 & 100 & 1 & -2.09402 & 0.008053 & 134.4 & 926.9 \\
\hline 37.8 & 100 & 0.5 & -2.09402 & 0.004027 & 105.3 & 726.4 \\
\hline 37.8 & 100 & 0.1 & -2.09402 & 0.000805 & 61.0 & 420.4 \\
\hline 54.4 & 130 & 25 & -3.85079 & 0.003525 & 100.5 & 693.4 \\
\hline 54.4 & 130 & 10 & -3.85079 & 0.00141 & 73.4 & 506.3 \\
\hline 54.4 & 130 & 5 & -3.85079 & 0.000705 & 58.4 & 402.6 \\
\hline 54.4 & 130 & 1 & -3.85079 & 0.000141 & 35.8 & 246.8 \\
\hline 54.4 & 130 & 0.5 & -3.85079 & $7.05 \mathrm{E}-05$ & 29.6 & 204.3 \\
\hline 54.4 & 130 & 0.1 & -3.85079 & $1.41 \mathrm{E}-05$ & 20.2 & 139.4 \\
\hline & & & & & & \\
\hline
\end{tabular}


Table 108: KP483 MEPDG Outputs

\begin{tabular}{|c|c|c|c|c|c|c|}
\hline $\begin{array}{c}\text { Temp } \\
\left({ }^{\circ} \mathbf{C}\right)\end{array}$ & $\begin{array}{c}\text { Temp } \\
\left({ }^{\circ} \mathbf{F}\right)\end{array}$ & $\begin{array}{c}\text { Frequency } \\
(\mathbf{H z})\end{array}$ & $\begin{array}{c}\text { Shift } \\
\text { Factor }\end{array}$ & $\begin{array}{c}\text { Reduced } \\
\text { Frequency }\end{array}$ & $\begin{array}{c}\mathbf{E}^{*} \\
(\mathbf{k s i})\end{array}$ & $\begin{array}{c}\mathbf{E}^{*} \\
(\mathbf{M P a})\end{array}$ \\
\hline-10.0 & 14 & 25 & 4.066143 & 291127.6 & 2731.0 & 18835.6 \\
\hline-10.0 & 14 & 10 & 4.066143 & 116451 & 2646.7 & 18254.0 \\
\hline-10.0 & 14 & 5 & 4.066143 & 58225.51 & 2574.3 & 17755.2 \\
\hline-10.0 & 14 & 1 & 4.066143 & 11645.1 & 2375.6 & 16384.3 \\
\hline-10.0 & 14 & 0.5 & 4.066143 & 5822.551 & 2276.0 & 15697.5 \\
\hline-10.0 & 14 & 0.1 & 4.066143 & 1164.51 & 2012.4 & 13879.5 \\
\hline 4.4 & 40 & 25 & 1.998683 & 2492.428 & 2142.5 & 14777.1 \\
\hline 4.4 & 40 & 10 & 1.998683 & 996.9714 & 1984.7 & 13688.3 \\
\hline 4.4 & 40 & 5 & 1.998683 & 498.4857 & 1856.6 & 12805.0 \\
\hline 4.4 & 40 & 1 & 1.998683 & 99.69714 & 1537.0 & 10600.4 \\
\hline 4.4 & 40 & 0.5 & 1.998683 & 49.84857 & 1393.5 & 9610.8 \\
\hline 4.4 & 40 & 0.1 & 1.998683 & 9.969714 & 1061.8 & 7323.0 \\
\hline 21.1 & 70 & 25 & -0.13468 & 18.33418 & 1185.9 & 8179.2 \\
\hline 21.1 & 70 & 10 & -0.13468 & 7.333673 & 1000.5 & 6900.4 \\
\hline 21.1 & 70 & 5 & -0.13468 & 3.666836 & 866.7 & 5977.5 \\
\hline 21.1 & 70 & 1 & -0.13468 & 0.733367 & 589.7 & 4067.1 \\
\hline 21.1 & 70 & 0.5 & -0.13468 & 0.366684 & 488.6 & 3369.9 \\
\hline 21.1 & 70 & 0.1 & -0.13468 & 0.073337 & 301.0 & 2076.1 \\
\hline 37.8 & 100 & 25 & -2.03937 & 0.228335 & 426.5 & 2941.7 \\
\hline 37.8 & 100 & 10 & -2.03937 & 0.091334 & 322.7 & 2225.9 \\
\hline 37.8 & 100 & 5 & -2.03937 & 0.045667 & 258.1 & 1780.0 \\
\hline 37.8 & 100 & 1 & -2.03937 & 0.009133 & 148.7 & 1025.9 \\
\hline 37.8 & 100 & 0.5 & -2.03937 & 0.004567 & 116.3 & 802.0 \\
\hline 37.8 & 100 & 0.1 & -2.03937 & 0.000913 & 65.4 & 451.2 \\
\hline 54.4 & 130 & 25 & -3.75028 & 0.004443 & 115.1 & 794.2 \\
\hline 54.4 & 130 & 10 & -3.75028 & 0.001777 & 82.9 & 572.0 \\
\hline 54.4 & 130 & 5 & -3.75028 & 0.000889 & 64.8 & 446.8 \\
\hline 54.4 & 130 & 1 & -3.75028 & 0.000178 & 37.2 & 256.5 \\
\hline 54.4 & 130 & 0.5 & -3.75028 & $8.89 \mathrm{E}-05$ & 29.7 & 204.6 \\
\hline 54.4 & 130 & 0.1 & -3.75028 & $1.78 \mathrm{E}-05$ & 18.3 & 126.2 \\
\hline & & & & & & \\
\hline
\end{tabular}


Table 109: WVP523 MEPDG Outputs

\begin{tabular}{|c|c|c|c|c|c|c|}
\hline $\begin{array}{c}\text { Temp } \\
\left({ }^{\circ} \mathbf{C}\right)\end{array}$ & $\begin{array}{c}\text { Temp } \\
\left({ }^{\circ} \mathbf{F}\right)\end{array}$ & $\begin{array}{c}\text { Frequency } \\
(\mathbf{H z})\end{array}$ & $\begin{array}{c}\text { Shift } \\
\text { Factor }\end{array}$ & $\begin{array}{c}\text { Reduced } \\
\text { Frequency }\end{array}$ & $\begin{array}{c}\mathbf{E}^{*} \\
(\mathbf{k s i})\end{array}$ & $\begin{array}{c}\mathbf{E}^{*} \\
(\mathbf{M P a})\end{array}$ \\
\hline-10.0 & 14 & 25 & 4.087379 & 305716.3 & 2822.8 & 19468.5 \\
\hline-10.0 & 14 & 10 & 4.087379 & 122286.5 & 2744.6 & 18929.3 \\
\hline-10.0 & 14 & 5 & 4.087379 & 61143.26 & 2676.9 & 18462.6 \\
\hline-10.0 & 14 & 1 & 4.087379 & 12228.65 & 2488.1 & 17160.4 \\
\hline-10.0 & 14 & 0.5 & 4.087379 & 6114.326 & 2392.1 & 16498.1 \\
\hline-10.0 & 14 & 0.1 & 4.087379 & 1222.865 & 2133.6 & 14715.4 \\
\hline 4.4 & 40 & 25 & 2.009121 & 2553.058 & 2258.0 & 15573.1 \\
\hline 4.4 & 40 & 10 & 2.009121 & 1021.223 & 2101.6 & 14494.8 \\
\hline 4.4 & 40 & 5 & 2.009121 & 510.6117 & 1973.3 & 13609.7 \\
\hline 4.4 & 40 & 1 & 2.009121 & 102.1223 & 1647.3 & 11361.7 \\
\hline 4.4 & 40 & 0.5 & 2.009121 & 51.06117 & 1498.5 & 10335.1 \\
\hline 4.4 & 40 & 0.1 & 2.009121 & 10.21223 & 1148.5 & 7921.2 \\
\hline 21.1 & 70 & 25 & -0.13538 & 18.30451 & 1274.8 & 8792.5 \\
\hline 21.1 & 70 & 10 & -0.13538 & 7.321805 & 1077.6 & 7431.9 \\
\hline 21.1 & 70 & 5 & -0.13538 & 3.660903 & 933.8 & 6440.3 \\
\hline 21.1 & 70 & 1 & -0.13538 & 0.732181 & 633.0 & 4365.5 \\
\hline 21.1 & 70 & 0.5 & -0.13538 & 0.36609 & 522.3 & 3602.2 \\
\hline 21.1 & 70 & 0.1 & -0.13538 & 0.073218 & 316.5 & 2182.7 \\
\hline 37.8 & 100 & 25 & -2.05002 & 0.222804 & 451.0 & 3110.8 \\
\hline 37.8 & 100 & 10 & -2.05002 & 0.089121 & 337.7 & 2329.3 \\
\hline 37.8 & 100 & 5 & -2.05002 & 0.044561 & 267.4 & 1844.0 \\
\hline 37.8 & 100 & 1 & -2.05002 & 0.008912 & 149.4 & 1030.7 \\
\hline 37.8 & 100 & 0.5 & -2.05002 & 0.004456 & 115.0 & 793.0 \\
\hline 37.8 & 100 & 0.1 & -2.05002 & 0.000891 & 62.1 & 428.1 \\
\hline 54.4 & 130 & 25 & -3.76987 & 0.004247 & 112.9 & 778.6 \\
\hline 54.4 & 130 & 10 & -3.76987 & 0.001699 & 79.5 & 548.0 \\
\hline 54.4 & 130 & 5 & -3.76987 & 0.000849 & 60.9 & 420.3 \\
\hline 54.4 & 130 & 1 & -3.76987 & 0.00017 & 33.5 & 231.0 \\
\hline 54.4 & 130 & 0.5 & -3.76987 & $8.49 \mathrm{E}-05$ & 26.2 & 181.0 \\
\hline 54.4 & 130 & 0.1 & -3.76987 & $1.7 \mathrm{E}-05$ & 15.6 & 107.4 \\
\hline & & & & & & \\
\hline
\end{tabular}


Table 110: WV766 MEPDG Outputs

\begin{tabular}{|c|c|c|c|c|c|c|}
\hline $\begin{array}{c}\text { Temp } \\
\left({ }^{\circ} \mathbf{C}\right)\end{array}$ & $\begin{array}{c}\text { Temp } \\
\left({ }^{\circ} \mathbf{F}\right)\end{array}$ & $\begin{array}{c}\text { Frequency } \\
(\mathbf{H z})\end{array}$ & $\begin{array}{c}\text { Shift } \\
\text { Factor }\end{array}$ & $\begin{array}{c}\text { Reduced } \\
\text { Frequency }\end{array}$ & $\begin{array}{c}\mathbf{E}^{*} \\
(\mathbf{k s i})\end{array}$ & $\begin{array}{c}\mathbf{E}^{*} \\
(\mathbf{M P a})\end{array}$ \\
\hline-10.0 & 14 & 25 & 3.901012 & 199045.2 & 2700.8 & 18627.7 \\
\hline-10.0 & 14 & 10 & 3.901012 & 79618.07 & 2614.3 & 18030.8 \\
\hline-10.0 & 14 & 5 & 3.901012 & 39809.03 & 2539.6 & 17515.4 \\
\hline-10.0 & 14 & 1 & 3.901012 & 7961.807 & 2332.2 & 16085.4 \\
\hline-10.0 & 14 & 0.5 & 3.901012 & 3980.903 & 2227.6 & 15363.7 \\
\hline-10.0 & 14 & 0.1 & 3.901012 & 796.1807 & 1949.2 & 13443.8 \\
\hline 4.4 & 40 & 25 & 1.917513 & 2067.538 & 2120.1 & 14622.4 \\
\hline 4.4 & 40 & 10 & 1.917513 & 827.0151 & 1956.3 & 13492.9 \\
\hline 4.4 & 40 & 5 & 1.917513 & 413.5075 & 1822.9 & 12572.4 \\
\hline 4.4 & 40 & 1 & 1.917513 & 82.70151 & 1488.8 & 10268.2 \\
\hline 4.4 & 40 & 0.5 & 1.917513 & 41.35075 & 1338.9 & 9234.4 \\
\hline 4.4 & 40 & 0.1 & 1.917513 & 8.270151 & 994.6 & 6859.6 \\
\hline 21.1 & 70 & 25 & -0.12921 & 18.56654 & 1165.6 & 8039.4 \\
\hline 21.1 & 70 & 10 & -0.12921 & 7.426617 & 972.4 & 6706.3 \\
\hline 21.1 & 70 & 5 & -0.12921 & 3.713308 & 833.3 & 5747.6 \\
\hline 21.1 & 70 & 1 & -0.12921 & 0.742662 & 548.8 & 3785.2 \\
\hline 21.1 & 70 & 0.5 & -0.12921 & 0.371331 & 446.8 & 3081.8 \\
\hline 21.1 & 70 & 0.1 & -0.12921 & 0.074266 & 262.3 & 1809.3 \\
\hline 37.8 & 100 & 25 & -1.95655 & 0.276309 & 407.5 & 2810.3 \\
\hline 37.8 & 100 & 10 & -1.95655 & 0.110523 & 301.2 & 2077.5 \\
\hline 37.8 & 100 & 5 & -1.95655 & 0.055262 & 236.1 & 1628.5 \\
\hline 37.8 & 100 & 1 & -1.95655 & 0.011052 & 129.1 & 890.6 \\
\hline 37.8 & 100 & 0.5 & -1.95655 & 0.005526 & 98.5 & 679.6 \\
\hline 37.8 & 100 & 0.1 & -1.95655 & 0.001105 & 52.4 & 361.3 \\
\hline 54.4 & 130 & 25 & -3.59798 & 0.006309 & 103.8 & 715.8 \\
\hline 54.4 & 130 & 10 & -3.59798 & 0.002524 & 72.4 & 499.2 \\
\hline 54.4 & 130 & 5 & -3.59798 & 0.001262 & 55.2 & 380.4 \\
\hline 54.4 & 130 & 1 & -3.59798 & 0.000252 & 30.0 & 206.6 \\
\hline 54.4 & 130 & 0.5 & -3.59798 & 0.000126 & 23.4 & 161.2 \\
\hline 54.4 & 130 & 0.1 & -3.59798 & $2.52 E-05$ & 13.8 & 95.2 \\
\hline & & & & & & \\
\hline
\end{tabular}


Table 111: WVP882 MEPDG Outputs

\begin{tabular}{|c|c|c|c|c|c|c|}
\hline $\begin{array}{c}\text { Temp } \\
\left({ }^{\circ} \mathbf{C}\right)\end{array}$ & $\begin{array}{c}\text { Temp } \\
\left({ }^{\circ} \mathbf{F}\right)\end{array}$ & $\begin{array}{c}\text { Frequency } \\
(\mathbf{H z})\end{array}$ & $\begin{array}{c}\text { Shift } \\
\text { Factor }\end{array}$ & $\begin{array}{c}\text { Reduced } \\
\text { Frequency }\end{array}$ & $\begin{array}{c}\mathbf{E}^{*} \\
(\mathbf{k s i})\end{array}$ & $\begin{array}{c}\mathbf{E}^{*} \\
(\mathbf{M P a})\end{array}$ \\
\hline-10.0 & 14 & 25 & 4.021699 & 262808.2 & 2752.8 & 18986.0 \\
\hline-10.0 & 14 & 10 & 4.021699 & 105123.3 & 2669.8 & 18413.3 \\
\hline-10.0 & 14 & 5 & 4.021699 & 52561.63 & 2597.5 & 17914.8 \\
\hline-10.0 & 14 & 1 & 4.021699 & 10512.33 & 2394.5 & 16514.7 \\
\hline-10.0 & 14 & 0.5 & 4.021699 & 5256.163 & 2290.8 & 15799.9 \\
\hline-10.0 & 14 & 0.1 & 4.021699 & 1051.233 & 2011.8 & 13875.6 \\
\hline 4.4 & 40 & 25 & 1.976836 & 2370.153 & 2159.4 & 14893.2 \\
\hline 4.4 & 40 & 10 & 1.976836 & 948.0611 & 1992.2 & 13740.0 \\
\hline 4.4 & 40 & 5 & 1.976836 & 474.0306 & 1855.2 & 12795.6 \\
\hline 4.4 & 40 & 1 & 1.976836 & 94.80611 & 1510.5 & 10417.6 \\
\hline 4.4 & 40 & 0.5 & 1.976836 & 47.40306 & 1355.2 & 9346.8 \\
\hline 4.4 & 40 & 0.1 & 1.976836 & 9.480611 & 998.3 & 6885.4 \\
\hline 21.1 & 70 & 25 & -0.13321 & 18.39643 & 1143.2 & 7884.3 \\
\hline 21.1 & 70 & 10 & -0.13321 & 7.358573 & 944.4 & 6513.6 \\
\hline 21.1 & 70 & 5 & -0.13321 & 3.679287 & 802.6 & 5535.4 \\
\hline 21.1 & 70 & 1 & -0.13321 & 0.735857 & 516.6 & 3563.2 \\
\hline 21.1 & 70 & 0.5 & -0.13321 & 0.367929 & 416.1 & 2869.9 \\
\hline 21.1 & 70 & 0.1 & -0.13321 & 0.073586 & 238.2 & 1643.1 \\
\hline 37.8 & 100 & 25 & -2.01708 & 0.240361 & 361.6 & 2494.0 \\
\hline 37.8 & 100 & 10 & -2.01708 & 0.096144 & 262.6 & 1811.3 \\
\hline 37.8 & 100 & 5 & -2.01708 & 0.048072 & 203.3 & 1402.3 \\
\hline 37.8 & 100 & 1 & -2.01708 & 0.009614 & 108.7 & 749.8 \\
\hline 37.8 & 100 & 0.5 & -2.01708 & 0.004807 & 82.5 & 568.9 \\
\hline 37.8 & 100 & 0.1 & -2.01708 & 0.000961 & 43.8 & 301.9 \\
\hline 54.4 & 130 & 25 & -3.70929 & 0.004883 & 83.0 & 572.4 \\
\hline 54.4 & 130 & 10 & -3.70929 & 0.001953 & 57.7 & 397.8 \\
\hline 54.4 & 130 & 5 & -3.70929 & 0.000977 & 44.0 & 303.7 \\
\hline 54.4 & 130 & 1 & -3.70929 & 0.000195 & 24.3 & 167.9 \\
\hline 54.4 & 130 & 0.5 & -3.70929 & $9.77 \mathrm{E}-05$ & 19.2 & 132.7 \\
\hline 54.4 & 130 & 0.1 & -3.70929 & $1.95 \mathrm{E}-05$ & 11.8 & 81.5 \\
\hline & & & & & & \\
\hline
\end{tabular}




\section{Appendix D: Fatigue}

\section{Phase Angle Drops}

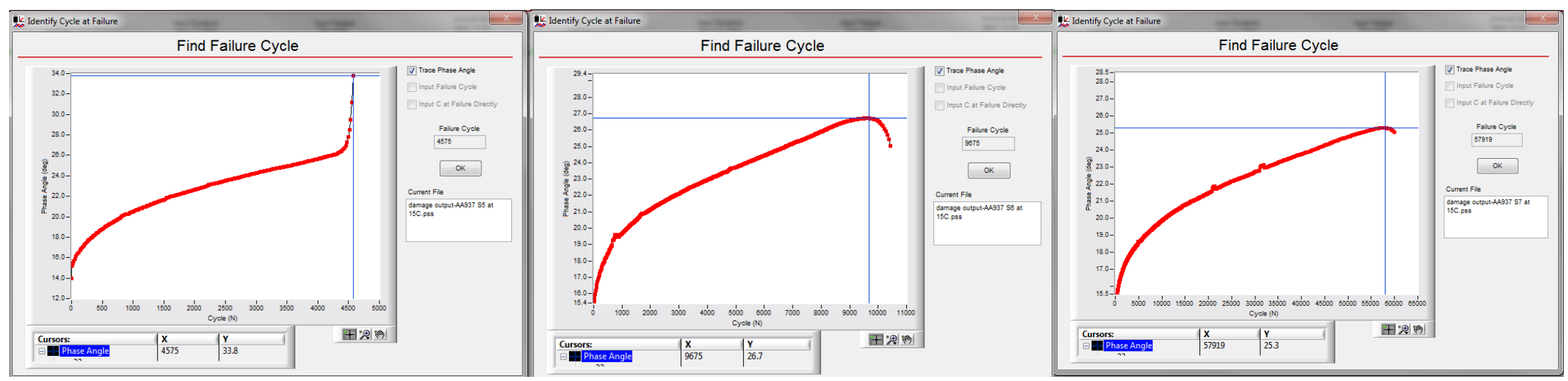

Figure 60: Phase Angle Drop for AA937 S5, S6, and S7

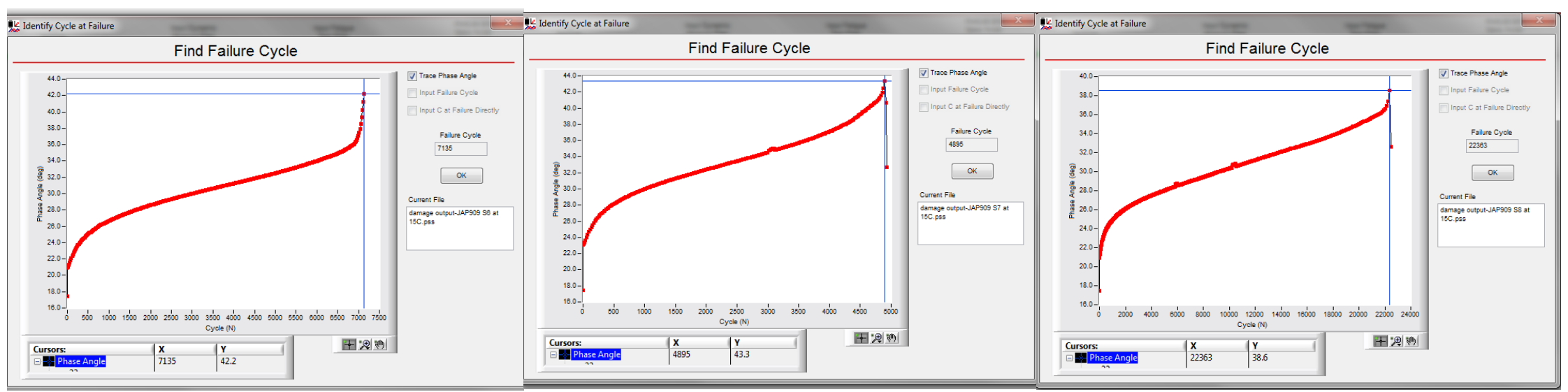

Figure 61: Phase Angle Drop for JAP909 S6, S7, and S8 


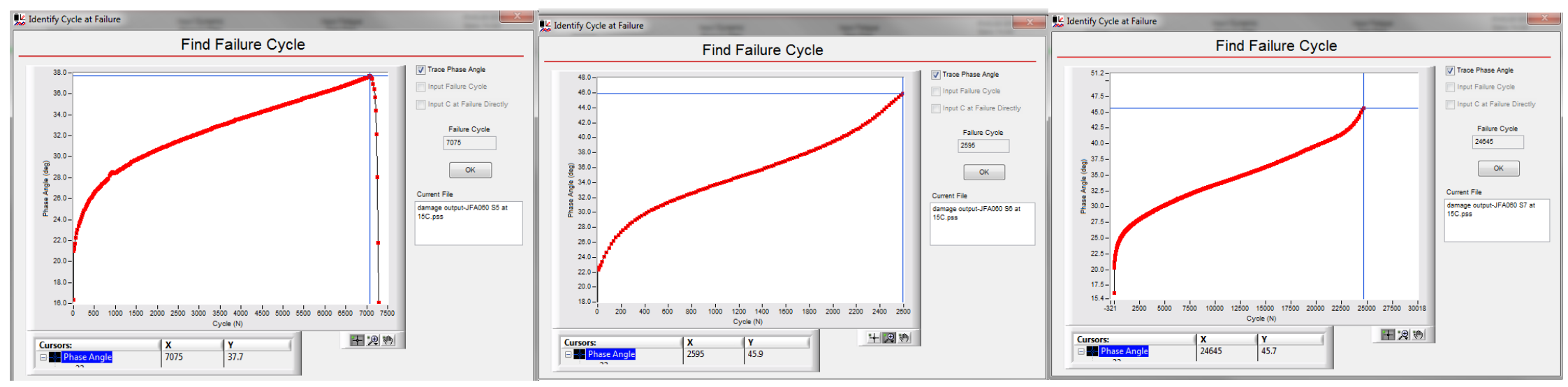

Figure 62: Phase Angle Drop for JFA060 S5, S6, and S7

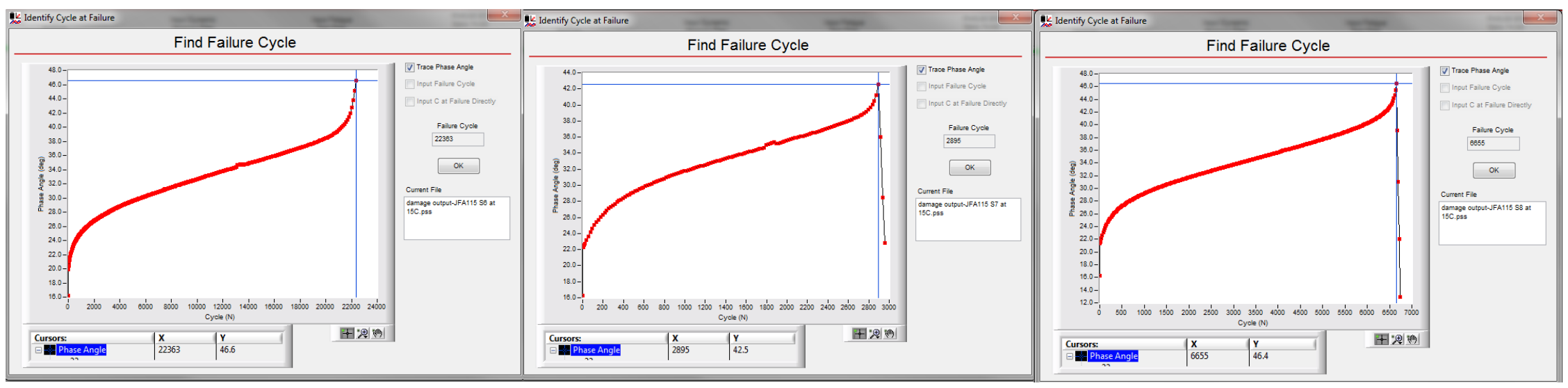

Figure 63: Phase Angle Drop for JFA115 S6, S7, and S8 

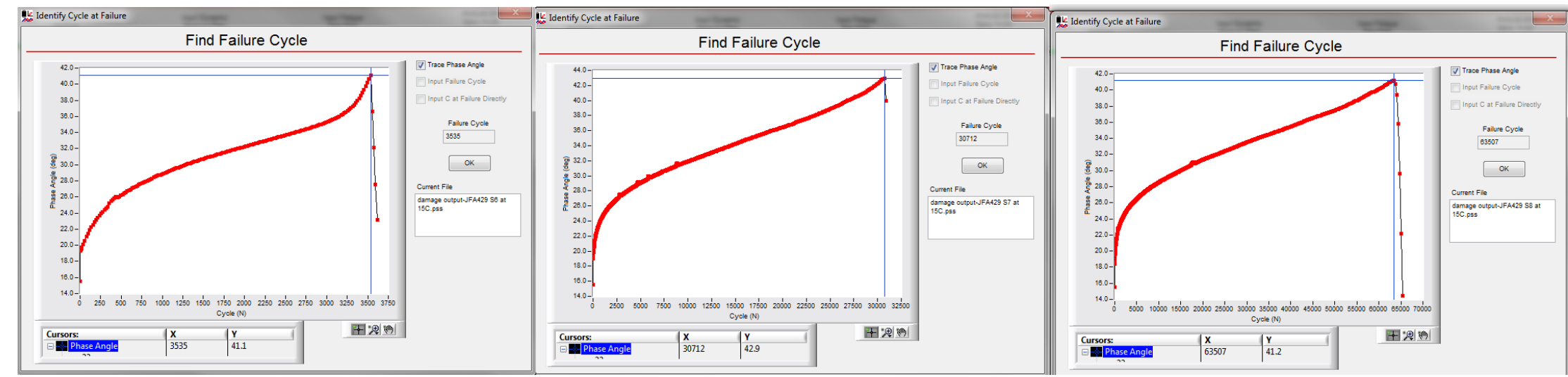

Figure 64: Phase Angle Drop for JFA429 S6, S7, and S8

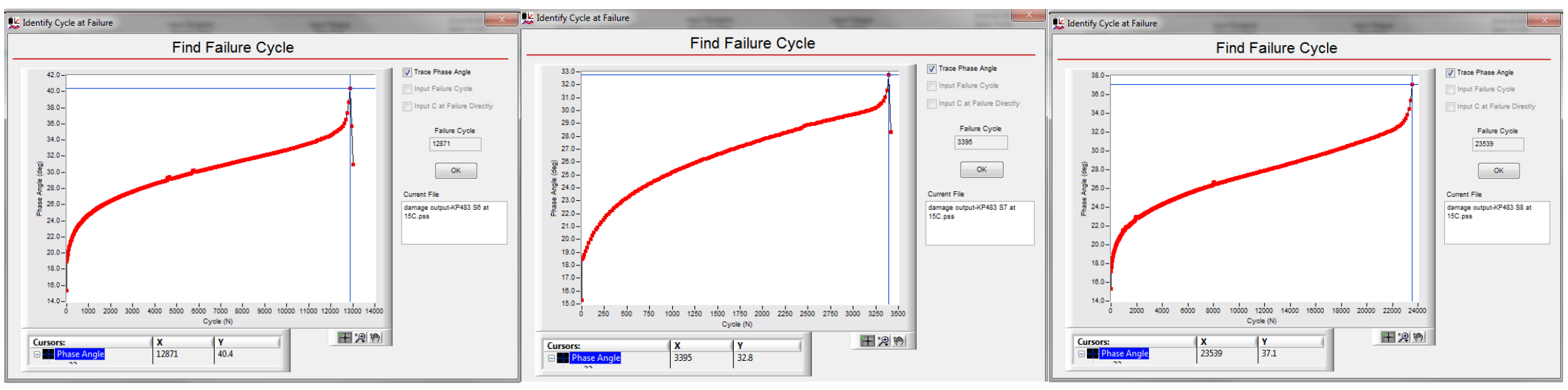

Figure 65: Phase Angle Drop for KP483 S6, S7, and S8 


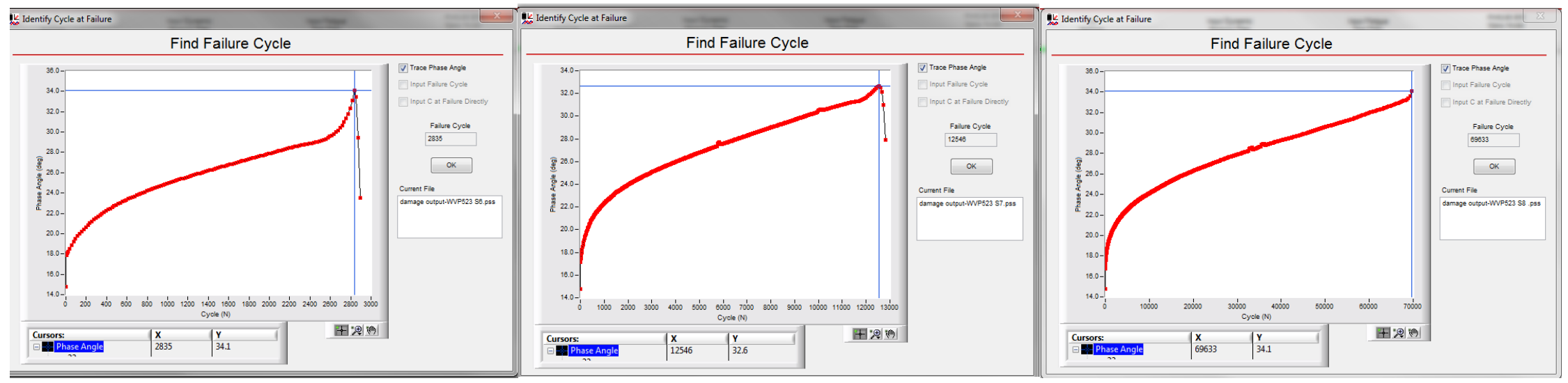

Figure 66: Phase Angle Drop for WVP523 S6, S7, and S8

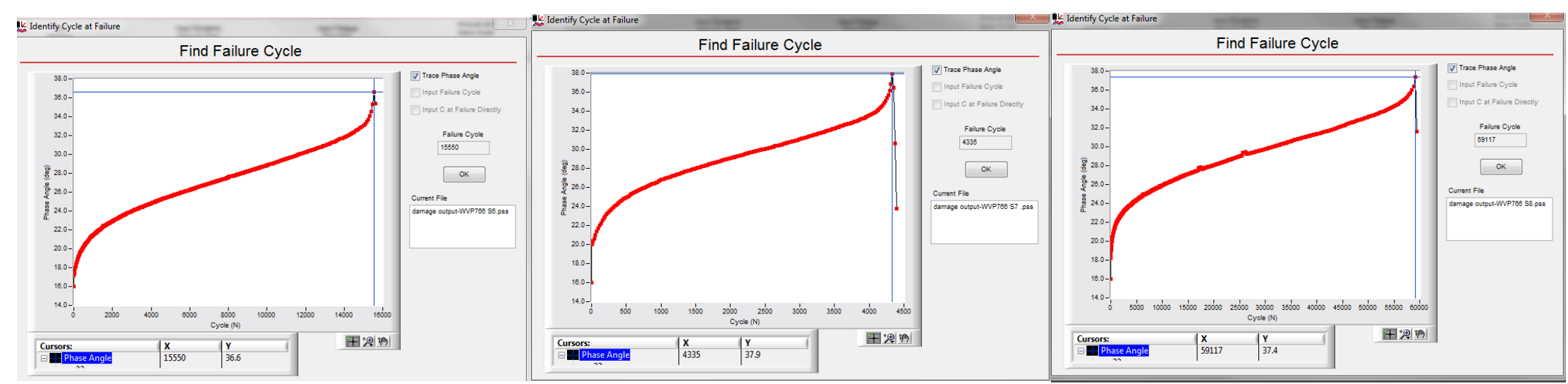

Figure 67: Phase Angle Drop for WVP766 S6, S7, and S8 


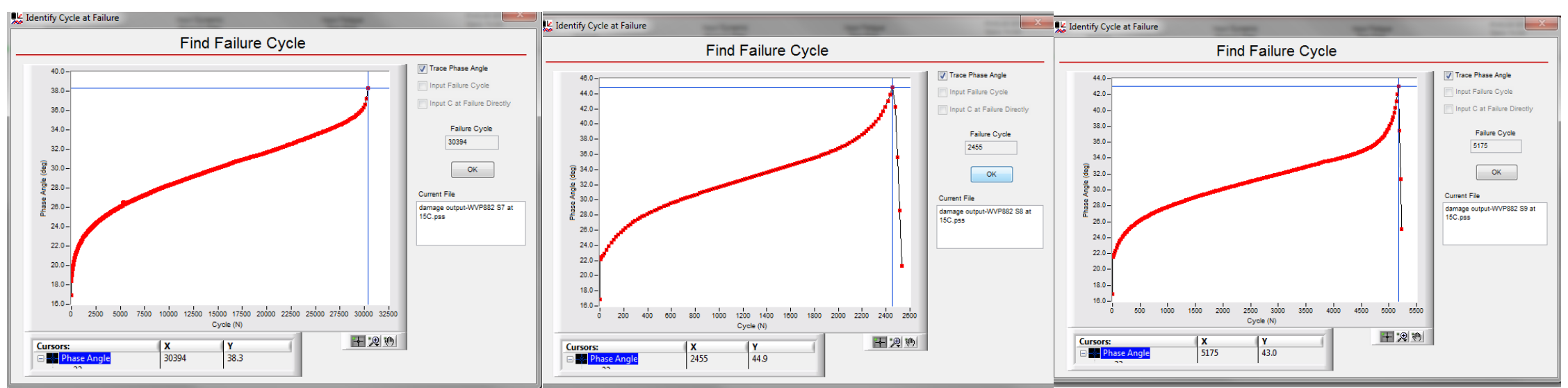

Figure 68: Phase Angle Drop for WVP882 S7, S8, and S9 


\section{Alpha-Fatigue Outputs}

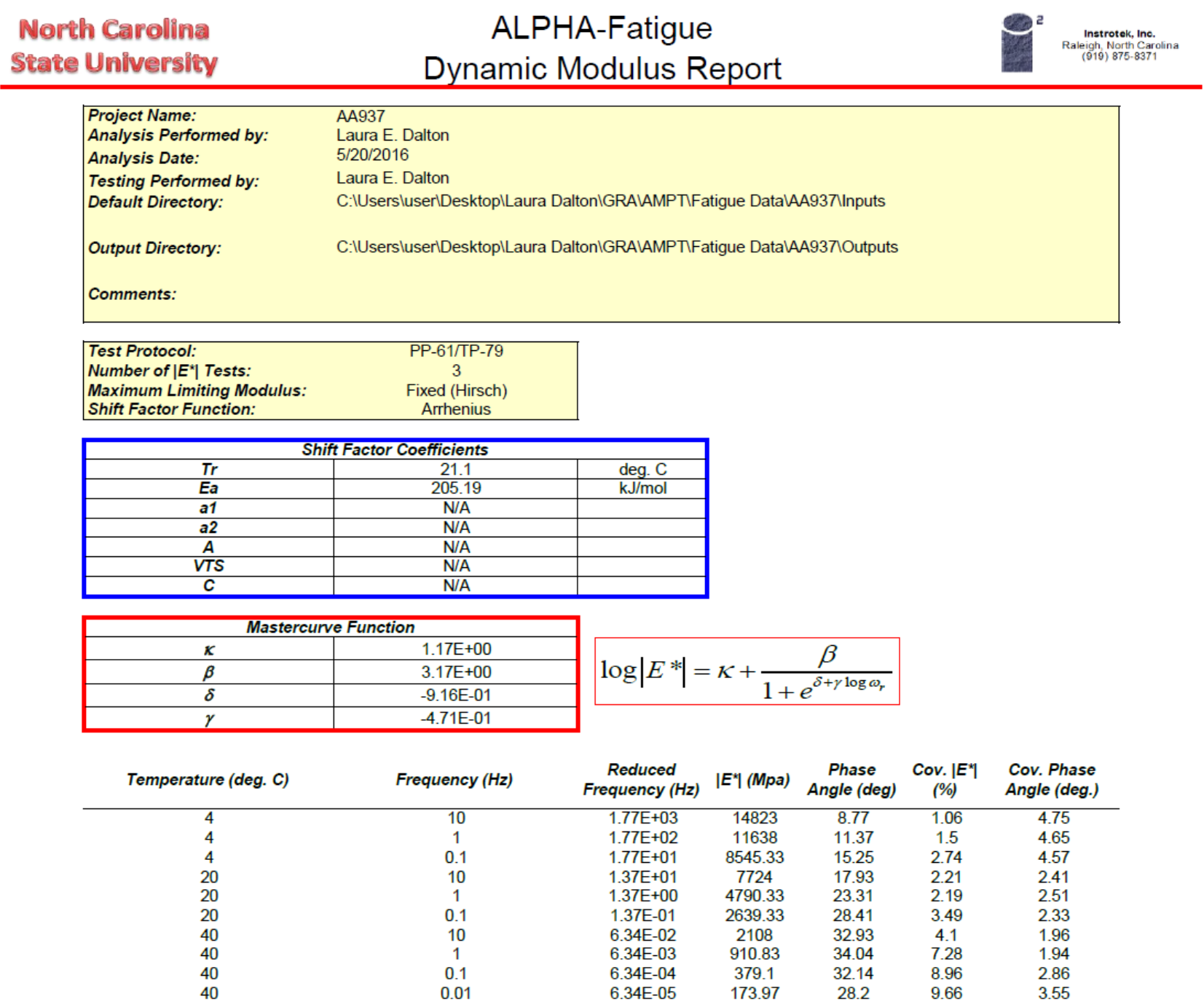

Figure 69: Alpha-Fatigue AA937 Peak Dynamic Modulus Output 


\section{North Carolina State University}

\section{ALPHA-Fatigue VECD Model Report}

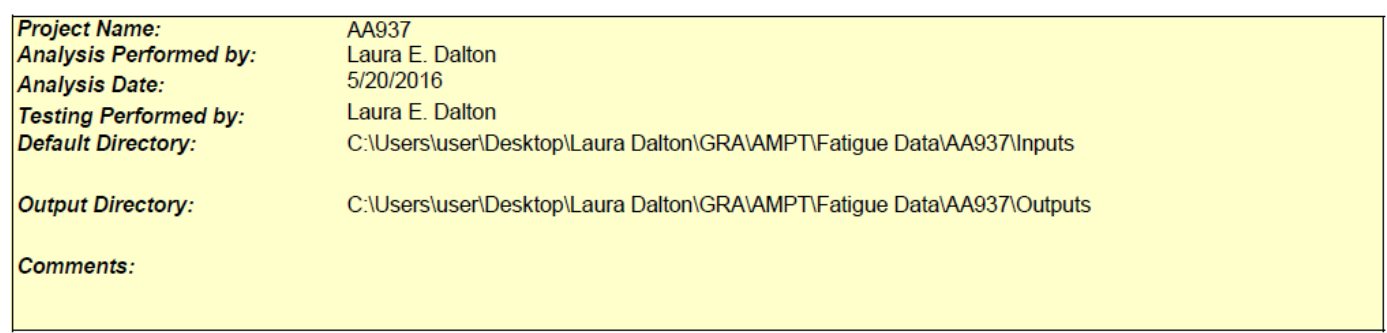

Number of Fatigue Tests: Damage Model Function: 3

Exponential

\begin{tabular}{|c|c|}
\hline \multicolumn{2}{|c|}{ Damage Model Coefficients } \\
\hline a & $-1.92 \mathrm{E}-05$ \\
\hline $\mathbf{b}$ & $9.32 \mathrm{E}-01$ \\
\hline $\mathbf{z}$ & N/A \\
\hline alpha & N/A \\
\hline Parameter in Failure Crit. & 3.711 \\
\hline Parameter s in Failure Crit. & $3.83 \mathrm{E}+05$ \\
\hline
\end{tabular}

$$
\begin{aligned}
& C=e^{a S^{b}} \quad C=1-y S^{z} \\
& N_{f}=r\left(G^{R}\right)^{s}
\end{aligned}
$$

\begin{tabular}{ccccccc} 
Test Name & Temperature (deg. C) & Frequency (Hz) $\begin{array}{c}\left|E^{*}\right|_{\text {LVE }} \\
\text { (MPa) }\end{array}$ & $\begin{array}{c}\left|E^{*}\right|_{\text {finger }} \\
(\text { MPa) }\end{array}$ & $\begin{array}{c}\text { Nf } \\
G^{R}\end{array}$ \\
\hline AA937 S5 & 15 & 10 & 9866.7 & 11379 & 4575 & $3.17 \mathrm{E}+02$ \\
AA937 S6 & 15 & 10 & 9877.4 & 11140 & 9655 & $1.08 \mathrm{E}+02$ \\
A4937 S7 & 15 & 10 & 9883.1 & 11349 & 57623 & $1.18 \mathrm{E}+01$
\end{tabular}

Figure 70: Alpha-Fatigue AA937 Peak Damage Functions Output 


$\begin{array}{ccc}\text { North Carolina } & \text { ALPHA-Fatigue } \\ \text { State University } & \text { Model Predictions Report }\end{array}$

\begin{tabular}{|c|c|}
\hline $\begin{array}{l}\text { Project Name: } \\
\text { Analysis Performed by: }\end{array}$ & $\begin{array}{l}\text { AA937 } \\
\text { Laura E. Dalton }\end{array}$ \\
\hline Analysis Date: & $5 / 20 / 2016$ \\
\hline Testing Performed by: & Laura E. Dalton \\
\hline Default Directory: & C:IUsersluserlDesktoplLaura DaltonIGRAIAMPTIFatigue DatalAA937VInputs \\
\hline Output Directory: & C:IUsersluserlDesktoplLaura DaltonIGRAIAMPTIFatigue DatalAA937\Outputs \\
\hline
\end{tabular}

\begin{tabular}{|c|c|}
\hline \multicolumn{2}{|c|}{ Traditional Strain Fatigue Relationship (kPa units) } \\
\hline K1 & $1.75 \mathrm{E}+13$ \\
\hline K2 & 7.188 \\
\hline K3 & -5.106 \\
\hline
\end{tabular}

\begin{tabular}{|c|c|}
\hline \multicolumn{2}{|c|}{ Traditional Stress Fatigue Relationship 1 ( $k P$ a units) } \\
\hline K1 & $6.10 \mathrm{E}-27$ \\
\hline K2 & -5.484 \\
\hline K3 & 6.842 \\
\hline
\end{tabular}

Traditional Stress Fatigue Relationship 2 ( $k$ Pa units)

\begin{tabular}{c|c}
\multicolumn{2}{c|}{ Traditional Stress Fatigue Relationship 2(kPa units) } \\
\hline K1 & $6.10 \mathrm{E}-27$ \\
\hline K2 & 5.484 \\
\hline$K 3$ & 1.358
\end{tabular}

Traditional Strain Fatigue Relationship (psi units)

\begin{tabular}{c|c} 
K1 & $9.16 \mathrm{E}+08$ \\
\hline 2 & 7.188 \\
\hline
\end{tabular}

\begin{tabular}{l|r}
\hline 2 & 7.188 \\
\hline$K 3$ & -5.106
\end{tabular}

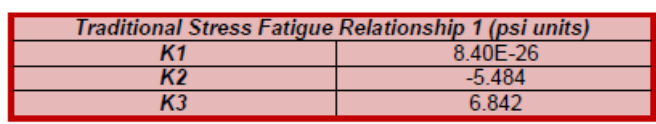

Traditional Stress Fatigue Relationship 2 (psi units)

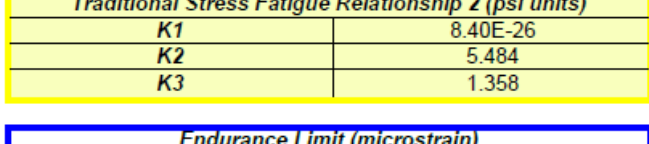

Temperature (deg. C)

ce Limit (microstrain)

\begin{tabular}{|c|c|}
\hline Temperature (deg. C) & Endurance Limit \\
\hline 5 & 51 \\
\hline 10 & 55 \\
\hline 15 & 61 \\
\hline 20 & 70 \\
\hline 25 & 91 \\
\hline
\end{tabular}

$$
N_{f}=K_{1}\left(\frac{1}{\varepsilon_{t}}\right)^{K_{2}}(|E *|)^{K_{3}}
$$$$
N_{f}=K_{1}\left(\sigma_{t}\right)^{K_{2}}(|E *|)^{K_{3}}
$$

$$
N_{f}=K_{1}\left(\frac{1}{\varepsilon_{t, \text { ini }}}\right)^{K_{2}}\left(\left|E^{*}\right|\right)^{K_{3}}
$$

$$
N_{f}=K_{1}\left(\frac{1}{\varepsilon_{t}}\right)^{K_{2}}(|E *|)^{K_{3}}
$$

$$
N_{f}=K_{1}\left(\sigma_{t}\right)^{K_{2}}(|E *|)^{K_{3}}
$$

$$
N_{f}=K_{1}\left(\frac{1}{\varepsilon_{t, \text { ini }}}\right)^{K_{2}}(|E *|)^{K_{3}}
$$

Figure 71: Alpha-Fatigue AA937 Peak Model Prediction Output 
North Carolina

State University

\section{ALPHA-Fatigue Dynamic Modulus Report}

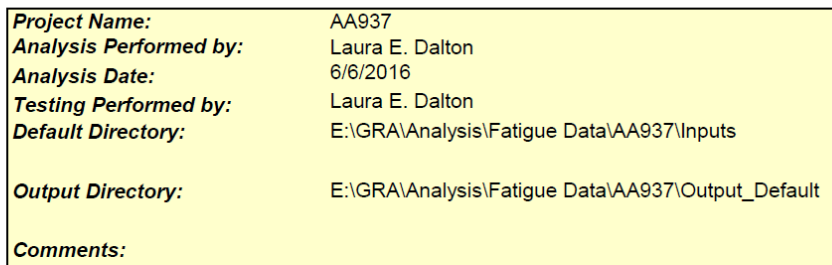

Test Protocol:

Number of $\left|E^{\star}\right|$ Tests:

Maximum Limiting Modulus: $\quad$ Fixed (Hirsch)

Shift Factor Function:

Arrhenius

\begin{tabular}{|c|c|c|}
\hline \multicolumn{3}{|c|}{ Shift Factor Coefficients } \\
\hline $\boldsymbol{T r}$ & 21.1 & deg. C \\
\hline $\boldsymbol{E a}$ & 205.19 & $\mathrm{~kJ} / \mathrm{mol}$ \\
\hline $\boldsymbol{a 1}$ & $\mathrm{N} / \mathrm{A}$ & \\
\hline $\boldsymbol{a} 2$ & $\mathrm{~N} / \mathrm{A}$ & \\
\hline $\boldsymbol{N}$ & $\mathrm{N} / \mathrm{A}$ & \\
\hline VTS & $\mathrm{N} / \mathrm{A}$ & \\
\hline $\boldsymbol{C}$ & $\mathrm{N} / \mathrm{A}$ & \\
\hline
\end{tabular}

\begin{tabular}{|c|c|}
\hline \multicolumn{2}{|c|}{ Mastercurve Function } \\
\hline $\boldsymbol{\alpha}$ & $1.17 \mathrm{E}+00$ \\
\hline$\beta$ & $3.17 \mathrm{E}+00$ \\
\hline$\delta$ & $-9.16 \mathrm{E}-01$ \\
\hline$\gamma$ & $-4.71 \mathrm{E}-01$ \\
\hline
\end{tabular}

$$
\log |E *|=\kappa+\frac{\beta}{1+e^{\delta+\gamma \log \omega_{r}}}
$$

\begin{tabular}{|c|c|c|c|c|c|c|}
\hline Temperature (deg. C) & Frequency $(\mathrm{Hz})$ & $\begin{array}{c}\text { Reduced } \\
\text { Frequency }(\mathrm{Hz})\end{array}$ & $\left|E^{\star}\right|$ (Mpa) & $\begin{array}{c}\text { Phase } \\
\text { Angle (deg) }\end{array}$ & $\begin{array}{c}\text { Cov. }\left|E^{\star}\right| \\
(\%)\end{array}$ & $\begin{array}{l}\text { Cov. Phase } \\
\text { Angle (deg.) }\end{array}$ \\
\hline 4 & 10 & $1.77 \mathrm{E}+03$ & 14823 & 8.77 & 1.06 & 4.75 \\
\hline 4 & 1 & $1.77 \mathrm{E}+02$ & 11638 & 11.37 & 1.5 & 4.65 \\
\hline 4 & 0.1 & $1.77 \mathrm{E}+01$ & 8545.33 & 15.25 & 2.74 & 4.57 \\
\hline 20 & 10 & $1.37 \mathrm{E}+01$ & 7724 & 17.93 & 2.21 & 2.41 \\
\hline 20 & 1 & $1.37 \mathrm{E}+00$ & 4790.33 & 23.31 & 2.19 & 2.51 \\
\hline 20 & 0.1 & $1.37 \mathrm{E}-01$ & 2639.33 & 28.41 & 3.49 & 2.33 \\
\hline 40 & 10 & $6.34 \mathrm{E}-02$ & 2108 & 32.93 & 4.1 & 1.96 \\
\hline 40 & 1 & $6.34 \mathrm{E}-03$ & 910.83 & 34.04 & 7.28 & 1.94 \\
\hline 40 & 0.1 & $6.34 \mathrm{E}-04$ & 379.1 & 32.14 & 8.96 & 2.86 \\
\hline 40 & 0.01 & $6.34 \mathrm{E}-05$ & 173.97 & 28.2 & 9.66 & 3.55 \\
\hline
\end{tabular}

Figure 72: Alpha-Fatigue AA937 Default Dynamic Modulus Output 


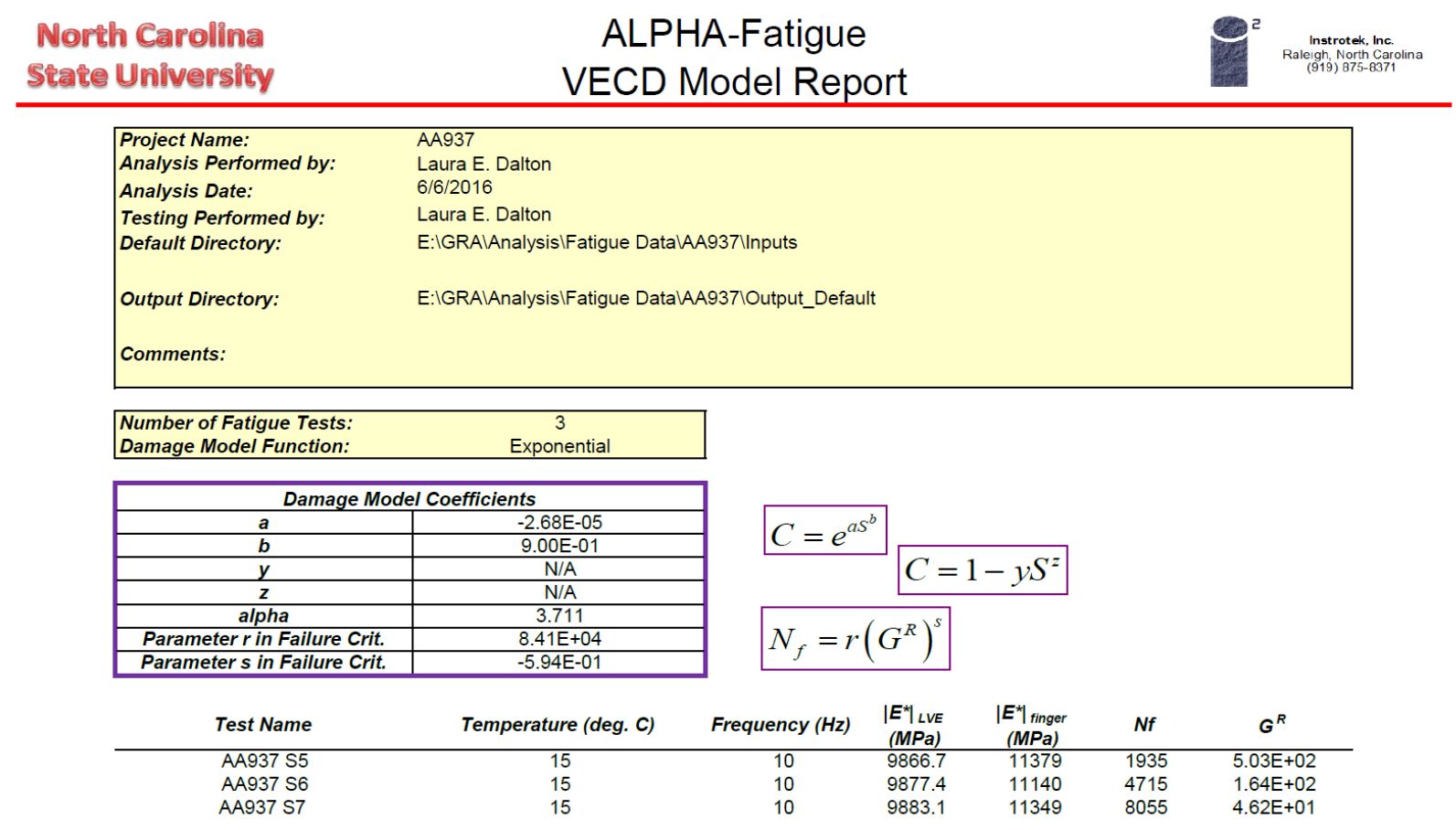

Figure 73: Alpha-Fatigue AA937 Default Damage Functions Output 


\begin{tabular}{|ll}
\hline Project Name: & AA937 \\
Analysis Performed by: & Laura E. Dalton \\
Analysis Date: & $6 / 6 / 2016$ \\
Testing Performed by: & Laura E. Dalton \\
Default Directory: & E:IGRALAnalysisIFatigue DatalAA937\Inputs \\
& \\
Output Directory: & E:IGRAVAnalysisIFatigue DatalAA937\Output_Default \\
Comments: &
\end{tabular}

\begin{tabular}{|c|c|}
\hline \multicolumn{2}{|c|}{ Traditional Strain Fatigue Relationship (kPa units) } \\
\hline K1 & $2.70 \mathrm{E}+04$ \\
\hline K2 & 4.237 \\
\hline K3 & -2.361 \\
\hline
\end{tabular}

$$
N_{f}=K_{1}\left(\frac{1}{\varepsilon_{t}}\right)^{K_{2}}\left(\left|E^{*}\right|\right)^{K_{3}}
$$

\begin{tabular}{|c|c|}
\hline \multicolumn{2}{|c|}{ Traditional Stress Fatigue Relationship 1 (kPa units) } \\
\hline K1 & $2.84 \mathrm{E}-10$ \\
\hline K2 & -4.42 \\
\hline K3 & 3.955 \\
\hline
\end{tabular}

$$
N_{f}=K_{1}\left(\sigma_{t}\right)^{K_{2}}(|E *|)^{K_{3}}
$$

Traditional Stress Fatigue Relationship 2 (kPa units)

\begin{tabular}{|c|c|}
\hline K1 & $2.84 \mathrm{E}-10$ \\
\hline K2 & 4.42 \\
\hline K3 & -0.465 \\
\hline
\end{tabular}

$$
N_{f}=K_{1}\left(\frac{1}{\varepsilon_{t, \text { ini }}}\right)^{K_{2}}(|E *|)^{K_{3}}
$$

Traditional Strain Fatigue Relationship (psi units)

\begin{tabular}{|c|c|}
\hline \multicolumn{2}{|c|}{ Traditional Strain Fatigue Relationship (psi units) } \\
\hline K1 & $2.83 \mathrm{E}+02$ \\
\hline K2 & 4.237 \\
\hline K3 & -2.361 \\
\hline \multicolumn{2}{|c|}{} \\
\hline Traditional Stress Fatigue Relationship 1 (psi units) \\
\hline K1 & $1.16 \mathrm{E}-10$ \\
\hline K2 & -4.42 \\
\hline K3 & 3.955 \\
\hline
\end{tabular}

$$
N_{f}=K_{1}\left(\frac{1}{\varepsilon_{t}}\right)^{K_{2}}(|E *|)^{K_{3}}
$$

Traditional Stress Fatigue Relationship 2 (psi units)

\begin{tabular}{|c|c|}
\hline \multicolumn{2}{|c|}{ Traditional Stress Fatigue Relationship 2 (psi units) } \\
\hline K1 & $1.16 \mathrm{E}-10$ \\
\hline K2 & 4.42 \\
\hline K3 & -0.465 \\
\hline
\end{tabular}

$$
N_{f}=K_{1}\left(\sigma_{t}\right)^{K_{2}}(|E *|)^{K_{3}}
$$

Temperature (deg. C)

Endurance Limit (microstrain)

\begin{tabular}{|c|c|}
\hline \multicolumn{2}{|c|}{ Endurance Limit (microstrain) } \\
\hline Temperature (deg. C) & Endurance Limit \\
\hline 5 & 24 \\
\hline 10 & 24 \\
\hline 15 & 26 \\
\hline 20 & 28 \\
\hline 25 & 34 \\
\hline
\end{tabular}

$$
N_{f}=K_{1}\left(\frac{1}{\varepsilon_{t, \text { ini }}}\right)^{K_{2}}(|E *|)^{K_{3}}
$$

Figure 74: Alpha-Fatigue AA937 Default Model Prediction Output 


\begin{tabular}{|c|c|c|c|c|c|c|}
\hline $\begin{array}{l}\text { North Carolina } \\
\text { State: Uniิversiిty }\end{array}$ & \multicolumn{3}{|c|}{$\begin{array}{c}\text { ALPHA-Fatigue } \\
\text { Dynamic Modulus Report }\end{array}$} & & $\begin{array}{l}\text { Instrotek, Inc. } \\
\text { Raleigh, North Caroli } \\
(919) 875-8371\end{array}$ \\
\hline $\begin{array}{l}\text { Project Name: } \\
\text { Analysis Performed by: } \\
\text { Analysis Date: } \\
\text { Testing Performed by: } \\
\text { Default Directory: } \\
\text { Output Directory: } \\
\text { Comments: }\end{array}$ & $\begin{array}{l}\text { JAP909 } \\
\text { Laura E. Dalton } \\
\text { 5/20/2016 } \\
\text { Laura E. Dalton } \\
\text { C:IUsersluserIDesktopILa } \\
\text { C:IUsersluserIDesktoplLa }\end{array}$ & $\begin{array}{l}\text { ItonIGRAIAMPTIFa } \\
\text { ItonIGRAIAMPTIFa }\end{array}$ & $\begin{array}{l}\text { tigue DatalJ } \\
\text { tigue DatalJ }\end{array}$ & AP909VInputs & & \\
\hline \multicolumn{3}{|l|}{$\begin{array}{l}\text { Test Protocol: } \\
\text { Number of }\left|E^{\star}\right| \text { Tests: } \\
\text { Maximum Limiting Modulus: } \\
\text { Shift Factor Function: } \\
\end{array}$} & & & & \\
\hline \multicolumn{3}{|c|}{ Shift Factor Coefficients } & & & & \\
\hline $\operatorname{Tr}$ & 21.1 & deg. C & & & & \\
\hline Ea & 196.16 & $\mathrm{~kJ} / \mathrm{mol}$ & & & & \\
\hline$a 1$ & $\mathrm{~N} / \mathrm{A}$ & & & & & \\
\hline a2 & N/A & & & & & \\
\hline$A$ & N/A & & & & & \\
\hline VTS & N/A & & & & & \\
\hline$C$ & $\mathrm{~N} / \mathrm{A}$ & & & & & \\
\hline \multicolumn{2}{|c|}{ Mastercurve Function } & \multirow{4}{*}{\multicolumn{3}{|c|}{$\log \left|E^{*}\right|=\kappa+\frac{\beta}{1+e^{\delta+\gamma \log \omega_{r}}}$}} & \multirow{6}{*}{\multicolumn{2}{|c|}{$\begin{array}{l}\text { Cov. Phase } \\
\text { Angle (deg.) }\end{array}$}} \\
\hline$\kappa$ & $1.58 \mathrm{E}+00$ & & & & & \\
\hline$\beta$ & $2.76 \mathrm{E}+00$ & & & & & \\
\hline$\delta$ & $-5.14 \mathrm{E}-01$ & & & & & \\
\hline$\gamma$ & $-6.25 \mathrm{E}-01$ & & & & & \\
\hline Temperature (deg. C) & Frequency $(\mathrm{Hz})$ & $\begin{array}{c}\text { Reduced } \\
\text { Frequency }(\mathrm{Hz})\end{array}$ & $\left|E^{\star}\right|(M p a)$ & $\begin{array}{c}\text { Phase } \\
\text { Angle (deg) }\end{array}$ & & \\
\hline 4 & 10 & $1.41 \mathrm{E}+03$ & 18175 & 11.75 & 8.72 & 5.66 \\
\hline 4 & 1 & $1.41 \mathrm{E}+02$ & 12997.67 & 16.19 & 10.1 & 4.86 \\
\hline 4 & 0.1 & $1.41 \mathrm{E}+01$ & 8387.33 & 21.81 & 10.73 & 4.01 \\
\hline 20 & 10 & $1.35 \mathrm{E}+01$ & 8049.67 & 23.63 & 4.58 & 0.13 \\
\hline 20 & 1 & $1.35 \mathrm{E}+00$ & 4344 & 29.71 & 4.63 & 0.17 \\
\hline 20 & 0.1 & $1.35 \mathrm{E}-01$ & 2003.67 & 33.46 & 5.04 & 0.21 \\
\hline 40 & 10 & 7.92E-02 & 1582.33 & 38.39 & 5.01 & 2.37 \\
\hline 40 & 1 & $7.92 \mathrm{E}-03$ & 579.13 & 34.15 & 2.49 & 1.47 \\
\hline 40 & 0.1 & $7.92 \mathrm{E}-04$ & 227.4 & 28.23 & 3.04 & 1.58 \\
\hline 40 & 0.01 & 7.92E-05 & 118.4 & 22.49 & 6.93 & 2.33 \\
\hline
\end{tabular}

Figure 75: Alpha-Fatigue JAP909 Peak Dynamic Modulus Output 


$\begin{array}{cc}\begin{array}{c}\text { North Carolina } \\ \text { State University }\end{array} & \text { ALPHA-Fatigue } \\ \text { VECD Model Report }\end{array}$

\begin{tabular}{|ll|}
\hline Project Name: & \\
Analysis Performed by: & JAP909 \\
Analysis Date: & Laura E. Dalton \\
Testing Performed by: & Laura E. Dalton \\
Default Directory: & C:IUsersluser|DesktoplLaura DaltonIGRAIAMPTIFatigue DatalJAP909IInputs \\
& \\
Output Directory: & C:IUsersluser|DesktoplLaura DaltonIGRAIAMPTIFatigue DatalJAP909IOutputs \\
Comments: & \\
\hline
\end{tabular}

Number of Fatigue Tests: 3 Damage Model Function: Exponential

\begin{tabular}{|c|c|}
\hline \multicolumn{2}{|c|}{ Damage Model Coefficients } \\
\hline $\boldsymbol{a}$ & $-4.80 \mathrm{E}-04$ \\
\hline $\boldsymbol{b}$ & $6.67 \mathrm{E}-01$ \\
\hline $\boldsymbol{z}$ & N/A \\
\hline alpha & N/A \\
\hline Parameter $\boldsymbol{r}$ in Failure Crit. & 3.361 \\
\hline Parameter s in Failure Crit. & $4.15 \mathrm{E}+05$ \\
\hline
\end{tabular}

$$
\begin{aligned}
& C=e^{a S^{b}} \quad C=1-y S^{z} \\
& N_{f}=r\left(G^{R}\right)^{s}
\end{aligned}
$$

\begin{tabular}{|c|c|c|c|c|c|c|}
\hline Test Name & Temperature (deg. C) & Frequency $(\mathrm{Hz})$ & $\begin{array}{c}\left|E^{\star}\right| \text { LVE } \\
(\mathrm{MPa})\end{array}$ & $\begin{array}{c}\left|E^{*}\right|_{\text {finger }} \\
(\mathrm{MPa})\end{array}$ & $N f$ & $G^{R}$ \\
\hline JAP909 S6 at $15 \mathrm{C}$ & 15 & 10 & 10602.8 & 11859 & 7135 & $3.52 \mathrm{E}+02$ \\
\hline JAP909 S7 & 15 & 10 & 10611.5 & 11921 & 4895 & $8.04 \mathrm{E}+02$ \\
\hline JAP909 S8 & 15 & 10 & 10595.1 & 11803 & 22363 & $8.07 E+01$ \\
\hline
\end{tabular}

Figure 76: Alpha-Fatigue JAP909 Peak Damage Functions Output 


\section{North Carolina} State University

\section{ALPHA-Fatigue Model Predictions Report}

\begin{tabular}{|c|c|}
\hline Project Name: & JAP909 \\
\hline Analysis Performed by: & Laura E. Dalton \\
\hline Analysis Date: & $5 / 20 / 2016$ \\
\hline Testing Performed by: & Laura E. Dalton \\
\hline Default Directory: & C:IUsersluser|DesktopILaura DaltonIGRAIAMPTIFatigue DatalJAP909IInputs \\
\hline Output Directory: & C:IUsersluser|DesktopILaura DaltonIGRAIAMPTIFatigue DatalJAP909|Outputs \\
\hline
\end{tabular}

Comments:

\begin{tabular}{|c|c|}
\hline \multicolumn{2}{|c|}{ Traditional Strain Fatigue Relationship (kPa units) } \\
\hline K1 & $4.51 \mathrm{E}+14$ \\
\hline K2 & 4.505 \\
\hline K3 & -3.812 \\
\hline
\end{tabular}

$$
N_{f}=K_{1}\left(\frac{1}{\varepsilon_{t}}\right)^{K_{2}}(|E *|)^{K_{3}}
$$

Traditional Stress Fatigue Relationship 1 (kPa units)

\begin{tabular}{|l|c|}
\hline K1 & $1.30 \mathrm{E}-10$ \\
\hline K2 & -4.22 \\
\hline
\end{tabular}

$N_{f}=K_{1}\left(\sigma_{t}\right)^{K_{2}}(|E *|)^{K_{3}}$

Traditional Stress Fatigue Relationship 2 (kPa units)

\begin{tabular}{c|c}
\multicolumn{2}{c}{ Traditional Stress Fatigue Relationship 2 (kPa units) } \\
\hline K1 & $1.30 \mathrm{E}-10$ \\
\hline K2 & 4.22 \\
\hline K3 & -0.288
\end{tabular}

$N_{f}=K_{1}\left(\frac{1}{\varepsilon_{t, i n i}}\right)^{K_{2}}(|E *|)^{K_{3}}$

Traditional Strain Fatigue Relationship (psi units) \begin{tabular}{l|r} 
K1 & $2.87 \mathrm{E}+1$ \\
\hline 2 & 4.505
\end{tabular}

\begin{tabular}{l|r}
$K 2$ & 4.505 \\
\hline
\end{tabular}

$-3.812$

$$
N_{f}=K_{1}\left(\frac{1}{\varepsilon_{t}}\right)^{K_{2}}(|E *|)^{K_{3}}
$$

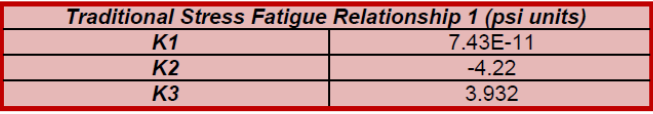

$$
N_{f}=K_{1}\left(\sigma_{t}\right)^{K_{2}}(\mid E *)^{K_{3}}
$$

Traditional Stress Fatigue Relationship 2 (psi units)

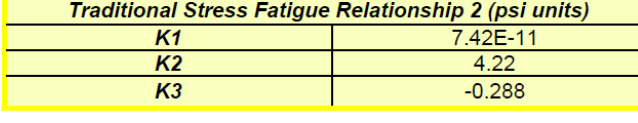

$$
N_{f}=K_{1}\left(\frac{1}{\varepsilon_{t, i n i}}\right)^{K_{2}}(|E *|)^{K_{3}}
$$

\begin{tabular}{|c|c|}
\hline \multicolumn{2}{|c|}{ Endurance Limit (microstrain) } \\
\hline Temperature (deg. C) & Endurance Limit \\
\hline 5 & 33 \\
\hline 10 & 36 \\
\hline 15 & 42 \\
\hline 20 & 50 \\
\hline 25 & 69 \\
\hline
\end{tabular}

Figure 77: Alpha-Fatigue JAP909 Peak Model Prediction Output 
North Carolina State University

\section{ALPHA-Fatigue Dynamic Modulus Report}

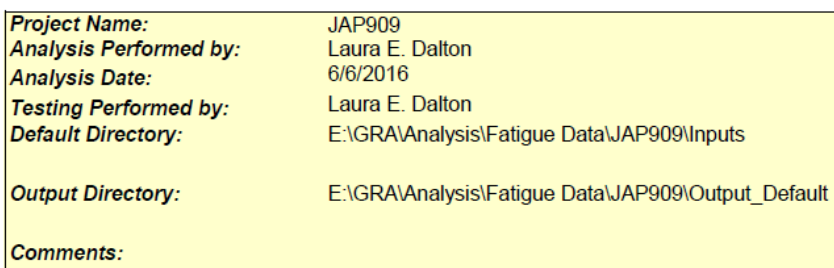

\begin{tabular}{|c|c|c|}
\hline \multicolumn{3}{|c|}{ Shift Factor Coefficients } \\
\hline Tr & 21.1 & deg. C \\
\hline Ea & 196.16 & $\mathrm{~kJ} / \mathrm{mol}$ \\
\hline$a 1$ & $\mathrm{~N} / \mathrm{A}$ & \\
\hline$a 2$ & $\mathrm{~N} / \mathrm{A}$ & \\
\hline A & $\mathrm{N} / \mathrm{A}$ & \\
\hline VTS & $\mathrm{N} / \mathrm{A}$ & \\
\hline C & $\mathrm{N} / \mathrm{A}$ & \\
\hline
\end{tabular}

\begin{tabular}{|c|c|}
\hline \multicolumn{2}{|c|}{ Mastercurve Function } \\
\hline$\kappa$ & $1.58 \mathrm{E}+00$ \\
\hline$\beta$ & $2.76 \mathrm{E}+00$ \\
\hline$\delta$ & $-5.14 \mathrm{E}-01$ \\
\hline$\gamma$ & $-6.25 \mathrm{E}-01$ \\
\hline \multirow{2}{*}{$\log \left|E^{*} *\right|=\kappa+\frac{\beta}{1+e^{\delta+\gamma \log \omega_{r}}}$} \\
\hline
\end{tabular}

Temperature (deg. C)

Frequency $(\mathrm{Hz})$

4
4
4
2
2
2
40
40
40
40

$\begin{array}{cc}10 & 1.41 \mathrm{E}+03 \\ 1 & 1.41 \mathrm{E}+02 \\ 0.1 & 1.41 \mathrm{E}+01 \\ 10 & 1.35 \mathrm{E}+01 \\ 1 & 1.35 \mathrm{E}+00 \\ 0.1 & 1.35 \mathrm{E}-01 \\ 10 & 7.92 \mathrm{E}-02 \\ 1 & 7.92 \mathrm{E}-03 \\ 0.1 & 7.92 \mathrm{E}-04 \\ 0.01 & 7.92 \mathrm{E}-05\end{array}$

$\left|E^{\star}\right|($ Mpa)
18175
12997.67

12997.67

8387.33

8049.67

4344

2003.67

1582.33

1582.33
579.13

227.4

118.4
Phase Angle (deg)

11.75
16.19

16.19
21.81

21.81
23.63

29.71

33.46

38.39

34.15
28.23

22.49
Cov. $\left|E^{\star}\right| \quad$ Cov. Phase (\%) Angle (deg.)

$8.72 \quad 5.66$

$\begin{array}{ll}8.72 & 4.86\end{array}$

$\begin{array}{ll}10.73 & 4.01\end{array}$

$4.58 \quad 0.13$

$\begin{array}{ll}4.63 & 0.17\end{array}$

$\begin{array}{ll}5.04 & 0.21\end{array}$

$\begin{array}{ll}5.01 & 2.37\end{array}$

$\begin{array}{ll}2.49 & 1.47 \\ 3.04 & 1.58\end{array}$

$\begin{array}{ll}3.04 & 1.58\end{array}$

Figure 78: Alpha-Fatigue JAP909 Default Dynamic Modulus Output 


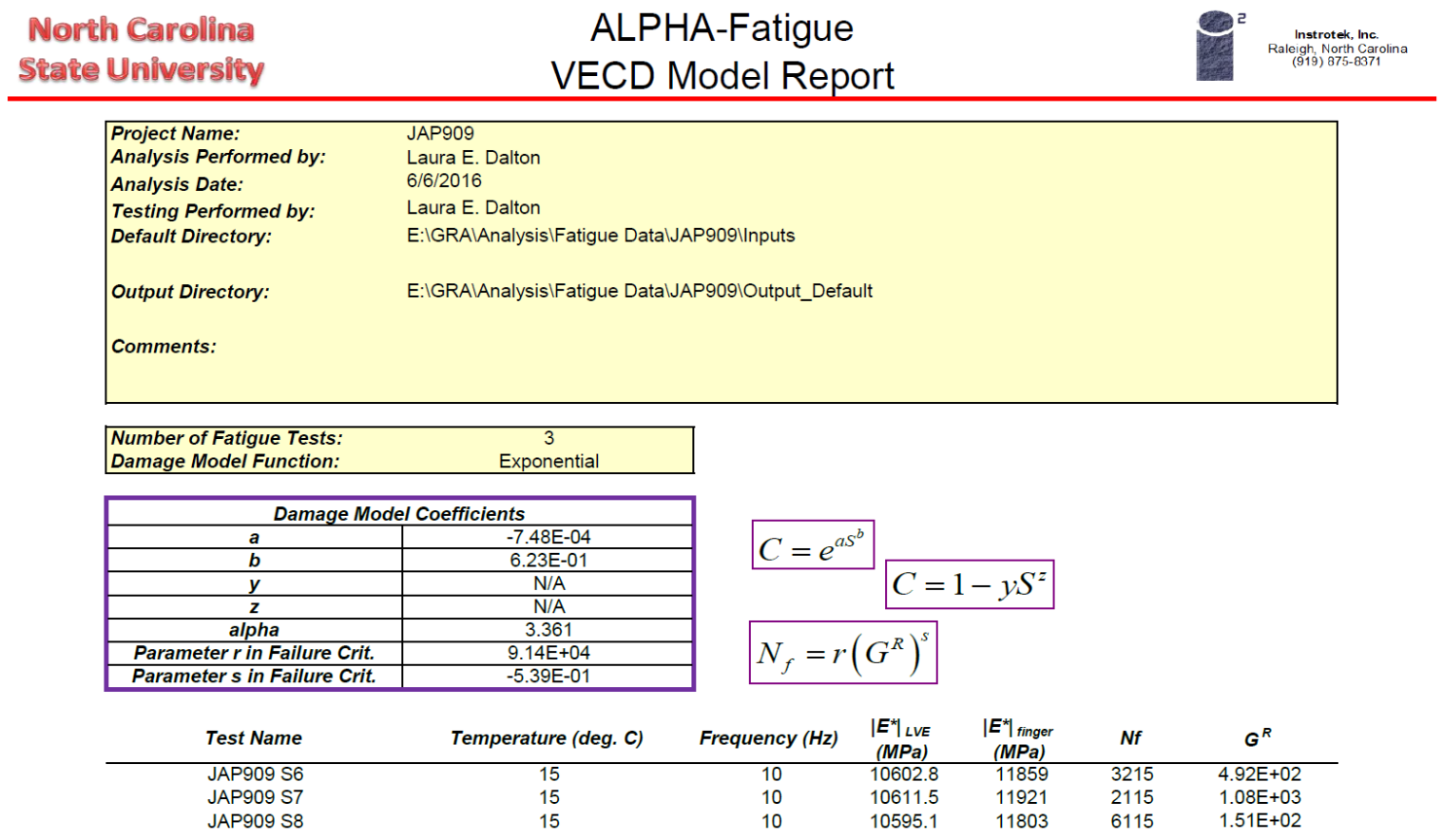

Figure 79: Alpha-Fatigue JAP909 Default Damage Functions Output 


\section{North Carolina}

Project Name: JAP909

Analysis Performed by: Laura E. Dalton

Analysis Date:

6/6/2016

Testing Performed by: Laura E. Dalton

Default Directory:

E:IGRAlAnalysisIFatigue DatalJAP909Unputs

Output Directory:

E:IGRAIAnalysisIFatigue DataWAP9091Output_Default

Comments:

\begin{tabular}{|c|c|}
\hline \multicolumn{2}{|c|}{ Traditional Strain Fatigue Relationship (kPa units) } \\
\hline K1 & $8.14 \mathrm{E}+08$ \\
\hline K2 & 2.899 \\
\hline K3 & -2.264 \\
\hline
\end{tabular}

$$
N_{f}=K_{1}\left(\frac{1}{\varepsilon_{t}}\right)^{K_{2}}(|E *|)^{K_{3}}
$$

\begin{tabular}{|c|c|}
\hline \multicolumn{2}{|c|}{ Traditional Stress Fatigue Relationship 1 (kPa units) } \\
\hline K1 & $5.24 \mathrm{E}-01$ \\
\hline$K 2$ & -3.308 \\
\hline$K 3$ & 2.088 \\
\hline
\end{tabular}

$$
N_{f}=K_{1}\left(\sigma_{t}\right)^{K_{2}}(|E *|)^{K_{3}}
$$

Traditional Stress Fatigue Relationship 2 (kPa units)

\begin{tabular}{c|c}
\multicolumn{2}{c}{ Traditional Stress Fatigue Relationship 2 (kPa units) } \\
\hline K1 & $5.24 \mathrm{E}-01$ \\
\hline K2 & 3.308 \\
\hline K3 & -1.219
\end{tabular}

$$
N_{f}=K_{1}\left(\frac{1}{\varepsilon_{t, \text { ini }}}\right)^{K_{2}}(|E *|)^{K_{3}}
$$

Traditional Strain Fatigue Relationship (psi units)

$$
\text { K1 }
$$

K3

$1.03 \mathrm{E}+07$

2.899

Traditional Stress Fatigue Relationship 1 (psi units)

$$
\text { K1 }
$$$$
\text { K2 }
$$

K3

-3.98E-02

2.088

Traditional Stress Fatigue Relationship 2 (psi units)

\begin{tabular}{|c|c|}
\hline Kraditional Stress Fatigue Relationship 2 (psi units) \\
\hline K2 & $4.98 \mathrm{E}-02$ \\
\hline K3 & 3.308 \\
\hline
\end{tabular}

Endurance Limit (microstrain)

\section{Temperature (deg. C) \\ Endurance Limit}

\begin{tabular}{|c|c|}
\hline 5 & Endurance Limit \\
\hline 10 & 9 \\
\hline 15 & 10 \\
\hline 20 & 11 \\
\hline 25 & 13 \\
\hline
\end{tabular}

$$
N_{f}=K_{1}\left(\frac{1}{\varepsilon_{t}}\right)^{K_{2}}(|E *|)^{K_{3}}
$$

$$
N_{f}=K_{1}\left(\sigma_{t}\right)^{K_{2}}(|E *|)^{K_{3}}
$$

$$
N_{f}=K_{1}\left(\frac{1}{\varepsilon_{t, i n i}}\right)^{K_{2}}(|E *|)^{K_{3}}
$$

Figure 80: Alpha-Fatigue JAP909 Default Model Prediction Output 


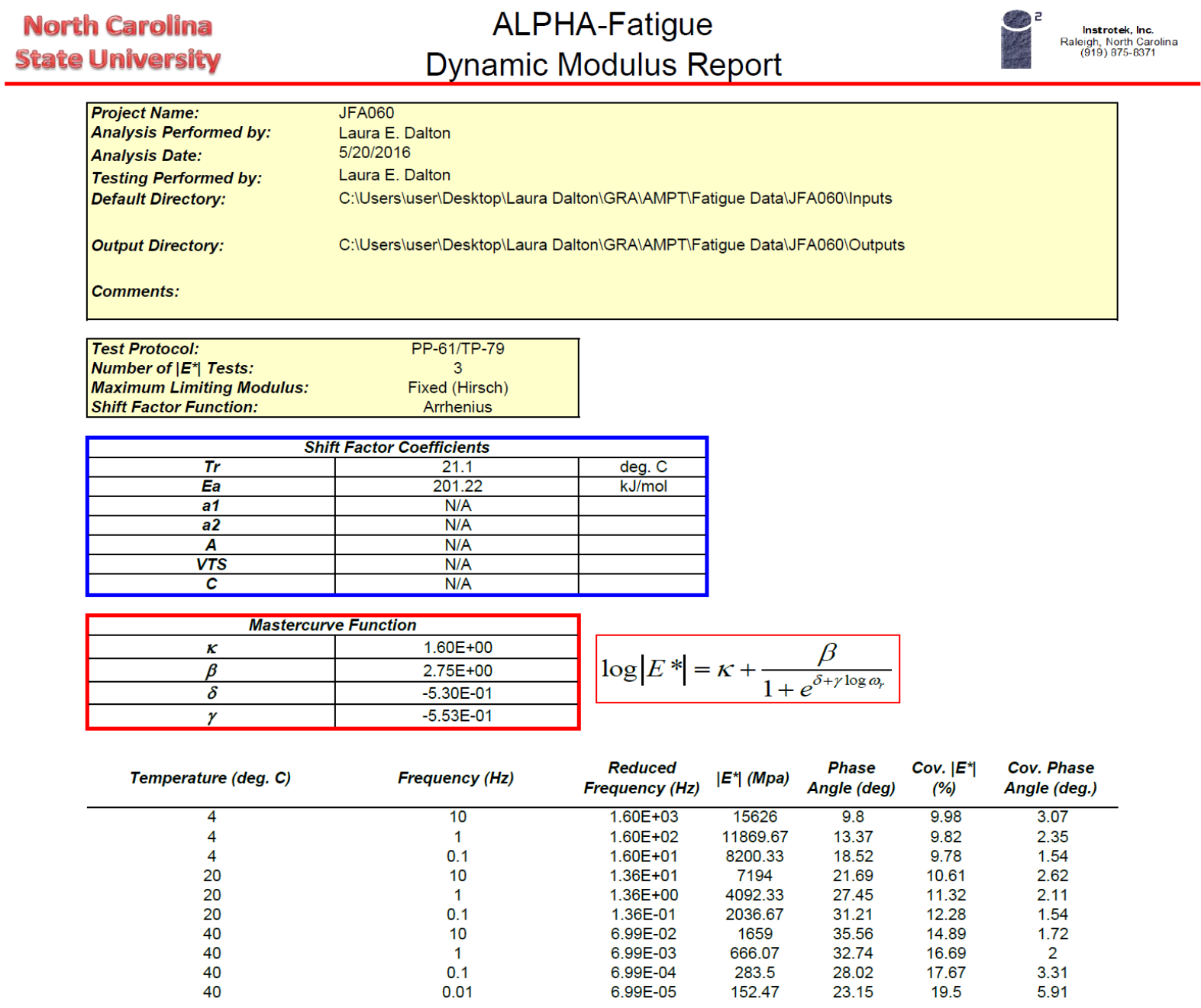

Figure 81: Alpha-Fatigue JFA060 Peak Dynamic Modulus Output 


$\begin{array}{ccc}\begin{array}{c}\text { North Carolina } \\ \text { State University }\end{array} & \text { ALPHA-Fatigue } \\ \text { VECD Model Report }\end{array}$

\begin{tabular}{ll}
\hline Project Name: & JFA060 \\
Analysis Performed by: & Laura E. Dalton \\
Analysis Date: & 5/20/2016 \\
Testing Performed by: & Laura E. Dalton \\
Default Directory: & C:IUsersluserIDesktoplLaura DaltonIGRAIAMPTIFatigue DatalJFA060Inputs \\
& \\
Output Directory: & C:IUsersluserIDesktoplLaura DaltonIGRAIAMPTIFatigue DatalJFA0601Outputs \\
Comments: &
\end{tabular}

Number of Fatigue Tests: Damage Model Function:

3 Exponential

\begin{tabular}{|c|c|}
\hline \multicolumn{2}{|c|}{ Damage Model Coefficients } \\
\hline $\boldsymbol{a}$ & $-1.11 \mathrm{E}-04$ \\
\hline $\boldsymbol{b}$ & $7.89 \mathrm{E}-01$ \\
\hline $\boldsymbol{z}$ & $\mathrm{N} / \mathrm{A}$ \\
\hline alpha & 3.657 \\
\hline Parameter $\boldsymbol{r}$ in Failure Crit. & $4.79 \mathrm{E}+05$ \\
\hline Parameter s in Failure Crit. & $-7.06 \mathrm{E}-01$ \\
\hline
\end{tabular}

$$
\begin{aligned}
& C=e^{a S^{b}} \quad C=1-y S^{z} \\
& N_{f}=r\left(G^{R}\right)^{s}
\end{aligned}
$$

\begin{tabular}{lcccccc} 
Test Name & Temperature (deg. C) & Frequency $(\mathbf{H z})$ & $\begin{array}{c}\left|E^{\star}\right| \text { LVE } \\
(\mathbf{M P a})\end{array}$ & $\begin{array}{c}\left|E^{\star}\right|_{\text {finger }} \\
(\mathbf{M P a})\end{array}$ & $\mathbf{N f}$ & $\mathbf{G}^{R}$ \\
\hline JFA060 S5 & 15 & 10 & 9682.1 & 9502 & 7075 & $2.80 \mathrm{E}+02$ \\
JFA060 S6 & 14.9 & 10 & 9723.6 & 10447 & 2595 & $1.84 \mathrm{E}+03$ \\
JFA060 S7 & 15 & 10 & 9705.3 & 10028 & 24645 & $8.16 \mathrm{E}+01$
\end{tabular}

Figure 82: Alpha-Fatigue JFA060 Peak Damage Functions Output 
North Carolina State University

\section{ALPHA-Fatigue Model Predictions Report}

\begin{tabular}{|ll}
\hline Project Name: & JFA060 \\
Analysis Performed by: & Laura E. Dalton \\
Analysis Date: & $5 / 20 / 2016$ \\
Testing Performed by: & Laura E. Dalton \\
Default Directory: & C:IUsersluserIDesktopILaura DaltonIGRAIAMPTIFatigue DatalJFA060VInputs \\
& C:IUsersluserIDesktopILaura DaltonIGRAIAMPTIFatigue DatalJFA060IOutputs \\
Output Directory: &
\end{tabular}

Comments:

\begin{tabular}{|c|c|}
\hline \multicolumn{2}{|c|}{ Traditional Strain Fatigue Relationship (kPa units) } \\
\hline K1 & $1.75 \mathrm{E}+16$ \\
\hline K2 & 5.191 \\
\hline K3 & -4.399 \\
\hline
\end{tabular}

$$
N_{f}=K_{1}\left(\frac{1}{\varepsilon_{t}}\right)^{K_{2}}(|E *|)^{K_{3}}
$$

\begin{tabular}{|c|c|}
\hline \multicolumn{2}{|c|}{ Traditional Stress Fatigue Relationship 1(kPa units) } \\
\hline K1 & $3.57 \mathrm{E}-16$ \\
\hline K2 & -5.034 \\
\hline K3 & 5.095 \\
\hline
\end{tabular}

$$
N_{f}=K_{1}\left(\sigma_{t}\right)^{K_{2}}(|E *|)^{K_{3}}
$$

\begin{tabular}{c|c}
\multicolumn{2}{c}{ Traditional Stress Fatigue Relationship 2 (kPa units) } \\
\hline K1 & $3.57 \mathrm{E}-16$ \\
\hline K2 & 5.034 \\
\hline K3 & 0.062
\end{tabular}

$$
\begin{aligned}
& N_{f}=K_{1}\left(\frac{1}{\varepsilon_{t, \text { ini }}}\right)^{K_{2}}(|E *|)^{K_{3}} \\
& N_{f}=K_{1}\left(\frac{1}{\varepsilon_{t}}\right)^{K_{2}}(|E *|)^{K_{3}}
\end{aligned}
$$

Traditional Strain Fatigue Relationship (psi units)

\begin{tabular}{c|c} 
K1 & $3.59 \mathrm{E}+12$ \\
\hline K2 & 5.191
\end{tabular}

K3

$-4.399$

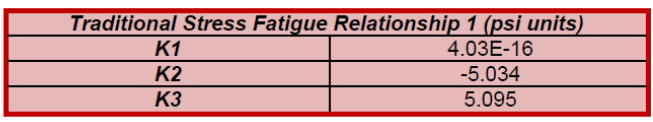

$$
N_{f}=K_{1}\left(\sigma_{t}\right)^{K_{2}}(|E *|)^{K_{3}}
$$

Traditional Stress Fatigue Relationship 2 (psi units)

\begin{tabular}{|c|c}
\hline K1 & $4.03 \mathrm{E}-16$ \\
\hline K2 & 5.034 \\
\hline K3 & 0.062 \\
\hline
\end{tabular}

$$
N_{f}=K_{1}\left(\frac{1}{\varepsilon_{t, i n i}}\right)^{K_{2}}(|E *|)^{K_{3}}
$$

\begin{tabular}{|c|c|}
\hline \multicolumn{2}{|c|}{ Endurance Limit (microstrain) } \\
\hline Temperature (deg. C) & Endurance Limit \\
\hline 5 & 44 \\
\hline 10 & 48 \\
\hline 15 & 55 \\
\hline 20 & 66 \\
\hline 25 & 91 \\
\hline
\end{tabular}

Figure 83: Alpha-Fatigue JFA060 Peak Model Prediction Output 
North Carolina

\begin{tabular}{|ll|}
\hline Project Name: & JFA060 \\
Analysis Performed by: & Laura E. Dalton \\
Analysis Date: & $6 / 6 / 2016$ \\
Testing Performed by: & Laura E. Dalton \\
Default Directory: & E:IGRALAnalysisIFatigue DatalJFA060VInputs \\
& \\
Output Directory: & E:IGRALAnalysisIFatigue DatalJFA0601Output_Default \\
Comments: &
\end{tabular}

\begin{tabular}{|lc|}
\hline Test Protocol: & PP-61/TP-79 \\
Number of |E1 Tests: & 3 \\
Maximum Limiting Modulus: & Fixed (Hirsch) \\
Shift Factor Function: & Amhenius \\
\hline
\end{tabular}

Shift Factor Function:

\begin{tabular}{|c|c|c|}
\hline \multicolumn{3}{|c|}{ Shift Factor Coefficients } \\
\hline Tr & 21.1 & deg. C \\
\hline Ea & 201.22 & $\mathrm{~kJ} / \mathrm{mol}$ \\
\hline a1 & N/A & \\
\hline a2 & N/A & \\
\hline NTS & N/A & \\
\hline$C$ & N/A & \\
\hline & N/A & \\
\hline
\end{tabular}

\begin{tabular}{|c|c|}
\hline \multicolumn{2}{|c|}{ Mastercurve Function } \\
\hline$\kappa$ & $1.60 \mathrm{E}+00$ \\
\hline$\beta$ & $2.75 \mathrm{E}+00$ \\
\hline$\delta$ & $-5.30 \mathrm{E}-01$ \\
\hline$\gamma$ & $-5.53 \mathrm{E}-01$ \\
\hline
\end{tabular}

$$
\log \left|E^{*}\right|=\kappa+\frac{\beta}{1+e^{\delta+\gamma \log \omega_{r}}}
$$

\begin{tabular}{ccccccc} 
Temperature (deg. C) & Frequency (Hz) & $\begin{array}{c}\text { Reduced } \\
\text { Frequency (Hz) }\end{array}$ & IEY (Mpa) & $\begin{array}{c}\text { Phase } \\
\text { Angle (deg) }\end{array}$ & $\begin{array}{c}\text { Cov. IEY } \\
\text { (\%) }\end{array}$ & $\begin{array}{c}\text { Cov. Phase } \\
\text { Angle (deg.) }\end{array}$ \\
\hline 4 & 10 & $1.60 \mathrm{E}+03$ & 15626 & 9.8 & 9.98 & 3.07 \\
4 & 1 & $1.60 \mathrm{E}+02$ & 11869.67 & 13.37 & 9.82 & 2.35 \\
4 & 0.1 & $1.60 \mathrm{E}+01$ & 8200.33 & 18.52 & 9.78 & 1.54 \\
20 & 10 & $1.36 \mathrm{E}+01$ & 7194 & 21.69 & 10.61 & 2.62 \\
20 & 1 & $1.36 \mathrm{E}+00$ & 4092.33 & 27.45 & 11.32 & 2.11 \\
20 & 0.1 & $1.36 \mathrm{E}-01$ & 2036.67 & 31.21 & 12.28 & 1.54 \\
40 & 10 & $6.99 \mathrm{E}-02$ & 1659 & 35.56 & 14.89 & 1.72 \\
40 & 1 & $6.99 \mathrm{E}-03$ & 686.07 & 32.74 & 16.69 & 2 \\
40 & 0.1 & $6.99 \mathrm{E}-04$ & 283.5 & 28.02 & 17.67 & 3.31 \\
40 & 0.01 & $6.99 \mathrm{E}-05$ & 152.47 & 23.15 & 19.5 & 5.91
\end{tabular}

Figure 84: Alpha-Fatigue JFA060 Default Dynamic Modulus Output 


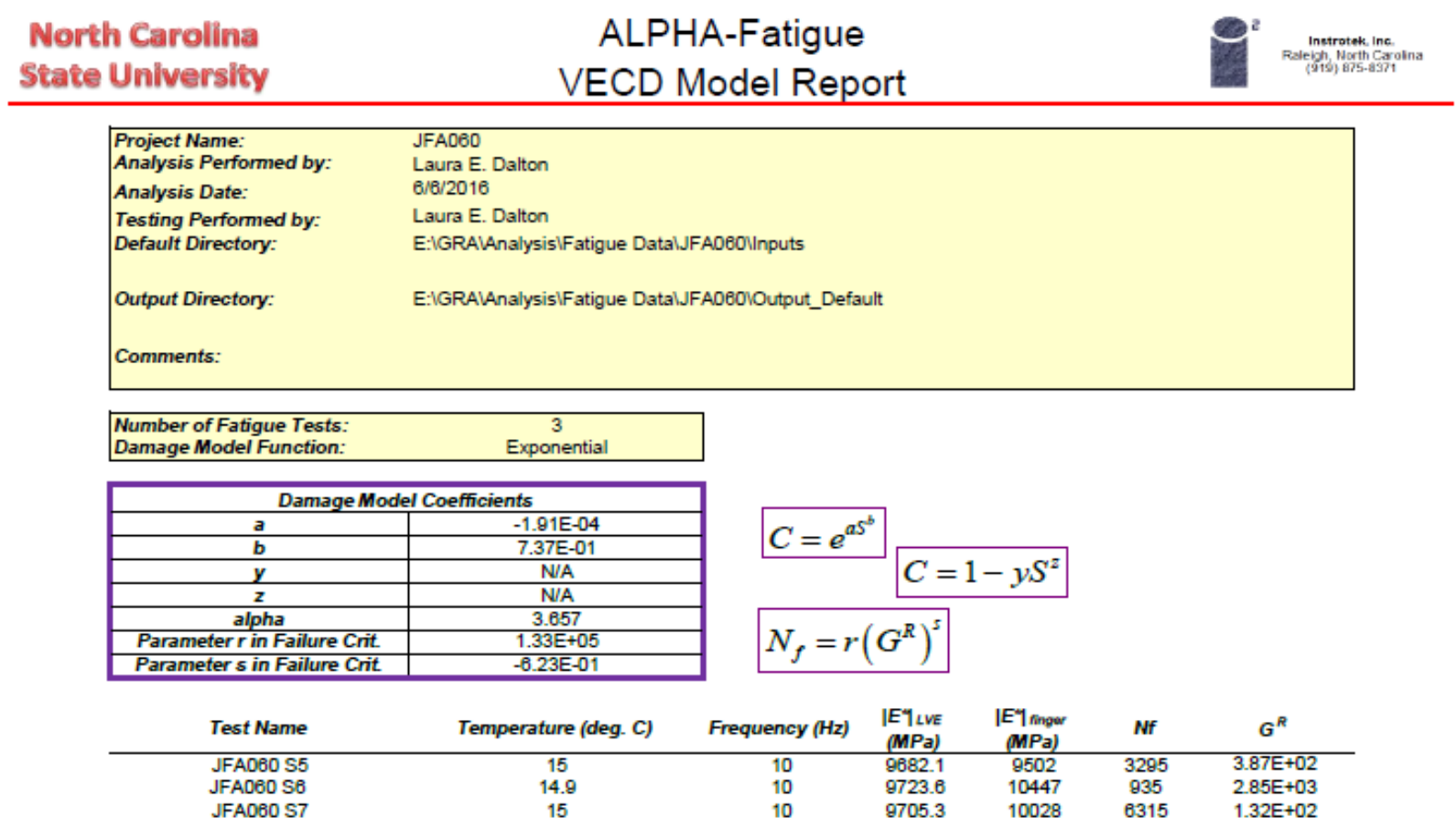

Figure 85: Alpha-Fatigue JFA060 Default Damage Functions Output 


\begin{tabular}{|c|c|}
\hline $\begin{array}{l}\text { North Carolina } \\
\text { State University }\end{array}$ & $\begin{array}{c}\text { ALPHA-Fatigue } \\
\text { Model Predictions Report }\end{array}$ \\
\hline \begin{tabular}{|l} 
Project Name: \\
Analysis Performed by: \\
Analysis Date: \\
Testing Performed by: \\
Default Directory: \\
Output Directory: \\
Comments:
\end{tabular} & $\begin{array}{l}\text { JFA060 } \\
\text { Laura E. Dalton } \\
\text { 6/6/2016 } \\
\text { Laura E. Dalton } \\
\text { E:IGRALAnalysisIFatigue DataiJFA060VInputs } \\
\text { E:IGRALAnalysisIFatigue DatalJFA0601Output_Default }\end{array}$ \\
\hline
\end{tabular}
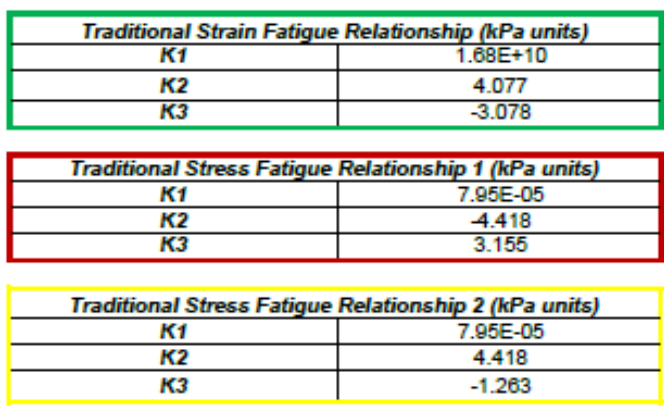

Traditional Strain Fatigue Relationship (psi units)

\begin{tabular}{|c|c|}
\hline \multicolumn{2}{|c|}{ Traditional Strain Fatigue Relationship (psi units) } \\
\hline K1 & $4.40 \mathrm{E}+07$ \\
\hline K2 & 4.077 \\
\hline K3 & -3.078 \\
\hline
\end{tabular}

\begin{tabular}{|c|c|}
\hline \multicolumn{2}{|c|}{ Traditional Stress Fatigue Relationship 1 (psi units) } \\
\hline K1 & $6.94 \mathrm{E}-08$ \\
\hline K2 & -4.418 \\
\hline K3 & 3.155 \\
\hline
\end{tabular}

Traditional Stress Fatigue Relationship 2 (psi units)

\begin{tabular}{|c|c|}
\multicolumn{2}{c}{ Traditional Stress Fatigue Relationship 2 (psi units) } \\
\hline K1 & $6.94 \mathrm{E}-06$ \\
\hline K2 & 4.418 \\
\hline K3 & -1.263 \\
\hline
\end{tabular}

\begin{tabular}{|c|c|}
\hline \multicolumn{2}{|c|}{ Endurance Limit (microstrain) } \\
\hline Temperature (deg. C) & Endurance Limit \\
\hline 5 & 21 \\
\hline 10 & 23 \\
\hline 15 & 26 \\
\hline 20 & 30 \\
\hline 25 & 39 \\
\hline
\end{tabular}

$$
N_{f}=K_{1}\left(\frac{1}{\varepsilon_{t}}\right)^{K_{2}}\left(\left|E^{*}\right|\right)^{K_{3}}
$$$$
N_{f}=K_{1}\left(\sigma_{t}\right)^{K_{2}}\left(\left|E^{*}\right|\right)^{K_{3}}
$$

$$
N_{f}=K_{1}\left(\frac{1}{\varepsilon_{t, \text { ini }}}\right)^{K_{2}}\left(\left|E^{*}\right|\right)^{K_{3}}
$$

$$
N_{f}=K_{1}\left(\frac{1}{\varepsilon_{t}}\right)^{K_{2}}\left(\left|E^{*}\right|\right)^{K_{3}}
$$

$$
N_{f}=K_{1}\left(\sigma_{t}\right)^{K_{2}}\left(\left|E^{*}\right|\right)^{K_{3}}
$$

$$
N_{f}=K_{1}\left(\frac{1}{\varepsilon_{t, \text { ini }}}\right)^{K_{2}}\left(\left|E^{*}\right|\right)^{K_{3}}
$$

Figure 86: Alpha-Fatigue JFA060 Default Model Prediction Output 


\section{North Carolina $\quad$ ALPHA-Fatigue State Unlversity

Project Name:

Analysis Performed by: Laura E. Dalton

Analysis Date: $\quad$ 5/20/2016

Testing Performed by: Laura E. Dalton

Default Directory: C:IUsersiuseriDesktoplLaura DaltonigRAVMPTVFatigue DataUFA115VInputs

Output Directory:

C:IUsersiuseriDesktoplLaura DaltonlGRAVMPTVFatigue DataWFA1151Outputs

Comments:

Test Protocol:

Number of |E1 Tests:

Maximum Limiting Modulus:

Shift Factor Function:

PP-81/TP-79

$$
3
$$

Fixed (Hirsch)

Amhenius

\begin{tabular}{|c|c|}
\hline \multicolumn{2}{|c|}{ Shift Factor Coefficients } \\
\hline Tr & 21.1 \\
\hline Ea & 204.18 \\
\hline$a 1$ & N/A \\
\hline a2 & N/A \\
\hline N & N/A \\
\hline VTS N/A \\
\hline$C$ & $1.49 E+00$ \\
\hline \multicolumn{2}{|c|}{ Mastercurve Function } \\
\hline $\boldsymbol{\beta}$ & $2.85 \mathrm{E}+00$ \\
\hline$\delta$ & $-5.93 \mathrm{E}-01$ \\
\hline$\gamma$ & $-5.03 \mathrm{E}-01$ \\
\hline
\end{tabular}

$\mathrm{kJ} / \mathrm{mo}$

Temperature (deg. C)

Frequency $(\mathrm{Hz})$

$\log \left|E^{*}\right|=\kappa+\frac{\beta}{1+e^{\delta+\gamma \log \omega_{r}}}$

\begin{tabular}{ccccccc} 
Temperature (deg. C) & Frequency (Hz) & $\begin{array}{c}\text { Reduced } \\
\text { Frequency (Hz) }\end{array}$ & IE1 (Mpa) & $\begin{array}{c}\text { Phase } \\
\text { Angle (deg) }\end{array}$ & $\begin{array}{c}\text { Cov. IE'1 } \\
\text { (\%) }\end{array}$ & $\begin{array}{c}\text { Cov. Phase } \\
\text { Angle (deg.) }\end{array}$ \\
\hline 4 & 10 & $1.72 \mathrm{E}+03$ & 14704.33 & 9.84 & 7.65 & 2.66 \\
4 & 1 & $1.72 \mathrm{E}+02$ & 11116 & 12.85 & 7.82 & 2.32 \\
4 & 0.1 & $1.72 \mathrm{E}+01$ & 7686.67 & 17.45 & 6.67 & 1.41 \\
20 & 10 & $1.37 \mathrm{E}+01$ & 6898.33 & 20.65 & 6.09 & 1.21 \\
20 & 1 & $1.37 \mathrm{E}+00$ & 3915 & 25.82 & 5.4 & 1.34 \\
20 & 0.1 & $1.37 \mathrm{E}-01$ & 2062 & 29.75 & 4.63 & 1.12 \\
40 & 10 & $6.50 \mathrm{E}-02$ & 1657 & 33.73 & 5.23 & 1.81 \\
40 & 1 & $6.50 \mathrm{E}-03$ & 700.5 & 32.29 & 5.33 & 1.96 \\
40 & 0.1 & $6.50 \mathrm{E}-04$ & 305.9 & 28.67 & 3.92 & 1.62 \\
40 & 0.01 & $6.50 \mathrm{E}-05$ & 160.2 & 24.17 & 5.74 & 2.3
\end{tabular}

Figure 87: Alpha-Fatigue JFA115 Peak Dynamic Modulus Output 


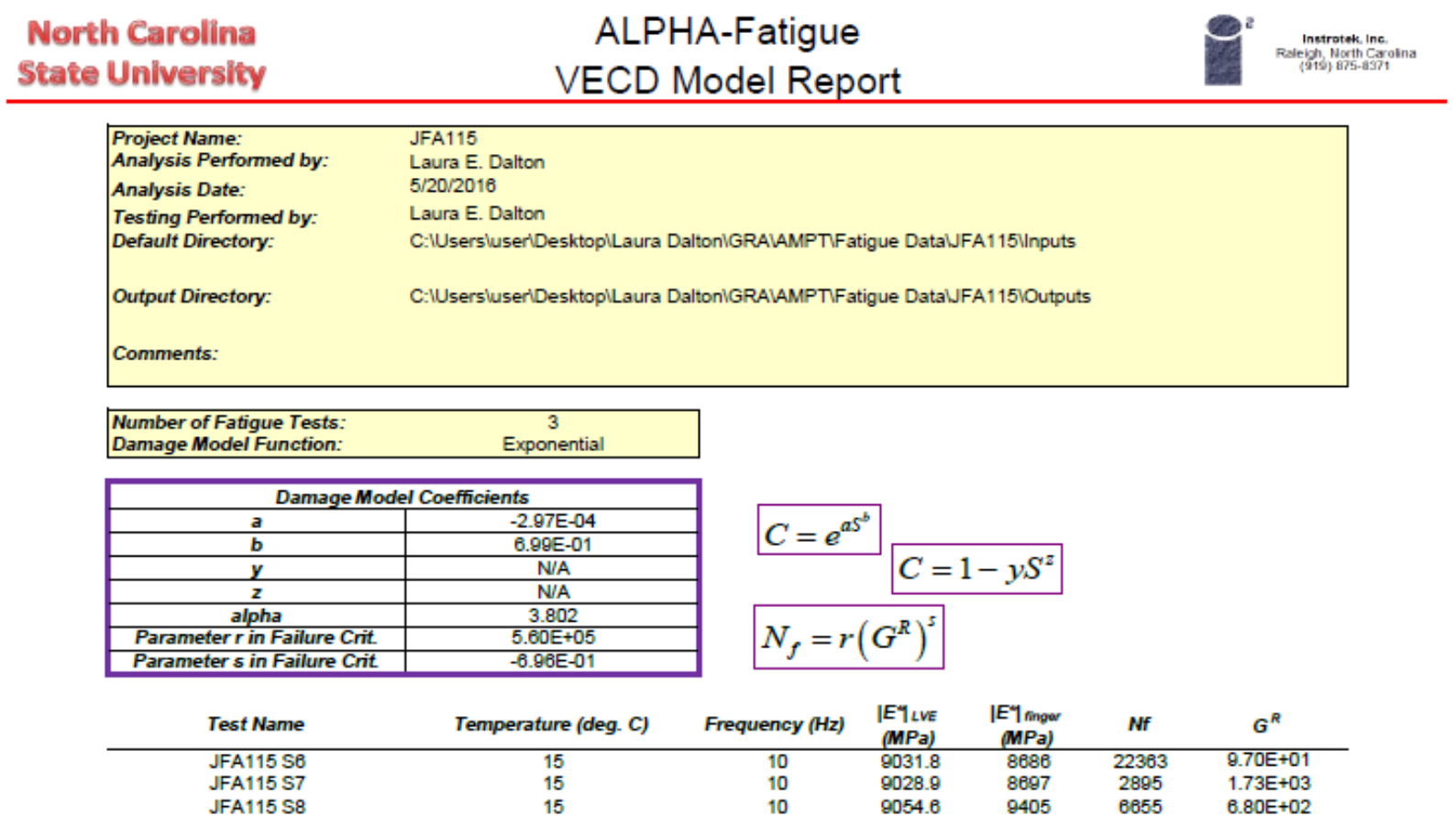

Figure 88: Alpha-Fatigue JFA115 Peak Damage Functions Output 


\begin{tabular}{ccc}
$\begin{array}{c}\text { North Carolina } \\
\text { State Unlversity }\end{array}$ & ALPHA-Fatigue \\
\hline
\end{tabular}

\begin{tabular}{|c|c|}
\hline $\begin{array}{l}\text { Project Name: } \\
\text { Analysis Performed by: } \\
\text { Analysis Date: }\end{array}$ & $\begin{array}{l}\text { JFA115 } \\
\text { Laura E. Dalton } \\
\text { 5/20/2016 }\end{array}$ \\
\hline $\begin{array}{l}\text { Testing Performed by: } \\
\text { Default Directory: }\end{array}$ & 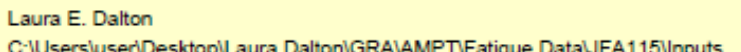 \\
\hline Output Directory: & C:IUsersiuseriDesktoplLaura DaltonlGRALAMPTVFatigue DataWFA115iOutputs \\
\hline
\end{tabular}

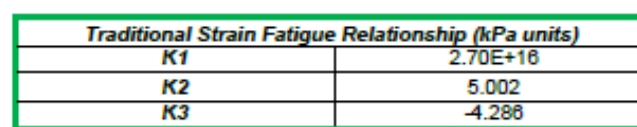

\begin{tabular}{|c|c|}
\hline \multicolumn{2}{|c|}{ Traditional Stress Fatigue Relationship 1(kPa units) } \\
\hline K1 & $9.69 \mathrm{E}-13$ \\
\hline K2 & -5.24 \\
\hline 3 & 4.714 \\
\hline
\end{tabular}

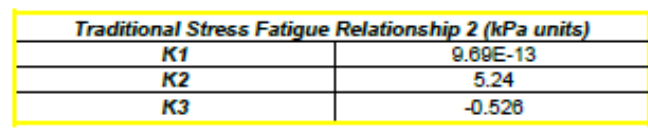

Traditional Strain Fatigue Relationship ( $\rho$ si units)

\begin{tabular}{|l|c|}
\hline K1 & $6.88 E+12$ \\
\hline$K 2$ & 5.002 \\
\hline$K 3$ & 4.286 \\
\hline
\end{tabular}

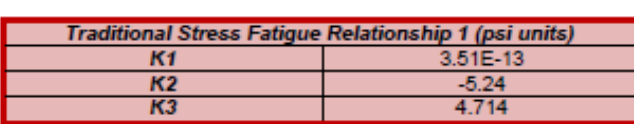

Traditional Stress Fatigue Relationship 2 (psi units)

\begin{tabular}{|c|c|}
\hline K1 & $351 F_{-13}$ \\
\hline$\frac{\pi 1}{K 2}$ & $\frac{3.511-13}{5.24}$ \\
\hline$\kappa 3$ & -0.526 \\
\hline \multicolumn{2}{|c|}{ Endurance Limit (microstrain) } \\
\hline Temperature (deg. C) & Endurance Limit \\
\hline 5 & 48 \\
\hline 10 & 54 \\
\hline 15 & 63 \\
\hline 20 & 76 \\
\hline 25 & 104 \\
\hline
\end{tabular}

$$
N_{f}=K_{1}\left(\frac{1}{\varepsilon_{t}}\right)^{K_{2}}\left(\left|E^{*}\right|\right)^{K_{3}}
$$$$
N_{f}=K_{1}\left(\sigma_{t}\right)^{K_{2}}\left(\left|E^{*}\right|\right)^{K_{3}}
$$

$$
N_{f}=K_{1}\left(\frac{1}{\varepsilon_{t, i n i}}\right)^{K_{2}}\left(\left|E^{*}\right|\right)^{K_{3}}
$$

$$
N_{f}=K_{1}\left(\frac{1}{\varepsilon_{t}}\right)^{K_{2}}\left(\left|E^{*}\right|\right)^{K_{3}}
$$

$$
N_{f}=K_{1}\left(\sigma_{t}\right)^{K_{2}}\left(\left|E^{*}\right|\right)^{K_{3}}
$$

$$
N_{f}=K_{1}\left(\frac{1}{\varepsilon_{t, i n i}}\right)^{K_{2}}\left(\left|E^{*}\right|\right)^{K_{3}}
$$

Figure 89: Alpha-Fatigue JFA115 Peak Model Prediction Output 


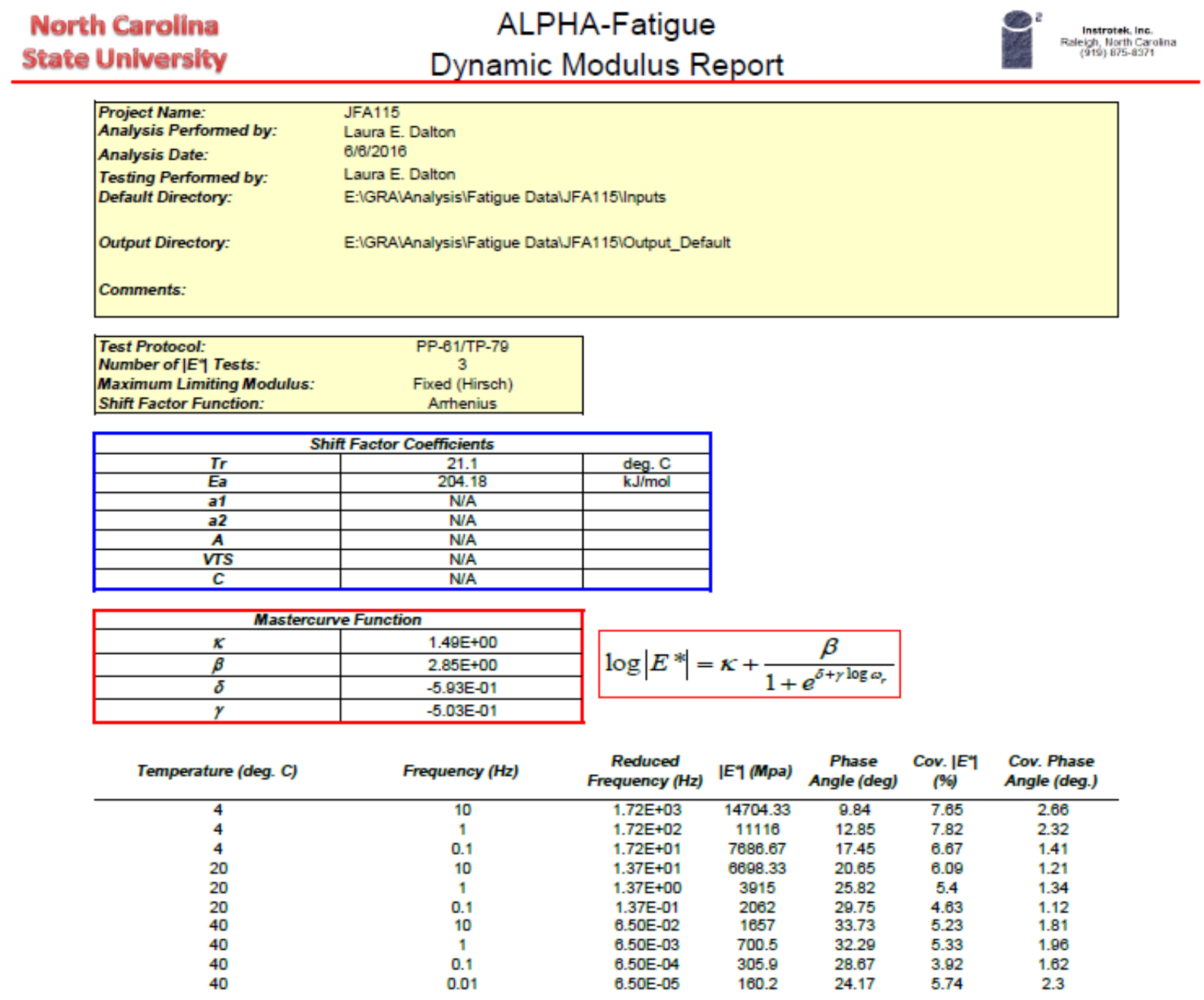

Figure 90: Alpha-Fatigue JFA115 Default Dynamic Modulus Output 


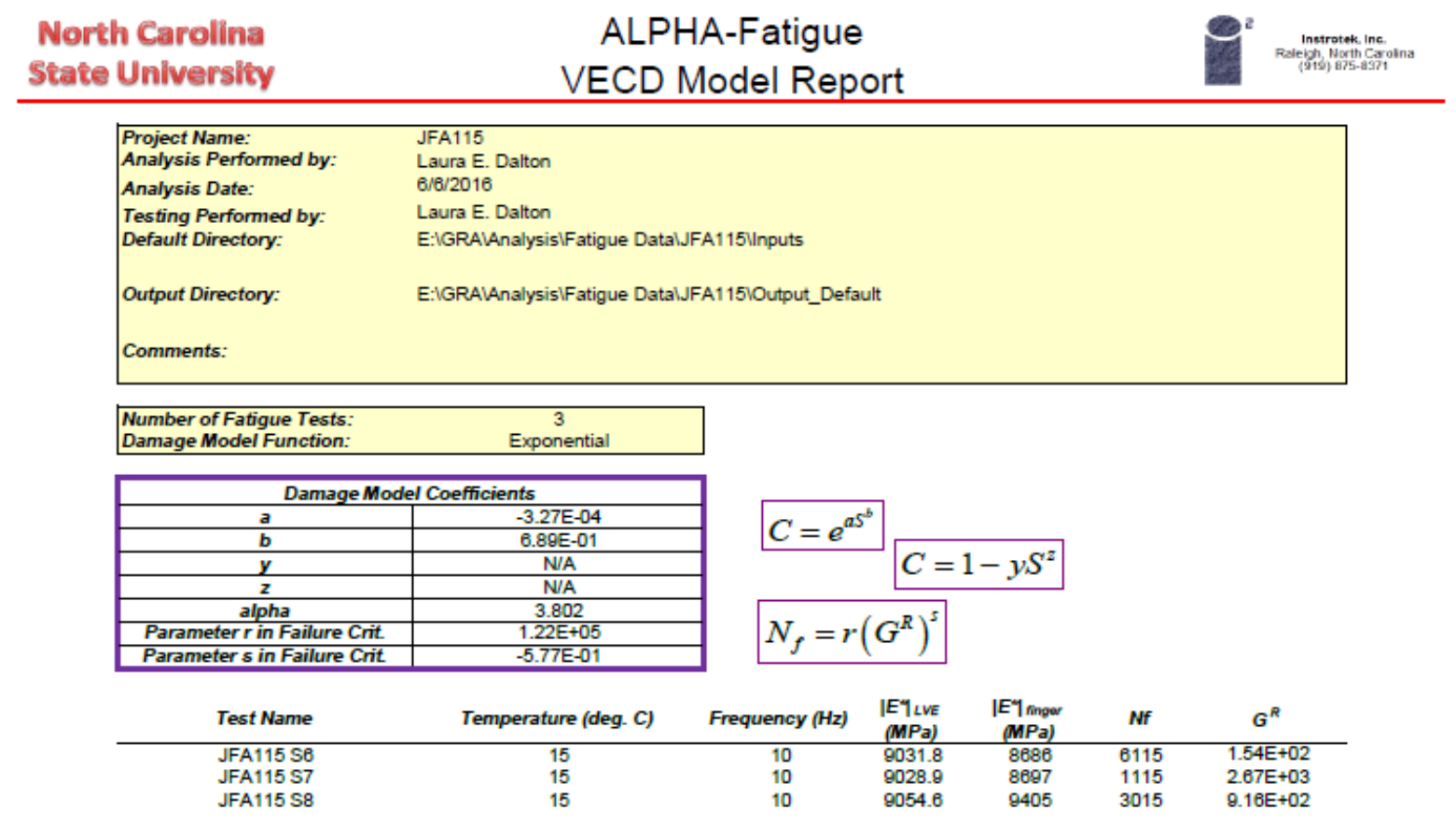

Figure 91: Alpha-Fatigue JFA115 Default Damage Functions Output 


\begin{tabular}{|c|c|}
\hline $\begin{array}{l}\text { North Carolina } \\
\text { State University }\end{array}$ & $\begin{array}{c}\text { ALPHA-Fatigue } \\
\text { Model Predictions Report }\end{array}$ \\
\hline $\begin{array}{l}\text { Project Name: } \\
\text { Analysis Performed by: } \\
\text { Analysis Date: } \\
\text { Testing Performed by: } \\
\text { Default Directory: } \\
\text { Output Directory: } \\
\text { Comments: }\end{array}$ & $\begin{array}{l}\text { JFA115 } \\
\text { Laura E. Dalton } \\
6 / 6 / 2016 \\
\text { Laura E. Dalton } \\
\text { E:IGRAVAnalysisIFatigue DatalJFA115VInputs } \\
\text { E:IGRA IAnalysisIFatigue DatalJFA1151Output_Default }\end{array}$ \\
\hline
\end{tabular}

\begin{tabular}{|c|c|}
\hline \multicolumn{2}{|c|}{ Traditional Strain Fatigue Relationship (kPa units) } \\
\hline$K 1$ & $5.21 \mathrm{E}+09$ \\
\hline$K 2$ & 3.46 \\
\hline$K 3$ & -2.659 \\
\hline
\end{tabular}

$$
N_{f}=K_{1}\left(\frac{1}{\varepsilon_{t}}\right)^{K_{2}}\left(\left|E^{*}\right|\right)^{K_{3}}
$$

\begin{tabular}{|c|c|}
\hline \multicolumn{2}{|c|}{ Traditional Stress Fatigue Relationship 1(kPa units) } \\
\hline K1 & $5.18 \mathrm{E}-03$ \\
\hline K2 & -4.307 \\
\hline K3 & 2.843 \\
\hline
\end{tabular}

$$
N_{f}=K_{1}\left(\sigma_{t}\right)^{K_{2}}\left(\left|E^{*}\right|\right)^{K_{3}}
$$

Traditional Stress Fatigue Relationship 2 (kPa units)

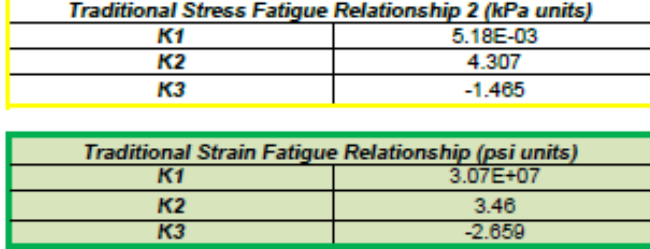

$$
N_{f}=K_{1}\left(\frac{1}{\varepsilon_{t, i n i}}\right)^{K_{2}}\left(\left|E^{*}\right|\right)^{K_{3}}
$$

\begin{tabular}{|c|c|}
\hline \multicolumn{2}{|c|}{ Traditional Stress Fatigue Relationship 1 (psi units) } \\
\hline K1 & $3.06 \mathrm{E}-04$ \\
\hline K2 & 4.307 \\
\hline K3 & 2.843 \\
\hline
\end{tabular}

$$
N_{f}=K_{1}\left(\frac{1}{\varepsilon_{t}}\right)^{K_{2}}\left(\left|E^{*}\right|\right)^{K_{3}}
$$

Traditional Stress Fatigue Relationship 2 (psi units)

\begin{tabular}{|c|c|}
\hline K1 & $3.06 \mathrm{E}-04$ \\
\hline K2 & 4.307 \\
\hline K3 & -1.465 \\
\hline
\end{tabular}

$$
N_{f}=K_{1}\left(\sigma_{t}\right)^{K_{2}}\left(\left|E^{*}\right|\right)^{K_{3}}
$$

Endurance Limit (microstrain)

\begin{tabular}{|c|c|}
\hline \multicolumn{2}{|c|}{ Endurance Limit (microstrain) } \\
\hline Temperature (deg. C) & Endurance Limit \\
\hline 5 & 17 \\
\hline 10 & 19 \\
\hline 15 & 21 \\
\hline 20 & 25 \\
\hline 25 & 33 \\
\hline
\end{tabular}

$$
N_{f}=K_{1}\left(\frac{1}{\varepsilon_{t, i n i}}\right)^{K_{2}}\left(\left|E^{*}\right|\right)^{K_{3}}
$$

Figure 92: Alpha-Fatigue JFA115 Default Model Prediction Output 


\begin{tabular}{ccc}
$\begin{array}{c}\text { North Carolina } \\
\text { State Unlversity }\end{array}$ & ALPHA-Fatigue \\
\hline
\end{tabular}

\begin{tabular}{|c|c|}
\hline $\begin{array}{l}\text { Project Name: } \\
\text { Analysis Performed by: }\end{array}$ & $\begin{array}{l}\text { JFA429 } \\
\text { Laura E. Dalton }\end{array}$ \\
\hline Analysis Date: & $5 / 20 / 2016$ \\
\hline Testing Performed by: & 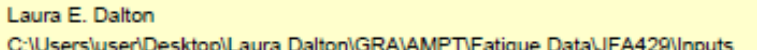 \\
\hline Default Directory: & C:IUsersluseriDesktoplLaura DaltonIGRAIAMPTIFatigue DataUFA4291Inputs \\
\hline Output Directory: & C:IUsersluseriDesktoplLaura DaltoniGRALAMPTIFatigue DataWFA4291Outputs \\
\hline
\end{tabular}

\begin{tabular}{|lc|}
\hline Test Protocol: & PP-61/TP-79 \\
Number of |E1 Tests: & 3 \\
Maximum Limiting Modulus: & Fixed (Hirsch) \\
Shift Factor Function: & Amhenius \\
\hline
\end{tabular}

\begin{tabular}{|c|c|c|}
\hline \multicolumn{3}{|c|}{ Shift Factor Coefficients } \\
\hline Tr & 21.1 & deg. C \\
\hline Ea & 205.57 & $\mathrm{~kJ} / \mathrm{mol}$ \\
\hline a1 & N/A & \\
\hline A2 & N/A & \\
\hline VTS & N/A & \\
\hline$C$ & N/A & \\
\hline & N/A & \\
\hline
\end{tabular}

\begin{tabular}{|c|c|}
\hline \multicolumn{2}{|c|}{ Mastercurve Function } \\
\hline$\kappa$ & $1.64 \mathrm{E}+00$ \\
\hline$\beta$ & $2.71 \mathrm{E}+00$ \\
\hline$\delta$ & $-5.61 \mathrm{E}-01$ \\
\hline$\gamma$ & $-5.22 \mathrm{E}-01$ \\
\hline \multirow{2}{*}{$\log \mid E^{*}$} & $=\kappa+\frac{\beta}{1+e^{\delta+\gamma \log \omega_{r}}}$ \\
\hline
\end{tabular}

\begin{tabular}{|c|c|c|c|c|c|c|}
\hline Temperature (deg. C) & Frequency $(\mathrm{Hz})$ & $\begin{array}{c}\text { Reduced } \\
\text { Frequency }(\mathrm{Hz})\end{array}$ & |Eฯ (Mpa) & $\begin{array}{c}\text { Phase } \\
\text { Angle (deg) }\end{array}$ & $\begin{array}{c}\text { Cov. }|E| \\
(\%)\end{array}$ & $\begin{array}{l}\text { Cov. Phase } \\
\text { Angle (deg.) }\end{array}$ \\
\hline 4 & 10 & $1.78 \mathrm{E}+03$ & 15098.33 & 9.67 & 5.44 & 2.84 \\
\hline 4 & 1 & $1.78 \mathrm{E}+02$ & 11605 & 13 & 5.17 & 1.71 \\
\hline 4 & 0.1 & $1.78 E+01$ & 8155.67 & 17.76 & 4.77 & 1.13 \\
\hline 20 & 10 & $1.37 E+01$ & 7395.33 & 20.54 & 4.59 & 1.11 \\
\hline 20 & 1 & $1.37 \mathrm{E}+00$ & 4354.67 & 25.83 & 4.49 & 0.91 \\
\hline 20 & 0.1 & 1.37E-01 & 2284.67 & 29.65 & 4.28 & 0.29 \\
\hline 40 & 10 & $6.28 \mathrm{E}-02$ & 1799.67 & 33.8 & 6.91 & 0.48 \\
\hline 40 & 1 & $6.28 \mathrm{E}-03$ & 739.37 & 31.58 & 7.08 & 1.16 \\
\hline 40 & 0.1 & $6.28 \mathrm{E}-04$ & 332.93 & 27.23 & 8.75 & 2.46 \\
\hline 40 & 0.01 & $6.28 \mathrm{E}-05$ & 189.1 & 22.52 & 10.97 & 3.77 \\
\hline
\end{tabular}

Figure 93: Alpha-Fatigue JFA429 Peak Dynamic Modulus Output 


\begin{tabular}{ccc}
$\begin{array}{c}\text { North Carolina } \\
\text { State Unlversity }\end{array}$ & ALPHA-Fatigue \\
\hline
\end{tabular}

\begin{tabular}{|c|c|}
\hline $\begin{array}{l}\text { Project Name: } \\
\text { Analysis Performed by: } \\
\text { Analysis Date: }\end{array}$ & $\begin{array}{l}\text { JFA429 } \\
\text { Laura E. Dalton } \\
5 / 20 / 2016\end{array}$ \\
\hline Testing Performed by: & Laura E. Dalton \\
\hline Default Directory: & C:IUsersiuseriDesktoplLaura DaltonIGRALAMPTFFatigue DataNFA429IInputs \\
\hline Output Directory: & C:IUsersiuserlDesktoplLaura DaltonlGRALAMPTIFatigue DataWFA4291Outputs \\
\hline Comments: & \\
\hline
\end{tabular}

\begin{tabular}{lc|}
\hline $\begin{array}{l}\text { Number of Fatigue Tests: } \\
\text { Damage Model Function: }\end{array}$ & 3 \\
\hline
\end{tabular}

\begin{tabular}{|c|c|}
\hline \multicolumn{2}{|c|}{ Damage Model Coefficients } \\
\hline a & $-1.37 \mathrm{E}-04$ \\
\hline b & $7.73 \mathrm{E}-01$ \\
\hline $\mathrm{y}$ & $\mathrm{N} / \mathrm{A}$ \\
\hline $\mathrm{z}$ & $\mathrm{N} / \mathrm{A}$ \\
\hline alpha & 3.85 \\
\hline Parameter in Failure Crit & $7.89 \mathrm{E}+05$ \\
\hline Parameter s in Failure Crit & $-7.97 \mathrm{E}-01$ \\
\hline
\end{tabular}

$$
\begin{aligned}
& C=e^{a S^{b}} C=1-y S^{z} \\
& N_{f}=r\left(G^{R}\right)^{s}
\end{aligned}
$$

\begin{tabular}{|c|c|c|c|c|c|c|}
\hline Test Name & Temperature (deg. C) & Frequency $(\mathrm{Hz})$ & $\begin{array}{l}\mid E^{\prime} \eta_{L V E} \\
(\mathrm{MPa})\end{array}$ & $\begin{array}{c}\left|E^{\prime}\right|_{\text {ningor }} \\
(\mathrm{MPa})\end{array}$ & Nf & $G^{R}$ \\
\hline JFA429 S6 & 15 & 10 & 9695.2 & 11478 & $\begin{array}{l}3535 \\
30712\end{array}$ & $8.61 E+02$ \\
\hline $\begin{array}{l}\text { JFA429 S7 } \\
\text { JFA429 \$8 }\end{array}$ & $\begin{array}{l}15 \\
15\end{array}$ & $\begin{array}{l}10 \\
10\end{array}$ & $\begin{array}{l}9678.4 \\
9688.9\end{array}$ & $\begin{array}{l}10234 \\
10244\end{array}$ & $\begin{array}{l}30712 \\
63507\end{array}$ & $\begin{array}{l}8.37 \mathrm{E}+01 \\
2.22 \mathrm{E}+01\end{array}$ \\
\hline
\end{tabular}

Figure 94: Alpha-Fatigue JFA060 Peak Damage Functions Output 
North Carolina State Unlversity
ALPHA-Fatigue Model Predictions Report

\begin{tabular}{|ll|}
\hline Project Name: & JFA429 \\
Analysis Performed by: & Laura E. Dalton \\
Analysis Date: & 5/20/2016 \\
Testing Performed by: & Laura E. Dalton \\
Default Directory: & C:IUsersiuseriDesktoplLaura Dal \\
Output Directory: & C:IUsersiuseriDesktoplLaura Dal \\
Comments: & \\
\hline \multicolumn{2}{|c|}{} \\
\hline \multicolumn{2}{|c|}{ Traditional Strain Fatigue Relationship (kPa units) } \\
\hline K1 & $3.12 \mathrm{E}+25$ \\
\hline$K 2$ & 7.851 \\
\hline$K 3$ & -7.098 \\
\hline
\end{tabular}

\begin{tabular}{|c|c|}
\hline \multicolumn{2}{|c|}{ Traditional Stress Fatigue Relationship 1 (kPa units) } \\
\hline K1 & $2.01 \mathrm{E}-21$ \\
\hline K2 & -5.731 \\
\hline K3 & 6.122 \\
\hline
\end{tabular}

$$
N_{f}=K_{1}\left(\frac{1}{\varepsilon_{t}}\right)^{K_{2}}\left(\left|E^{*}\right|\right)^{K_{3}}
$$

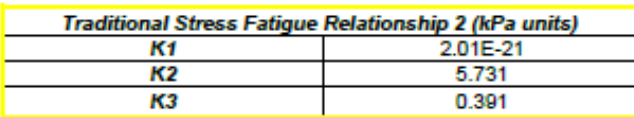

$N_{f}=K_{1}\left(\sigma_{t}\right)^{K_{2}}\left(\left|E^{*}\right|\right)^{K_{3}}$

Traditional Strain Fatigue Relationship (psi units) K1 K2 $3.48 \mathrm{E}+18$

\begin{tabular}{|c|c|}
\hline \multicolumn{2}{|c|}{ Traditional Strain Fatigue Relationship (psi units) } \\
\hline K1 & $3.48 \mathrm{E}+19$ \\
\hline K2 & 7.851 \\
\hline K3 & -7.098 \\
\hline
\end{tabular}

$N_{f}=K_{1}\left(\frac{1}{\varepsilon_{t, \text { ini }}}\right)^{K_{2}}\left(\left|E^{*}\right|\right)^{K_{3}}$

\begin{tabular}{|c|c|}
\hline \multicolumn{2}{|c|}{ Traditional Stress Fatigue Relationship 1 (psi units) } \\
\hline K1 & $4.27 \mathrm{E}-21$ \\
\hline K2 & -5.731 \\
\hline K3 & 6.122 \\
\hline
\end{tabular}

$N_{f}=K_{1}\left(\frac{1}{\varepsilon_{t}}\right)^{K_{2}}(|E *|)^{K_{3}}$

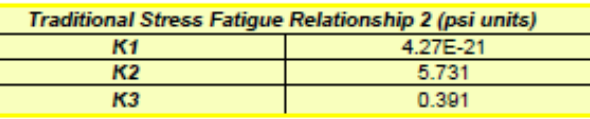

$N_{f}=K_{1}\left(\sigma_{t}\right)^{K_{2}}\left(\left|E^{*}\right|\right)^{K_{3}}$

\begin{tabular}{|c|c|}
\hline K1 & $4.27 \mathrm{E}-21$ \\
\hline K2 & 5.731 \\
\hline$\kappa 3$ & 0.391 \\
\hline \multicolumn{2}{|c|}{ Endurance Limit (microstrain) } \\
\hline Temperature (deg. C) & Endurance Limit \\
\hline 5 & 67 \\
\hline 10 & 75 \\
\hline 15 & 90 \\
\hline 20 & 111 \\
\hline 25 & 154 \\
\hline
\end{tabular}

$$
N_{f}=K_{1}\left(\frac{1}{\varepsilon_{t, \text { ini }}}\right)^{K_{2}}\left(\left|E^{*}\right|\right)^{K_{3}}
$$

Figure 95: Alpha-Fatigue JFA429 Peak Model Prediction Output 


\begin{tabular}{ccc}
$\begin{array}{c}\text { North Carolina } \\
\text { State Unlversity }\end{array}$ & ALPHA-Fatigue \\
\hline
\end{tabular}

\begin{tabular}{|ll|}
\hline $\begin{array}{l}\text { Project Name: } \\
\text { Analysis Performed by: }\end{array}$ & JFA429 \\
Analysis Date: & $6 / 6 / 2016$ \\
Testing Performed by: & Laura E. Dalton \\
Default Directory: & E:IGRALAnalysisIFatigue DatalJFA429Inputs \\
Output Directory: & E:IGRALAnalysisIFatigue DataiJFA4291Output_Default
\end{tabular}

\begin{tabular}{|lc|}
\hline Test Protocol: & PP-61/TP-79 \\
Number of |E1 Tests: & 3 \\
Maximum Limiting Modulus: & Fixed (Hirsch) \\
Shift Factor Function: & Amhenius \\
\hline
\end{tabular}

Shift Factor Function:

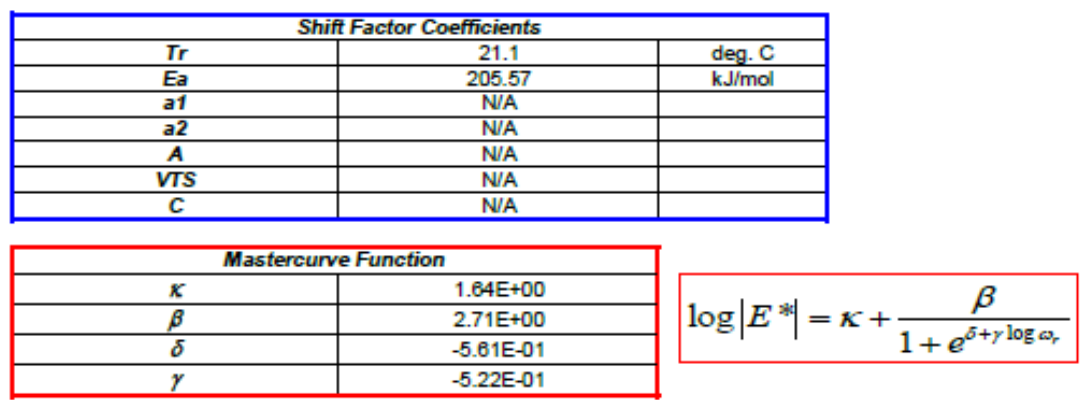

\begin{tabular}{ccccccc} 
Temperature (deg. C) & Frequency (Hz) & $\begin{array}{c}\text { Reduced } \\
\text { Frequency (Hz) }\end{array}$ & IE1 (Mpa) & $\begin{array}{c}\text { Phase } \\
\text { Angle (deg) }\end{array}$ & $\begin{array}{c}\text { Cov. IEY } \\
\text { (\%) }\end{array}$ & $\begin{array}{c}\text { Cov. Phase } \\
\text { Angle (deg.) }\end{array}$ \\
\hline 4 & 10 & $1.78 \mathrm{E}+03$ & 15098.33 & 9.67 & 5.44 & 2.84 \\
4 & 1 & $1.78 \mathrm{E}+02$ & 11605 & 13 & 5.17 & 1.71 \\
4 & 0.1 & $1.78 \mathrm{E}+01$ & 8155.67 & 17.76 & 4.77 & 1.13 \\
20 & 10 & $1.37 \mathrm{E}+01$ & 7395.33 & 20.54 & 4.59 & 1.11 \\
20 & 1 & $1.37 \mathrm{E}+00$ & 4354.67 & 25.83 & 4.49 & 0.91 \\
20 & 0.1 & $1.37 \mathrm{E}-01$ & 2284.67 & 29.65 & 4.28 & 0.29 \\
40 & 10 & $6.28 \mathrm{E}-02$ & 1799.67 & 33.8 & 6.91 & 0.48 \\
40 & 1 & $6.28 \mathrm{E}-03$ & 739.37 & 31.58 & 7.08 & 1.16 \\
40 & 0.1 & $6.28 \mathrm{E}-04$ & 332.93 & 27.23 & 8.75 & 2.46 \\
40 & 0.01 & $6.28 \mathrm{E}-05$ & 189.1 & 22.52 & 10.97 & 3.77
\end{tabular}

Figure 96: Alpha-Fatigue JFA429 Default Dynamic Modulus Output 


$\begin{array}{cc}\begin{array}{c}\text { North Carolina } \\ \text { State University }\end{array} & \text { ALPHA-Fatigue } \\ \text { VECD Model Report }\end{array}$

\begin{tabular}{|c|c|}
\hline $\begin{array}{l}\text { Project Name: } \\
\text { Annalysis Performed by: }\end{array}$ & JFA429 \\
\hline Analysis Date: & 6/6/2016 \\
\hline Testing Performed by: & Laura E. Dalton \\
\hline Default Directory: & E:IGRA|Analysis|Fatigue DatalJFA428IInputs \\
\hline Output Directory: & E:IGRA|Analysis|Fatigue DataIJFA42910utput_Default \\
\hline
\end{tabular}

\begin{tabular}{|lc|}
\hline $\begin{array}{l}\text { Number of Fatigue Tests: } \\
\text { Damage Model Function: }\end{array}$ & 3 \\
\hline
\end{tabular}

\begin{tabular}{|c|c|c|c|}
\hline \multicolumn{2}{|c|}{ Damage Model Coefficients } & & \\
\hline$a$ & $-1.08 E-04$ & \multirow{2}{*}{$C=e^{a S^{b}}$} & \multirow{3}{*}{$C=1-y S^{z}$} \\
\hline$\frac{b}{y}$ & $\frac{7.96 \mathrm{E}-01}{\mathrm{~N} / \mathrm{A}}$ & & \\
\hline$z$ & N/A & \multirow{3}{*}{\multicolumn{2}{|c|}{$N_{f}=r\left(G^{R}\right)^{s}$}} \\
\hline alpha & 3.85 & & \\
\hline $\begin{array}{l}\text { Parameter } r \text { in Failure Crit } \\
\text { Parameter } s \text { in Failure Crit }\end{array}$ & $\begin{array}{l}9.11 \mathrm{E}+04 \\
-5.77 \mathrm{E}-01\end{array}$ & & \\
\hline
\end{tabular}

\begin{tabular}{|c|c|c|c|c|c|c|}
\hline Test Name & Temperature (deg. C) & Frequency $(\mathrm{Hz})$ & $\begin{array}{c}\mid E Y_{L V E} \\
(\mathrm{MPa})\end{array}$ & $\begin{array}{c}|E|_{\text {finow }} \\
(\mathrm{MPa})\end{array}$ & Nf & $G^{R}$ \\
\hline $\begin{array}{l}\text { JFA429 S6 } \\
\text { JFA429 S7 }\end{array}$ & $\begin{array}{l}15 \\
15\end{array}$ & $\begin{array}{l}10 \\
10\end{array}$ & $\begin{array}{l}9695.2 \\
9678.4\end{array}$ & $\begin{array}{l}11478 \\
10234\end{array}$ & $\begin{array}{l}1455 \\
6775\end{array}$ & $\begin{array}{l}1.25 E+03 \\
1.06 E+02\end{array}$ \\
\hline JFA429 S8 & 15 & 10 & 9688.9 & 10244 & 8315 & $5.55 \mathrm{E}+01$ \\
\hline
\end{tabular}

Figure 97: Alpha-Fatigue JFA429 Default Damage Functions Output 


\begin{tabular}{cc}
$\begin{array}{c}\text { North Carolina } \\
\text { State Unlversity }\end{array}$ & ALPHA-Fatigue \\
\hline
\end{tabular}

\begin{tabular}{|ll|}
\hline $\begin{array}{ll}\text { Project Name: } \\
\text { Analysis Performed by: }\end{array}$ & JFA429 \\
Analysis Date: & 6/6/2016 \\
Testing Performed by: & Laura E. Dalton \\
Default Directory: & E:IGRALAnalysisIFatigue DataIJFA429Inputs \\
& \\
Output Directory: & E:IGRALAnalysisIFatigue DatalJFA4291Output_Default \\
Comments: & \\
\hline
\end{tabular}

\begin{tabular}{|c|c|}
\hline \multicolumn{2}{|c|}{ Traditional Strain Fatigue Relationship (kPa units) } \\
\hline K1 & $8.35 \mathrm{E}+08$ \\
\hline$K 2$ & 3.542 \\
\hline$K 3$ & -2.621 \\
\hline
\end{tabular}

$$
N_{f}=K_{1}\left(\frac{1}{\varepsilon_{t}}\right)^{K_{2}}\left(\left|E^{*}\right|\right)^{K_{3}}
$$

\begin{tabular}{|c|c|}
\hline \multicolumn{2}{|c|}{ Traditional Stress Fatigue Relationship 1 (kPa units) } \\
\hline K1 & $3.63 \mathrm{E}-06$ \\
\hline K2 & 4.513 \\
\hline K3 & 3.35 \\
\hline
\end{tabular}

$$
N_{f}=K_{1}\left(\sigma_{t}\right)^{K_{2}}\left(\left|E^{*}\right|\right)^{K_{3}}
$$

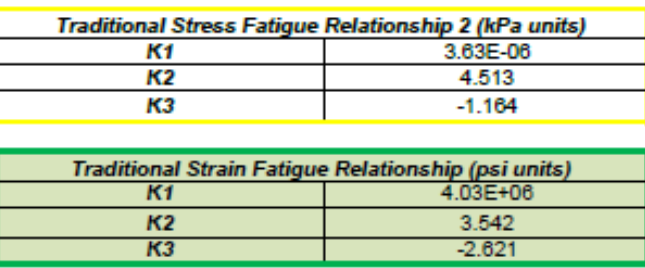

$$
N_{f}=K_{1}\left(\frac{1}{\varepsilon_{t, i n i}}\right)^{K_{2}}\left(\left|E^{*}\right|\right)^{K_{3}}
$$

$$
N_{f}=K_{1}\left(\frac{1}{\varepsilon_{t}}\right)^{K_{2}}\left(\left|E^{*}\right|\right)^{K_{3}}
$$

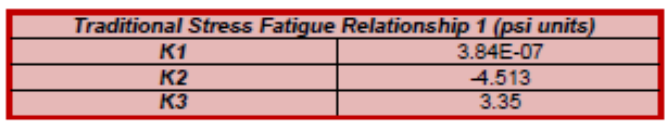

$$
N_{f}=K_{1}\left(\sigma_{t}\right)^{K_{2}}\left(\left|E^{*}\right|\right)^{K_{3}}
$$

Traditional Stress Fatigue Relationship 2 (psi units)

\begin{tabular}{c|c}
\hline Traditional Stress Fatigue Relationship 2 (psi units) \\
\hline K1 & $3.84 \mathrm{E}-07$ \\
\hline K3 & 4.513 \\
\hline
\end{tabular}

$$
N_{f}=K_{1}\left(\frac{1}{\varepsilon_{t, \text { ini }}}\right)^{K_{2}}(|E *|)^{K_{s}}
$$

\begin{tabular}{|c|c|}
\hline \multicolumn{2}{|c|}{ Endurance Limit (microstrain) } \\
\hline Temperature (deg. C) & Endurance Limit \\
\hline 5 & 17 \\
\hline 10 & 18 \\
\hline 15 & 20 \\
\hline 20 & 23 \\
\hline 25 & 29 \\
\hline
\end{tabular}

Figure 98: Alpha-Fatigue JFA429 Default Model Prediction Output 
North Carolina State University

\section{ALPHA-Fatigue Dynamic Modulus Report}

\begin{tabular}{|c|c|}
\hline $\begin{array}{l}\text { Project Name: } \\
\text { Analysis Performed by: }\end{array}$ & KP483 \\
\hline Analysis Date: & $5 / 23 / 2016$ \\
\hline Testing Performed by: & Laura E. Dalton \\
\hline Default Directory: & C:IUsersluseriDesktoplLaura DaltonlGRALAMPTIFatigue DataIKP483Unputs \\
\hline Output Directory: & C:IUsersluseriDesktoplLaura DaltonIGRAIAMPTVFatigue DatalKP4831Outputs \\
\hline
\end{tabular}

Test Protoco

Number of |E' Tests:

PP-61/TP-79

Maximum Limiting Modulus: $\quad$ Fixed (Hirsch)

Shift Factor Function:

\begin{tabular}{|c|c|c|}
\hline \multicolumn{3}{|c|}{ Shift Factor Coefficients } \\
\hline Tr & 21.1 & $\mathrm{deg} . \mathrm{C}$ \\
\hline Ea & 200.21 & $\mathrm{~kJ} / \mathrm{mol}$ \\
\hline$a 1$ & N/A & \\
\hline$a 2$ & N/A & \\
\hline$A$ & N/A & \\
\hline VTS & N/A & \\
\hline$C$ & N/A & \\
\hline
\end{tabular}

\begin{tabular}{|c|c|}
\hline \multicolumn{2}{|c|}{ Mastercurve Function } \\
\hline $\boldsymbol{\beta}$ & $1.29 \mathrm{E}+00$ \\
\hline$\delta$ & $3.05 \mathrm{E}+00$ \\
\hline$\gamma$ & $-7.76 \mathrm{E}-01$ \\
\hline$\delta$ & $-4.70 \mathrm{E}-01$ \\
\hline
\end{tabular}

$\log \left|E^{*}\right|=\kappa+\frac{\beta}{1+e^{\delta+\gamma \log \omega_{r}}}$

\begin{tabular}{ccccccc} 
Temperature (deg. C) & Frequency (Hz) & $\begin{array}{c}\text { Reduced } \\
\text { Frequency (Hz) }\end{array}$ & IE1 (Mpa) & $\begin{array}{c}\text { Phase } \\
\text { Angle (deg) }\end{array}$ & $\begin{array}{c}\text { Cov. IEY } \\
\text { (\%) }\end{array}$ & $\begin{array}{c}\text { Cov. Phase } \\
\text { Angle (deg.) }\end{array}$ \\
\hline 4 & 10 & $1.56 \mathrm{E}+03$ & 14182 & 9.72 & 8.4 & 2.84 \\
4 & 1 & $1.56 \mathrm{E}+02$ & 10907.33 & 12.49 & 8.46 & 2.69 \\
4 & 0.1 & $1.56 \mathrm{E}+01$ & 7807.67 & 16.47 & 8.25 & 2.47 \\
20 & 10 & $1.36 \mathrm{E}+01$ & 6984.33 & 19.33 & 4.42 & 2.19 \\
20 & 1 & $1.36 \mathrm{E}+00$ & 4208.67 & 24.44 & 2.89 & 2.2 \\
20 & 0.1 & $1.36 \mathrm{E}-01$ & 2292.33 & 28.74 & 1.94 & 2.06 \\
40 & 10 & $7.17 \mathrm{E}-02$ & 1929 & 32.79 & 7.17 & 1.94 \\
40 & 1 & $7.17 \mathrm{E}-03$ & 852.1 & 33.13 & 8.24 & 2.04 \\
40 & 0.1 & $7.17 \mathrm{E}-04$ & 365.17 & 30.8 & 9.93 & 2.52 \\
40 & 0.01 & $7.17 \mathrm{E}-05$ & 174.47 & 26.67 & 11.32 & 2.65
\end{tabular}

Figure 99: Alpha-Fatigue KP483 Peak Dynamic Modulus Output 


$\begin{array}{ccc}\begin{array}{c}\text { North Carolina } \\ \text { State Unlversity }\end{array} & \text { ALPHA-Fatigue } \\ \text { VECD Model Report }\end{array}$

\begin{tabular}{|c|c|}
\hline $\begin{array}{l}\text { Project Name: } \\
\text { Analysis Performed by: }\end{array}$ & $\begin{array}{l}\text { KP483 } \\
\text { Laura E. Dalton }\end{array}$ \\
\hline Analysis Date: & $5 / 23 / 2016$ \\
\hline Testing Performed by: & Laura E. Dalton \\
\hline Default Directory: & C:IUsersiuseriDesktoplLaura DaltonIGRAVMPTIFatigue DataIKP483Inputs \\
\hline Output Directory: & C:IUsersluseriDesktoplLaura DaltonIGRALAMPTIFatigue DataIKP4831Outputs \\
\hline Comments: & \\
\hline
\end{tabular}

\begin{tabular}{|lc|}
\hline $\begin{array}{l}\text { Number of Fatigue Tests: } \\
\text { Damage Model Function: }\end{array}$ & 3 \\
\hline
\end{tabular}

\begin{tabular}{|c|c|c|}
\hline \multicolumn{2}{|c}{ Damage Model Coefficients } \\
\hline 3
\end{tabular}

\begin{tabular}{|c|c|}
\hline \multicolumn{2}{|c|}{ Damage Model Coefficients } \\
\hline $\mathbf{a}$ & $-1.47 \mathrm{E}-05$ \\
\hline $\mathbf{b}$ & $9.57 \mathrm{E}-01$ \\
\hline $\mathbf{N} / \mathrm{A}$ \\
\hline alpha & N/A \\
\hline Parameter in Failure Crit. & 3.811 \\
\hline Parameter s in Failure Crit & $6.01 \mathrm{E}+05$ \\
\hline
\end{tabular}

$$
\begin{aligned}
& C=e^{a S^{b}} C=1-y S^{z} \\
& N_{f}=r\left(G^{R}\right)^{s}
\end{aligned}
$$

\begin{tabular}{|c|c|c|c|c|c|c|}
\hline Test Name & Temperature (deg. C) & Frequency $(\mathrm{Hz})$ & $\begin{array}{l}\mid E{ }^{\prime} \text { IVVE } \\
(\mathrm{MPa})\end{array}$ & $\begin{array}{c}\text { IEY } \text { fingow } \\
\text { (MPa) }\end{array}$ & Nf & $G^{R}$ \\
\hline KP483 S6 & 15 & 10 & 9104.7 & 8161 & 12871 & $1.54 E+02$ \\
\hline KP483 S7 & 15 & 10 & 9100.4 & 8995 & 3395 & $6.42 E+02$ \\
\hline KP483 S8 & 15 & 10 & 9112.3 & 9688 & 23539 & $5.41 E+01$ \\
\hline
\end{tabular}

Figure 100: Alpha-Fatigue KP483 Peak Damage Functions Output 
North Carolina State University
ALPHA-Fatigue Model Predictions Report

Project Name:

Analysis Performed by:

Analysis Date:

Testing Performed by:

Default Directory:

Laura E. Dalton

$5 / 23 / 2016$

Laura E. Dalton

C:IUsersiuseriDesktoplLaura DaltonIGRAIAMPTVFatigue DataIKP483Inputs

Output Directory:

C:IUsersiuseriDesktoplLaura DaltoniGRAIAMPTIFatigue DataIKP4831Outputs

Comments:

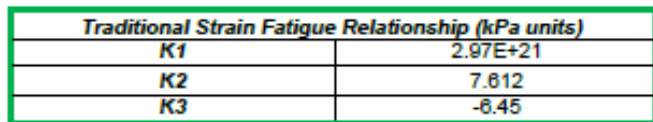

$N_{f}=K_{1}\left(\frac{1}{\varepsilon_{t}}\right)^{K_{2}}\left(\left|E^{*}\right|\right)^{K_{3}}$

\begin{tabular}{|c|c|}
\hline \multicolumn{2}{|c|}{ Traditional Stress Fatigue Relationship 1 (kPa units) } \\
\hline K1 & $\mathrm{NaN}$ \\
\hline$K 2$ & $\mathrm{NaN}$ \\
\hline$K 3$ & $\mathrm{NaN}$ \\
\hline
\end{tabular}

$N_{f}=K_{1}\left(\sigma_{t}\right)^{K_{2}}\left(\left|E^{*}\right|\right)^{K_{3}}$

Traditional Stress Fatigue Relationship 2 (kPa units)

\begin{tabular}{c|c|}
\hline \multicolumn{2}{c}{ Traditional Stress Fatigue Relationship 2 (kPa units) } \\
\hline K1 & $\mathrm{NaN}$ \\
\hline K2 & $\mathrm{NaN}$ \\
\hline K3 & $\mathrm{NaN}$ \\
\hline
\end{tabular}

$N_{f}=K_{1}\left(\frac{1}{\varepsilon_{t, i n i}}\right)^{K_{2}}\left(\left|E^{*}\right|\right)^{K_{s}}$

Traditional Strain Fatigue Relationship (psi units)

\begin{tabular}{l|c} 
K1 & $1.16 \mathrm{E}+16$ \\
\hline K2 & 7.612 \\
\hline
\end{tabular}

\begin{tabular}{l|r}
$K 2$ & 7.612 \\
\hline$K 3$ & -6.45
\end{tabular}

$N_{f}=K_{1}\left(\frac{1}{\varepsilon_{t}}\right)^{K_{2}}\left(\left|E^{*}\right|\right)^{K_{3}}$

Traditional Stress Fatigue Relationship 1 (psi units)

\begin{tabular}{l|l} 
K1 & NaN \\
\hline$K 2$ & NaN
\end{tabular}

\begin{tabular}{l|l} 
K2 & NaN \\
\hline K3 & NaN \\
\hline
\end{tabular}

Traditional Stress Fatigue Relationship 2 (psi units)

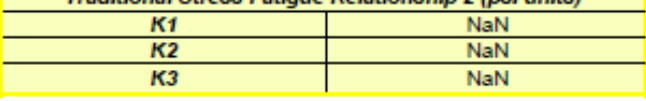

$N_{f}=K_{1}\left(\sigma_{t}\right)^{K_{2}}\left(\left|E^{*}\right|\right)^{K_{3}}$

Endurance Limit (microstrain)

Temperature (deg. C) $\quad$ Endurance Limit

\begin{tabular}{|c|c|}
\hline 5 & Endurance Limit \\
\hline 10 & 64 \\
\hline 15 & 70 \\
\hline 20 & 82 \\
\hline 25 & 97 \\
\hline
\end{tabular}

$N_{f}=K_{1}\left(\frac{1}{\varepsilon_{t, i n i}}\right)^{K_{2}}\left(\left|E^{*}\right|\right)^{K_{3}}$

Figure 101: Alpha-Fatigue KP483 Peak Model Prediction Output 


\section{North Carolina State Unlversity}

\section{ALPHA-Fatigue Dynamic Modulus Report}

\begin{tabular}{|c|c|}
\hline $\begin{array}{l}\text { Project Name: } \\
\text { Analysis Performed by: }\end{array}$ & $\begin{array}{l}\text { KP483 } \\
\text { Laura E. Dalton } \\
6 / 21 / 2016\end{array}$ \\
\hline Analysis Date: & $6 / 21 / 2016$ \\
\hline $\begin{array}{l}\text { Testing Performed by: } \\
\text { Default Directory: }\end{array}$ & $\begin{array}{l}\text { Laura E. Dalton } \\
\text { E:IGRAIThesis/Analysis/Fatigue DatalKP483Unputs }\end{array}$ \\
\hline Output Directory: & E:IGRAIThesis/Analysis।Fatigue DataiKP483।Output_Default \\
\hline
\end{tabular}

Test Protocol:

Number of |E1 Tests:

Maximum Limiting Modulus: $\quad$ Fixed (Hirsch)

Shift Factor Function:

Amed (Hirsch)

\begin{tabular}{|c|c|c|}
\hline \multicolumn{3}{|c|}{ Shift Factor Coefficients } \\
\hline Tr & 21.1 & $\mathrm{deg}$. C \\
\hline Ea & 200.21 & $\mathrm{~kJ} / \mathrm{mol}$ \\
\hline$a 1$ & N/A & \\
\hline$a 2$ & N/A & \\
\hline$A$ & N/A & \\
\hline VTS & N/A & \\
\hline$C$ & N/A & \\
\hline
\end{tabular}

\begin{tabular}{|c|c|}
\hline \multicolumn{2}{|c|}{ Mastercurve Function } \\
\hline$\kappa$ & $1.29 \mathrm{E}+00$ \\
\hline$\beta$ & $3.05 \mathrm{E}+00$ \\
\hline$\delta$ & $-7.76 \mathrm{E}-01$ \\
\hline$\gamma$ & $-4.70 \mathrm{E}-01$ \\
\hline \multirow{2}{*}{$\log \left|E^{*}\right|=\kappa+\frac{\beta}{1+e^{\delta+\gamma \log \omega_{r}}}$} \\
\hline
\end{tabular}

\begin{tabular}{|c|c|c|c|c|c|c|}
\hline Temperature (deg. C) & Frequency $(\mathrm{Hz})$ & $\begin{array}{c}\text { Reduced } \\
\text { Frequency }(\mathrm{Hz})\end{array}$ & |E1 (Mpa) & $\begin{array}{c}\text { Phase } \\
\text { Angle (deg) }\end{array}$ & $\begin{array}{c}\text { Cov. } \mid E\rceil \\
(\%)\end{array}$ & $\begin{array}{l}\text { Cov. Phase } \\
\text { Angle (deg.) }\end{array}$ \\
\hline 4 & 10 & $1.56 \mathrm{E}+03$ & 14182 & 9.72 & 8.4 & 2.84 \\
\hline 4 & 1 & $1.56 \mathrm{E}+02$ & 10907.33 & 12.49 & 8.46 & 2.69 \\
\hline 4 & 0.1 & $1.56 \mathrm{E}+01$ & 7807.67 & 16.47 & 8.25 & 2.47 \\
\hline 20 & 10 & $1.36 \mathrm{E}+01$ & 6984.33 & 19.33 & 4.42 & 2.19 \\
\hline 20 & 1 & $1.36 \mathrm{E}+00$ & 4208.67 & 24.44 & 2.89 & 2.2 \\
\hline 20 & 0.1 & $1.36 \mathrm{E}-01$ & 2292.33 & 28.74 & 1.94 & 2.06 \\
\hline 40 & 10 & $7.17 \mathrm{E}-02$ & 1929 & 32.79 & 7.17 & 1.94 \\
\hline 40 & 1 & 7.17E-03 & 852.1 & 33.13 & 8.24 & 2.04 \\
\hline 40 & 0.1 & $7.17 \mathrm{E}-04$ & 365.17 & 30.8 & 9.93 & 2.52 \\
\hline 40 & 0.01 & $7.17 \mathrm{E}-05$ & 174.47 & 26.67 & 11.32 & 2.65 \\
\hline
\end{tabular}

Figure 102: Alpha-Fatigue KP483 Default Dynamic Modulus Output 


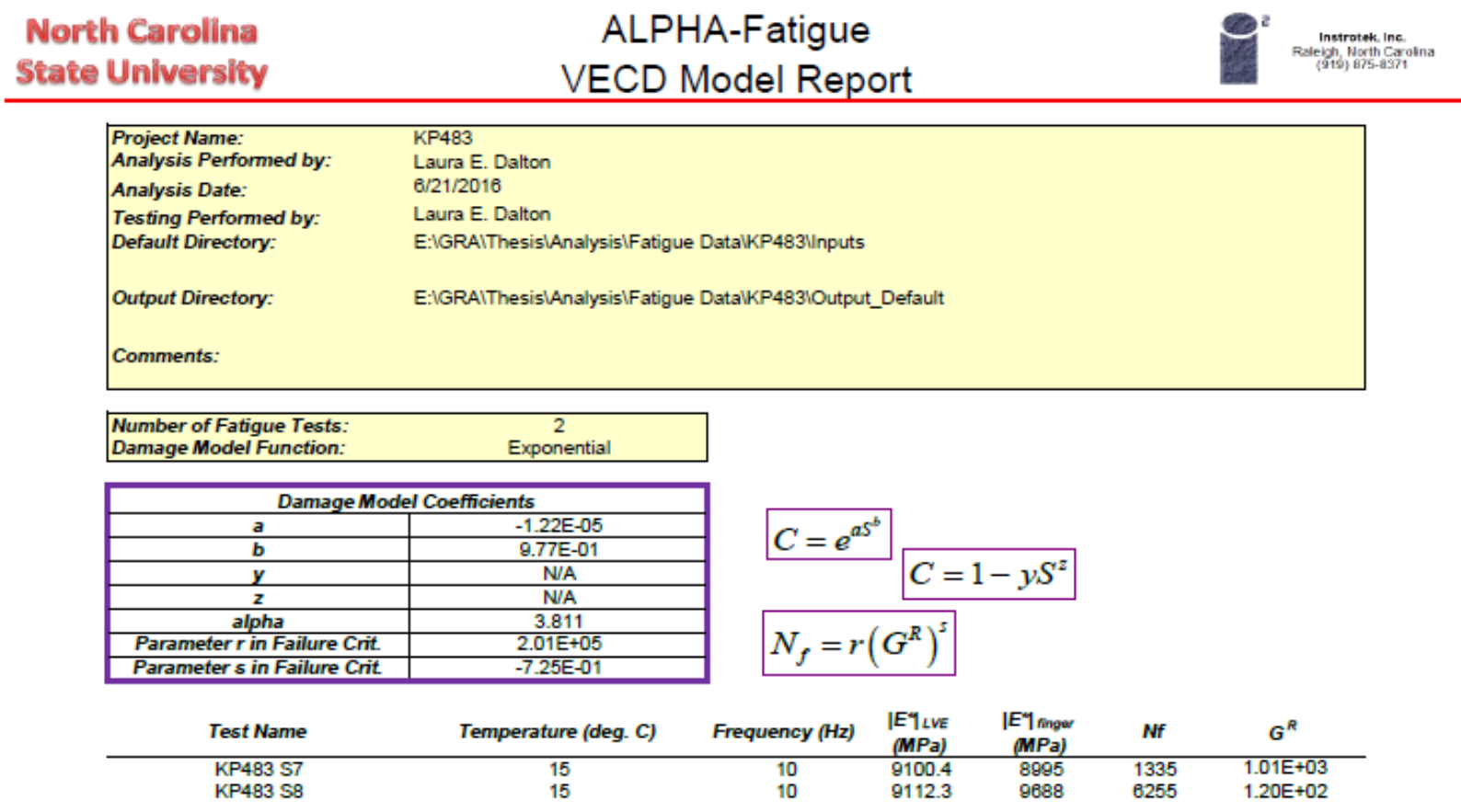

Figure 103: Alpha-Fatigue KP483 Default Damage Functions Output 
North Carolina State University
ALPHA-Fatigue Model Predictions Report

\begin{tabular}{|c|c|}
\hline $\begin{array}{l}\text { Project Name: } \\
\text { Analysis Performed by: }\end{array}$ & $\begin{array}{l}\text { KP483 } \\
\text { Laura E. Dalton }\end{array}$ \\
\hline Analysis Date: & $6 / 21 / 2016$ \\
\hline Testing Performed by: & Laura E. Dalton \\
\hline Default Directory: & E:IGRAIThesis \AnalysislFatigue D \\
\hline Output Directory: & E:IGRAIThesis\Analysis'Fatigue D \\
\hline \multicolumn{2}{|l|}{ Comments: } \\
\hline \multicolumn{2}{|c|}{ Traditional Strain Fatigue Relationship (kPa units) } \\
\hline K1 & $\begin{array}{r}9.75 \mathrm{E}+08 \\
\end{array}$ \\
\hline K2 & 6.153 \\
\hline K3 & -4.013 \\
\hline
\end{tabular}

\begin{tabular}{|c|c|}
\hline \multicolumn{2}{|c|}{ Traditional Stress Fatigue Relationship 1 (kPa units) } \\
\hline K1 & $9.82 \mathrm{E}-19$ \\
\hline K2 & -5.453 \\
\hline K3 & 5.656 \\
\hline
\end{tabular}

$$
N_{f}=K_{1}\left(\frac{1}{\varepsilon_{t}}\right)^{K_{2}}\left(\left|E^{*}\right|\right)^{K_{3}}
$$

Traditional Stress Fatigue Relationship 2 (kPa units)

\begin{tabular}{c|c} 
K1 & $9.82 \mathrm{E}-19$ \\
\hline K2 & 5.453 \\
\hline 3 & 0.203
\end{tabular}

$$
N_{f}=K_{1}\left(\sigma_{t}\right)^{K_{2}}\left(\left|E^{*}\right|\right)^{K_{3}}
$$

Traditional Strain Fatigue Relationship (psi units)

$$
\text { K1 }
$$

K3

$.20 \mathrm{E}+$

$-4.013$

$$
N_{f}=K_{1}\left(\frac{1}{\varepsilon_{t, \text { ini }}}\right)^{K_{2}}\left(\left|E^{*}\right|\right)^{K_{3}}
$$

$$
N_{f}=K_{1}\left(\frac{1}{\varepsilon_{t}}\right)^{K_{2}}\left(\left|E^{*}\right|\right)^{K_{3}}
$$

\begin{tabular}{|c|c|}
\hline \multicolumn{2}{|c|}{ Traditional Stress Fatigue Relationship 1 (psi units) } \\
\hline K1 & $1.45 \mathrm{E}-18$ \\
\hline K2 & -5.453 \\
\hline K3 & 5.656 \\
\hline
\end{tabular}

$$
N_{f}=K_{1}\left(\sigma_{t}\right)^{K_{2}}\left(\left|E^{*}\right|\right)^{K_{3}}
$$

Traditional Stress Fatigue Relationship 2 (psi units)

\begin{tabular}{|c|c|}
\hline K1 & $1.45 \mathrm{E}-18$ \\
\hline K2 3 & 5.453 \\
\hline
\end{tabular}

$$
N_{f}=K_{1}\left(\frac{1}{\varepsilon_{t, \text { nin }}}\right)^{K_{2}}\left(\left|E^{*}\right|\right)^{K_{3}}
$$

Figure 104: Alpha-Fatigue KP483 Default Model Prediction Output 


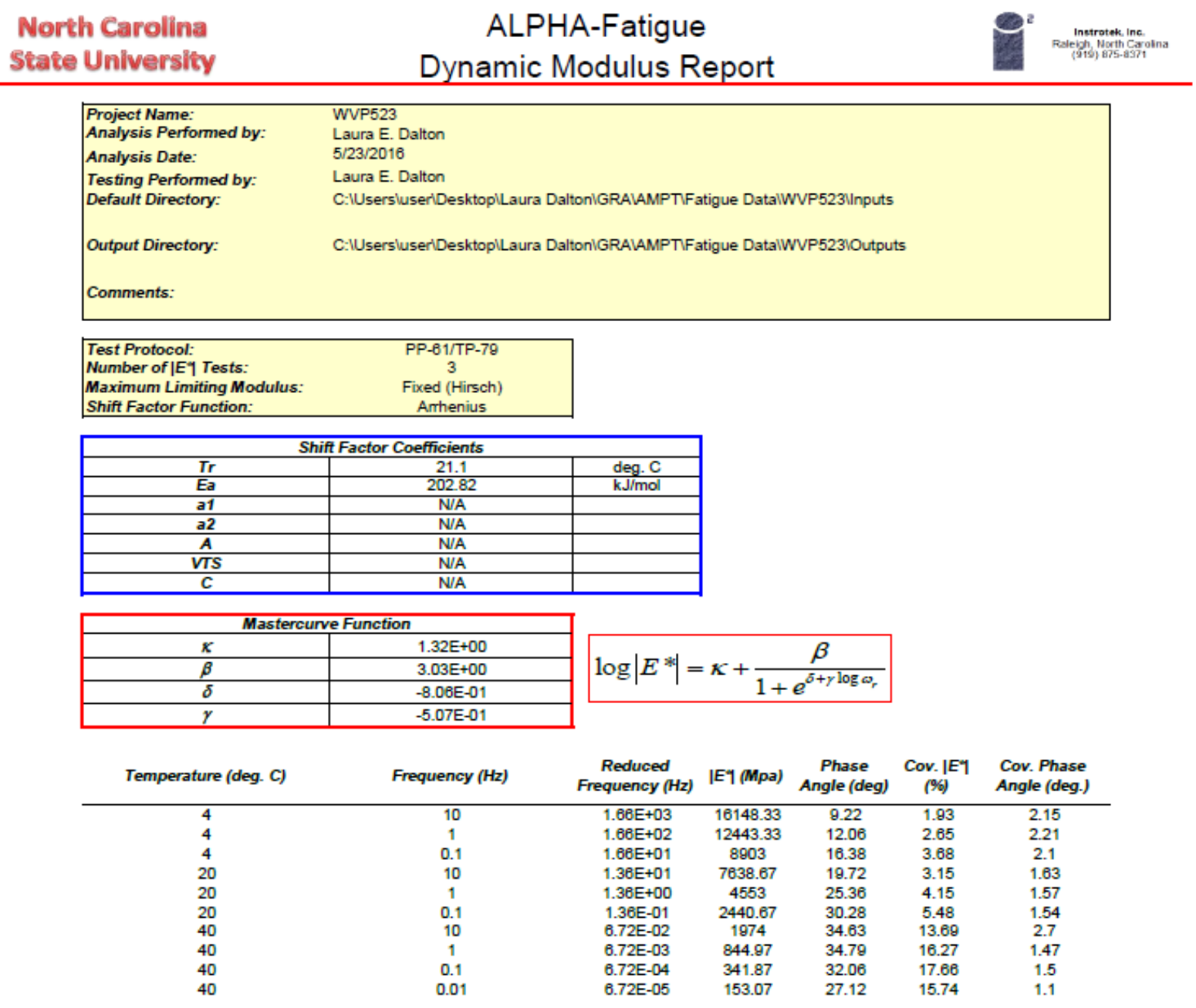

Figure 105: Alpha-Fatigue WVP523 Peak Dynamic Modulus Output 


$\begin{array}{cc}\begin{array}{c}\text { North Carolina } \\ \text { State Unlversity }\end{array} & \text { ALPHA-Fatigue } \\ \text { VECD Model Report }\end{array}$

\begin{tabular}{|c|c|}
\hline $\begin{array}{l}\text { Project Name: } \\
\text { Analysis Performed by: }\end{array}$ & $\begin{array}{l}\text { WVP523 } \\
\text { Laura E. Dalton }\end{array}$ \\
\hline Analysis Date: & $5 / 23 / 2016$ \\
\hline Testing Performed by: & $\begin{array}{l}\text { Laura E. Dalton } \\
\text { C-lUsersluseriDesktoplLaura DaltonlGRAIAMPTFatique DatalWYP523Inputs }\end{array}$ \\
\hline Output Directory: & C:IUsersiuseriDesktoplLaura DaltoniGRAIAMPTFFatigue DataiWVP5231Outputs \\
\hline Comments: & \\
\hline
\end{tabular}

\begin{tabular}{|lc|}
\hline $\begin{array}{l}\text { Number of Fatigue Tests: } \\
\text { Damage Model Function: }\end{array}$ & 3 \\
\hline
\end{tabular}

\begin{tabular}{|c|c|c|c|c|c|c|}
\hline \multicolumn{2}{|c|}{ Damage Model Coefficients } & \multirow{3}{*}{$C=e^{a 5^{b}}$} & \multirow{4}{*}{\multicolumn{2}{|c|}{$C=1-y S^{z}$}} & & \\
\hline$a$ & $-3.54 E-05$ & & & & & \\
\hline$\frac{b}{y}$ & 8.85E-01 & & & & & \\
\hline$\frac{y}{z}$ & N/A & & & & & \\
\hline $\begin{array}{c}z \\
\text { alpha }\end{array}$ & $\frac{\text { N/A }}{3.629}$ & & & & & \\
\hline Parameter $r$ in Failure Crit. & $5.37 \mathrm{E}+05$ & $N_{f}=r($ & $G^{R}$ & & & \\
\hline Parameter s in Failure Crit. & $-8.07 E-01$ & & & & & \\
\hline Test Name & Temperature (deg. C) & Frequency $(\mathrm{Hz})$ & $\begin{array}{l}\text { IEY LVE } \\
(\mathrm{MPa})\end{array}$ & $\begin{array}{l}\text { IEY }\left.\right|_{\text {mingor }} \\
(\mathrm{MPa})\end{array}$ & Nf & $G^{R}$ \\
\hline WVP523 S6 & 15 & 10 & 10169.5 & 10763 & 2835 & $5.92 \mathrm{E}+02$ \\
\hline WVP523 S7 & 15 & 10 & 10168.3 & 10720 & 12546 & $1.27 \mathrm{E}+02$ \\
\hline WVP523 S8 & 15 & 10 & 10161.7 & 10555 & 69633 & 1.17E+01 \\
\hline
\end{tabular}

Figure 106: Alpha-Fatigue WVP523 Peak Damage Functions Output 
North Carolina State University

\section{ALPHA-Fatigue Model Predictions Report}

\begin{tabular}{|c|c|}
\hline $\begin{array}{l}\text { Project Name: } \\
\text { Analysis Performed by: }\end{array}$ & $\begin{array}{l}\text { WVP523 } \\
\text { Laura E. Dalton }\end{array}$ \\
\hline Analysis Date: & $5 / 23 / 2016$ \\
\hline Testing Performed by: & Laura E. Dalton \\
\hline Default Directory: & C:IUsersluseriDesktoplLaura DaltonlGRAIAMPTVFatigue DatalWVP523IInputs \\
\hline Output Directory: & C:UsersiuseriDesktoplLaura DaltonlGRAVAMPTVFatigue DatalWVP5231Outputs \\
\hline
\end{tabular}

\begin{tabular}{|c|c|}
\hline \multicolumn{2}{|c|}{ Traditional Strain Fatigue Relationship (kPa units) } \\
\hline K1 & $5.49 \mathrm{E}+20$ \\
\hline K2 & 8.161 \\
\hline K3 & -6.672 \\
\hline
\end{tabular}

\begin{tabular}{|c|c|}
\hline \multicolumn{2}{|c|}{ Traditional Stress Fatigue Relationship 1 (kPa units) } \\
\hline K1 & $1.39 \mathrm{E}-26$ \\
\hline K2 & -5.42 \\
\hline K3 & 6.744 \\
\hline
\end{tabular}

\begin{tabular}{|c|c|}
\hline \multicolumn{2}{|c|}{ Traditional Stress Fatigue Relationship 2 (kPa units) } \\
\hline K1 & $1.39 \mathrm{E}-26$ \\
\hline K2 & 5.42 \\
\hline K3 & 1.323 \\
\hline
\end{tabular}

Traditional Strain Fatigue Relationship (psi units)

\begin{tabular}{|c|c|}
\hline \multicolumn{2}{|c|}{ Traditional Strain Fatigue Relationship (psi units) } \\
\hline K1 & $1.40 \mathrm{E}+15$ \\
\hline K2 & 8.161 \\
\hline K3 & -6.672 \\
\hline
\end{tabular}

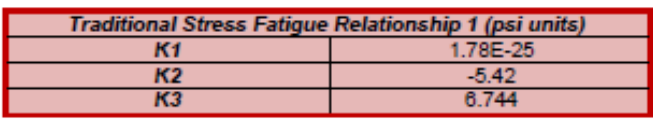

Traditional Stress Fatigue Relationship 2 (psi units)

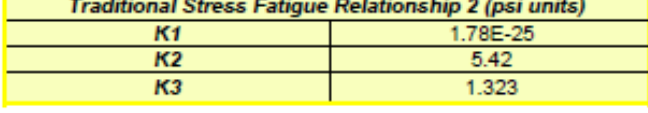

Endurance Limit (microstrain)

\begin{tabular}{|c|c|}
\hline \multicolumn{2}{|c|}{ Endurance Limit (microstrain) } \\
\hline Temperature (deg. C) & Endurance Limit \\
\hline 5 & 58 \\
\hline 10 & 63 \\
\hline 15 & 73 \\
\hline 20 & 86 \\
\hline 25 & 117 \\
\hline
\end{tabular}

$$
N_{f}=K_{1}\left(\frac{1}{\varepsilon_{t}}\right)^{K_{2}}\left(\left|E^{*}\right|\right)^{K_{3}}
$$

$N_{f}=K_{1}\left(\sigma_{t}\right)^{K_{2}}\left(\left|E^{*}\right|\right)^{K_{3}}$

$$
N_{f}=K_{1}\left(\frac{1}{\varepsilon_{t, \text { ini }}}\right)^{K_{2}}\left(\left|E^{*}\right|\right)^{K_{3}}
$$

$$
N_{f}=K_{1}\left(\frac{1}{\varepsilon_{t}}\right)^{K_{2}}\left(\left|E^{*}\right|\right)^{K_{3}}
$$

$$
N_{f}=K_{1}\left(\sigma_{t}\right)^{K_{2}}\left(\left|E^{*}\right|\right)^{K_{3}}
$$

$$
N_{f}=K_{1}\left(\frac{1}{\varepsilon_{t, i n i}}\right)^{K_{2}}\left(\left|E^{*}\right|\right)^{K_{3}}
$$

Figure 107: Alpha-Fatigue WVP523 Peak Model Prediction Output 


\begin{tabular}{cc}
$\begin{array}{c}\text { North Carollina } \\
\text { State Unlversity }\end{array}$ & ALPHA-Fatigue \\
\hline
\end{tabular}

\begin{tabular}{|ll}
\hline $\begin{array}{l}\text { Project Name: } \\
\text { Analysis Performed by: }\end{array}$ & WVP523 \\
Analysis Date: & Laura E. Dalton \\
$\begin{array}{l}\text { Testing Performed by: } \\
\text { Default Directory: }\end{array}$ & Laura E. Dalton \\
& E:IGRALAnalysisIFatigue DatalWVP523VInputs \\
Output Directory: & E:IGRAVAnalysisIFatigue DatalWVP5231Output_Default \\
Comments: &
\end{tabular}

\begin{tabular}{|lc|}
\hline Test Protocol: & PP-81/TP-79 \\
Number of |E1 Tests: & 3 \\
Maximum Limiting Modulus: & Fixed (Hirsch) \\
Shift Factor Function: & Amhenius \\
\hline
\end{tabular}

Shift Factor Function:

Shift Factor Coefficients

\begin{tabular}{|c|c|c|}
\hline \multicolumn{3}{|c|}{ Shift Factor Coefficients } \\
\hline Tr & 21.1 & deg. C \\
\hline Ea & 202.82 & $\mathrm{~kJ} / \mathrm{mol}$ \\
\hline$a 1$ & N/A & \\
\hline$a 2$ & N/A & \\
\hline$A$ & N/A & \\
\hline VTS & N/A & \\
\hline$C$ & N/A & \\
\hline
\end{tabular}

\begin{tabular}{|c|c|}
\hline \multicolumn{2}{|c|}{ Mastercurve Function } \\
\hline $\boldsymbol{\beta}$ & $1.32 \mathrm{E}+00$ \\
\hline$\delta$ & $3.03 \mathrm{E}+00$ \\
\hline$\gamma$ & $-8.06 \mathrm{E}-01$ \\
\hline & $-5.07 \mathrm{E}-01$ \\
\hline
\end{tabular}

$\log \left|E^{*}\right|=\kappa+\frac{\beta}{1+e^{\delta+\gamma \log \omega_{r}}}$

\begin{tabular}{|c|c|c|c|c|c|c|}
\hline Temperature (deg. C) & Frequency $(\mathrm{Hz})$ & $\begin{array}{c}\text { Reduced } \\
\text { Frequency }(\mathrm{Hz})\end{array}$ & |E1 (Mpa) & $\begin{array}{c}\text { Phase } \\
\text { Angle (deg) }\end{array}$ & $\begin{array}{c}\text { Cov. |EY } \\
(\%)\end{array}$ & $\begin{array}{l}\text { Cov. Phase } \\
\text { Angle (deg.) }\end{array}$ \\
\hline 4 & 10 & $1.66 \mathrm{E}+03$ & 16148.33 & 9.22 & 1.93 & 2.15 \\
\hline 4 & 1 & $1.68 \mathrm{E}+02$ & 12443.33 & 12.06 & 2.65 & 2.21 \\
\hline 4 & 0.1 & $1.68 \mathrm{E}+01$ & 8903 & 16.38 & 3.68 & 2.1 \\
\hline 20 & 10 & $1.36 \mathrm{E}+01$ & 7638.67 & 19.72 & 3.15 & 1.63 \\
\hline 20 & 1 & $1.36 \mathrm{E}+00$ & 4553 & 25.36 & 4.15 & 1.57 \\
\hline 20 & 0.1 & $1.36 \mathrm{E}-01$ & 2440.67 & 30.28 & 5.48 & 1.54 \\
\hline 40 & 10 & $6.72 \mathrm{E}-02$ & 1974 & 34.63 & 13.69 & 2.7 \\
\hline 40 & 1 & $6.72 \mathrm{E}-03$ & 844.97 & 34.79 & 16.27 & 1.47 \\
\hline 40 & 0.1 & $6.72 \mathrm{E}-04$ & 341.87 & 32.06 & 17.68 & 1.5 \\
\hline 40 & 0.01 & $6.72 \mathrm{E}-05$ & 153.07 & 27.12 & 15.74 & 1.1 \\
\hline
\end{tabular}

Figure 108: Alpha-Fatigue WVP523 Default Dynamic Modulus Output 


$\begin{array}{cc}\begin{array}{c}\text { North Carolina } \\ \text { State Unlversity }\end{array} & \text { ALPHA-Fatigue } \\ \text { VECD Model Report }\end{array}$

\begin{tabular}{|ll|}
\hline $\begin{array}{l}\text { Project Name: } \\
\text { Analysis Performed by: }\end{array}$ & WVP523 \\
Analysis Date: & Laura E. Dalton \\
Testing Performed by: & Laura E. Dalton \\
Default Directory: & E:IGRAlAnalysisIFatigue DatalWVP523VInputs \\
& E:IGRAlAnalysisIFatigue DatalWVP5231Output_Default \\
Output Directory: & \\
Comments: & \\
\hline
\end{tabular}

\begin{tabular}{|lc|}
\hline $\begin{array}{l}\text { Number of Fatigue Tests: } \\
\text { Damage Model Function: }\end{array}$ & 3 \\
& Exponential \\
\hline
\end{tabular}

\begin{tabular}{|c|c|}
\hline \multicolumn{2}{|c|}{ Damage Model Coefficients } \\
\hline $\mathbf{a}$ & $-3.57 \mathrm{E}-05$ \\
\hline $\mathbf{b}$ & $8.83 \mathrm{E}-01$ \\
\hline $\mathbf{N}$ & $\mathrm{N} / \mathrm{A}$ \\
\hline N/Pha & 3.629 \\
\hline Parameter r in Failure Crit. & $1.08 \mathrm{E}+05$ \\
\hline Parameter s in Failure Crit. & $-6.37 \mathrm{E}-01$ \\
\hline
\end{tabular}

\begin{tabular}{|c|c|c|c|c|c|c|}
\hline Test Name & Temperature (deg. C) & Frequency $(\mathrm{Hz})$ & $\begin{array}{r}\mid E Y_{L V E} \\
(\mathrm{MPa})\end{array}$ & $\begin{array}{c}\text { IE'/ ningor } \\
\text { (MPa) }\end{array}$ & Nf & $G^{R}$ \\
\hline WVP523 S6 & 15 & 10 & 10169.5 & 10763 & 1095 & $1.04 E+03$ \\
\hline WVP523 S7 & 15 & 10 & 10168.3 & 10720 & 5095 & $2.03 E+02$ \\
\hline WVP523 S8 & 15 & 10 & 10181.7 & 10555 & 8355 & $4.25 E+01$ \\
\hline
\end{tabular}

Figure 109: Alpha-Fatigue WVP523 Default Damage Functions Output 


\begin{tabular}{|c|c|}
\hline $\begin{array}{l}\text { North Carolina } \\
\text { State University }\end{array}$ & $\begin{array}{l}\text { ALPHA-Fatigue } \\
\text { Model Predictions Report }\end{array}$ \\
\hline \begin{tabular}{|l} 
Project Name: \\
Analysis Performed by: \\
Analysis Date: \\
Testing Performed by: \\
Default Directory: \\
Output Directory: \\
Comments:
\end{tabular} & $\begin{array}{l}\text { WVP523 } \\
\text { Laura E. Dalton } \\
\text { 6/6/2016 } \\
\text { Laura E. Dalton } \\
\text { E:IGRAVAnalysisIFatigue DatalWVP523Inputs } \\
\text { E:IGRAVAnalysisIFatigue DataiWVP5231Output_Default }\end{array}$ \\
\hline
\end{tabular}

\begin{tabular}{|c|c|}
\hline \multicolumn{2}{|c|}{ Traditional Strain Fatigue Relationship (kPa units) } \\
\hline$K 1$ & $2.44 \mathrm{E}+06$ \\
\hline$K 2$ & 4.62 \\
\hline$K 3$ & -2.851 \\
\hline
\end{tabular}

$$
N_{f}=K_{1}\left(\frac{1}{\varepsilon_{t}}\right)^{K_{2}}\left(\left|E^{*}\right|\right)^{K_{3}}
$$

\begin{tabular}{|c|c|}
\hline \multicolumn{2}{|c|}{ Traditional Stress Fatigue Relationship 1(kPa units) } \\
\hline K1 & $2.42 \mathrm{E}-11$ \\
\hline$K 2$ & 4.528 \\
\hline$K 3$ & 4.148 \\
\hline
\end{tabular}

$$
N_{f}=K_{1}\left(\sigma_{t}\right)^{K_{2}}\left(\left|E^{*}\right|\right)^{K_{3}}
$$

\begin{tabular}{c|c}
\hline \multicolumn{2}{|c|}{ Traditional Stress Fatigue Relationship 2 (kPa units) } \\
\hline K1 & $2.42 \mathrm{E}-11$ \\
\hline K2 & 4.528 \\
\hline K3 & -0.383 \\
\hline
\end{tabular}

$$
N_{f}=K_{1}\left(\frac{1}{\varepsilon_{t, \text { ini }}}\right)^{K_{2}}\left(\left|E^{*}\right|\right)^{K_{s}}
$$

Traditional Strain Fatigue Relationship (psi units)

\begin{tabular}{c|c} 
K1 & $9.91 \mathrm{E}+0$ \\
\hline K2 & 4.62 \\
\hline 3 & -2.851 \\
\hline
\end{tabular}

$$
N_{f}=K_{1}\left(\frac{1}{\varepsilon_{t}}\right)^{K_{2}}\left(\left|E^{*}\right|\right)^{K_{3}}
$$

\begin{tabular}{|c|c|}
\hline K1 & $1.16 \mathrm{E}-11$ \\
\hline K2 & 4.528 \\
\hline$\kappa 3$ & -0.383 \\
\hline \multicolumn{2}{|c|}{ Endurance Limit (microstrain) } \\
\hline Temperature (deg. C) & Endurance Limit \\
\hline 5 & 25 \\
\hline 10 & 26 \\
\hline 15 & 28 \\
\hline 20 & 30 \\
\hline 25 & 38 \\
\hline
\end{tabular}

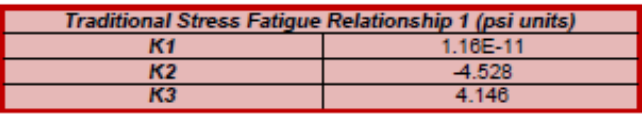

$$
N_{f}=K_{1}\left(\sigma_{t}\right)^{K_{2}}\left(\left|E^{*}\right|\right)^{K_{3}}
$$

Traditional Stress Fatigue Relationship 2 (psi units)

$$
N_{f}=K_{1}\left(\frac{1}{\varepsilon_{t, \text { ini }}}\right)^{K_{2}}\left(\left|E^{*}\right|\right)^{K_{3}}
$$

Figure 110: Alpha-Fatigue WVP523 Default Model Prediction Output 


$\begin{array}{ccc}\begin{array}{c}\text { North Carolina } \\ \text { State Unlversity }\end{array} & \text { ALPHA-Fatigue } \\ \text { Dynamic Modulus Report }\end{array}$

\begin{tabular}{|c|c|}
\hline $\begin{array}{l}\text { Project Name: } \\
\text { Analysis Performed by: }\end{array}$ & $\begin{array}{l}\text { WVP766 } \\
\text { Laura E. Dalton }\end{array}$ \\
\hline Analysis Date: & $5 / 23 / 2016$ \\
\hline Testing Performed by: & Laura E. Dalton \\
\hline Default Directory: & C:IUsersiuseriDesktopiLaura DaltoniGRALMPTVFatigue DataiWVP766inputs \\
\hline Output Directory: & C:IUsersluseriDesktoplLaura DaltoniGRALMPTVFatigue DatalWVP766iOutputs \\
\hline
\end{tabular}

\begin{tabular}{|c|c|c|}
\hline $\begin{array}{l}\text { Test Protocol: } \\
\text { Number of |E1 Tests: } \\
\text { Maximum Limiting Modulus: } \\
\text { Shift Factor Function: }\end{array}$ & $\begin{array}{c}\text { PP-61/TP-79 } \\
3 \\
\text { Fixed (Hirsch) } \\
\text { Amhenius } \\
\end{array}$ & \\
\hline \multicolumn{3}{|c|}{ Shift Factor Coefficients } \\
\hline $\mathrm{Tr}$ & 21.1 & deg. C \\
\hline Ea & 192.07 & $\mathrm{~kJ} / \mathrm{mol}$ \\
\hline a1 & N/A & \\
\hline a2 & N/A & \\
\hline$A$ & N/A & \\
\hline VTS & N/A & \\
\hline$c$ & N/A & \\
\hline
\end{tabular}

\begin{tabular}{|c|c|}
\hline \multicolumn{2}{|c|}{ Mastercurve Function } \\
\hline$\kappa$ & $1.15 \mathrm{E}+00$ \\
\hline$\beta$ & $3.19 \mathrm{E}+00$ \\
\hline$\delta$ & $-7.71 \mathrm{E}-01$ \\
\hline$\gamma$ & $-4.94 \mathrm{E}-01$ \\
\hline \multirow{2}{*}{$\log \mid E^{*}$} & \multicolumn{1}{|c}{$\mid=\kappa+\frac{\beta}{1+e^{\delta+\gamma \log \omega_{r}}}$} \\
\hline
\end{tabular}

\begin{tabular}{ccccccc} 
Temperature (deg. C) & Frequency $\mathbf{( H z )}$ & $\begin{array}{c}\text { Reduced } \\
\text { Frequency } \mathbf{H z} \text { ) }\end{array}$ & IE1 (Mpa) & $\begin{array}{c}\text { Phase } \\
\text { Angle (deg) }\end{array}$ & $\begin{array}{c}\text { Cov. IE1 } \\
\text { (\%) }\end{array}$ & $\begin{array}{c}\text { Cov. Phase } \\
\text { Angle (deg.) }\end{array}$ \\
\hline 4 & 10 & $1.27 \mathrm{E}+03$ & 13985.33 & 10.22 & 6.52 & 3.05 \\
4 & 1 & $1.27 \mathrm{E}+02$ & 10501.67 & 13.46 & 7.64 & 3.11 \\
4 & 0.1 & $1.27 \mathrm{E}+01$ & 7370.67 & 18.03 & 7.23 & 2.95 \\
20 & 10 & $1.34 \mathrm{E}+01$ & 6752 & 20.45 & 2.76 & 0.43 \\
20 & 1 & $1.34 \mathrm{E}+00$ & 3937 & 26.35 & 2.2 & 0.27 \\
20 & 0.1 & $1.34 \mathrm{E}-01$ & 2010 & 31.31 & 2.64 & 1.02 \\
40 & 10 & $8.76 \mathrm{E}-02$ & 1805.33 & 34.98 & 5.47 & 1.07 \\
40 & 1 & $8.76 \mathrm{E}-03$ & 726.47 & 35.02 & 5.12 & 1 \\
40 & 0.1 & $8.76 \mathrm{E}-04$ & 288.2 & 31.7 & 3.85 & 1.91 \\
40 & 0.01 & $8.76 \mathrm{E}-05$ & 129.8 & 26.21 & 1.27 & 1.8
\end{tabular}

Figure 111: Alpha-Fatigue WVP766 Peak Dynamic Modulus Output 


$\begin{array}{ccc}\begin{array}{c}\text { North Carolina } \\ \text { State University }\end{array} & \text { ALPHA-Fatigue } \\ \text { VECD Model Report }\end{array}$

\begin{tabular}{|ll|}
\hline Project Name: & WVP768 \\
Analysis Performed by: & Laura E. Dalton \\
Analysis Date: & $5 / 23 / 2016$ \\
Testing Performed by: & Laura E. Dalton \\
Default Directory: & C:IUsersiuseriDesktopiLaura DaltoniGRAVAMPTIFatigue DatalWVP766IInputs \\
& \\
Output Directory: & C:IUsersiuseriDesktopiLaura DaltoniGRALAMPTVFatigue DatalWVP766iOutputs \\
& \\
Comments: & \\
\hline
\end{tabular}

\begin{tabular}{|lc|}
\hline $\begin{array}{l}\text { Number of Fatigue Tests: } \\
\text { Damage Model Function: }\end{array}$ & 3 \\
\hline
\end{tabular}

Damage Model Coefficients

\begin{tabular}{|c|c|c|c|}
\hline \multicolumn{2}{|c|}{ Damage Model Coefficients } & \multirow{2}{*}{$C=e^{a S^{b}}$} & \\
\hline$a$ & $-1.01 \mathrm{E}-04$ & & \multirow{3}{*}{$C=1-y S^{z}$} \\
\hline$\frac{b}{y}$ & $\frac{7.92 \mathrm{E}-01}{\mathrm{~N} / \mathrm{A}}$ & & \\
\hline$z$ & N/A & \multirow{3}{*}{$N_{f}=r\left(G^{R}\right)^{s}$} & \\
\hline alpha & 3.58 & & \\
\hline $\begin{array}{l}\text { Parameter in Failure Crit } \\
\text { Parameter } s \text { in Failure Crit }\end{array}$ & $\begin{array}{l}5.33 E+05 \\
-7.47 E-01\end{array}$ & & $\left.F^{R}\right)^{-}$ \\
\hline
\end{tabular}

\begin{tabular}{|c|c|c|c|c|c|c|}
\hline Test Name & Temperature (deg. C) & Frequency $(\mathrm{Hz})$ & $\begin{array}{l}\mid E M_{\text {LVE }} \\
(\mathrm{MPa} \text { ) }\end{array}$ & $\begin{array}{l}\mid E Y_{\text {finpor }} \\
(\mathrm{MPa})\end{array}$ & Nf & $G^{R}$ \\
\hline $\begin{array}{l}\text { WVP766 S6 } \\
\text { WYP766 S7 }\end{array}$ & $\begin{array}{l}15 \\
15\end{array}$ & $\begin{array}{l}10 \\
10\end{array}$ & $\begin{array}{l}8872.8 \\
88678\end{array}$ & $\begin{array}{l}9757 \\
9678\end{array}$ & $\begin{array}{l}15550 \\
4335\end{array}$ & $\begin{array}{l}1.05 E+02 \\
8.08 E+02\end{array}$ \\
\hline WVP768 S8 & 15 & 10 & 8878.4 & 9231 & 59117 & $\begin{array}{l}0.462+02 \\
1.97 E+01\end{array}$ \\
\hline
\end{tabular}

Figure 112: Alpha-Fatigue WVP766 Peak Damage Functions Output 
Project Name:

Analysis Performed by:

Analysis Date:

WVP766

Laura E. Dalton

$5 / 23 / 2016$

Laura E. Dalton

Testing Performed by:

Default Directory:

C:IUsersiuseriDesktopiLaura DaltonIGRALAMPTFatigue DataiWVP766IInputs

Output Directory:

C:IUsersiuseriDesktoplLaura DaltoniGRAIAMPTIFatigue DatalWVP7861Outputs

Comments:

\begin{tabular}{|c|c|}
\hline \multicolumn{2}{|c|}{ Traditional Strain Fatigue Relationship (kPa units) } \\
\hline K1 & $6.59 \mathrm{E}+17$ \\
\hline K2 & 6.154 \\
\hline K3 & -5.129 \\
\hline
\end{tabular}

$$
N_{f}=K_{1}\left(\frac{1}{\varepsilon_{t}}\right)^{K_{2}}\left(\left|E^{*}\right|\right)^{K_{3}}
$$

\begin{tabular}{|c|c|}
\hline \multicolumn{2}{|c|}{ Traditional Stress Fatigue Relationship 1 (kPa units) } \\
\hline K1 & $3.09 \mathrm{E}-17$ \\
\hline K2 & -5.119 \\
\hline K3 & 5.327 \\
\hline
\end{tabular}

$$
N_{f}=K_{1}\left(\sigma_{t}\right)^{K_{2}}\left(\left|E^{*}\right|\right)^{K_{3}}
$$

\begin{tabular}{|c|c|}
\hline \multicolumn{2}{|c|}{ Traditional Stress Fatigue Relationship 2 (kPa units) } \\
\hline K1 & $3.09 E-17$ \\
\hline K2 & 5.119 \\
\hline K3 & 0.208 \\
\hline
\end{tabular}

$$
N_{f}=K_{1}\left(\frac{1}{\varepsilon_{t, i n i}}\right)^{K_{2}}\left(\left|E^{*}\right|\right)^{K_{3}}
$$

Traditional Strain Fatigue Relationship (psi units)

\begin{tabular}{c|c} 
K1 & $3.30 \mathrm{E}+13$ \\
K2 & 6.154 \\
\hline
\end{tabular}

\begin{tabular}{l|r}
$K 2$ & 6.154 \\
\hline$K 3$ & -5.129
\end{tabular}

$$
N_{f}=K_{1}\left(\frac{1}{\varepsilon_{t}}\right)^{K_{2}}(|E *|)^{K_{3}}
$$

\begin{tabular}{|c|c|}
\hline \multicolumn{2}{|c|}{ Traditional Stress Fatigue Relationship 1 (psi units) } \\
\hline K1 & $4.62 \mathrm{E}-17$ \\
\hline K2 & -5.119 \\
\hline K3 & 5.327 \\
\hline
\end{tabular}

$$
N_{f}=K_{1}\left(\sigma_{t}\right)^{K_{2}}\left(\left|E^{*}\right|\right)^{K_{3}}
$$

Traditional Stress Fatigue Relationship 2 (psi units)

\begin{tabular}{|c|c|}
\hline K1 & $4.62 \mathrm{E}-17$ \\
\hline K2 & 5.119 \\
\hline K3 & 0.208 \\
\hline
\end{tabular}

$$
N_{f}=K_{1}\left(\frac{1}{\varepsilon_{t, \text { ini }}}\right)^{K_{2}}\left(\left|E^{*}\right|\right)^{K_{3}}
$$

\begin{tabular}{|c|c|}
\hline \multicolumn{2}{|c|}{ Endurance Limit (microstrain) } \\
\hline Temperature (deg. C) & Endurance Limit \\
\hline 5 & 56 \\
\hline 10 & 61 \\
\hline 15 & 72 \\
\hline 20 & 85 \\
\hline 25 & 114 \\
\hline
\end{tabular}

Figure 113: Alpha-Fatigue WVP766 Peak Model Prediction Output 


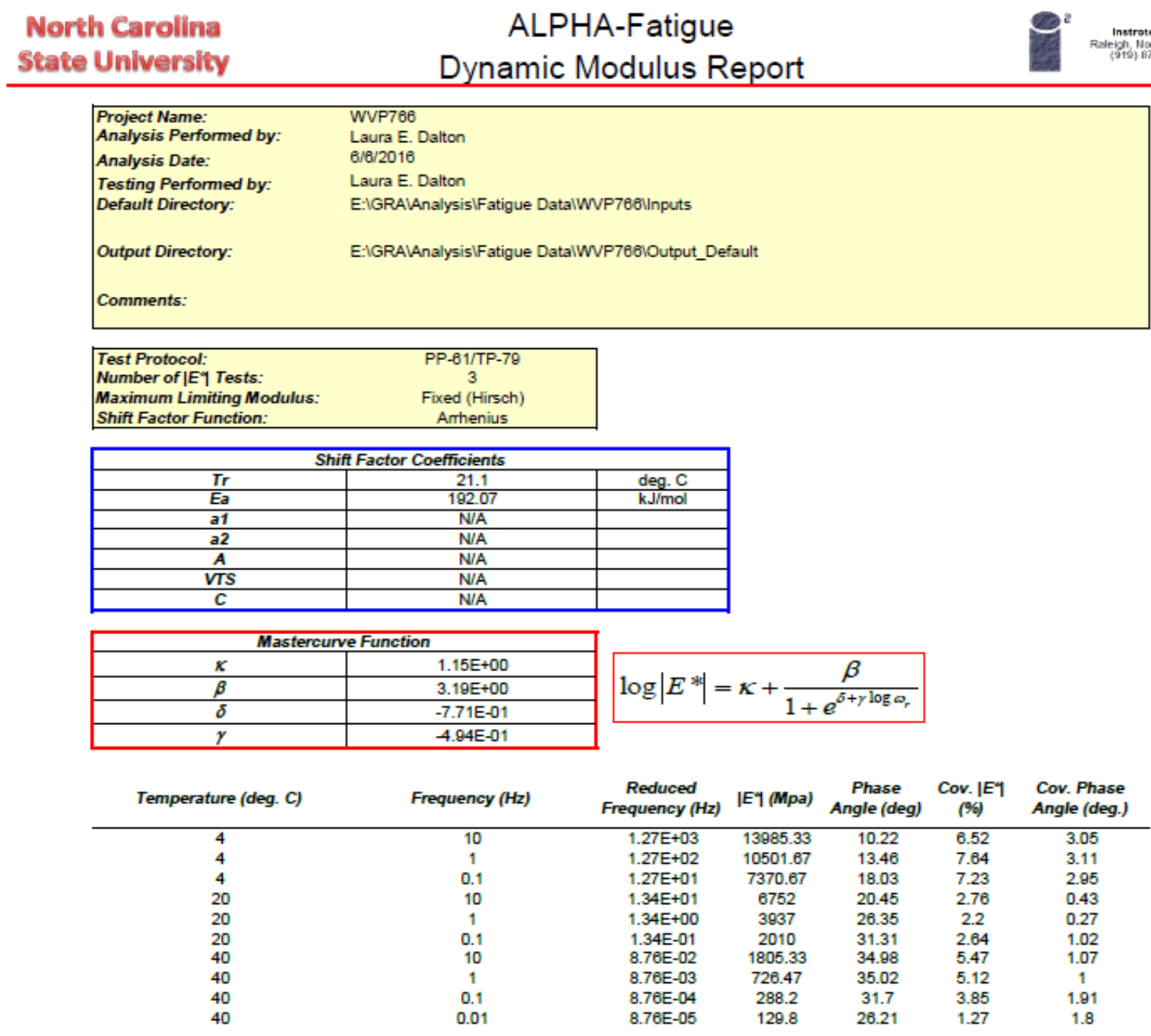

Figure 114: Alpha-Fatigue WVP766 Default Dynamic Modulus Output 


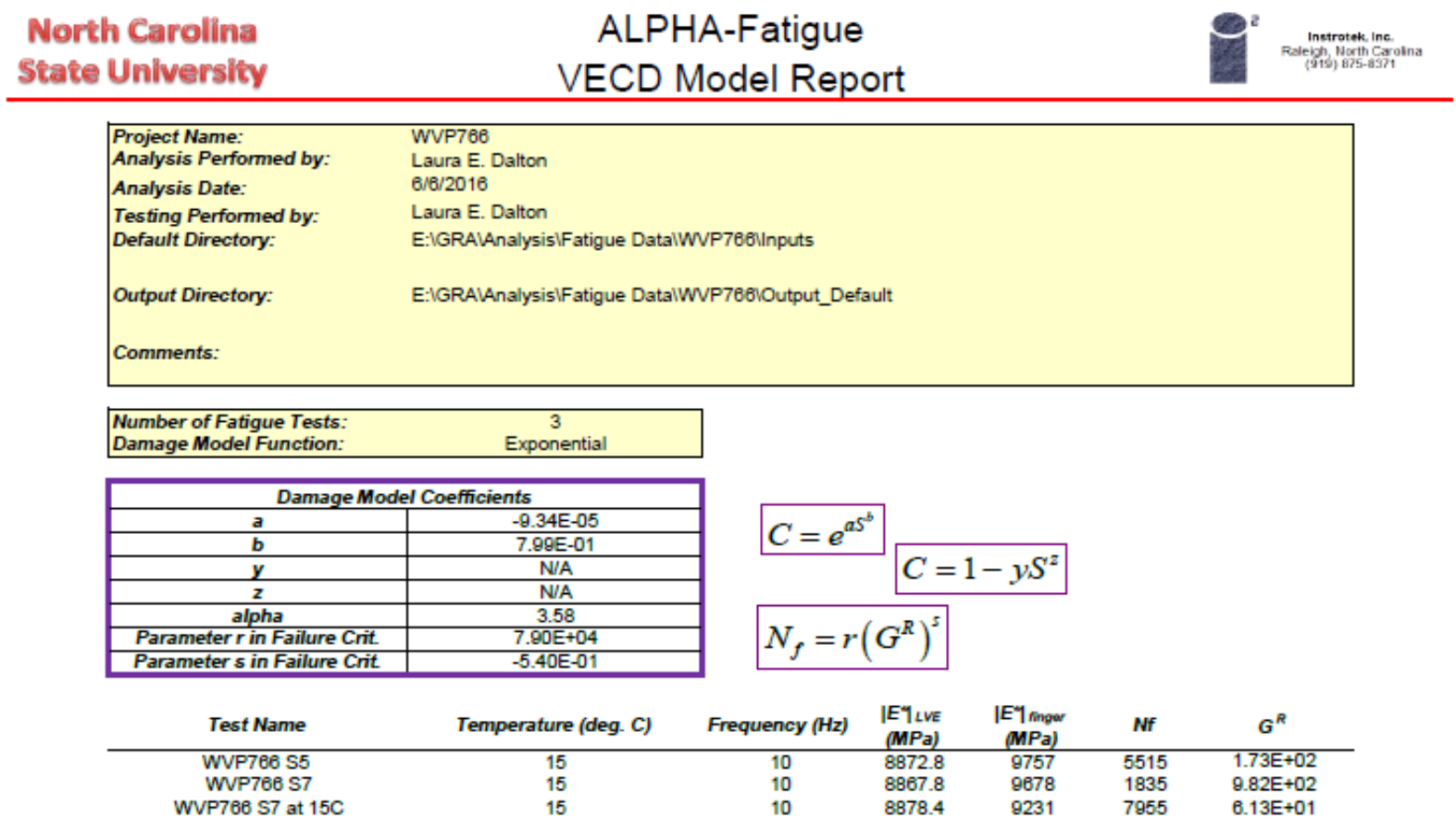

Figure 115: Alpha-Fatigue WVP766 Default Damage Functions Output $\left(S 7\right.$ at $15^{\circ} \mathrm{C}$ is S8) 


\begin{tabular}{|c|c|}
\hline $\begin{array}{l}\text { North Carolina } \\
\text { State University }\end{array}$ & $\begin{array}{c}\text { ALPHA-Fatigue } \\
\text { Model Predictions Report }\end{array}$ \\
\hline \begin{tabular}{|l} 
Project Name: \\
Analysis Performed by: \\
Analysis Date: \\
Testing Performed by: \\
Default Directory: \\
Output Directory: \\
Comments:
\end{tabular} & $\begin{array}{l}\text { WVP768 } \\
\text { Laura E. Dalton } \\
\text { 6/6/2016 } \\
\text { Laura E. Dalton } \\
\text { E:IGRAVAnalysisIFatigue DatalWVP766Inputs } \\
\text { E:IGRAVAnalysisIFatigue DatalWVP7861Output_Default }\end{array}$ \\
\hline
\end{tabular}

\begin{tabular}{|c|c|}
\hline \multicolumn{2}{|c|}{ Traditional Strain Fatigue Relationship (kPa units) } \\
\hline K1 & $1.45 \mathrm{E}+07$ \\
\hline K2 & 3.241 \\
\hline K3 & -2.202 \\
\hline
\end{tabular}

$$
N_{f}=K_{1}\left(\frac{1}{\varepsilon_{t}}\right)^{K_{2}}\left(\left|E^{*}\right|\right)^{K_{3}}
$$

\begin{tabular}{|c|c|}
\hline \multicolumn{2}{|c|}{ Traditional Stress Fatigue Relationship 1(kPa units) } \\
\hline K1 & $2.97 \mathrm{E}-04$ \\
\hline K2 & -3.845 \\
\hline 3 & 2.828 \\
\hline
\end{tabular}

$$
N_{f}=K_{1}\left(\sigma_{t}\right)^{K_{2}}\left(\left|E^{*}\right|\right)^{K_{3}}
$$

\begin{tabular}{c|c}
\multicolumn{2}{c}{ Traditional Stress Fatigue Relationship 2 (kPa units) } \\
\hline K1 & $2.97 \mathrm{E}-04$ \\
\hline K2 & 3.845 \\
\hline K3 & -1.018 \\
\hline
\end{tabular}

$$
\begin{aligned}
& N_{f}=K_{1}\left(\frac{1}{\varepsilon_{t, \text { ini }}}\right)^{K_{2}}\left(\left|E^{*}\right|\right)^{K_{3}} \\
& N_{f}=K_{1}\left(\frac{1}{\varepsilon_{t}}\right)^{K_{2}}\left(\left|E^{*}\right|\right)^{K_{3}}
\end{aligned}
$$

Traditional Strain Fatigue Relationship (psi units)

\begin{tabular}{|c|c|}
\hline K1 & $2.07 \mathrm{E}+05$ \\
\hline K2 & 3.241 \\
\hline K3 & -2.202 \\
\hline
\end{tabular}

\begin{tabular}{|c|c|}
\hline \multicolumn{2}{|c|}{ Traditional Stress Fatigue Relationship 1 (psi units) } \\
\hline K1 & $4.17 \mathrm{E}-05$ \\
\hline K2 & -3.845 \\
\hline K3 & 2.828 \\
\hline
\end{tabular}

$$
N_{f}=K_{1}\left(\sigma_{t}\right)^{K_{2}}\left(\left|E^{*}\right|\right)^{K_{3}}
$$

Traditional Stress Fatigue Relationship 2 (psi units)

\begin{tabular}{c|c}
\hline Traditional Stress Fatigue Relationship 2 (psi units) \\
\hline K1 & $4.17 \mathrm{E}-05$ \\
\hline K2 & 3.845 \\
\hline 3 & -1.018 \\
\hline
\end{tabular}

$$
N_{f}=K_{1}\left(\frac{1}{\varepsilon_{t, i n i}}\right)^{K_{2}}\left(\left|E^{*}\right|\right)^{K_{3}}
$$

\begin{tabular}{|c|c|}
\hline \multicolumn{2}{|c|}{ Endurance Limit (microstrain) } \\
\hline Temperature (deg. C) & Endurance Limit \\
\hline 5 & 16 \\
\hline 10 & 16 \\
\hline 15 & 18 \\
\hline 20 & 20 \\
\hline 25 & 25 \\
\hline
\end{tabular}

Figure 116: Alpha-Fatigue WVP766 Default Model Prediction Output 
North Carolina

State University

\section{ALPHA-Fatigue Dynamic Modulus Report}

\begin{tabular}{|c|c|c|c|c|c|c|}
\hline $\begin{array}{l}\text { Project Name: } \\
\text { Analysis Performed by: }\end{array}$ & \multicolumn{6}{|l|}{$\begin{array}{l}\text { WVP882 } \\
\text { Laura E. Dalton } \\
5 / 23 / 2016\end{array}$} \\
\hline Analysis Date: & \multirow{2}{*}{\multicolumn{6}{|c|}{ Laura E. Dalton }} \\
\hline Testing Performed by: & & & & & & \\
\hline Default Directory: & \multicolumn{6}{|c|}{ C:IUsersluseriDesktoplLaura DaltonlGRAVMPTIFatigue DatalWVP882IInputs } \\
\hline Output Directory: & \multicolumn{6}{|c|}{ C:UsersluseriDesktoplLaura DaltoniGRALAMPTVatigue DatalWVP8821Outputs } \\
\hline \multicolumn{7}{|l|}{ Comments: } \\
\hline \multicolumn{3}{|l|}{$\begin{array}{l}\text { Test Protocol: } \\
\text { Number of |E1 Tests: } \\
\text { Maximum Limiting Modulus: } \\
\text { Shift Factor Function: }\end{array}$} & & & & \\
\hline \multicolumn{3}{|c|}{ Shift Factor Coefficients } & & & & \\
\hline $\operatorname{Tr}$ & 21.1 & deg. C & & & & \\
\hline Ea & 198.02 & $\mathrm{kJJ} / \mathrm{mol}$ & & & & \\
\hline a1 & N/A & & & & & \\
\hline a2 & N/A & & & & & \\
\hline$A$ & N/A & & & & & \\
\hline VTS & N/A & & & & & \\
\hline$C$ & N/A & & & & & \\
\hline \multicolumn{2}{|c|}{ Mastercurve Function } & & & & \multirow[b]{6}{*}{$\begin{array}{c}\text { Cov. |EY } \\
(\%)\end{array}$} & \multirow[b]{6}{*}{$\begin{array}{l}\text { Cov. Phase } \\
\text { Angle (deg.) }\end{array}$} \\
\hline $\boldsymbol{\kappa}$ & $1.22 \mathrm{E}+00$ & \multirow{3}{*}{\multicolumn{3}{|c|}{$\log \left|E^{*}\right|=\kappa+\frac{\beta}{1+e^{\delta+\gamma \log \omega_{r}}}$}} & & \\
\hline$\beta$ & $3.12 \mathrm{E}+00$ & & & & & \\
\hline$\delta$ & $-6.80 E-01$ & & & & & \\
\hline$\gamma$ & $-5.11 E-01$ & & & & & \\
\hline Temperature (deg. C) & Frequency $(\mathrm{Hz})$ & $\begin{array}{c}\text { Reduced } \\
\text { Frequency }(\mathrm{Hz})\end{array}$ & |E (Mpa) & $\begin{array}{c}\text { Phase } \\
\text { Angle (deg) }\end{array}$ & & \\
\hline 4 & 10 & $1.47 \mathrm{E}+03$ & 14490.67 & 10.36 & 4.27 & 4.17 \\
\hline 4 & 1 & $1.47 \mathrm{E}+02$ & 10880 & 13.74 & 5.49 & 3.93 \\
\hline 4 & 0.1 & $1.47 \mathrm{E}+01$ & 7487.33 & 18.5 & 6.48 & 3.66 \\
\hline 20 & 10 & $1.35 \mathrm{E}+01$ & 6463.33 & 21.89 & 3.64 & 1.75 \\
\hline 20 & 1 & $1.35 \mathrm{E}+00$ & 3840 & 27.64 & 3.78 & 2.03 \\
\hline 20 & 0.1 & $1.35 \mathrm{E}-01$ & 1837.67 & 31.84 & 4.12 & 1.96 \\
\hline 40 & 10 & $7.56 \mathrm{E}-02$ & 1554 & 36.2 & 3.91 & 1 \\
\hline 40 & 1 & $7.56 \mathrm{E}-03$ & 614.9 & 35.23 & 5.45 & 1.43 \\
\hline 40 & 0.1 & $7.56 \mathrm{E}-04$ & 239.33 & 31.57 & 5.15 & 1.8 \\
\hline 40 & 0.01 & $7.56 \mathrm{E}-05$ & 111.53 & 26.09 & 2.15 & 3.91 \\
\hline
\end{tabular}

Figure 117: Alpha-Fatigue WVP882 Peak Dynamic Modulus Output 
Project Name:

Analysis Performed by: Laura E. Dalton

Analysis Date:

$5 / 23 / 2016$

Testing Performed by: Laura E. Dalton

Default Directory:

C:IUsersiuseriDesktoplLaura DaltonIGRALAMPTFatigue DatalWVP882IInputs

Output Directory:

C:UsersiuseriDesktoplLaura DaltonIGRAMMPTVatigue DatalWVP8821Outputs

Comments:

Number of Fatigue Tests:

Damage Model Function:

3

\begin{tabular}{|c|c|}
\hline \multicolumn{2}{|c|}{ Damage Model Coefficients } \\
\hline $\mathbf{a}$ & $-2.74 \mathrm{E}-04$ \\
\hline $\mathbf{y}$ & $7.14 \mathrm{E}-01$ \\
\hline $\mathbf{N} / \mathrm{A}$ \\
\hline alpha & N/A \\
\hline Parameter r in Failure Crit. & 3.531 \\
\hline Parameter s in Failure Crit & $3.23 \mathrm{E}+05$ \\
\hline
\end{tabular}

$$
\begin{aligned}
& C=e^{a S^{5}} \quad C=1-y S^{z} \\
& N_{f}=r\left(G^{R}\right)^{s}
\end{aligned}
$$

\begin{tabular}{|c|c|c|c|c|c|c|}
\hline Test Name & Temperature (deg. C) & Frequency $(\mathrm{Hz})$ & $\begin{array}{r}\mid E Y_{L V E} \\
\text { (MPa) }\end{array}$ & $\begin{array}{c}\text { [EY } Y_{\text {ningor }} \\
\text { (MPa) }\end{array}$ & Nf & $G^{R}$ \\
\hline WVP882 S7 & 15 & 10 & 8821.6 & 9419 & 30394 & $4.07 \mathrm{E}+01$ \\
\hline WVP882 S8 & 15 & 10 & 8838.7 & 9676 & 2455 & $2.07 E+03$ \\
\hline WVP882 S9 & 15 & 10 & 8830.2 & 8978 & 5175 & $5.12 \mathrm{E}+02$ \\
\hline
\end{tabular}

Figure 118: Alpha-Fatigue WVP882 Peak Damage Functions Output 


\begin{tabular}{|c|c|c|c|}
\hline $\begin{array}{l}\text { North Carolina } \\
\text { State University }\end{array}$ & Model P & $\begin{array}{l}\text {-Fatigue } \\
\text { ctions Report }\end{array}$ & 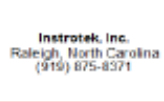 \\
\hline $\begin{array}{l}\text { Project Name: } \\
\text { Analysis Performed by: } \\
\text { Analysis Date: } \\
\text { Testing Performed by: } \\
\text { Default Directory: } \\
\text { Output Directory: } \\
\text { Comments: }\end{array}$ & $\begin{array}{l}\text { WVP882 } \\
\text { Laura E. Dalton } \\
\text { 5/23/2016 } \\
\text { Laura E. Dalton } \\
\text { C:UsersiuseriDesktoplLau } \\
\text { C:IUsersiuseriDesktoplLau }\end{array}$ & nIGRAWAMPTFatigue DatalWVP882IInputs & \\
\hline $\begin{array}{c}\text { Traditional Strain F } \\
\text { K1 } \\
K 2 \\
K 3 \\
\end{array}$ & 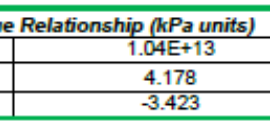 & $N_{f}=K_{1}\left(\frac{1}{\varepsilon_{t}}\right)^{K_{2}}\left(\left|E^{*}\right|\right)^{K_{3}}$ & \\
\hline $\begin{array}{c}\text { Traditional Stress } F \\
K 1 \\
K 2 \\
K 3 \\
\end{array}$ & $\begin{array}{l}\text { e Relationship 1(kPa units) } \\
\begin{array}{c}.21 \mathrm{E}-10 \\
4.536 \\
3.978 \\
\end{array}\end{array}$ & $N_{f}=K_{1}\left(\sigma_{t}\right)^{K_{2}}\left(\left|E^{*}\right|\right)^{K_{3}}$ & \\
\hline $\begin{array}{c}\text { Traditional Stress F } \\
K 1 \\
K 2 \\
K 3 \\
\end{array}$ & $\begin{array}{l}\text { e Relationship 2 (kPa units) } \\
\begin{array}{|c|}.21 \mathrm{E}-10 \\
4.536 \\
-0.56\end{array} \\
\end{array}$ & $N_{f}=K_{1}\left(\frac{1}{\varepsilon_{t, \text { ini }}}\right)^{K_{2}}\left(\left|E^{*}\right|\right)^{K_{3}}$ & \\
\hline $\begin{array}{c}\text { Traditional Strain } \\
K 1 \\
K 2 \\
K 3 \\
\end{array}$ & $\begin{array}{l}\text { Ue Relationship ( } \rho \text { si units) } \\
\begin{array}{|c|}1.40 \mathrm{E}+10 \\
4.178 \\
-3.423 \\
\end{array}\end{array}$ & $N_{f}=K_{1}\left(\frac{1}{\varepsilon_{t}}\right)^{K_{2}}\left(\left|E^{*}\right|\right)^{K_{3}}$ & \\
\hline $\begin{array}{c}\text { Traditional Stress F } \\
K 1 \\
K 2 \\
K 3 \\
\end{array}$ & $\begin{array}{l}\text { e Relationship 1 (psi units) } \\
\begin{array}{|c|}2.78 \mathrm{E}-10 \\
4.536 \\
3.978 \\
\end{array}\end{array}$ & $N_{f}=K_{1}\left(\sigma_{t}\right)^{K_{2}}\left(\left|E^{*}\right|\right)^{K_{3}}$ & \\
\hline $\begin{array}{c}\text { Traditional Stress F } \\
K 1 \\
K 2 \\
K 3\end{array}$ & $\begin{array}{l}\text { e Relationship 2 (psi units) } \\
\begin{array}{|c|}2.78 E-10 \\
4.536 \\
-0.56\end{array}\end{array}$ & $N_{f}=K_{1}\left(\frac{1}{\varepsilon_{t, \text { ini }}}\right)^{K_{2}}\left(\left|E^{*}\right|\right)^{K_{3}}$ & \\
\hline $\begin{array}{c}\text { Enduran } \\
\text { Temperature (deg. C } \\
5 \\
10 \\
15 \\
20 \\
25 \\
\end{array}$ & 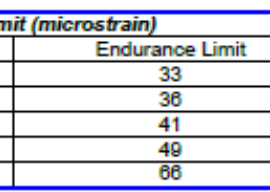 & & \\
\hline
\end{tabular}

Figure 119: Alpha-Fatigue WVP882 Peak Model Prediction Output 
North Carolina

State University

\section{ALPHA-Fatigue Dynamic Modulus Report}

\begin{tabular}{|ll|}
\hline Project Name: & WVP882 \\
Analysis Performed by: & Laura E. Dalton \\
Analysis Date: & 6/6/2016 \\
$\begin{array}{l}\text { Testing Performed by: } \\
\text { Default Directory: }\end{array}$ & Laura E. Dalton \\
& E:IGRALAnalysisIFatigue DataiWVP882IInputs \\
Output Directory: & E:IGRALAnalysisIFatigue DataiWVP8821Output_Default \\
& \\
Comments: & \\
\hline
\end{tabular}

Test Protocol:

Number of |E\ Tests:

Maximum Limiting Modulus:

Shift Factor Function:

Amhenius

\begin{tabular}{|c|c|c|}
\hline \multicolumn{3}{|c|}{ Shift Factor Coefficients } \\
\hline Tr & 21.1 & deg. C \\
\hline Ea & 198.02 & $\mathrm{~kJ} / \mathrm{mol}$ \\
\hline$a 1$ & N/A & \\
\hline$a 2$ & N/A & \\
\hline$A$ & N/A & \\
\hline VTS & N/A & \\
\hline$C$ & N/A & \\
\hline
\end{tabular}

\begin{tabular}{|c|c|}
\hline \multicolumn{2}{|c|}{ Mastercurve Function } \\
\hline $\boldsymbol{\beta}$ & $1.22 \mathrm{E}+00$ \\
\hline$\delta$ & $3.12 \mathrm{E}+00$ \\
\hline$\gamma$ & $-6.80 \mathrm{E}-01$ \\
\hline & $-5.11 \mathrm{E}-01$ \\
\hline
\end{tabular}

$$
\log \left|E^{*}\right|=\kappa+\frac{\beta}{1+e^{\delta+\gamma \log \omega_{r}}}
$$

\begin{tabular}{ccccccc} 
Temperature (deg. C) & Frequency $(\mathbf{H z})$ & $\begin{array}{c}\text { Reduced } \\
\text { Frequency (Hz) }\end{array}$ & IE1 (Mpa) & $\begin{array}{c}\text { Phase } \\
\text { Angle (deg) }\end{array}$ & $\begin{array}{c}\text { Cov. IEY } \\
\text { (\%) }\end{array}$ & $\begin{array}{c}\text { Cov. Phase } \\
\text { Angle (deg.) }\end{array}$ \\
\hline 4 & 10 & $1.47 \mathrm{E}+03$ & 14490.67 & 10.36 & 4.27 & 4.17 \\
4 & 1 & $1.47 \mathrm{E}+02$ & 10880 & 13.74 & 5.49 & 3.93 \\
4 & 0.1 & $1.47 \mathrm{E}+01$ & 7487.33 & 18.5 & 6.48 & 3.66 \\
20 & 10 & $1.35 \mathrm{E}+01$ & 6463.33 & 21.89 & 3.64 & 1.75 \\
20 & 1 & $1.35 \mathrm{E}+00$ & 3640 & 27.64 & 3.78 & 2.03 \\
20 & 0.1 & $1.35 \mathrm{E}-01$ & 1837.67 & 31.84 & 4.12 & 1.96 \\
40 & 10 & $7.56 \mathrm{E}-02$ & 1554 & 36.2 & 3.91 & 1 \\
40 & 1 & $7.56 \mathrm{E}-03$ & 614.9 & 35.23 & 5.45 & 1.43 \\
40 & 0.1 & $7.56 \mathrm{E}-04$ & 239.33 & 31.57 & 5.15 & 1.8 \\
40 & 0.01 & $7.56 \mathrm{E}-05$ & 111.53 & 26.09 & 2.15 & 3.91
\end{tabular}

Figure 120: Alpha-Fatigue WVP882 Default Dynamic Modulus Output 


\begin{tabular}{|c|c|}
\hline $\begin{array}{l}\text { North Carolina } \\
\text { State University }\end{array}$ & $\begin{array}{c}\text { ALPHA-Fatigue } \\
\text { VECD Model Report }\end{array}$ \\
\hline 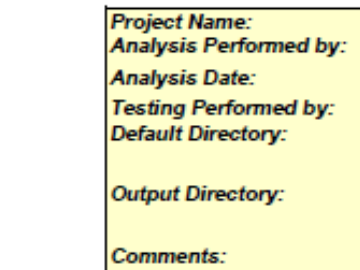 & $\begin{array}{l}\text { WVP882 } \\
\text { Laura E. Dalton } \\
\text { 6/8/2016 } \\
\text { Laura E. Dalton } \\
\text { E:IGRALAnalysisIFatigue DatalWVP882Inputs } \\
\text { E:IGRALAnalysisIFatigue DatalWVP8821Output_Default }\end{array}$ \\
\hline
\end{tabular}

\begin{tabular}{|c|c|c|c|c|c|c|}
\hline \begin{tabular}{|l} 
Number of Fatigue Tests: \\
Damage Model Function:
\end{tabular} & $\begin{array}{c}3 \\
\text { Exponential } \\
\end{array}$ & & & & & \\
\hline \multicolumn{2}{|c|}{ Damage Model Coefficients } & \multirow{3}{*}{$C=e^{a S^{b}}$} & \multirow{4}{*}{\multicolumn{2}{|c|}{$C=1-y S^{z}$}} & \multirow[b]{8}{*}{ Nf } & \multirow[b]{8}{*}{$G^{R}$} \\
\hline$a$ & $-3.85 \mathrm{E}-04$ & & & & & \\
\hline$\frac{b}{y}$ & $\frac{6.80 E-01}{\mathrm{~N} / \mathrm{A}}$ & & & & & \\
\hline$z$ & N/A & \multirow{4}{*}{\multicolumn{2}{|c|}{$N_{f}=r\left(G^{R}\right)^{s}$}} & & & \\
\hline alpha & 3.531 & & & \multirow[b]{4}{*}{$\begin{array}{l}|E|_{\text {finow }} \\
(\mathrm{MPa})\end{array}$} & & \\
\hline $\begin{array}{l}\text { Parameter } r \text { in Failure Crit. } \\
\text { Parameter } \mathrm{s} \text { in Failure Crit }\end{array}$ & $7.48 E+04$ & & & & & \\
\hline Parameter $s$ in Failure Crit & $-5.41 \mathrm{E}-01$ & & & & & \\
\hline Test Name & Temperature (deg. C) & Frequency $(\mathrm{Hz})$ & $\begin{array}{l}\text { IEY IVE } \\
(M P a)\end{array}$ & & & \\
\hline WVP882 S7 & 15 & 10 & 8821.6 & 9419 & 6635 & $8.34 E+01$ \\
\hline WVP882 S8 & 15 & 10 & 8838.7 & 9678 & 935 & $3.03 E+03$ \\
\hline WVP882 S9 & 15 & 10 & 8830.2 & 8978 & 2255 & $7.35 \mathrm{E}+02$ \\
\hline
\end{tabular}

Figure 121: Alpha-Fatigue WVP882 Default Damage Functions Output 


\begin{tabular}{ccc}
$\begin{array}{c}\text { North Carolina } \\
\text { State Unlversity }\end{array}$ & ALPHA-Fatigue \\
\hline
\end{tabular}

\begin{tabular}{|ll|}
\hline Project Name: & WVP882 \\
Analysis Performed by: & Laura E. Dalton \\
Analysis Date: & 6/8/2016 \\
Testing Performed by: & Laura E. Dalton \\
Default Directory: & E:IGRALAnalysisIFatigue DatalWVP882IInputs \\
& \\
Output Directory: & E:IGRAVAnalysisIFatigue DatalWVP8821Output_Default \\
& \\
Comments: & \\
\hline
\end{tabular}

\begin{tabular}{|c|c|}
\hline \multicolumn{2}{|c|}{ Traditional Strain Fatigue Relationship (kPa units) } \\
\hline K1 & $2.36 \mathrm{E}+08$ \\
\hline$K 2$ & 3.069 \\
\hline$K 3$ & -2.296 \\
\hline
\end{tabular}

$$
N_{f}=K_{1}\left(\frac{1}{\varepsilon_{t}}\right)^{K_{2}}\left(\left|E^{*}\right|\right)^{K_{3}}
$$

\begin{tabular}{|c|c|}
\hline \multicolumn{2}{|c|}{ Traditional Stress Fatigue Relationship 1 (kPa units) } \\
\hline K1 & $1.14 \mathrm{E}-01$ \\
\hline$K 2$ & -3.62 \\
\hline$K 3$ & 2.328 \\
\hline
\end{tabular}

$$
N_{f}=K_{1}\left(\sigma_{t}\right)^{K_{2}}\left(\left|E^{*}\right|\right)^{K_{3}}
$$

\begin{tabular}{|c|c|}
\hline \multicolumn{2}{|c|}{ Traditional Stress Fatigue Relationship 2 (kPa units) } \\
\hline K1 & $1.14 \mathrm{E}-01$ \\
\hline K2 & 3.62 \\
\hline K3 & -1.292 \\
\hline
\end{tabular}

$$
N_{f}=K_{1}\left(\frac{1}{\varepsilon_{t, \text { ini }}}\right)^{K_{2}}\left(\left|E^{*}\right|\right)^{K_{3}}
$$

\begin{tabular}{|c|c|}
\hline \multicolumn{2}{|c|}{ Traditional Strain Fatigue Relationship (psi units) } \\
\hline K1 & $2.81 \mathrm{E}+06$ \\
\hline K2 & 3.069 \\
\hline K3 & -2.296 \\
\hline
\end{tabular}

$$
N_{f}=K_{1}\left(\frac{1}{\varepsilon_{t}}\right)^{K_{2}}\left(\left|E^{*}\right|\right)^{K_{3}}
$$

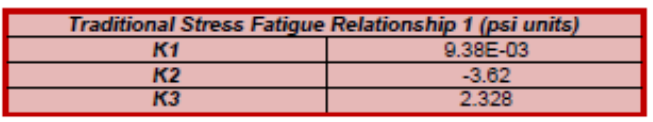

$$
N_{f}=K_{1}\left(\sigma_{t}\right)^{K_{2}}\left(\left|E^{*}\right|\right)^{K_{3}}
$$

Traditional Stress Fatigue Relationship 2 (psi units)

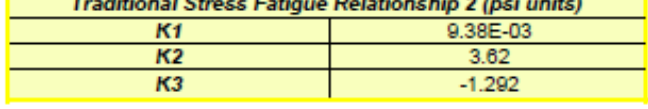

$$
N_{f}=K_{1}\left(\frac{1}{\varepsilon_{t, \text { nni }}}\right)^{K_{2}}\left(\left|E^{*}\right|\right)^{K_{3}}
$$

\begin{tabular}{|c|c|}
\hline \multicolumn{2}{|c|}{ Endurance Limit (microstrain) } \\
\hline Temperature (deg. C) & Endurance Limit \\
\hline 5 & 11 \\
\hline 10 & 12 \\
\hline 15 & 14 \\
\hline 20 & 16 \\
\hline 25 & 21 \\
\hline
\end{tabular}

Figure 122: Alpha-Fatigue WVP882 Default Model Prediction Output 


\section{Appendix E: Flow Number}

Francken Model Fitting Coefficients

\begin{tabular}{|c|c|c|c|c|c|}
\hline Mix & REP & $\mathbf{A}$ & B & C & D \\
\hline \multirow{4}{*}{ AA937 } & S8 & 1865 & 0.399 & 1714 & 0.0017 \\
\hline & S9 & 1944 & 0.384 & 2204 & 0.0013 \\
\hline & S10 & 1762 & 0.398 & 1797 & 0.0015 \\
\hline & S11 & 1823 & 0.393 & 1734 & 0.0014 \\
\hline \multirow{4}{*}{ JAP909 } & S5 & 1377 & 0.467 & 1436 & 0.0039 \\
\hline & S9 & 2075 & 0.412 & 1545 & 0.0040 \\
\hline & S10 & 1972 & 0.410 & 2125 & 0.0031 \\
\hline & S11 & 1977 & 0.422 & 1266 & 0.0041 \\
\hline \multirow{4}{*}{ JFA060 } & S8 & 2117 & 0.398 & 1686 & 0.00351 \\
\hline & S9 & 2018 & 0.403 & 1456 & 0.00323 \\
\hline & S10 & 1870 & 0.427 & 617 & 0.00458 \\
\hline & S11 & 1753 & 0.392 & 1030 & 0.00235 \\
\hline \multirow{3}{*}{ JFA115 } & S9 & 1905 & 0.417 & 818 & 0.00485 \\
\hline & S10 & 2230 & 0.393 & 1177 & 0.00416 \\
\hline & S11 & 2111 & 0.366 & 1057 & 0.00247 \\
\hline \multirow{2}{*}{ JFA429 } & S9 & 1709 & 0.390 & 903 & 0.00284 \\
\hline & S10 & 1508 & 0.396 & 693 & 0.00217 \\
\hline \multirow{4}{*}{ KP483 } & S5 & 1344 & 0.428 & 584 & 0.00314 \\
\hline & S9 & 1831 & 0.374 & 936 & 0.00213 \\
\hline & S10 & 1590 & 0.410 & 612 & 0.00306 \\
\hline & S11 & 1737 & 0.392 & 721 & 0.00265 \\
\hline \multirow{4}{*}{ WVP523 } & S9 & 1252 & 0.412 & 1674 & 0.00153 \\
\hline & S10 & 1381 & 0.410 & 1351 & 0.00183 \\
\hline & S11 & 1265 & 0.418 & 1361 & 0.00183 \\
\hline & S12 & 1475 & 0.401 & 2289 & 0.00158 \\
\hline \multirow{4}{*}{ WVP766 } & S9 & 1751 & 0.442 & 900 & 0.00566 \\
\hline & S10 & 2017 & 0.418 & 1102 & 0.00478 \\
\hline & S11 & 1511 & 0.428 & 955 & 0.00351 \\
\hline & $\mathrm{S} 12$ & 1878 & 0.412 & 771 & 0.00447 \\
\hline \multirow{4}{*}{ WVP882 } & S5 & 1379 & 0.493 & 744 & 0.00538 \\
\hline & S6 & 1485 & 0.458 & 1000 & 0.00413 \\
\hline & S10 & 1942 & 0.430 & 1195 & 0.00454 \\
\hline & S11 & 2024 & 0.417 & 1479 & 0.00377 \\
\hline
\end{tabular}




\section{Appendix F: Additional Images of Laboratory Equipment}

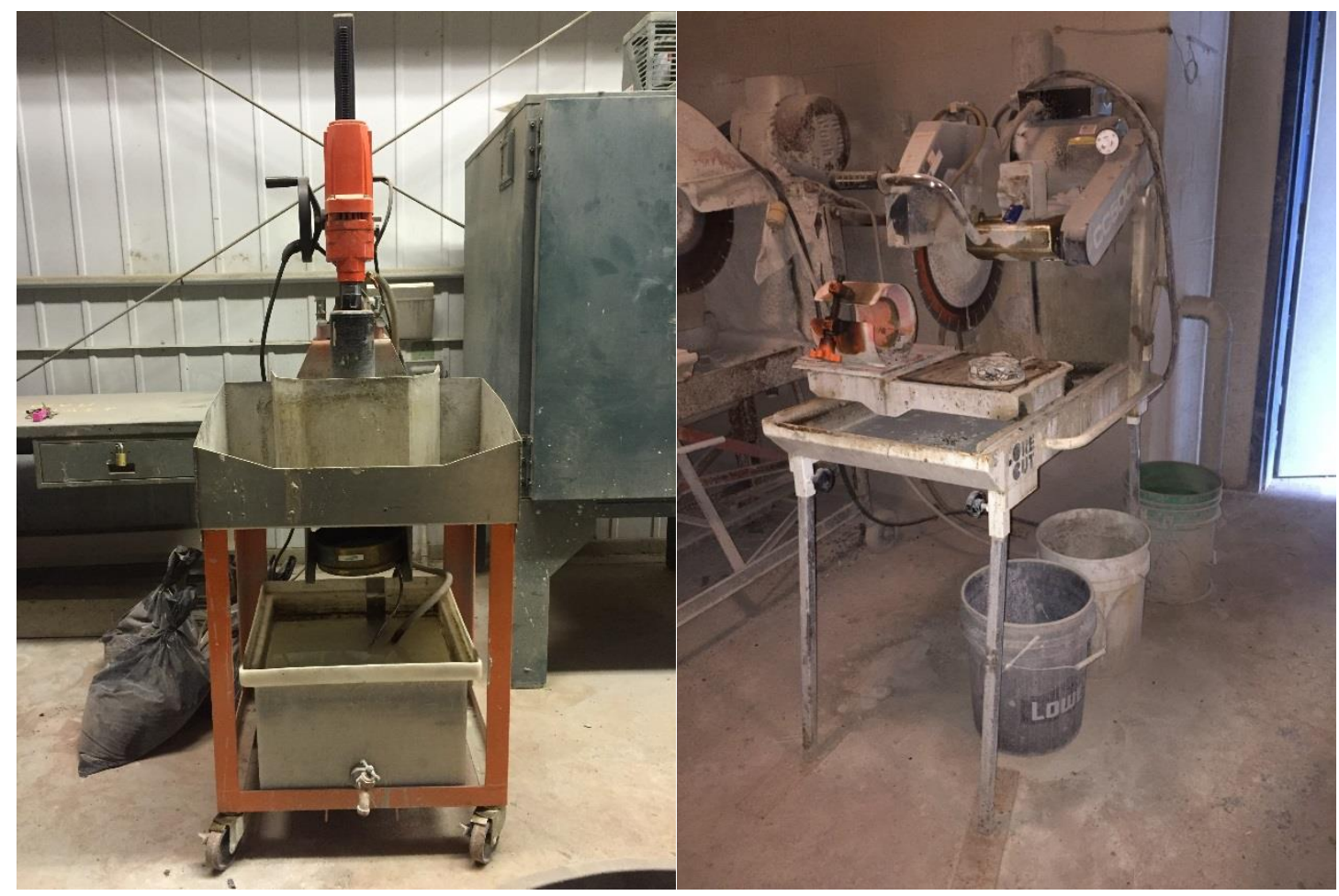

Figure 123: Coring and Sawing Laboratory Equipment

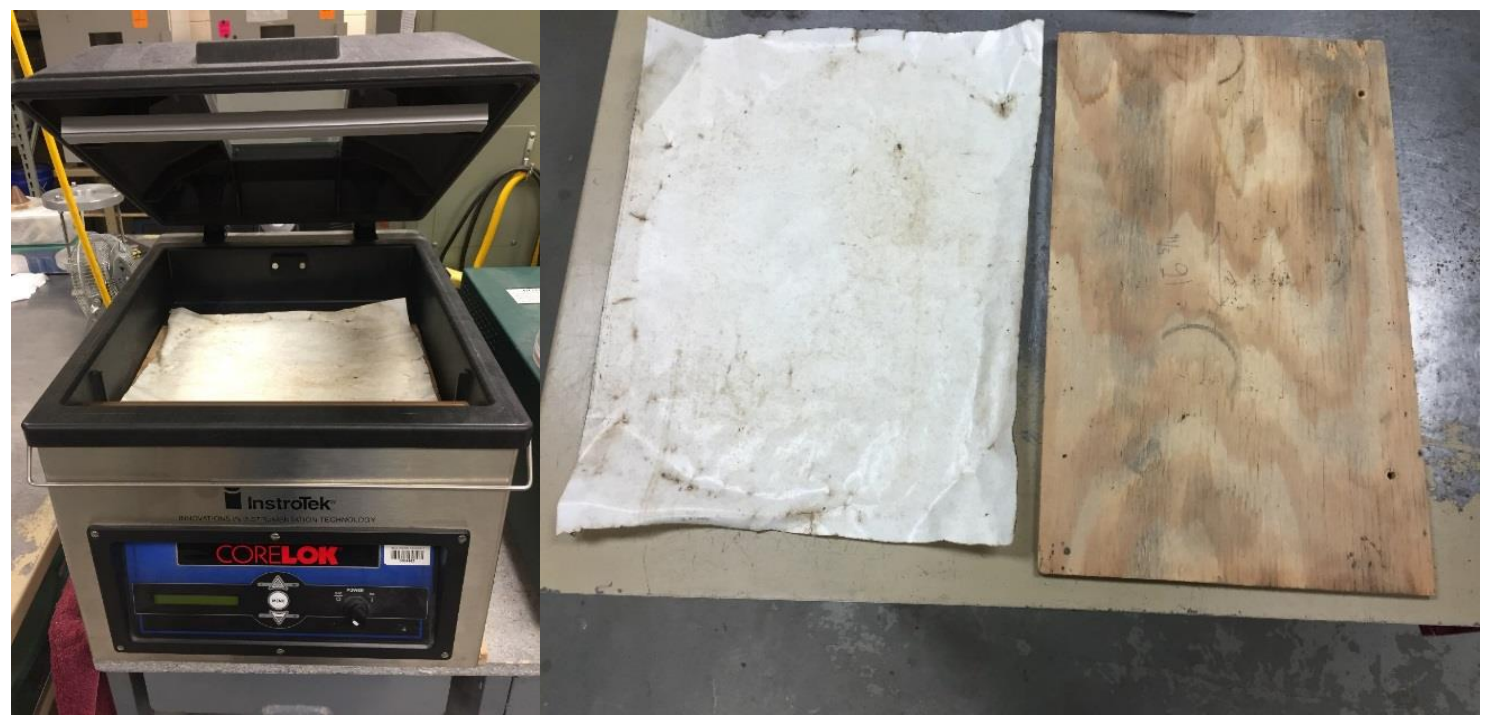

Figure 124: CoreLok Adjustments for Gyratory Samples 


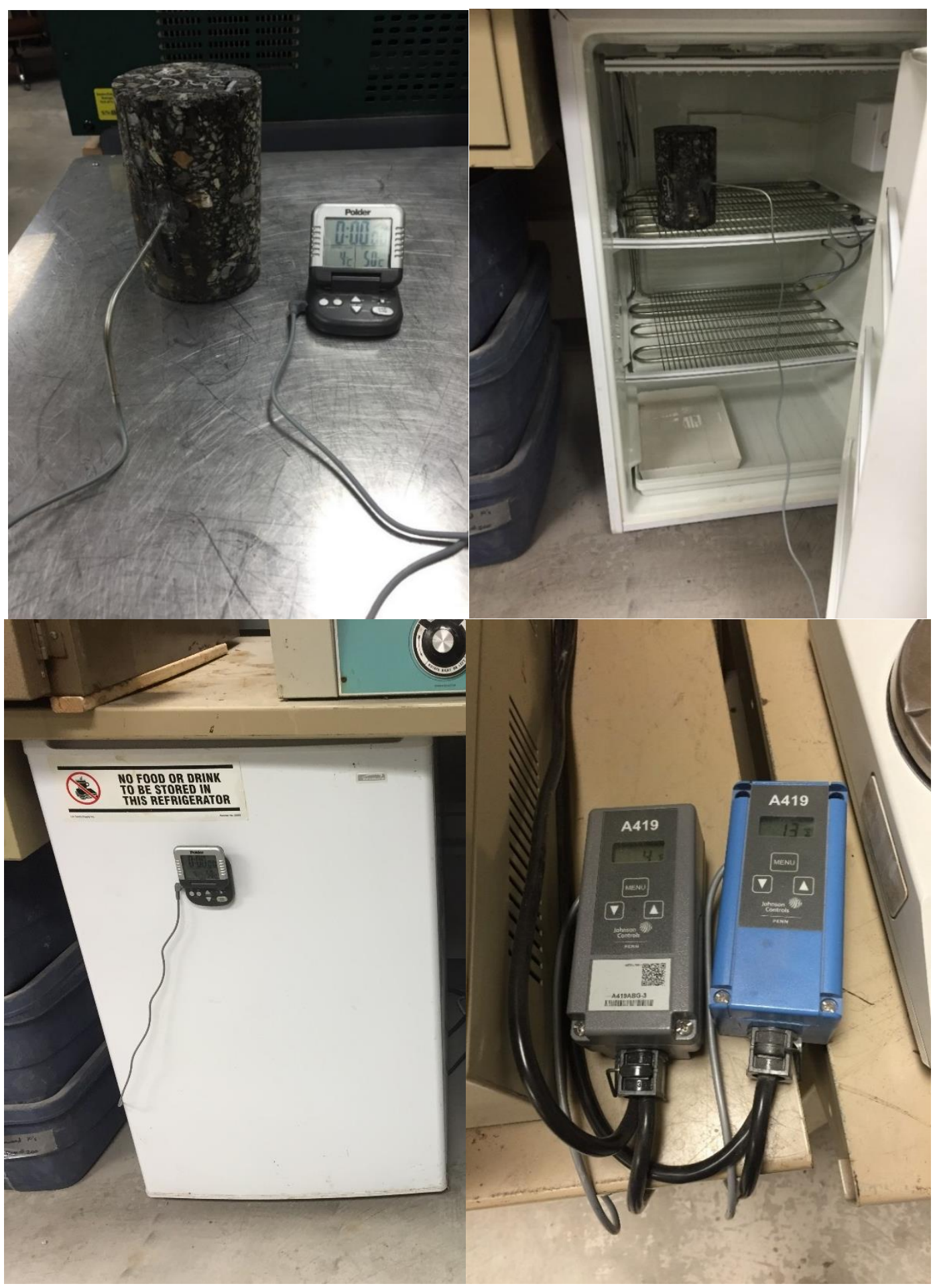

Figure 125: Conditional Chamber for Temperatures $17^{\circ} \mathrm{C}$ and Lower 